\title{
Mississippi River Adaptive Hydraulics Model Development and Evaluation, Commerce to New Madrid, Missouri, Reach
}

MRG\&P Report No. 35 • January 2021

\section{MRG\&P} Mississippi River Geomorphology \& Potamology Program

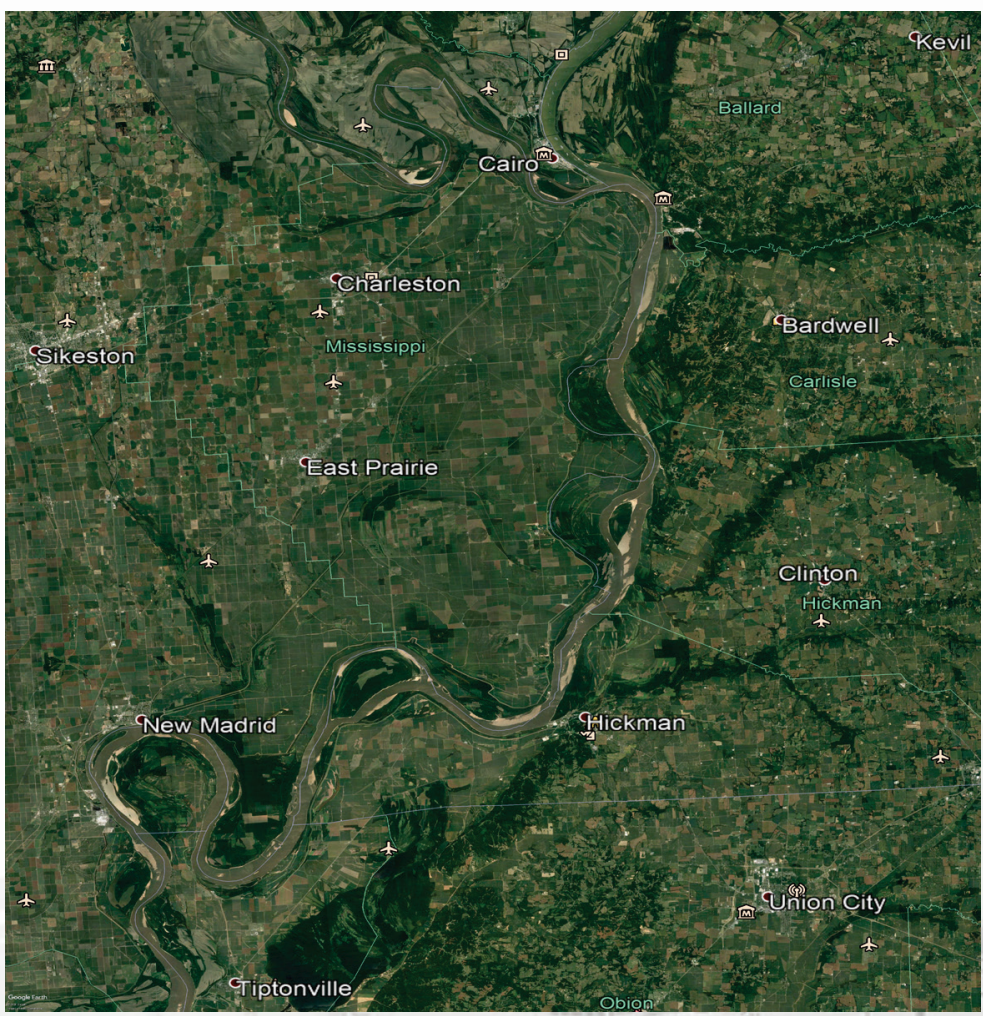





\section{Mississippi River Adaptive Hydraulics Model Development and Evaluation, Commerce to New Madrid, Missouri, Reach}

Roger A. Gaines

Hydraulics and Hydrology Branch

US Army Corps of Engineers, Memphis District

167 North Main Street, b202

Memphis, TN 38103

Stephen C. Sanborn, William H. McAnally, and Christopher M. Wallen

Dynamic Solutions, LLC

6421 Deane Hill Drive

Knoxville, TN 37919

Final report

Approved for public release; distribution is unlimited

Prepared for USACE Mississippi Valley Division

Vicksburg, MS 39181-0080

Under Project Number 127672, USACE MVD 


\section{Abstract}

A numerical, two-dimensional hydrodynamic model of the Mississippi River, from Thebes, IL, to Tiptonville, TN (128 miles/206 km), was developed using the Adaptive Hydraulics model. The study objective assessed current patterns and flow distributions and their possible impacts on navigation due to Birds Point New Madrid Floodway (BPNMF) operations and the Len Small (LS) levee break. The model was calibrated to stage, discharge, and velocity data for the 2011, 2015-2016, and 2017 floods. The calibrated model was used to run four scenarios, with the BPNMF and the LS breach alternately active/open and inactive/closed. Effects from the LS breach being open are increased river velocities upstream of the breach, decreased velocities from the breach to Thompson Landing, no effects on velocity below the confluence, and cross-current velocities greater than 3.28 $\mathrm{ft} / \mathrm{s}(1.0 \mathrm{~m} / \mathrm{s})$ within $1186.8 \mathrm{ft}(60 \mathrm{~m})$ of the bankline revetment. Effects from BPNMF operation are increased river velocities above the confluence, decreased velocities from the BPNMF upper inflow crevasse (Upper Fuseplug) to New Madrid, cross-current velocities greater than $1.5 \mathrm{ft} / \mathrm{s}(0.5$ $\mathrm{m} / \mathrm{s}$ ) only near the right bank where flow re-enters the river from the BPNMF lower inflow/outflow crevasse Number 2 (Lower Fuseplug) and St. Johns Bayou.

DISCLAIMER: The contents of this report are not to be used for advertising, publication, or promotional purposes. Citation of trade names does not constitute an official endorsement or approval of the use of such commercial products. All product names and trademarks cited are the property of their respective owners. The findings of this report are not to be construed as an official Department of the Army position unless so designated by other authorized documents.

DESTROY THIS REPORT WHEN NO LONGER NEEDED. DO NOT RETURN IT TO THE ORIGINATOR. 


\section{Contents}

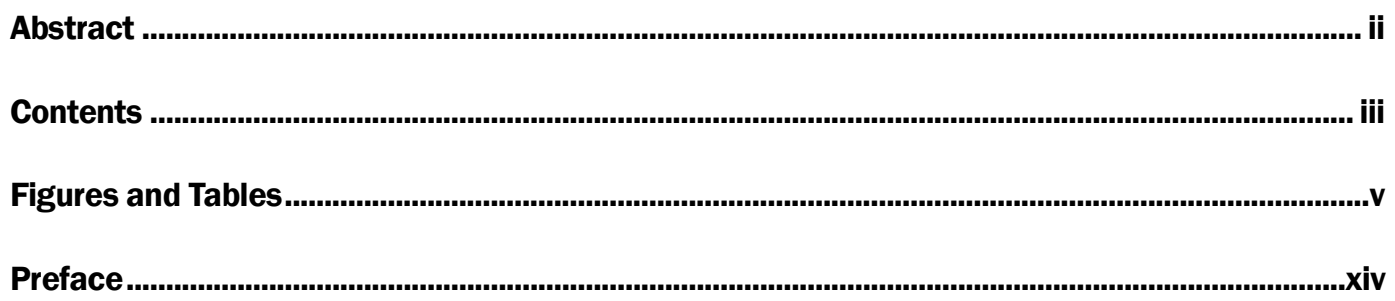

1 Introduction ............................................................................................................................................ 1

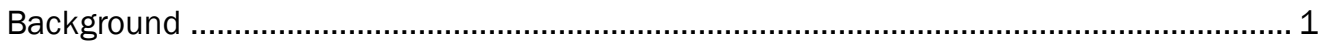

2011 Flood and Birds Point New Madrid Floodway (BPNMF) activation .................................. 2

2015-2016 Upper Mississippi River flood and LS levee breach ......................................... 5

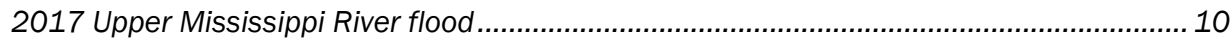

Notable flood modeling efforts........................................................................... 11

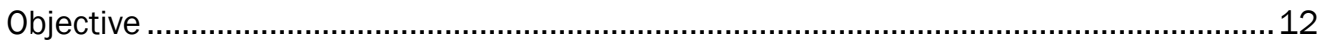

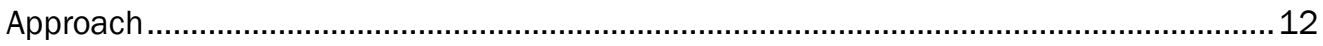

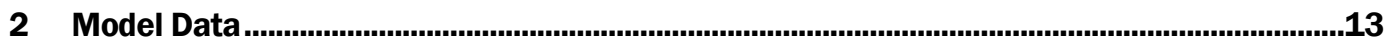

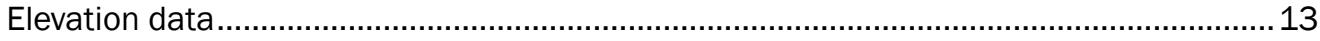

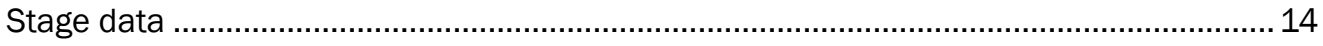

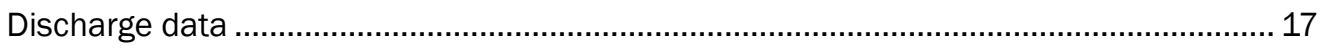

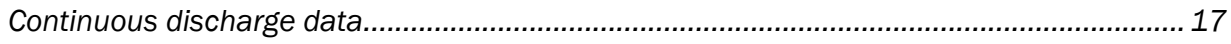

Acoustic Doppler current profiler (ADCP) discharge data - 2011 flood................................ 17

ADCP discharge data near the LS levee breach.............................................................. 19

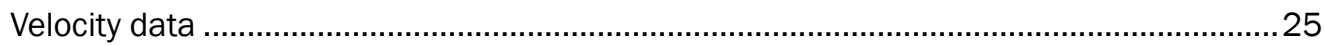

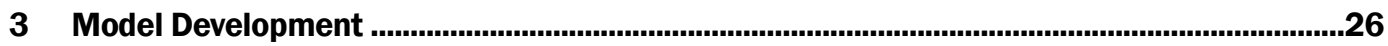

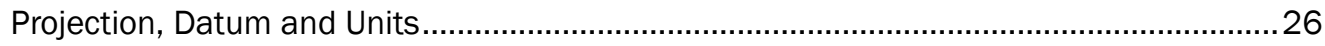

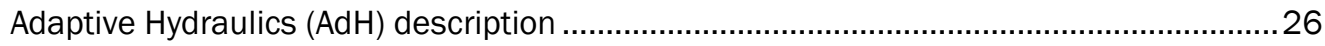

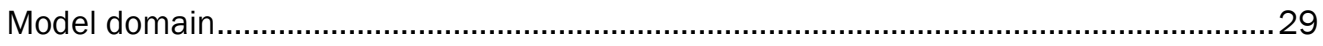

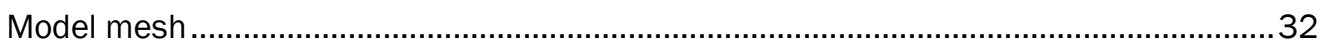

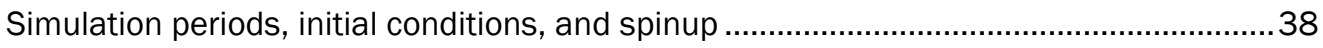

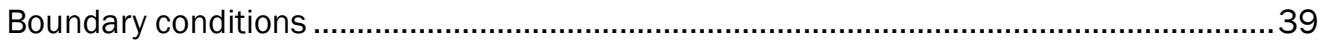

Model parameters........................................................................................................ 44

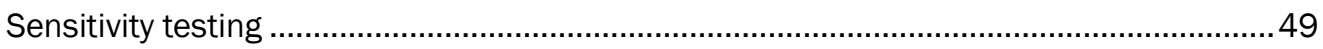

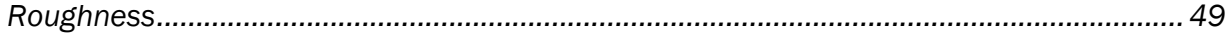

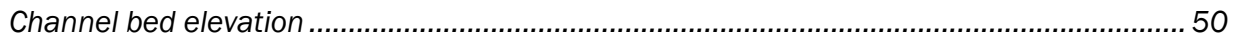

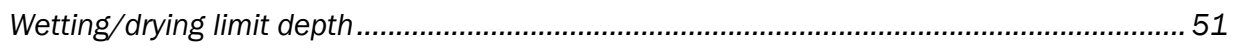

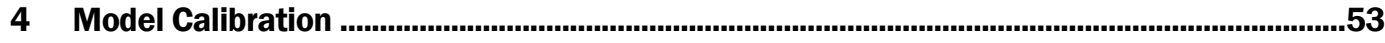

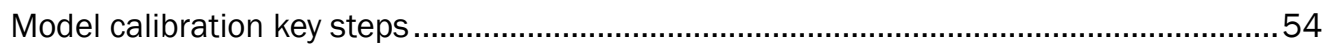

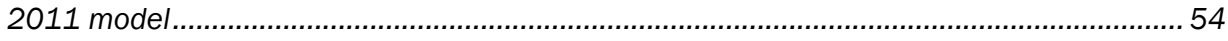

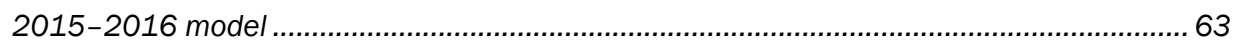

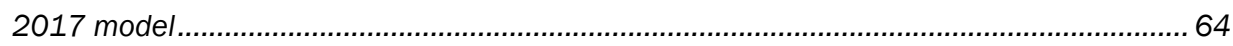

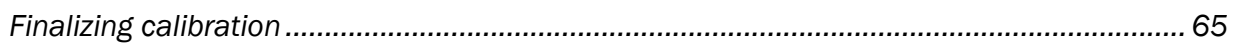




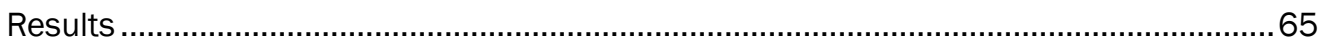

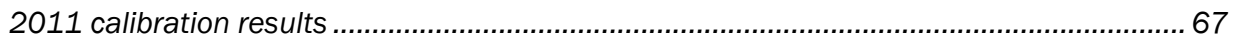

2015-2016 calibration results...................................................................................... 78

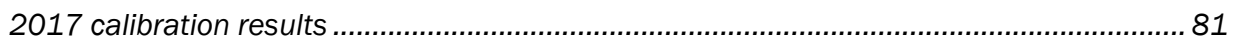

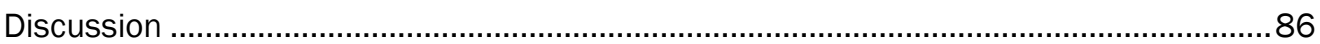

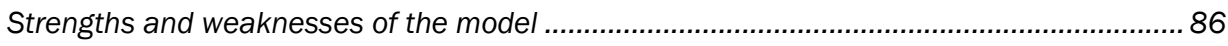

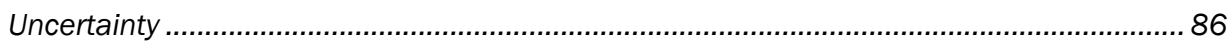

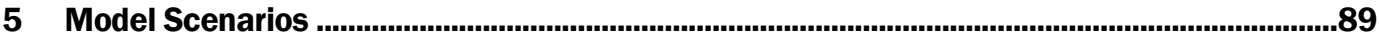

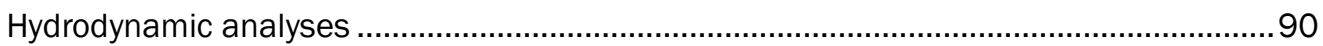

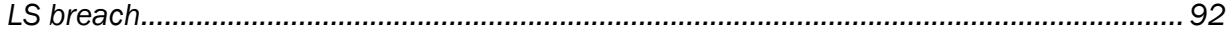

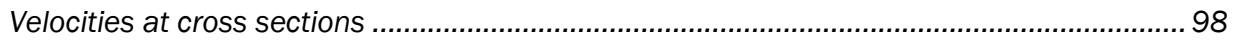

Channel centerline velocity analysis ............................................................................... 103

Cross-current velocities ............................................................................................ 107

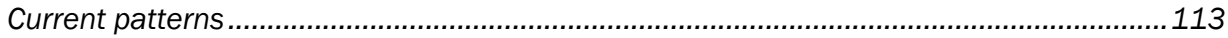

Summary - LS breach ............................................................................................. 117

Birds Point New Madrid Floodway (BPNMF) breach analyses .....................................120

Breach discharge ......................................................................................................... 120

Velocities at cross sections ........................................................................................ 124

Channel centerline velocity analysis ............................................................................. 128

Cross-current velocities ......................................................................................... 132

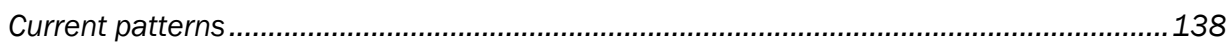

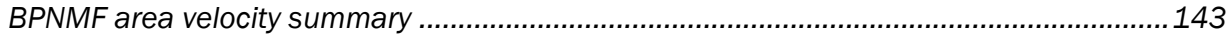

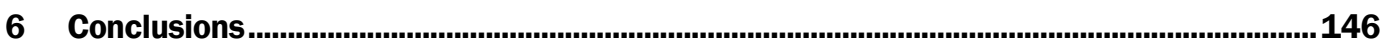

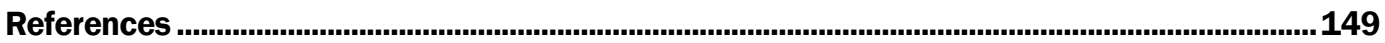

Appendix A: Calibration Plots..................................................................................................... 151

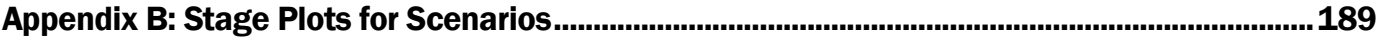

Unit Conversion Factors ............................................................................................................. 208

Acronyms and Abbreviations .................................................................................................209

\section{Report Documentation Page}




\section{Figures and Tables}

\section{Figures}

Figure 1-1. Project area showing the model domain.

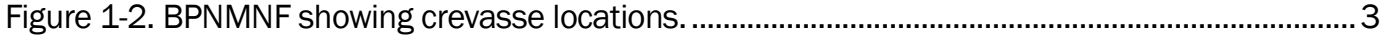

Figure 1-3. NASA Earth Observatory satellite image showing flooding on the Mississippi River on May 4, 2011.

Figure 1-4. Looking north from near the location of the (future) LS breach, January 1 , 2016. (Note: all photos in this section are from David C. Gordon).

Figure 1-5. Aerial photo of the LS breach, looking east-southeast through the breach, January 2, 2016.

Figure 1-6. US Geological Survey (USGS) Mississippi River at Thebes stage response to the LS levee breach.

Figure 1-7. Aerial photo of LS levee breach on January 2, 2016.

Figure 1-8. Aerial photo of LS breach and floodplain inundation, January 5, 2016. The red arrow highlights the extents of the breach.

Figure 1-9. Aerial photo of LS breach, January 19, 2016

Figure 1-10. Looking north-northwest (upstream) at Mississippi River bankline repair, February 17, 2016.

Figure 1-11. Aerial photo of LS breach showing bankline repair, February 17, 2016 .........................9

Figure 1-12. Aerial photo of LS breach, looking southeast, May 8, 2017. .......................................10

Figure 2-1. General locations of the USGS discharge measurement cross-sections.........................18

Figure 2-2. ADCP tracks for measurements taken 1/3/2016 at the LS breach. ..............................21

Figure 2-3. ADCP tracks for measurements taken 5/8/2017 at the LS breach................................24

Figure 2-4. Discharge for Mississippi River at Thebes USGS station and upstream discharge provided in the USACE tabular data. .25

Figure 3-1. Extents of the model domain..........................................................................................

Figure 3-2. Discharge at Olmsted and $8 \mathrm{~km}$ below Olmsted for BPNMF operation and no operation (i.e., "No Ops") conditions.

Figure 3-3. Detail of model mesh near BPNMF upper crevasse. .......................................................34

Figure 3-4. Detail of model mesh near LS levee breach. ....................................................................35

Figure 3-5. Mesh elevations - 2011 model. .......................................................................................37

Figure 3-6. Mesh convergence testing results - stage at Cairo for four different adaption schemes.

Figure 3-7. Model boundary condition locations ..............................................................................40

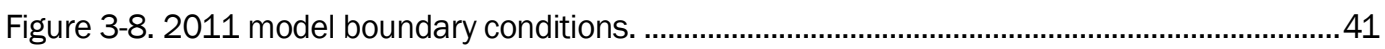

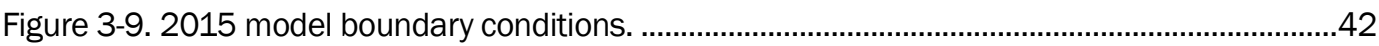

Figure 3-10. 2017 model boundary conditions. ……………………….........................................43

Figure 3-11. Material types in the model mesh. …………..................................................................46

Figure 3-12. Material types in the model mesh near the LS breach. ..................................................4

Figure 3-13. Material types in the model mesh near the BPNMF upper crevasse.............................48 
Figure 3-14. Effective drag in AdH as a function of depth for two values of Manning's $n$ (MNG) and URV.

Figure 3-15. Channel Manning's $n$ sensitivity testing results at Birds Point on the Mississippi River.

Figure 3-16. Channel bed elevation sensitivity testing results at Birds Point on the Mississippi River.

Figure 3-17. Wetting/drying parameter sensitivity test stage results at Birds Point, 2011 event.

Figure 3-18. Wetting/drying parameter sensitivity test stage results in the middle of the BPNMF. .52

Figure 4-1. BPNMF crevasse locations. .56

Figure 4-2. BPNMF upper crevasse node strings, each with a specified failure time series used in $\mathrm{AdH}$ model. .57

Figure 4-3. Upper crevasse failure time series used in AdH model. .57

Figure 4-4. BPNMF lower crevasse node strings, each with a specified failure time series

Figure 4-5. Lower crevasse failure time series as used in AdH model. 58

Figure 4-6. BPNMF middle crevasse node strings, each with a specified failure time series as used in AdH model.

Figure 4-7. Middle crevasse failure time series as used in AdH model. 60

Figure 4-8. Stage vs. discharge for both modeled and observed stages at Hickman, showing the loop effect.

Figure 4-9. Modeled and observed stage at Birds Point for two models - the "High channel $n$ " model having $n$-values 0.004 higher in the channel.

Figure 4-10. Modeled and observed discharge into the BPNMF for two models - the

"High channel $n$ " model having $n$-values 0.004 higher in the channel..

Figure 4-11. LS breach openings for the 2015 model. .64

Figure 4-12. Stage calibration river station locations. .66

Figure 4-13. Modeled and observed stage at Birds Point, 2011 event. 68

Figure 4-14. Longitudinal profile plot of stage for the Mississippi River. Stages pre- (5/2) and post-activation (5/3) of the BPNMF (Note: Wickliffe and Columbus datums are suspect).

Figure 4-15. Stage calibration stations in the BPNMF. .70

Figure 4-16. Modeled and observed stage at the Upper - $\mathrm{km} 3$ station in the BPNMF....................71

Figure 4-17. Discharge calibration cross-section locations (abbreviations: MR Mississippi River; OR - Ohio River).

Figure 4-18. Model and observed discharge below the BPNMF upper crevasse..............................74

Figure 4-19. Transect paths below the confluence used for velocity comparisons............................75

Figure 4-20. Transect paths below the upper breach used for velocity comparisons.

Figure 4-21. Transect 001 on 5/1/2011 showing vector divergence through floodplain tree line $($ Red line $=$ transect line; width of the white coloring indicates the velocity magnitude).

Figure 4-22. Modeled and observed stage at Birds Point, 2015 event.

Figure 4-23. Longitudinal profile plot of stage for the entire reach on $1 / 2 / 2016$. (Note: Wickliffe and Columbus datums are suspect). 
Figure 4-24. Modeled LS outflow. Dashes represent the two ADCP measurements of LS outflow; center triangle is the computed average.

Figure 4-25. Modeled and observed stage at Birds Point, 2017 event.

Figure 4-26. Longitudinal profile plot of stage for the Mississippi River near the peak of the 2017 flood event. (Note: Wickliffe and Columbus datums are suspect.)

Figure 4-27. Modeled Mississippi River flow upstream and downstream of the LS breach and discharge through the breach for the 2017 event. Dashed lines represent uncertainty bounds on the observed (tabular and processed ADCP) discharge measurements.

Figure 5-1. Conceptual model of a barge tow moving through the model velocity field, with the sail line shown in red

Figure 5-2. Depiction of cross-stream velocity at a mesh node in relation to the velocity vector and sail line.

Figure 5-3. Locations of discharge observation cross sections at LS.

Figure 5-4. Model discharge above and through the LS levee breach, Scenarios $1 \mathrm{~B}$ and 2B, 2011 event.

Figure 5-5. Model discharge above and through the LS levee breach, Scenarios $1 \mathrm{~A}$ and 1B, 2015 event.

Figure 5-6. Model discharge above and through the LS levee breach, Scenarios $1 \mathrm{~A}$ and 1B, 2017 event.

Figure 5-7. Locations of velocity analysis cross sections near LS breach.

Figure 5-8. Velocity magnitude for cross sections (looking downstream) near the LS breach, all scenarios, 5/3/2011 at 9:00 a.m. 100

Figure 5-9. Velocity magnitude for cross sections (looking downstream) near the LS breach, scenarios $1 \mathrm{~A}$ and $1 \mathrm{~B}, 1 / 1 / 2016$ at 9:00 p.m.

Figure 5-10. Velocity magnitude for cross sections (looking downstream) for cross sections near the LS breach, scenarios $1 A$ and $1 B, 5 / 5 / 2017$ at 9:00 p.m. 102

Figure 5-11. Velocity magnitude at the channel centerline, 5/3/2011 at 9:00 a.m.

Figure 5-12. Velocity magnitude at the channel centerline for Scenario $1 \mathrm{~A}$ and $1 \mathrm{~B}$, 1/1/2016 at 9:00 p.m.

Figure 5-13. Velocity magnitude at the channel centerline for Scenario 1A and 1B, 5/5/2017 at 9:00 a.m.

Figure 5-14. Scenario $1 \mathrm{~B}$ velocity vectors and cross-stream velocity magnitude contours at 5/3/2011 at 9:00 a.m. Sail lines shown in magenta - one mid-channel and one near the left bank. Distances along the left bank sail line are shown for later analysis in Figures 5-18 and 5-19. 108

Figure 5-15. Scenario $1 \mathrm{~B}$ velocity vectors and cross-stream velocity magnitude contours at 1/1/2016 at 9:00 p.m. Sail lines shown in magenta - one mid-channel and one near the left bank.

Figure 5-16. Scenario $1 \mathrm{~B}$ velocity vectors and cross-stream velocity magnitude contours at 5/5/2017 at 9:00 a.m. Sail lines shown in magenta - one mid-channel and one near the left bank.

Figure 5-17. Scenario $2 \mathrm{~B}$ velocity vectors and cross-stream velocity magnitude contours at 5/3/2011 at 9:00 a.m. Sail lines shown in magenta - one mid-channel and one near the left bank.

Figure 5-18. Cross-current velocity magnitude near the LS breach along the left bank sail line (upstream end is distance zero) for all Scenarios - 5/3/2011 at 9:00 a.m. 
Figure 5-19. Cross-current velocity magnitude near the LS breach along the left bank sail line (upstream end is distance zero), for Scenario 1B, near the peak of each flood event.

Figure 5-20. Velocity contours and vectors in the vicinity of the LS levee breach, for Scenarios 1A (upper panel) and 2A (lower panel), 5/3/2011 at 9:00 a.m.

Figure 5-21. Velocity contours and vectors in the vicinity of the LS levee breach, for Scenarios 1B (upper panel) and 2B (lower panel), 5/3/2011 at 9:00 a.m.

Figure 5-22. Velocity contours and vectors in the vicinity of the LS levee breach, for Scenarios 1A (upper panel) and 1B (lower panel), 1/1/2016 9:00 p.m.

Figure 5-23. Velocity contours and vectors in the vicinity of the LS levee breach, for Scenarios 1A (upper panel) and 1B (lower panel), 5/5/2017 at 9:00 a.m.

Figure 5-24. Difference in velocity between Scenarios $1 \mathrm{~B}$ and $1 \mathrm{~A}$ (calculated as $1 \mathrm{~B}$ minus 1A) for 5/5/2017 at 9:00 a.m.

Figure 5-25. Breach strings for the upper crevasse for the 2011 scenario simulations.

Figure 5-26. Breach string failure time series for the upper crevasse for the 2011 scenario simulations.

Figure 5-27. Breach string failure time series for the middle and lower crevasse for the 2011 scenario simulations.

Figure 5-28. Flow through the BPNMF upper crevasse into the floodway for each Scenario, for the 2011 event.

Figure 5-29. Locations of velocity analysis cross sections near BPNMF upper crevasse

Figure 5-30. Velocity across the channel (looking downstream) for cross sections near the BPNMF upper crevasse, all scenarios, 5/3/2011 at 9:00 a.m. Note that the Scenario 1 and Scenario 2 profiles are nearly identical, thus plotted on top of one another.

Figure 5-31. Velocity across the channel (looking downstream) for cross sections near the BPNMF upper crevasse, Scenarios $1 \mathrm{~A}$ and 1B, 1/1/2016 at 9:00 p.m. Note that the profiles are nearly identical, thus plotted on top of one another...

Figure 5-32. Velocity across the channel (looking downstream) for cross sections near the BPNMF upper crevasse, Scenarios $1 A$ and 1B, 5/5/2017 at 9:00 p.m. Note that the profiles are nearly identical, thus plotted on top of one another.

Figure 5-33. Velocity magnitude at the channel centerline for all scenarios, 5/3/2011 at 9:00 a.m.

Figure 5-34. Velocity magnitude at the channel centerline for all scenarios, 1/1/2016 at 9:00 p.m.

Figure 5-35. Velocity magnitude at the channel centerline for all scenarios, 5/5/2017 at 9:00 a.m.

Figure 5-36. Scenario $1 \mathrm{~A}$ velocity vectors and cross-stream velocity magnitude contours at 5/3/2011 at 9:00 a.m. Sail lines shown in magenta - one mid-channel and one near the right bank. Distances along the left bank sail line are shown for profile analysis. Crosscurrent velocities in the magenta boxes are discussed.

Figure 5-37. Scenario $1 \mathrm{~A}$ velocity vectors and cross-stream velocity magnitude contours at 1/1/2016 at 9:00 p.m. Sail lines shown in magenta - one mid-channel and one near the right bank.

Figure 5-38. Scenario $1 \mathrm{~A}$ velocity vectors and cross-stream velocity magnitude contours at 5/5/2017 at 9:00 a.m. Sail lines shown in magenta - one mid-channel and one near the right bank... 
Figure 5-39. Scenario $2 A$ velocity vectors and cross-stream velocity magnitude contours at 5/3/2011 at 9:00 a.m. Sail lines shown in magenta - one mid-channel and one near the right bank.

Figure 5-40. Cross-current velocity magnitude near the BPNMF upper crevasse along the right bank sail line (upstream end is distance zero) for Scenario $1 \mathrm{~A}$, at the velocity peak for each year.

Figure 5-41. Cross-current velocity magnitude near the BPNMF upper crevasse along the right bank sail line (upstream end is distance zero) for each scenario, 5/3/2011. Note: Scenarios $1 \mathrm{~A}$ and $1 \mathrm{~B}$ and $2 \mathrm{~A}$ and $2 \mathrm{~B}$ are nearly identical.

Figure 5-42. Scenario $2 A$ velocity vectors and cross-stream velocity magnitude contours on 5/6/2011 at 7:00 p.m., near peak BPNMF outflow, lower crevasse. Sail line is shown in magenta - mid-channel.

Figure 5-43. Velocity contours and vectors in the vicinity of the BPNMF upper crevasse, for Scenario $1 \mathrm{~A}, 5 / 3 / 2011$ at 9:00 a.m.

Figure 5-44. Velocity contours and vectors in the vicinity of the BPNMF upper crevasse, for Scenario $1 \mathrm{~A}, 1 / 1 / 2016$ at 9:00 p.m.

Figure 5-45. Velocity contours and vectors in the vicinity of the BPNMF upper crevasse, for Scenario $1 A, 5 / 5 / 2017$ at 9:00 a.m.

Figure 5-46. Velocity contours and vectors in the vicinity of the BPNMF upper crevasse, for Scenario 2A, 5/3/2011 at 9:00 a.m.

Figure 5-47. Difference in velocity between Scenarios $2 \mathrm{~A}$ and $1 \mathrm{~A}$ (calculated as $2 \mathrm{~A}$ minus 1A) for 5/3/2011 at 9:00 a.m.

Figure 5-48. Difference in velocity between Scenarios $2 \mathrm{~A}$ and $1 \mathrm{~A}$ (calculated as $2 \mathrm{~A}$ minus 1A) for 5/3/2011 at 9:00 a.m.

Figure A-1. Modeled and observed stage at New Madrid, 2011 event.

Figure A-2. Modeled and observed stage at Hickman, 2011 event. ............................................. 152

Figure A-3. Modeled and observed stage at Cairo, 2011 event..................................................... 153

Figure A-4. Modeled and observed stage at Birds Point, 2011 event. ........................................... 153

Figure A-5. Modeled and observed stage at Price Landing, 2011 event.

Figure A-6. Modeled and observed stage at Upper BPNMF - km 0 (365751089080301), 2011 event.

Figure A-7. Modeled and observed stage at Upper BPNMF - km 3 (365538089080001), 2011 event.

Figure A-8. Modeled and observed stage at Upper BPNMF - km 7 (365452089105201), 2011 event. 156

Figure A-9. Modeled and observed stage at Middle BPNMF - km 23 (364635089145003), 2011 event.

Figure A-10. Modeled and observed stage at Middle BPNMF - km 25 (364634089180501), 2011 event.

Figure A-11. Modeled and observed stage at Lower BPNMF - km 41 (363912089224801), 2011 event.

Figure A-12. Modeled and observed stage at Lower BPNMF - km 54 (363537089300001), 2011 event. 158

Figure A-13. Modeled and observed stage at Lower East BPNMF - km 42 (363514089134101), 2011 event. 
Figure A-14. Modeled and observed discharge of the Mississippi River above Cairo, 2011 event

Figure A-15. Modeled and observed discharge of the Ohio River below Cairo, 2011 event. 159

Figure A-16. Modeled and observed discharge of the Mississippi River below the confluence, 2011 event.

Figure A-17. Modeled and observed discharge of the Mississippi River below Birds Point, 2011 event 160

Figure A-18. Modeled and observed discharge at Birds Point Upper Crevasse, 2011 event. ....... 161

Figure A-19. Modeled and observed discharge of the Mississippi River at Hickman, 2011 event.

Figure A-20. Modeled and observed discharge at Birds Point Middle Crevasse, 2011 event.

Figure A-21. Modeled and observed discharge exiting Birds Point, 2011 event. ......................... 162

Figure A-22. Modeled and observed discharge at Birds Point Lower Crevasse, 2011 event. ....... 163

Figure A-23. Modeled and observed discharge at Birds Point Gap, 2011 event. 163

Figure A-24. Modeled and observed discharge of the Mississippi River at Tiptonville, 2011 event. 164

Figure A-25. Modeled and observed velocity below the confluence at Transect 002 on $4 / 28 / 2011$

Figure A-26. Modeled and observed velocity below the confluence at Transect 003 on $4 / 28 / 2011$.

Figure A-27. Modeled and observed velocity below the confluence at Transect 000 on $4 / 30 / 2011$ 166

Figure A-28. Modeled and observed velocity below the confluence at Transect 001 on $4 / 30 / 2011$. 166

Figure A-29. Modeled and observed velocity below the confluence at Transect 000 on $5 / 1 / 2011$.

Figure A-30. Modeled and observed velocity below the confluence at Transect 001 on $5 / 1 / 2011$.

Figure A-31. Modeled and observed velocity below the breach at Transect 000 on $5 / 3 / 2011$

Figure A-32. Modeled and observed velocity below the breach at Transect 001 on $5 / 3 / 2011$

Figure A-33. Modeled and observed velocity below the breach at Transect 001 on $5 / 4 / 2011$

Figure A-34. Modeled and observed velocity below the breach at Transect 003 on $5 / 4 / 2011$

Figure A-35. Modeled and observed velocity below the breach at Transect 000 on $5 / 5 / 2011$

Figure A-36. Modeled and observed velocity below the breach at Transect 001 on

$5 / 5 / 2011$

Figure A-37. Modeled and observed velocity below the breach at Transect 000 on $5 / 6 / 2011$

Figure A-38. Modeled and observed velocity below the breach at Transect 001 on 
Figure A-39. Modeled and observed velocity below the breach at Transect 000 on 5/14/2011.

Figure A-40. Modeled and observed velocity below the breach at Transect 001 on $5 / 14 / 2011$.

Figure A-41. Modeled and observed velocity direction below the confluence at Transect 002 on $4 / 28 / 2011$.

Figure A-42. Modeled and observed velocity direction below the confluence at Transect 003 on $4 / 28 / 2011$.

Figure A-43. Modeled and observed velocity direction below the confluence at Transect 000 on 4/30/2011.

Figure A-44. Modeled and observed velocity direction below the confluence at Transect 001 on 4/30/2011.

Figure A-45. Modeled and observed velocity direction below the confluence at Transect 000 on $5 / 1 / 2011$

Figure A-46. Modeled and observed velocity direction below the confluence at Transect 001 on $5 / 1 / 2011$.

Figure A-47. Modeled and observed velocity direction below the breach at Transect 000 on $5 / 3 / 2011$.

Figure A-48. Modeled and observed velocity direction below the breach at Transect 001 on $5 / 3 / 2011$.

Figure A-49. Modeled and observed velocity direction below the breach at Transect 001 on $5 / 4 / 2011$.

Figure A-50. Modeled and observed velocity direction below the breach at Transect 003 on $5 / 4 / 2011$.

Figure A-51. Modeled and observed velocity direction below the breach at Transect 000 on $5 / 5 / 2011$.

Figure A-52. Modeled and observed velocity direction below the breach at Transect 001 on $5 / 5 / 2011$.

Figure A-53. Modeled and observed velocity direction below the breach at Transect 000 on $5 / 6 / 2011$.

Figure A-54. Modeled and observed velocity direction below the breach at Transect 001 on $5 / 6 / 2011$.

Figure A-55. Modeled and observed velocity direction below the breach at Transect 000 on $5 / 14 / 2011$.

Figure A-56. Modeled and observed velocity direction below the breach at Transect 001 on $5 / 14 / 2011$.

Figure A-57. Modeled and observed stage at New Madrid, 2015 event.

Figure A-58. Modeled and observed stage at Hickman, 2015 event............................................. 181

Figure A-59. Modeled and observed stage at Cairo, 2015 event. .................................................. 182

Figure A-60. Modeled and observed stage at Birds Point, 2015 event......................................... 182

Figure A-61. Modeled and observed stage at Thompson Landing, 2015 event............................ 183

Figure A-62. Modeled and observed stage at Price Landing, 2015 event...................................... 183

Figure A-63. Modeled and observed stage at Commerce, 2015 event. ......................................... 184

Figure A-64. Modeled and observed stage at New Madrid, 2017 event. ....................................... 185

Figure A-65. Modeled and observed stage at Hickman, 2017 event.............................................. 185 
Figure A-66. Modeled and observed stage at Cairo, 2017 event.................................................... 186

Figure A-67. Modeled and observed stage at Birds Point, 2017 event. .......................................... 186

Figure A-68. Modeled and observed stage at Thompson Landing, 2017 event............................. 187

Figure A-69. Modeled and observed stage at Price Landing, 2017 event...................................... 187

Figure A-70. Modeled and observed stage at Commerce, 2017 event. .......................................... 188

Figure B-1. Scenario stages, 2011 event..................................................................................... 190

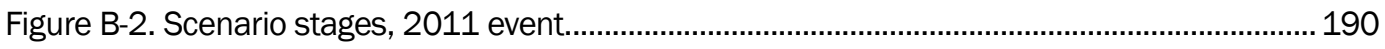

Figure B-3. Scenario stages, 2011 event................................................................................. 191

Figure B-4. Scenario stages, 2011 event................................................................................ 191

Figure B-5. Scenario stages, 2011 event................................................................................. 192

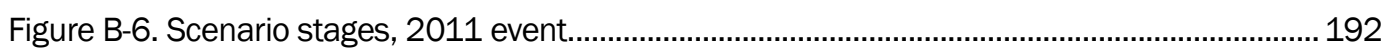

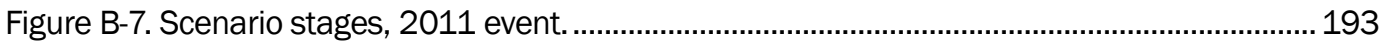

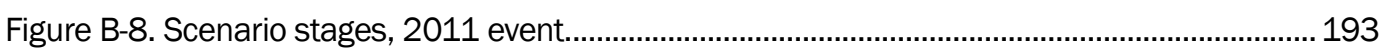

Figure B-9. Scenario stages, 2011 event............................................................................... 194

Figure B-10. Scenario 1A and 1B stages, 2015 event. ............................................................... 195

Figure B-11. Scenario 1A and 1B stages, 2015 event. ................................................................ 195

Figure B-12. Scenario 1A and 1B stages, 2015 event. .............................................................. 196

Figure B-13. Scenario 1A and 1B stages, 2015 event. ............................................................... 196

Figure B-14. Scenario 1A and 1B stages, 2015 event. .............................................................. 197

Figure B-15. Scenario 1A and 1B stages, 2015 event. ................................................................. 197

Figure B-16. Scenario 1A and 1B stages, 2015 event. .............................................................. 198

Figure B-17. Scenario 1A and 1B stages, 2015 event............................................................... 198

Figure B-18. Scenario 1A and 1B stages, 2015 event. .............................................................. 199

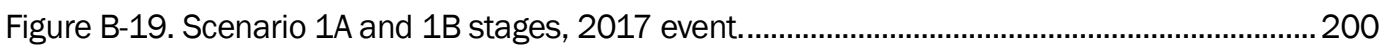

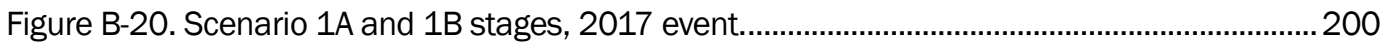

Figure B-21. Scenario 1A and 1B stages, 2017 event............................................................... 201

Figure B-22. Scenario 1A and 1B stages, 2017 event................................................................ 201

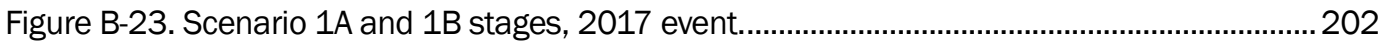

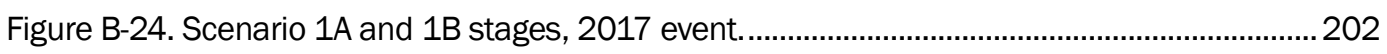

Figure B-25. Scenario 1A and 1B stages, 2017 event.................................................................2 203

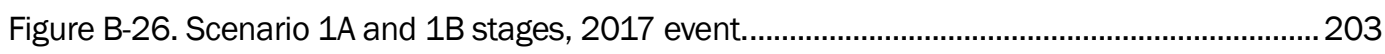

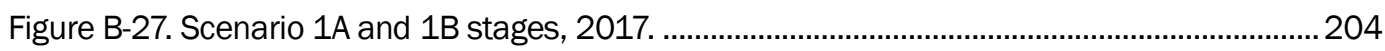

Figure B-28. 5/3/2011 water surface elevation longitudinal profile. ........................................... 205

Figure B-29. 1/1/2015 water surface elevation longitudinal profile. ……………………….......2 206

Figure B-30. 5/5/2017 water surface elevation longitudinal profile (note 2017 calibration model is identical to Scenario $1 \mathrm{~B})$..

\section{Tables}

Table 2-1. Summary of stage data source, time period, original datum, and interval. ......................15

Table 2-2. Summary of datum conversions for Lower Mississippi River stage gages........................16 
Table 2-3. LS tabular ADCP discharge data provided by USACE

Table 2-4. Summary of flow measurement data near the LS breach. "Table" indicates the value came from Table 2-3, "Inferred Table" means the value was calculated based on the "Table," and "N/A" indicates data were not available.

Table 3-1. Horizontal projection.

Table 3-2. Elevation data utilized for each simulation period, building from the base, each subsequent layer (higher number) taking precedent. 36

Table 3-3. Mesh convergence testing run parameters and max number of nodes............................38

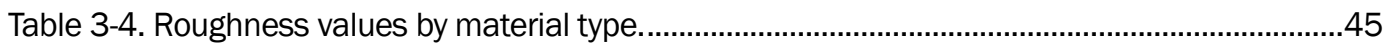

Table 4-1. Stage calibration statistics for the 2011 event.............................................................67

Table 4-2. Stage calibration statistics for BPNMF gages during the 2011 event. ............................. 71

Table 4-3. Discharge calibration statistics for the 2011 event (abbreviations: MR Mississippi River; OR - Ohio River) .72

Table 4-4. Average velocity comparisons for transects below the confluence. .77

Table 4-5. Average velocity comparisons for transects below breach. . .77

Table 4-6. Stage calibration statistics for the 2015 event .78

Table 4-7. Stage calibration statistics for the 2017 event. .82

Table 5-1. Modeled peak discharge in the Mississippi River above the LS breach and breach outflow for each event. 


\section{Preface}

The research documented in this report was conducted for the US Army Corps of Engineers (USACE), Mississippi Valley Division (MVD), as part of the Mississippi River Geomorphology and Potamology (MRG\&P) Program, under Project Number 127672, USACE MVD. The MRG\&P Program is part of the Mississippi River and Tributaries Project and is managed by the USACE MVD and Districts. At the time of publication of this report, the MRG\&P Program Director was Dr. James W. Lewis. The MVD Commander was MG Diana M. Holland, and the MVD Director of Programs was Mr. Edward E. Belk.

The work was performed by contract services from Dynamic Solutions, LLC, under subcontract to ARCADIS US, Inc. Investigation oversight and direction was provided by The Hydraulics and Hydrology Branch of the Engineering and Construction Division, Memphis District. At the time of publication Mr. Michael B. Clay was Chief of the Hydraulics and Hydrology Branch, Mr. Steven Williamson was Chief of the Engineering and Construction Division, and the Memphis District Commander was COL Zachary L. Miller. 


\section{Introduction}

\section{Background}

The study reach (Figure 1-1) has experienced three significant floods in the last decade. During the 2011 flood, the Mississippi River reached its historic peak at Cairo, IL, and for the first time since the flood of 1937, the Birds Point New Madrid Floodway (BPNMF) was activated. The 2015 flood on the Upper Mississippi (the Upper Mississippi refers to the river above the confluence with the Ohio River) reached historically high discharges above 1,050,000 cubic feet per second (cfs) or 29,700 cubic meters per second (cms), at Thebes, IL, and resulted in a breach of the Len Small (LS) levee near Miller City, IL, on January 2, 2016. Another large flood on the Upper Mississippi River occurred in 2017, with discharge at Thebes, IL, reaching $928,000 \mathrm{cfs}(26,300 \mathrm{cms})$ and flowing through the still-open crevasse at LS.

Figure 1-1. Project area showing the model domain.

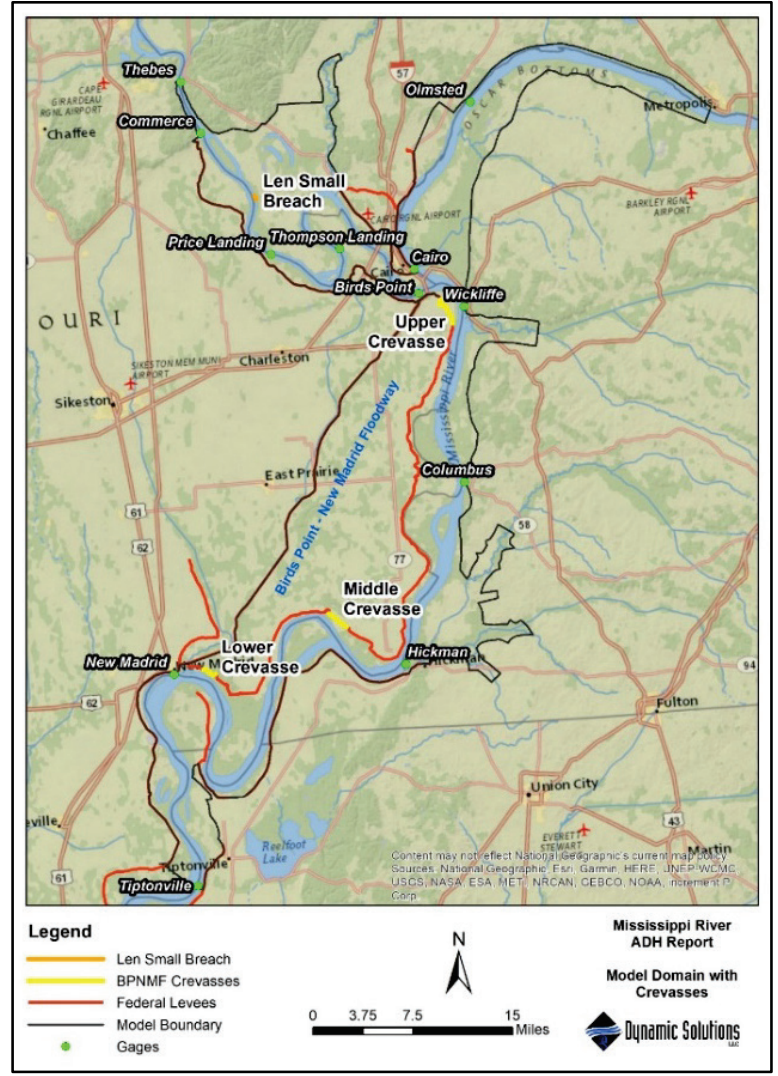




\section{Flood and Birds Point New Madrid Floodway (BPNMF) activation}

The BPNMF was commissioned in response to the devastating 1927 flood. It is designed to prevent the Mississippi River and Tributaries (MR\&T) Project Design Flood from exceeding the design elevations on the Mississippi River levees near the confluence of the Mississippi and Ohio Rivers (the confluence). The BPNMF (Figure 1-2) includes 133,000 acres $(53,823$ hectares) of land and is 35 miles $(56 \mathrm{~km})$ long and typically $4-10$ miles $(6.5-16 \mathrm{~km})$ wide. The east side of the BPNMF is bounded by the MR\&T frontline levee, and its west boundary is defined by a setback levee between Birds Point, MO, and New Madrid, MO. The upper fuseplug lies just downstream from the confluence and contains the inflow crevasse (referenced herein as Upper Crevasse and Upper Fuseplug). The upper (inflow) crevasse controls inflow to the floodway during activation. At the downstream end of the BPNMF there is a $1,500 \mathrm{ft}(460 \mathrm{~m})$ gap that serves as an outlet for interior and flood drainage and a lower fuseplug that contains the inflow/outflow crevasse number 2 (referenced herein as Lower Crevasse and Lower Fuseplug). The combination of the gap and the lower inflow/outflow crevasse number 2 control outflow during activation. The middle inflow/outflow crevasse number 1 (referenced herein as Middle Crevasse) is designed to introduce floodwaters upon activation and to aid in draining the floodway after the crest passes. There is no middle fuseplug component.

The 2011 flood was the result of persistent rains in both the Upper Mississippi and Ohio River basins. On the morning of May 2, 2011, the river stage in Cairo, IL, reached $61 \mathrm{ft}$ (18.6 meters), the trigger for activation of the floodway, and the forecast called for the river to peak at $63.5 \mathrm{ft}$ (19.4 meters) on May 5. Ultimately, the BPNMF upper inflow crevasse was activated on May 2, 2011, at 10 p.m. local time (Camillo 2012). The river stage was $61.7 \mathrm{ft}$ (18.8 meters) at Cairo, IL.

The rapid rise of the river and dangerous conditions resulted in BPNMF operations being different from the project design scenario. Due to the dangerous conditions and severe weather, field operations were falling behind the intended timing milestones for BPNMF activation, and explosives crews were running out of explosive material needed to detonate all three crevasses. Consequently, while activation of the upper (inflow) crevasse was designed to detonate 11,099 $\mathrm{ft}(3,380 \mathrm{~m})$ of levee, only 9,000 ft (2,740 m) were crevassed (Camillo 2012). Explosives crews moved to the lower (inflow/outflow number 2) crevasse and detonated 
approximately 4,100 $\mathrm{ft}(1,250 \mathrm{~m})$ of levee on May 3 at 12:40 pm local time (Camillo 2012). Design length for the lower crevasse (inflow/outflow number 2) was $5,500 \mathrm{ft}(1,676 \mathrm{~m})$, which was the same design length for the middle crevasse (inflow/outflow number 1). On May 5, crews detonated the middle crevasse using an alternate explosive agent, which was not as effective and the resulting crevasse opening was not consistent with the designed detonation (Camillo 2012).

Figure 1-2. BPNMNF showing crevasse locations.

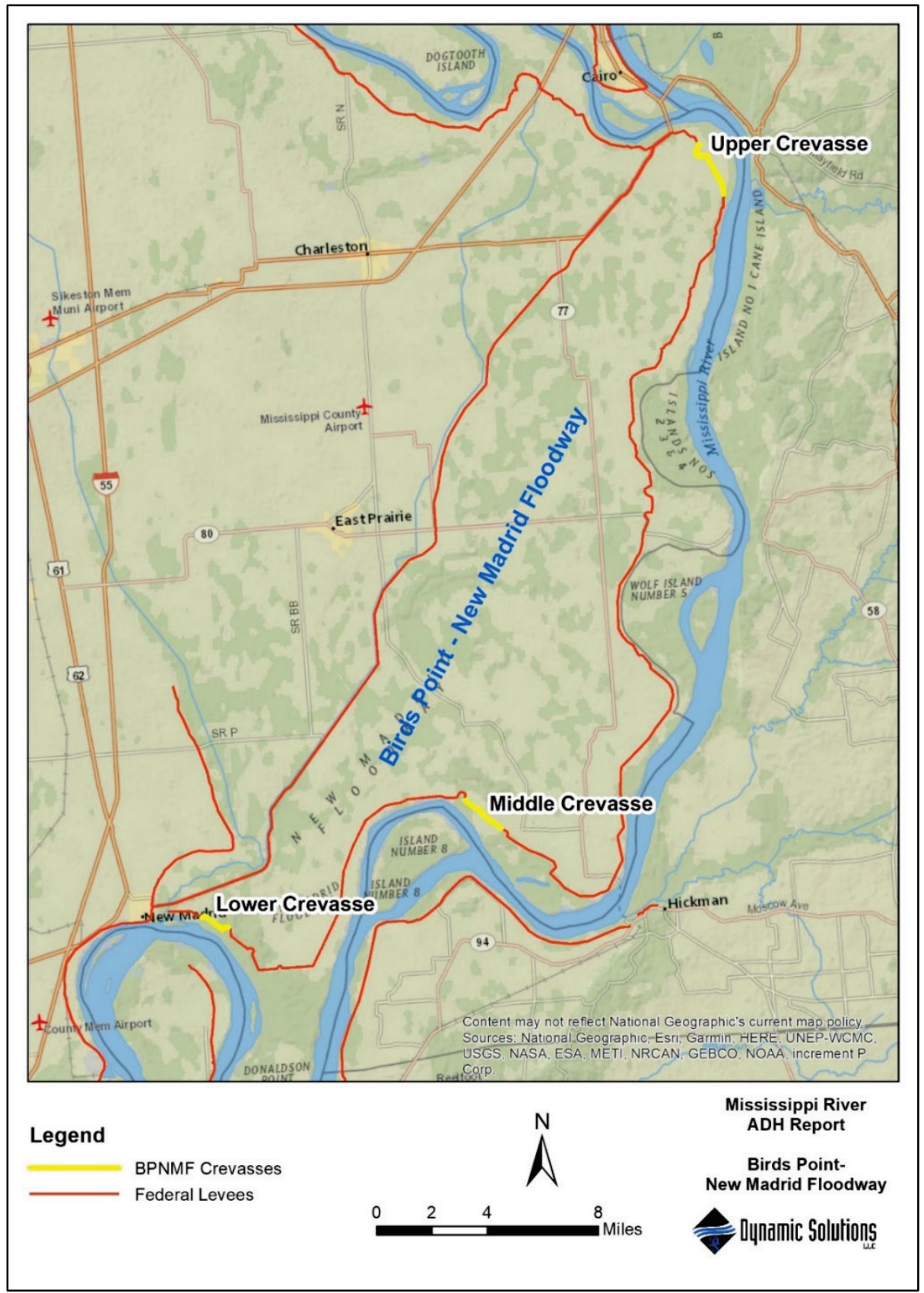


On May 5, when the predicted stage at Cairo was to hit $63.5 \mathrm{ft}(19.4 \mathrm{~m})$ without the floodway activation, the actual stage following BPNMF activation was nearly $4 \mathrm{ft}(1.2 \mathrm{~m})$ lower. Based on USGS discharge measurements, it was estimated that the BPNMF carried 400,000 cfs $(11,326 \mathrm{cms})$ at its peak, $150,000 \mathrm{cfs}(4,250 \mathrm{cms})$ below its stated design capacity. The peak discharge at the confluence reached approximately 2.1 million cfs $(59,500 \mathrm{cms})$, which was less than the project design flood of 2.36 million cfs $(66,800 \mathrm{cms})$. Operation of the BPNMF had accomplished its purpose: protecting the levee system and preventing significant flooding outside the Federal levees. A satellite photo (Figure 1-3) (NASA 2011) showed the extent of flooding on May 4, 2011.

Figure 1-3. NASA Earth Observatory satellite image showing flooding on the Mississippi River on May 4, 2011.

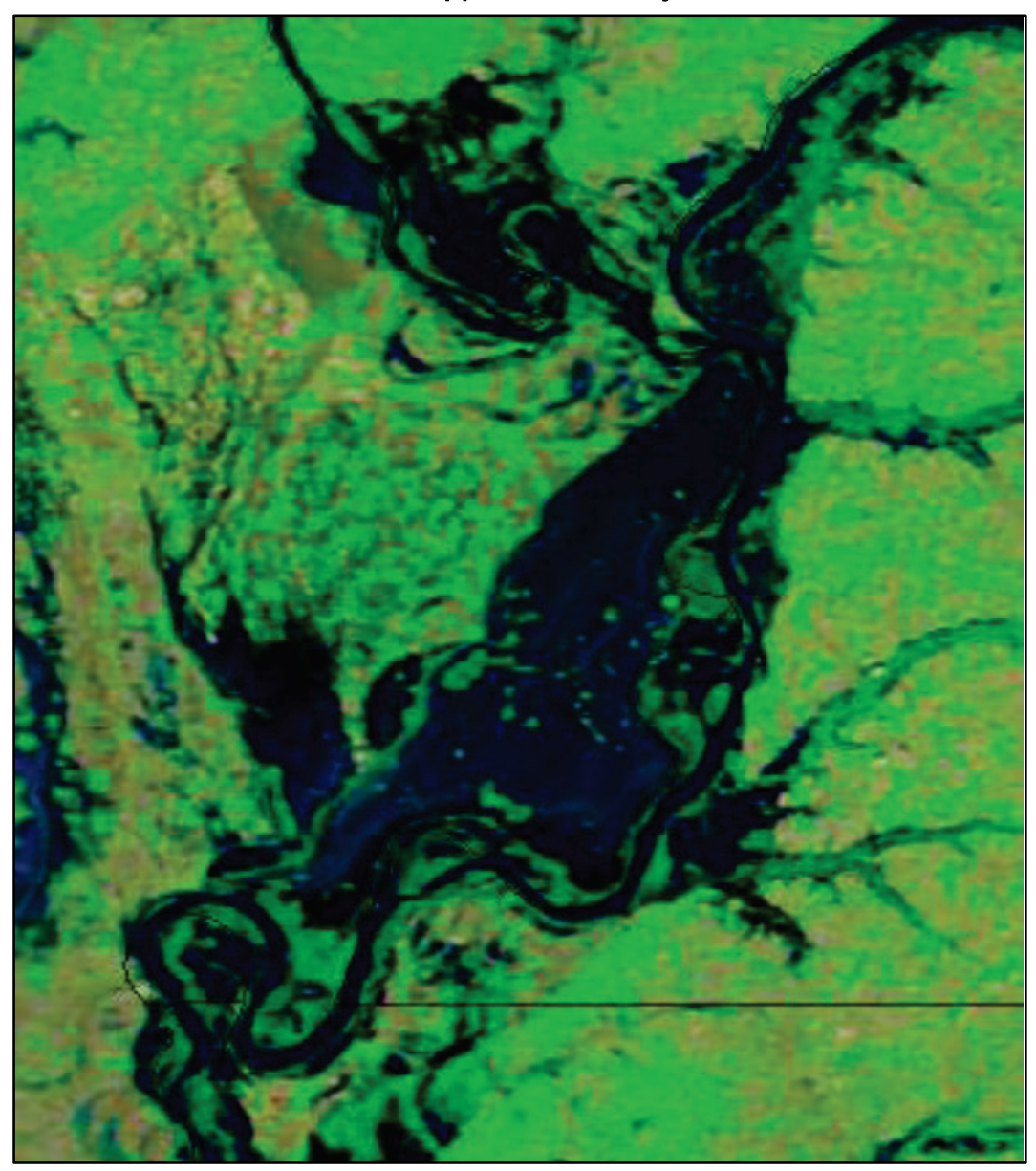




\section{5-2016 Upper Mississippi River flood and LS levee breach}

An infusion of tropical moisture in December 2015 resulted in heavy rainfall across Missouri and southern Illinois. The Mississippi River reached a peak flow of $1,050,000 \mathrm{cfs}(29,700 \mathrm{cms})$ at Thebes, IL, the highest level since 1844. By January 1, 2016, the Thompson Bend floodplain (Miller City, IL) was inundated by backwater flooding topping the river banks below the terminus of the LS levee.

Water was also beginning to spill over the LS levee near the site of the impending breach (Figure 1-4). During the overnight hours of January 1 2, the LS levee breached just upstream of river mile 33 (Figure 1-5). The width of the breach in Figure 1-5 was approximately $920 \mathrm{ft}(280 \mathrm{~m})$. The water level reduction resulting from the breach was evident at the Thebes USGS gage, showing a drop of $1.4 \mathrm{ft}(0.4 \mathrm{~m})$ between 6:00 and 9:00 a.m on January 2 (Figure 1-6). Figure 1-7 shows an aerial view of the breach on January 2.

Figure 1-4. Looking north from near the location of the (future) LS breach, January 1, 2016.

(Note: all photos in this section are from David C. Gordon)

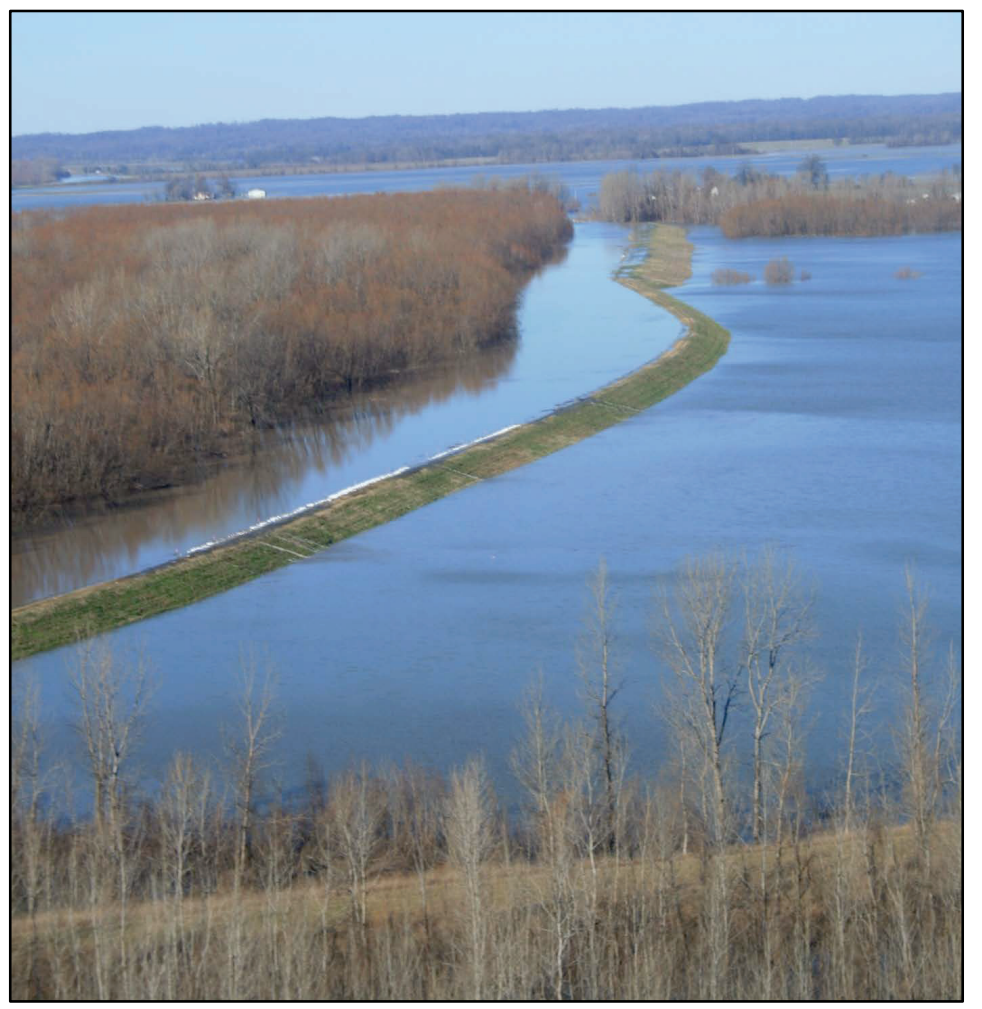


Figure 1-5. Aerial photo of the LS breach, looking east-southeast through the breach, January 2, 2016.

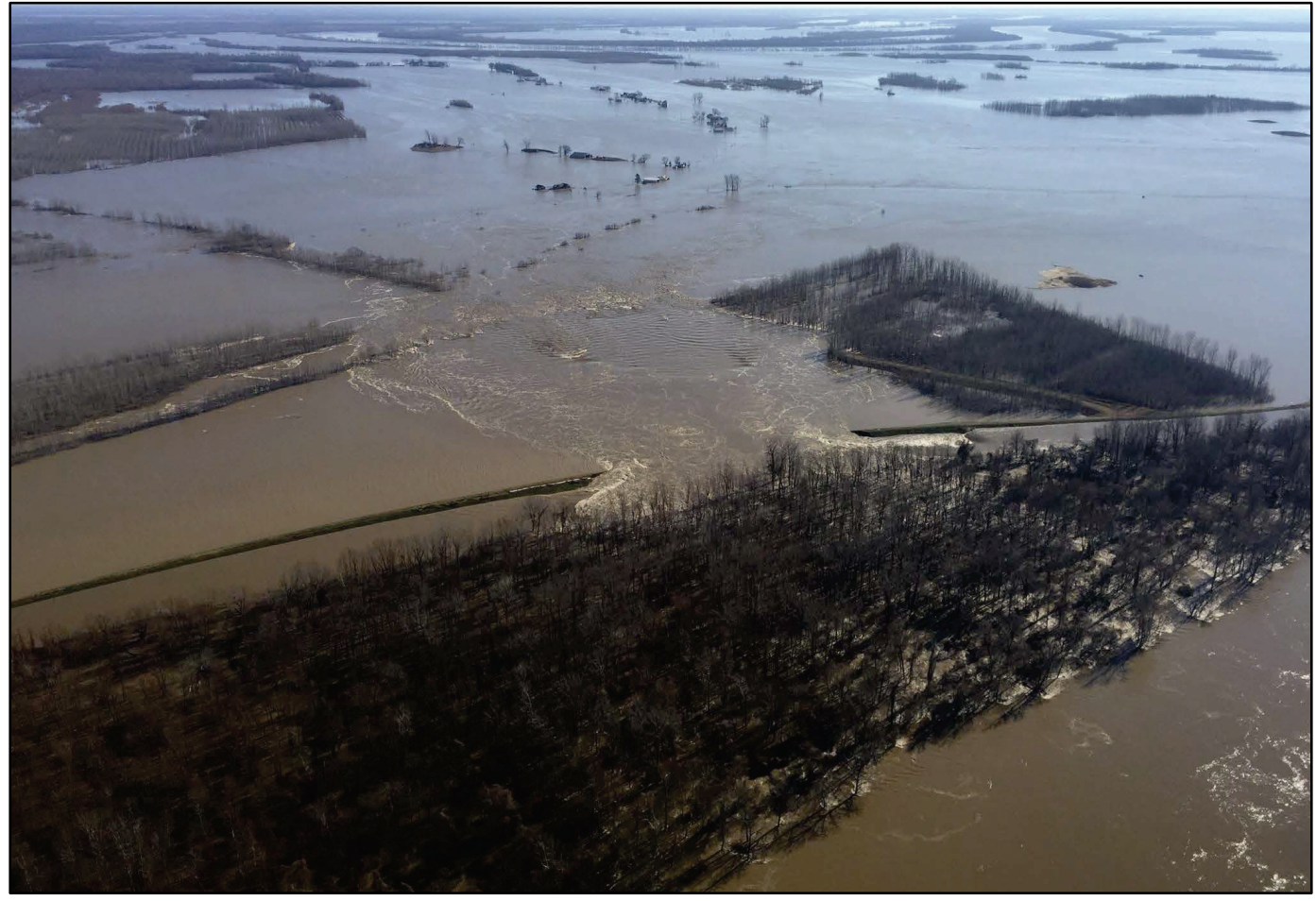

Figure 1-6. US Geological Survey (USGS) Mississippi River at Thebes stage response to the LS levee breach.

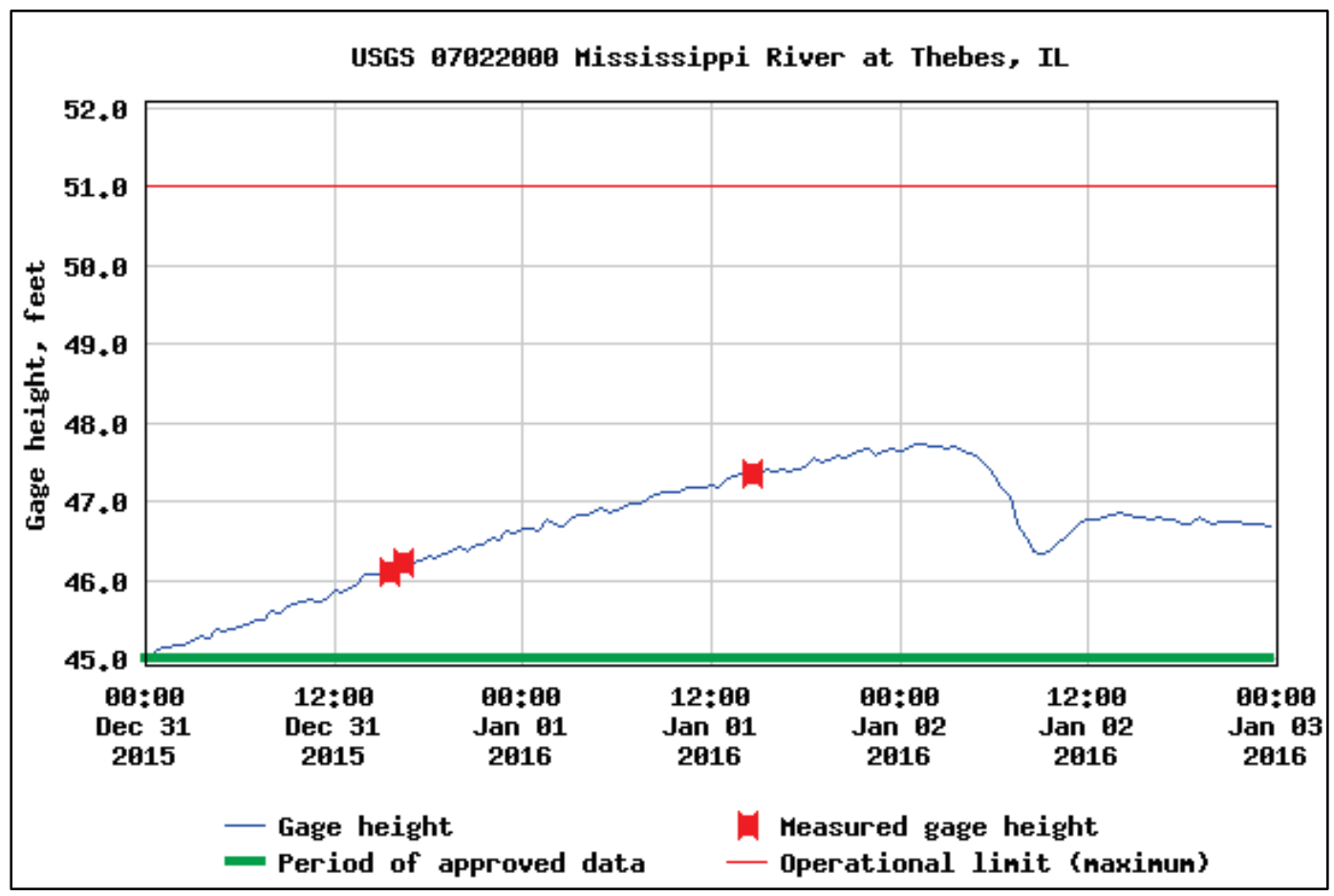


Figure 1-7. Aerial photo of LS levee breach on January 2, 2016.

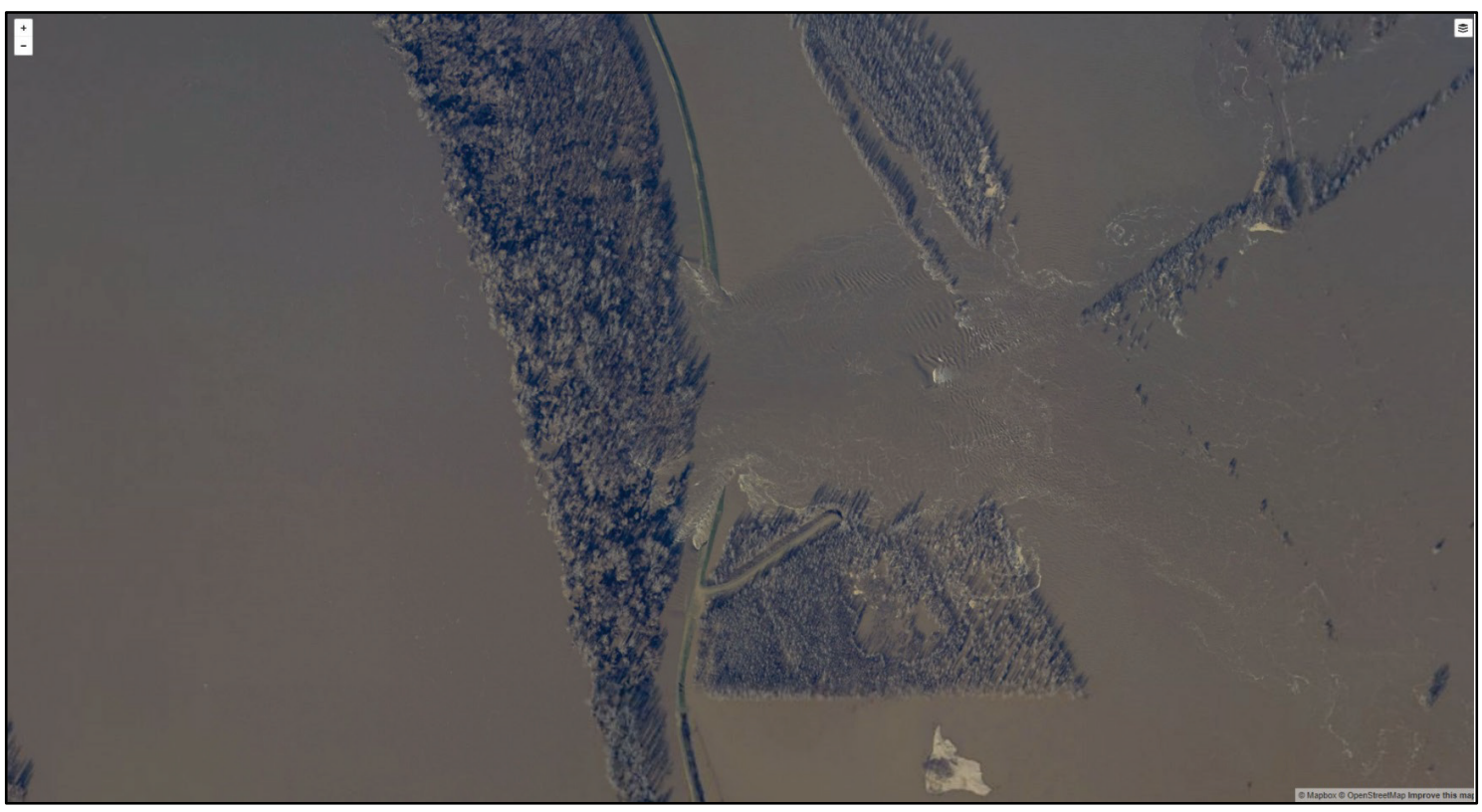

The breach widened over the next few days as evidenced by Figure 1-8, an aerial photo from January 5 , showing the breach expanded to a width of approximately $4,100 \mathrm{ft}(1,250 \mathrm{~m})$. The timing of breach progression between January 2 and January 5 was not documented in the sources available. Figure 1-9 provides a closer look at the extents of the breach on January 19, 2016, showing its expansion as lowering stages revealed the extent of the opening.

The St. Louis District constructed a rock berm along the riverbank to maintain navigation but left an opening to allow for boat access to make additional repairs. Photos from February 17, 2016, show the repair from ground level at the south end of the breach (Figure 1-10) and from an aerial perspective (Figure 1-11). The Len Small levee is not a federal levee and has not been reconstructed at the location of the breach. 
Figure 1-8. Aerial photo of LS breach and floodplain inundation, January 5, 2016. The red arrow highlights the extents of the breach.

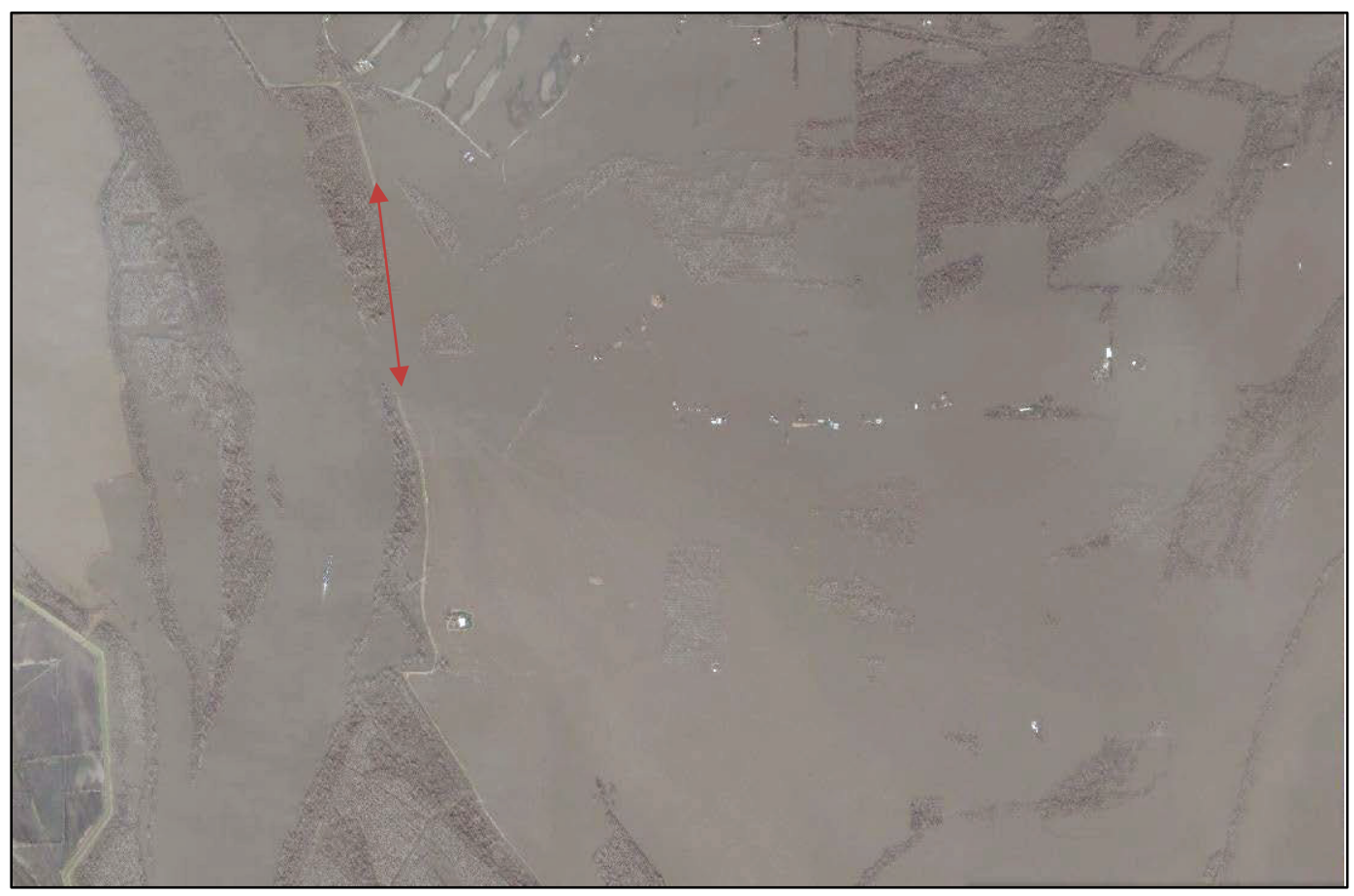

Figure 1-9. Aerial photo of LS breach, January 19, 2016.

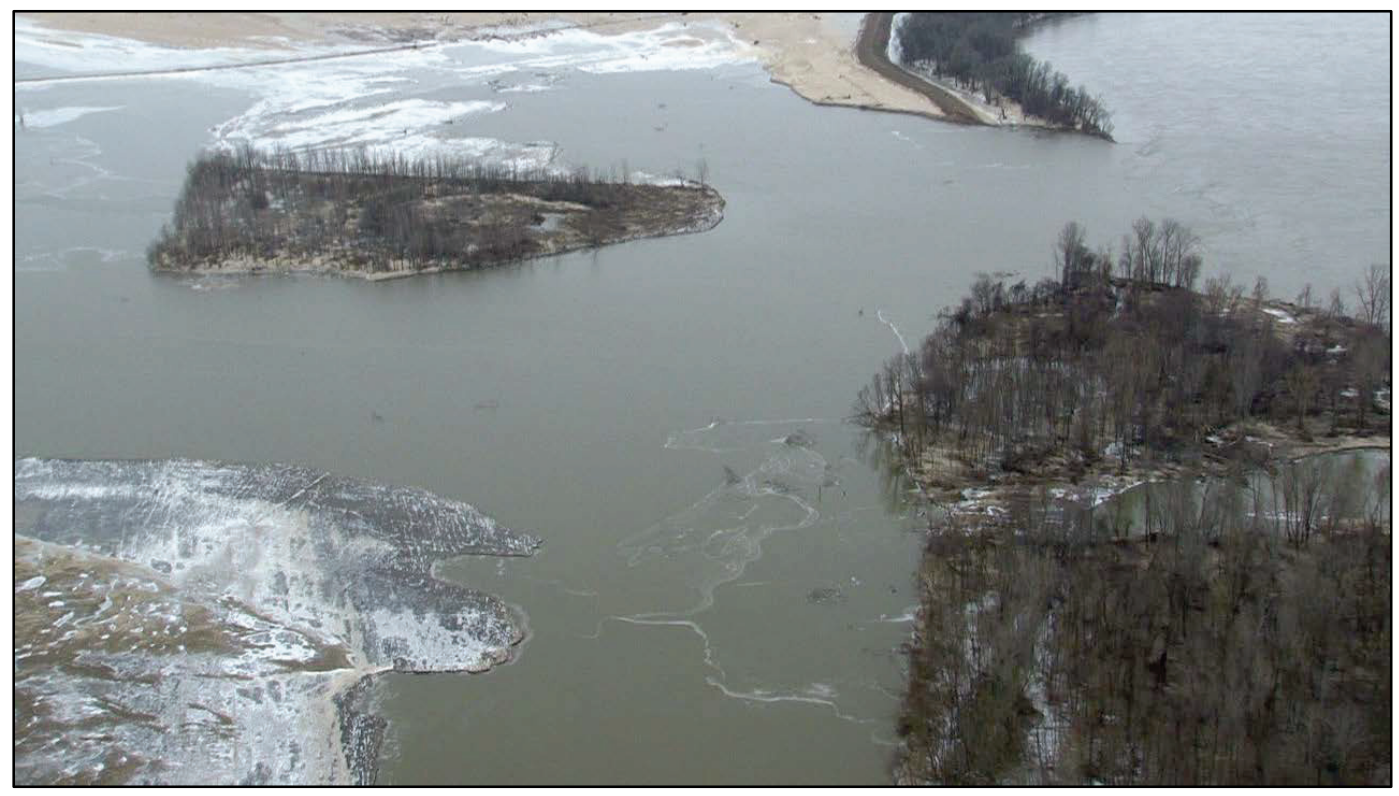


Figure 1-10. Looking north-northwest (upstream) at Mississippi River bankline repair, February 17, 2016.

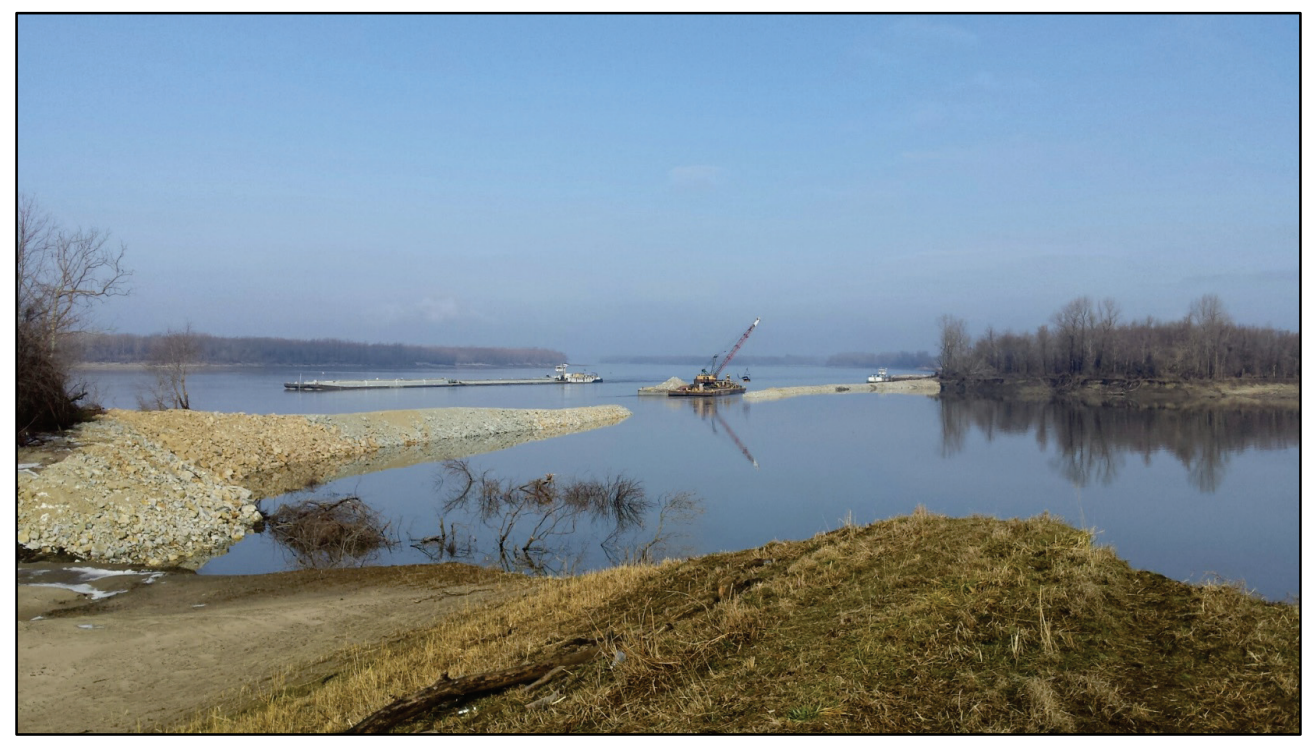

Figure 1-11. Aerial photo of LS breach showing bankline repair, February 17, 2016.

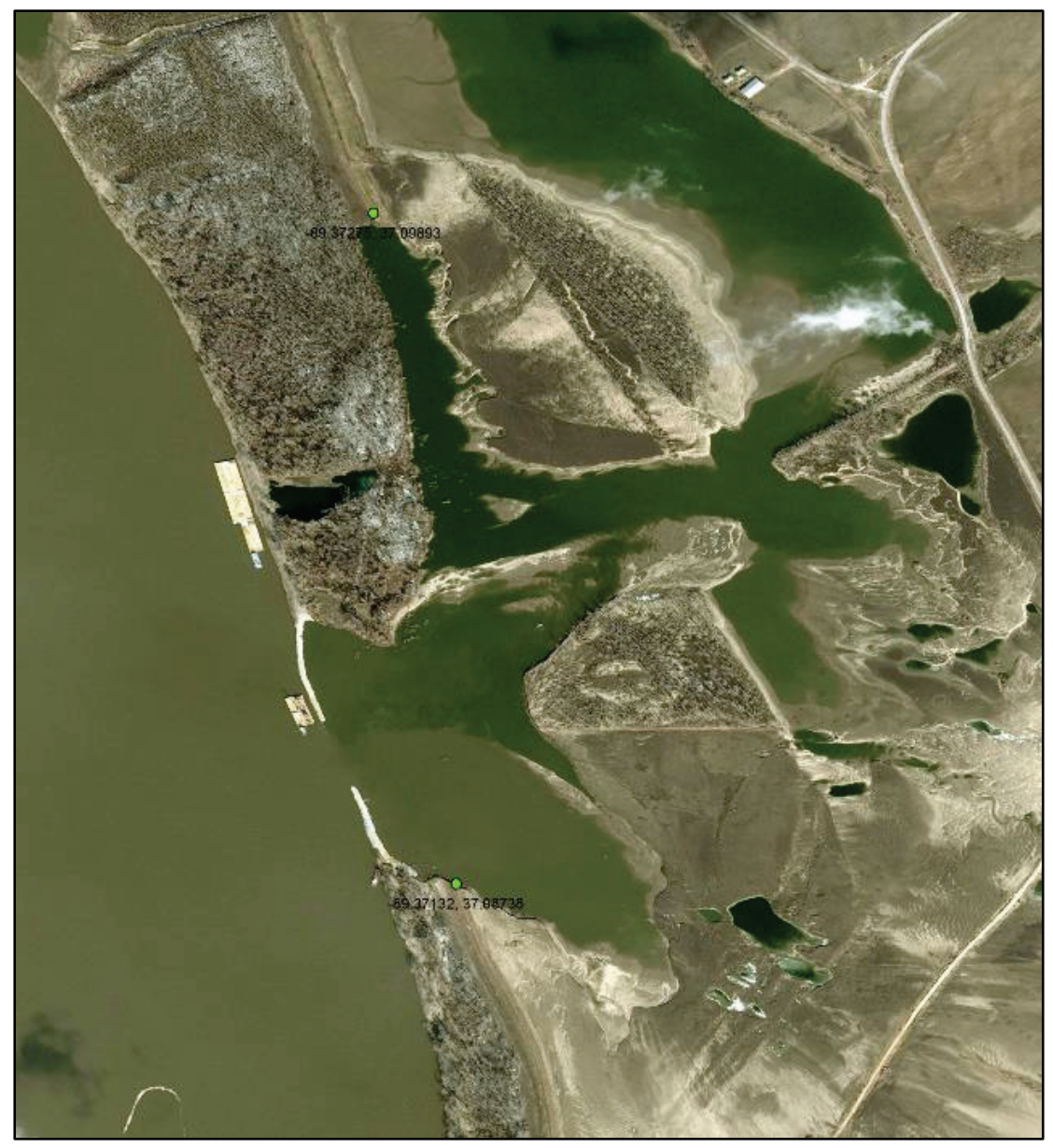




\section{Upper Mississippi River flood}

A series of low pressure systems in April 2017 resulted in high volumes of rainfall in southern Missouri and southern Illinois (Heimann et al. 2018). The Mississippi River at Thebes, IL, peaked at a discharge of 928,000 cfs $(26,300 \mathrm{cms})$ on May 6, 2017. The only floods with higher discharges at the Thebes gage within the recorded data occurred in 1844, 1993, and 2016. The high stages resulted in a large amount of water flowing through the LS breach, as shown in Figure 1-12. The USGS measured the flow through the LS breach during the flood, with discharges reported as high as $370,000 \mathrm{cfs}(10,500 \mathrm{cms})$. These data are discussed in detail in the discharge data section of Chapter 2. Also, several bathymetric surveys near the area of the breach were performed.

Flow through the LS breach is of particular interest as it is possible that the river will form a cutoff, disrupting navigation in the Upper Mississippi River. The flow path across Thompson Bend is 4 miles $(6.4 \mathrm{~km})$ while the path of the main Mississippi River channel is 16 miles $(25.7 \mathrm{~km})$. Additionally, outdraft currents near the LS breach could pose a navigational hazard.

Figure 1-12. Aerial photo of LS breach, looking southeast, May 8, 2017.

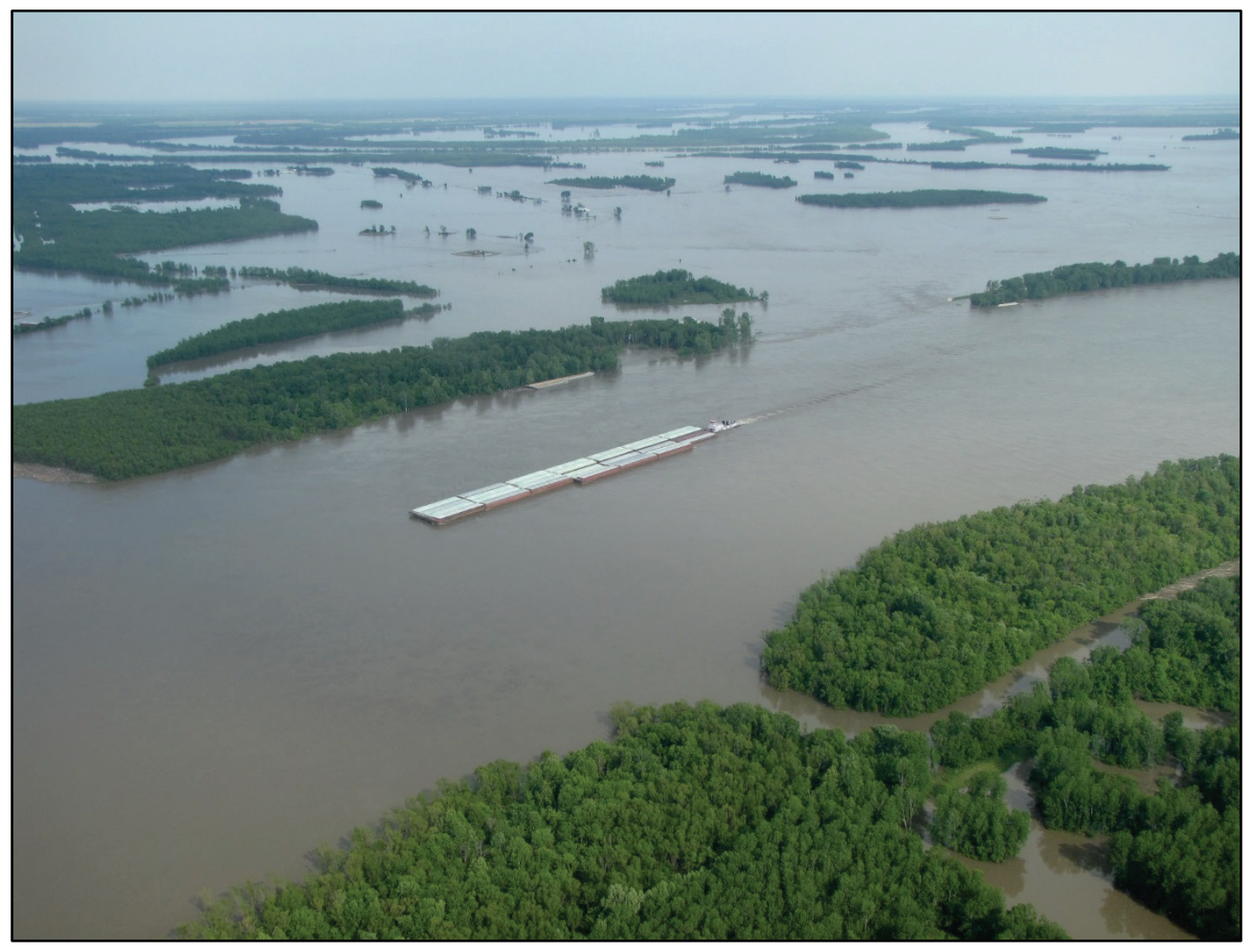




\section{Notable flood modeling efforts}

There have been two recent modeling efforts covering the reach from Commerce to New Madrid: the Mississippi River Flowline Assessment using a one-dimensional (1D) (two-dimensional [2D] in some floodplain areas) Hydrologic Engineering Center River Analysis System (HEC-RAS) model developed by the US Army Corps of Engineers (USACE), Memphis District (Lewis et al. 2018) and a 2D study performed by Luke et al. (2015). Discharge from the Ohio River proved a major source of uncertainty for both modeling efforts.

After the 2011 flood, USACE districts worked to create a comprehensive HEC-RAS model of the Mississippi River. The Memphis District developed the model for the reach studied herein. The boundaries for this model were Chester, IL, on the Mississippi River, Smithland, KY, on the Ohio River, and the downstream boundary was located at Greenville, MS. The model was calibrated to the conditions in 2002, 2008, and 2011. The floodway was included as a 2D polygon and operated for the 2011 event. The model was calibrated to both low and high flows. To calibrate the model for the flood period in 2011, an adjustment was made to the Ohio River flows used as the upstream boundary condition. This was accomplished by matching stages at Smithland to estimate the flow (Lewis et al. 2018). The model produced average errors for stage ranging from 0.4 to $0.7 \mathrm{ft}$ ( 0.12 to $0.21 \mathrm{~m}$ ) with differences for peak stages between $\mathrm{o}$ and $1.0 \mathrm{ft}$ ( $\mathrm{o}$ and $.30 \mathrm{~m}$ ) on the Mississippi River between Commerce and New Madrid, MO.

Luke et al. (2015) used the 2D LISFLOOD-FP model to simulate the 2011 flood event to compare damages associated with the flood as it happened with active BPNMF operation through levee breaching versus a passive operation scenario where the BPNMF was only allowed to overtop the frontline levee and planned crevasse locations. This model used a $10 \mathrm{~m}$ (32.8 ft) Digital Elevation Model (DEM) to depict river and floodplain geometry. The river geometry was further refined with assumptions of channel geometry, not actual bathymetric data. Calibration was refined by modifying Manning's roughness coefficients, local levee crest elevations, Ohio River discharges, and the BPNMF levee failure rates. Model results indicated that activating the BPNMF by deliberate breaching reduced peak stages upstream of the activation site by $0.8 \mathrm{~m}(2.62 \mathrm{ft})$ and that the overall flooding extent was similar for this activation and passive, overtopping scenarios. 


\section{Objective}

The objective of this study is to calculate current patterns and flow distribution along the Mississippi River for the area between Commerce, MO, and New Madrid, MO. This analysis will simulate three recent flooding events to improve understanding of the hydraulic behavior through this reach. This information will also be used to assess navigation concerns and issues.

\section{Approach}

This investigation developed a 2D Adaptive Hydraulics (AdH) model of 128 miles (206 km) of the Mississippi River for the area between Commerce, MO, and New Madrid, MO. AdH Version 4.6 build 2017.07.20 was used for the study. The model domain stretched from Thebes, IL, to Tiptonville, TN, on the Mississippi River and included the Ohio River from Metropolis, IL, to the confluence of the Mississippi (Figure 1-1). The model was calibrated to, and scenarios were run for, the 2011, 2015-2016 (often simplified to 2015), and 2017 flood events. Specific attention was given to BPNMF operation and the Miller City/Len Small (MC/LS) levee break and their possible impacts on navigation in the reach. This investigation used the AdH software to develop and calibrate a 2D hydraulic model of the area between Commerce, MO, and New Madrid, MO. The approach to this investigation is described in more detail in Chapter 3 Model Development. 


\section{Model Data}

\section{Elevation data}

Elevation data, as defined for this report, consists of both bathymetric (below water) and topographic (above water) data. It provides the foundation for the computational grid of the hydrodynamic model.

Elevation data used in this study were primarily derived from two comprehensive DEMs which contain seamless river and overbank data. A seamless DEM for the Upper Mississippi River channel and floodplains was developed by the USGS based on USACE bathymetry and Light Detection and Ranging (LiDAR) data (UMRR LTRM 2016). The USACE Memphis District provided a separate seamless DEM, also based on bathymetric surveys and LiDAR that covered the entire model domain. The minor irregularities observed in the DEM were resolved by taking additional measures when developing the model mesh. The two seamless DEMs were re-projected, re-sampled ( $5 \mathrm{~m}$ resolution), and mosaicked, with the Upper Mississippi River DEM taking precedent. This DEM was referred to as the "MR_Base_DEM."

The seamless DEM data did not have channel elevation data for the Ohio River above Olmsted Lock and Dam. Bathymetric data above that point, to Metropolis, were extracted from the Mississippi River Flowline HEC-RAS model. The RASMAPPER tool was used to create a DEM from the model cross-section information. This was referred to as the "Ohio_River_DEM."

Detailed elevation data for levee crests and river structures were utilized. Point data were extracted from National Levee Database (NLD) products. Point elevation data for structures in the river were provided by the USACE Memphis District.

Ideally, the dates of elevation data surveys are coincident with a model simulation period. A wealth of elevation data exists for the Mississippi River from Commerce to the confluence that allowed for the adjustment of mesh elevations for each calibration period (discussed further in "Chapter 3, Model Development"). Comprehensive channel bathymetry surveys were performed in 2015 and 2016. Comprehensive LiDAR surveys of the floodplain were performed in 2016 and 2017. Surveys of the scour hole at 
the mouth of the LS Breach were taken in January, February, and June of 2016 and again in 2017.

\section{Stage data}

River stage data within the reach were provided by the USACE, primarily in HEC-DSS (CEIWR-HEC 2009) files. Stage data were available for the stations at Commerce, Price Landing, Thompson Landing, and Birds Point on the Mississippi River above the confluence, at Cairo on the Ohio River immediately above the confluence, and on the Lower Mississippi River at Wickliffe, Columbus, Hickman, New Madrid, and Tiptonville (the downstream model boundary). Table 2-1 provides a summary for each stage data station including data source, time period, original datum, and temporal resolution.

Stage data referenced to the local gage datum were converted to NGVD29 using the datum provided by the USACE Rivergages website (USACE 2017) and then converted to NAVD88 using Corpscon (USACE 2004). Table 2-2 shows the pertinent information for the gages that required conversion from the local datum. Hickman, New Madrid, and Tiptonville were resurveyed in 2007 when the Mississippi River Low Water Reference Plane (LWRP) was updated. The reference from that re-survey was utilized (row 2 in the Table 2-2) as it provides the most accurate conversion. During model calibration, it became evident that the observed elevations at Wickliffe and Columbus were not congruent with observed or model simulated elevations at Cairo and Hickman. It was concluded that the datums calculated for Wickliffe and Columbus using Corpscon were inaccurate; therefore, results for these stations are shown in some cases (e.g., Figure 4-14) but were not used to calibrate the model. Lewis et al. (2018) did not report results for Wickliffe or Columbus.

When the BPNMF was activated in 2011, the USGS operated 38 stations that collected stage data within the floodway. For this study, eight representative stations were chosen for calibration purposes. 
Table 2-1. Summary of stage data source, time period, original datum, and interval.

\begin{tabular}{|c|c|c|c|c|}
\hline Station & Source & Time Period & Original Datum & Interval \\
\hline Commerce & Commerce\&Thompson.xlsx & 1Dec2015 - 30May2017 & NAVD88 & Daily (Assume 8:00 SMS time) \\
\hline \multirow{3}{*}{$\begin{array}{l}\text { Price } \\
\text { Landing }\end{array}$} & MVM.dss & 1Jan2011 - 31Mar2014 & NAVD88 & Hourly \\
\hline & 2016.dss & 20Dec2015 - 19Jan2016 & Local Gage Datum & 6-Hour \\
\hline & Observed2017Data.dss & 9Apr2017 - 31Jul2017 & Local Gage Datum & 6-Hour \\
\hline \multirow{3}{*}{$\begin{array}{l}\text { Thompson } \\
\text { Landing }\end{array}$} & Commerce\&Thompson.xlsx & 1Dec2015 - 20Dec2015 & NAVD88 & Daily (Assume 8:00 SMS time) \\
\hline & 2016.dss & 20Dec2015 - 19Jan2016 & NGVD29 & 6-Hour \\
\hline & Commerce\&Thompson.xlsx & 20Jan2016 - 30May2017 & NAVD88 & Daily (Assume 8:00 SMS time) \\
\hline \multirow{3}{*}{ Birds Point } & MVM.dss & 2011 & NAVD88 & Hourly \\
\hline & 2016.dss & 20Dec2015 - 19Jan2016 & NGVD29 & 6-Hour \\
\hline & Observed2017Data.dss & 27Apr2017 - 31Jul2017 & Local Gage Datum & 6-Hour \\
\hline \multirow{2}{*}{ Cairo } & Hourly_Raw_Stage_Data.dss & All & Local Gage Datum & Hourly \\
\hline & Observed2017Data.dss & 20Apr2017 - 24Apr2017 & Local Gage Datum & 6-Hour \\
\hline \multirow{3}{*}{ Wickliffe } & MVM.dss & 2011 & NAVD88 & Daily (Assume 8:00 SMS time) \\
\hline & Hourly_Raw_Stage_Data.dss & 14Jan2014 - 01Jan2018 & Local Gage Datum & Hourly \\
\hline & MVM_gages.dss & 20Apr2017 - 24Apr2017 & Local Gage Datum & Daily (Assume 8:00 SMS time) \\
\hline Columbus & MVM_gages.dss & 20Apr2017 - 23Apr2017 & Local Gage Datum & Daily (Assume 8:00 SMS time) \\
\hline \multirow{2}{*}{ Hickman } & Hourly_Raw_Stage_Data.dss & All & Local Gage Datum & Hourly \\
\hline & MVM_gages.dss & 20Apr2017 - 23Apr2017 & Local Gage Datum & Daily (Assume 8:00 SMS time) \\
\hline \multirow{2}{*}{ New Madrid } & Hourly_Raw_Stage_Data.dss & All & Local Gage Datum & Hourly \\
\hline & MVM_gages.dss & 20Apr2017 - 23Apr2017 & Local Gage Datum & Daily (Assume 8:00 SMS time) \\
\hline
\end{tabular}


Table 2-2. Summary of datum conversions for Lower Mississippi River stage gages.

\begin{tabular}{|c|c|c|c|c|c|c|c|c|}
\hline Row & Value & $\begin{array}{l}\text { Ohio River - } \\
\text { Cairo }\end{array}$ & $\begin{array}{l}\text { Miss. River - } \\
\text { Wickliffe }\end{array}$ & $\begin{array}{l}\text { Miss. River - } \\
\text { Columbus }\end{array}$ & $\begin{array}{l}\text { Miss. River - } \\
\text { Hickman }\end{array}$ & $\begin{array}{l}\text { Miss. River - } \\
\text { New Madrid }\end{array}$ & $\begin{array}{l}\text { Miss. River - } \\
\text { Tiptonville }\end{array}$ & Description \\
\hline 1 & Difference (ft) & -- & -- & -- & -0.59 & -0.14 & -0.02 & Calculated (2) - (3) \\
\hline 2 & 2007 LWRP NAVD88 (ft) & unavailable & unavailable & unavailable & 264.36 & 255.71 & 245.35 & USACE Provided \\
\hline 3 & NAVD88 Datum (ft) & 270.87 & 269.52 & 266.74 & 264.95 & 255.85 & 245.37 & Calculated (4) + (5) \\
\hline 4 & NGVD29 Datum (ft) & 270.47 & 269.12 & 266.38 & 264.73 & 255.48 & 245.14 & from Rivergages.com \\
\hline 5 & NGVD29 to NAVD88 (ft) & 0.40 & 0.40 & 0.36 & 0.22 & 0.37 & 0.23 & $\begin{array}{l}\text { Conversion from } \\
\text { Corpscon }\end{array}$ \\
\hline
\end{tabular}




\section{Discharge data}

\section{Continuous discharge data}

The Mississippi River at Thebes, IL, USGS site (07022000) provided a reliable record of discharge as the entirety of the river is contained between the bluffs flanking the river. The station at Thebes has daily discharge reported since 1933. This gage provided the upstream Mississippi River flow boundary for the model.

Flood flows in the Ohio River near the confluence were more difficult to measure because of the large amount of overbank conveyance. The USGS operated a station with a discharge rating at Metropolis (USGS 03611500) until 2015 and began operating a station at Olmsted (USGS 03612600) in 2013, which also reports discharge. The "Chapter 3, Boundary Conditions" section discusses how these data were utilized.

Two tributaries enter the study reach during flood flows; Humphrey Creek flows into the Ohio River approximately 12 miles (19 km) above the confluence, and Mayfield Creek flows into the Mississippi River south of Wickliffe, KY, 3 miles ( $4.8 \mathrm{~km}$ ) below the confluence. St. Johns Bayou enters the Mississippi River near New Madrid, IL; however, it was assumed that during flood flows on the Mississippi River, the flood gates at the federal levee are closed. Flows from Humphrey Creek and St. Johns Bayou were generated by the National Weather Service model and provided by the USACE Memphis District.

\section{Acoustic Doppler current profiler (ADCP) discharge data - 2011 flood}

The USGS collected discrete discharge data in the Mississippi River, Ohio River, and BPNMF during the 2011 flood (Koenig and Holmes 2013), which were used for model calibration. Figure 2-1 shows the general locations of the USGS discharge cross sections that were used for model calibration. 
Figure 2-1. General locations of the USGS discharge measurement cross-sections.

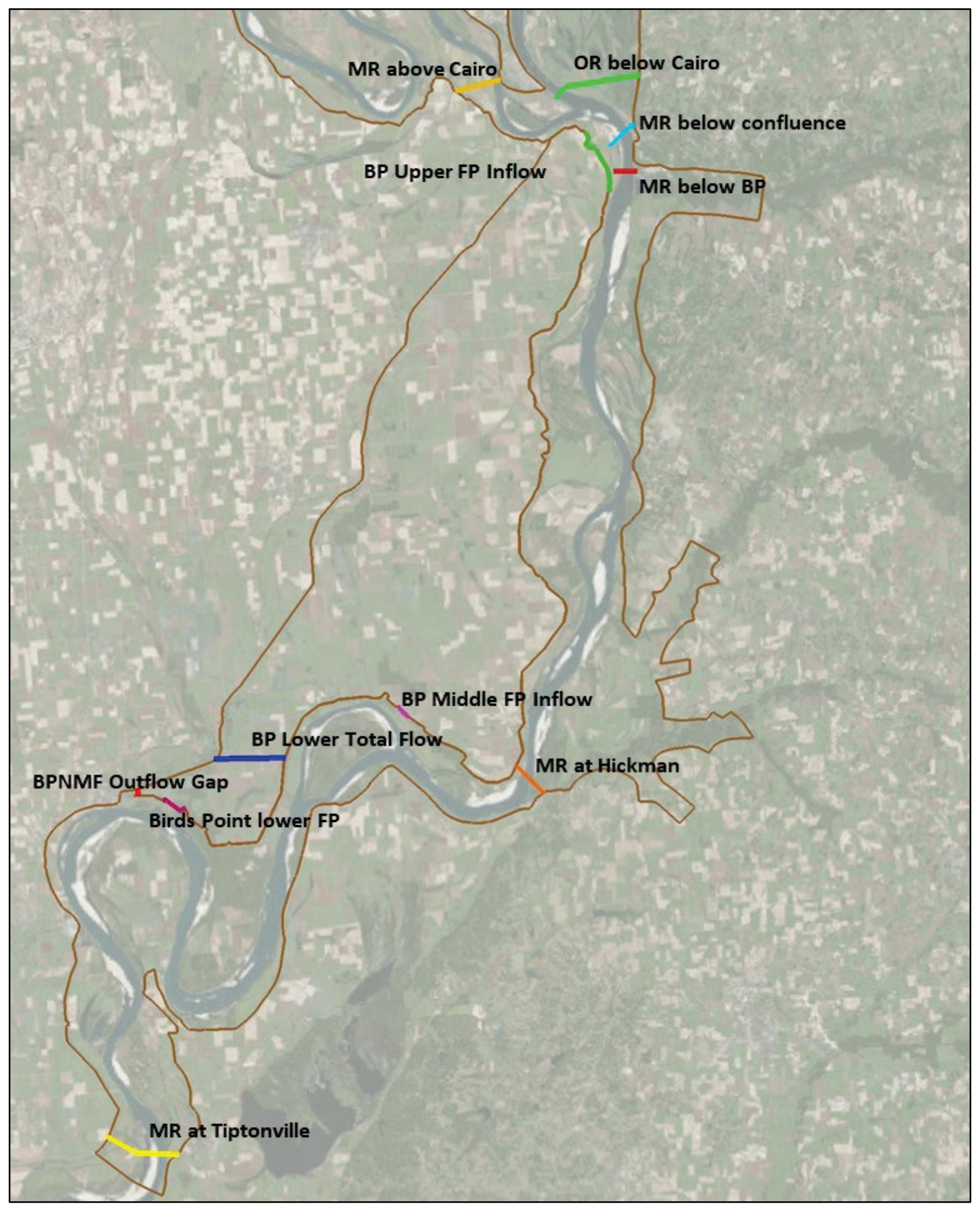




\section{ADCP discharge data near the LS levee breach}

The USGS performed discharge measurements at the LS levee breach, using an ADCP, immediately following the breach in 2016 and during the 2017 flood event. Discharge data were provided by the USACE Memphis District. Discharges for upstream flow, flow through the LS breach, and the percentage of total flow through LS were given in tabular form as shown in Table 2-3. Differing methods were employed to determine flow through the breach as shown in the tabulation. Some reported discharges were by direct measurement while others were the result of indirect calculation (upstream - downstream = breach flow). It was not known which values from the table of flows were measured and which were computed. At the time of publication, raw ADCP data files were only available for the January 2016, 5/7/2017, and 5/8/2017 measurements. The raw ADCP data available were assessed using both the QRev (Version 3.43) (Mueller 2016) and WinRiver II (Teledyne 2008) software packages. Each software package used different filters and interpolation schemes, so the estimates of discharge vary.

While rigorous processing of the $\mathrm{ADCP}$ data was not within the scope of the study, the compiled and interpreted ADCP data were utilized to develop a comprehensive interpretation of the flow distribution at the LS levee breach (Table 2-4), as discussed below.

Table 2-3. LS tabular ADCP discharge data provided by USACE.

\begin{tabular}{|l|c|c|c|}
\hline \multicolumn{4}{|c|}{ LS ADCP Discharge Data } \\
\hline Date & Upstream Flow (cfs) & $\begin{array}{c}\text { Flow through Breach } \\
\text { (cfs) }\end{array}$ & $\begin{array}{c}\text { Split through Breach } \\
\text { (percent) }\end{array}$ \\
\hline 02Jan2016 & $1,000,000$ & 200,000 & 20 \\
\hline 03May2017 & 750,000 & 170,000 & 23 \\
\hline 07May2017 & 920,000 & 360,000 & 40 \\
\hline 08May2017 & $1,020,000$ & 370,000 & 36 \\
\hline 09May2017 & 780,000 & 290,000 & 37 \\
\hline
\end{tabular}

January 2016 discharge data

The tabular data suggest outflow through the LS breach on 1/2/2016 was $5,660 \mathrm{cms}$ (200,000 cfs). The daily discharges for the Mississippi River at Thebes were $29,200 \mathrm{cms}(1,030,000 \mathrm{cfs})$ on $1 / 2 / 2016$ and $28,600 \mathrm{cms}$ (1,010,000 cfs) on $1 / 3 / 2016$. 
Raw ADCP files provided by the USACE Memphis District indicate discharge measurements were taken for the LS outflow on 1/3/2016. Figure 2-2 shows the locations of the transects. Notes from the 1/3/2016 data indicated that transects 005 and 006 were the transects that best represented flows through the LS breach. The QRev software indicated discharges for transect 005 and 006 to be 5,420 and 4,420 $\mathrm{cms}(191,000$ and $156,000 \mathrm{cfs}$ ) for an estimated average discharge of 4,920 cms $(174,000 \mathrm{cfs})$. There was a $10 \%$ difference between the calculated and average discharge at each transect. The WinRiver software indicated discharges of 5,380 and $5,350 \mathrm{cms}(190,000$ and $189,000 \mathrm{cfs})$, for an average of $5,360 \mathrm{cms}(189,000 \mathrm{cfs})$ for transects 005 and 006.

It was not known whether the values listed in the tabular data for $1 / 2 / 2016$ were from a separate measurement or if an error was made in reporting the date. The measured values for LS outflow discharge nearly matched, and sources did not mention multiple discharge measurement events, so it was assumed that the tabular data were referring to the 1/3/2016 data.

Mueller and Wagner (2009) suggest that a minimum of four transects (two in each direction) be taken to measure steady flow, and if the discharge for any of the four differ by more than $5 \%$ from the mean, four more transects should be taken, and the mean of all eight transects used to compute total discharge. 
Figure 2-2. ADCP tracks for measurements taken $1 / 3 / 2016$ at the LS breach.

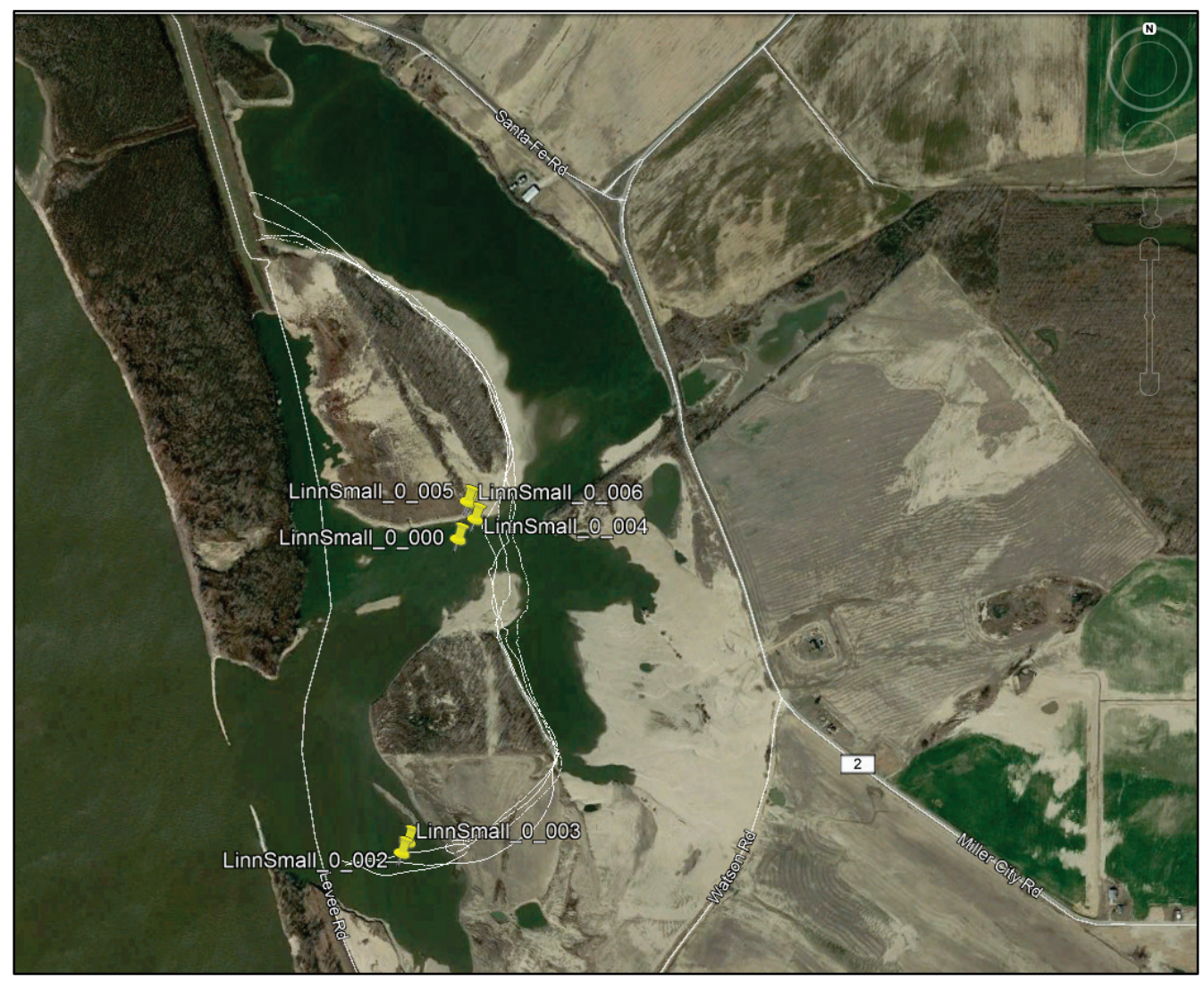

May 2017 discharge data

Raw ADCP data were available for measurement events on 5/7/2017 and 5/8/2017. Raw data were not available for 5/3/2017 and 5/9/2017 measurements. A summary of tabular, processed raw data, and daily average discharge reported at the USGS Mississippi River at Thebes gage is given in Table 2-4 and summarized herein.

A review of the raw data for the 5/7/2017 event revealed that only one direct discharge cross-section measurement was performed, measuring outflow at the LS breach. Both the QRev and the WinRiver software gave numerous warnings about the quality of the data, particularly in the vicinity of the main flow path. The QRev software reported a discharge of $6,600 \mathrm{cms}(233,000 \mathrm{cfs})$ and the WinRiver software reported a flow of $10,000 \mathrm{cms}(353,000 \mathrm{cfs})$. As a result, these data were used with an understanding of the uncertainty associated with discharge measurements at this location. 
The 5/8/2017 measurement event measured discharge at cross-sections upstream and downstream of the LS breach as shown in Figure 2-3. Two discharge transects were performed upstream of the LS breach and four downstream. QRev reported an average upstream discharge of 29,200 cms $(1,032,000 \mathrm{cfs})$ and an average downstream discharge of $18,290 \mathrm{cms}$ $(646,000 \mathrm{cfs})$. Upstream discharge estimated by the ADCP was $19 \%$ higher than the daily average at Thebes and higher than any hourly discharge reported during that flood event. Plotting the USACE tabular data (Figure 2-4) against hourly discharge at Thebes shows that the 5/8/2017 data were an outlier. 
Table 2-4. Summary of flow measurement data near the LS breach. "Table" indicates the value came from Table 2-3, "Inferred Table" means the value was calculated based on the "Table," and "N/A" indicates data were not available.

\begin{tabular}{|c|c|c|c|c|c|c|}
\hline \multirow[b]{2}{*}{ Date } & \multicolumn{2}{|c|}{ Upstream Flow } & \multicolumn{2}{|c|}{ Breach Flow } & \multicolumn{2}{|c|}{ Downstream Flow } \\
\hline & Table & Other Data & Table & ADCP Estimate & Inferred Table & ADCP Estimate \\
\hline $\begin{array}{l}\text { May 3, } \\
2017\end{array}$ & $\begin{array}{c}21,200 \mathrm{cms} \\
(750,000 \mathrm{cfs})\end{array}$ & $\begin{array}{c}\text { USGS Thebes: } \\
21,900 \mathrm{cms}(773,000 \mathrm{cfs})\end{array}$ & $\begin{array}{c}4,800 \mathrm{cms} \\
(170,000 \mathrm{cfs})\end{array}$ & N/A & $\begin{array}{l}16,400 \mathrm{cms} \\
(580,000 \mathrm{cfs})\end{array}$ & $\mathrm{N} / \mathrm{A}$ \\
\hline $\begin{array}{l}\text { May } 7 \\
2017\end{array}$ & $\begin{array}{c}26,100 \mathrm{cms} \\
(920,000 \mathrm{cfs})\end{array}$ & $\begin{array}{c}\text { USGS Thebes: } \\
25,600 \mathrm{cms}(905,000 \mathrm{cfs})\end{array}$ & $\begin{array}{c}10,200 \mathrm{cms} \\
(360,000) \mathrm{cfs}\end{array}$ & $\begin{array}{c}\text { QRev: } \\
6,600 \mathrm{cms} \\
(233,000 \mathrm{cfs}) \\
\text { WinRiver: } \\
10,000 \mathrm{cms} \\
(353,000 \mathrm{cfs})\end{array}$ & $\begin{array}{l}15,900 \mathrm{cms} \\
(560,000 \mathrm{cfs})\end{array}$ & N/A \\
\hline $\begin{array}{l}\text { May 8, } \\
2017\end{array}$ & $\begin{array}{c}28,900 \mathrm{cms} \\
(1,020,000 \mathrm{cfs})\end{array}$ & $\begin{array}{c}\text { USGS Thebes: } \\
24,500 \text { cms ( } 864,000 \mathrm{cfs}) \\
\text { QRev: } \\
29,200 \mathrm{cms}(1,032,000 \mathrm{cfs}) \\
\text { WinRiver: } \\
28,700 \mathrm{cms}(1,015,000 \mathrm{cfs})\end{array}$ & $\begin{array}{c}10,800 \mathrm{cms} \\
(380,000 \mathrm{cfs})\end{array}$ & $\mathrm{N} / \mathrm{A}$ & $\begin{array}{l}18,100 \mathrm{cms} \\
(640,000 \mathrm{cfs})\end{array}$ & $\begin{array}{c}\text { QRev: } \\
18,290 \mathrm{cms} \\
(646,000 \mathrm{cfs}) \\
\text { WinRiver: } \\
18,100 \mathrm{cms} \\
(641,000 \mathrm{cfs})\end{array}$ \\
\hline $\begin{array}{l}\text { May 9, } \\
2017\end{array}$ & $\begin{array}{c}22,100 \mathrm{cms} \\
(780,000 \mathrm{cfs})\end{array}$ & $\begin{array}{c}\text { USGS Thebes: } \\
23,100 \mathrm{cms}(816,000 \mathrm{cfs})\end{array}$ & $\begin{array}{c}8,200 \mathrm{cms} \\
(290,000 \mathrm{cfs})\end{array}$ & N/A & $\begin{array}{c}13,900 \mathrm{cms} \\
(490,000 \mathrm{cfs})\end{array}$ & N/A \\
\hline
\end{tabular}


Figure 2-3. ADCP tracks for measurements taken 5/8/2017 at the LS breach.

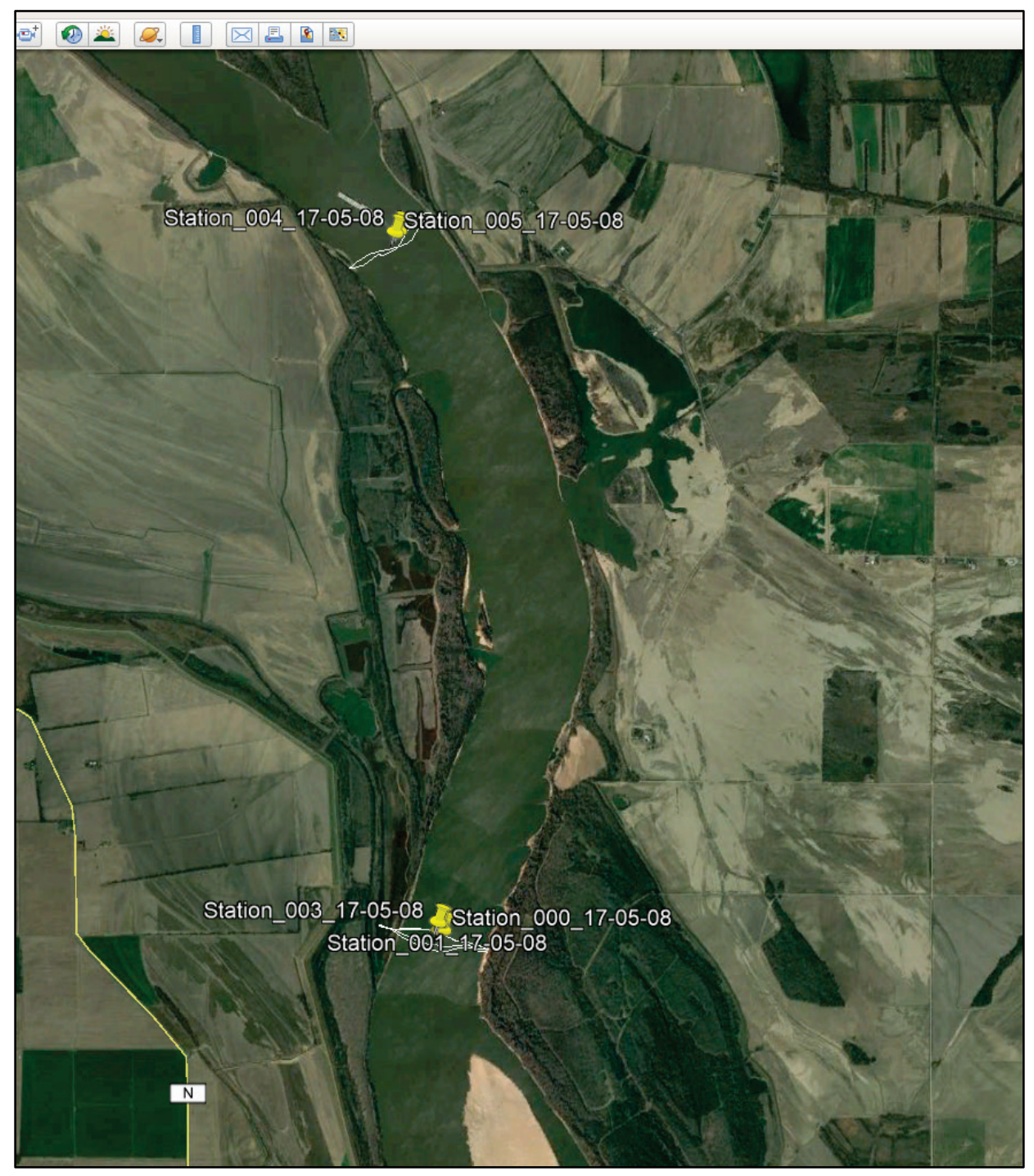


Figure 2-4. Discharge for Mississippi River at Thebes USGS station and upstream discharge provided in the USACE tabular data.

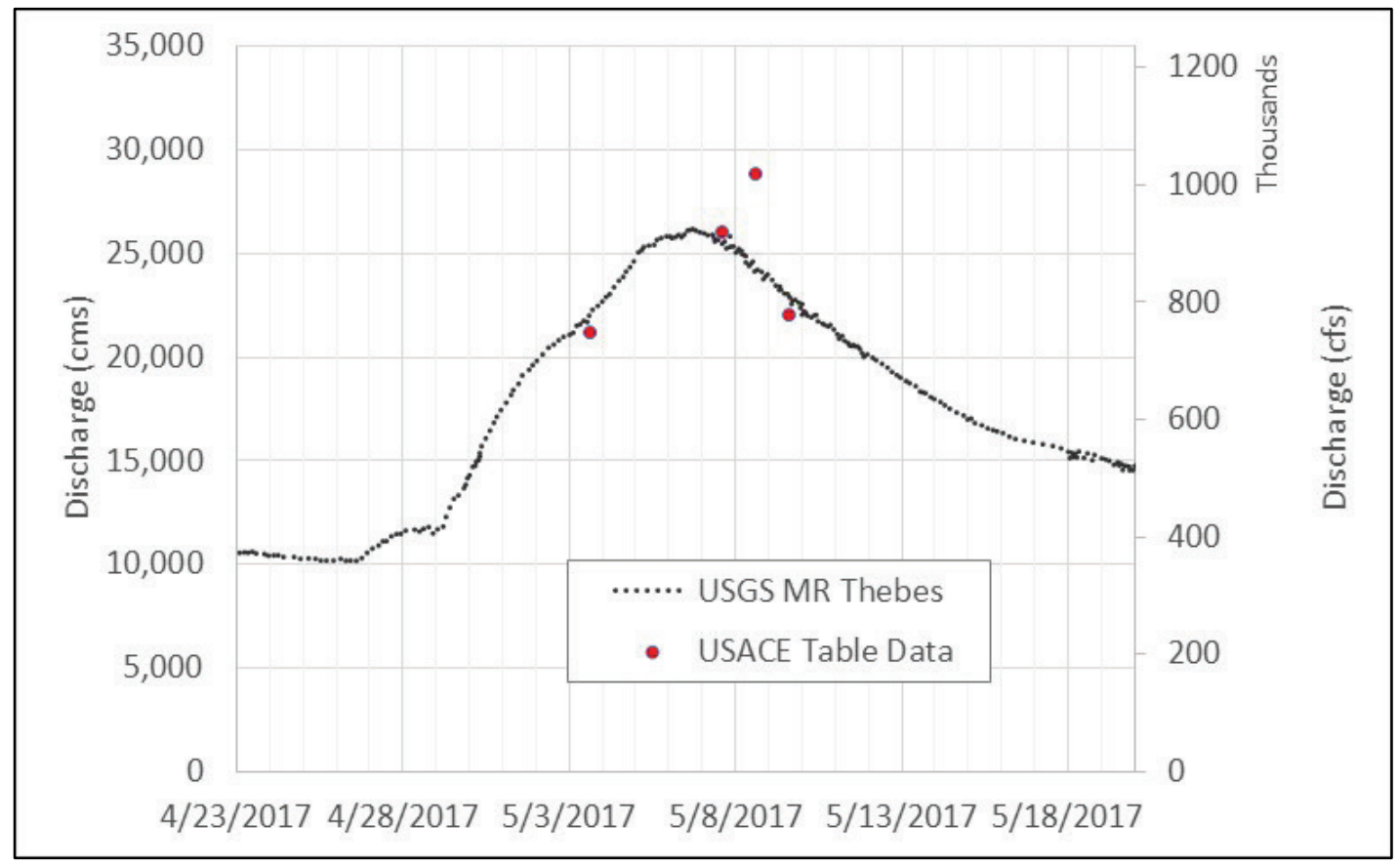

Error bounds for LS discharge data

A critical step to utilizing the LS discharge data, both tabular and processed ADCP, included applying appropriate error bounds. Considered in the estimated error bounds were the range of computed discharges among transects at the same cross-section, the less than recommended number of transect measurements performed, and comparison to more reliable data at Thebes. Because the discharge transect data varied as much as $15 \%$ for a single composite measurement, an observation error of $\pm 15 \%$ was adopted as an appropriate estimation of error bounds for the discharge data near LS.

\section{Velocity data}

Depth-averaged velocity data were published by the USGS (Koenig and Holmes 2013) for the ADCP data taken during the 2011 flood. The general locations of the cross sections are shown in Figure 2-1. Model calibration focused on comparisons to the cross sections taken in the Mississippi River near the entrance of the BPNMF. Comparisons were not made to velocity data near the BPNMF crevasse locations as examinations showed that it is highly dependent on the geometry of the resulting opening. Failure geometry for crevasses was not available. 


\section{Model Development}

\section{Projection, Datum and Units}

The modeling study was performed in SI units, and therefore, modeling results are primarily reported in SI. Future studies in the reach will include sediment transport, for which the AdH model requires the use of SI units.

The horizontal projection for the model and data, ultimately, was Albers, as defined below in Table 3-1. In ArcGIS (ESRI 2017), this is named as the "USA_Contiguous_Albers_Equal_Area_Conic_USGS_version". The vertical projection is NAVD88, meters.

Table 3-1. Horizontal projection.

\begin{tabular}{|l|l|}
\hline Parameter & Value \\
\hline Projection & Albers \\
\hline False Easting & 0.0 \\
\hline False Northing & 0.0 \\
\hline Central Meridian & -96.0 \\
\hline Standard Parallel 1 & 29.5 \\
\hline Standard Parallel 2 & 45.5 \\
\hline Latitude of Origin & 23.0 \\
\hline Units & meters \\
\hline $\begin{array}{l}\text { Geographic } \\
\text { Coordinate System }\end{array}$ & \begin{tabular}{l} 
GCS North American \\
\hline Datum
\end{tabular} \\
\hline Prime Meridian & Greenwich American 1983 \\
\hline Angular Unit & Degree \\
\hline
\end{tabular}

\section{Adaptive Hydraulics (AdH) description}

The AdH model software was recommended as the hydrodynamic modeling software to be used for this study (AdH Version 4.31) (Berger et al. 2013; Savant et al. 2020). The AdH model has been specially developed to handle the complex hydrodynamics associated with dam and levee failure problems. 
AdH is a conservative, implicit, finite element hydrodynamic and constituent transport model developed by the US Army Engineer Research and Development Center, Coastal and Hydraulics Laboratory. AdH is capable of simulating overland flow, and $2 \mathrm{D}$ or $3 \mathrm{D}$ shallow water problems, with the current study utilizing the 2D shallow water module. The $2 \mathrm{D}$ shallow water equations used for this application are a result of the vertical integration of the equations of mass and momentum conservation for incompressible fluids under the hydrostatic pressure assumption. Written in conservative form, the $2 \mathrm{D}$ shallow water equations are

$$
\frac{\partial \mathbf{U}}{\partial t}+\frac{\partial \mathbf{F}}{\partial x}+\frac{\partial \mathbf{G}}{\partial y}+\mathbf{H}=0
$$

where

$$
\begin{gathered}
\mathbf{U}=\left\{\begin{array}{c}
h \\
u h \\
v h
\end{array}\right\} \\
\mathbf{F}=\left\{\begin{array}{c}
u h \\
u^{2} h+\frac{1}{2} g h^{2}-h \frac{\sigma_{x x}}{\rho} \\
u v h-h \frac{\sigma_{y x}}{\rho}
\end{array}\right\} \\
\mathbf{G}=\left\{\begin{array}{c}
u v h-h \frac{\sigma_{x y}}{\rho} \\
v^{2} h+\frac{1}{2} g h^{2}-h \frac{\sigma_{y y}}{\rho}
\end{array}\right\}
\end{gathered}
$$

and 


$$
\mathbf{H}=\left\{\begin{array}{c}
0 \\
g h \frac{\partial z_{b}}{\partial x}+n^{2} g h \frac{u \sqrt{u^{2}+v^{2}}}{C_{o} h^{1 / 3}} \\
g h \frac{\partial z_{b}}{\partial y}+n^{2} g h \frac{v \sqrt{u^{2}+v^{2}}}{C_{o} h^{1 / 3}}
\end{array}\right\}
$$

where

$$
\begin{aligned}
\rho= & \text { fluid density } \\
g= & \text { gravitational acceleration } \\
z b= & \text { riverbed elevation } \\
n= & \text { Manning's roughness coefficient } \\
h= & \text { flow depth } \\
u= & \mathrm{x} \text {-component of velocity } \\
v= & \mathrm{y} \text {-component of velocity } \\
C_{o}= & \text { dimensional conversion coefficient (1 for SI units; } 1.486 \text { for US } \\
& \text { customary units) } \\
\sigma^{\prime} \mathrm{s}= & \text { the Reynolds stresses due to turbulence, where the first } \\
& \text { subscript indicates the direction and the second indicates the } \\
& \text { face on which the stress acts. }
\end{aligned}
$$

The Reynolds stresses are determined using the Boussinesq approximation to the gradient in the mean currents:

$$
\begin{aligned}
& \sigma_{x x}=2 \rho v_{t} \frac{\partial u}{\partial x} \\
& \sigma_{y y}=2 \rho v_{t} \frac{\partial v}{\partial y}
\end{aligned}
$$

and

$$
\sigma_{x y}=\sigma_{y x}=2 \rho v_{t}\left(\frac{\partial u}{\partial y}+\frac{\partial v}{\partial x}\right)
$$

where $v_{\mathrm{t}}=$ kinematic eddy viscosity (which varies spatially). 
The AdH shallow water equations are placed in conservative form so that mass balance and the balance of momentum and pressure are identical across an interface. This is important in order to match the speed and height of a surge or hydraulic jump.

The equations are solved in a finite element computational grid. The quality of the numerical solution depends on the choice of the basis/trial function and the test function. The trial function determines how the variables are represented, and the test function determines the manner in which the differential equation is enforced. In the Galerkin approach, the test functions are chosen to be identical with the trial functions. When the flow is advection dominated, the Galerkin approach produces oscillatory behavior, and the Galerkin form of the test function cannot detect the presence of a node-to-node oscillation and so allows this spurious solution. The approach used in AdH is to enrich the standard Galerkin test function with an additional term that can detect and control this spurious solution (Savant et al. 2010).

One of the major benefits of AdH is its ability to automatically adapt the mesh in areas where additional spatial resolution is needed to properly resolve the hydrodynamics. This process is done by normalizing the results so that an error quantity is determined for each element. If this error exceeds the tolerance set by the user, then the element is refined. AdH is also able to enlarge previously refined areas when the added resolution is no longer needed. AdH contains other essential features such as wetting and drying, completely coupled sediment and salt transport, and wind effects. A series of modularized libraries make it possible for AdH to include vessel movement, friction descriptions, as well as a host of other crucial features. AdH can run in parallel or on a single processor and runs on both Windows systems and UNIX-based computer systems. Berger et al. (2013) and Savant et al. (2010, 2020) provide an in-depth description of the AdH surface water model.

\section{Model domain}

The model domain encompasses 128 miles of the Mississippi River from Thebes, IL, to Tiptonville, TN, on the Mississippi River and upstream on the Ohio River from the confluence to Metropolis, IL (Figure 3-1). The primary area of interest is the Mississippi River between Commerce, MO, and New Madrid, MO. Particular interest was paid to the areas of the river near the LS breach and the BPNMF upper (inflow) crevasse to analyze the 
currents as a result of the breaches. The federal levees, or adequate natural high ground, defined the lateral extents of the model.

Model testing was performed to ensure the downstream boundary at Tiptonville and Ohio River upstream boundary did not affect conditions in the primary area of interest. To test the downstream stage boundary at Tiptonville, an additional model was run with the boundary $3 \mathrm{~km}$ (2 miles) farther upstream. Results showed stages at New Madrid changed by an average of $0.01 \mathrm{~m}$ from changing the location of the downstream boundary.

Testing was also performed on the Ohio River boundary location. The decision for upstream boundary location was partly based on having a reasonable domain computationally. This testing was to assess change in flow at the upstream Ohio boundary (which was within the backwater influence of the Mississippi River) due to the change induced by BPNM floodway operation. For the sake of computational requirements, it was determined that $0.5 \%$ change in $\mathrm{Q}$ at Metropolis was acceptable (tradeoff between computational requirements and accuracy of upstream boundary influence). To extend the model farther upstream on the Ohio to a location where there was no backwater influence would introduce unnecessary complexity-basically the Tennessee and Cumberland tributaries, plus locks and dams, would have to be introduced into the model domain. This would have resulted in significantly more mesh computation points as well as internal boundaries. In the end it was determined that those additional complications and computational requirements were not justified to achieve the desired outcomes from model scenarios. Discharge and slopes in the Ohio River at Olmsted and locations upstream were evaluated for conditions where the BPNMF was operated and when it was not.

Figure 3-2 shows discharges in the Ohio River at Olmsted and farther upstream, 5.3 miles ( $8.5 \mathrm{~km}$ ) below Metropolis, for conditions when BPNMF operated and when it did not. There was an increase in discharge at Olmsted of $1140 \mathrm{cms}$ (40,000 cfs, 3.3\%), when the floodway operated; conveyance increased, water surface slopes steepened, and a considerable volume of water was drawn out of the lower reaches of the Ohio River. The change in discharge $8 \mathrm{~km}$ below Metropolis was much smaller, on the order of $200 \mathrm{cms}$ (7,000 cfs, $0.5 \%)$. This analysis showed that placement of the Ohio River boundary at Metropolis was acceptable. 
Figure 3-1. Extents of the model domain.

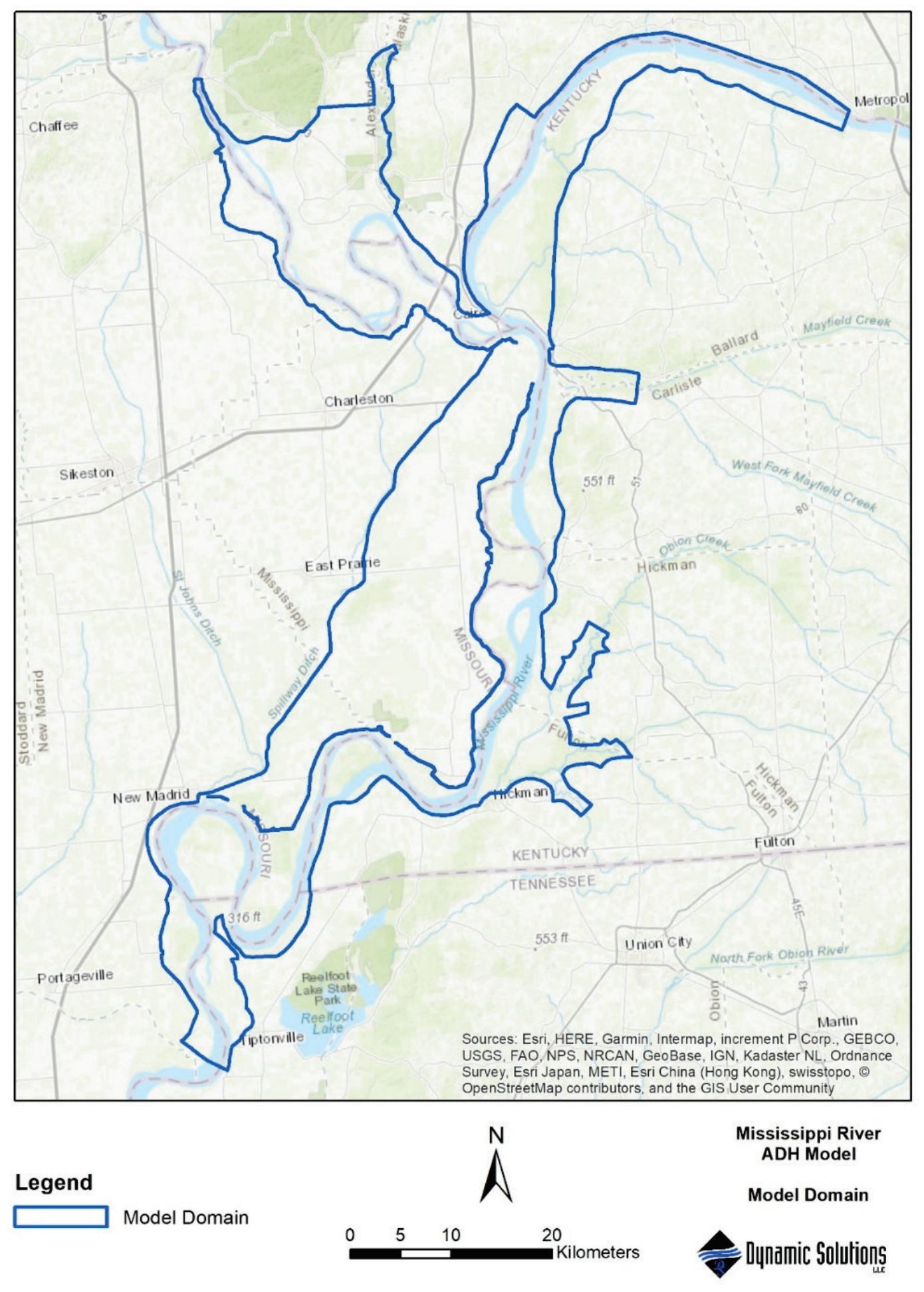


Figure 3-2. Discharge at Olmsted and $8 \mathrm{~km}$ below Olmsted for BPNMF operation and no operation (i.e., "No Ops") conditions.

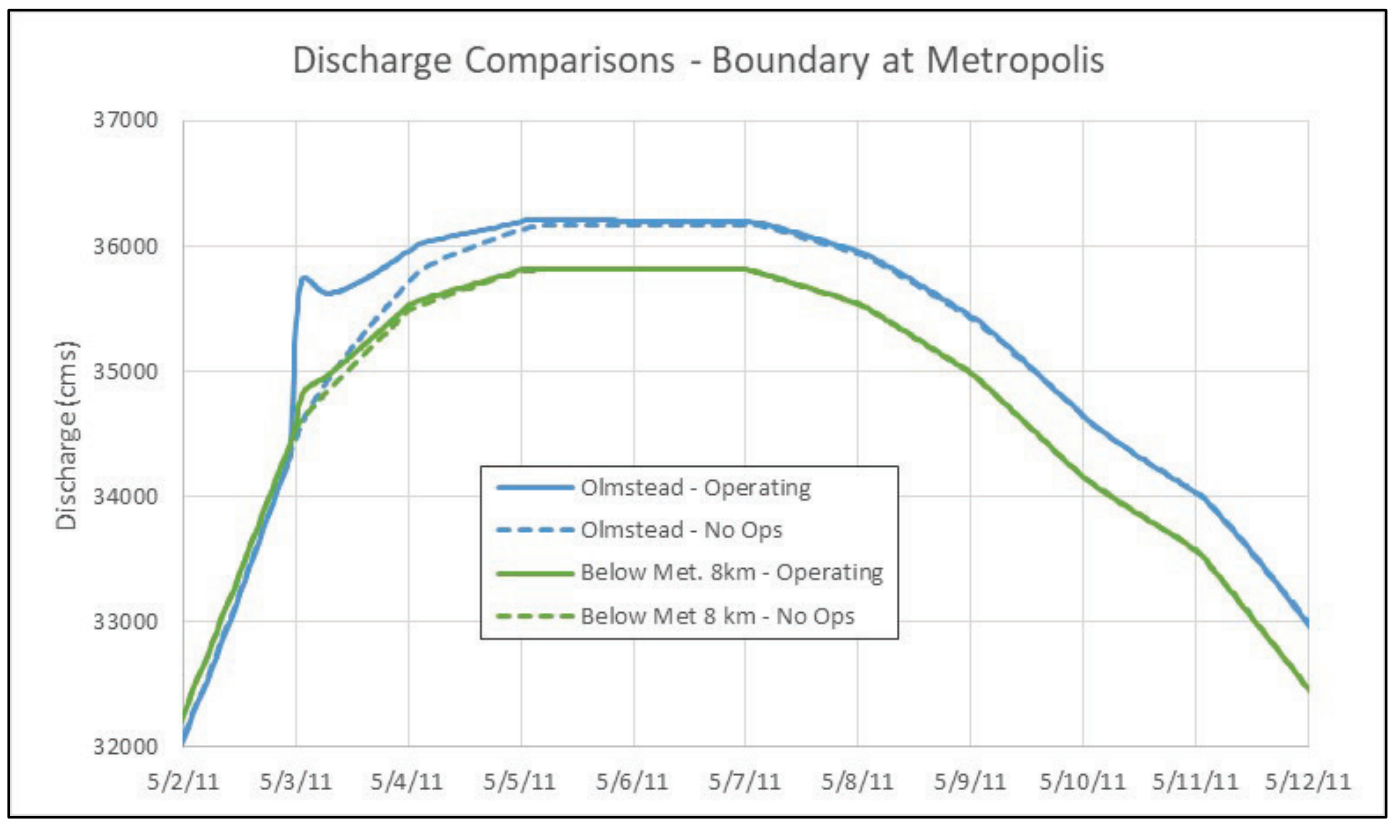

\section{Model mesh}

The construction of an accurate computational grid of the model domain is a critical component for development of the hydrodynamic model. A numerical model grid must balance fidelity to the physical domain and spatial resolution with model computational time to ensure that it can efficiently achieve study objectives. High-resolution grids can produce detailed model results, but if the run times are excessive, the overall utility of the model will be impaired.

The computational mesh sets the physical template for the model. Planimetrically, the grid mesh defines the channels and their spatial resolution, and the elevation data define the channel cross sections and mesh surface. The planimetric information was derived from aerial photography, linework for levees and other constructed features, and the elevation data.

The AdH model grid had 88,573 computational nodes and 174,293 elements without adaption. Typically, there were 15 to 20 nodes across the channel with at least 10 nodes across the low-flow channel, which resulted in typical channel elements in the Mississippi River that were $100-150$ feet $(30-45 \mathrm{~m})$ wide. Resolution was tighter near the LS Breach and BPNMF crevasse locations. The LS, Powers Island, and Fulton County 
levees, and BPNMF crevasse sections were all explicitly detailed in the mesh, with two nodes at the crest to prevent artificial leakage. These features were purposefully made a constant, wider than actual width (30 $50 \mathrm{ft}$ or $10-15 \mathrm{~m}$ ) for more efficient meshing and computations. The mesh is shown near the BPNMF upper crevasse and LS breach in Figure 3-3 and Figure 3-4, respectively.

Elevations for model mesh nodes were interpolated from the DEMs, levee and structure crest elevations, scour surveys, and other data discussed in the "Elevation Data" heading in Section 2. The elevation data used to assign mesh elevations were different for each calibration mesh, as time coincident data were used whenever possible. The elevation data in each model mesh were interpolated from the following data sources, listed in order of application (meaning data with higher numbers superseded data with lower numbers), as defined in Table 3-2. The "Base" number refers to any previous mesh that served as the basis for further modifications. Last, detailed modifications were made in areas where bathymetry was either unavailable or not detailed enough. These areas include the lakes east of the LS levee just north of the 2015 breach, the Mayfield Creek channel, and the main drainage canal that connects to St. Johns Bayou at the bottom of the BPNMF. The model mesh with elevations for the 2011 model are shown in Table 3-2 and Figure 3-5. 
Figure 3-3. Detail of model mesh near BPNMF upper crevasse.

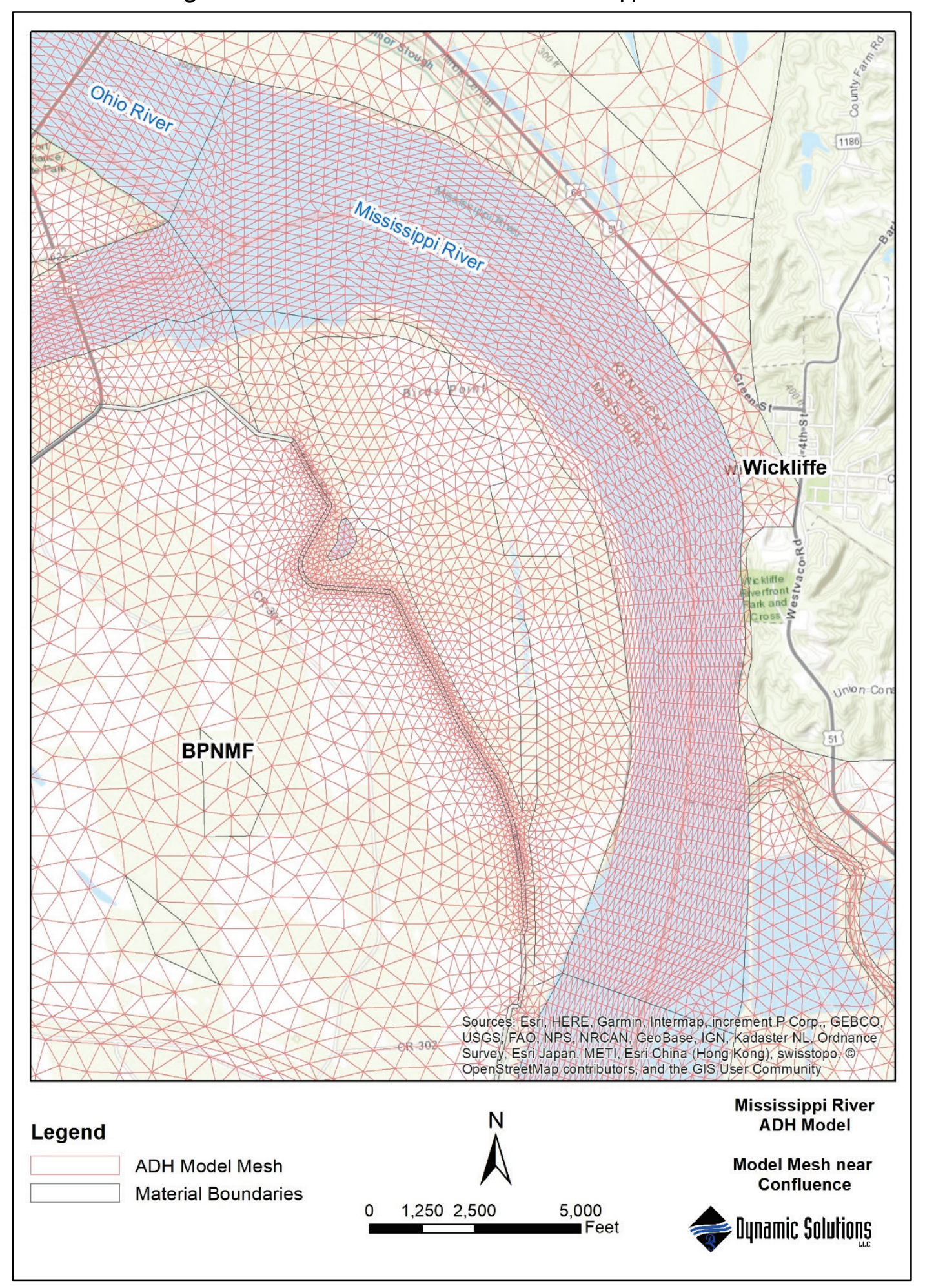


Figure 3-4. Detail of model mesh near LS levee breach.

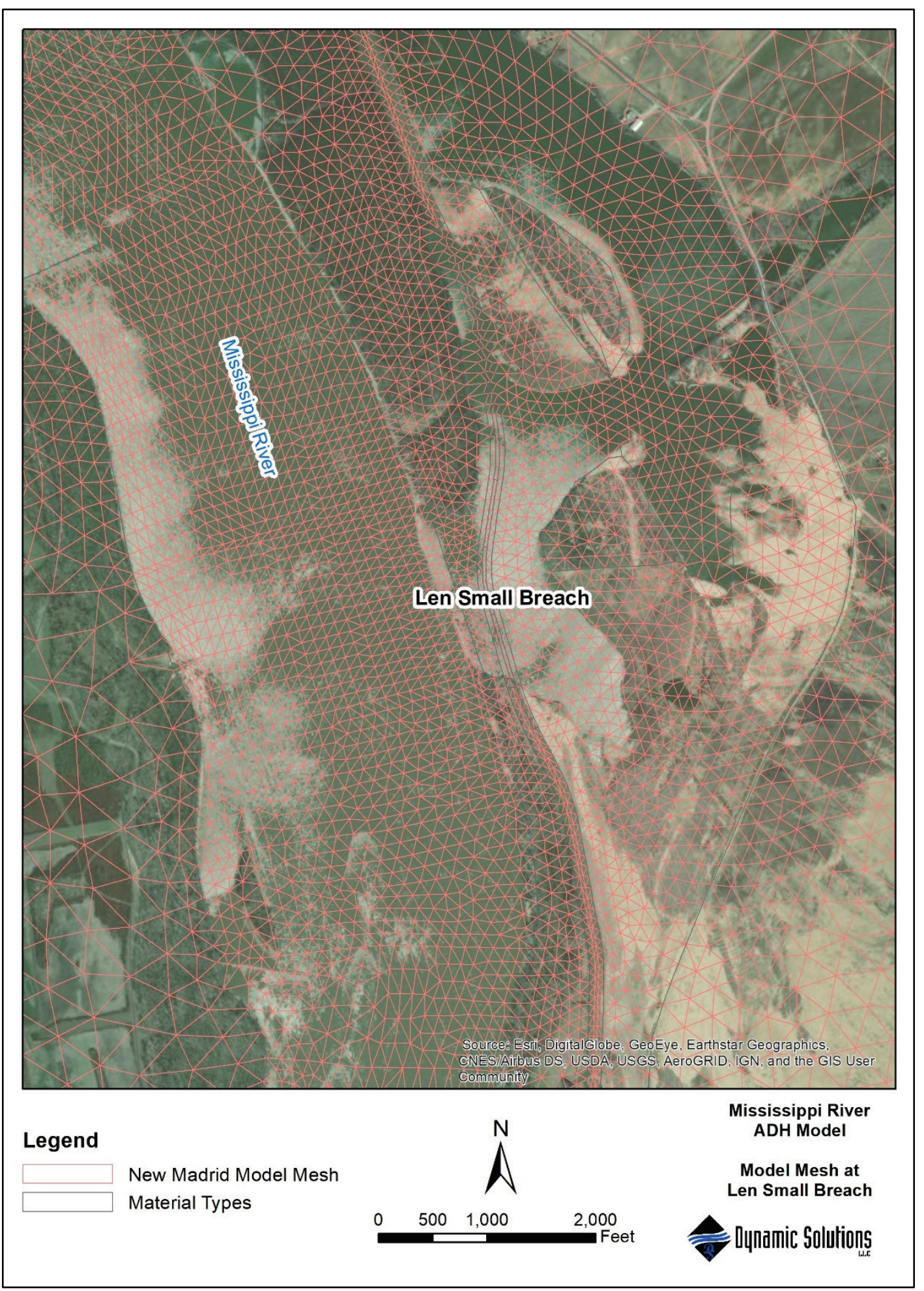


Table 3-2. Elevation data utilized for each simulation period, building from the base, each subsequent layer (higher number) taking precedent.

\begin{tabular}{|c|l|l|l|}
\hline No. & 2011 Mesh & 2015-2016 Mesh & 2017 Mesh \\
\hline Base & None & 2011 Mesh & 2015 Mesh \\
\hline 1 & MR_Base_DEM & $\begin{array}{l}\text { 2015 comprehensive } \\
\text { Upper Mississippi River } \\
\text { bathymetry }\end{array}$ & $\begin{array}{l}\text { 2017 LS scour survey } \\
\text { DEM }\end{array}$ \\
\hline 2 & Ohio_River_DEM & $\begin{array}{l}\text { 2016 LiDAR- Thompson } \\
\text { Bend floodplain }\end{array}$ & $\begin{array}{l}\text { LS bankline repair design } \\
\text { drawing }\end{array}$ \\
\hline 3 & NLD levee point data & NLD levee point data & $\begin{array}{l}\text { 2017 LiDAR - Thompson } \\
\text { Bend floodplain }\end{array}$ \\
\hline 4 & $\begin{array}{l}\text { Mississippi River structure } \\
\text { crest point data }\end{array}$ & $\begin{array}{l}\text { Mississippi River structure } \\
\text { crest point data }\end{array}$ & NLD levee point data \\
\hline 5 & (N/A) & M/A) & $\begin{array}{l}\text { Mississippi River structure } \\
\text { crest point data }\end{array}$ \\
\hline
\end{tabular}


Figure 3-5. Mesh elevations - 2011 model.

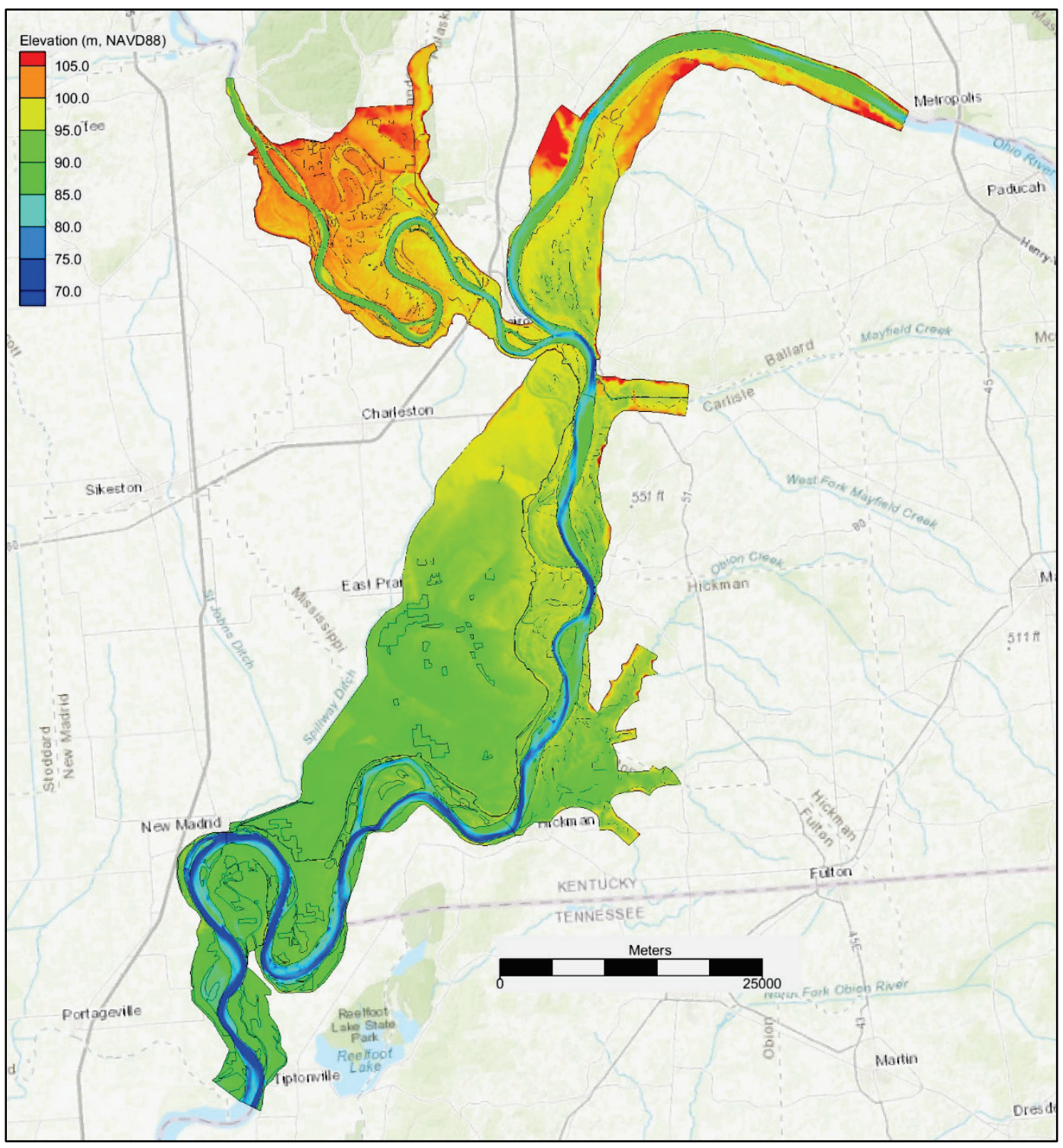

Mesh convergence tests were performed to ensure model results were independent of mesh resolution. Tighter refinement tolerance parameters (lower solution refinement tolerance (SRT) values on the MP SRT input for the AdH software) were utilized in the channel and floodplain to produce a finer resolution mesh. Table 3-3 shows the channel and floodplain adaption thresholds (adaption on, allowed a maximum of two refinement levels, AdH input card MP ML 1) and maximum number of nodes for each mesh convergence run. Figure 3-6 shows stages at Cairo for four runs testing grid convergence, as listed in the columns in Table 3-3. The runs with adaption enabled in the channel ("All_Adap", 
"All_Adap_Fine", and "Chan_Adap") produce essentially identical stage results at Cairo, IL. "Base" run stages are $0.36 \mathrm{ft}(0.11 \mathrm{~m})$ higher on the rising limb and $0.26 \mathrm{ft}(0.08 \mathrm{~m})$ higher at the peak than runs with channel adaption enabled. Results were similar at other locations. The mesh convergence testing runs indicated that the "Chan_Adap" mesh refinement tolerance parameters were adequate for numerical convergence. An adaption refinement tolerance (SRT value) of 40 in the channel and no adaption in the floodplain was demonstrated to produce adequate mesh resolution.

Table 3-3. Mesh convergence testing run parameters and max number of nodes.

\begin{tabular}{|l|l|c|c|c|}
\hline Values & Base & All_Adap & All_Adap_Fine & Chan_Adap \\
\hline Channel SRT & Adaption OFF & 30 & 20 & 40 \\
\hline Floodplain SRT & Adaption OFF & 100 & 75 & Adaption OFF \\
\hline $\begin{array}{l}\text { Max Number of } \\
\text { Nodes }\end{array}$ & 86,477 & 110,389 & 117,268 & 104,284 \\
\hline
\end{tabular}

Figure 3-6. Mesh convergence testing results - stage at Cairo for four different adaption schemes.

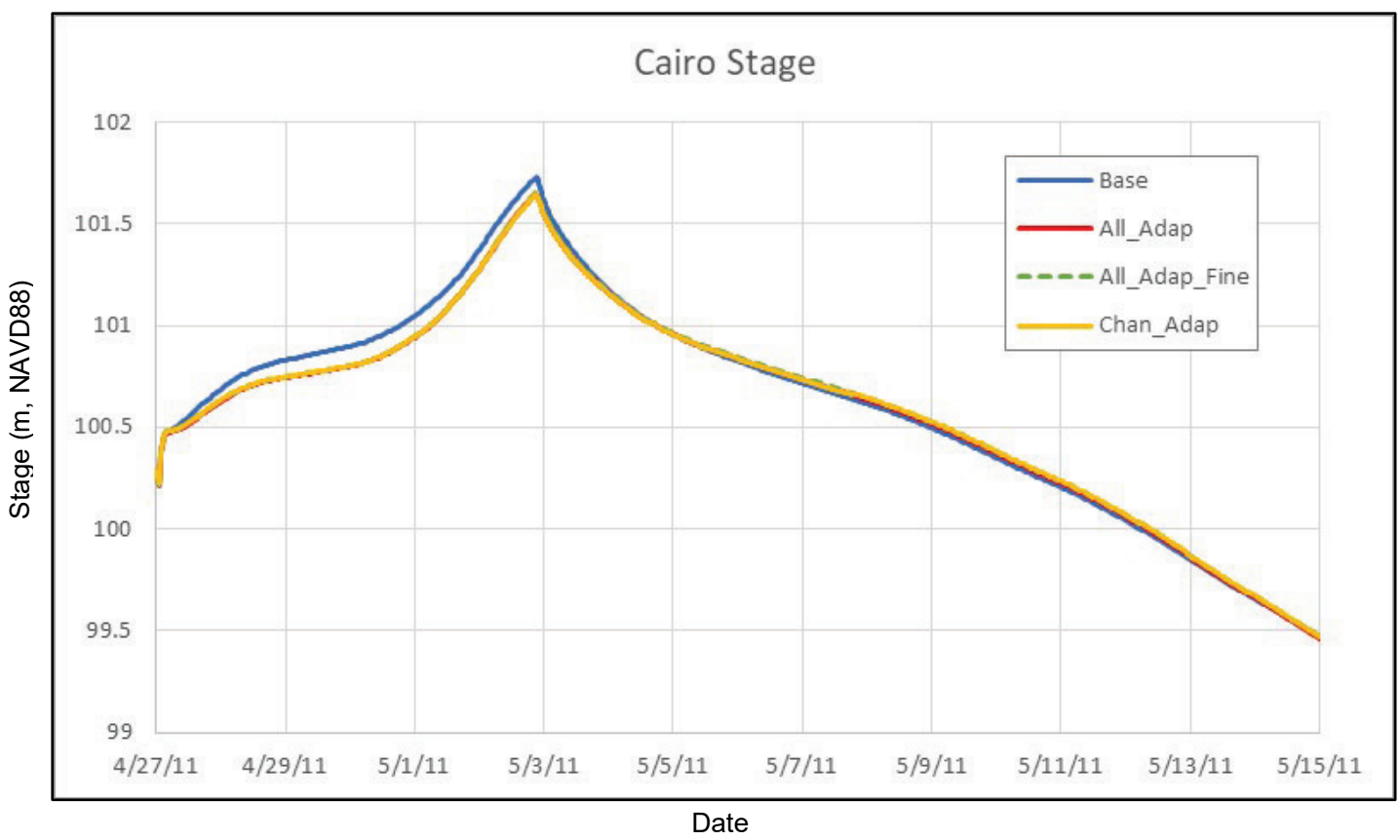

\section{Simulation periods, initial conditions, and spinup}

Three flooding events were specified for model calibration: 2011, 20152016, and 2017. The 2011 model simulation period was $4 / 16 / 2011$ to $5 / 31 / 2011$. The 2015 event simulation period was $12 / 20 / 2015$ to $1 / 16 / 2016$. The 2017 event simulation period was $4 / 21 / 2017$ to $5 / 20 / 2017$. 
Initial conditions for the calibration runs were based on the results of previous simulations and were close to expected initial values. Depth was the only parameter specified for initial conditions. One day of model spinup was required to wash out the initial conditions.

\section{Boundary conditions}

Discharge for the Mississippi River at Thebes, Ohio River at Metropolis, and two tributary inflows and tailwater stage at Tiptonville provide the external driving forces for the model. Locations of the model boundary conditions are shown on Figure 3-7. For all model simulation periods, the boundary conditions were constructed as follows:

- the Mississippi River discharge boundary utilized hourly discharge data from the USGS Mississippi River at the Thebes, Illinois gage

- the Mississippi River downstream stage boundary utilized stage data from the Tiptonville, Tennessee gage (adjusted to NAVD88 datum) (USACE 2017)

- inflows from Humphry and Mayfield Creeks used discharge estimates provided by the National Weather Service (NWS) (Lewis et al. 2018).

The Ohio River flow boundary condition utilized multiple data sources. For 2011, discharge for the Ohio River at Metropolis was extracted from the Mississippi River Flowline Assessment HEC-RAS model. USACE Memphis District staff performed extensive testing (Lewis et al. 2018) to provide the best estimate of discharge from the Ohio River (as discussed in the "Discharge Data" section above). These data also produced the best model results. For the 2015 and 2017 events, discharge data from the USGS Ohio River at Olmstead (USGS 2015) gage were utilized. Travel time from Metropolis to Olmstead, which varies by discharge, was estimated to be $5 \mathrm{hr}$ for flood flows as determined by model testing. To create the boundary condition time series, observed discharge at Olmstead was shifted back $5 \mathrm{hr}$ to provide time-consistent discharge at Metropolis. The boundary condition time series used in the model are displayed graphically for the 2011 event on Figure 3-8, for the 2015 event on Figure 3-9, and for the 2017 event on Figure 3-10. 
Figure 3-7. Model boundary condition locations.

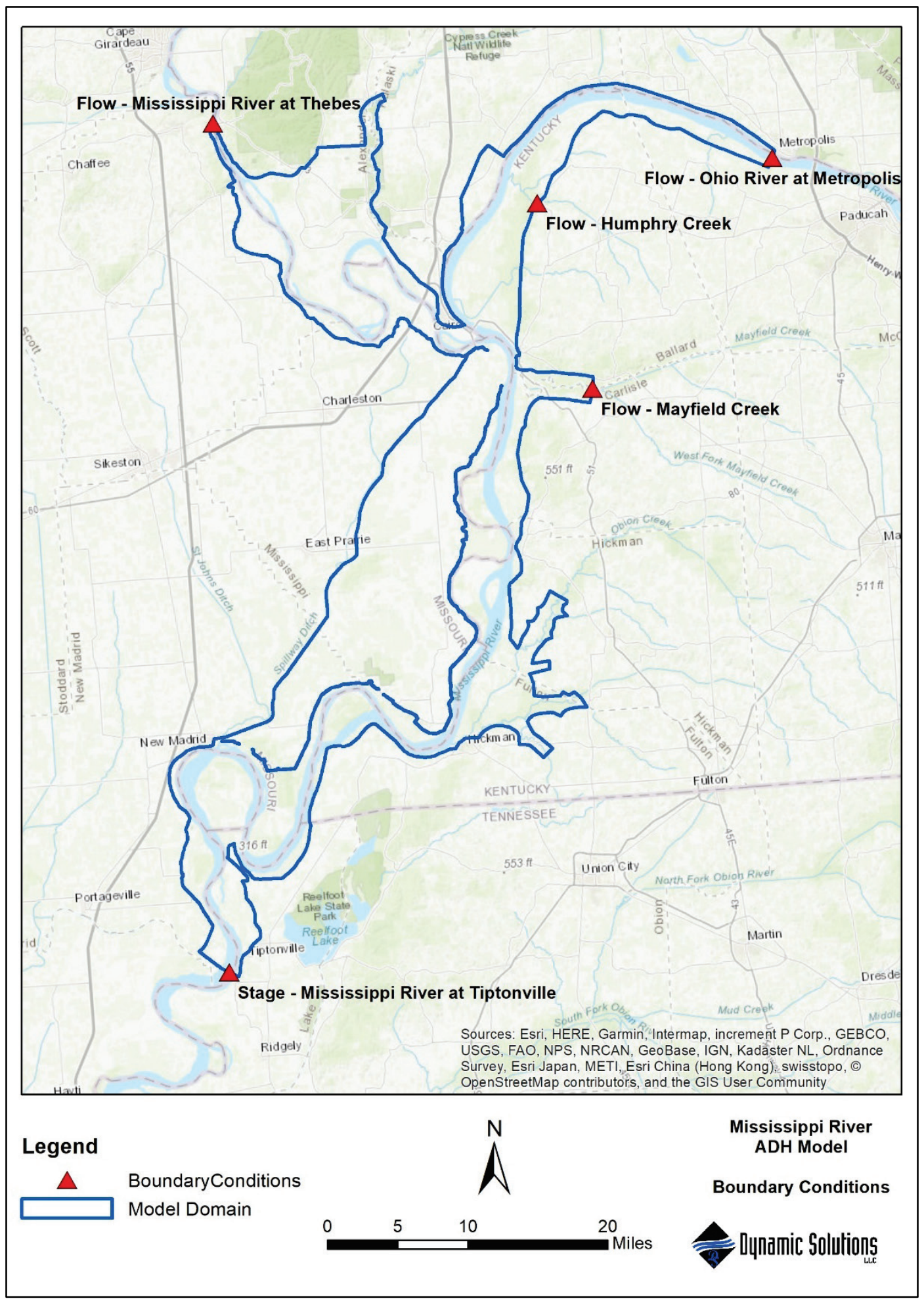


Figure 3-8. 2011 model boundary conditions.

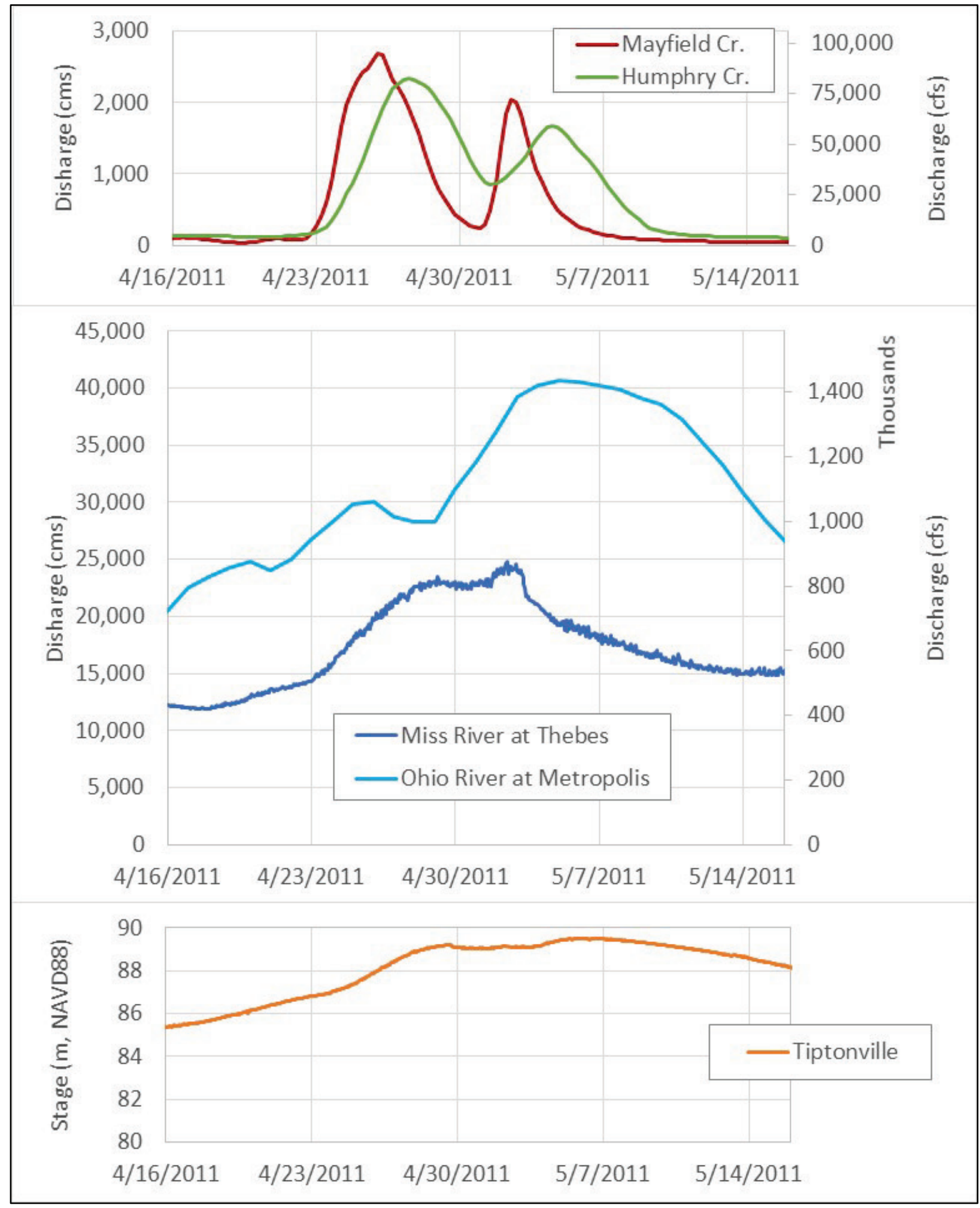


Figure 3-9. 2015 model boundary conditions.

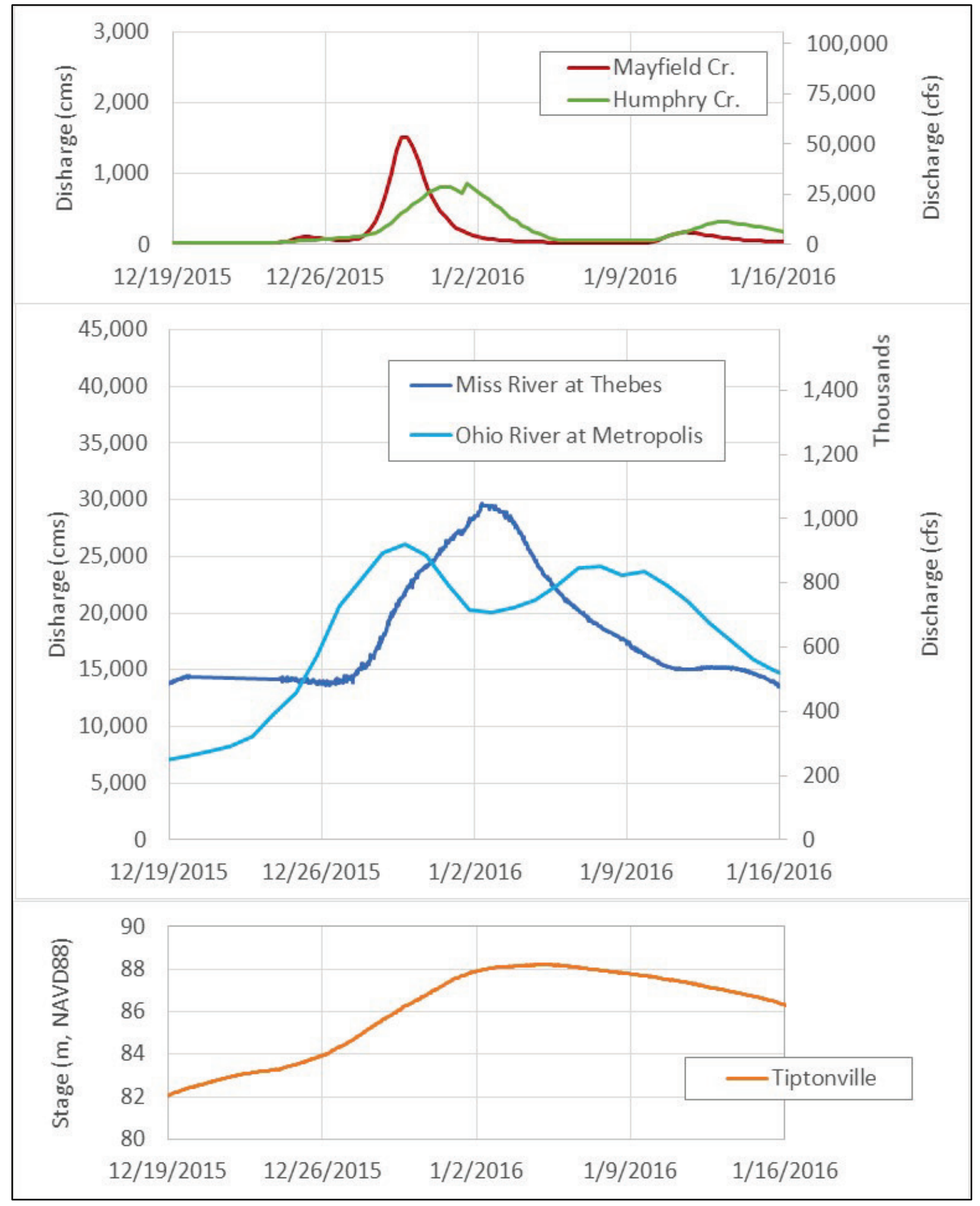


Figure 3-10. 2017 model boundary conditions.

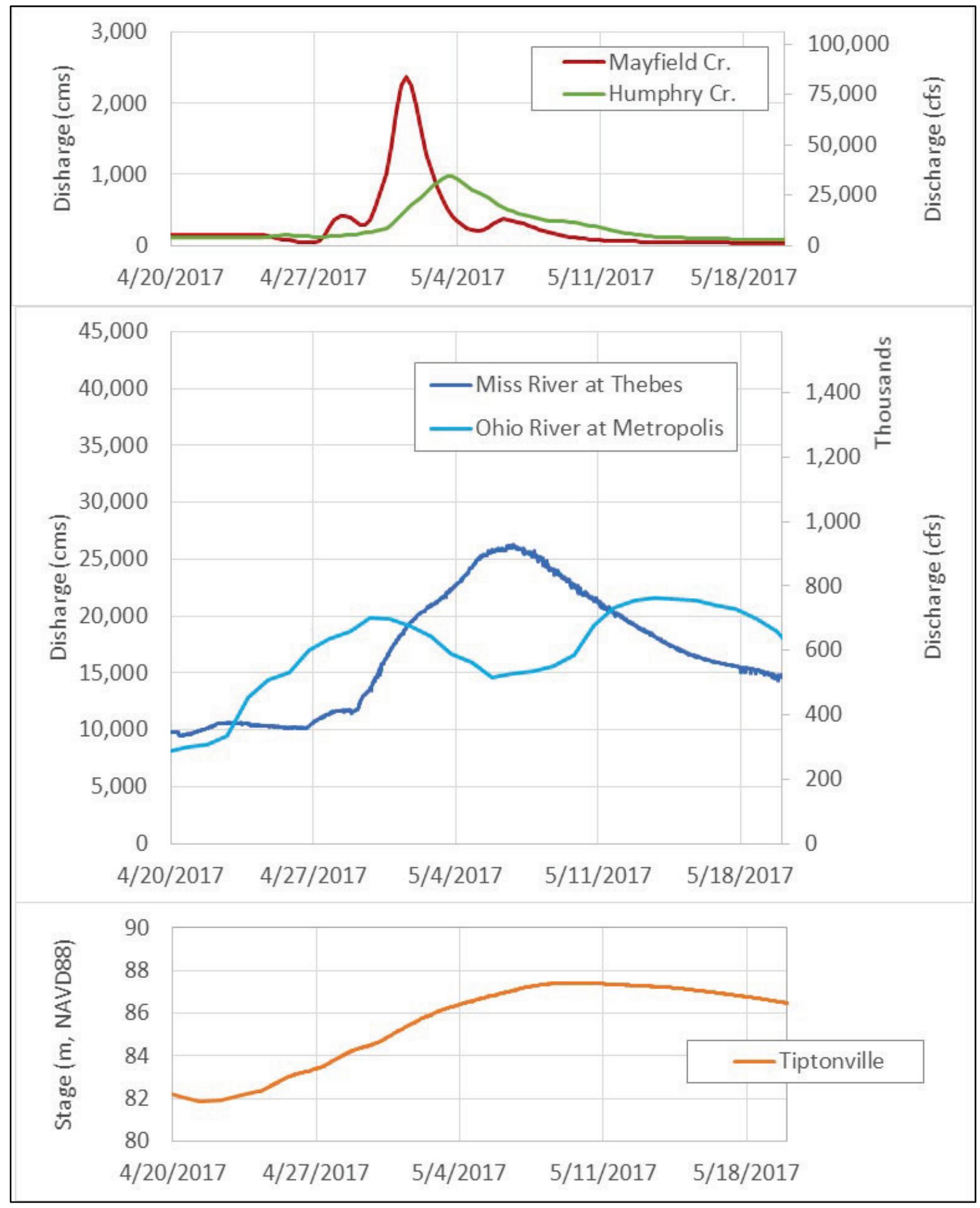




\section{Model parameters}

To properly partition bottom roughness, eddy viscosity, and mesh adaption parameters, 32 material types (categories of elements) were defined for the model. The material types are summarized in Table 3-4 and shown for the entire domain in Figure 3-11, for the area near the LS breach in Figure 3-12, and for the area near the BPNMF upper crevasse in Figure 3-13.

Bottom roughness is parameterized two different ways in the model. The Manning's roughness coefficient (Manning's $n$ ) is used for most areas in the model except forested areas in the vicinity of the LS breach and BPNMF upper crevasse. The Mississippi River is split into seven reaches with Manning's $n$ values ranging from 0.027 to 0.029. Open land in the floodplain was assigned $n$-values of 0.04 , and trees within the channel and floodplain were assigned $n$-values of 0.06. Internally, AdH converts the Manning's $n$ coefficient provided to a roughness height that is then used to calculate drag on the fluid. The roughness height implementation is depth dependent, meaning large flow depths will result in a relatively lower drag force. Bottom roughness for the forested areas near the breaches used the unsubmerged rigid vegetation (URV) friction option available in the AdH model. The URV friction method uses the parameters entered - roughness height, stem diameter, and stem density - to compute a coefficient to use in computing shear stress resulting from current through rigid vegetation. This method accounts for the drag flow through the obstructions and the skin drag (Berger et al. 2013). The values used for forest roughness were a roughness height of $13 \mathrm{ft}(4 \mathrm{~m})$ (which corresponds to an $n$-value of approximately 0.05), stem diameter of $0.2 \mathrm{~m}(0.66 \mathrm{ft})$, and vegetation density of $0.25 \mathrm{stems} / \mathrm{m}^{2}$ ( 0.25 stems/10 ft ${ }^{2}$ ). Figure 3-14 shows the effective drag coefficient utilized internally in AdH for Manning's $n$ and URV values utilized in the model.

For eddy viscosity in these simulations, the isotropic estimated eddy viscosity (EEV card, method 1 in $\mathrm{AdH}$ ) method was used throughout the modeling domain. The wetting and drying tolerance for the model (DTL card in AdH) was set to $1.6 \mathrm{ft}(0.5 \mathrm{~m})$. While this value has units of length, it is not simply a threshold for which a cell is considered dry; this parameter controls how AdH captures the hydrodynamic shock of a model cell becoming wet or dry. Assignment of lower values for this parameter simulates wetting and drying processes more exactly. The value of $1.5 \mathrm{ft}$ $(0.5 \mathrm{~m})$ was chosen based on prior experience and testing as discussed in the "Sensitivity Testing" section in Chapter 3. 
Table 3-4. Roughness values by material type.

\begin{tabular}{|c|c|c|c|}
\hline Type & Material & Value & Description \\
\hline MNG & 1 & 0.029 & MRchan_R1 (Thebes to Price Landing) \\
\hline MNG & 2 & 0.04 & Floodplain Open Land \\
\hline MNG & 3 & 0.026 & Ohio River \\
\hline MNG & 4 & 0.026 & Levee \\
\hline MNG & 5 & 0.026 & BPNMF Upper Crevasse \\
\hline MNG & 6 & 0.026 & BPNMF Middle Crevasse \\
\hline MNG & 7 & 0.026 & BPNMF Lower Crevasse \\
\hline MNG & 8 & 0.06 & Floodplain Trees \\
\hline MNG & 9 & 0.035 & Floodplain Water \\
\hline MNG & 10 & 0.06 & Channel Trees \\
\hline MNG & 11 & 0.029 & MRchan_R2 (Price to Thompson Land) \\
\hline MNG & 12 & 0.029 & MRchan_R3 (Thompson L to Conf) \\
\hline MNG & 13 & 0.029 & MRchan_R4 (Conf to Columbus) \\
\hline MNG & 14 & 0.029 & MRchan_R5 (Columbus to Hickman) \\
\hline MNG & 15 & 0.027 & MRchan_R6 (Hickman to New Madrid) \\
\hline MNG & 16 & 0.027 & MRchan_R7 (New Madrid to Tiptonville) \\
\hline MNG & 17 & 0.028 & BPNMF_Breach_Nav (MR near BP breach) \\
\hline MNG & 18 & 0.029 & LS_Breach_Nav (MR near LS breach) \\
\hline MNG & 19 & 0.035 & BPNMF Floodplain \\
\hline URV & 20 & $\begin{array}{c}4,0.2 * \\
0.25^{*}\end{array}$ & Near BPNMF Upper FP Trees \\
\hline MNG & 21 & 0.035 & Near BPNMF Upper FP Water \\
\hline URV & 22 & $\begin{array}{c}4,0.2^{*} \\
0.25^{*}\end{array}$ & LS Breach Trees \\
\hline MNG & 23 & 0.035 & LS Breach Floodplain \\
\hline MNG & 24 & 0.03 & LS Breach Water \\
\hline MNG & 25 & 0.03 & LS Breach 1 \\
\hline MNG & 26 & 0.03 & LS Breach 2 \\
\hline MNG & 27 & 0.03 & LS Breach 3 \\
\hline MNG & 28 & 0.03 & LS Breach 4 \\
\hline MNG & 29 & 0.03 & BPNMF Middle FP Breach 2 \\
\hline MNG & 30 & 0.035 & BPNMF Floodplain near Upper FP \\
\hline MNG & 31 & 0.03 & LS Breach Levee \\
\hline MNG & 32 & 0.03 & Material for LS MDS string \\
\hline
\end{tabular}


Figure 3-11. Material types in the model mesh.

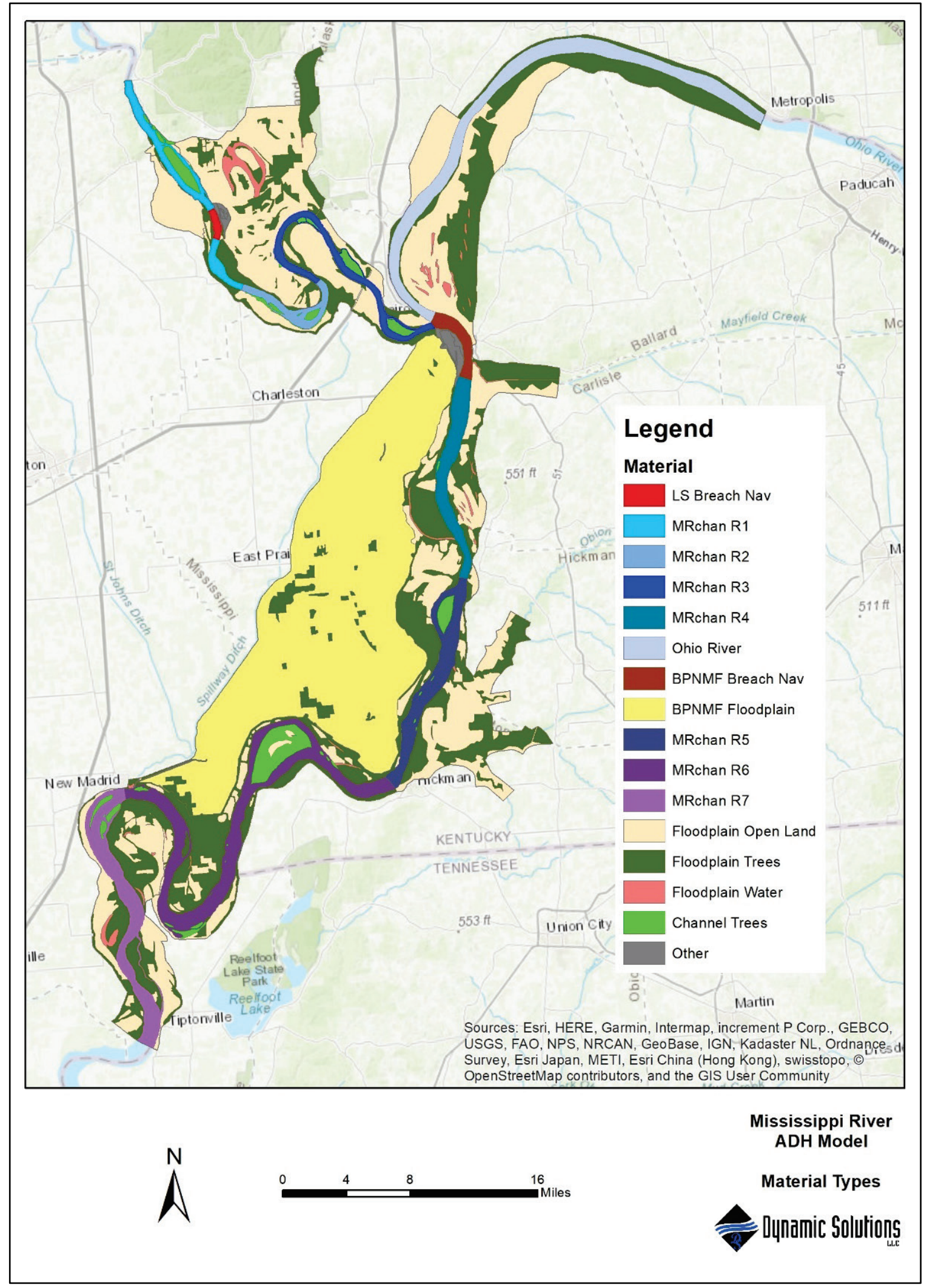


Figure 3-12. Material types in the model mesh near the LS breach.

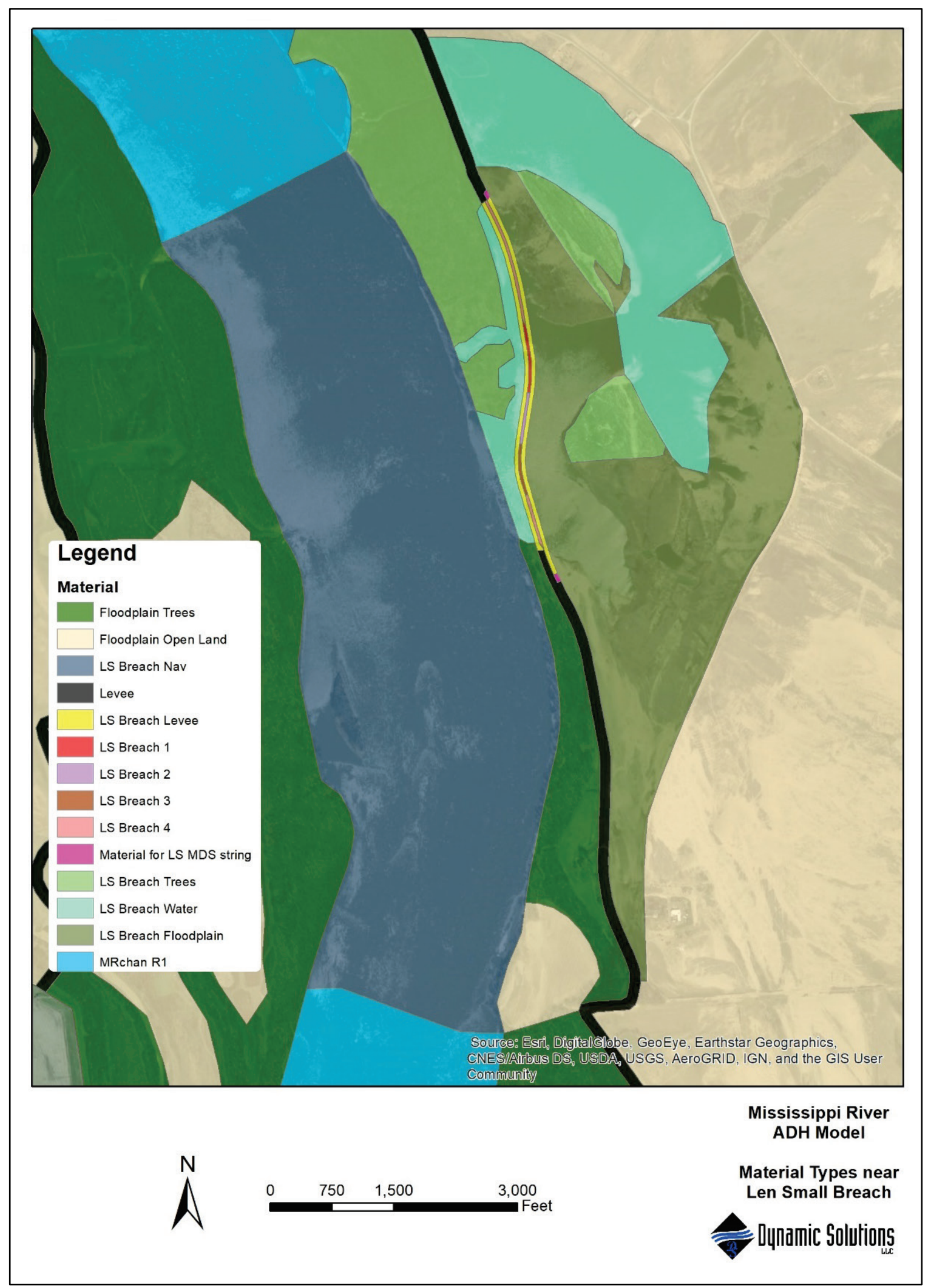


Figure 3-13. Material types in the model mesh near the BPNMF upper crevasse.

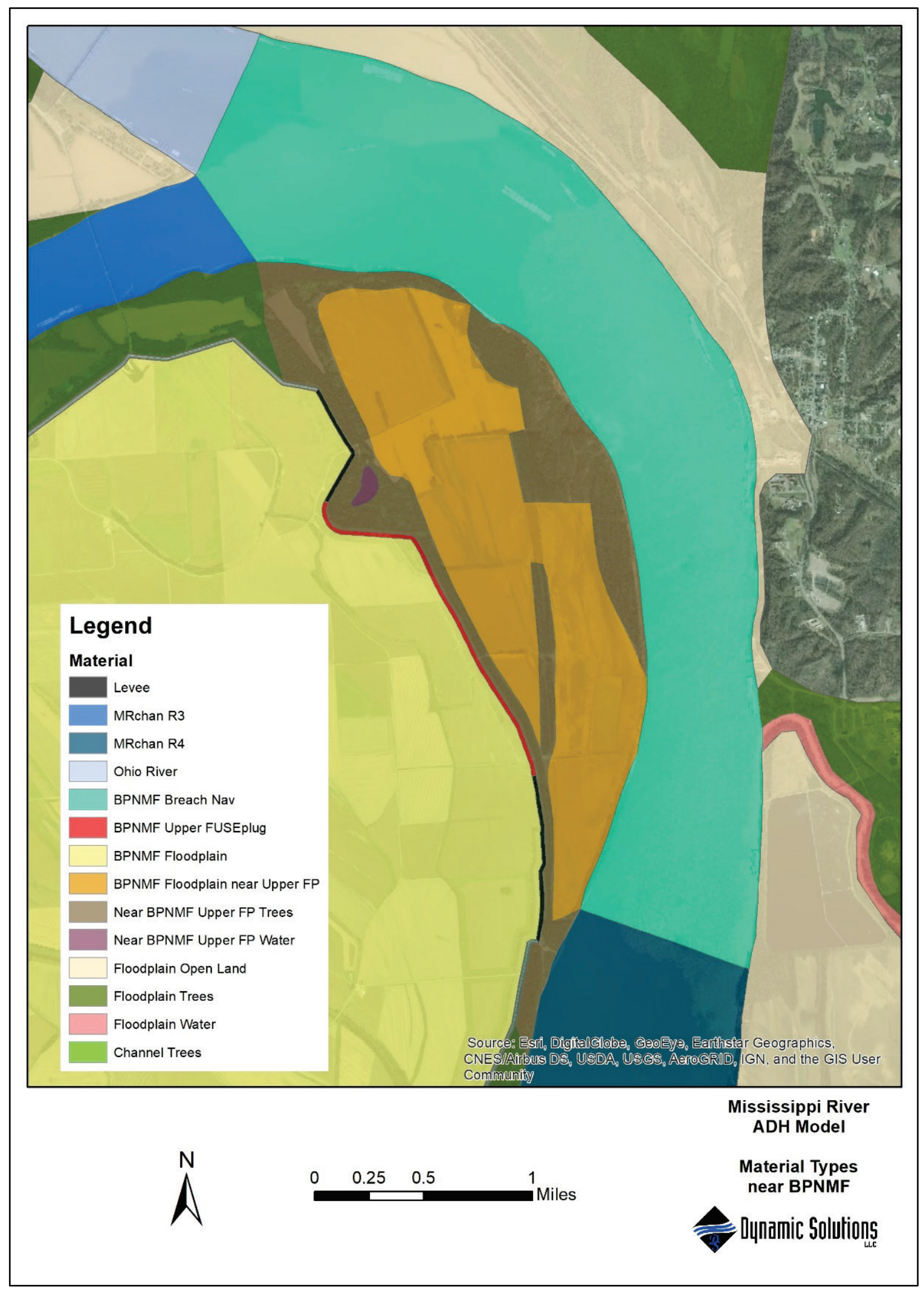


Vorticity transport was enabled in the model using the standard formulation and coefficients. This allows the model to more accurately simulate the distribution of velocity in bends in the river.

AdH utilizes a semi-implicit scheme with adaptive time-stepping for time integration of the model. The maximum time-step allowed for this model was $400 \mathrm{~s}$. AdH, however, will automatically decrease the time-step if the hydrodynamic solution does not converge numerically.

Figure 3-14. Effective drag in AdH as a function of depth for two values of Manning's $n$ (MNG) and URV.

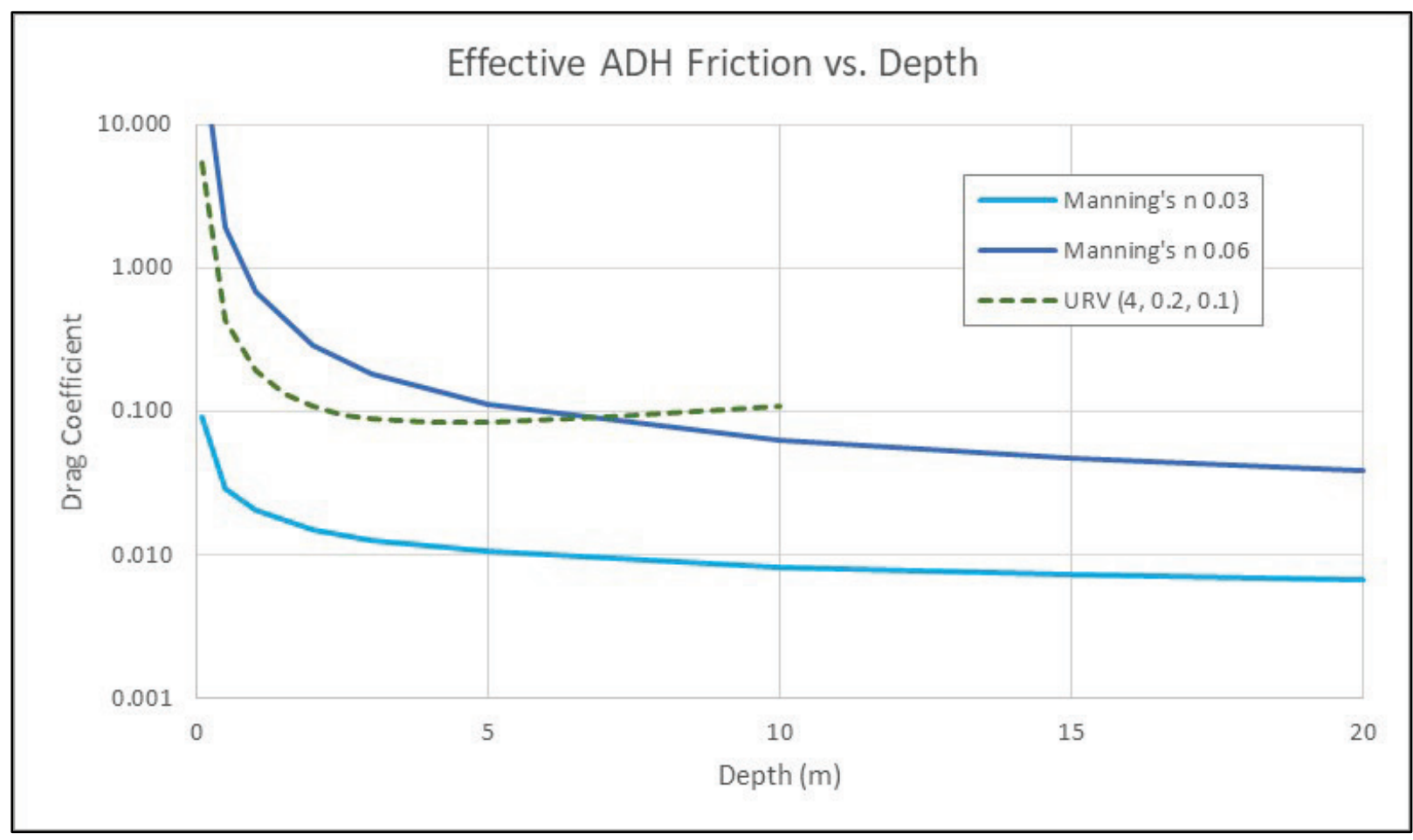

\section{Sensitivity testing}

Sensitivity tests are conducted to evaluate the response of the model to a change in a given input parameter. This provides an indication of how sensitive the solution is to a particular input parameter, provides information for uncertainty analysis, and gives confidence in model functionality.

\section{Roughness}

Channel roughness is a critical adjustment parameter for calibration of model stages. To generally test model response to a change in channel 
roughness, channel Manning's $n$ values were adjusted up and down by 0.004 , with the "Base" model having an average $n$-value of 0.03. Figure 3-15 shows differences in stage at Birds Point on the Mississippi River for a time period used during testing, March 2011. The 0.004 change in channel Manning's $n$ results in approximately $1.6 \mathrm{ft}(0.5 \mathrm{~m})$ change in stage, with higher roughness producing increased stage. These results are reasonable and aided in adjustments during the calibration process. Further roughness testing results are shown in the "Model Calibration" section.

Figure 3-15. Channel Manning's $n$ sensitivity testing results at Birds Point on the Mississippi River.

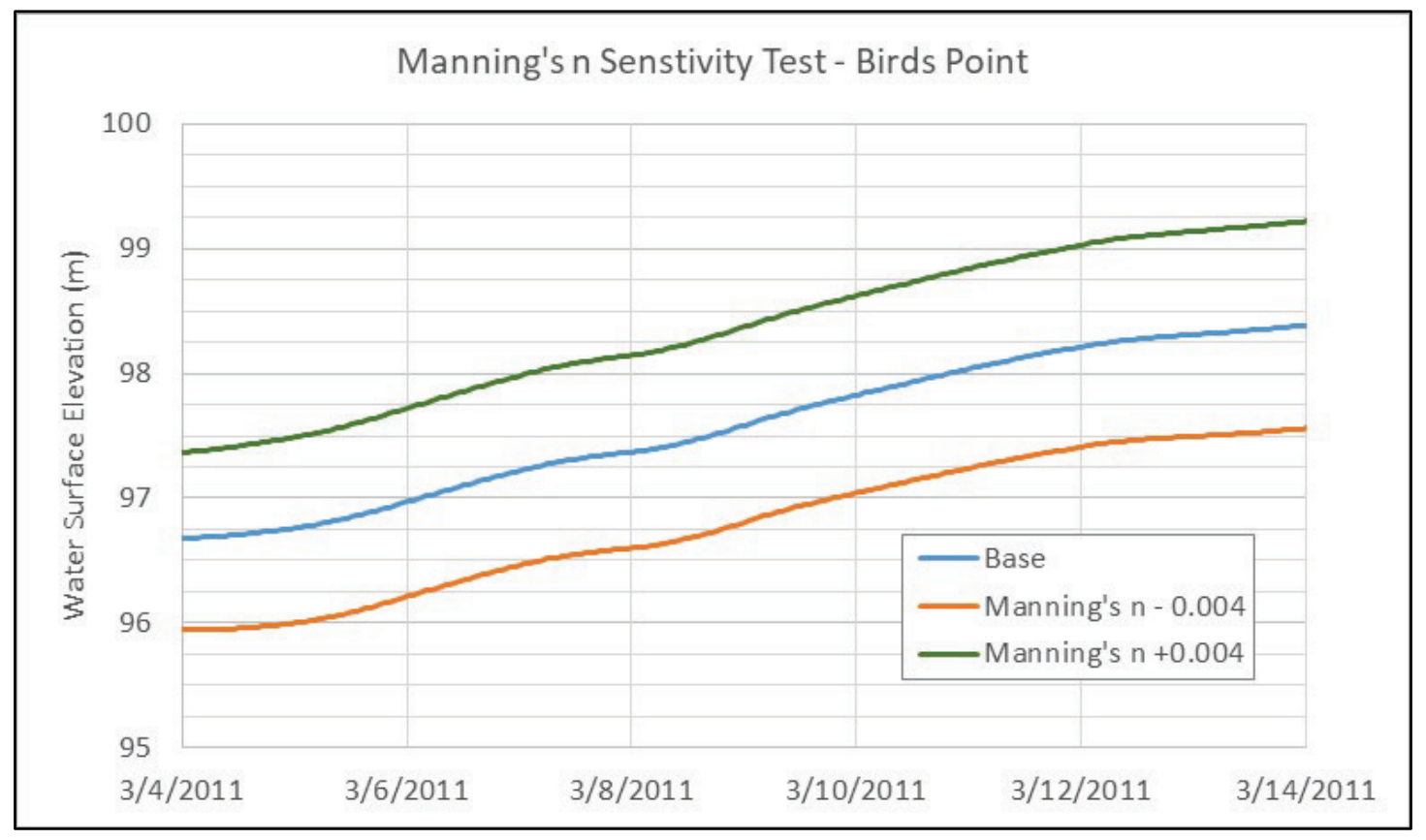

\section{Channel bed elevation}

Channel bed elevation has a substantial impact on model results and is in a constant state of change thus being a significant source of model uncertainty. Bed elevation was increased and decreased by $1.6 \mathrm{ft}(0.5 \mathrm{~m})$ to assess its impact on model stage. Figure 3-16 shows the results of these tests for stage at Birds Point during the 2011 flood. The results show stage differences of $0.8 \mathrm{ft}(0.25 \mathrm{~m})$ higher for increased bed elevations and $0.8 \mathrm{ft}$ $(0.25 \mathrm{~m})$ lower for decreased bed elevations. 
Figure 3-16. Channel bed elevation sensitivity testing results at Birds Point on the Mississippi River.

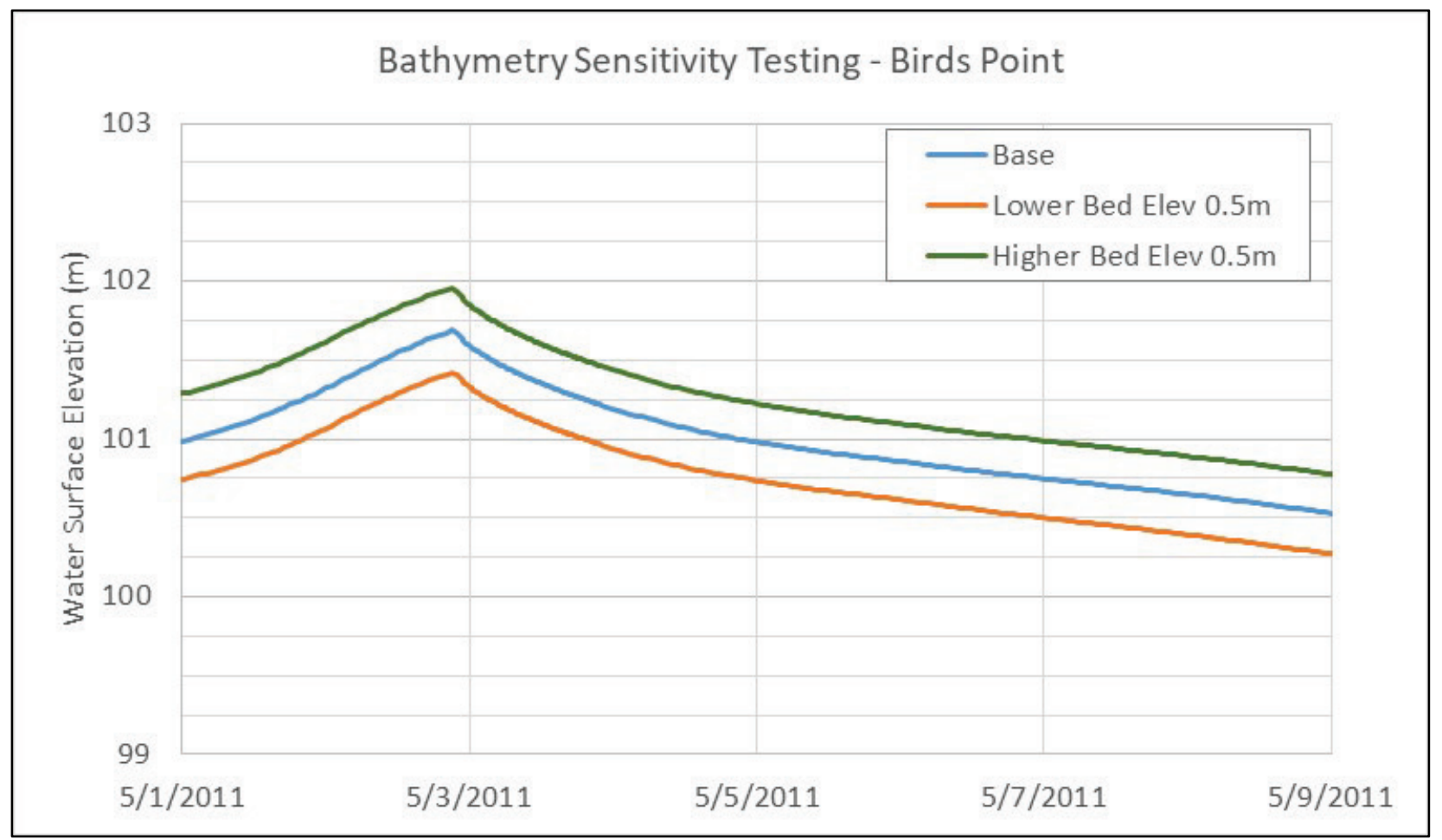

Wetting/drying limit depth

The wetting/drying limit depth (this is labeled as the DTL card within the AdH software) can be adjusted to control model stability at the wet/dry front. As stated in the "Model Parameters" section, higher values result in a more stable but less accurate solution at the wet/dry front. Model processes affected by this parameter are wetting and drying that occur on the floodplains and the progression of the wave front at the time of a levee breach. A DTL of 0.5 was found to produce a stable and accurate solution. A lower value of DTL (0.3), which produced a more accurate but less efficient solution, was tested. Figure 3-17 shows that stages at Birds Point during the peak of the 2011 flood were nearly identical for DTL values of 0.3 and 0.5 .

To demonstrate the effect of DTL on flood wave propagation, stage at a station mid-way down the BPNMF was evaluated for DTL values of 0.3 and 0.5. Figure 3-18 shows that the lower DTL value lowers stages by approximately $0.1 \mathrm{~m}$ during the arrival of the breach flood wave, but stages were nearly identical once water depth was greater than $1 \mathrm{~m}$. Testing indicated that using a DTL of 0.5 resulted in the model being much more stable and computationally efficient. 
Figure 3-17. Wetting/drying parameter sensitivity test stage results at Birds Point, 2011 event.

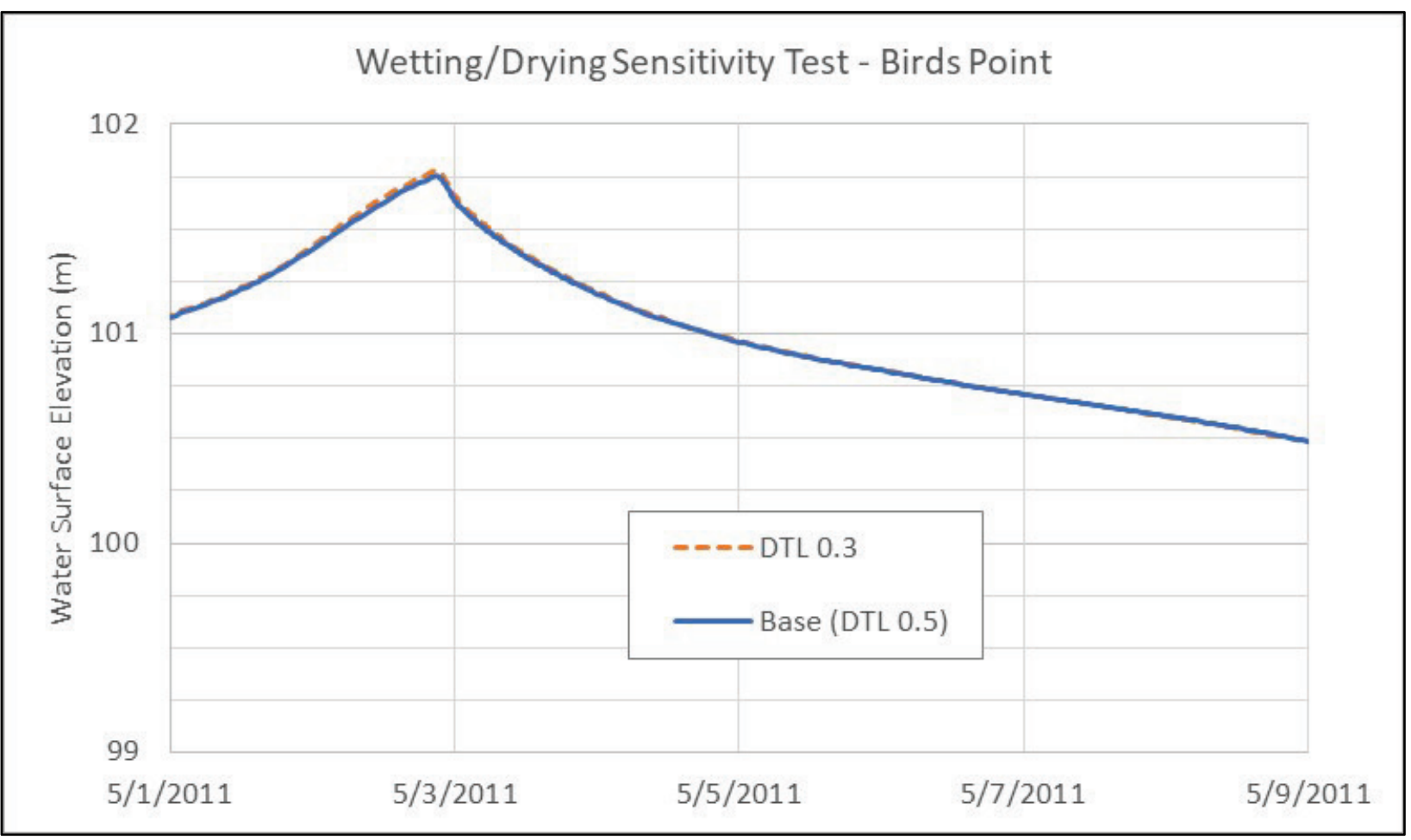

Figure 3-18. Wetting/drying parameter sensitivity test stage results in the middle of the BPNMF.

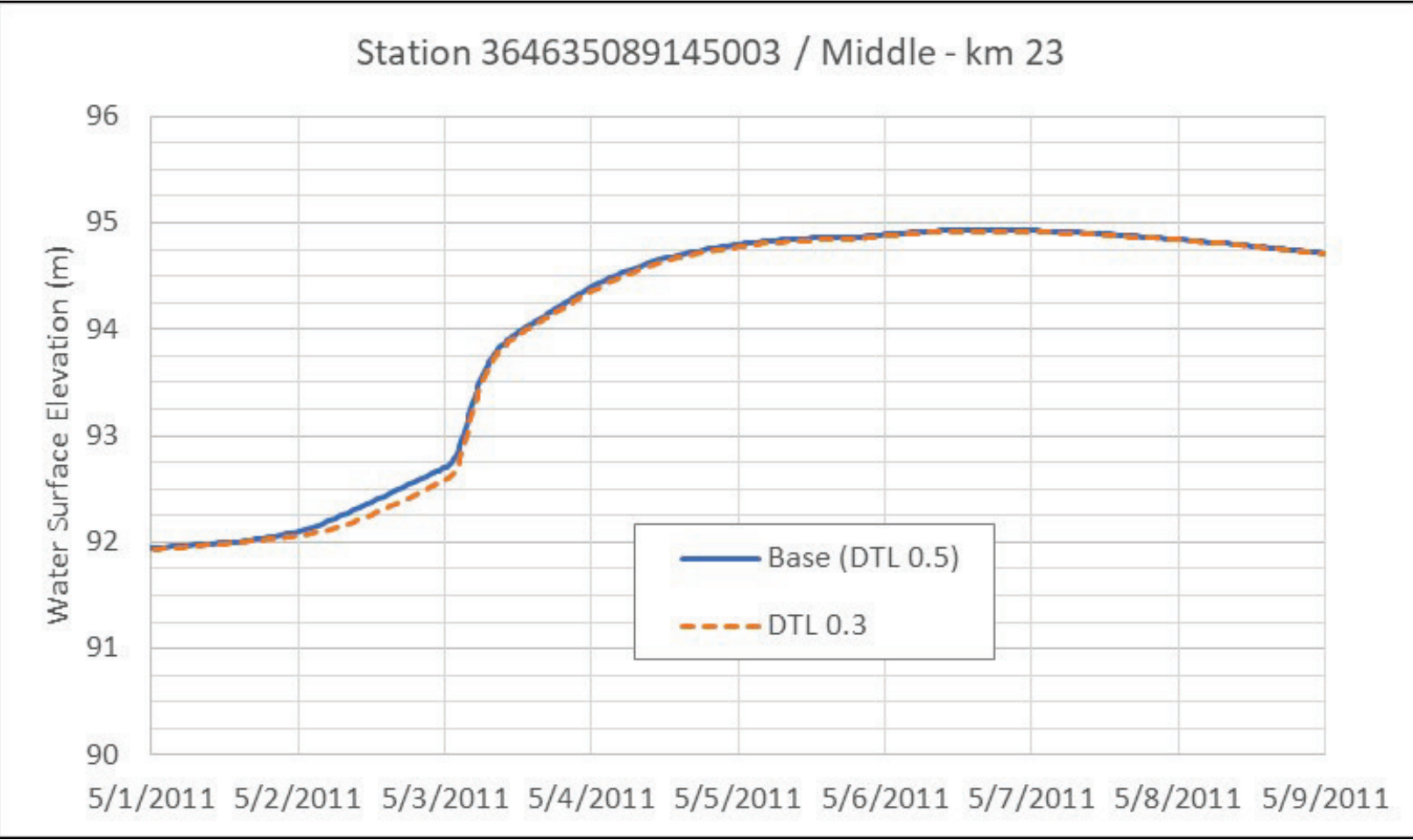




\section{Model Calibration}

Calibration is a multi-step process through which the model is skillfully adjusted to satisfactorily reproduce the critical system processes and match observed data sets. Model performance and skill assessment of the Mississippi River AdH model were evaluated to determine the endpoint for model calibration using a weight of evidence approach that has been widely adopted for surface water modeling studies. The weight of evidence approach included the following steps: (a) visual inspection of plots of model results compared to observed data sets as station time series and (b) analysis of model performance statistics. The weight-of-evidence approach recognizes that the model, as an approximation of a complex riverine system, will not be able to provide perfect agreement with observed data, and as such, perfect agreement is not specified as a performance criterion for the model. Model performance statistics are used, not as absolute criteria for acceptance or rejection of the validated model results but rather as guidelines to supplement visual inspections of model-data plots to determine the most appropriate endpoint for calibration. The weight-of-evidence approach thus acknowledges the approximate nature of a numerical model and the inherent uncertainty in external forcing data, elevation data, AdH model coefficients, and the observed data themselves. Model results are interpreted in terms of performance statistics to accurately portray uncertainty for the user (EPA 2009a; NAS 2012).

Root mean squared (RMS) error is used as a model-data comparison statistic for channel discharges and velocities below the Mississippi and Ohio River confluence and below the Birds Point upper crevasse. This statistic is computed using the following equation:

$$
R M S=\sqrt{\frac{\sum_{i=1}^{N}\left(O_{i}-X_{i}\right)^{2}}{N}}
$$

where $O$ is the observed value, $X$ is the corresponding model value in space and time, and $N$ is the number of valid model-data pairs. The relative RMS (rRMS) statistic is simply the RMS value divided by the range of the observed data to provide a normalized value of the RMS error. In some cases where the range of data is very small, rRMS can be very large even 
though the absolute errors are minor. Both RMS and rRMS statistics should be examined to properly understand the accuracy of the model.

The Nash-Sutcliffe model efficiency coefficient (NSE) is also used as a model-data comparison statistic for the channel discharges below the confluence and upper crevasse. This statistic is computed using the following equation:

$$
N S E=1-\frac{\sum_{t=1}^{T}\left(Q_{m}^{t}-Q_{0}^{t}\right)^{2}}{\sum_{t=1}^{T}\left(Q_{0}^{t}-\overline{Q_{0}}\right)^{2}}
$$

where $Q_{o}{ }^{\mathrm{t}}$ is the observed discharge at time $t, Q_{m}$ is the corresponding model discharge, and $\overline{Q_{0}}$ is the mean observed discharge. NSE values range from $-\infty$ to 1 . An NSE value of 1 denotes uniformity between model and observed discharge. An NSE value of o means a model discharge is as accurate as the mean of the observed discharges. An NSE value less than zero indicates that the mean observed discharge is a better estimate of discharge than the model, statistically.

\section{Model calibration key steps}

With the mesh built, elevation data properly interpolated and assigned, boundary condition data gathered, and model testing complete, the calibration effort began. The general approach for calibration was to build the mesh and model for 2011 flood event, calibrate to those conditions, move forward with mesh and elevation modifications, and - based on what was learned from the 2011 event - calibrate for the 2015 and 2017 events. Then, roughness parameters were adjusted to be consistent and provide good results for all three flood events.

\section{1 model}

The primary adjustments made to the 2011 model to achieve calibration were to

- utilize the proper discharge boundary time series for the Ohio River

- build an accurate failure time series for the BPNMF crevasses

- adjust roughness values.

For the Ohio River discharges, three different time series were tested: USGS Ohio River at Metropolis flows, USGS flows increased by $7 \%$, and the flow time series extracted from the USACE Mississippi Flowline model 
(Lewis et al. 2018). The discharges from the Flowline model, recommended for use by USACE Memphis staff, did indeed produce the best results.

Failure time series for the BPNMF crevasses were necessary to define the failure rate of the crevasses. The exact timing of the failure activation was taken from the Mississippi River Flowline model and verified in the Camillo (2012) report. Theoretically, BPNMF activation across the entire length of a crevasse occurs within a few seconds from explosives detonation with the activated length determined by the loading operation. However, the exact failure rates of the crevasses and ensuing flow development were unknown and were adjusted (in the AdH model) to fit observed discharge data collected in the floodway. The Flowline Model was used as a guide for modeled failure rates of the crevasses, but ultimately the failure rates were calibrated to the observed discharge data in the BPNMF and by examining ADCP data near the crevasses for clues on failure timing. The AdH model requires the user to define a collection, or "string" in AdH nomenclature, of nodes and a time series assigning the changing elevations (in this case lowering, e.g., failure) of those nodes. Figure 4-1 shows the locations of the crevasses which allow flow into and out of the BPNMF.

The upper crevasse was the first to be activated, with the detonation beginning at May 2, 21:04 Central Standard Time (CST) (Lewis et al. 2018; Camillo 2012). The subsequent failure occurred in darkness, and limited data on failure rate and shape were available for the breach. Typical breaches tend to grow outwards from the initial failure in both width and in depth. Because the BPNMF activation involved explosives along a length of levee, the physical failure rate was expected to be rapid over the crevasse length. However, no data exist to confirm physical characteristics of the opening geometry at onset of demolition or through time. To replicate this complex process within the AdH model, the full length of the breach was failed in staggered sections using the internal levee breach option (BR USR card). Figure 4-2 highlights the locations of the levee sections, and Figure 4-3 shows time-series curves of the levee section failures as used in the $\mathrm{AdH}$ model to reproduce observed data collected within the floodway. As demonstrated in the plot, the Middle, North1, and South1 sections were failed together, with the remaining sections failing afterward. The failure time-series curves are sine wave functions, mimicking the functionality in HEC-RAS. Not shown on the plot is the North3 curve, which failed 4 days later as observed in photos and observed discharge analysis. 
Figure 4-1. BPNMF crevasse locations.

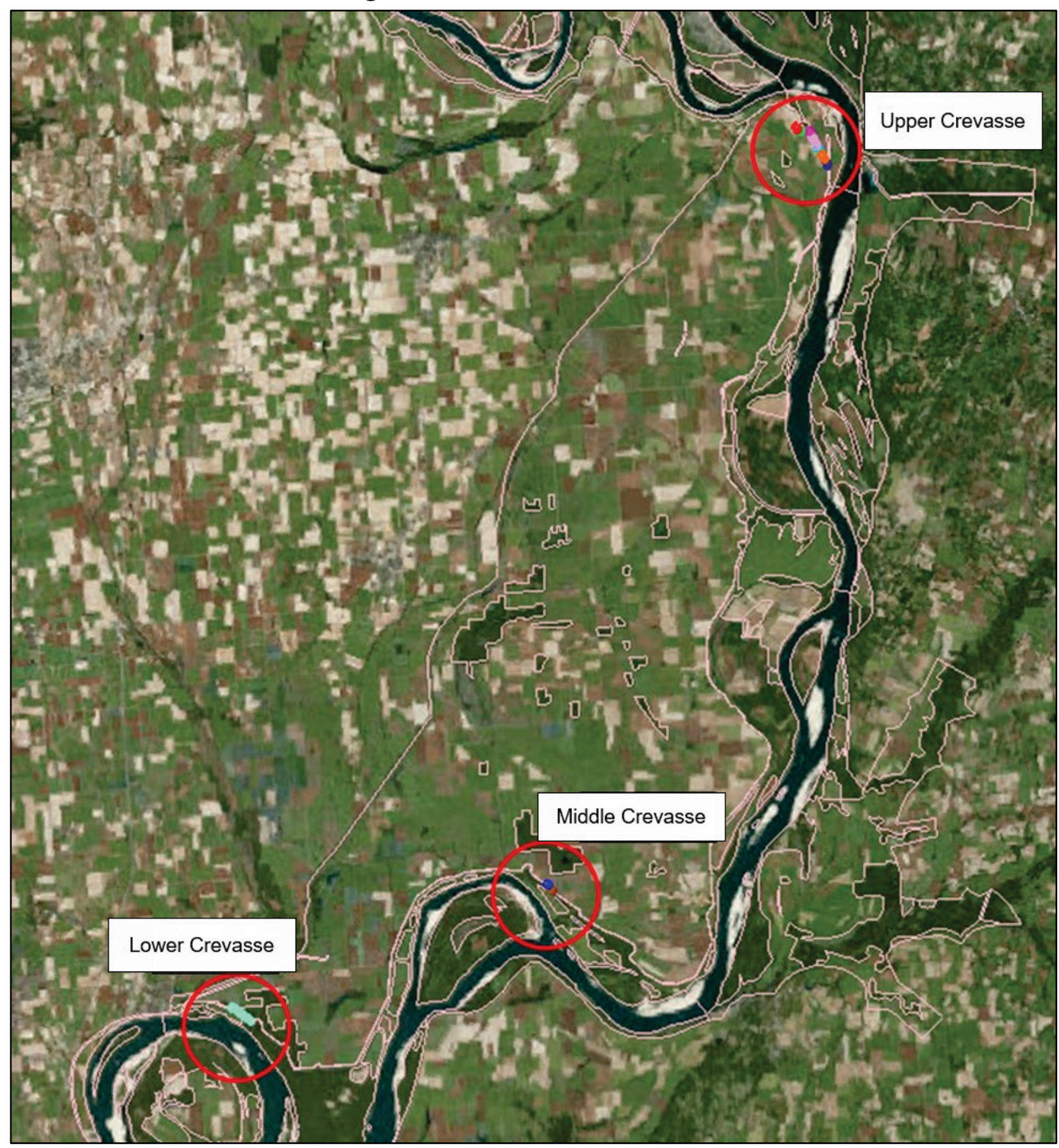


Figure 4-2. BPNMF upper crevasse node strings, each with a specified failure time series used in AdH model.

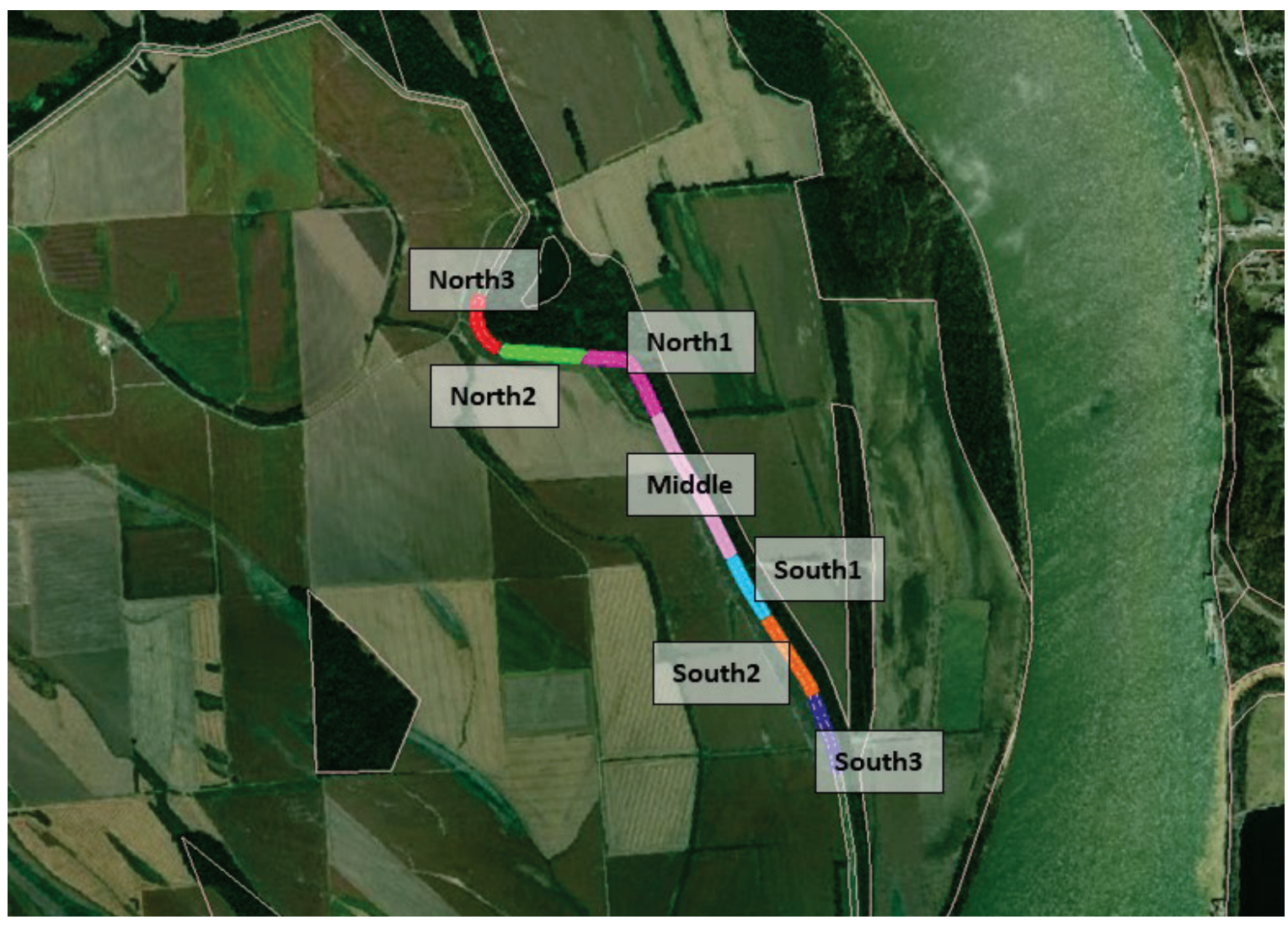

Figure 4-3. Upper crevasse failure time series used in AdH model.

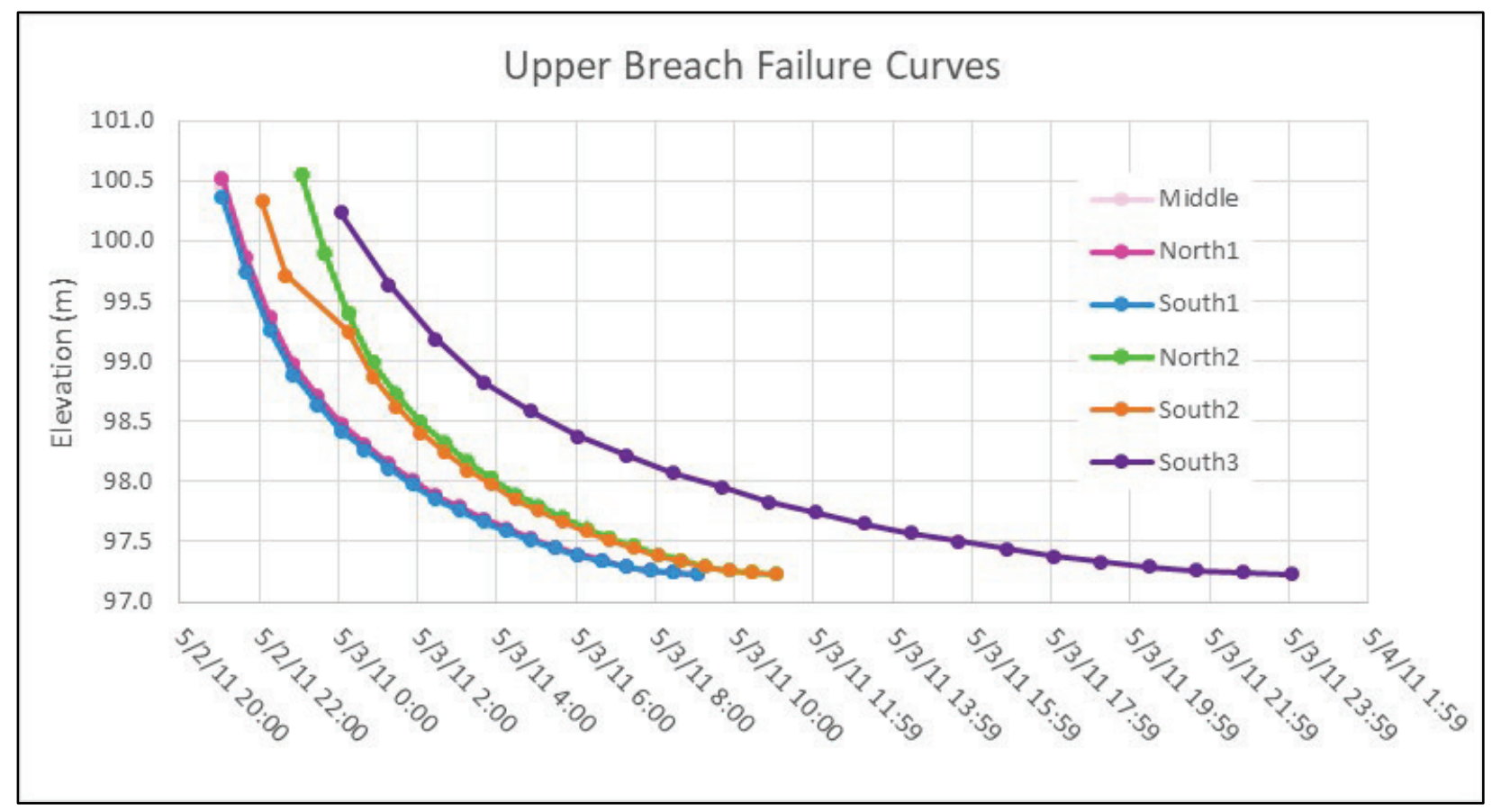


The lower crevasse was simulated as a single section failure on May 3, 11:35 CST (Lewis et al. 2018; Camillo 2012, stated 12:40) using a timeseries failure curve, with total duration of failure of $12 \mathrm{hr}$. Figure 4-4 shows the lower breach location, and Figure 4-5 shows the time-series curve that was used in the model for the failure.

The middle crevasse was activated on May 5, 13:34 CST (Lewis et al. 2018) in three sections - an initial breach and then two secondary breaches on either side. The failure curves were generated by viewing ADCP velocity data near the breach, analyzing the inflow discharge time series, and ultimately iterating to fit the observed data. Figure 4-6 shows the modeled levee sections, and Figure 4-7 shows the time-series curves for the sections. Note that both the secondary sections failed simultaneously so there is only one curve representing those sections.

Figure 4-4. BPNMF lower crevasse node strings, each with a specified failure time series as used in AdH model.

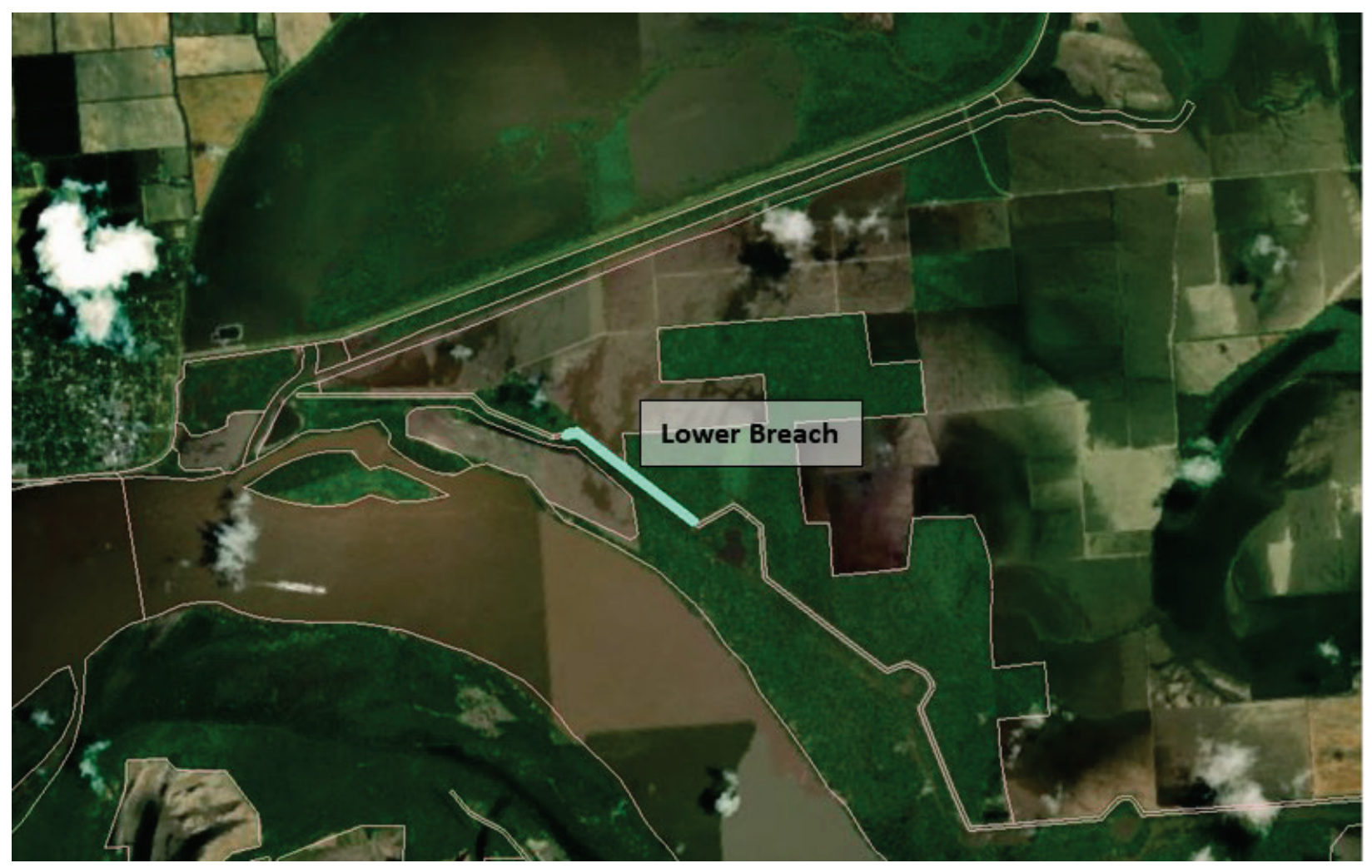


Figure 4-5. Lower crevasse failure time series as used in AdH model.

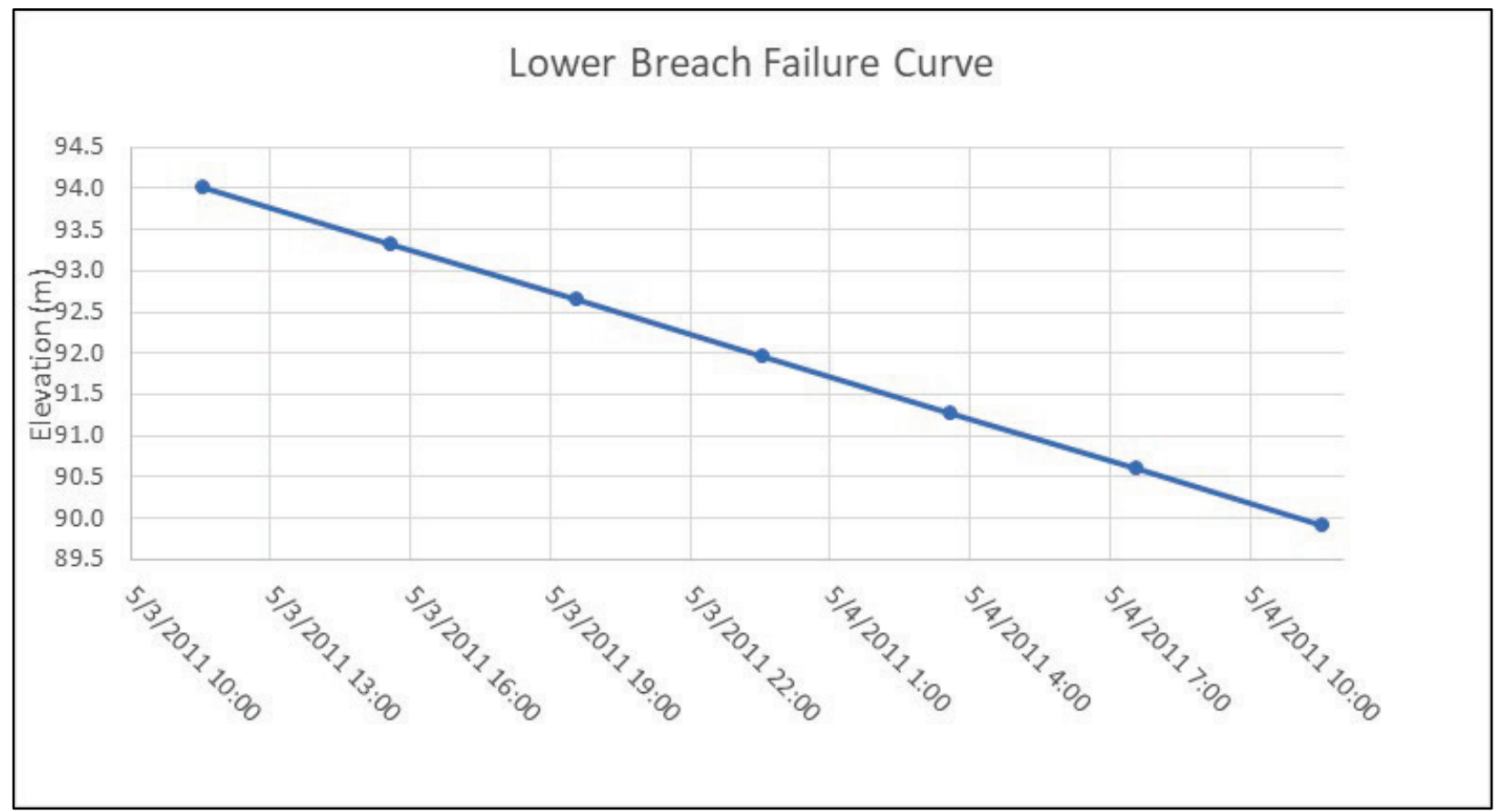

Figure 4-6. BPNMF middle crevasse node strings, each with a specified failure time series as used in AdH model.

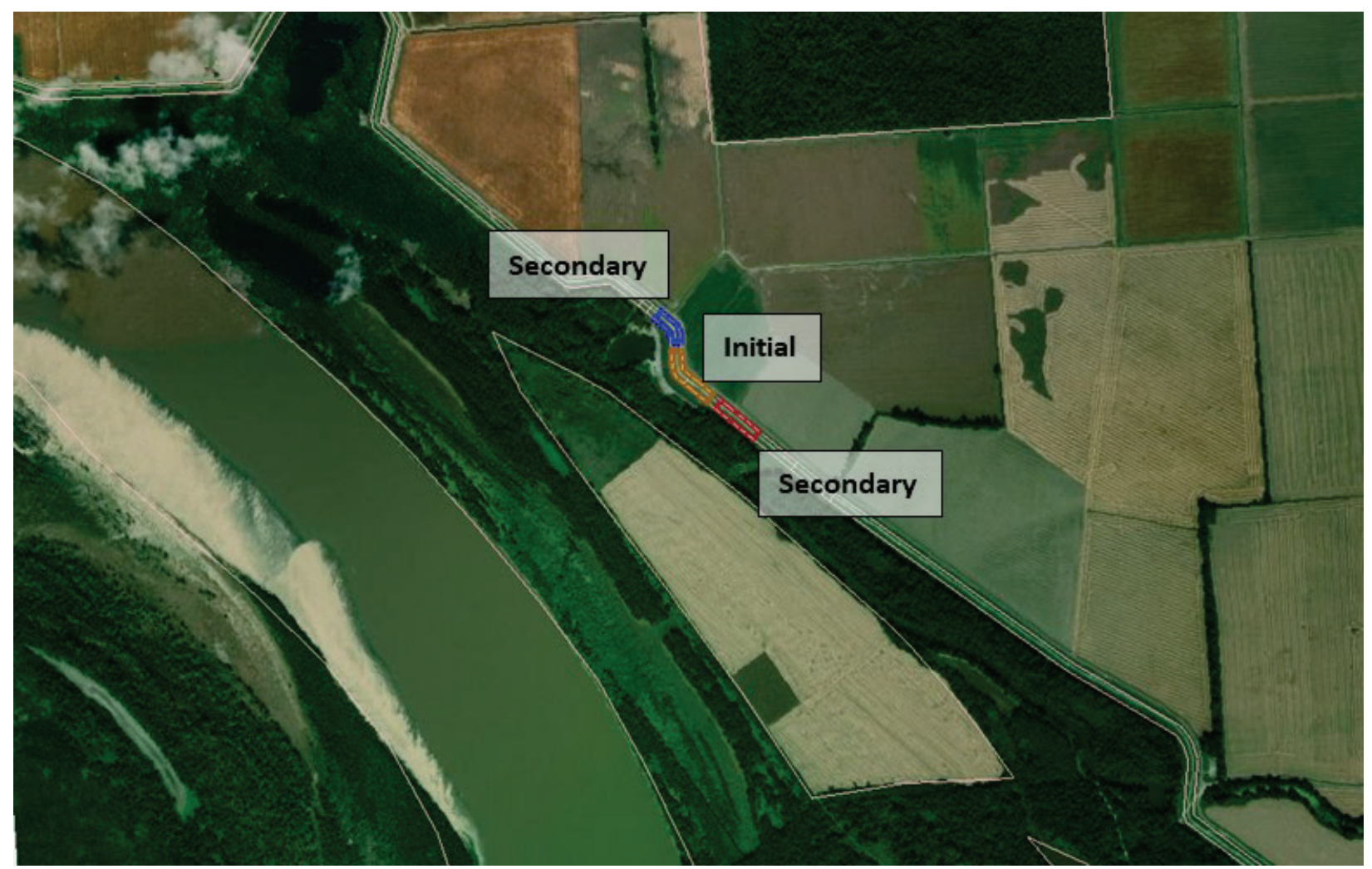


Figure 4-7. Middle crevasse failure time series as used in AdH model.

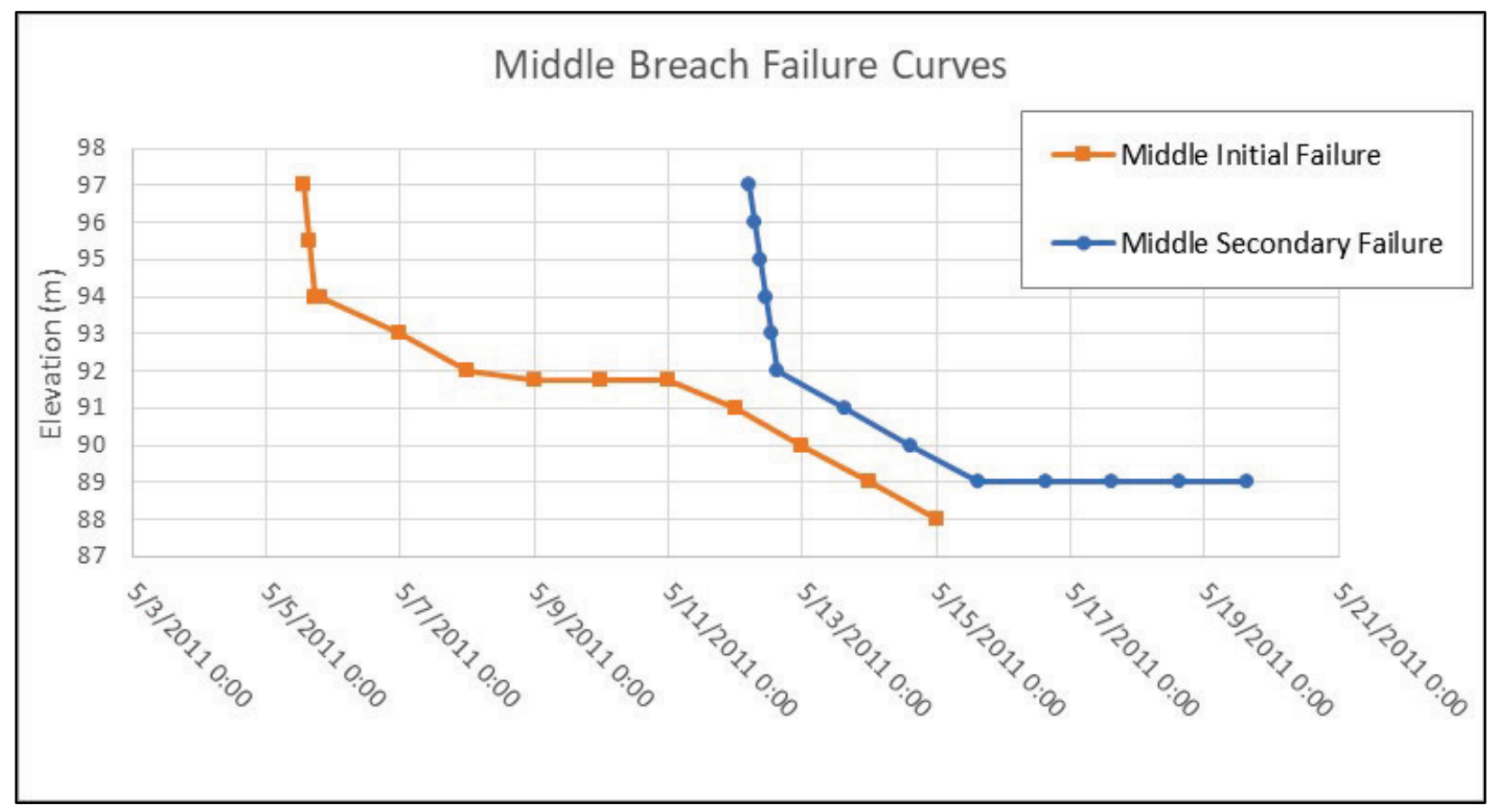

Manning's $n$ values in the channel and floodplain were adjusted to match observed stage data while iterating boundary condition and crevasse operation time series. As has been documented previously on the Mississippi River (Huval 1979), the "loop effect" was evident when comparing modeled to observed stages in the river. The loop effect (also known as hysteresis or dynamic loop) refers to hysteresis in the stagedischarge curve, as different stages result from the same discharge depending on whether the flow occurs on the rising or falling limb of the hydrograph. The loop effect results in higher stages on the falling limb of the hydrograph than on the rising limb (lower stages) for a given discharge. Factors contributing to hysteresis include hydrodynamics (varying slopes, unsteady flow, and varying force distributions) and boundary roughness (resulting from sediment transport effects like bed shear stresses, bed formation [such as dune height, intensity, and aspect ratio]) that change through the entire rising and falling sequence. For the purposes of this report, the loop effect on the Mississippi River is categorized into two elements: (1) the hydrodynamic effect of the friction slope being steeper than the bed slope for rising conditions that result in more discharge being passed at a given stage and (2) the boundary roughness changes originating from a steeper friction slope on the rising limb that produces higher shear stress and therefore higher stream power, which in turn, results in lower-roughness bedforms in the river. Element 1 
- the steeper friction slope - is accounted for in the AdH model as it uses the full dynamic wave version of the shallow water equations, but element 2 - the roughness effects - is not accounted for.

This is demonstrated by examining model results and observed stages at Hickman. Figure 4-8 plots two separate stage-discharge series, one using modeled stages and one using observed stages. The modeled stages on the rising limb (solid lines) are coincident with observed stages, but on the receding limb (dashed lines), modeled stages are lower than observed. The loop effect is demonstrated in both the modeled and observed rating curves, but it is not as strong in the model because the roughness effects are not accounted for. The AdH model does not allow for varying roughness over time. The model was calibrated to the rising limb stages, with the understanding that stages would be under predicted on the falling limb.

One critical part of the 2011 model calibration effort included developing an understanding of the discharge into the BPNMF through the upper crevasse. Initial discharges into the floodway were dependent upon the failure rate of the upper crevasse. The discharge over the entire flood hydrograph was dependent on the modeled stage on the river side of the upper crevasse, and the friction specified at the entrance of the floodway, particularly the forested areas. This represented a challenge, as the stage in the river and flow into the floodway affect one another. Figure 4-9 shows the difference in stage at the Birds Point, MO, gage for a model with channel $n$-values increased by 0.004 . From $5 / 6 / 2011$ to the end of the simulation, stages at Birds Point are in much better agreement with observed data, accounting for increased bedform roughness on the receding limb. The higher river stages result in larger discharges into the BPNMF through the upper crevasse, as shown on Figure 4-10.

Once the 2011 model calibration was nearly complete, efforts to calibrate the 2015 and 2017 model were performed using the understanding gained. 
Figure 4-8. Stage vs. discharge for both modeled and observed stages at Hickman, showing the loop effect.

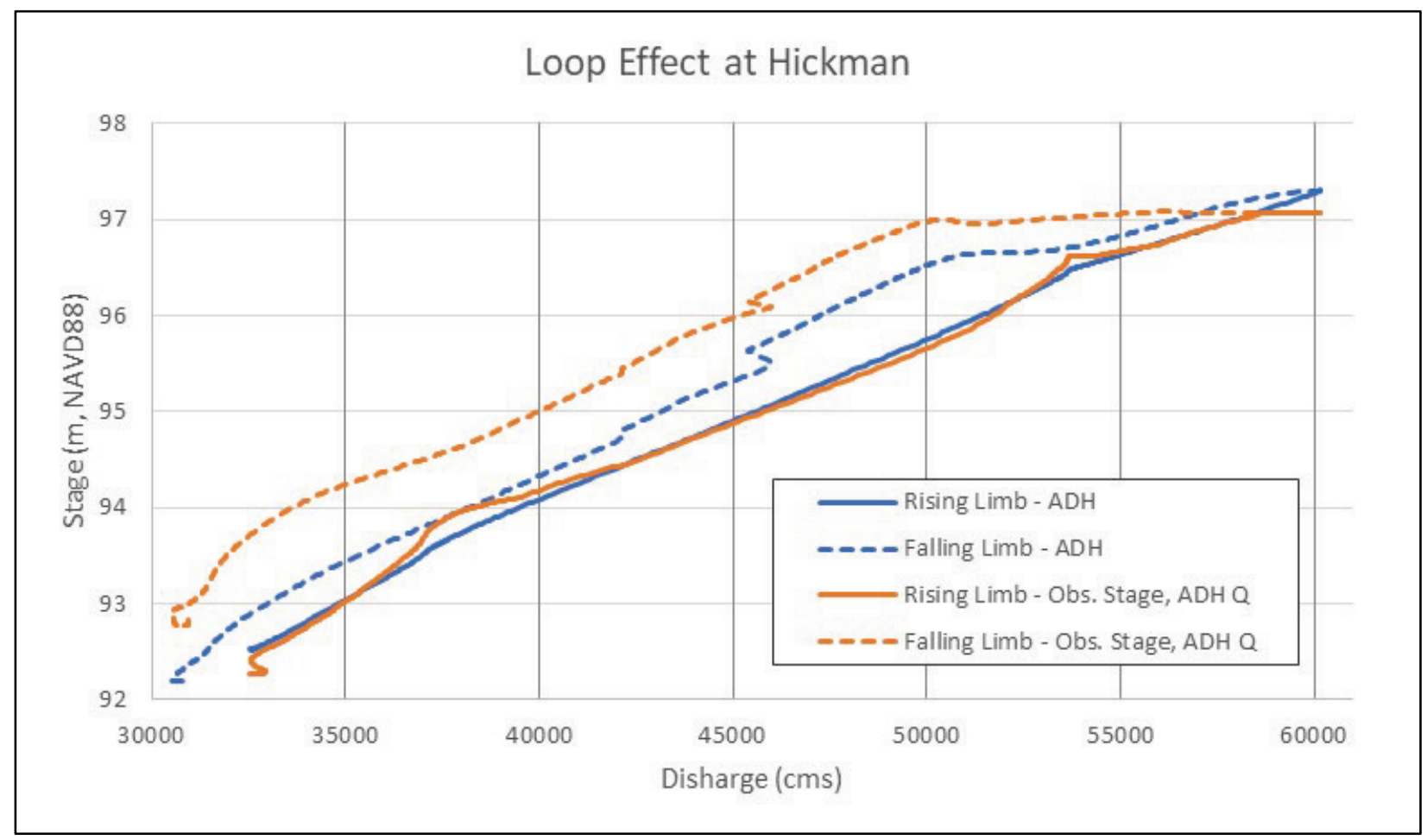

Figure 4-9. Modeled and observed stage at Birds Point for two models - the "High channel $n$ " model having $n$-values 0.004 higher in the channel.

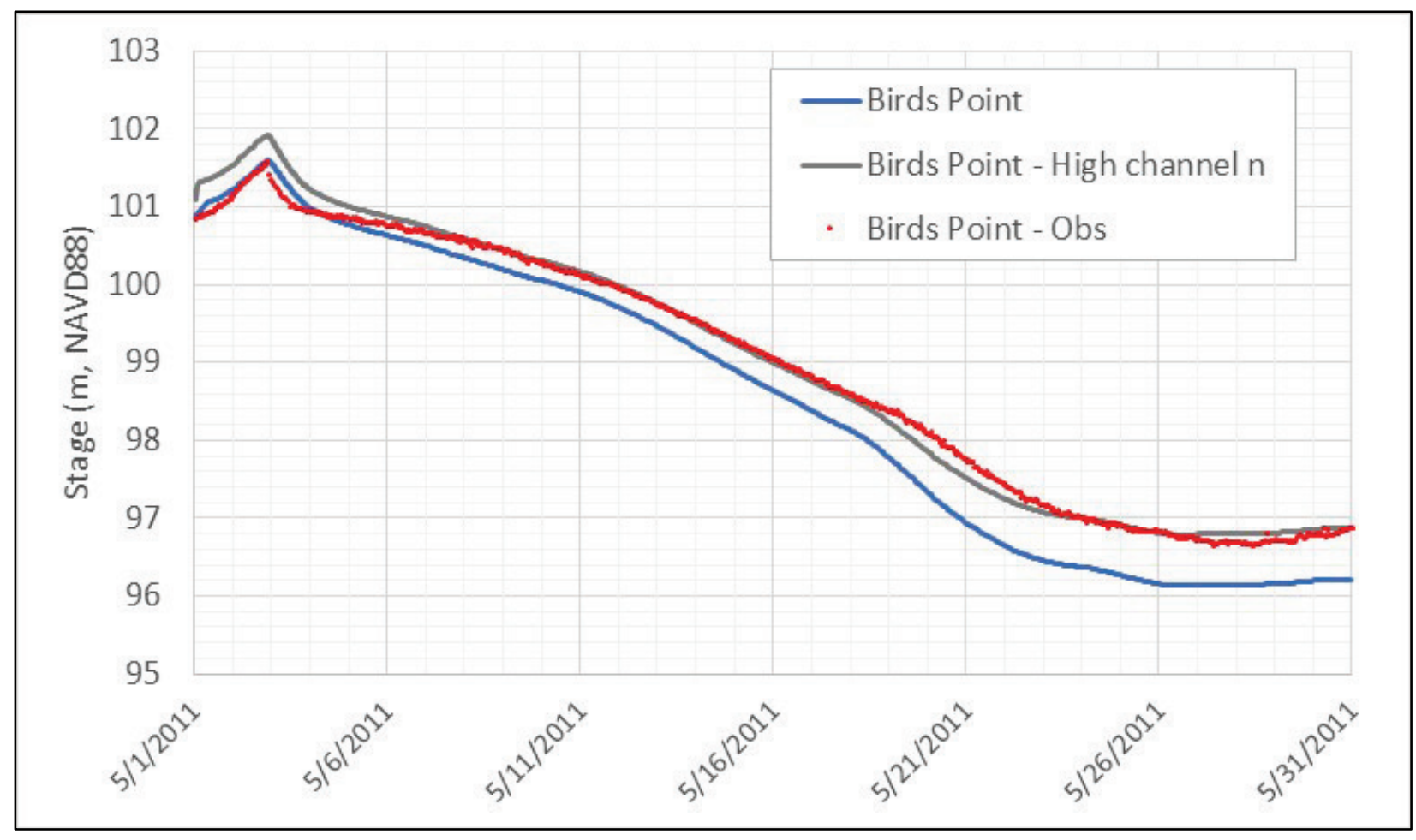


Figure 4-10. Modeled and observed discharge into the BPNMF for two models - the "High channel $n$ " model having $n$-values 0.004 higher in the channel.

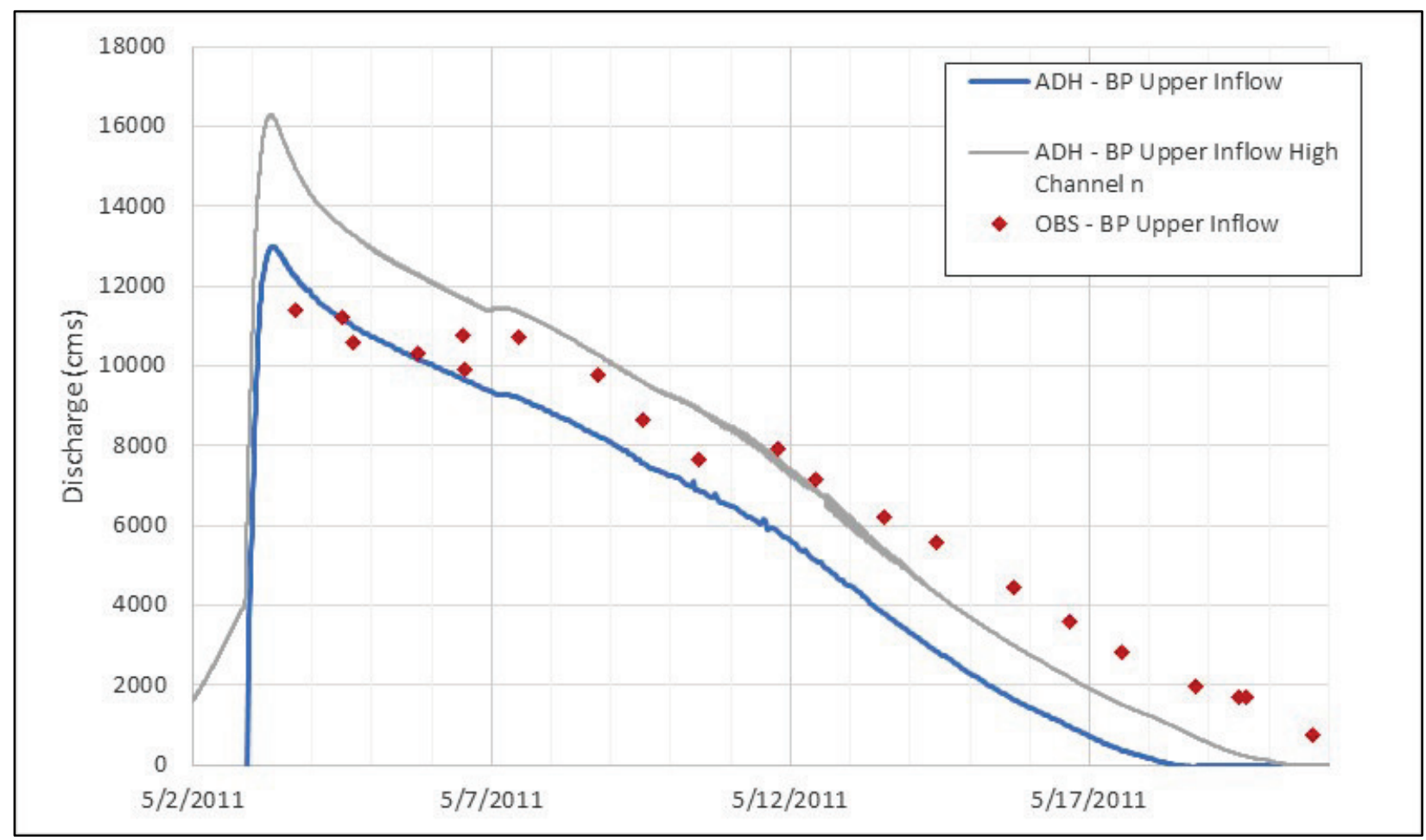

2015-2016 model

The primary objective of the 2015 flood model was to correctly model the outflow from the LS levee breach. With the 2011 simulation nearly calibrated, the initial setup of the 2015 model (updated elevation data and boundary condition data) produced good results for stage and the primary focus was on getting the LS outflow correct. The breach width on 1/2/2016 and 1/5/2016 is known from aerial photography (Figure 1-7 and Figure 1-8), but the progression is otherwise unknown. The LS levee was set to fail at 1/2/2016 o:00 to a width of $919 \mathrm{ft}(280 \mathrm{~m})$. Three more sections of levee were set to fail at $24 \mathrm{hr}$ increments beginning on 1/4/2016 0:00 (Figure 4-11). 
Figure 4-11. LS breach openings for the 2015 model.

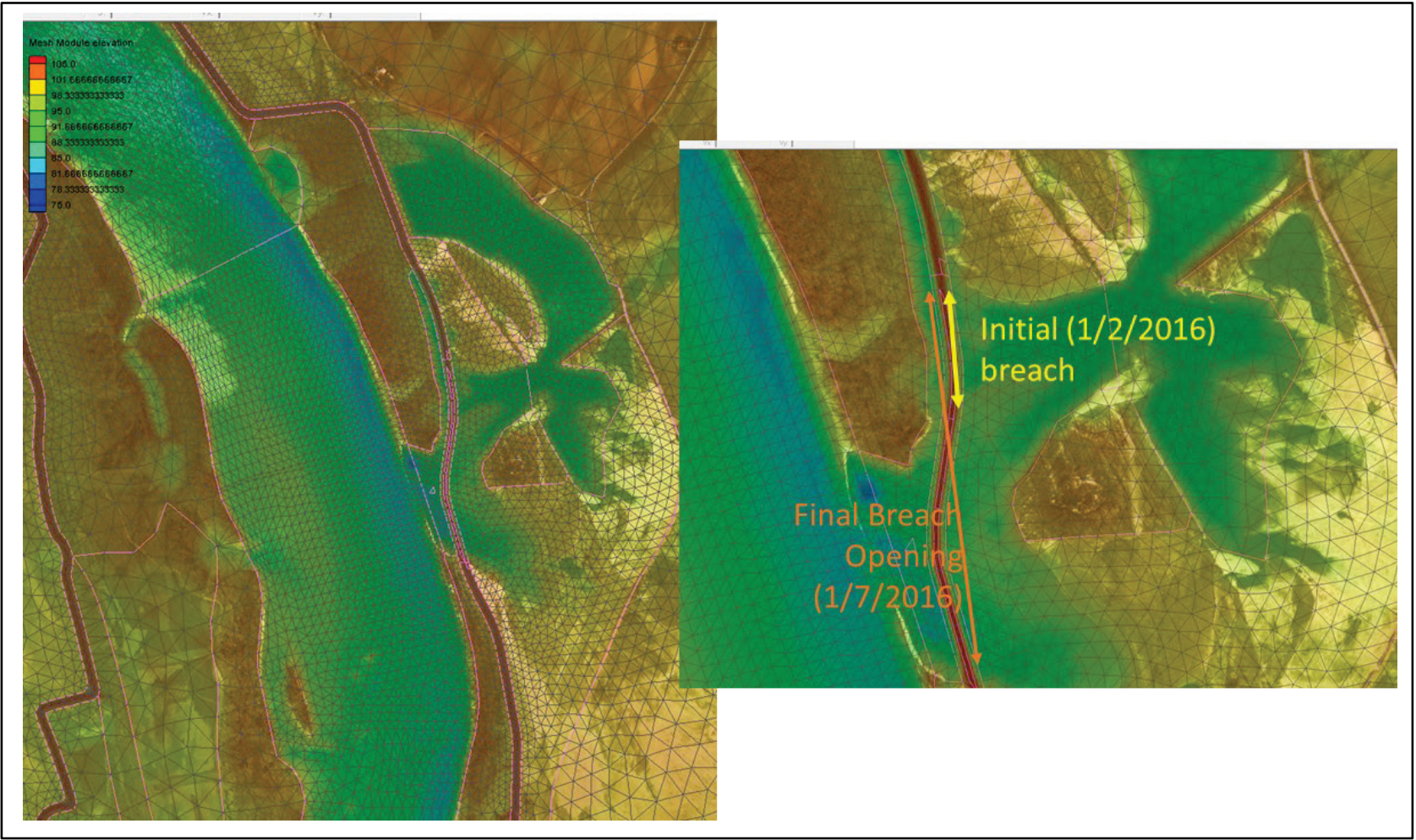

Grid convergence testing was performed with respect to the LS breach. In the original (and final) mesh, the LS breach spanned nine nodes. The mesh tested for grid convergence had resolution doubled within approximately $2 \mathrm{~km}$ of the breach and quadrupled within $500 \mathrm{~m}$ of the breach. The modeled outflow from the LS breach was identical for the refined grids, indicating the initial resolution was adequate.

Testing was also performed for unsubmerged rigid vegetation roughness parameters (AdH software input record URV) for the forest west of the initial breach. A reasonable range of URV roughness parameters led to a range of breach outflows for the $919 \mathrm{ft}(280 \mathrm{~m})$ wide breach of between 3,900 and 5,000 cms (135,000 to 175,000 cms). Final determination of URV parameters was determined by adjusting values at the LS and BPNMF upper crevasse forested areas for all three model simulation time periods, viewing all outflow and stage results, and choosing the most sensible values.

\section{7 model}

The primary objective of the 2017 flood model was also to correctly model the outflow from the LS levee breach. With the 2011 simulation nearly 
calibrated and the 2015 model producing good results, the 2017 model (updated elevation data and boundary condition data) produced good results for stage, and again the primary focus was on getting the LS outflow correct. Grid convergence testing for the breach opening was performed for the 2015 model so the primary parameter to calibrate was roughness near the breach and over the Thompson Landing floodplain.

\section{Finalizing calibration}

Results for stages, breach discharges, and channel velocities were analyzed in light of the testing described above. A consistent set of roughness parameters was chosen and applied to each model simulation period. The weight of evidence was considered across all simulation periods, and the calibration finalized.

\section{Results}

Results for the calibration of stage, discharge, and velocity (for the 2011 model) for the 2011, 2015, and 2017 flood events are included herein. The location of stage calibration at River stations is shown on Figure 4-12. 
Figure 4-12. Stage calibration river station locations.

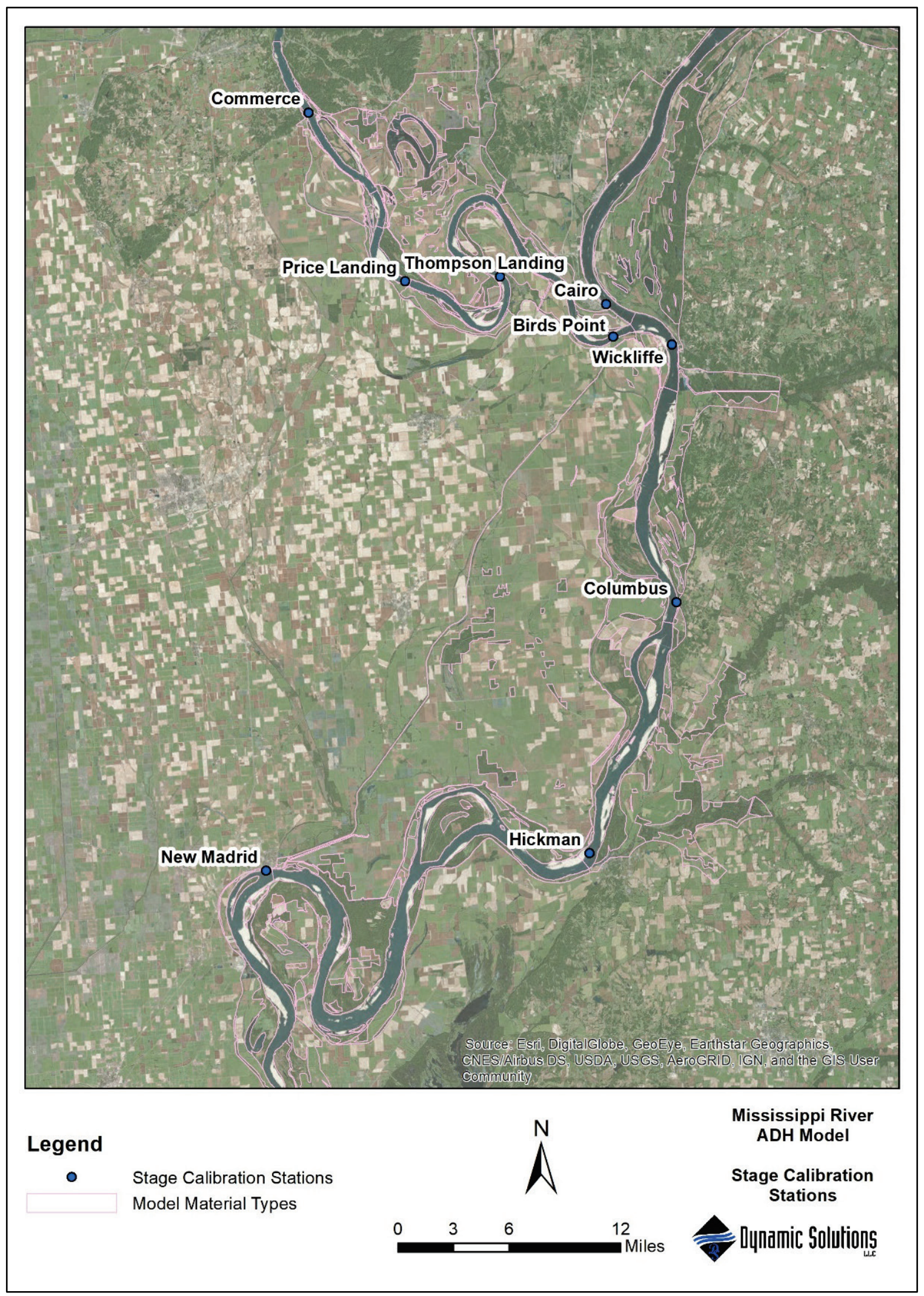




\section{1 calibration results}

\section{Stage}

Stage calibration results for the river stations for the 2011 simulation, are shown in Table 4-1. RMS values for the entire simulation period, 4/16$5 / 31 / 2011$, range from 0.17 to $0.38 \mathrm{~m}$ (0.55 to $1.25 \mathrm{ft}$ ) (not including Wickliffe and Columbus due to suspect datums). rRMS errors range from $3.9 \%$ to $7.4 \%$. Time-series plots comparing modeled to observed stage are shown in Appendix A, Figures A-1 through A-5. Modeled and observed stage at Birds Point, MO (a duplicate of Figure A-4), is shown in Figure 4-13. The time-series plots and statistics show that modeled rising limb stages are in better agreement with observed data, with RMS values between 0.11 and $0.20 \mathrm{~m}$ ( 0.36 and $0.66 \mathrm{ft}$ ). The loop effect results in simulated model stages that are too low on the falling limb. The difference in peak stages ranges from $0.01 \mathrm{~m}$ to $0.23 \mathrm{~m}$ (0.03 to $0.75 \mathrm{ft}$ ). Figure 4-14 shows a longitudinal profile (distance along the channel centerline) of stages along the Mississippi River near the peak of the 2011 flood, before and after the BPNMF is activated.

Table 4-1. Stage calibration statistics for the 2011 event.

\begin{tabular}{|l|c|c|c|c|}
\hline Station & RMS $(\mathrm{m})$ & $\begin{array}{c}\text { Rising Limb } \\
\text { RMS }(\mathrm{m})\end{array}$ & $\begin{array}{c}\text { Diff at Peak } \\
(\mathrm{m})\end{array}$ & RMS (ft) \\
\hline New Madrid & 0.31 & 0.11 & 0.07 & 1.02 \\
\hline Hickman & 0.30 & 0.13 & 0.17 & 0.97 \\
\hline Birds Point & 0.38 & 0.12 & 0.05 & 1.25 \\
\hline Thompson Landing & \multicolumn{5}{|c|}{ No Data } \\
\hline Price Landing & 0.17 & 0.20 & 0.01 & 0.55 \\
\hline Commerce & \multicolumn{5}{|c|}{ No Data } \\
\hline Cairo & 0.29 & 0.17 & 0.23 & 0.94 \\
\hline
\end{tabular}


Figure 4-13. Modeled and observed stage at Birds Point, 2011 event.

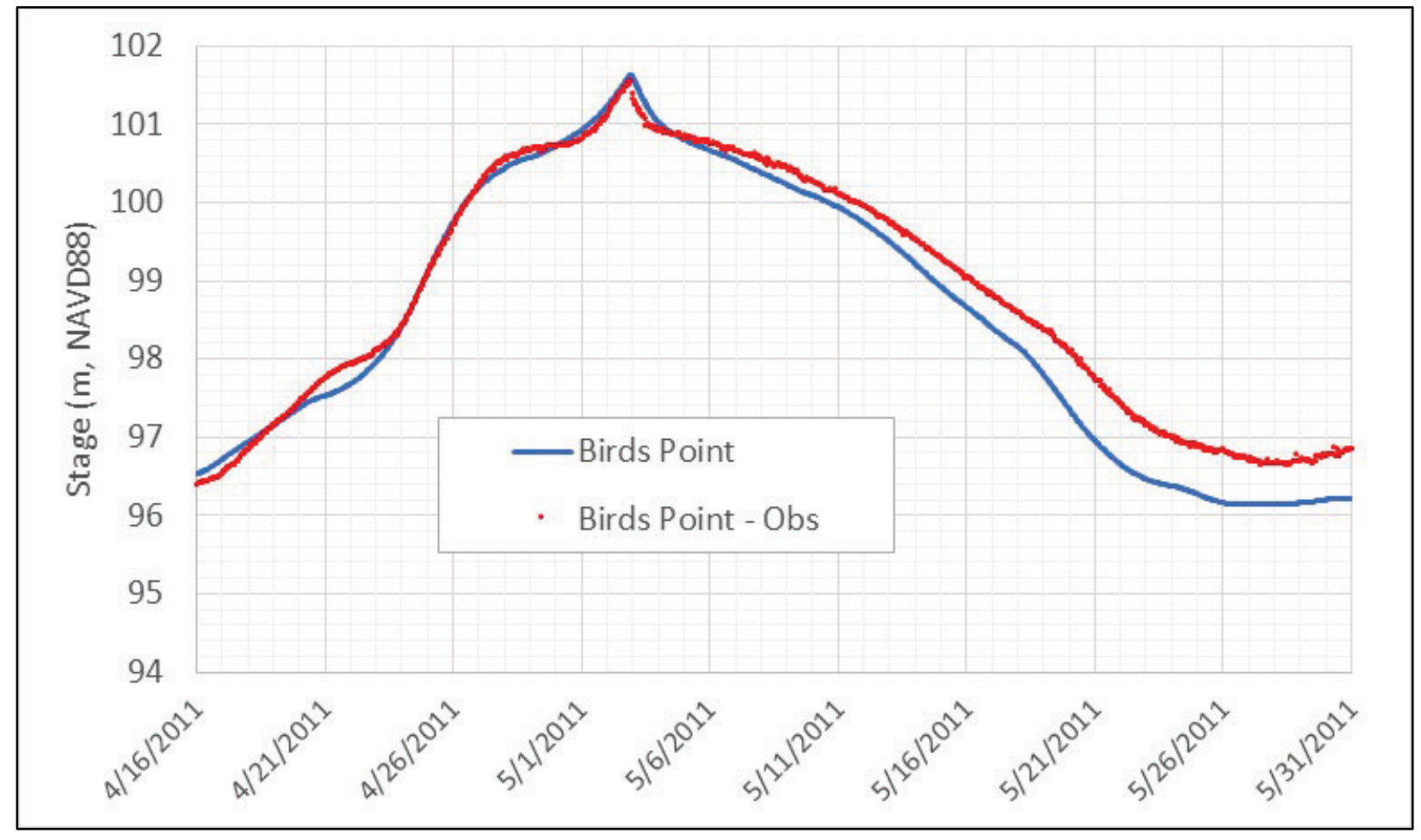


Figure 4-14. Longitudinal profile plot of stage for the Mississippi River. Stages pre- (5/2) and post-activation (5/3) of the BPNMF (Note: Wickliffe and Columbus datums are suspect).

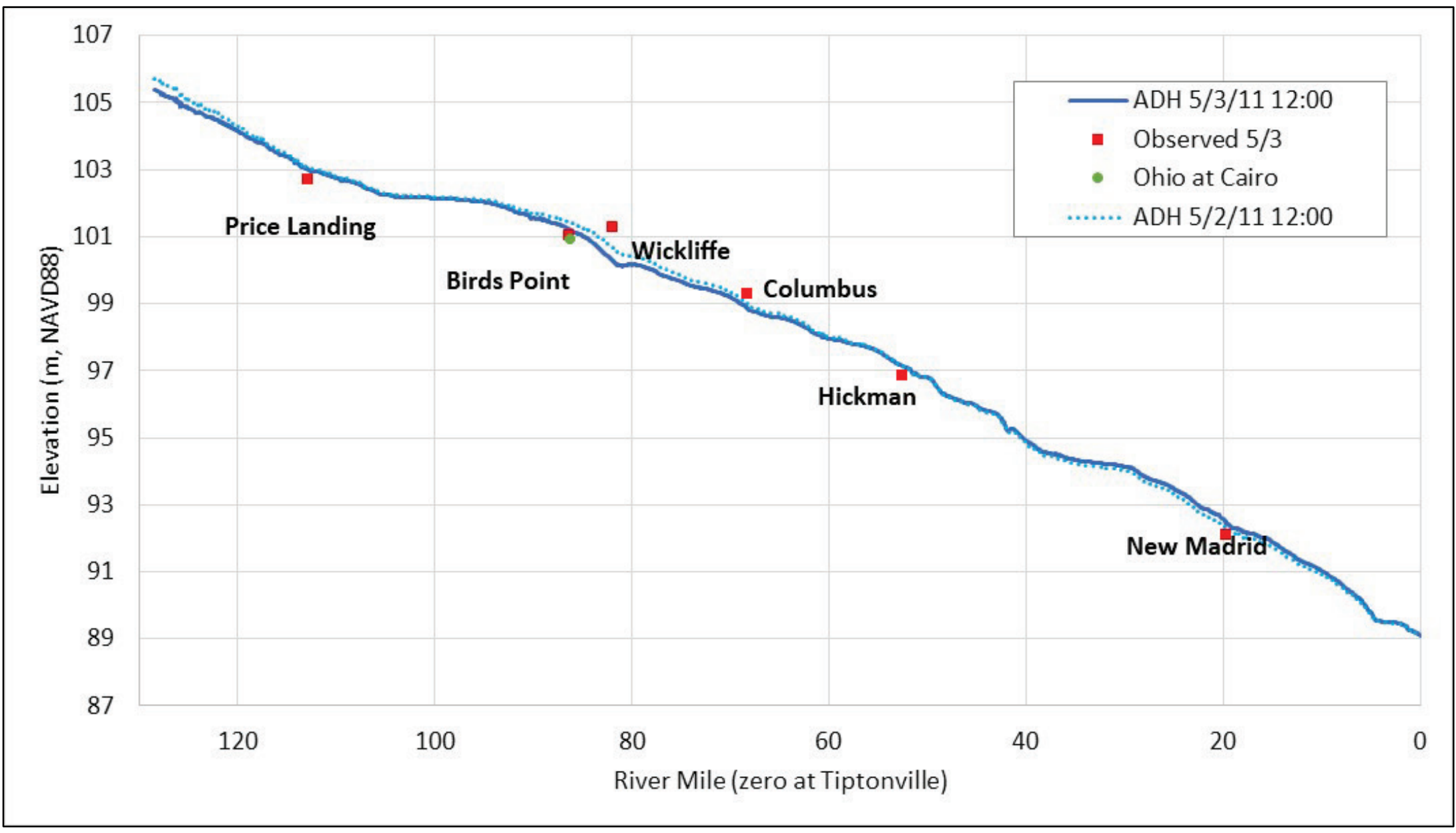


Stage calibration results for the eight stations utilized within the BPNMF (Figure 4-15) are shown in Table 4-2. RMS values range from 0.19 to 0.47 $\mathrm{m}$ (0.62 to $1.53 \mathrm{ft}$ ). rRMS errors range from $12.0 \%$ to $19.2 \%$. Time-series plots comparing modeled to observed stage are shown in Appendix A, Figures A-6 through A-13. Modeled and observed stage at the Upper $3 \mathrm{~km}$ station is shown in Figure 4-16 (a duplicate of Figure A-7). The time-series plots show good general agreement for both the timing of the floodwave and stages. Simulated peak stages in the upper floodway match observed stages well, are too high mid-way down the floodway, and good near the lower end. Modeled stages in the floodway generally remain higher than observed data after the peak.

Figure 4-15. Stage calibration stations in the BPNMF.

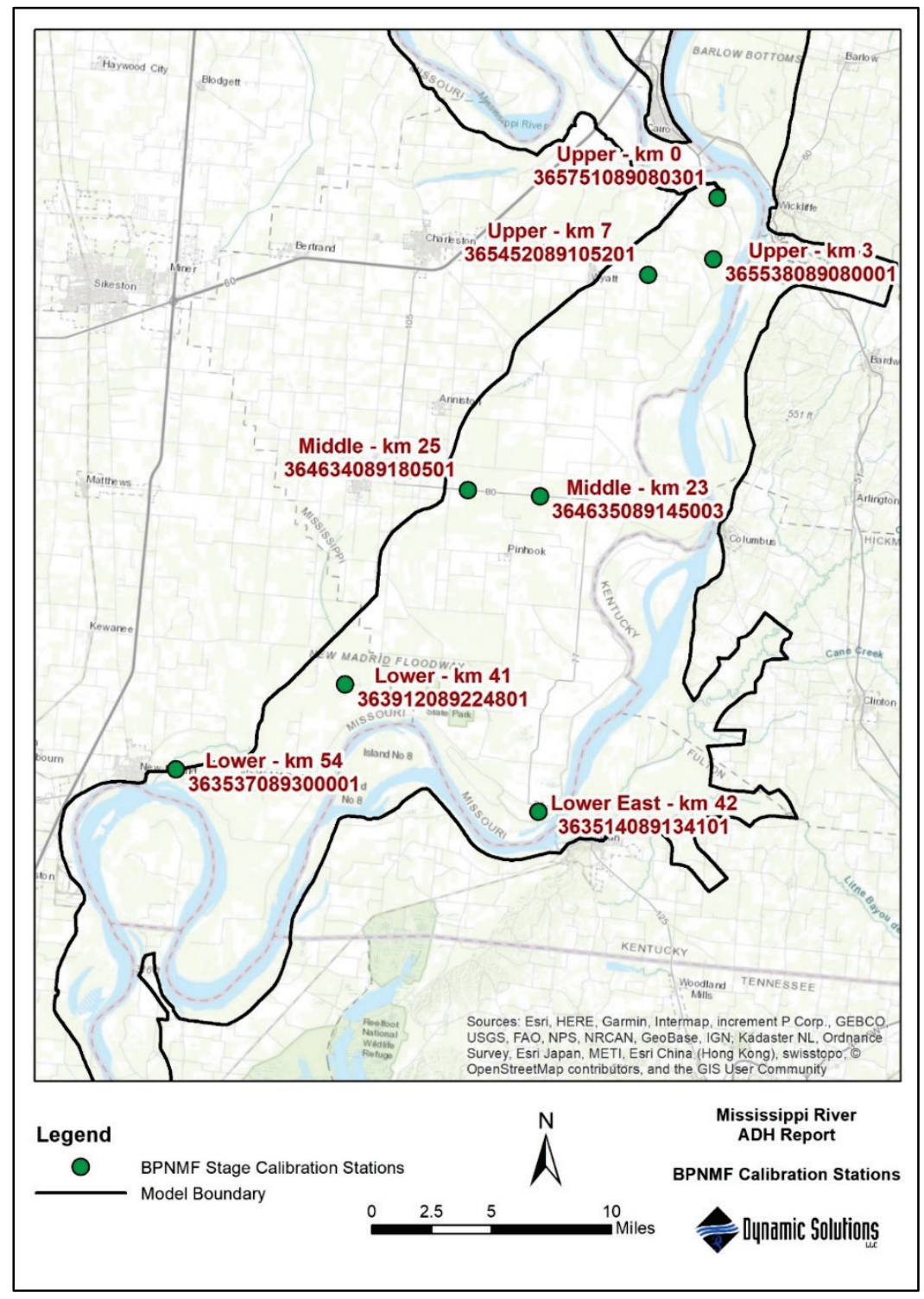


Table 4-2. Stage calibration statistics for BPNMF gages during the 2011 event.

\begin{tabular}{|l|c|c|c|c|}
\hline Name & RMS (m) & rRMS & RMS (ft) & Gage No. \\
\hline Upper - km 0 & 0.19 & $19.2 \%$ & 0.62 & 365751089080301 \\
\hline Upper - km 3 & 0.21 & $19.2 \%$ & 0.69 & 365538089080001 \\
\hline Upper - km 7 & 0.22 & $17.6 \%$ & 0.73 & 365452089105201 \\
\hline Middle - km 23 & 0.47 & $17.4 \%$ & 1.53 & 364635089145003 \\
\hline Middle - km 25 & 0.28 & $16.2 \%$ & 0.91 & 364634089180501 \\
\hline Lower - km 41 & 0.44 & $12.8 \%$ & 1.44 & 363912089224801 \\
\hline Lower - km 54 & 0.28 & $18.8 \%$ & 0.91 & 363537089300001 \\
\hline Lower East - km 42 & 0.21 & $12.0 \%$ & 0.70 & 363514089134101 \\
\hline
\end{tabular}

Figure 4-16. Modeled and observed stage at the Upper - km 3 station in the BPNMF.

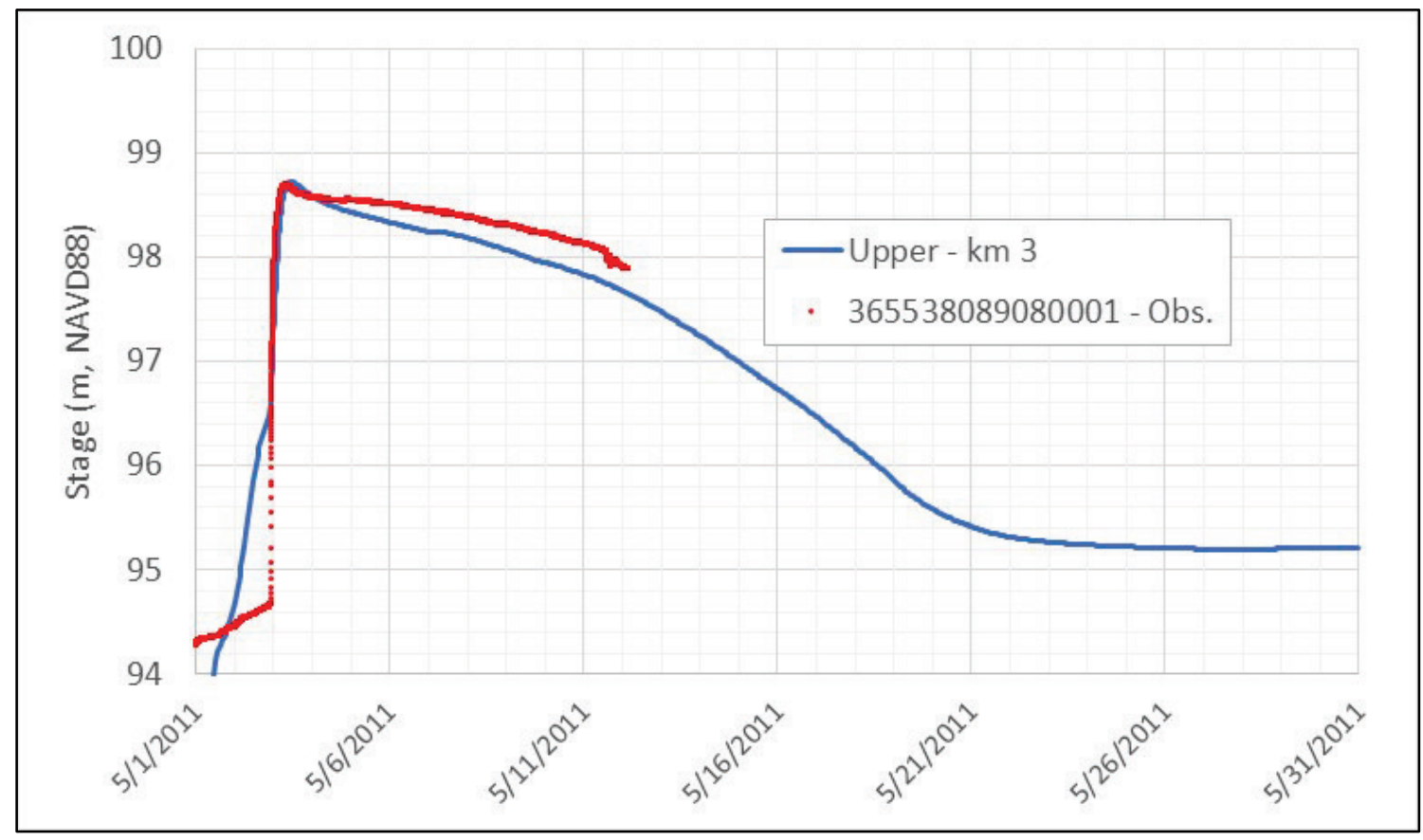

Discharge

Discharge calibration station locations are shown in Figure 4-17 and statistics for seven of the stations with sufficient data are shown in Table 4-3. NSE statistics range from 0.29 to 0.90. Discharge in the Mississippi and Ohio Rivers is largely determined by the specified boundary conditions, secondarily by the attenuation of the hydrograph. Calibration was not adjusted to match these observed river flows, but the model was adjusted to replicate flow through the BPNMF. Discharge through the upper crevasse, labeled BPNMF Upper FP) Inflow in 
Figure 4-17, has an NSE of 0.90 and the total flow in the lower floodway (BPNMF Lower Total Flow) an NSE of 0.86 , indicating very good modeldata agreement. Time-series plots comparing modeled to observed stage for the seven stations, and four others for which NSE was not computed due to the low number of observations are shown in Appendix A, Figures A-14 through A-24. Modeled and observed discharge through the upper crevasse into the BPNMF (a duplicate of Figure A-18) are shown in Figure 4-18.

Table 4-3. Discharge calibration statistics for the 2011 event (abbreviations: MR - Mississippi River; OR - Ohio River)

\begin{tabular}{|l|c|c|c|c|}
\hline Station & Pairs & NSE & RMS (cms) & rRMS \\
\hline MR above Cairo & 32 & 0.78 & 2132 & $15.3 \%$ \\
\hline OR below Cairo & 46 & 0.41 & 3403 & $15.8 \%$ \\
\hline MR below BPNMF Inflow & 10 & 0.29 & 5282 & $31.1 \%$ \\
\hline BPNMF Upper FP Inflow & 32 & 0.90 & 1370 & $12.0 \%$ \\
\hline BPNMF Middle FP Inflow & 30 & 0.68 & 487 & $19.8 \%$ \\
\hline BPNMF Lower Total Flow & 36 & 0.86 & 1418 & $13.2 \%$ \\
\hline
\end{tabular}


Figure 4-17. Discharge calibration cross-section locations (abbreviations:

MR - Mississippi River; OR - Ohio River).

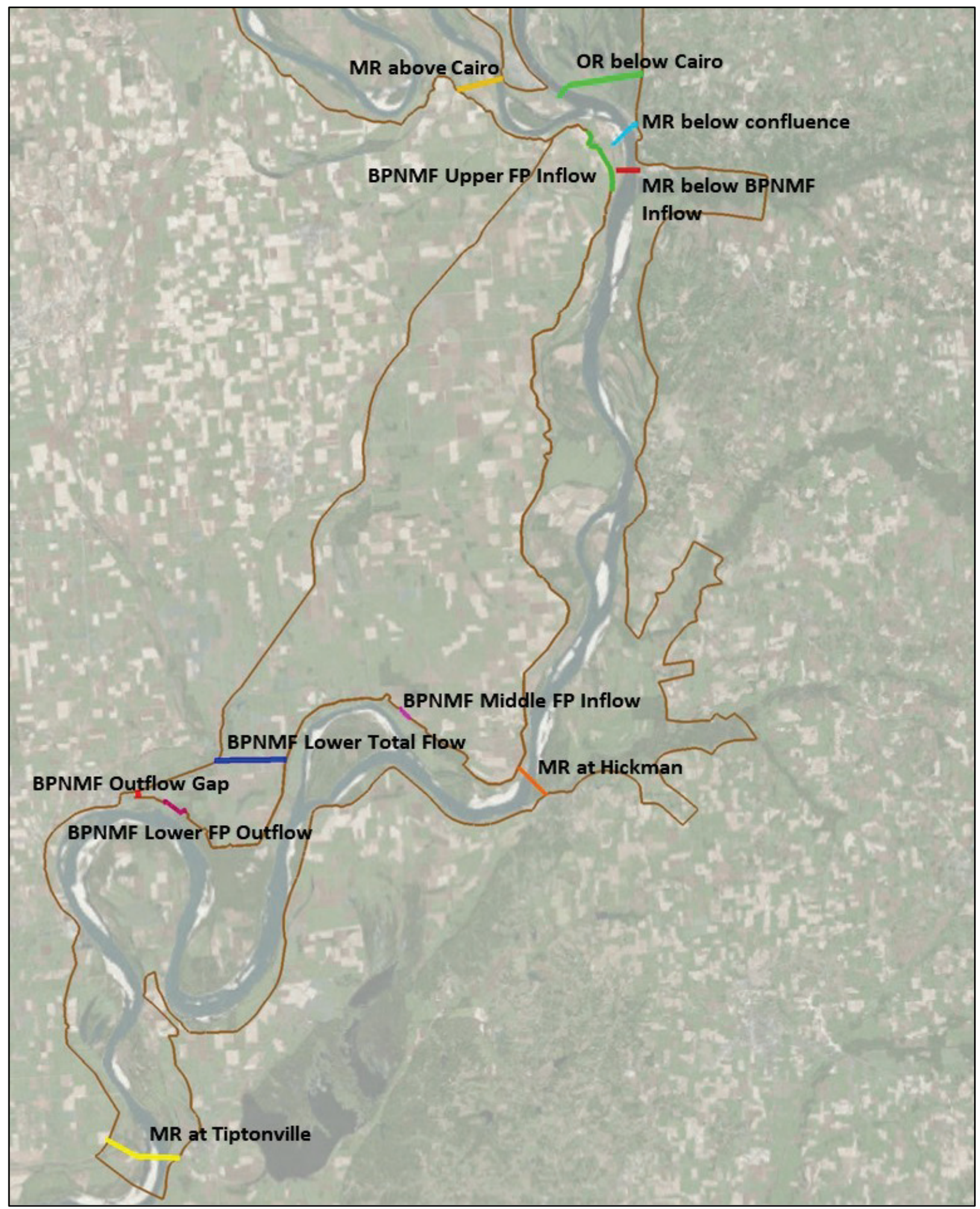


Figure 4-18. Model and observed discharge below the BPNMF upper crevasse.

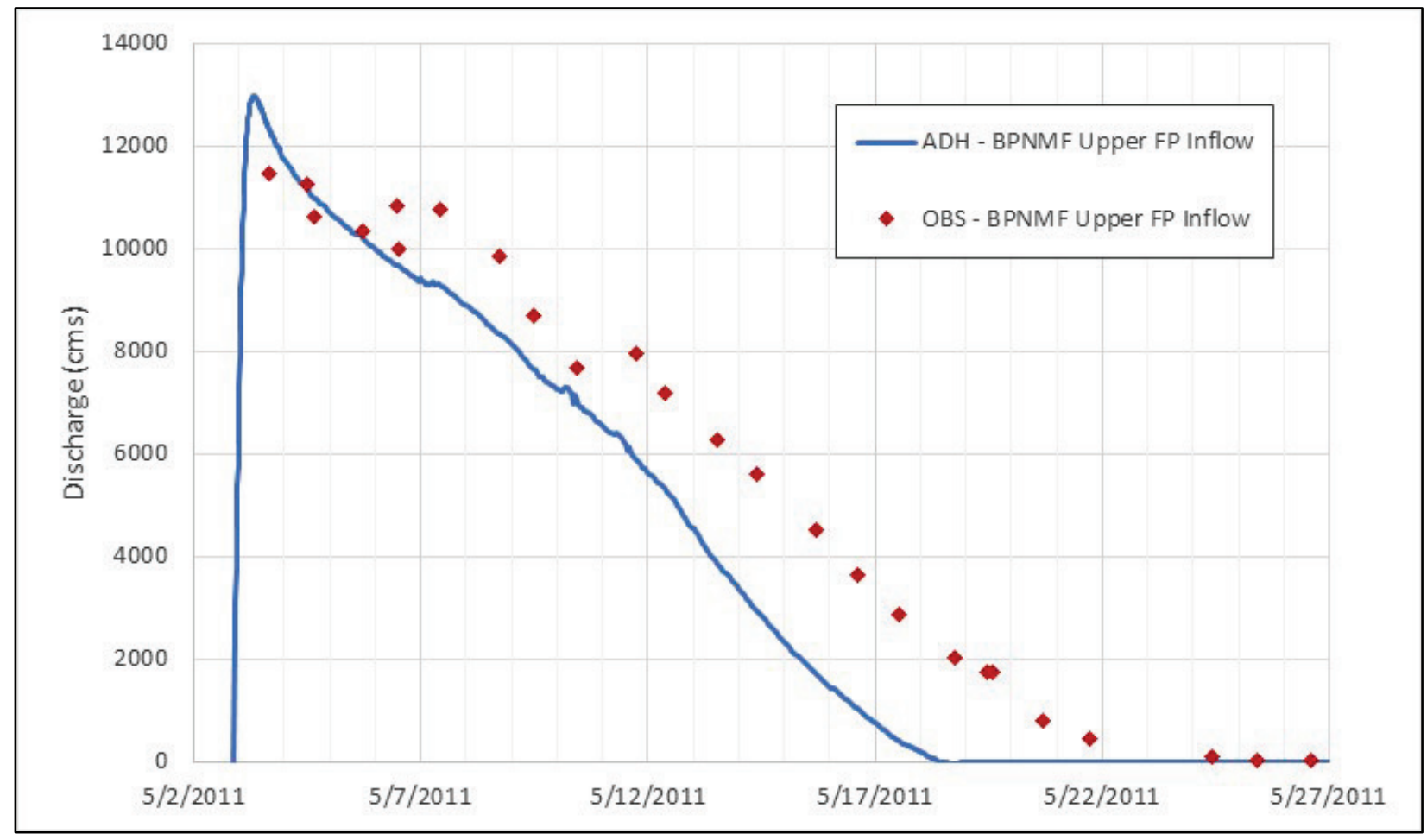

Velocity

During the 2011 flood, the USGS used an ADCP to collect velocity (and discharge) data in the Mississippi River and near the crevasses in the BPNMF. Comparisons of modeled velocity magnitude and direction were made in the Mississippi River and floodplain in the reach adjacent to the BPNMF upper crevasse. The observed depth-averaged velocity data (in $\mathrm{x}-$ and y-vector format) were imported into Surface-water Modeling System (SMS) (Aquaveo 2010). SMS was then used to make model-data comparisons of velocity magnitude and direction along each observation transect. The locations of the transects selected for comparison are shown in Figure 4-19 for paths adjacent to the BPNMF upper crevasse and Figure 4-20 for transects immediately below the upper crevasse. 
Figure 4-19. Transect paths below the confluence used for velocity comparisons.

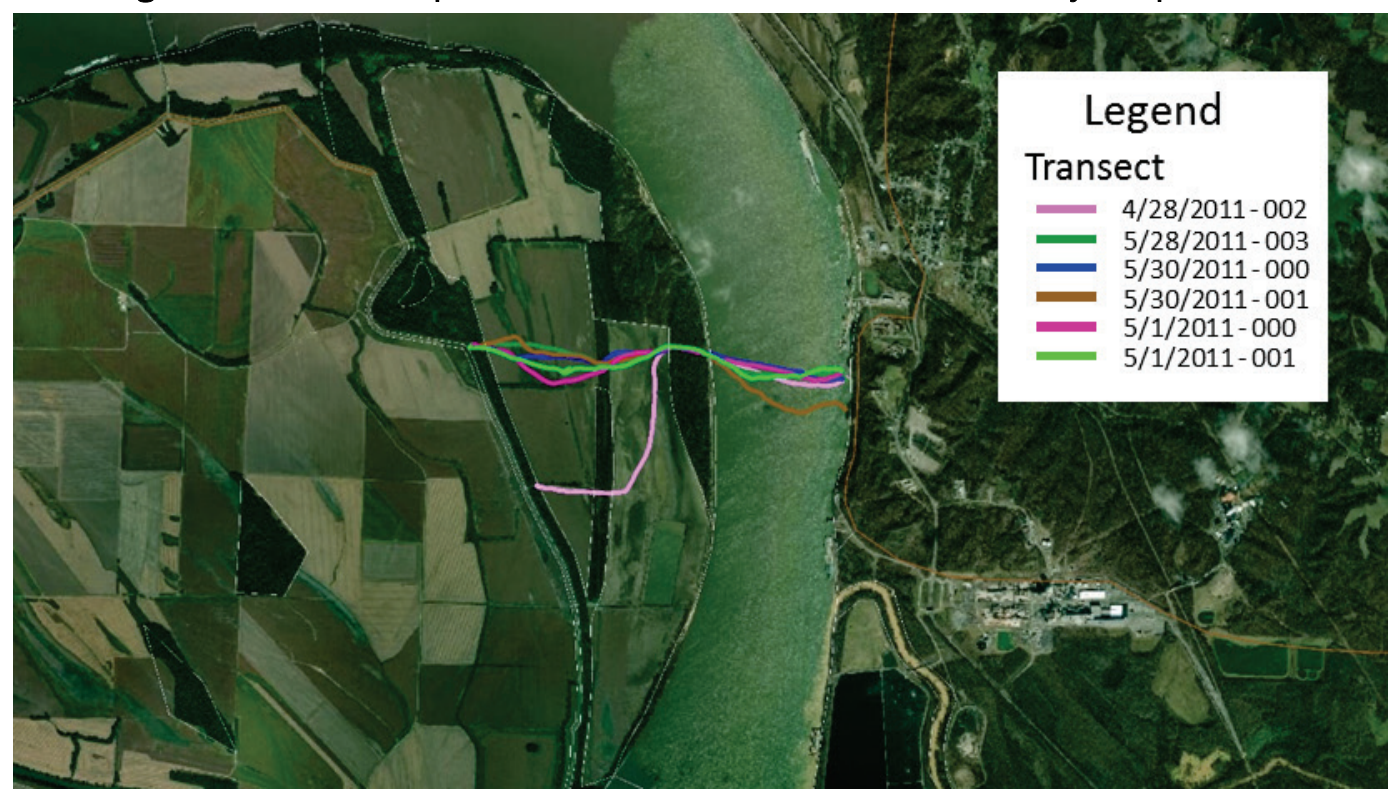

Figure 4-20. Transect paths below the upper breach used for velocity comparisons.

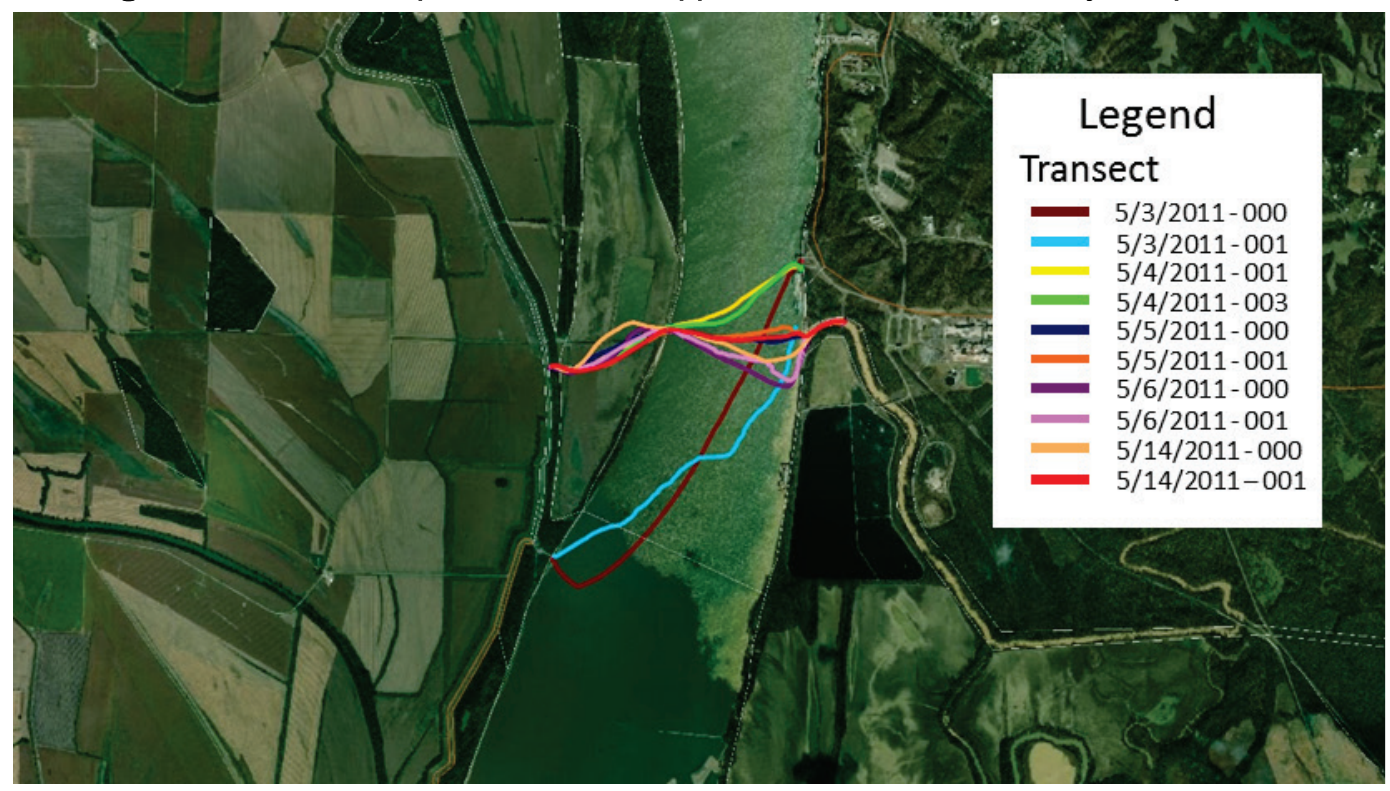

Table 4-4 and Table 4-5 show the average observed and model velocity for each transect as well as the RMS error. Differences in the average observed and model velocities for transects below the confluence ranged from 0.00 to $0.05 \mathrm{~m} / \mathrm{s}(0.00$ to $0.16 \mathrm{ft} / \mathrm{s})$. The differences in the average observed and model velocities for transects below the breach ranged from 0.00 to $0.33 \mathrm{~m} / \mathrm{s}(0.00$ to $1.08 \mathrm{ft} / \mathrm{s})$. RMS errors range from 0.20 to $0.48 \mathrm{~m} / \mathrm{s}$ (0.66 to $1.57 \mathrm{ft} / \mathrm{s}$ ) for transects below the confluence. Transects below the confluence have rRMS values ranging from $5 \%$ to $14 \%$. The RMS values 
range from 0.40 to $0.60 \mathrm{~m} / \mathrm{s}(1.31-1.96 \mathrm{ft} / \mathrm{s})$ for transects below the breach. Transects below the breach have rRMS values ranging from $8 \%$ to 18\%. Figure A-25 through Figure A-40 show model-data comparisons for each of the transects. Transect distance is from the left descending bank to the right descending bank. The model velocities were more accurate within the channel. Model velocities were generally lower than observed velocities across the floodplain. Model velocities for transects below the breach were approximately $0.5 \mathrm{~m} / \mathrm{s}(1.6 \mathrm{ft} / \mathrm{s})$ lower than observed velocities over the floodplain. The good agreement of modeled versus observed channel velocity indicates that flow in the model was properly partitioned between the channel and floodplain.

Model-data comparisons were also made to velocity direction. The velocity directions were extracted from SMS and converted into bearings (using a convention of north being zero, moving clockwise). The velocity direction comparisons for each transect are shown in Appendix A, Figure A-41 through Figure A-56. The black line on each plot shows the extent of the river channel. Oscillations between low and high bearings are a result of the definition of bearing, as the difference in bearing between a velocity vector oriented at 359 degrees and a vector oriented at 2 degrees, for example, is only 2 degrees.

A common divergence of direction at 900 to $1,200 \mathrm{~m} \mathrm{(2,952} \mathrm{to} 3,937 \mathrm{ft})$ from the left bank is evident on Figures A-41 through A-46, which occurs on the right overbank adjacent to the channel. Aerial photography shows that these transects traverse a lateral opening approximately $300 \mathrm{~m}(984$ $\mathrm{ft}$ ) wide in a forested area (Figure 4-21). The divergence in velocity directions are likely caused by turbulent flow as the water passes through the trees.

Velocity depends greatly on local physical conditions including both bathymetry and roughness and/or vegetation where processes governing velocity occur at spatial scales smaller than the model grid. The calibration statistics and time-series plots indicate the model replicates velocity very well at the locations examined. 
Table 4-4. Average velocity comparisons for transects below the confluence.

\begin{tabular}{|l|c|c|c|c|c|c|}
\hline \multicolumn{7}{|c|}{ Below Confluence Transects } \\
\hline Date & $4 / 28 / 2011$ & $4 / 30 / 2011$ & \multicolumn{2}{|c|}{$5 / 1 / 2011$} \\
\hline Transect ID & 002 & 003 & 000 & 001 & 002 & 003 \\
\hline Time Recorded & $15: 09$ & $15: 36$ & $10: 13$ & $10: 59$ & $12: 01$ & $12: 28$ \\
\hline Avg. Model Velocity (m/s) & 1.31 & 1.73 & 1.26 & 1.48 & 1.25 & 1.22 \\
\hline Avg. Observed Velocity (m/s) & 1.31 & 1.53 & 1.29 & 1.53 & 1.23 & 1.28 \\
\hline RMS (m/s) & 0.38 & 0.48 & 0.24 & 0.28 & 0.20 & 0.22 \\
\hline rRMS & $11 \%$ & $14 \%$ & $7 \%$ & $7 \%$ & $5 \%$ & $5 \%$ \\
\hline
\end{tabular}

Table 4-5. Average velocity comparisons for transects below breach.

\begin{tabular}{|l|c|c|c|c|c|c|c|c|c|c|}
\hline \multicolumn{10}{|c|}{ Below Breach Transects } \\
\hline Date & $5 / 3 / 2011$ & $5 / 4 / 2011$ & $5 / 5 / 2011$ & $5 / 6 / 2011$ & \multicolumn{2}{|c|}{$5 / 14 / 2011$} \\
\hline Transect ID & 000 & 001 & 001 & 003 & 000 & 001 & 000 & 001 & 000 & 001 \\
\hline Time Recorded & $11: 19$ & $11: 36$ & $14: 05$ & $14: 30$ & $9: 54$ & $10: 10$ & $13: 08$ & $13: 26$ & $17: 28$ & $17: 44$ \\
\hline Avg. Model Velocity (m/s) & 2.31 & 2.20 & 1.99 & 2.00 & 1.35 & 1.53 & 1.33 & 1.59 & 1.26 & 1.33 \\
\hline Avg. Observed Velocity (m/s) & 2.10 & 2.16 & 2.04 & 2.00 & 1.68 & 1.74 & 1.49 & 1.65 & 1.48 & 1.39 \\
\hline RMS (m/s) & 0.47 & 0.40 & 0.54 & 0.60 & 0.59 & 0.53 & 0.58 & 0.49 & 0.46 & 0.44 \\
\hline rRMS & $14 \%$ & $14 \%$ & $12 \%$ & $15 \%$ & $9 \%$ & $8 \%$ & $18 \%$ & $14 \%$ & $14 \%$ & $15 \%$ \\
\hline
\end{tabular}

Figure 4-21. Transect 001 on 5/1/2011 showing vector divergence through floodplain tree line (Red line = transect line; width of the white coloring indicates the velocity magnitude).

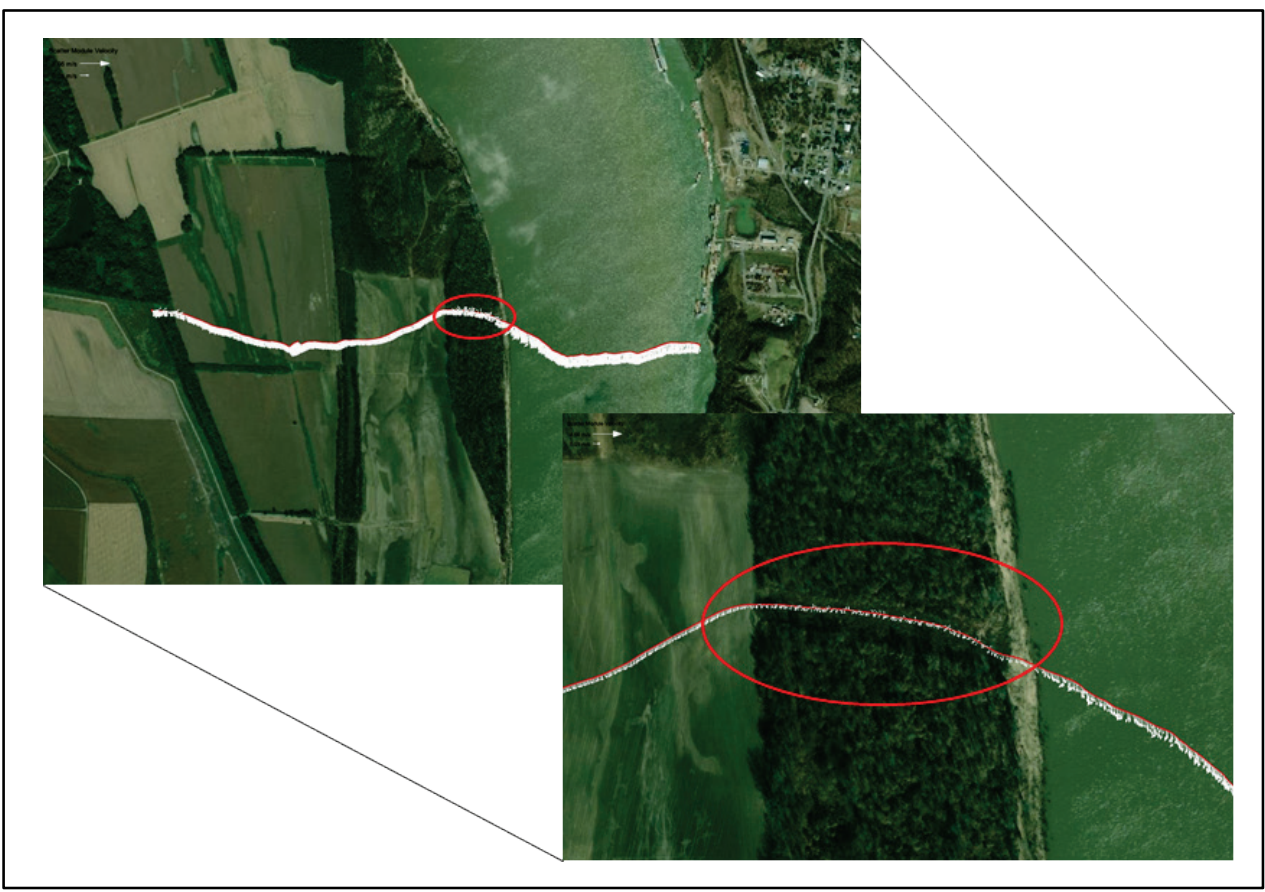




\section{5-2016 calibration results}

\section{Stage}

Stage calibration results for the river stations for the 2015 flood event simulation are shown in Table 4-6 RMS values for the simulation period $12 / 20 / 2015$ to $1 / 16 / 2016$ range from 0.11 to $0.34 \mathrm{~m}$ (0.36 to $1.11 \mathrm{ft}$ ); not including Wickliffe and Columbus due to suspect datums. rRMS range from $1.7 \%$ to $7.0 \%$. Time-series plots comparing modeled to observed stage are shown in Appendix A, Figures A-57 through A-63. Modeled and observed stage at Birds Point, MO (a duplicate of A-60) is shown in Figure 4-22. Figure 4-23 shows a longitudinal profile of stages along the Mississippi River near the peak of the 2015 flood. The time-series plots show that modeled rising limb stages are in better agreement with observed data than falling limb due to the loop effect. The difference in peak stages ranges from $-0.23 \mathrm{~m}$ to $0.1 \mathrm{~m}$ (-0.75 to $0.33 \mathrm{ft}$ ).

Table 4-6. Stage calibration statistics for the 2015 event.

\begin{tabular}{|l|c|c|c|c|}
\hline Station & RMS $(\mathrm{m})$ & $\begin{array}{c}\text { Rising Limb } \\
\text { RMS }(\mathrm{m})\end{array}$ & $\begin{array}{c}\text { Difference } \\
\text { at Peak }(\mathrm{m})\end{array}$ & RMS (ft) \\
\hline New Madrid & 0.11 & 0.08 & -0.09 & 0.36 \\
\hline Hickman & 0.16 & 0.15 & 0.09 & 0.52 \\
\hline Birds Point & 0.34 & 0.21 & -0.07 & 1.11 \\
\hline Thompson Land. & 0.29 & 0.18 & -0.23 & 0.95 \\
\hline Price Land. & 0.17 & 0.14 & 0.02 & 0.55 \\
\hline Commerce & 0.30 & 0.25 & 0.10 & 0.98 \\
\hline Cairo & 0.25 & 0.29 & 0.10 & 0.83 \\
\hline
\end{tabular}


Figure 4-22. Modeled and observed stage at Birds Point, 2015 event.

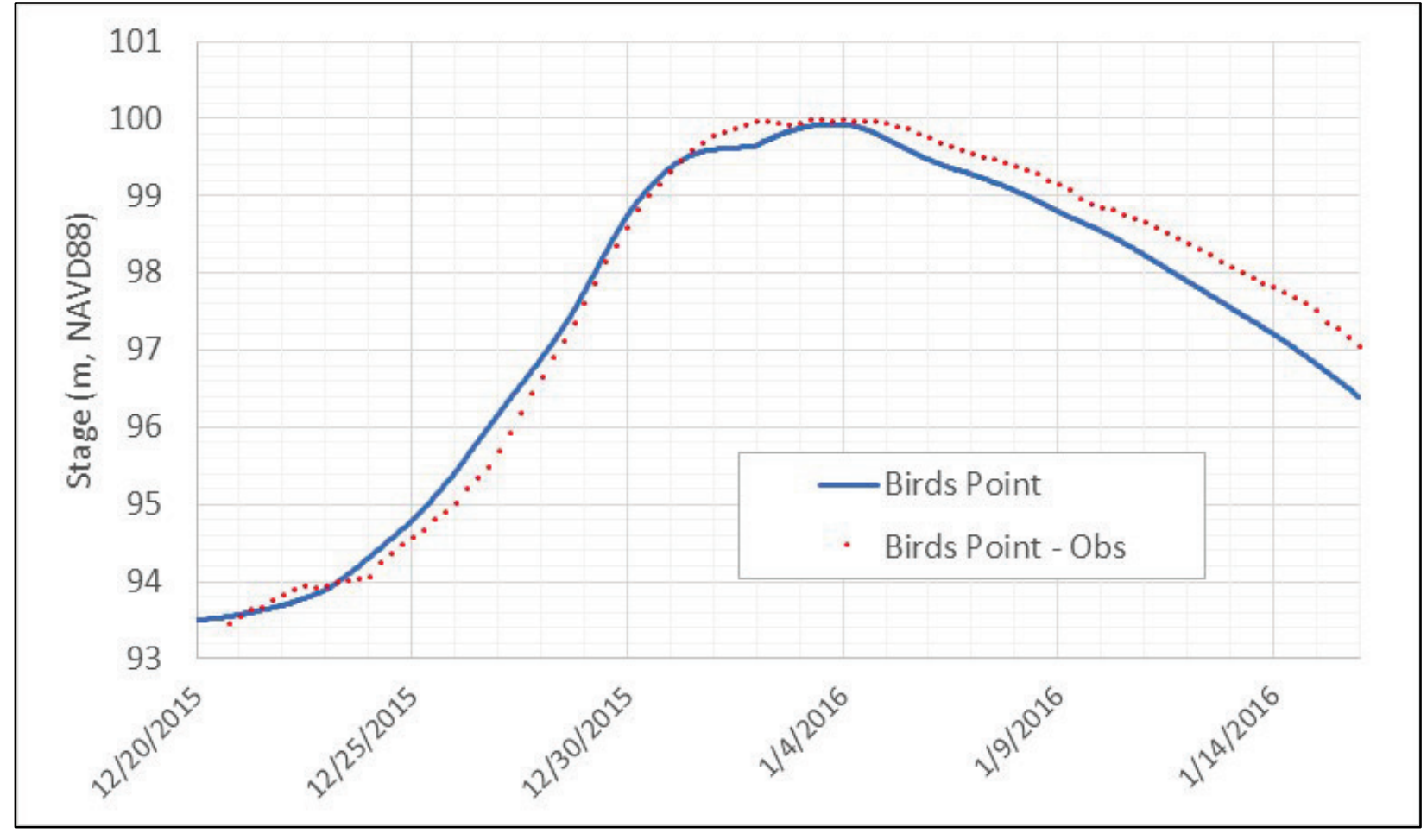


Figure 4-23. Longitudinal profile plot of stage for the entire reach on 1/2/2016. (Note: Wickliffe and Columbus datums are suspect).

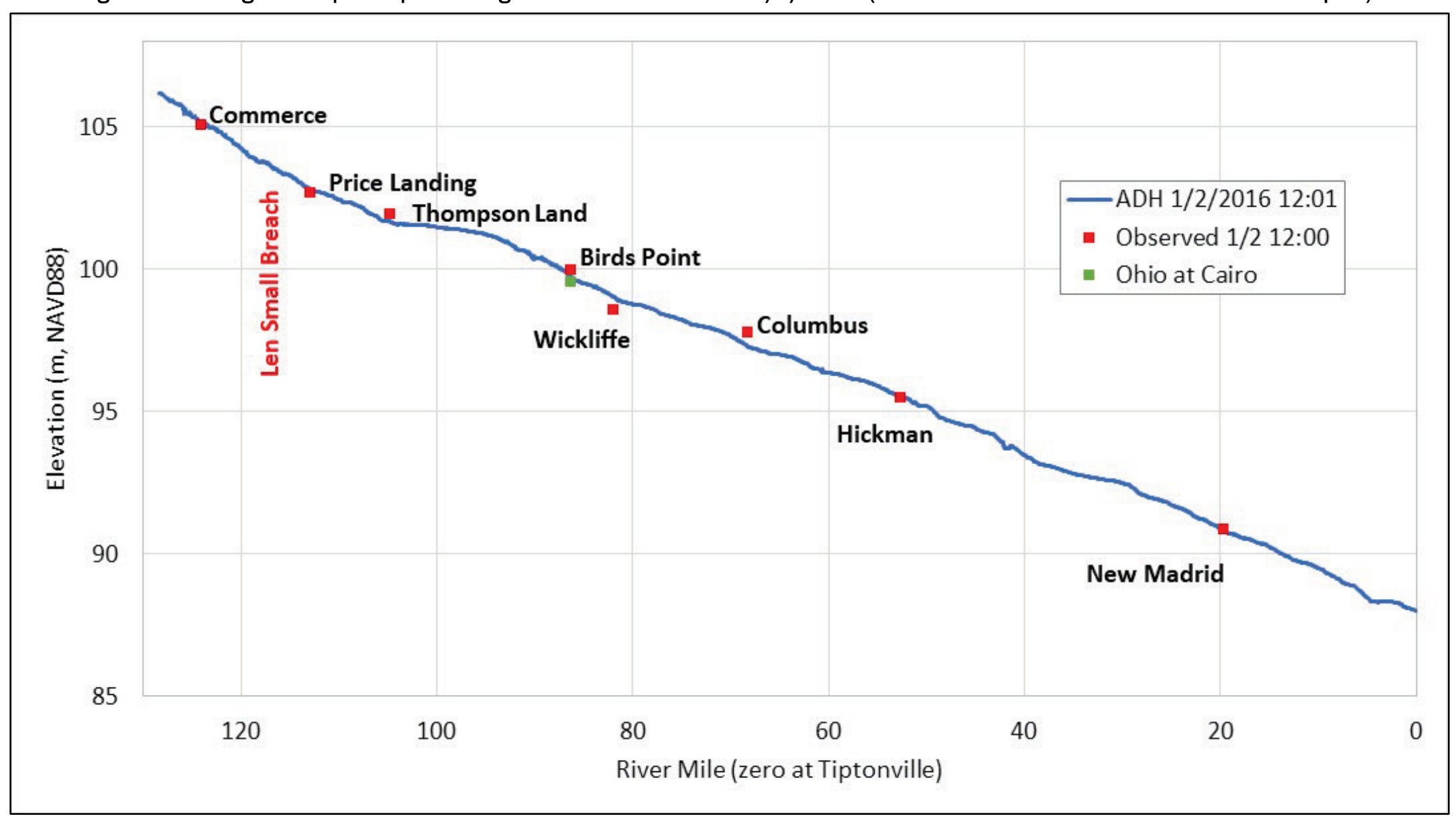




\section{LS breach discharge}

One set of field observations of outflow (ADCP data) from the LS breach taken on 1/3/2016 during the 2015 flood was available. Figure 4-24 shows the modeled LS outflow discharge and the single observation of outflow with appropriate uncertainty bounds. As discussed in the discharge data section of Chapter 2, the two ADCP transects yielded flow estimates ranging from 3,900 to $5,600 \mathrm{cms}$ ( 138,000 to $200,000 \mathrm{cfs})$. The modeled outflow on $1 / 3 / 2016$ at $13: 15$ is $4,470 \mathrm{cms}(158,000 \mathrm{cfs})$, which falls within those bounds. The breach outflow from $1 / 4$ to $1 / 5$ is dependent on the model assumed failure rate of the breach as the true failure rate is unknown.

Figure 4-24. Modeled LS outflow. Dashes represent the two ADCP measurements of LS outflow; center triangle is the computed average.

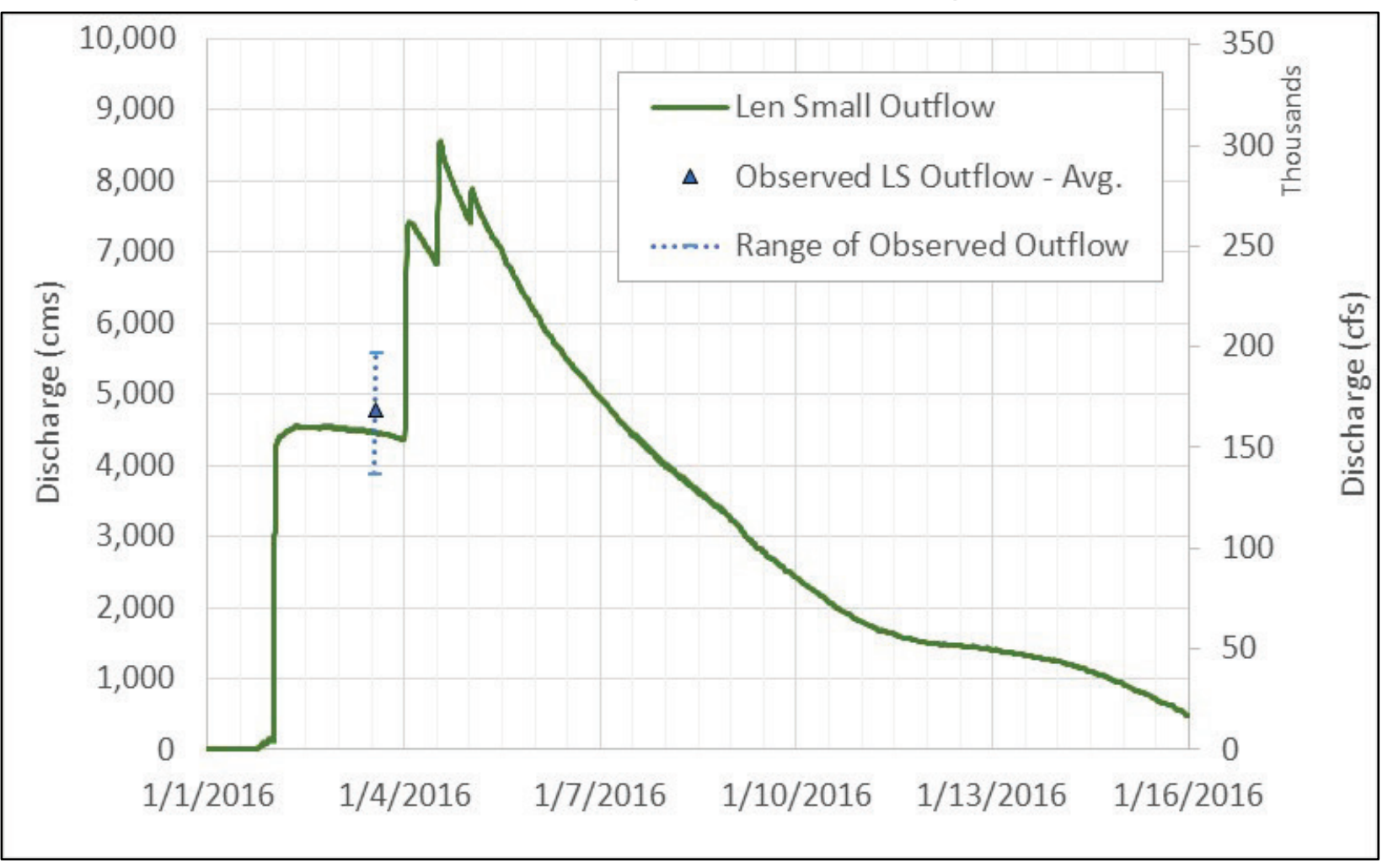

\section{7 calibration results}

Stage

Stage calibration results for the river stations, for the 2017 flood event simulation, are shown in Table 4-7 RMS values for the simulation period 4/21/2017 to 5/20/2017, ranged from 0.14 to $0.40 \mathrm{~m}$ (0.46 to $1.31 \mathrm{ft}$ ); not including Wickliffe and Columbus due to suspect datums. rRMS errors 
ranged from $2.3 \%$ to $6.6 \%$. Time-series plots comparing modeled to observed stage are shown in Appendix A, Figures A-64 through A-70. Modeled and observed stage at Birds Point, MO (a duplicate of A-67), is shown in Figure 4-25. Figure 4-26 shows a longitudinal profile of stages along the Upper Mississippi River near the peak of the 2017 flood. The difference in peak stages ranged from $-0.36 \mathrm{~m}$ to $0.14 \mathrm{~m}(-1.18$ to $0.46 \mathrm{ft})$.

Table 4-7. Stage calibration statistics for the 2017 event.

\begin{tabular}{|l|c|c|c|c|c|}
\hline Station & RMS (m) & rRMS & $\begin{array}{c}\text { Rising Limb } \\
\text { RMS }(\mathrm{m})\end{array}$ & $\begin{array}{c}\text { Difference } \\
\text { at Peak (m) }\end{array}$ & RMS (ft) \\
\hline New Madrid & 0.14 & $2.3 \%$ & 0.17 & -0.10 & 0.44 \\
\hline Hickman & 0.28 & $4.4 \%$ & 0.36 & -0.12 & 0.92 \\
\hline Birds Point & 0.24 & $16.0 \%$ & 0.30 & -0.36 & 0.78 \\
\hline Thompson Land. & 0.37 & $6.6 \%$ & 0.43 & 0.11 & 1.23 \\
\hline Price Land. & 0.19 & $4.4 \%$ & 0.22 & -0.25 & 0.63 \\
\hline Commerce & 0.14 & $2.8 \%$ & 0.17 & 0.14 & 0.45 \\
\hline Cairo & 0.40 & $6.1 \%$ & 0.51 & -0.04 & 1.30 \\
\hline
\end{tabular}

Figure 4-25. Modeled and observed stage at Birds Point, 2017 event.

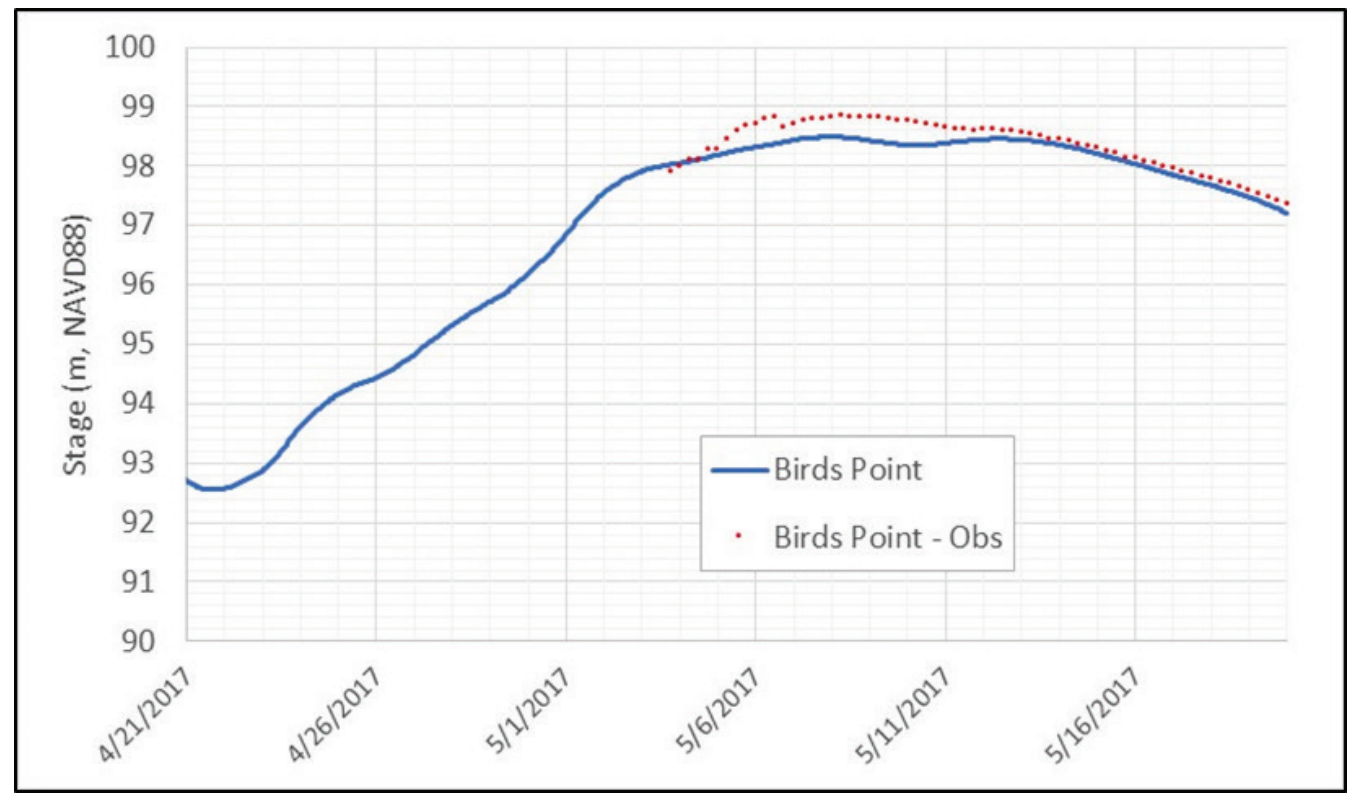


Figure 4-26. Longitudinal profile plot of stage for the Mississippi River near the peak of the 2017 flood event. (Note: Wickliffe and Columbus datums are suspect.)

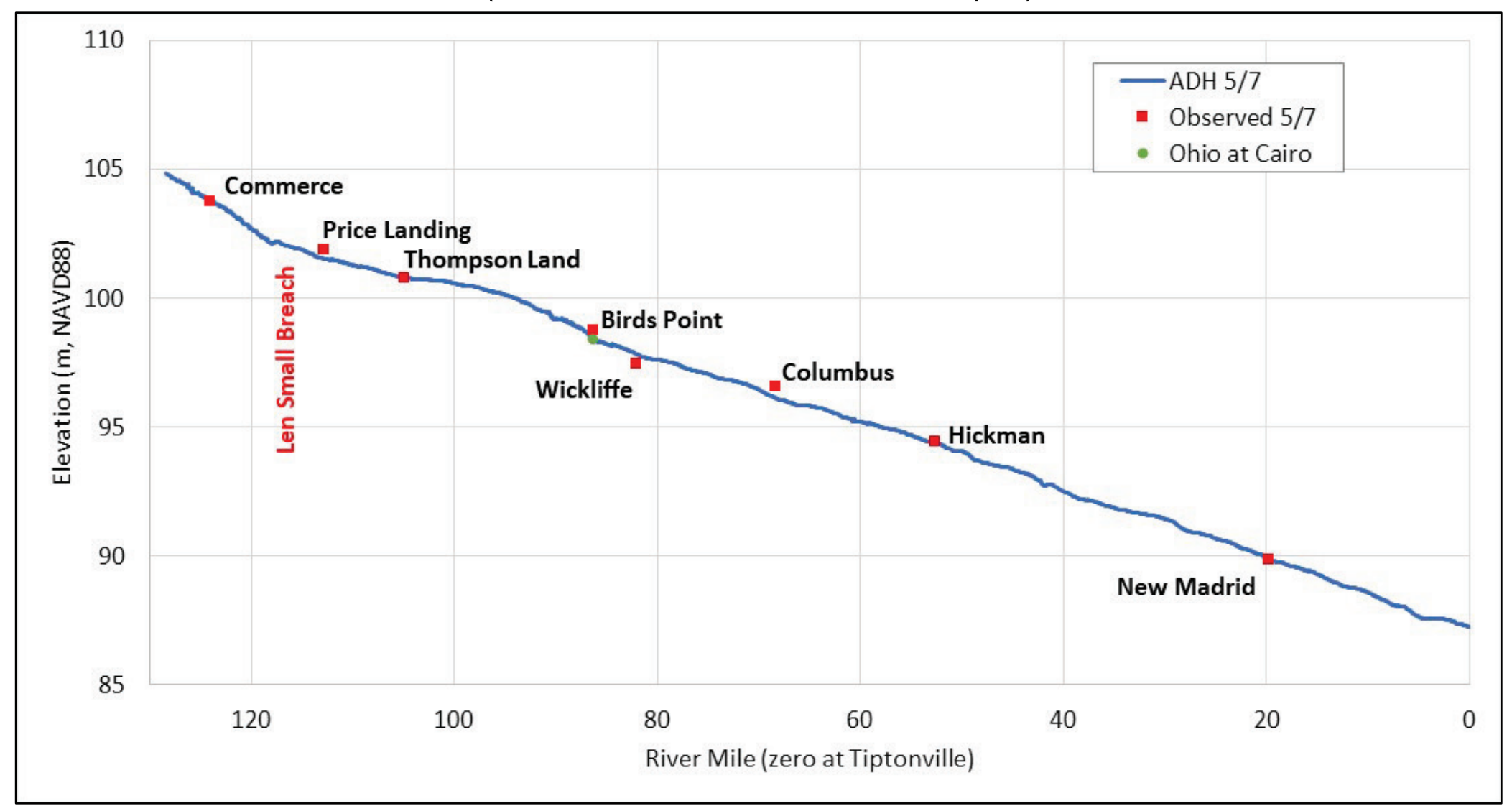




\section{LS breach discharge}

Tabular data for LS outflow was available for four days during the 2017 flood. Two sets of observed discharge (ADCP) data for that period were processed including one transect of direct measurement of outflow from the breach on $5 / 7$ and several transects of flow in the river upstream and downstream of the breach on $5 / 8$.

Figure 4-27 shows the modeled LS outflow discharge and the observed upstream, downstream, and outflow discharges with appropriate uncertainty bounds. Uncertainty bounds on the tabular discharge data for Mississippi River flows are $\pm 15 \%$. The uncertainty bounds for the single direct outflow measurement on 5/7 (blue dashed line) are set to the range of discharge estimates given by the two ADCP processing software packages. The discharge estimate from the $\mathrm{QRev}$ software is $6,600 \mathrm{cms}$ (blue diamond). The LS outflow discharges from the tabular data $(5 / 3$, $5 / 8$, and 5/9) are calculated from the difference of the measured upstream and downstream flow on the Mississippi River. Therefore, the uncertainty bounds on the outflow are the larger of the two input variables, therefore \pm $15 \%$ of the upstream discharge. The modeled LS outflow falls within the uncertainty bounds of the observed data. 
Figure 4-27. Modeled Mississippi River flow upstream and downstream of the LS breach and discharge through the breach for the 2017 event. Dashed lines represent uncertainty bounds on the observed (tabular and processed ADCP) discharge measurements.

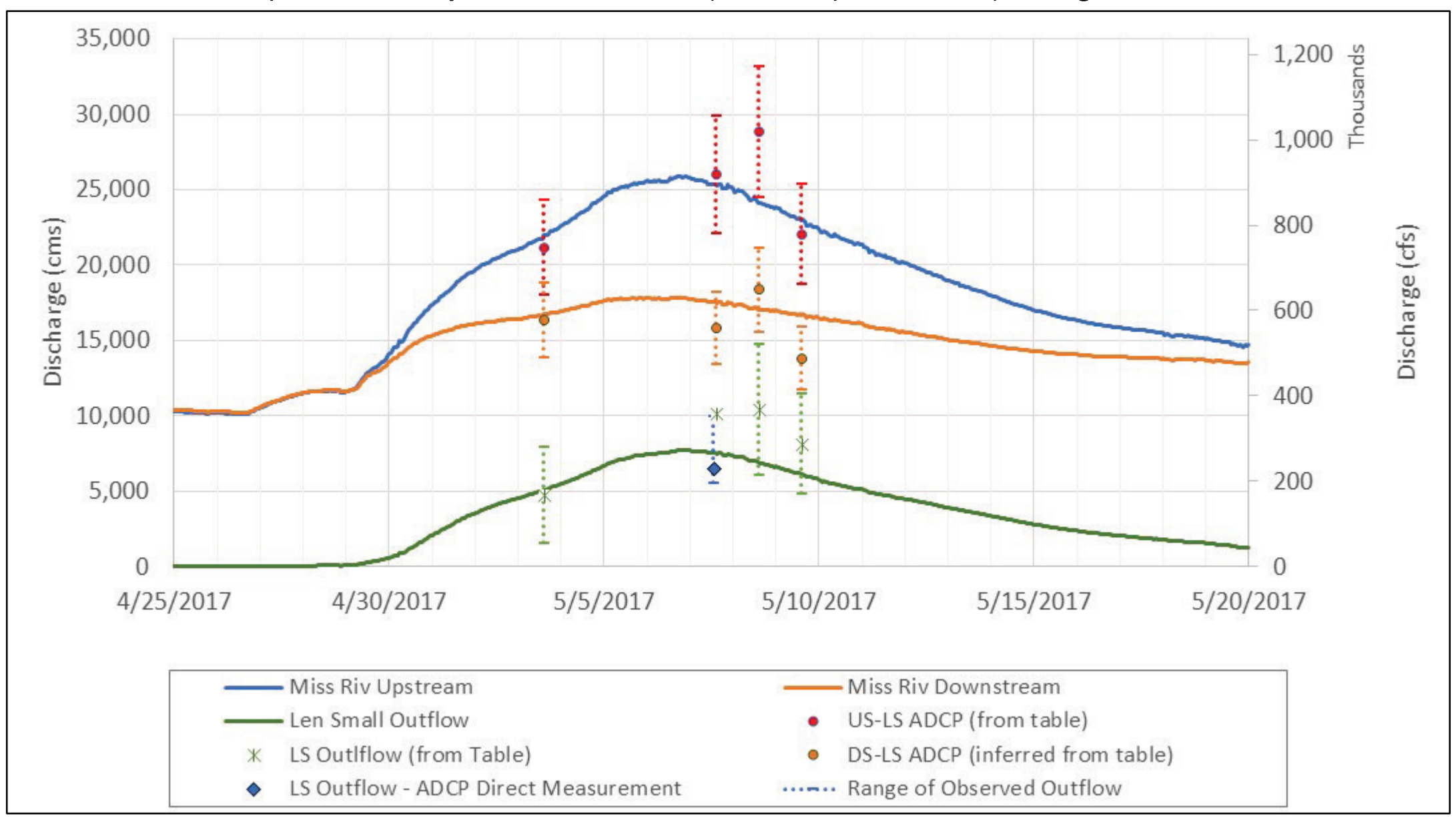




\section{Discussion}

\section{Strengths and weaknesses of the model}

The Mississippi River 2D AdH model accurately simulated stage, velocity magnitude and direction, and discharge through levee breaches in the reach from Commerce, MO, to New Madrid, MO, for medium to high flood flows. The model provided information-rich output allowing the user to analyze many advanced processes. Cross-current velocities were mapped in detail to inform navigational assessments. Lateral water level variations across the channel, on the order of $0.25 \mathrm{~m}(0.82 \mathrm{ft})$ were simulated just upstream of Wickliffe, KY. Also, detailed inundation timing and flow path visualization across the floodplains was used to understand flooding processes. The AdH model allowed for multiple parameterizations of roughness. The Manning's roughness implementation used in the channels is depth-dependent, eliminating the need for adjusting $n$-values by depth as is often done in $1 \mathrm{D}$ models in the Mississippi River. The URV roughness functionality was used to accurately simulate the physics of flow through trees and provides better representation of roughness through the stands of trees, which affects the discharge through levee breaches.

The Mississippi River AdH model does have some shortcomings. The model takes significant computational resources to run. A 1-month simulation takes approximately $24 \mathrm{hr}$ to run, using 30 virtual processors (15 cores, with hyperthreading) on a high-performance desktop computer. The output data for one run can reach $15 \mathrm{~GB}$ in size, which is cumbersome to store and transfer. The addition of time-dependent roughness assignment would improve stage results during the falling limb of flood hydrographs, where the model consistently under predicts stage.

\section{Uncertainty}

All environmental model results should be used with an appreciation of the uncertainty bounds of the model (EPA 2009b; NAS 2012). The best source of data to define uncertainty bounds consists of model calibration goodness-of-fit metrics that are interpreted with information obtained from model sensitivity tests.

All observed data contain measurement error. Stage observations are typically accurate to less than $0.03 \mathrm{~m}(0.1 \mathrm{ft})$, but the uncertainty of the 
measured datum must also be accounted for. Uniform measurement errors of $\pm 0.03 \mathrm{~m}$ ( $\pm 0.1 \mathrm{ft}$ ) for stage, $\pm 10 \%$ for velocity, and $\pm 15 \%$ for discharge based on experience and the analysis of data herein were assumed. Model and measurement uncertainties are essentially independent, which means that their combined uncertainty can be determined by quadrature (square root of the sum of squares of independent errors).

The Base-to-Plan comparison principle declares that relative changes between base and plan results are more accurate than absolute changes. To the extent that uncertainties in both are introduced by the same mechanisms (structural error), and perhaps self-compensating, errors in Base-to-Plan comparisons can, in part, cancel each other out. Generally, the uncertainty band can be estimated for Base-to-Plan comparisons as one-half of the overall uncertainty bounds estimated from model and measurement uncertainty.

Model calibration statistics for stage are shown in Table 4-1, Table 4-2, Table 4-6, and Table 4-7. Model performance was based on evaluation of three approximately 1-month-long flood simulations. The model was shown to skillfully replicate stages in the Mississippi River (and BPNMF during the 2011 flood) during flows greater than $10,000 \mathrm{cms}(350,000 \mathrm{cms})$ in the Upper Mississippi River. Using the data presented in the tables, the average RMS error for stage is $0.26 \mathrm{~m}(0.85 \mathrm{ft})$, and the average rRMS error is $4.8 \%$. Combining this with the assumed $0.03 \mathrm{~m}$ observed stage error yields, by quadrature, an estimated overall stage uncertainty of $0.26 \mathrm{~m}(0.85 \mathrm{ft})$ or $4.8 \%$. Base-to-Plan uncertainty bounds were therefore estimated at $0.13 \mathrm{~m}$ $(0.43 \mathrm{ft})$ or $2.4 \%$, as one-half of the overall uncertainty.

Model calibration statistics for velocity are shown in Table 4-4 and Table 4-5. These are discrete measurements taken at flood flows in only one reach of the channel. Care should be used when extrapolating the velocity uncertainty. The average rRMS error for velocity was $11 \%$. Combining this with the assumed 10\% sampling error yields, by quadrature, an estimated overall uncertainty of $\pm 15 \%$. Base-to-Plan uncertainty bounds were estimated at $\pm 8 \%$, as one-half of the overall uncertainty.

Model calibration statistics for discharge are shown for the 2011 flood event in Table 4-3. Statistics were not calculated for the 2015 and 2017 events due 
to the paucity of data. These are discrete measurements taken at flood flows. Discharge in the river channels is dominated by the boundary conditions. The only statistical comparison of flow through a breach was made for the BPNMF upper crevasse inflow, which was $12 \%$. The loop effect negatively impacted the simulations resulting in lower than observed discharge into the floodway (Figure 4-10). Combining the $12 \%$ model error with the assumed $15 \%$ sampling error by quadrature yields an estimated overall breach discharge uncertainty of $\pm 19 \%$. Base-to-Plan uncertainty bounds were estimated at $\pm 9 \%$, as one-half of the overall uncertainty. 


\section{Model Scenarios}

The purpose for model scenarios was to evaluate model response with particular emphasis on assessing potential implications to navigation and current patterns.

The calibrated model was used to run four cases, for the flood events specified:

- Scenario 1A: No break in Miller City-LS (MC-LS) levee and no BPNMF operation; for all three flood events

- Scenario 1B: Break in MC-LS levee and no BPNMF operation; for all three flood events

- Scenario 2A: No break in MC-LS levee and with BPNMF operation; for all three flood events

- Scenario 2B: Break in MC-LS levee with BPNMF operation; for the 2011 event.

Note that the Scenario 1B, 2017 flood event is the same as the 2017 calibration run. The scenario conditions include MC-LS levee open, no BPNMF operation, and 2017 bathymetry/topography for the mesh. Therefore, the results reported for Scenario 1B, 2017 flood event are from the 2017 calibration model. The expanded velocity and current pattern analyses are provided in this section.

For BPNMF operation in Scenarios 2A and 2B, the trigger for floodway activation is $61.0 \mathrm{ft}$ on the Cairo gage (Note: $61.0 \mathrm{ft}$ is the local datum, this translates to $101.15 \mathrm{~m}$ NAVD88). Note that scenario $2 \mathrm{~A}$ is effectively the 2011 event calibration run. Results from Scenario 1A were used to determine the timing of BPNMF activation. The trigger elevation based on model results occurred on 5/1/2011 at 22:00. The peak stage (elevation) at Cairo for the 2015 and 2017 events was $99.77 \mathrm{~m}$ and $98.42 \mathrm{~m}$, (Cairo gage reading of $56.5 \mathrm{ft}$ and $52.0 \mathrm{ft}$ ) respectively, both lower than the trigger elevation. Therefore, Scenarios 2A and 2B were only run for the 2011 event. The full 11,099 linear feet of the upper crevasse was activated in the model for scenarios $2 \mathrm{~A}$ and $2 \mathrm{~B}$. 


\section{Hydrodynamic analyses}

Scenario hydrodynamic results were analyzed for all scenarios with an eye toward navigational interests. Discharges through open/activated breaches were tabulated, and channel velocity magnitudes along the channel centerline and at key channel cross sections were analyzed. Current patterns and differences were analyzed. Also, cross currents in navigational areas near the breaches were analyzed.

In this report, velocity magnitude refers to the total depth averaged velocity magnitude, in any direction. Velocity magnitudes have been extracted at points along a cross-section and points along a longitudinal profile.

Navigational cross-current velocity is the velocity calculated perpendicular to a defined sail line or sail lines. Cross currents can have adverse impacts on navigation. Figure 5-1 shows a hypothetical case with a ship moving near the LS breach. Velocities near the left bank (looking downstream) are directed out of the river, at some angle to the sail line(s). Software code was developed to quantify the magnitude of cross-stream velocity with respect to a defined sail line or lines. It computes the cross-current velocity at each node with respect to the closest sail-line vertex. Figure 5-2 shows a hypothetical sail line, velocity vector, and the cross-stream velocity vector. The program takes the mesh file ( $3 \mathrm{dm})$, velocity output (*_ovl.dat file), and an input file (Nav_Input.dat) with sail-line coordinates and bearings and calculates the cross-stream velocity at each mesh node in the channel (not calculated for the overbanks). This allows the user to display color contours of cross-stream velocity in SMS to visually identify areas of concern for navigation.

The output is given at all points in the Mississippi River channel. Crosscurrent output should be viewed and analyzed with the understanding that the cross current is calculated from, and therefore totally dependent on, the user-defined sail line(s). There are areas within the channel where the sail line (likely the channel centerline) differs from what would be considered the dominant streamline direction, particularly around islands or near the banks.

The cross-current velocities were provided as a tool to identify areas of concern for navigation. The calculation of cross-current velocity is based 
on depth-averaged velocity magnitudes from the model. Barge tows on the Mississippi River typically draft up to $9 \mathrm{ft}(2.74 \mathrm{~m})$, so a near-surface velocity would be the preferred metric. Based on $\mathrm{ADCP}$ data taken in the Mississippi River channel in the vicinity of LS, surface velocity is $5 \%$ to $10 \%$ greater than depth-averaged velocity meaning modeled cross-current velocities were likely underpredicted. The correction, however, is not performed because the $5 \%$ to $10 \%$ additional magnitude is within the uncertainty bounds of model velocity.

Figure 5-1. Conceptual model of a barge tow moving through the model velocity field, with the sail line shown in red.

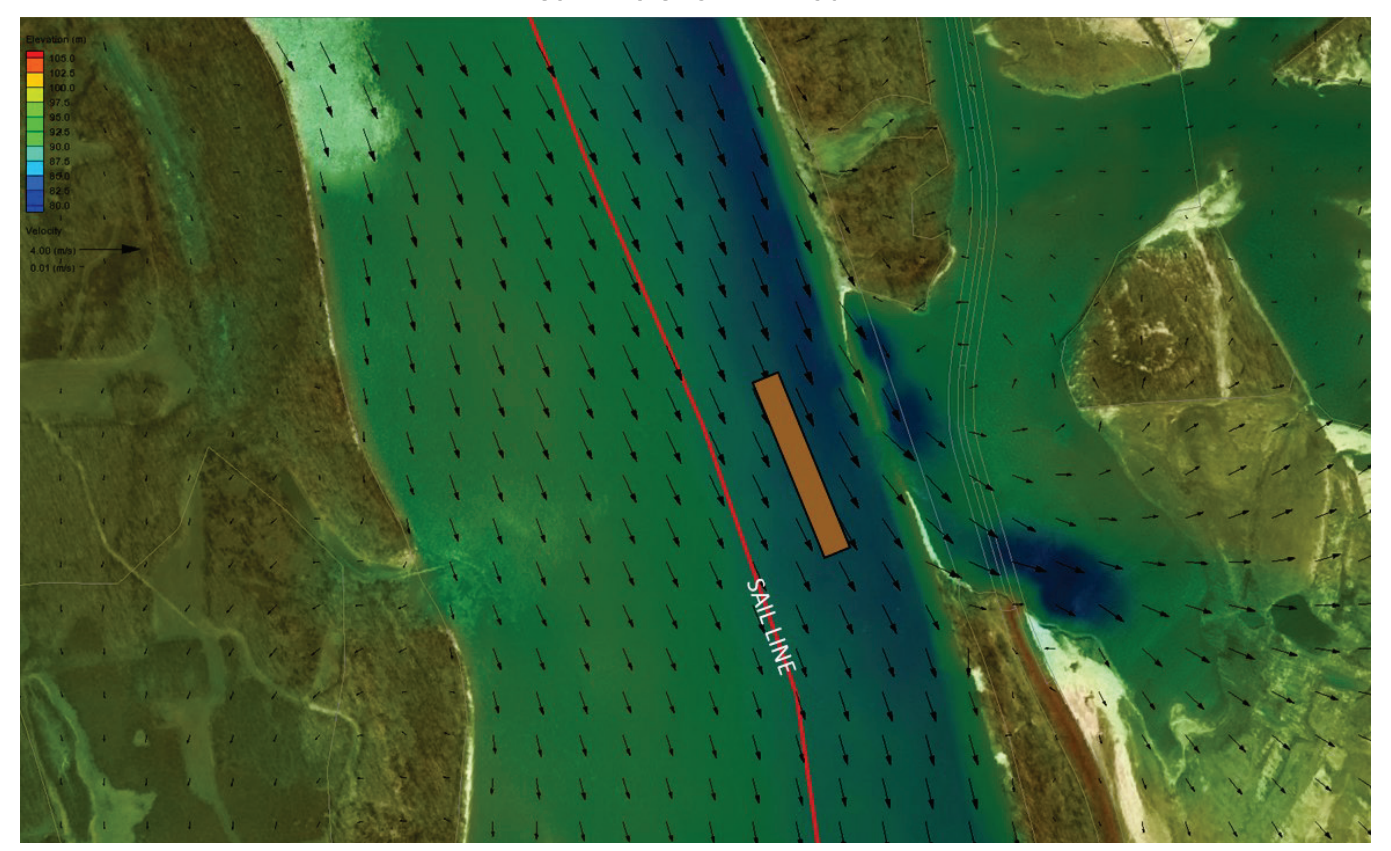


Figure 5-2. Depiction of cross-stream velocity at a mesh node in relation to the velocity vector and sail line.

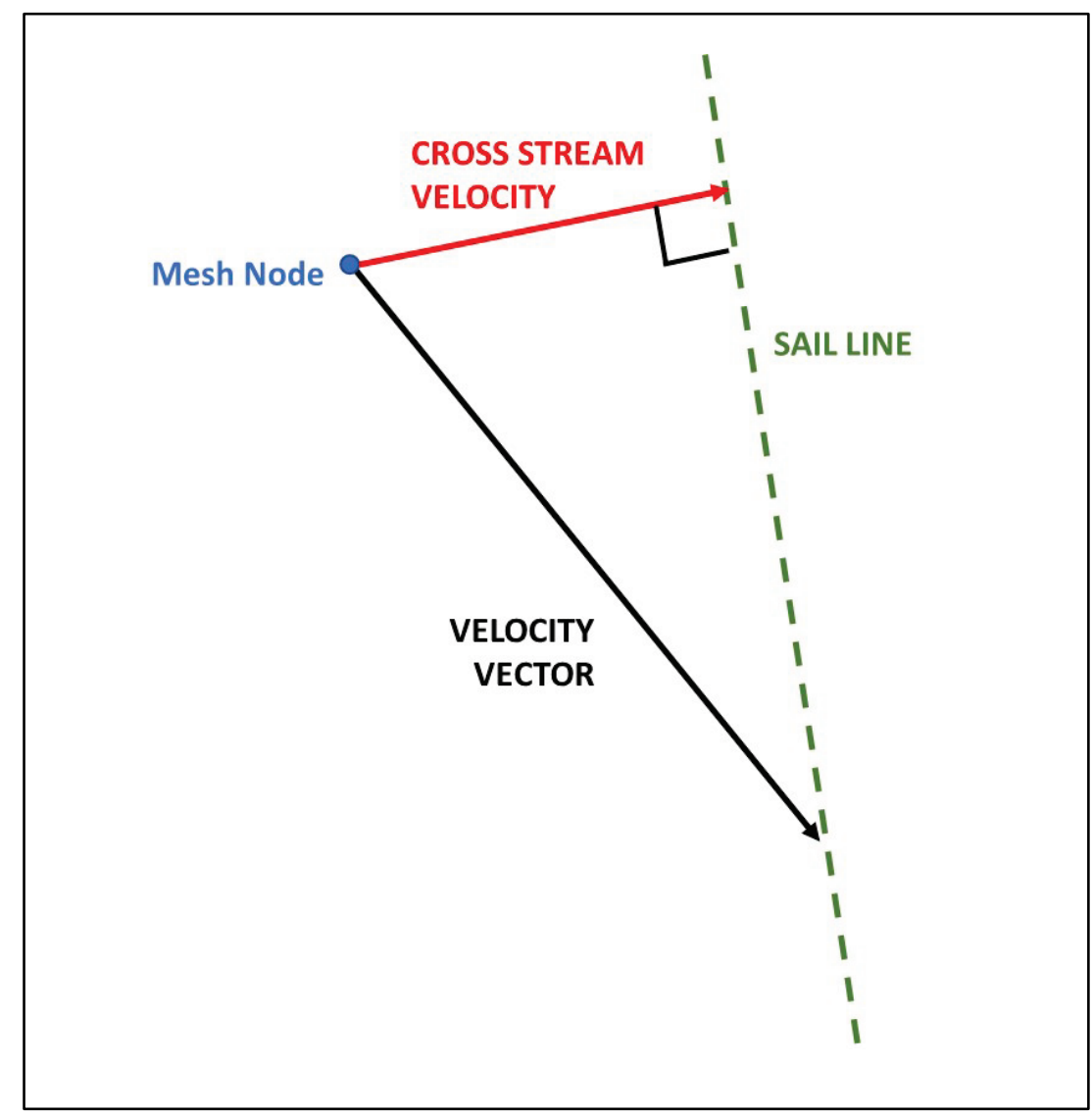

\section{LS breach}

Hydrographs, stages, and flow dynamics were analyzed for each of the flood events. Stage time-series plots at each calibration station are shown in Appendix B, Figures B-1 to B-9 for the 2011 event, Figures B-1O - B-18 for the 2015 event, and Figures B-19 to B-27 for the 2017 event. Longitudinal profile plots of stage are shown in Figures B-28 to B-30. Distribution of discharge through the reach was based on ranges as shown in Figure 5-3. Peak discharge through the LS breach (when it is open: Scenarios 1B and 2B for 2011; Scenario 1B for 2015 and 2017) is shown for each flood event in Table $5-1$. The percentage of Mississippi River flow exiting the LS breach is estimated to be $37 \%, 35 \%$, and $30 \%$ for Scenario 1B, for the 2011, 2015, and 2017 events, respectively. For Scenario 2B, 2011 event, the outflow magnitude and percentage were nearly the same as Scenario 1B. This means that activation of the BPNMF resulted in minor impacts on outflow at the LS breach for conditions similar to those simulated. 
For the 2011 event, the most informative comparisons were between Scenarios 1B and 2B (LS open for both, BPNMF operating for 2B), shown in Figure 5-4. As discussed above, the peak upstream flow and peak LS outflow were nearly the same for Scenarios $1 \mathrm{~B}$ and 2B; however, LS outflow on the receding limb is greater for Scenario 1B. Scenario 2B had lower river stages near LS on the receding limb as a result of BPNMF operation lowering stages in this reach. Consequently, Scenario $2 \mathrm{~B}$ had lower LS outflow on the receding limb than Scenario 1B, which had higher stages at LS.

Only Scenarios 1A (no LS breach) and 1B (with LS breach open) were run for the 2015 and 2017 events, and discharges are compared in Figure 5-5 and Figure 5-6, respectively. For the 2015 event, the hydrograph at the location upstream of LS was altered as a result of the dynamics of the LS breach opening. It was not altered considerably for the 2017 event, which had a lower peak main channel discharge and a lower outflow percentage.

The 2011 flood had the lowest Upper Mississippi River discharge of the three, but the highest stages (peak of $103.1 \mathrm{~m}[338.25 \mathrm{ft}$ ] in the river adjacent to LS) and the highest percentage of outflow through LS. The 2017 event had the lowest peak stage (102.4 $\mathrm{m}$ [335.96 ft] in the river adjacent to LS) and the lowest percent outflow. The analysis suggests roads and high ground $1 \mathrm{~km}(0.6 \mathrm{mi})$ east of the LS breach provided some hydraulic control on the outflow. Areas with greater depths provided less restriction to outflow.

Table 5-1. Modeled peak discharge in the Mississippi River above the LS breach and breach outflow for each event.

\begin{tabular}{|c|c|c|c|}
\hline Event & $\begin{array}{c}\text { Miss River Peak } \\
\text { at LS (cms) }\end{array}$ & $\begin{array}{c}\text { LS Peak Outflow } \\
\text { (cms) }\end{array}$ & Percent Outflow \\
\hline $2011-1 B$ & 23,860 & 8,810 & $37 \%$ \\
\hline $2011-2 B$ & 24,130 & 8,720 & $36 \%$ \\
\hline $2015-1 B$ & 28,630 & 10,070 & $35 \%$ \\
\hline $2017-1 B$ & 26,030 & 7,750 & $30 \%$ \\
\hline
\end{tabular}


Figure 5-3. Locations of discharge observation cross sections at LS.

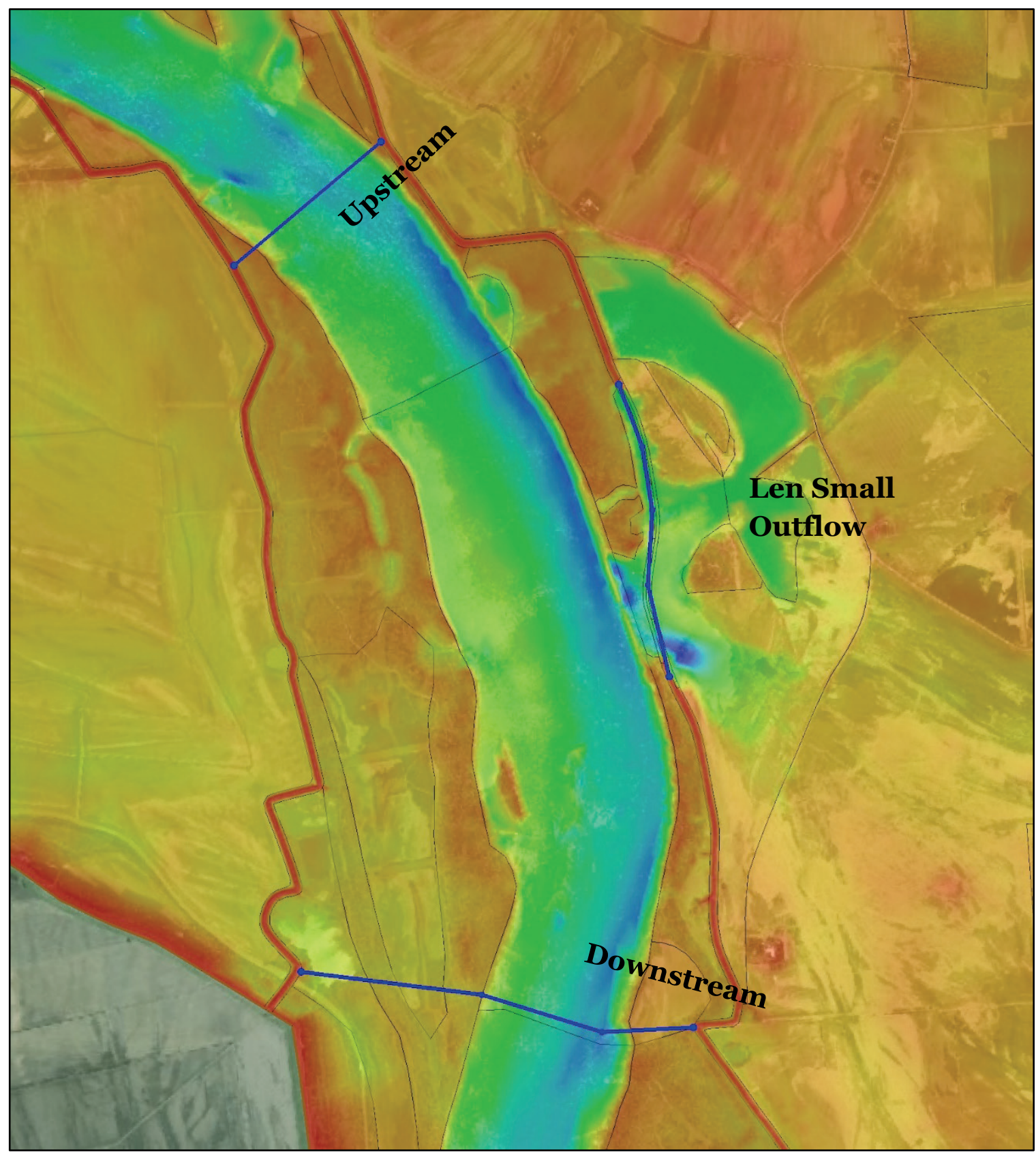


Figure 5-4. Model discharge above and through the LS levee breach, Scenarios 1B and 2B, 2011 event.

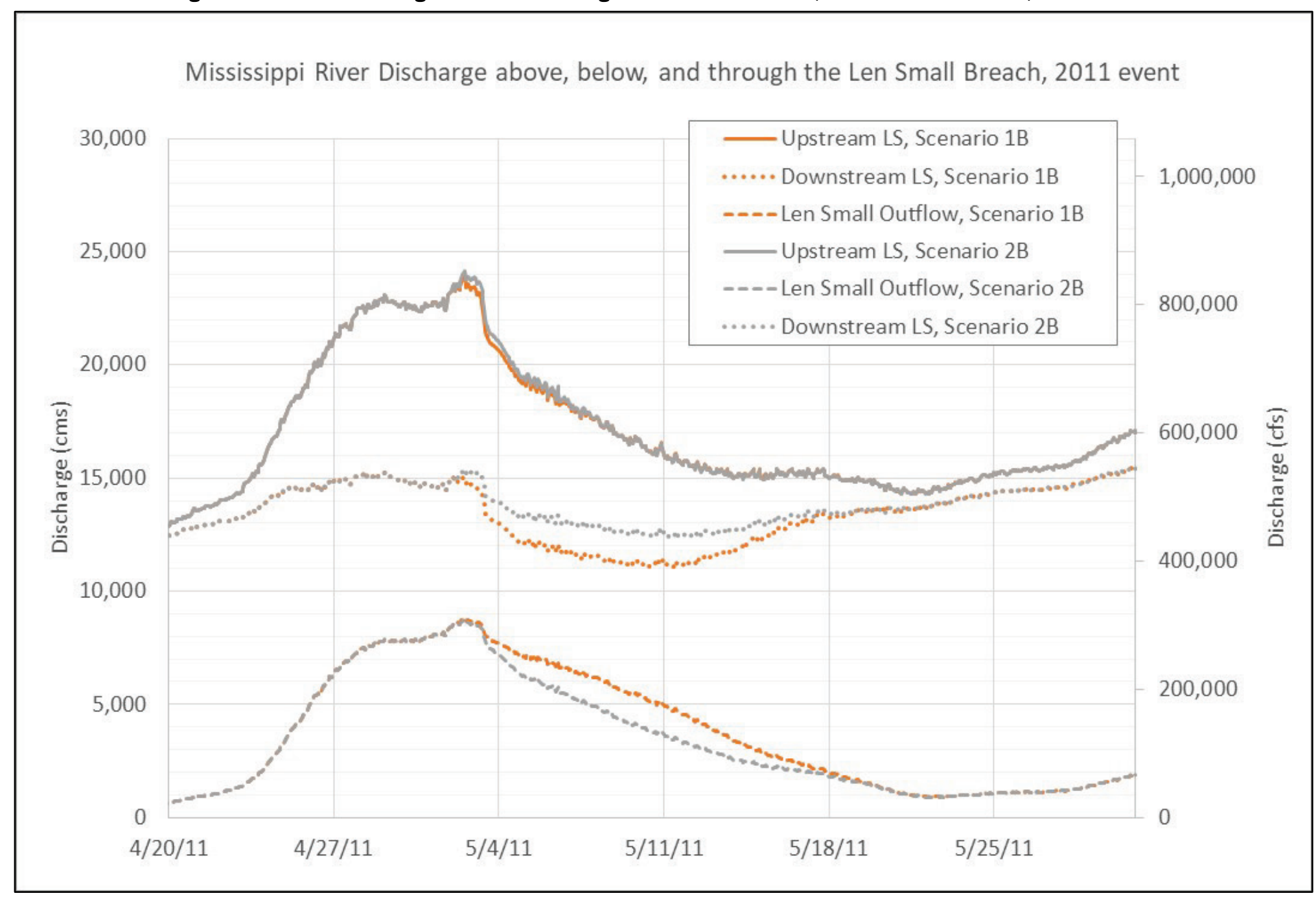


Figure 5-5. Model discharge above and through the LS levee breach, Scenarios 1A and 1B, 2015 event.

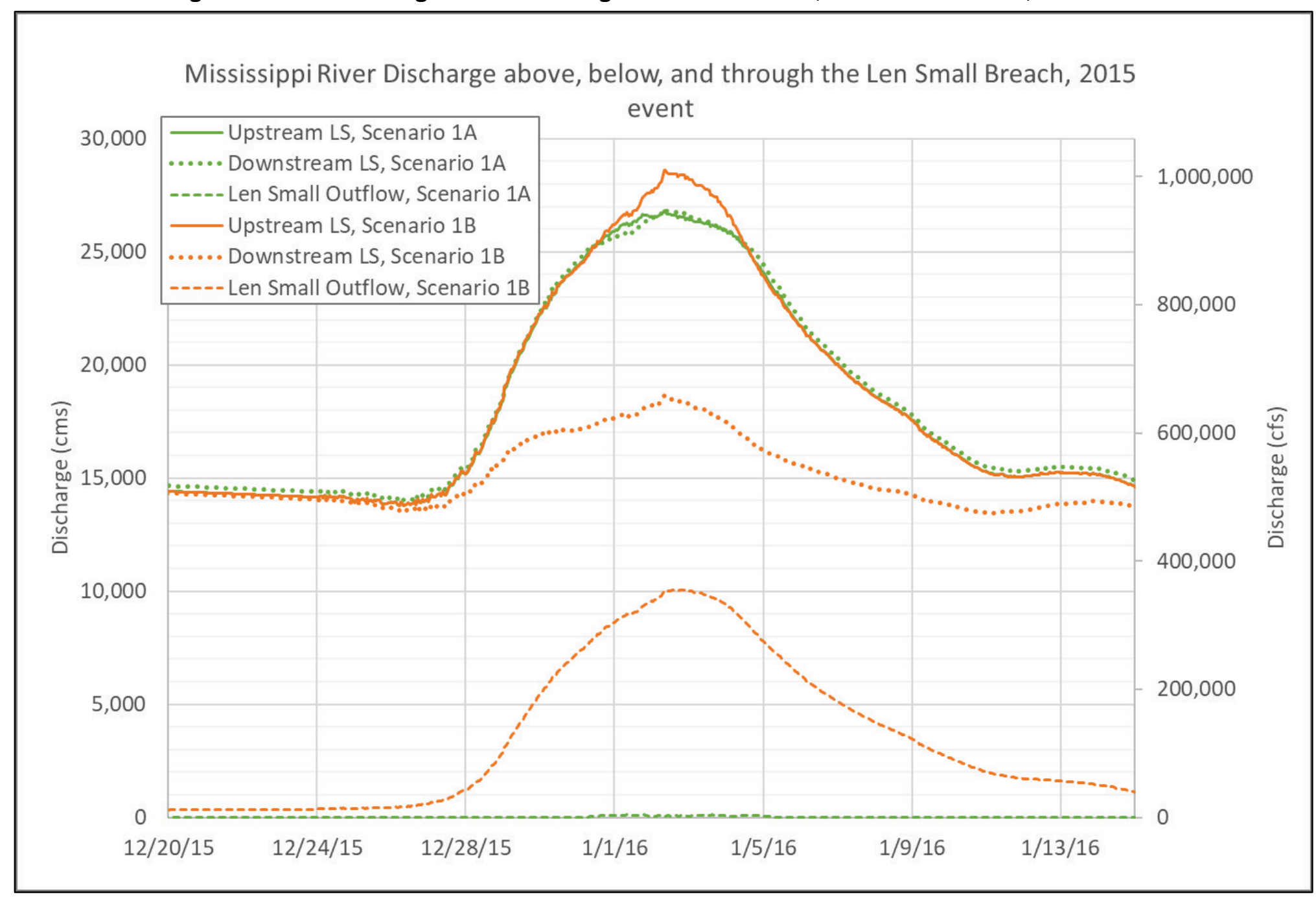


Figure 5-6. Model discharge above and through the LS levee breach, Scenarios 1A and 1B, 2017 event.

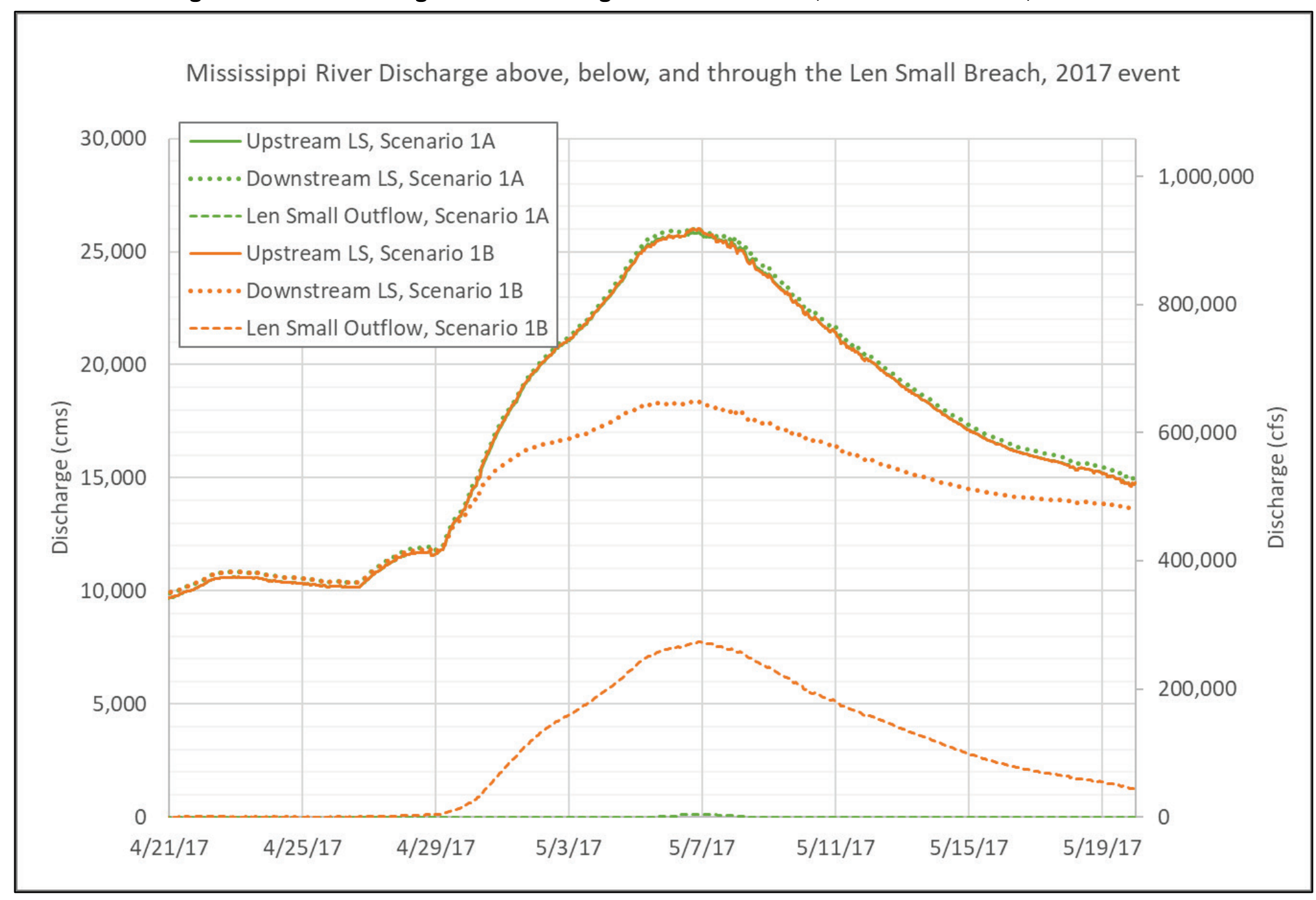




\section{Velocities at cross sections}

Velocity magnitude at cross-sections upstream, adjacent to, and downstream (shown on Figure 5-7) of the LS breach were analyzed.

Velocity magnitudes for the 2011 event near its peak (5/3/2011 at 9:00 a.m.) are shown in Figure 5-8. When the BPNMF was operating (Scenarios 2A and $2 \mathrm{~B})$ :

- Velocities were higher at all cross sections (2A vs. 1A; 2B vs. 1B) due to its effect of lowering stages in the upper river.

When the LS breach was open

- $\quad$ at the upstream cross section, velocities were higher (1B vs. 1A; 2B vs. 2A).

- at the adjacent cross section, velocities were higher on the left (descending) side of the channel and lower along the right descending bank.

- at the downstream cross section, velocities were lower due to the lower discharge below the breach.

Velocity magnitudes near the peaks of the 2015 (shown at 1/1/2016 at 9:00 p.m.) and 2017 (shown at 5/5/2017 at 9:00 p.m.) are shown on Figure 5-9 and Figure 5-10. When LS was open (Scenario 1B)

- at the upstream cross section, velocities were generally higher due to the larger conveyance downstream with the breach open.

- at the adjacent cross section, velocities were also generally higher and is largest along the left bank (descending) at the adjacent cross section.

- at the downstream cross section, velocities were lower due to the lower channel discharges below the LS outflow. 
Figure 5-7. Locations of velocity analysis cross sections near LS breach.

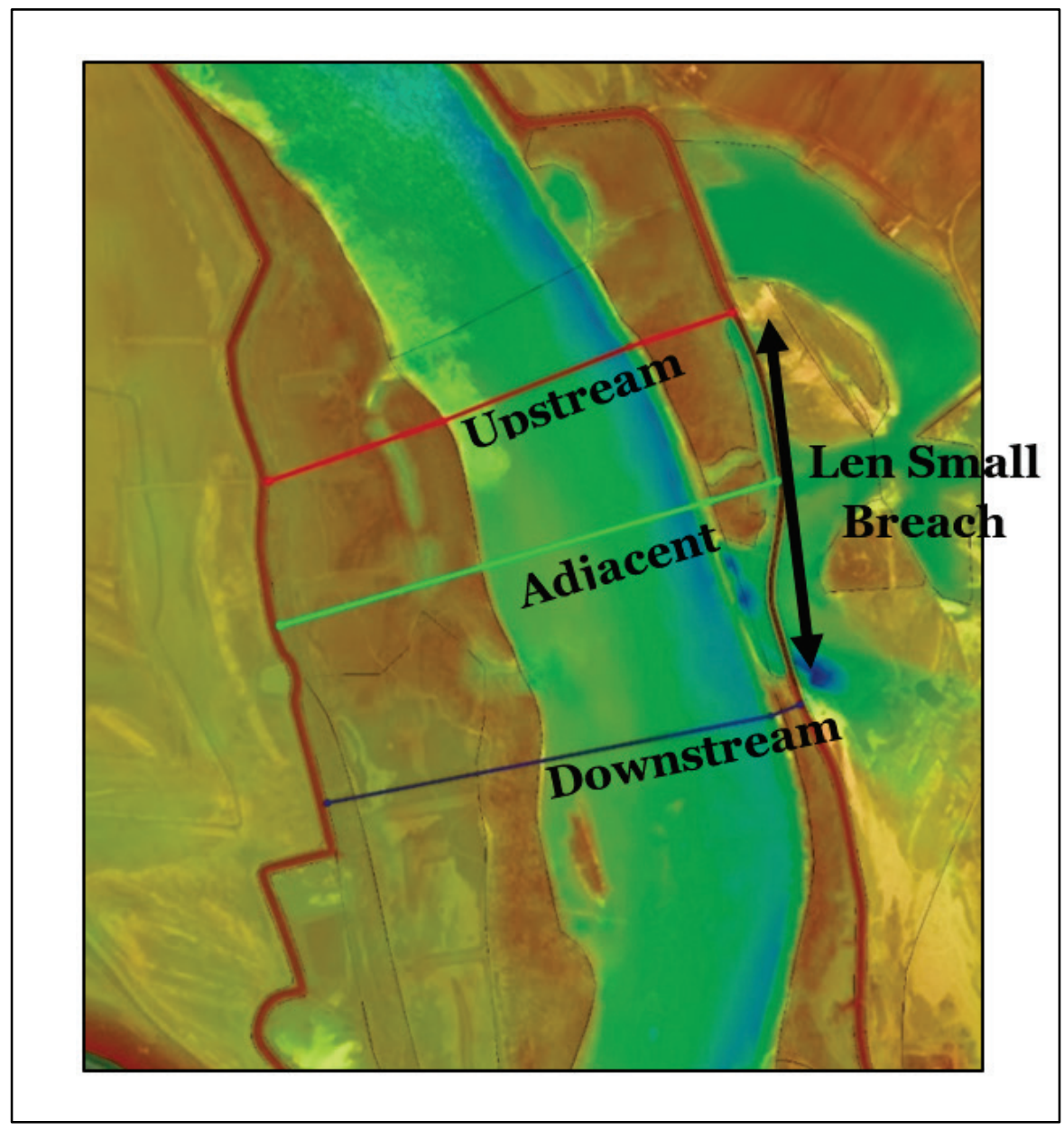


Figure 5-8. Velocity magnitude for cross sections (looking downstream) near the LS breach, all scenarios, 5/3/2011 at 9:00 a.m.
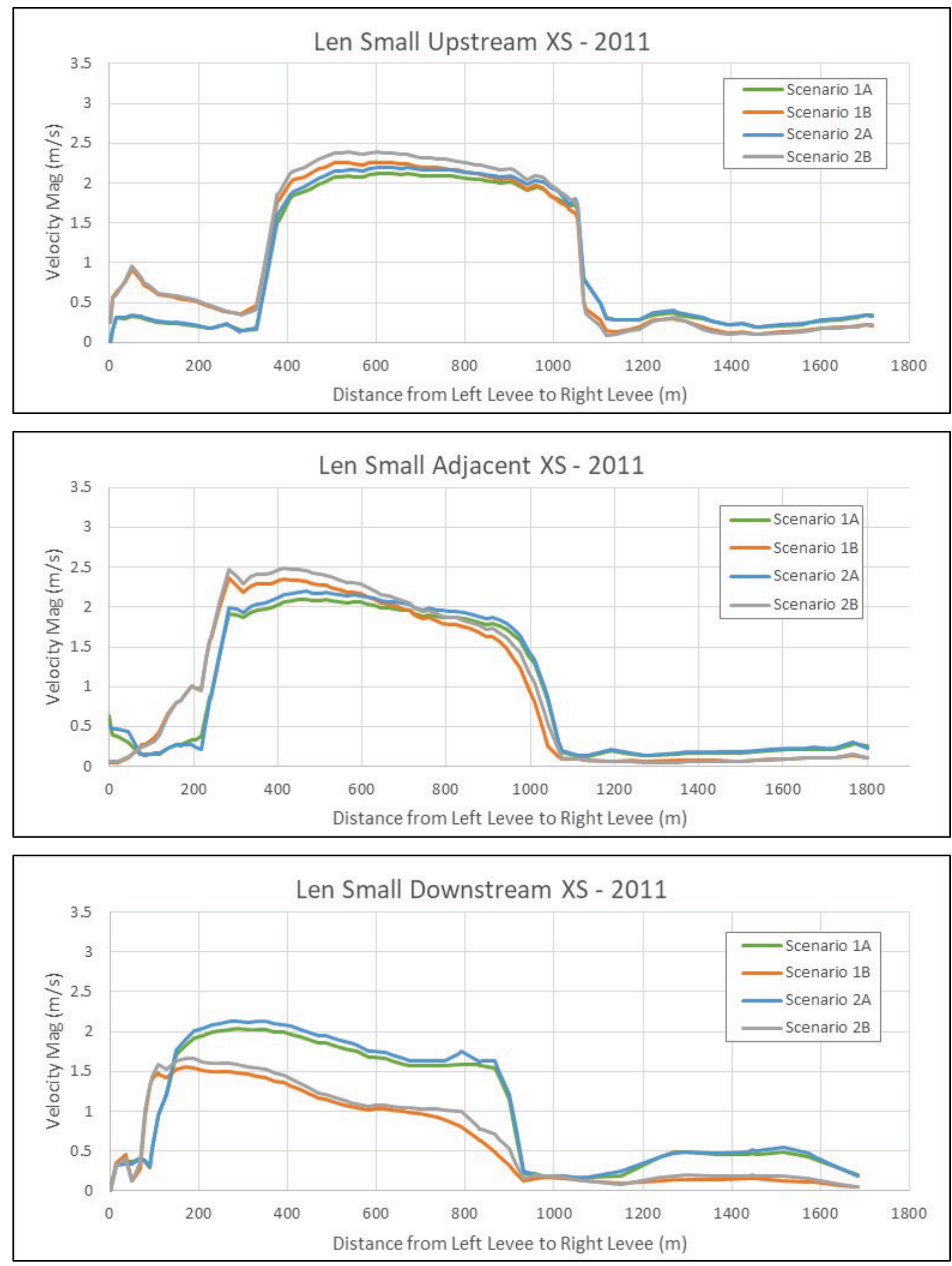
Figure 5-9. Velocity magnitude for cross sections (looking downstream) near the LS breach, scenarios $1 \mathrm{~A}$ and $1 \mathrm{~B}, 1 / 1 / 2016$ at 9:00 p.m.
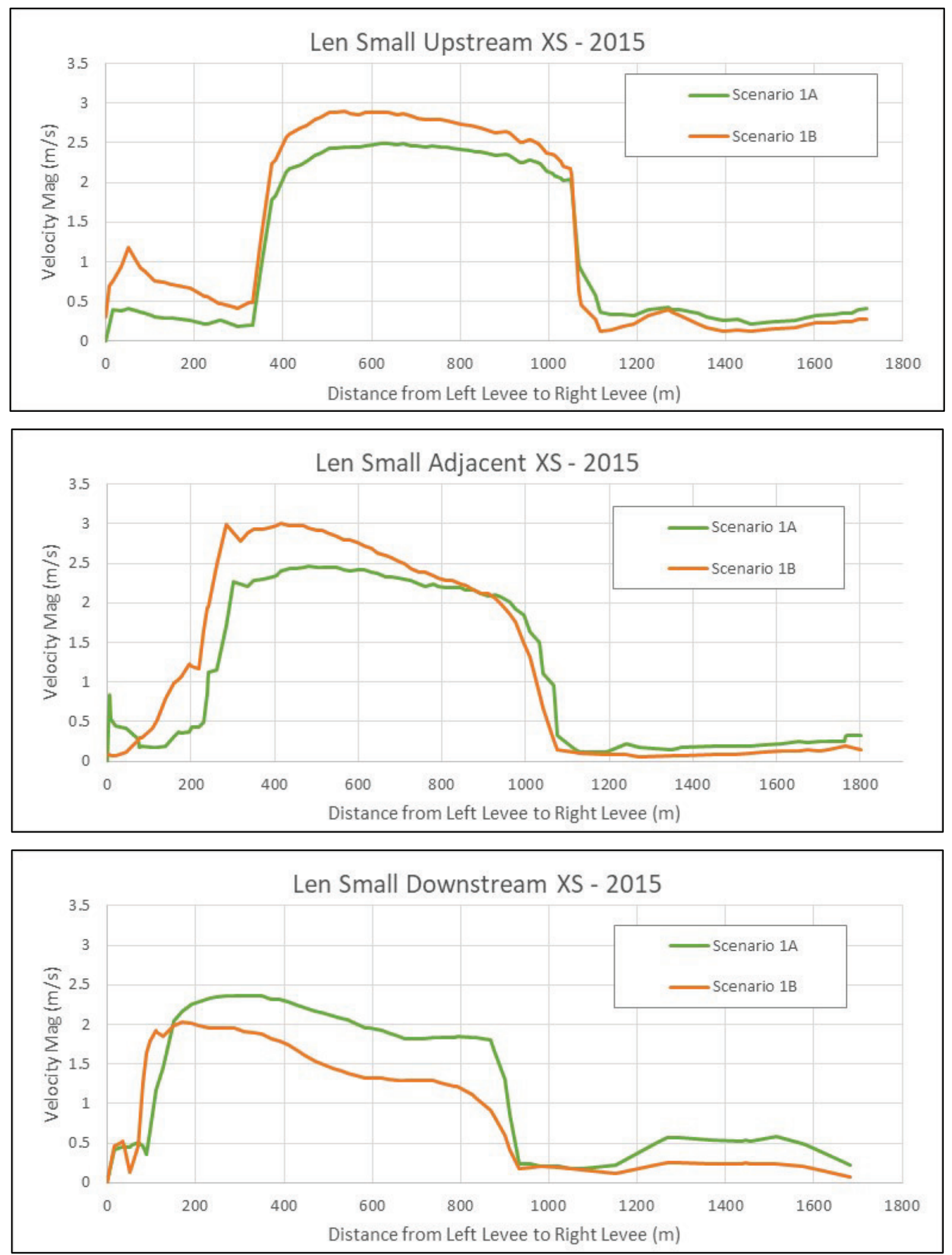
Figure 5-10. Velocity magnitude for cross sections (looking downstream) for cross sections near the LS breach, scenarios 1A and 1B, 5/5/2017 at 9:00 p.m.
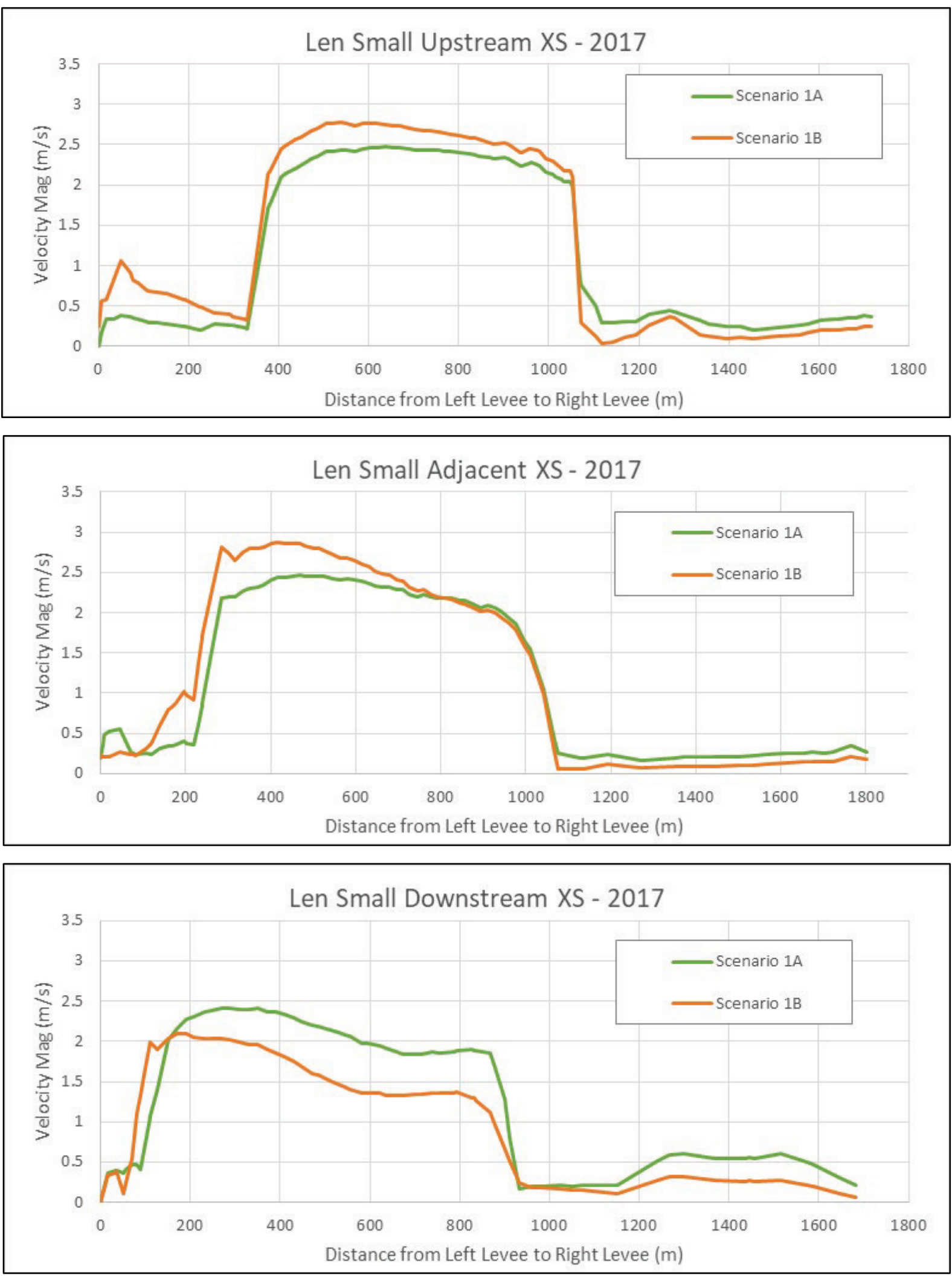


\section{Channel centerline velocity analysis}

Velocity magnitudes extracted from the Mississippi River channel centerline were analyzed near to the time of maximum velocity. Channel centerline velocities at this snapshot in time near the peak of each flood are shown for the Mississippi River upstream of Wickliffe, KY, in Figure 5-11 through Figure 5-13.

The BPNMF operation (comparing Scenario $2 \mathrm{~A}$ to $1 \mathrm{~A}$ and $2 \mathrm{~B}$ to $1 \mathrm{~B}$ ) resulted in higher velocities in the Mississippi River above the breach all the way to Thebes, IL (Figure 5-11). The BPNMF operation resulted in steeper hydraulic slopes, lower stages, and higher velocities.

The LS levee breach can be understood by comparing Scenarios $1 \mathrm{~A}$ and $1 \mathrm{~B}$, and additionally Scenarios 2A and 2B for the 2011 event. Working upstream from Wickliffe, velocity differences were minor between the confluence and Thompson Landing where the outflow from the LS breach begins to re-enter the river channel. Velocities for scenarios with LS breach open $(1 \mathrm{~B}$ and $2 \mathrm{~B}$ ) were lower in the reach from Thompson Landing to the LS breach due to the lower in-channel discharge (water exiting the river and entering the floodplain through the LS breach). Velocities near and just upstream of the LS breach were slightly higher in Scenario $1 \mathrm{~B}$ and 2B. Upstream of LS, velocities remained higher for Scenario $1 \mathrm{~B}$ and $2 \mathrm{~B}$ as the result of locally lower stages and steeper hydraulic slopes in the river when the LS breach is open. 
Figure 5-11. Velocity magnitude at the channel centerline, 5/3/2011 at 9:00 a.m.

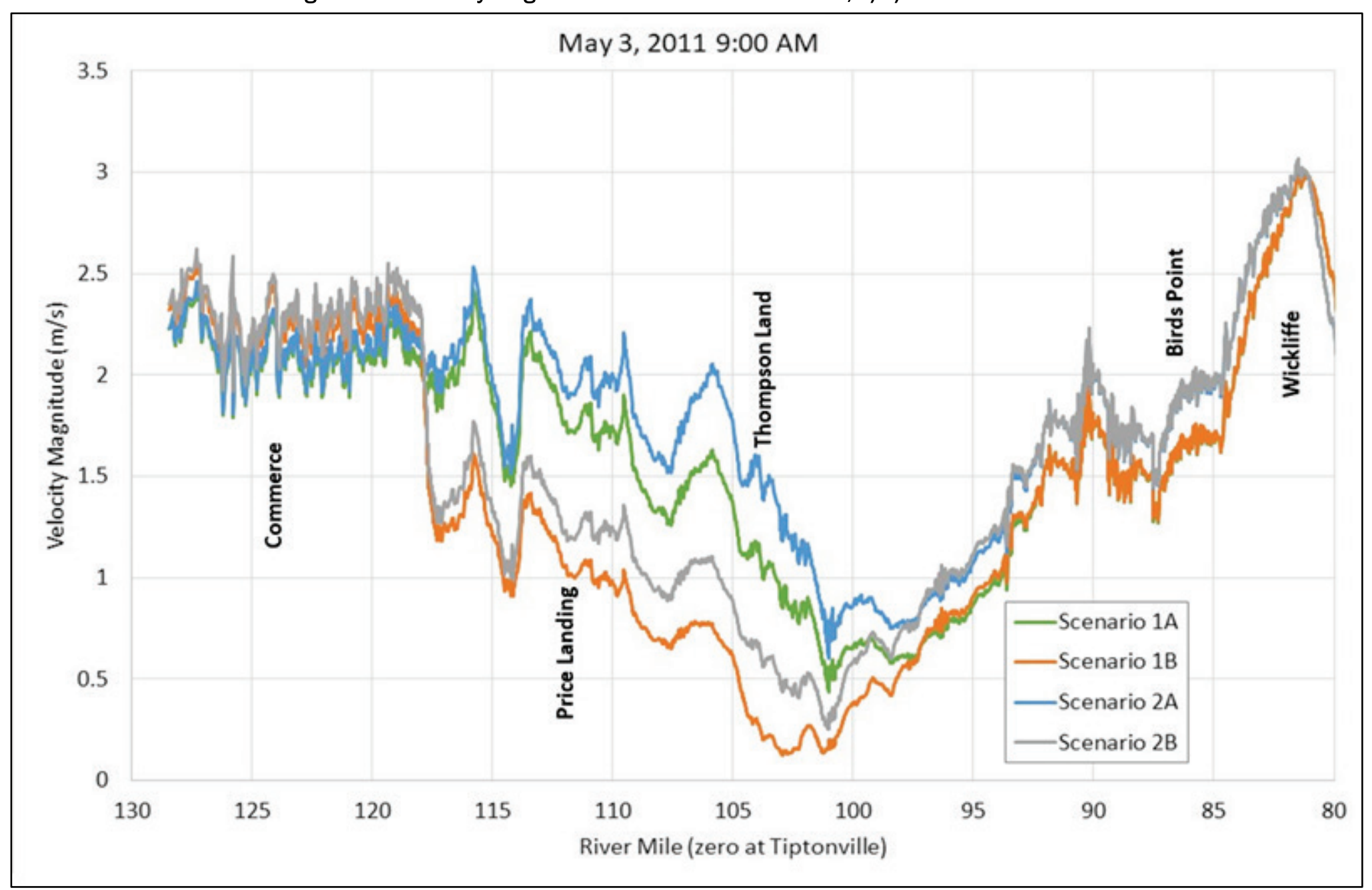


Figure 5-12. Velocity magnitude at the channel centerline for Scenario 1A and 1B, 1/1/2016 at 9:00 p.m.

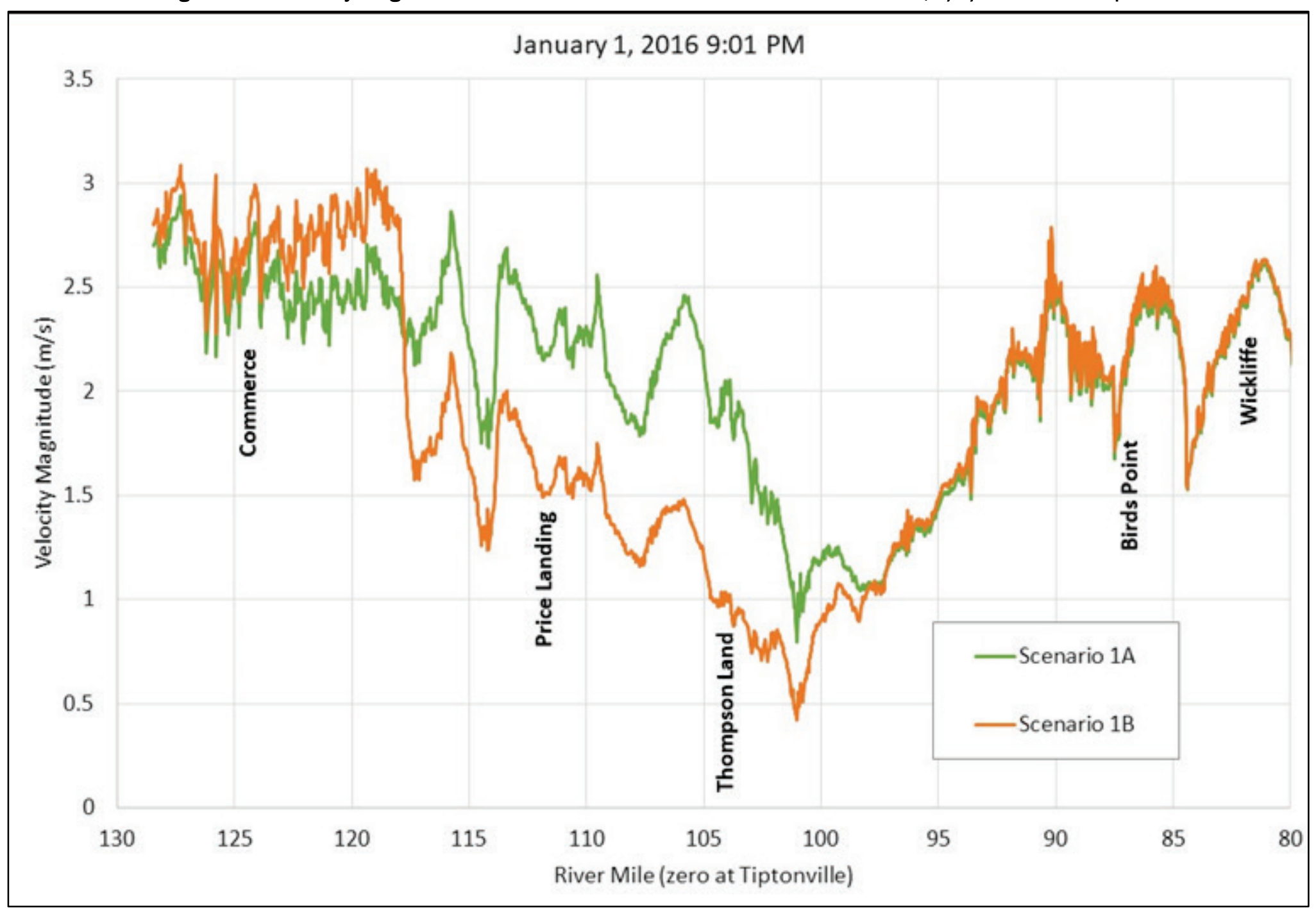


Figure 5-13. Velocity magnitude at the channel centerline for Scenario 1A and 1B, 5/5/2017 at 9:00 a.m.

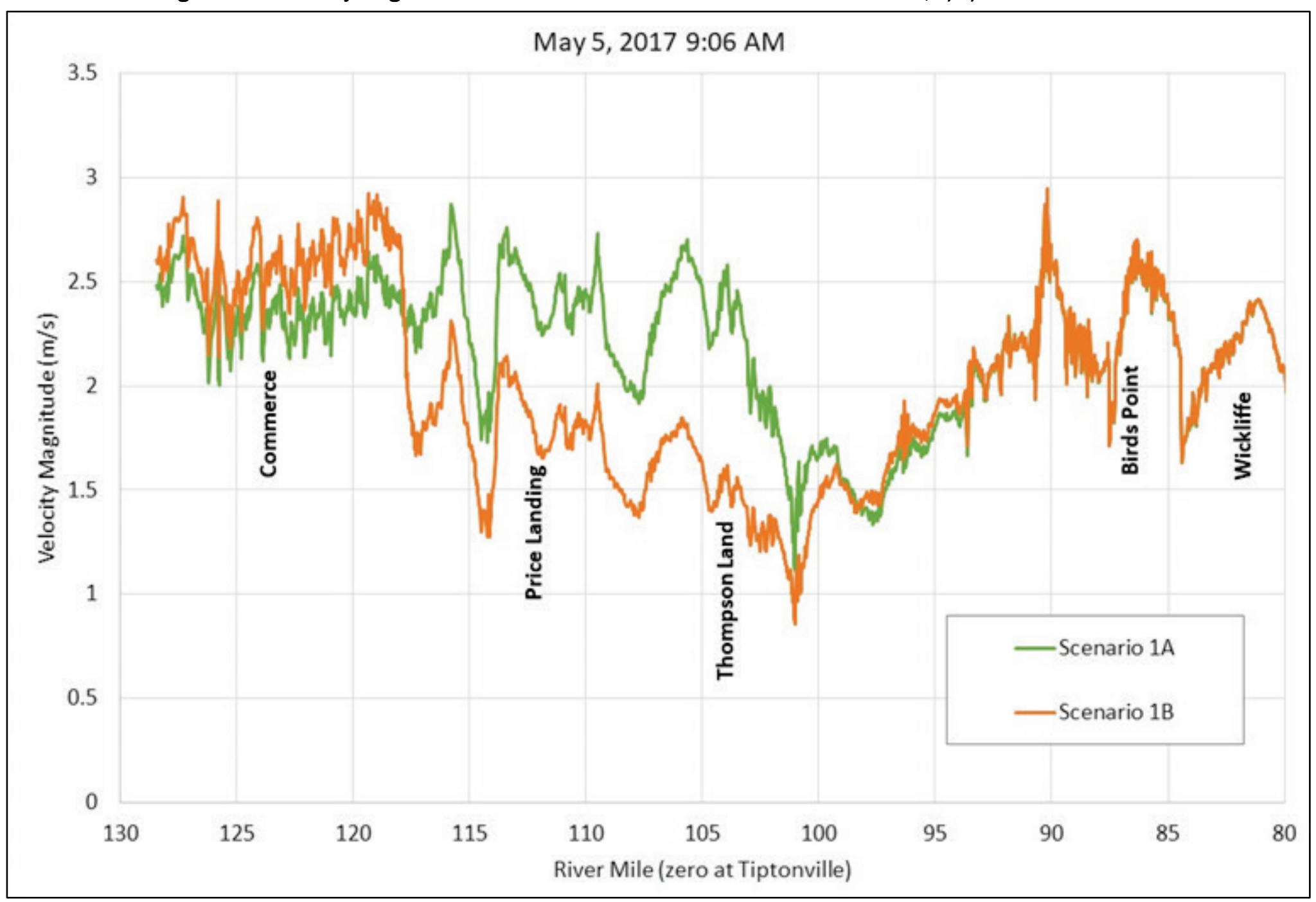




\section{Cross-current velocities}

Cross-current velocities were computed (as described in the introduction of Section 2) near LS for each model run. Two sail lines were utilized, one near the channel centerline and one near the left bank, closer to the LS breach (Figure 5-14). The navigation channel is along the left descending bank along this reach.

Figure 5-14 through Figure 5-17 show cross-current velocity magnitude (color contours) with velocity vectors for Scenario 1B for times near peak flows for the 2011, 2015, and 2017 events, respectively. The cross-current velocity for all years followed the same spatial pattern, with the greatest cross currents occurring over the bankline revetment constructed at the river bank near the opening of the LS Breach in 2016. Cross-current velocities greater than $1.0 \mathrm{~m} / \mathrm{s}(3.28 \mathrm{ft} / \mathrm{s})$ extended approximately $30 \mathrm{~m}$ ( $98.4 \mathrm{ft}$ ) into the channel from the top of the revetment.

Cross-current velocity magnitudes were extracted for the sail line near the left bank. The left bank sail line was approximately $60 \mathrm{~m}(196.8 \mathrm{ft})$ from the bankline revetment at the mouth of the LS Breach, and the stationing for analysis is shown in Figure 5-14. Figure 5-18 shows the cross-current velocity magnitude for each Scenario for the 2011 event. Scenarios $1 \mathrm{~A}$ and 2A (LS closed) show that cross-current velocities remain below $0.2 \mathrm{~m} / \mathrm{s}$ $(0.66 \mathrm{ft} / \mathrm{s})$ and are nearly the same whether the BPNMF is operating $(2 \mathrm{~A})$ or not (1A). For Scenarios 1B and 2B (LS open), cross-current velocity magnitudes reached $0.8 \mathrm{~m} / \mathrm{s}(2.62 \mathrm{ft} / \mathrm{s})$ near the primary LS breach opening $(1,300 \mathrm{~m}(4,265 \mathrm{ft})$ down the left bank sail line). Comparing crosscurrent velocities for each flood event, for Scenario 1B (Figure 5-19; LS open), the 2015 event had the highest cross-current velocities, reaching 1.0 $\mathrm{m} / \mathrm{s}(3.28 \mathrm{ft} / \mathrm{s})$ on the left bank sail line.

Cross currents resulting from waters flowing through the LS breach reentering the channel below Thompson Landing were limited to within 30 $\mathrm{m}(98.4 \mathrm{ft})$ of the bankline, topping out at $0.5 \mathrm{~m} / \mathrm{s}(1.6 \mathrm{ft} / \mathrm{s})$. 
Figure 5-14. Scenario $1 \mathrm{~B}$ velocity vectors and cross-stream velocity magnitude contours at 5/3/2011 at 9:00 a.m. Sail lines shown in magenta - one mid-channel and one near the left bank. Distances along the left bank sail line are shown for later analysis

in Figures 5-18 and 5-19.

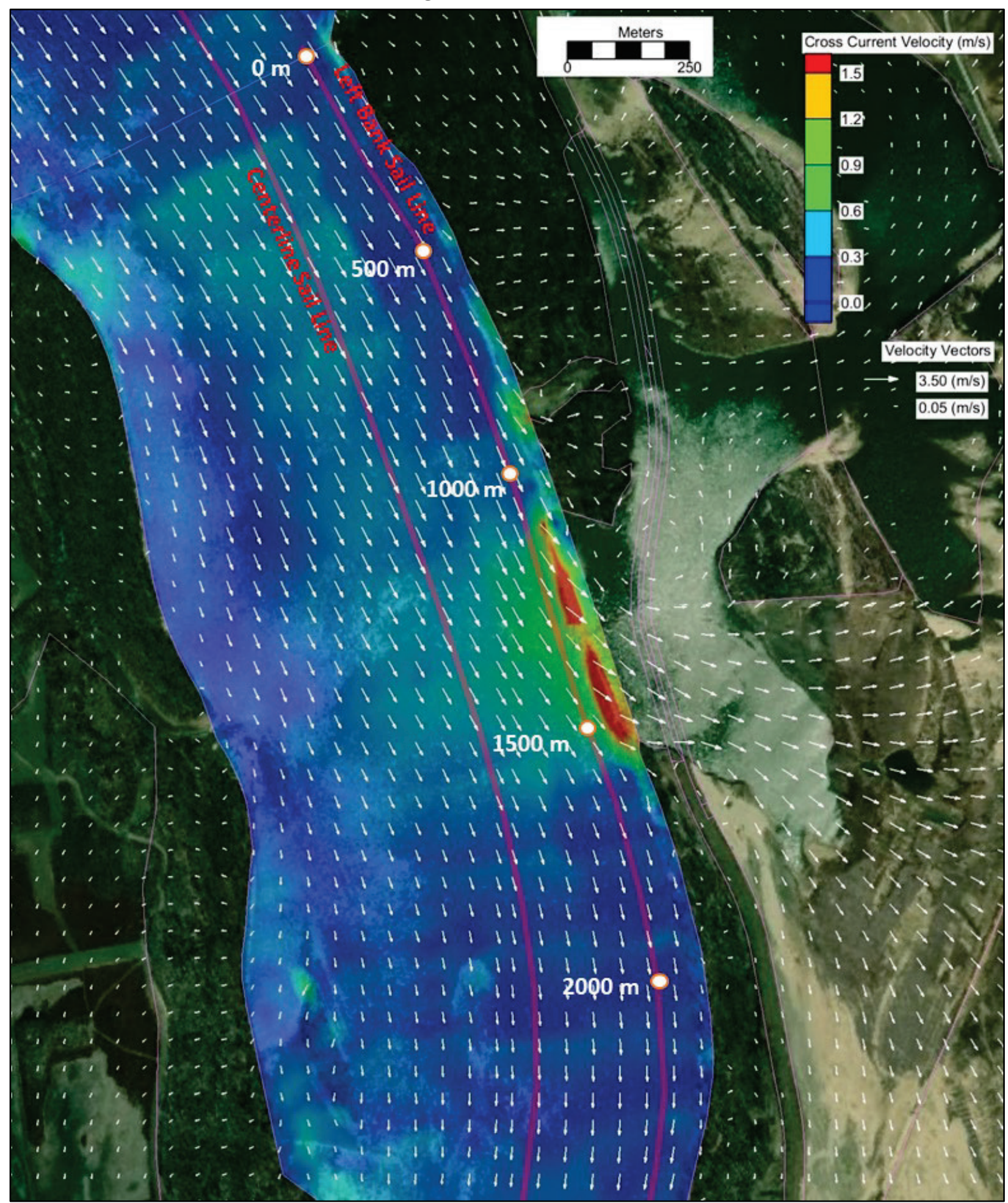


Figure 5-15. Scenario $1 \mathrm{~B}$ velocity vectors and cross-stream velocity magnitude contours at 1/1/2016 at 9:00 p.m. Sail lines shown in magenta - one mid-channel and one near the left bank.

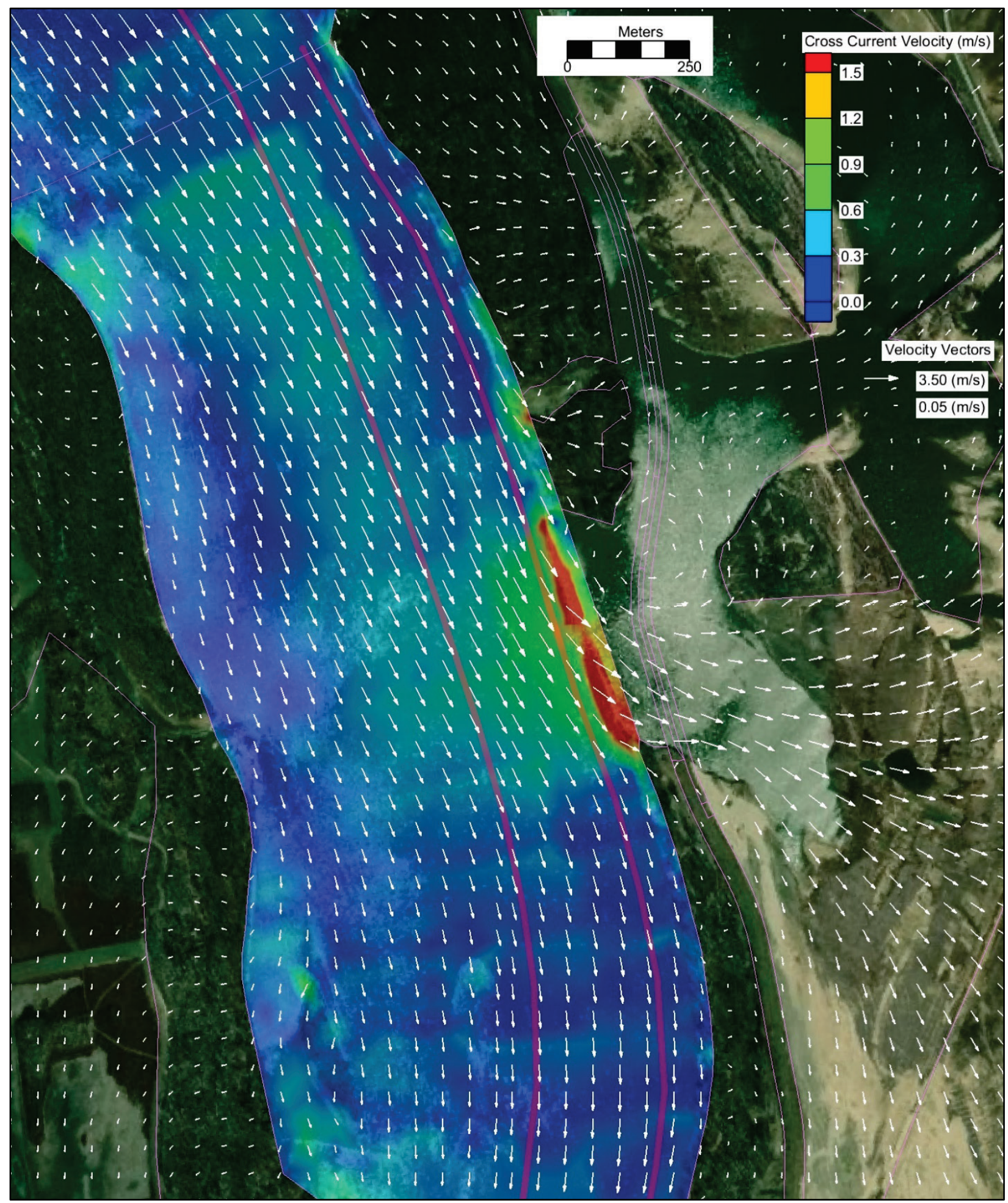


Figure 5-16. Scenario $1 \mathrm{~B}$ velocity vectors and cross-stream velocity magnitude contours at 5/5/2017 at 9:00 a.m. Sail lines shown in magenta - one mid-channel and one near the left bank.

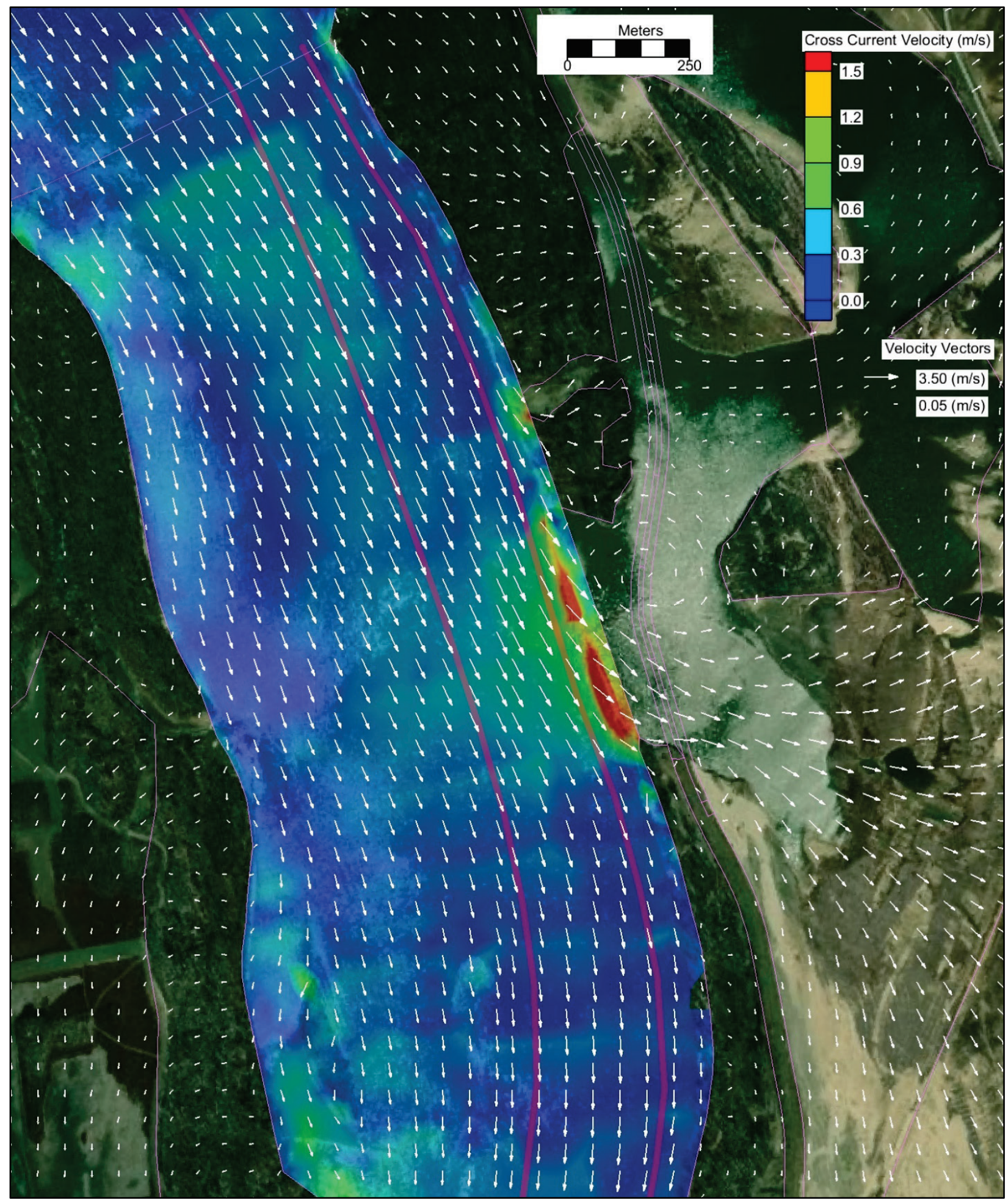


Figure 5-17. Scenario $2 \mathrm{~B}$ velocity vectors and cross-stream velocity magnitude contours at 5/3/2011 at 9:00 a.m. Sail lines shown in magenta - one mid-channel and one near the left bank.

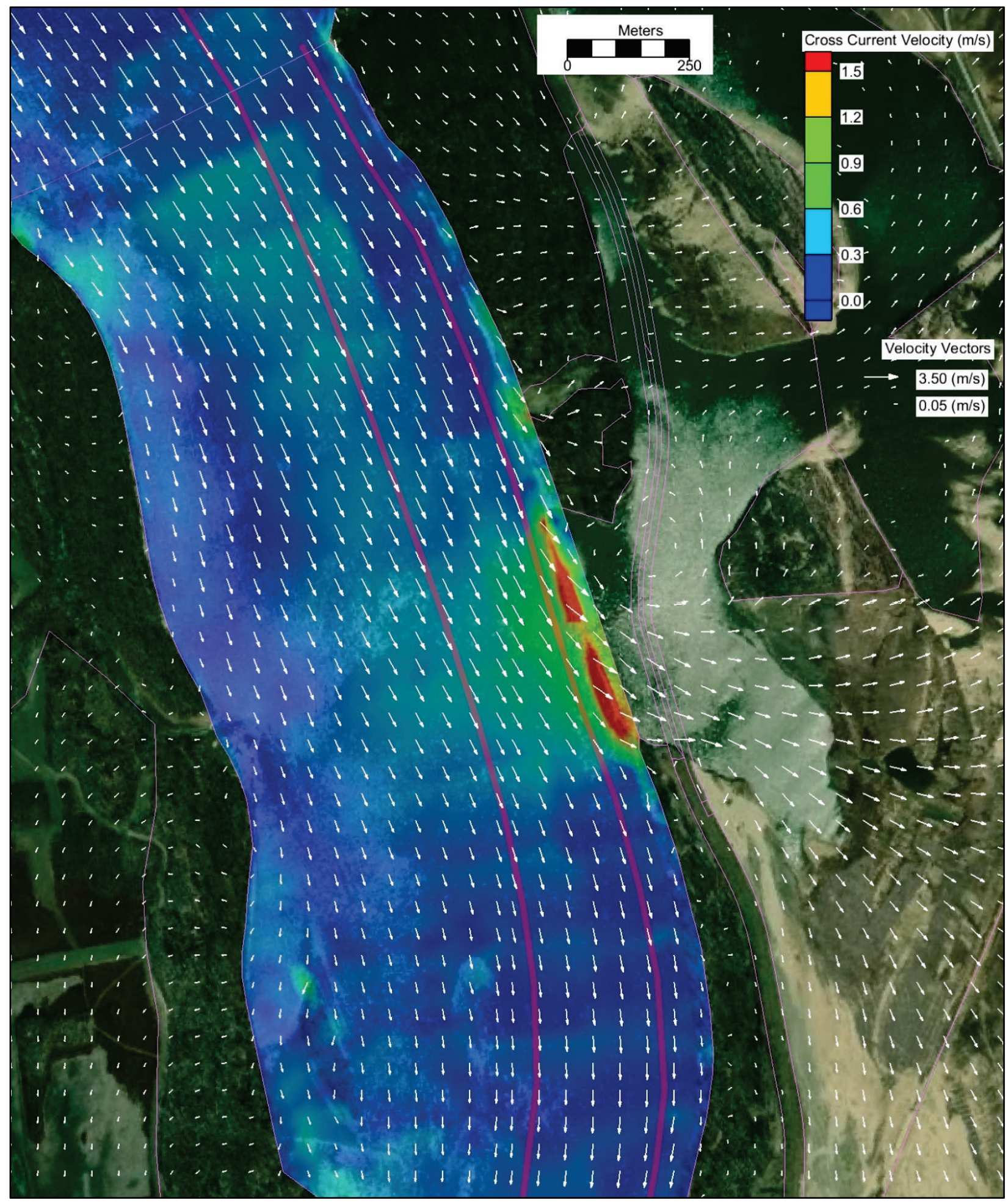


Figure 5-18. Cross-current velocity magnitude near the LS breach along the left bank sail line (upstream end is distance zero) for all Scenarios - 5/3/2011 at 9:00 a.m.

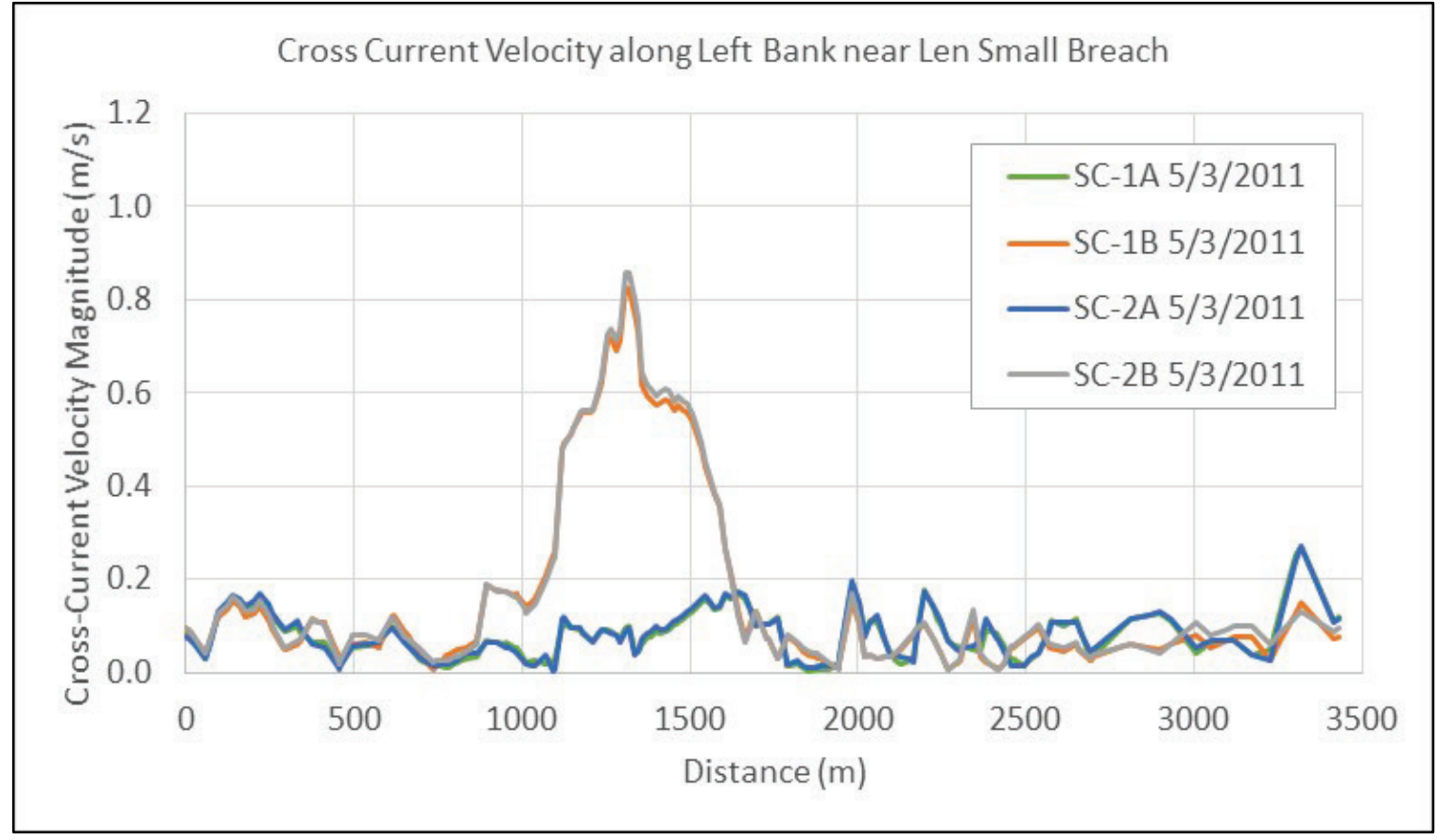

Figure 5-19. Cross-current velocity magnitude near the LS breach along the left bank sail line (upstream end is distance zero), for Scenario 1B, near the peak of each flood event.

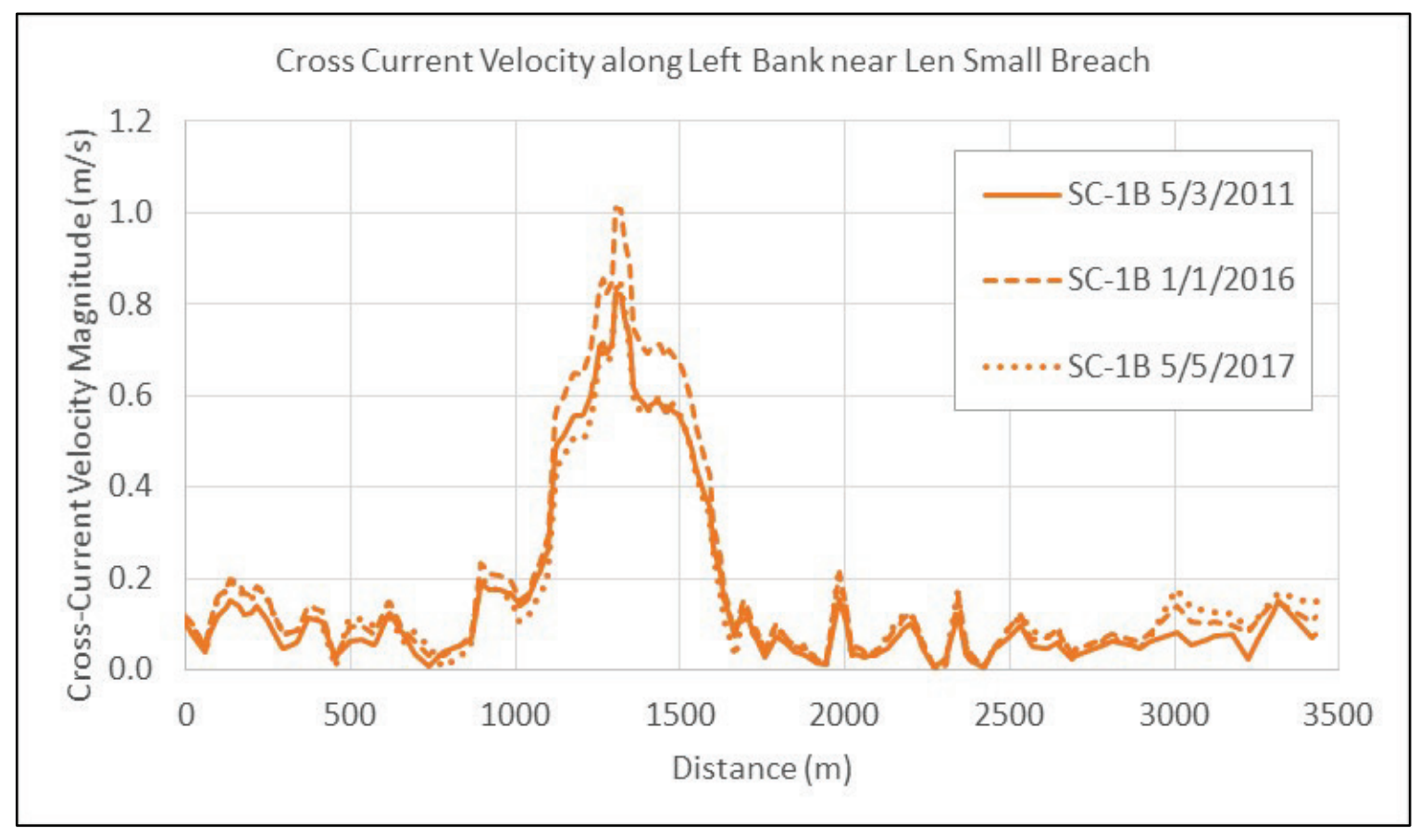




\section{Current patterns}

Current patterns for each flood event are shown as contours and vectors of velocity near the LS breach for Scenarios $1 \mathrm{~A}$ and $1 \mathrm{~B}$ on Figure $5^{-20}$, Scenarios $1 \mathrm{~B}$ and $2 \mathrm{~B}$ on Figure 5-21, Scenarios $1 \mathrm{~A}$ and $1 \mathrm{~B}$ on Figure 5-22 and Figure 5-23. Current patterns for Scenario 1B, 2017 flood event, are shown near the LS breach (Figure 5-23, lower panel). In-channel vectors were typically oriented in the along-channel direction, except within approximately $80 \mathrm{~m}(262.5 \mathrm{ft})$ of the bankline where currents bend east as result of the breach. Within the breach, current velocity out of the river at the south end of the breach reached $2.6 \mathrm{~m} / \mathrm{s}(8.5 \mathrm{ft} / \mathrm{s})$. North of the outflow jet, a large eddy formed as the flow separated from the jet and was backed up by higher elevation land. Patterns were similar for the 2011 and 2015 events but with lower velocities (owing to lower discharge in this reach) and a less defined and powerful eddy in the opening of the breach. 
Figure 5-20. Velocity contours and vectors in the vicinity of the LS levee breach, for Scenarios $1 \mathrm{~A}$ (upper panel) and 2A (lower panel), 5/3/2011 at 9:00 a.m.
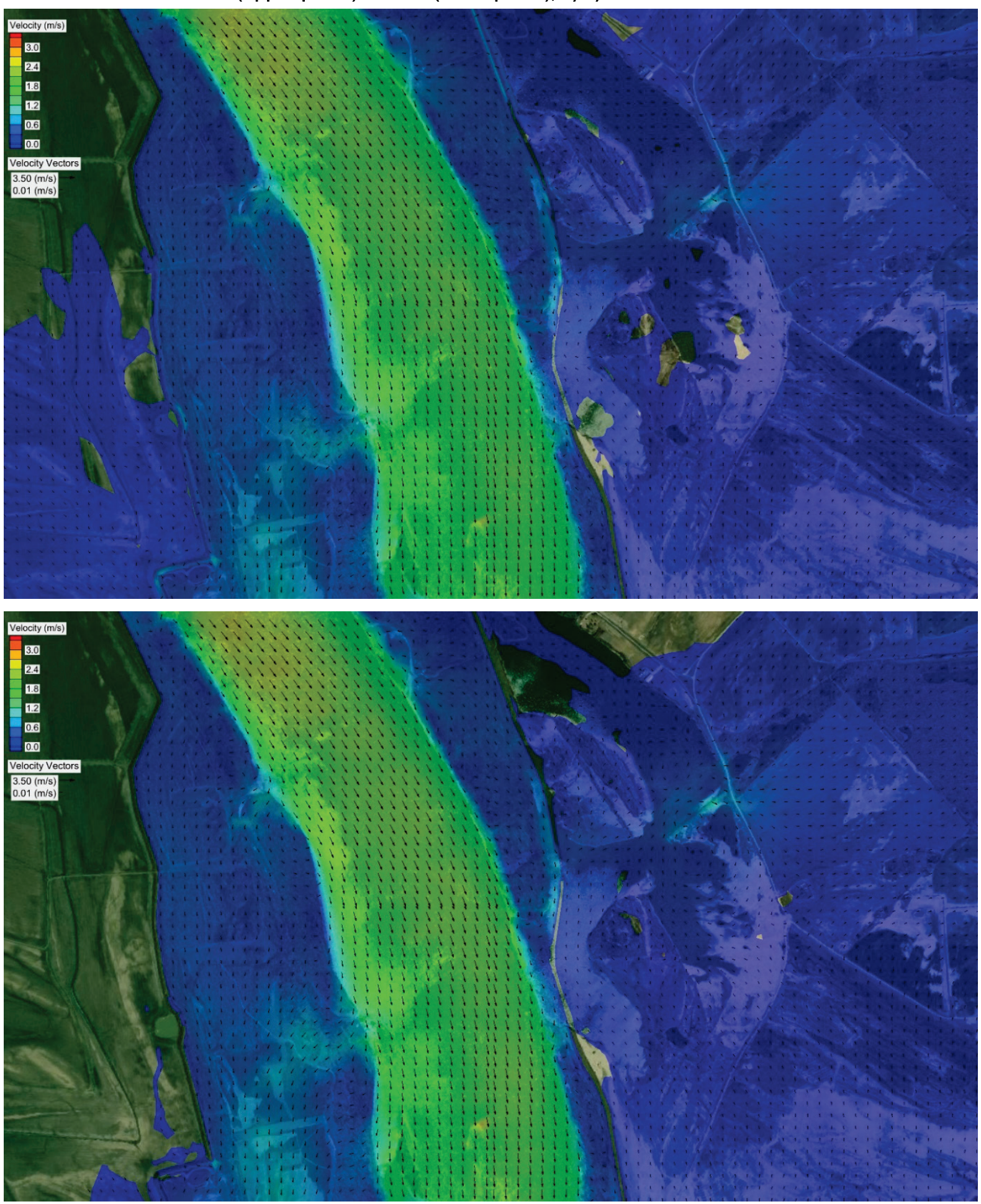
Figure 5-21. Velocity contours and vectors in the vicinity of the LS levee breach, for Scenarios 1B (upper panel) and 2B (lower panel), 5/3/2011 at 9:00 a.m.
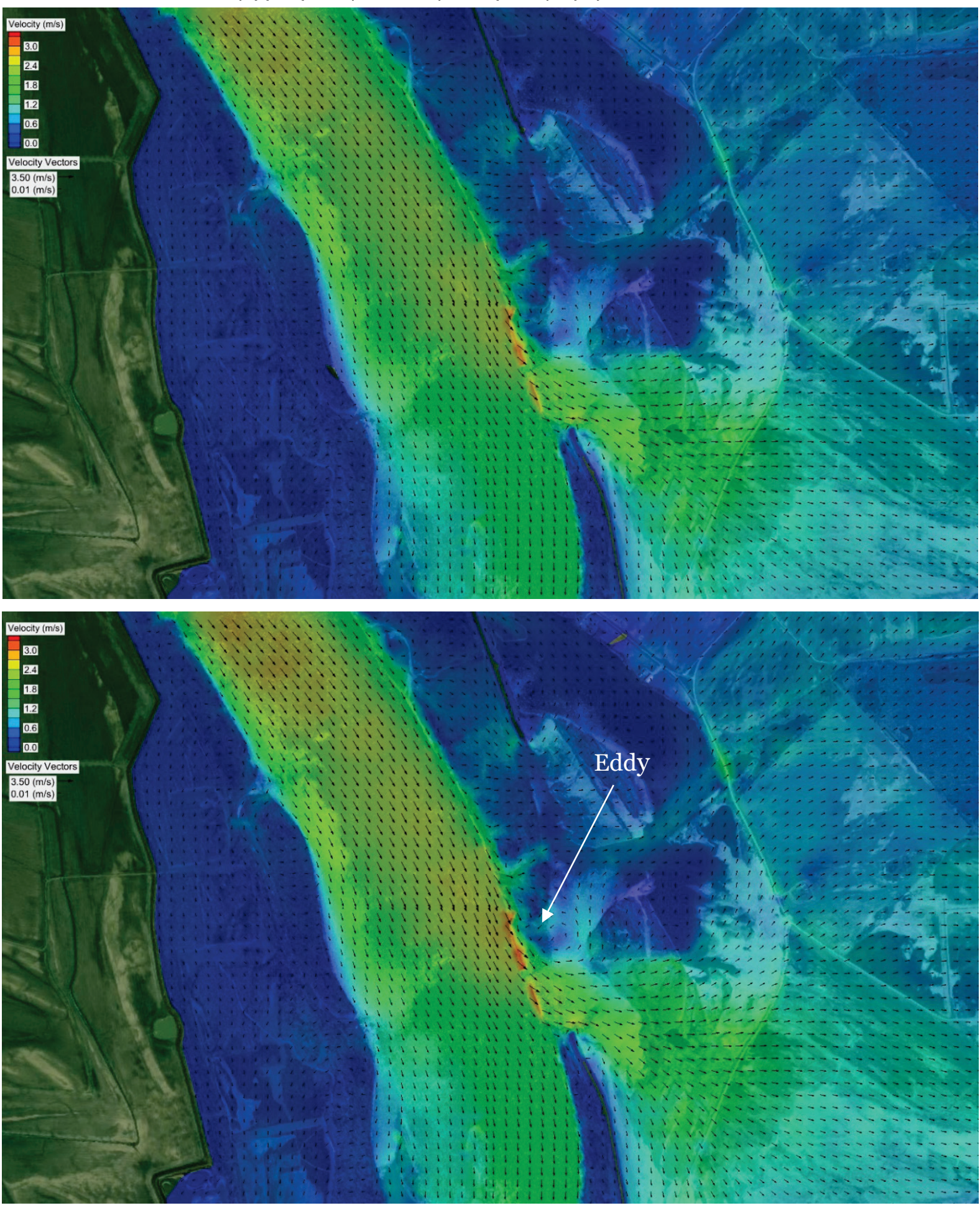
Figure 5-22. Velocity contours and vectors in the vicinity of the LS levee breach, for Scenarios 1A (upper panel) and 1B (lower panel), 1/1/2016 9:00 p.m.
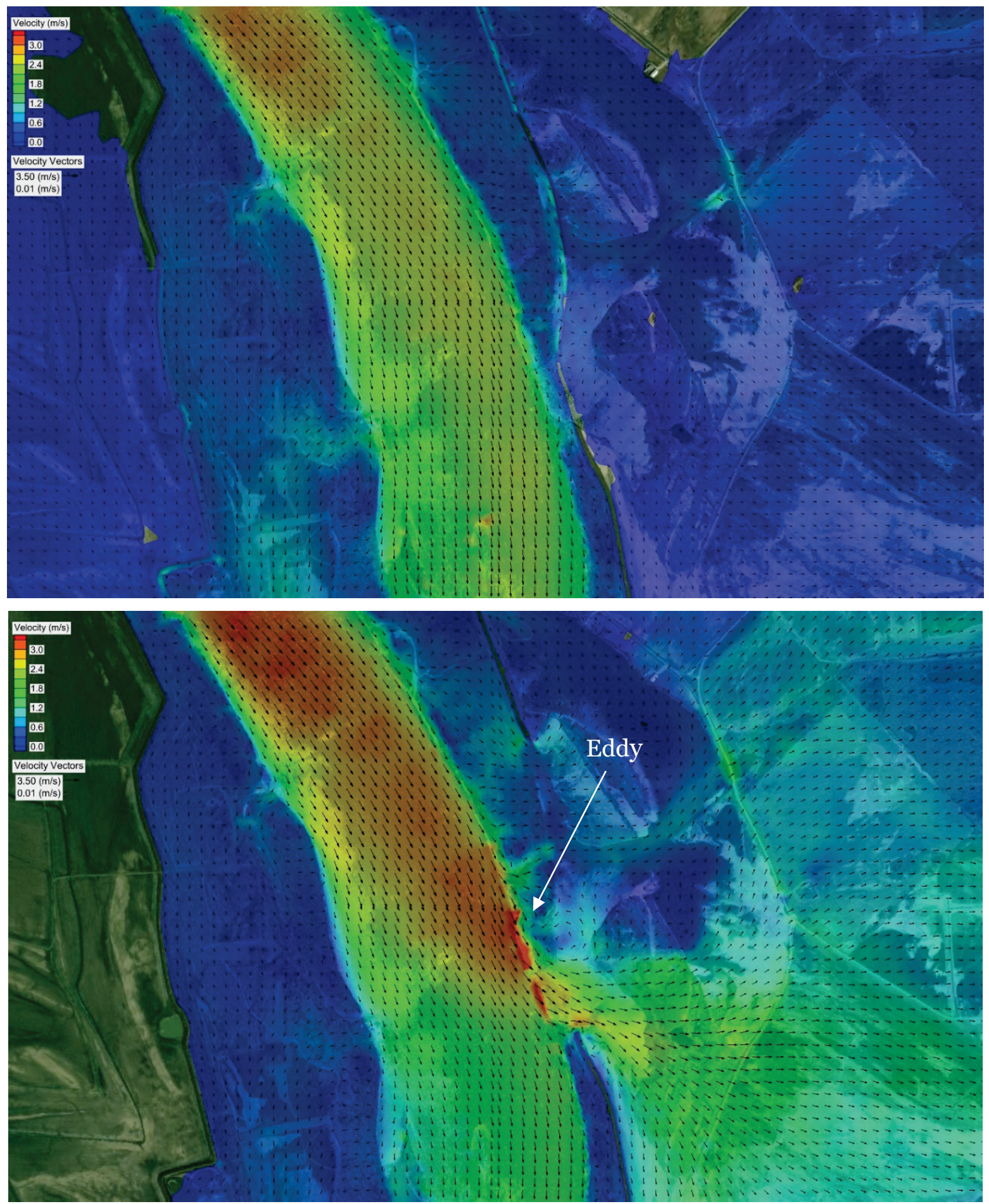
Figure 5-23. Velocity contours and vectors in the vicinity of the LS levee breach, for Scenarios 1A (upper panel) and 1B (lower panel), 5/5/2017 at 9:00 a.m.
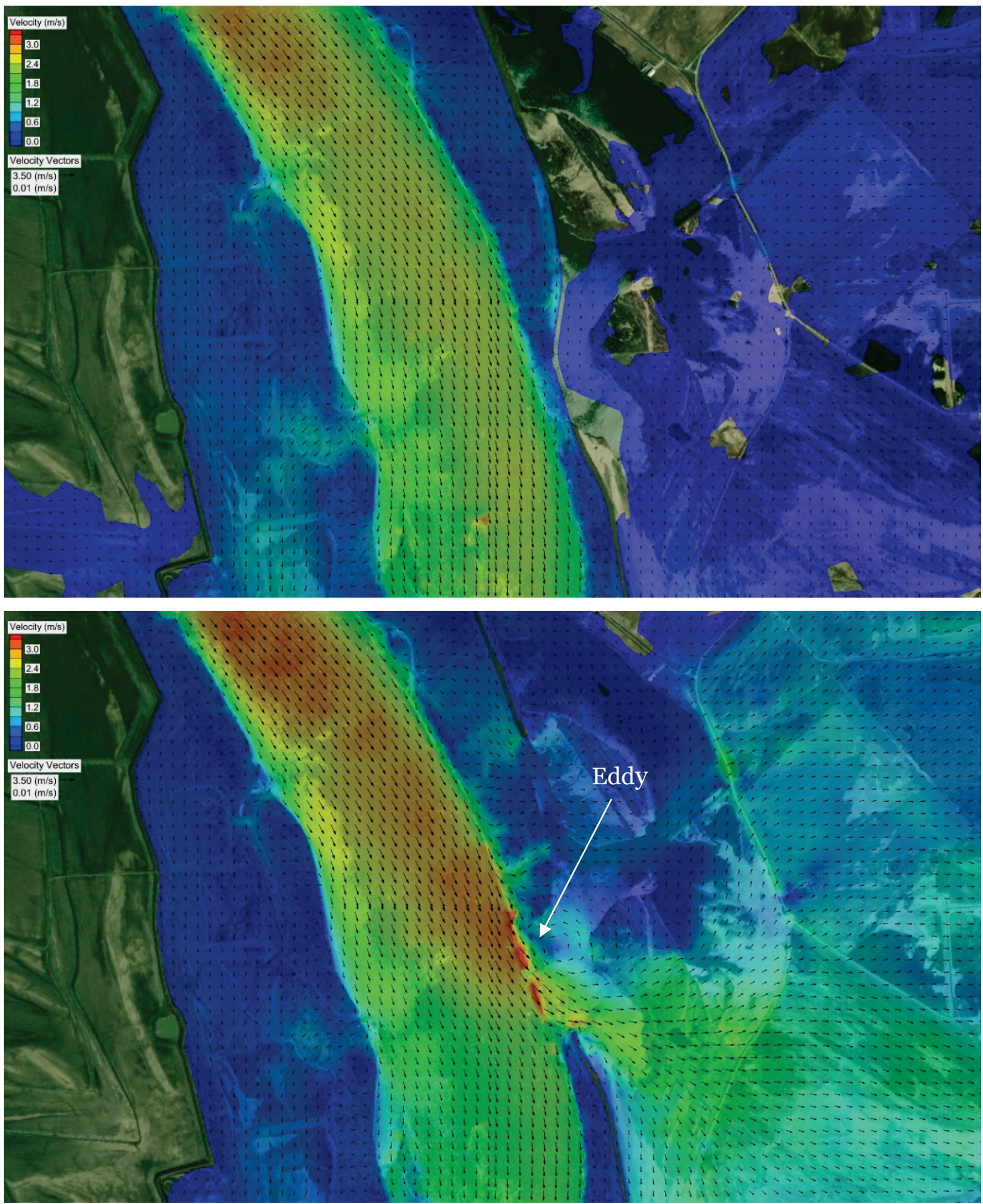

\section{Summary - LS breach}

With respect to navigation concerns, analysis of the maximum velocity patterns associated with the LS breach provided the following results: 
- Increased velocities were observed upstream of the breach extending to Commerce in a range typically between $0.2-0.3 \mathrm{~m} / \mathrm{s}(0.66-$ $0.98 \mathrm{ft} / \mathrm{s})$.

- Decreased velocities were observed from LS to Thompson Landing in a range typically $0.5 \mathrm{~m} / \mathrm{s}(1.6 \mathrm{ft} / \mathrm{s})$ to as much as $1.0 \mathrm{~m} / \mathrm{s}(3.28 \mathrm{ft} / \mathrm{s})$ lower.

- Cross-current velocities were greater than $1.0 \mathrm{~m} / \mathrm{s}(3.26 \mathrm{ft} / \mathrm{s})$ in the vicinity of the breach opening, particularly within $60 \mathrm{~m}(196.8 \mathrm{ft})$ of the bankline revetment.

Figure 5-24 displays the difference in velocity between Scenarios $1 \mathrm{~B}$ and 1A (LS breach open and closed), calculated as Scenario 1B minus 1A. Red colors indicate an increase in velocity for Scenario $1 \mathrm{~B}$, blue colors a decrease. This provides an illustration of the increase in velocity above LS, a decrease in velocities from LS to Thompson Landing, and a minor change in velocity below the Birds Point gage.

Activation of the BPNMF resulted in higher velocities in the Upper Mississippi River with the differences gradually decreasing in a direction upstream from the BPNMF. The difference in velocities was very small (less than $0.1 \mathrm{~m} / \mathrm{s}$ ) in the vicinity of Commerce. 
Figure 5-24. Difference in velocity between Scenarios 1B and 1A (calculated as 1B minus 1A) for 5/5/2017 at 9:00 a.m.

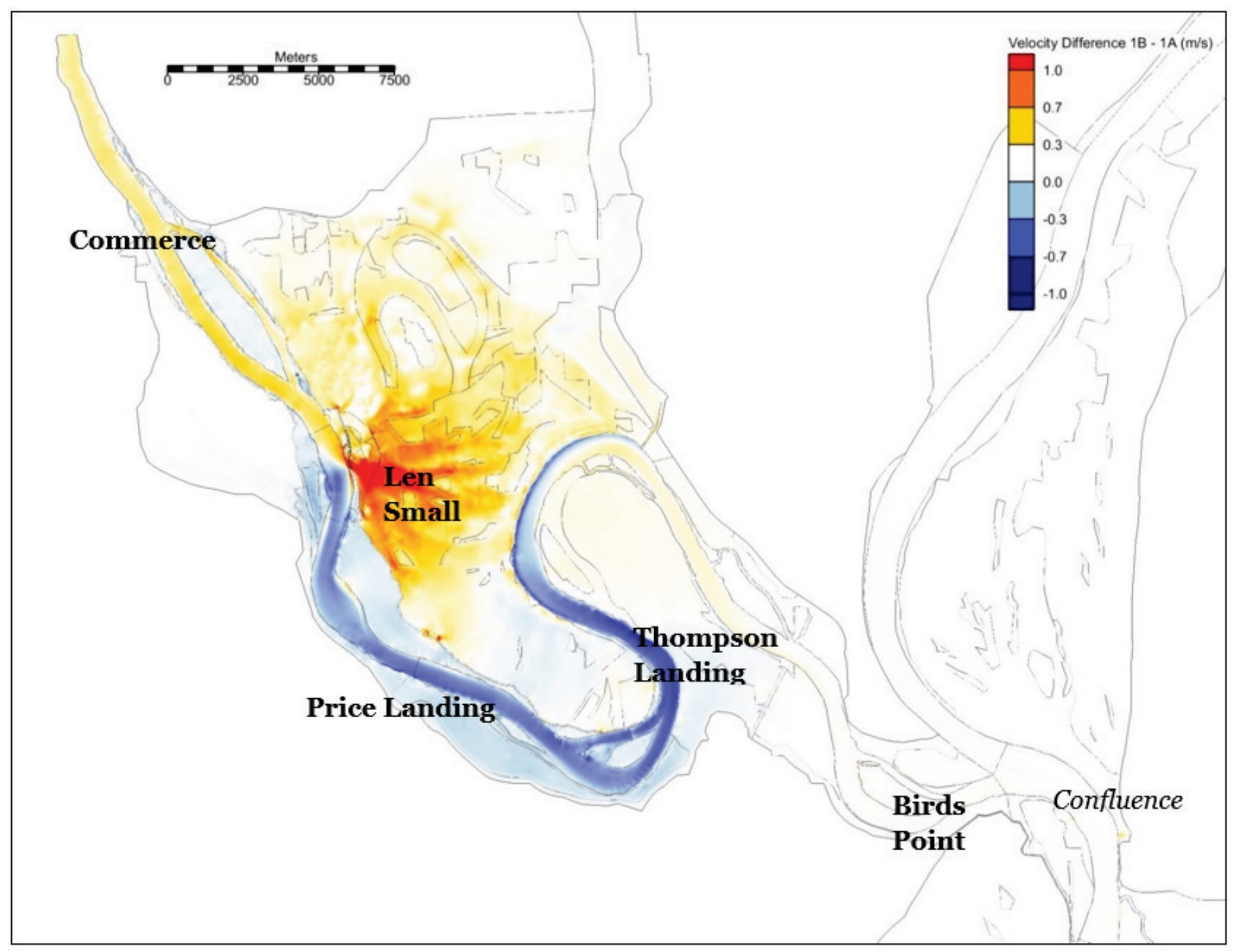




\section{Birds Point New Madrid Floodway (BPNMF) breach analyses}

\section{Breach discharge}

The BPNMF was operated for Scenarios $2 \mathrm{~A}$ and $2 \mathrm{~B}$. It was operated as stated in the beginning of the "Model Scenarios" section:

"For BPNMF operation in Scenarios 2A and 2B, the trigger for floodway activation was $61.0 \mathrm{ft}$ on the Cairo gage (note: $61.0 \mathrm{ft}$ is the local datum, this translates to $101.15 \mathrm{~m}$ NAVD88). Results from Scenario $1 \mathrm{~A}$ were used to determine the timing of BPNMF activation. The trigger elevation based on model results was 5/1/2011 at 22:00. The peak stage (elevation) at Cairo for the 2015 and 2017 events were $99.77 \mathrm{~m}$ and $98.42 \mathrm{~m}$, (Cairo gage reading of $56.5 \mathrm{ft}$ and $52.0 \mathrm{ft}$ ) respectively, both lower than the trigger elevation. Therefore, Scenarios $2 \mathrm{~A}$ and $2 \mathrm{~B}$ were only run for the 2011 event. The full 11,099 linear feet of the upper crevasse was activated."

Water from the river also flows into the floodway during the 2011 event for Scenarios $1 \mathrm{~A}$ and $1 \mathrm{~B}$ (BPNMF not operating) as river stages were high enough to overtop the upper crevasse. For Scenarios 2A and 2B, ideal breach failures were simulated for the upper, middle, and lower crevasses. A new North4 Section was added to extend the upper crevasse to model failure of the full 3,350 m (11,099 ft) length of the crevasse (Figure 5-25). The time series for all upper breach strings (Figure 5-26) were created to mimic the general width and depth of failure which occurred in 2011.

The lower crevasse width was unchanged. The activation occurred at the same interval after the upper crevasse as was done in 2011. The rate of failure was unchanged. The entire middle crevasse was activated for the scenario simulations. The activation occurred at the same interval after the upper crevasse as was done in 2011. Figure 5-27 shows the timing curves for the lower and middle crevasses for the 2011 Scenarios.

Discharge from the river into the floodway (over and through the Upper Fuseplug and inflow crevasse) for each Scenario, for the 2011 event is shown in Figure 5-28. For scenarios where the BPNMF is closed (Scenarios $1 \mathrm{~A}$ and $1 \mathrm{~B}$ ), peak discharge is approximately $2,600 \mathrm{cms}$ (92,000 cfs), and for scenarios where BPNMF is operating, the peak discharge is approximately $12,400 \mathrm{cms}$. 
Figure 5-25. Breach strings for the upper crevasse for the 2011 scenario simulations.

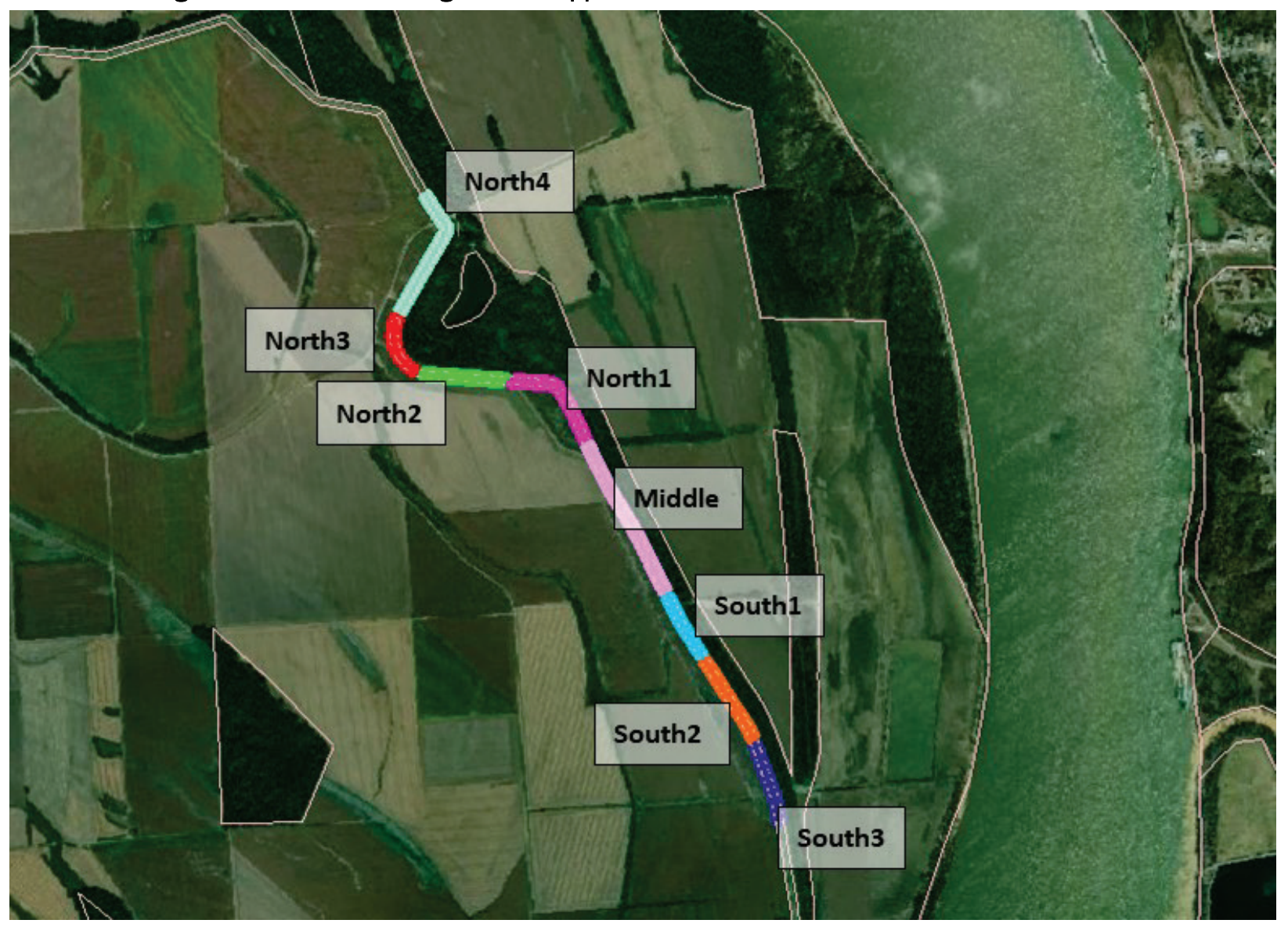

Figure 5-26. Breach string failure time series for the upper crevasse for the 2011 scenario simulations.

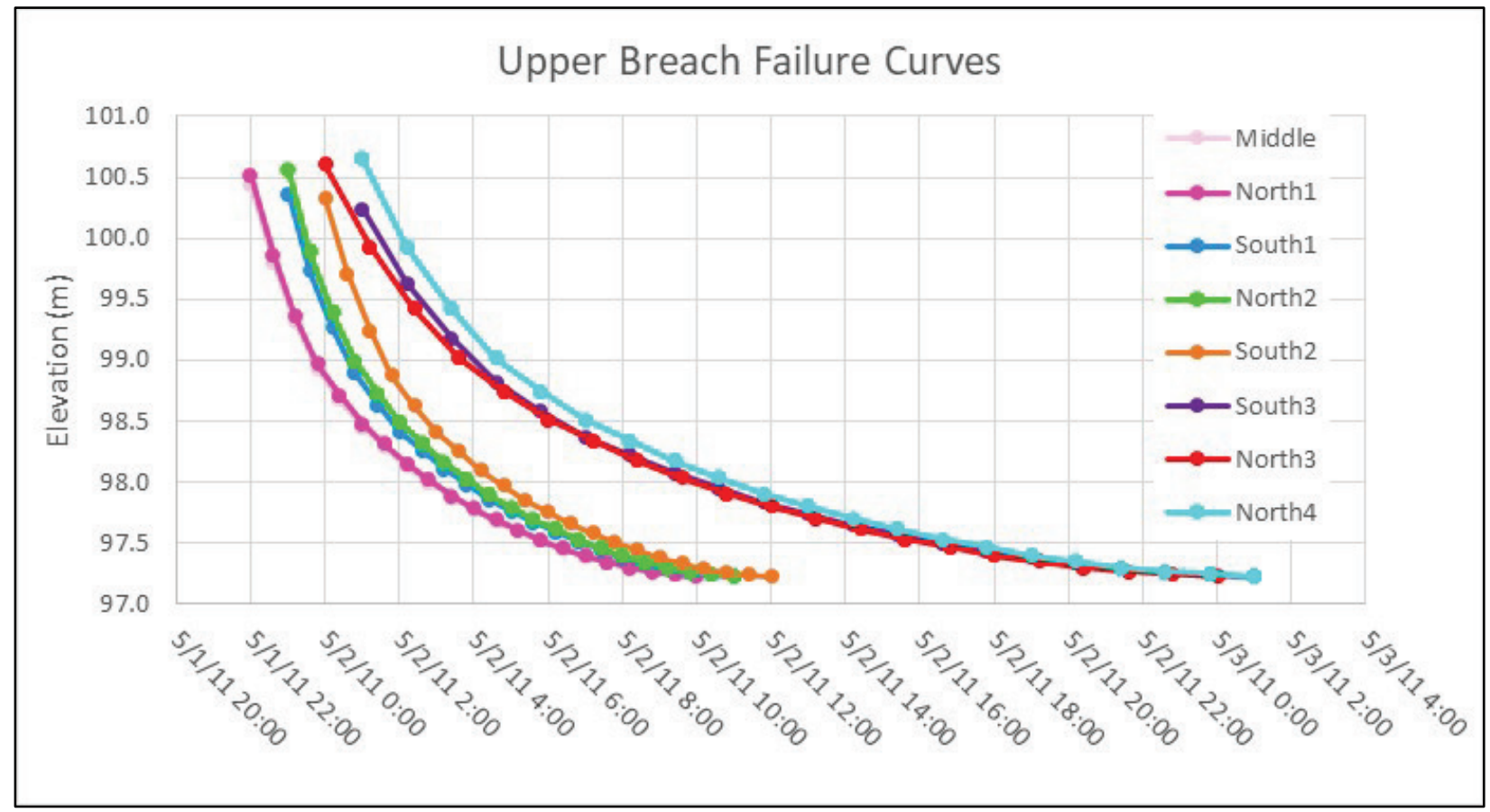


Figure 5-27. Breach string failure time series for the middle and lower crevasse for the 2011 scenario simulations.

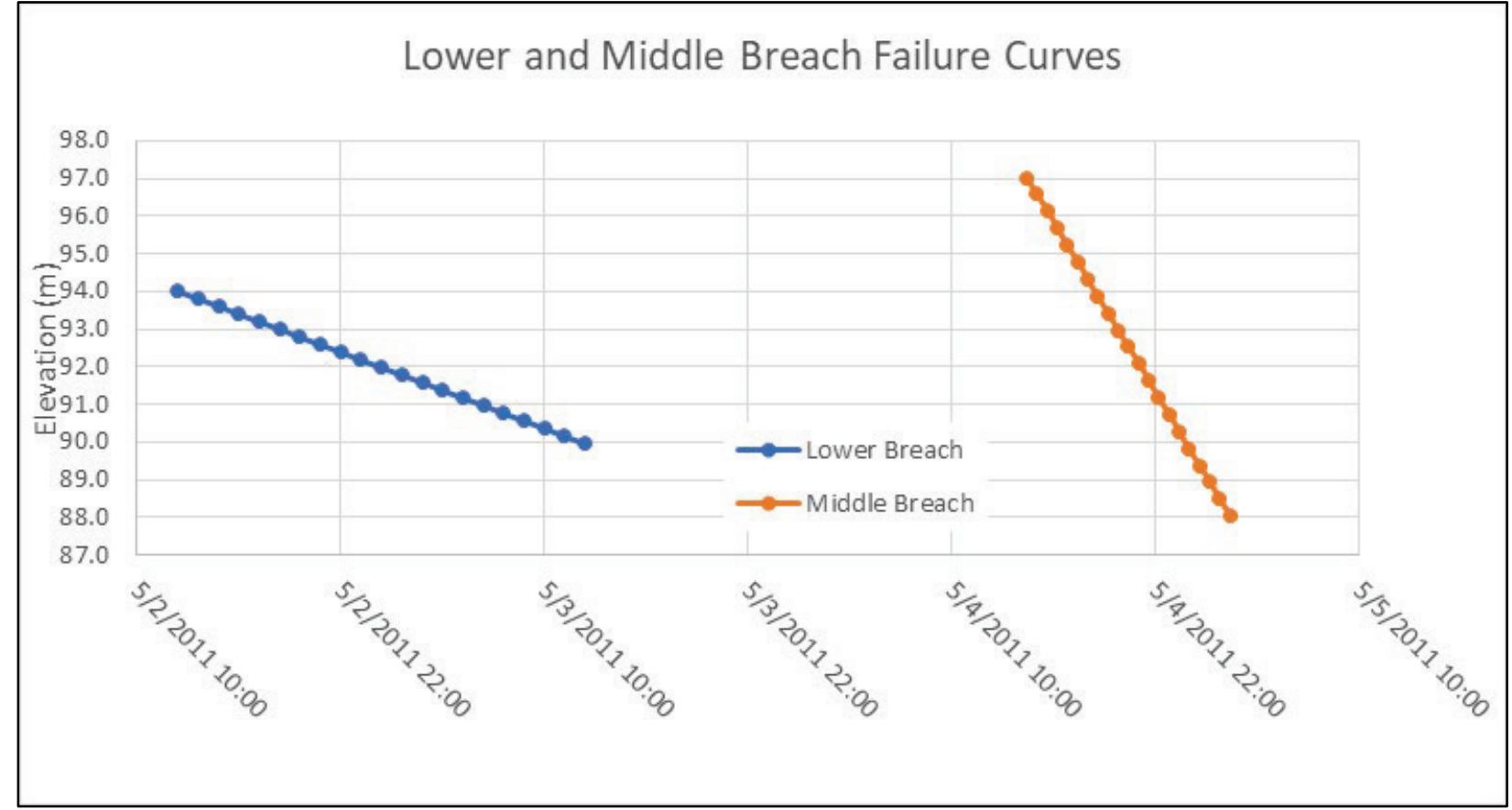


Figure 5-28. Flow through the BPNMF upper crevasse into the floodway for each Scenario, for the 2011 event.

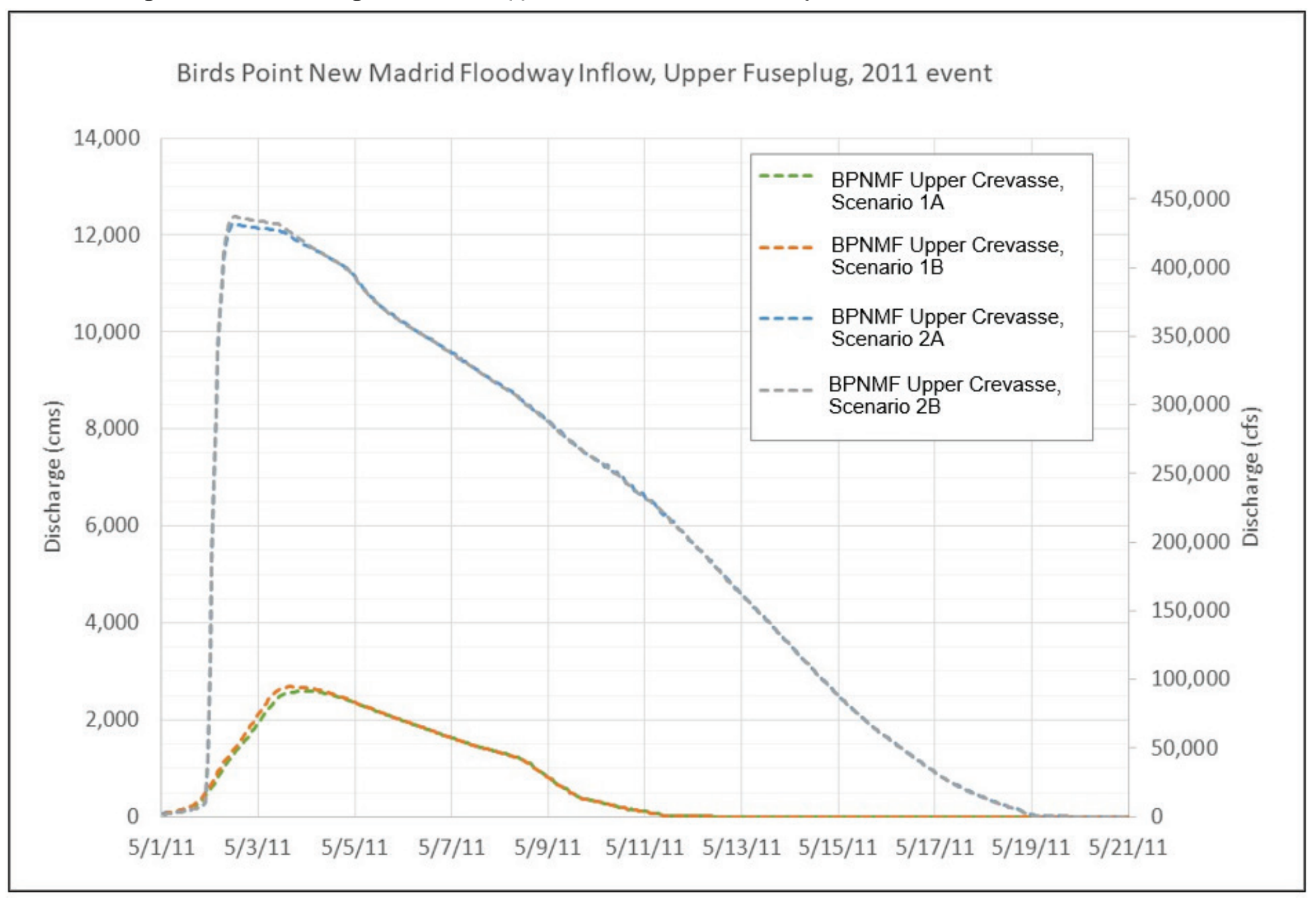




\section{Velocities at cross sections}

Velocity magnitudes at cross sections upstream, adjacent to, and downstream (shown on Figure 5-29) of the Birds Point upper crevasse were analyzed and are shown on Figure 5-30, Figure 5-31, and Figure 5-32.

Velocities near the Birds Point upper crevasse for all events were nearly identical when comparing Scenarios $1 \mathrm{~A}$ and $1 \mathrm{~B}$ (all events) and Scenarios 2A and 2B (2011 event). This means that the LS breach had virtually no effect on velocities in this reach of the Mississippi River.

The BPNMF was activated only for the 2011 event Scenario 2A and 2B runs. When BPNMF was operating, channel velocities at the upstream and adjacent cross sections were slightly higher, by between 0.1 and $0.25 \mathrm{~m} / \mathrm{s}$. For the adjacent cross-section, the spike in velocity $2,400 \mathrm{~m}$ from the left levee (Figure 5-30) for Scenarios 2A and 2B is the result of water flowing into the BPNMF. Velocities at the downstream cross section were lower when BPNMF was operating as a result of lower discharge at that cross section.

Figure 5-29. Locations of velocity analysis cross sections near BPNMF upper crevasse

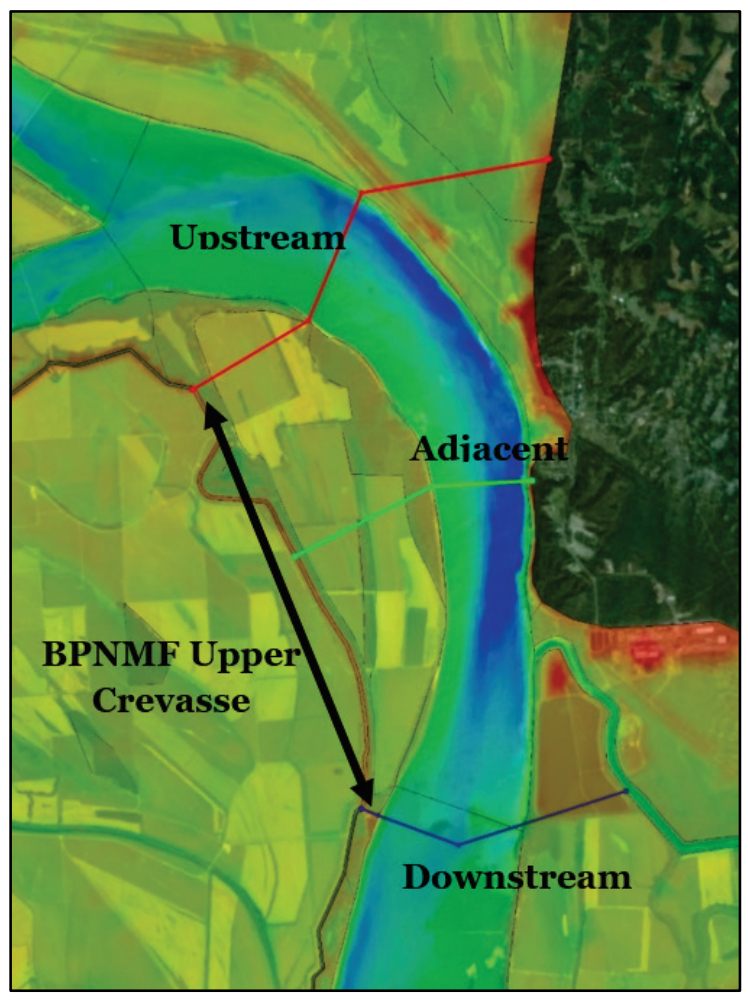


Figure 5-30. Velocity across the channel (looking downstream) for cross sections near the BPNMF upper crevasse, all scenarios, 5/3/2011 at 9:00 a.m. Note that the Scenario 1 and Scenario 2 profiles are nearly identical, thus plotted on top of one another.
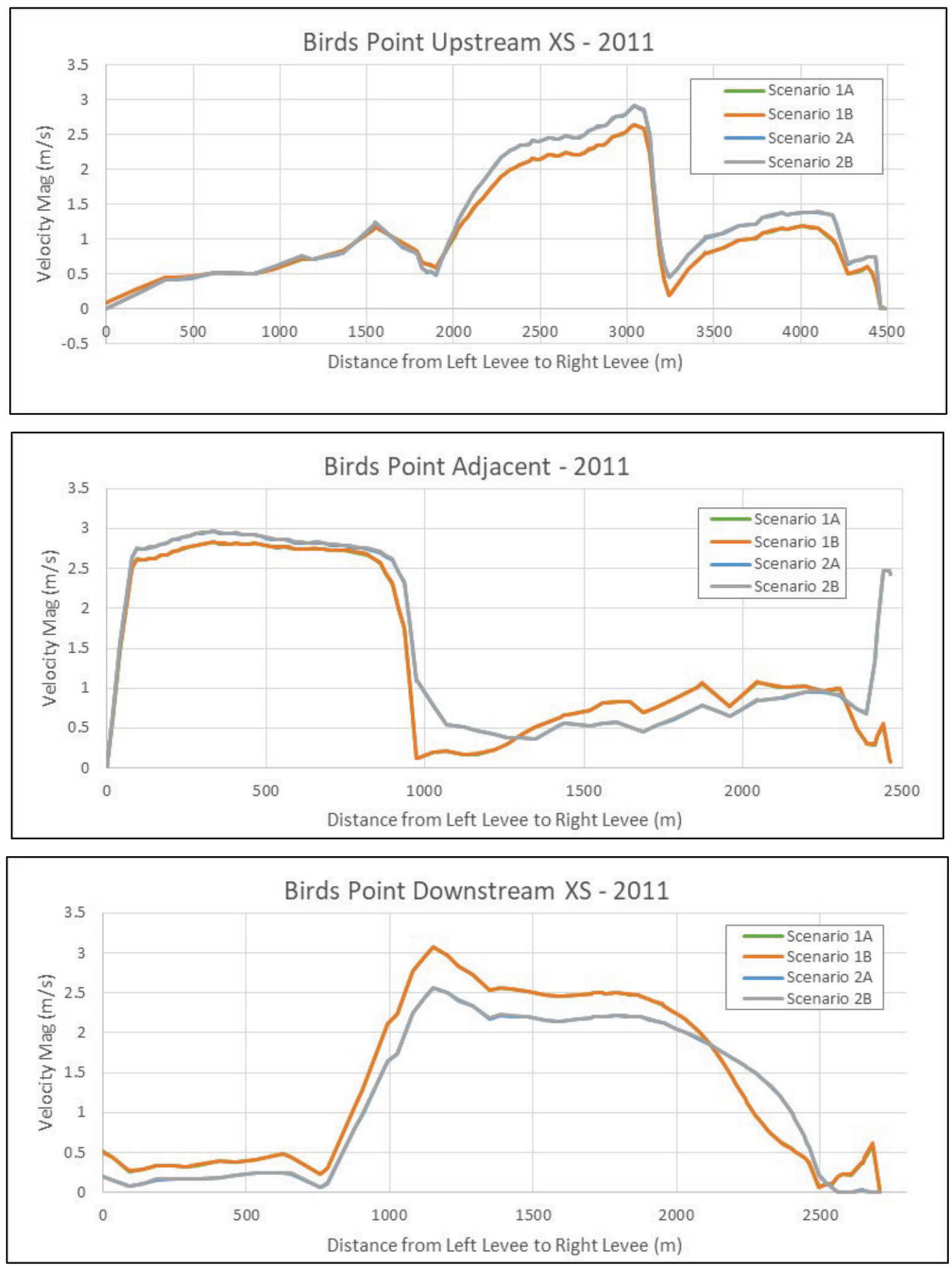
Figure 5-31. Velocity across the channel (looking downstream) for cross sections near the BPNMF upper crevasse, Scenarios 1A and 1B, 1/1/2016 at 9:00 p.m. Note that the profiles are nearly identical, thus plotted on top of one another.
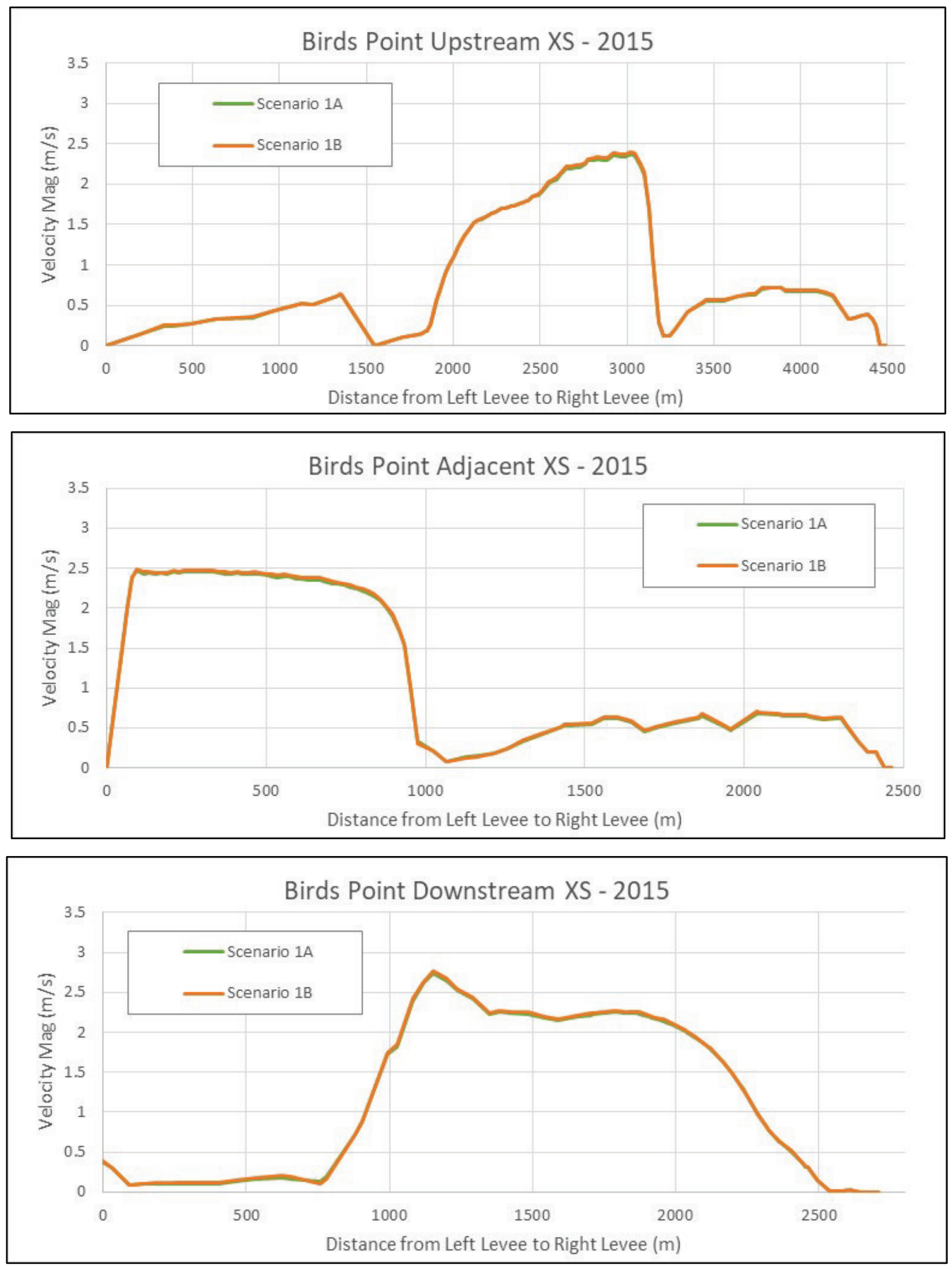
Figure 5-32. Velocity across the channel (looking downstream) for cross sections near the BPNMF upper crevasse, Scenarios 1A and 1B, 5/5/2017 at 9:00 p.m. Note that the profiles are nearly identical, thus plotted on top of one another.
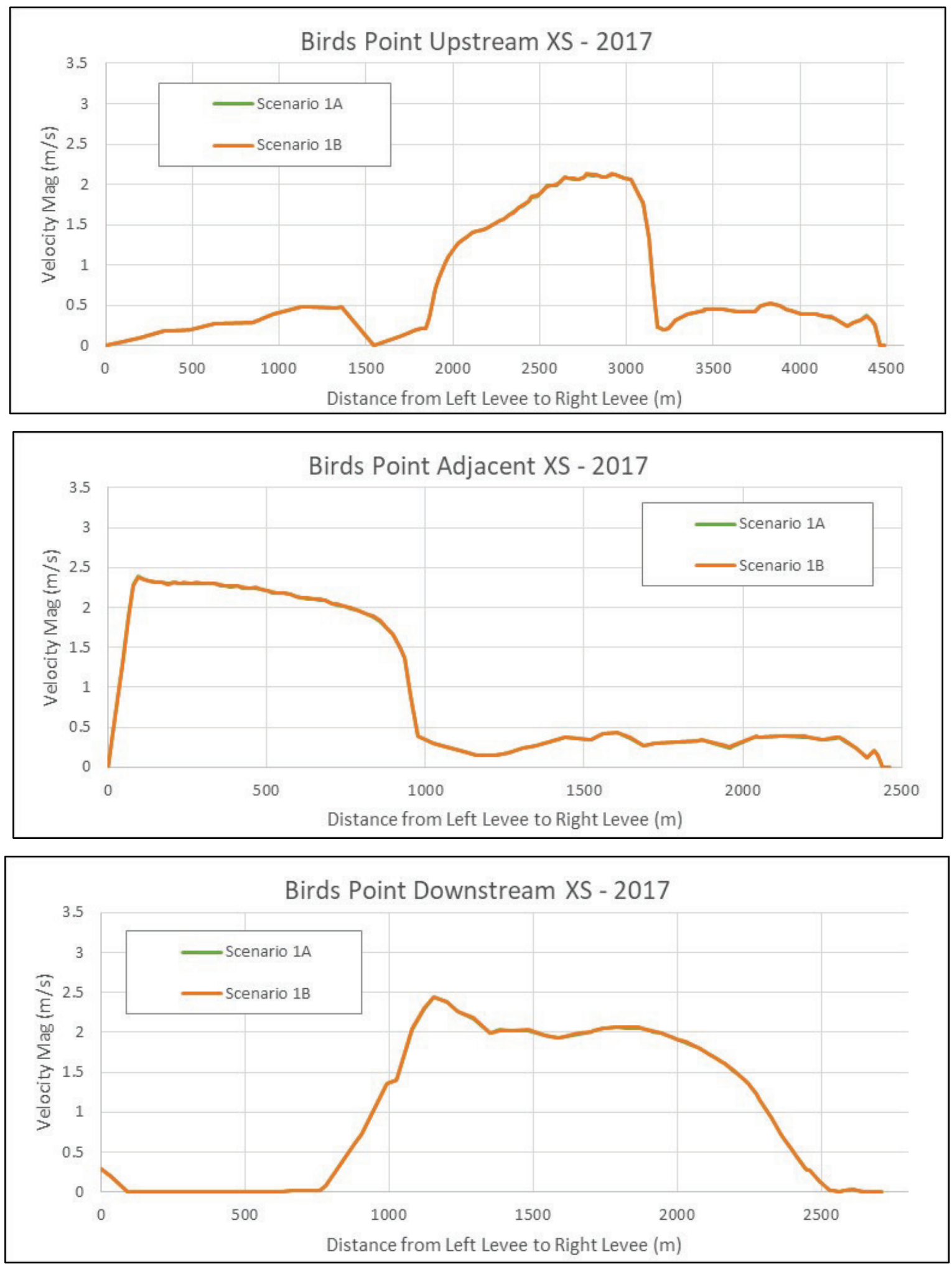


\section{Channel centerline velocity analysis}

Velocity magnitudes extracted from the Mississippi River channel centerline were analyzed near the time when maximum velocity occurred. Channel centerline velocities at this snapshot in time for each flood event are shown for the Mississippi River downstream of Wickliffe, KY, in Figure 5-33 through Figure 5-35.

As noted in the previous section, the LS breach (open or closed) had virtually no effect on velocities below the confluence as evidenced by comparisons of Scenario $1 \mathrm{~A}$ to $1 \mathrm{~B}$ (all events) and Scenario $2 \mathrm{~A}$ to $2 \mathrm{~B}$ (2011 event).

The BPNMF was only activated for the 2011 event Scenario 2A and 2B runs. When BPNMF was operating, velocities in the Mississippi River from the BPNMF upper crevasse to New Madrid, where water from the BPNMF re-enters, were lower (Figure 5-33) due to lower discharges in the reach. 
Figure 5-33. Velocity magnitude at the channel centerline for all scenarios, 5/3/2011 at 9:00 a.m.

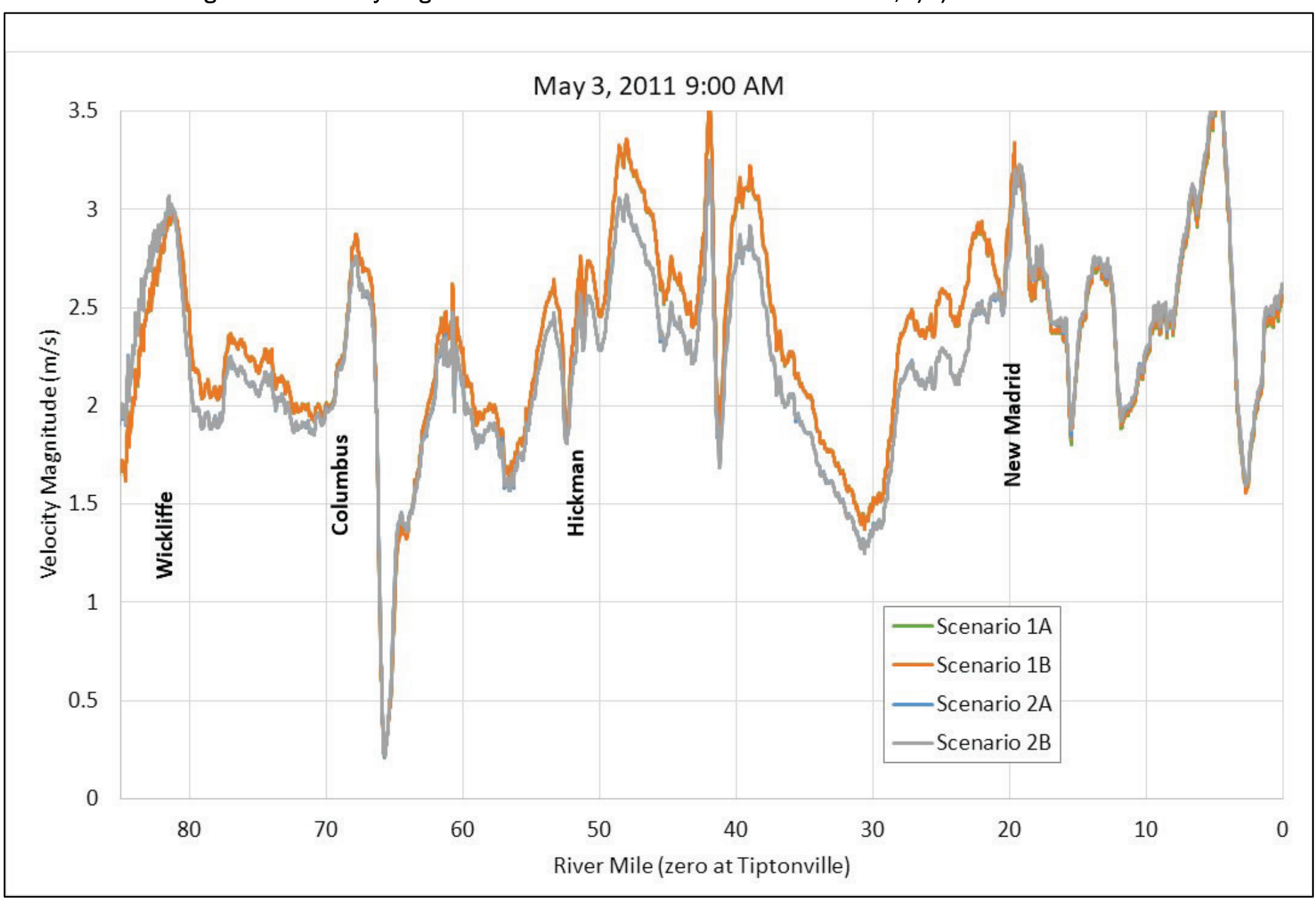


Figure 5-34. Velocity magnitude at the channel centerline for all scenarios, 1/1/2016 at 9:00 p.m.

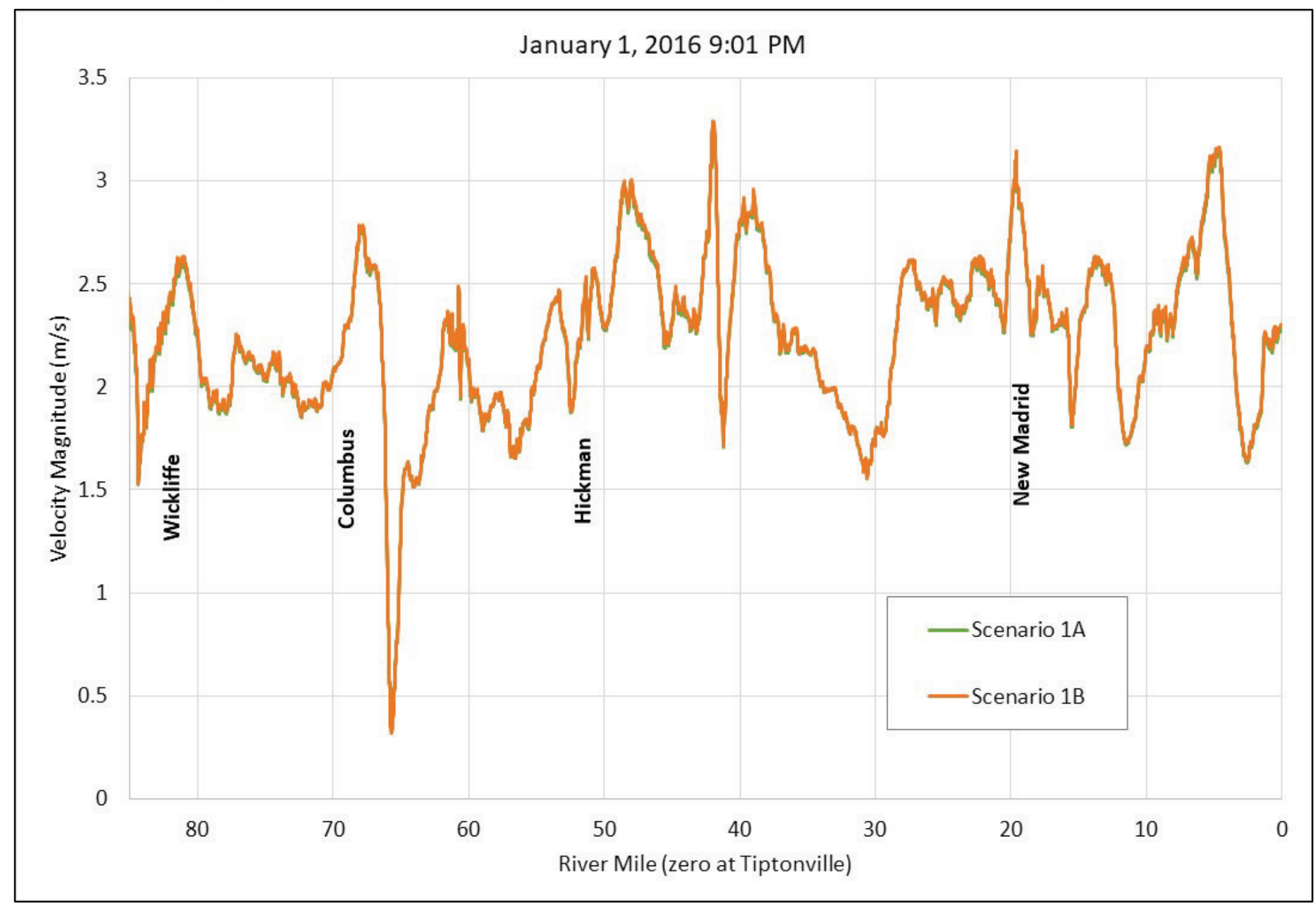


Figure 5-35. Velocity magnitude at the channel centerline for all scenarios, 5/5/2017 at 9:00 a.m.

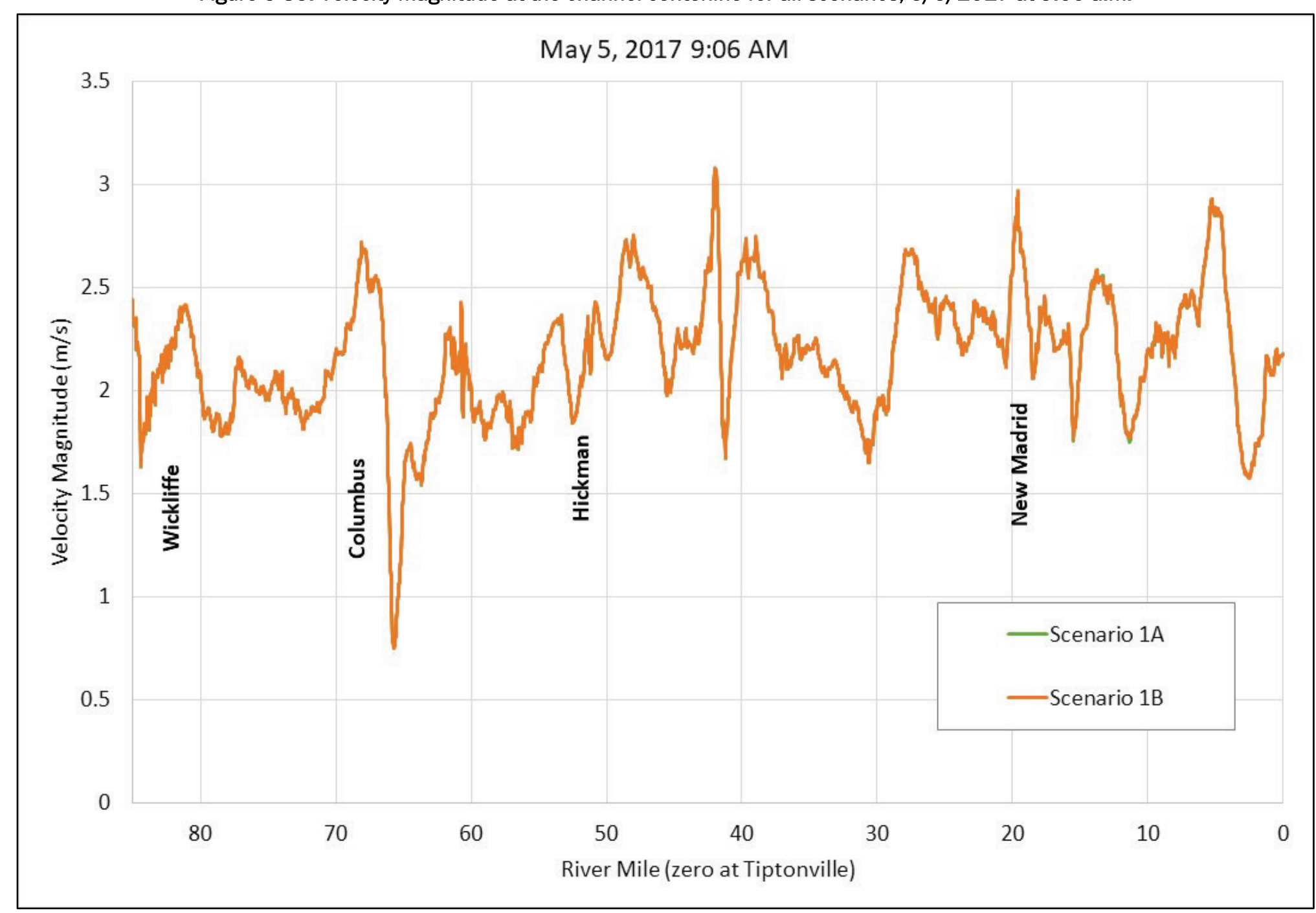




\section{Cross-current velocities}

Cross-current velocities near the BPNMF upper crevasse were computed (as described in the introduction of Chapter 5) for each model run. Two sail lines were utilized, one near the channel centerline and one near the right bank, closer to the BPNMF upper crevasse. The navigation channel within this reach is generally along the left descending bank. The stationing for analysis of the right bank sail is shown in Figure 5-36.

Figure 5-36 through Figure 5-38 show cross-current velocity magnitude (color contours) with velocity vectors for Scenario 1A (BPNMF not operating) for times near peak flows for the 2011, 2015, and 2017 events, respectively. The cross-current velocity for all years follows the same spatial pattern, with cross-current velocities generally less than $0.5 \mathrm{~m} / \mathrm{s}$. Figure 5-36 has two areas highlighted, one upstream and one downstream, where cross-current velocities are higher (between 0.5 and $0.9 \mathrm{~m} / \mathrm{s}$ ). The higher cross currents in the upstream box were due to the sail line crossing through the current from the Ohio River. The higher cross currents in the downstream box were due to the channel becoming wider with currents fanning out and becoming not parallel to the sail line. Figure 5-40 shows cross-current velocity extracted from the right bank sail line. Cross currents along the right bank were low, less than $0.4 \mathrm{~m} / \mathrm{s}$, as the BPNMF remains closed in Scenarios $1 \mathrm{~A}$ and $1 \mathrm{~B}$.

Figure 5-39 shows cross-current velocity magnitude (color contours) with velocity vectors for Scenario 2A, when the BPNMF is operating and LS is closed. A plot of Scenario 2B - BPNMF open and LS open is not shown since it was demonstrated that the LS breach has little effect on velocity downstream of the confluence. Cross currents in the channel were not markedly different when BPNMF is operating. Figure 5-41 shows crosscurrent velocity extracted from the right bank sail line. There was an increase in cross-current velocity between stations 2,500 and $3,100 \mathrm{~m}$, to a maximum of $0.5 \mathrm{~m} / \mathrm{s}$ near the right bank sail line.

Cross-current velocities near the BPNMF lower crevasse and gap outflow for Scenario 2A (BPNMF operating) are shown on Figure 5-42. Cross currents greater than $0.5 \mathrm{~m} / \mathrm{s}$ due to floodway outflow were evident in the channel only within $60 \mathrm{~m}$ (196.8 ft) of the right bank below the lower crevasse and within $300 \mathrm{~m}(984 \mathrm{ft})$ of the outflow of St. Johns Bayou. 
Figure 5-36. Scenario $1 A$ velocity vectors and cross-stream velocity magnitude contours at $5 / 3 / 2011$ at 9:00 a.m. Sail lines shown in magenta - one mid-channel and one near the right bank. Distances along the left bank sail line are shown for profile analysis. Cross-current velocities in the magenta boxes are discussed.

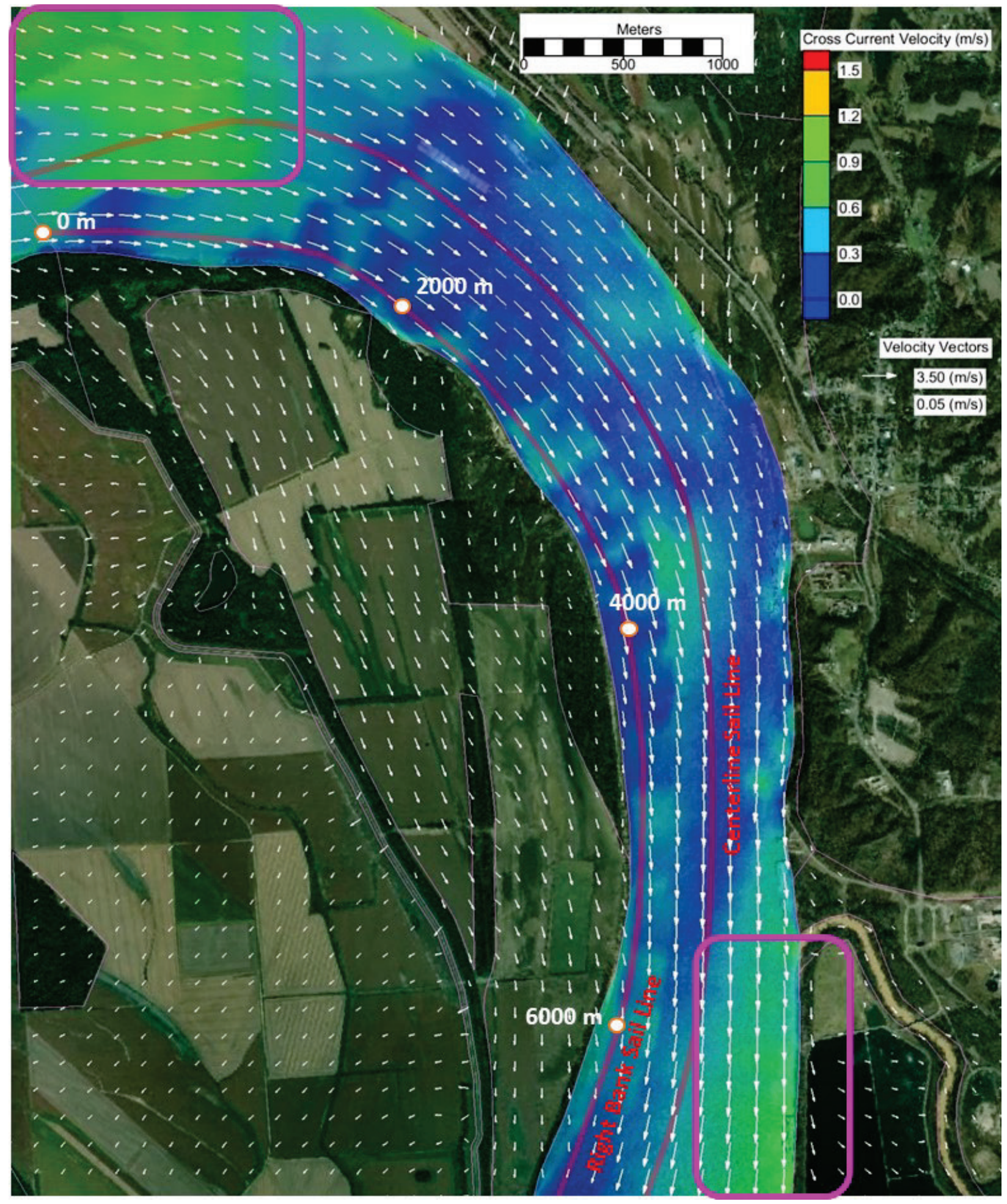


Figure 5-37. Scenario $1 \mathrm{~A}$ velocity vectors and cross-stream velocity magnitude contours at $1 / 1 / 2016$ at 9:00 p.m. Sail lines shown in magenta - one mid-channel and one near the right bank.

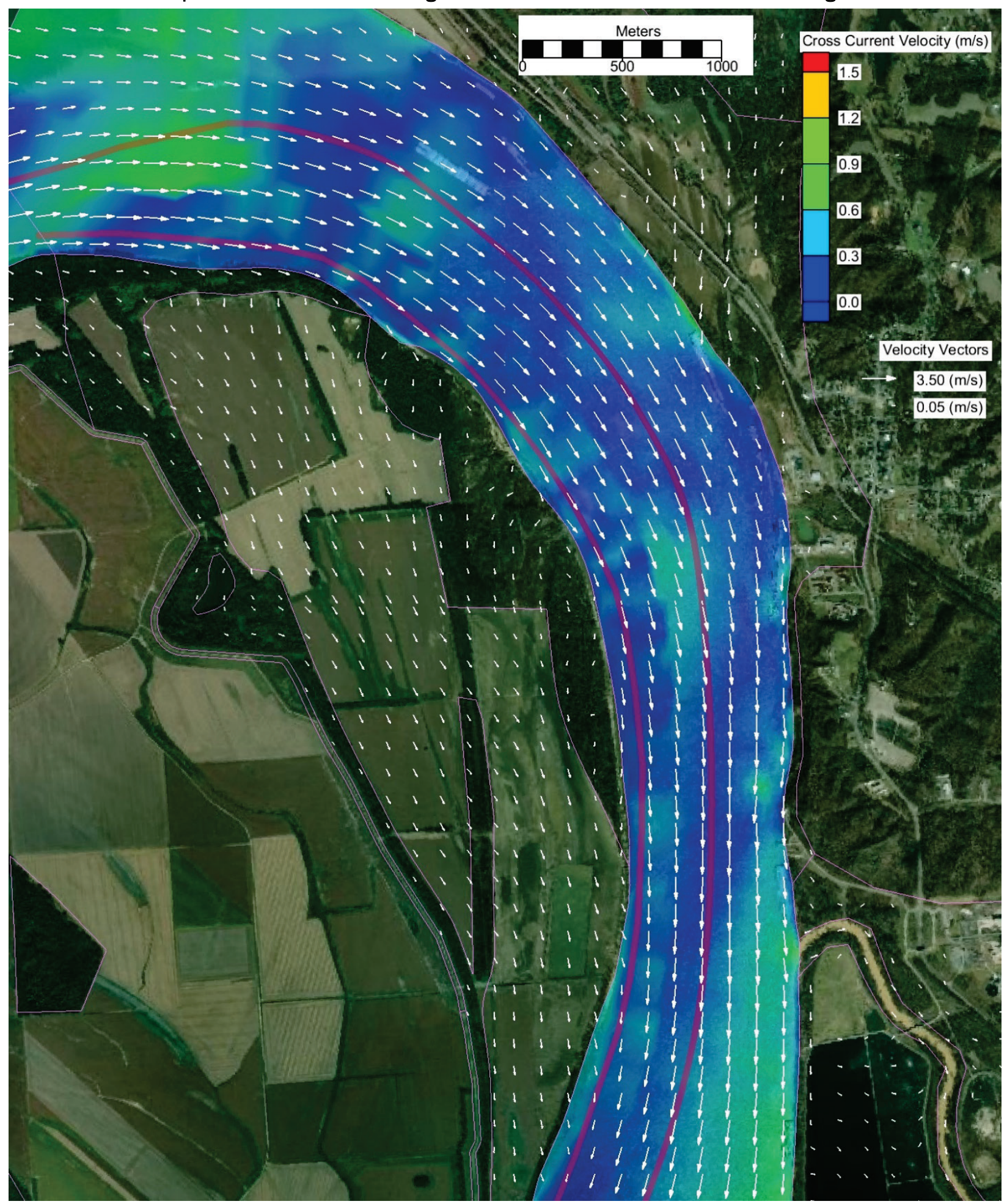


Figure 5-38. Scenario $1 A$ velocity vectors and cross-stream velocity magnitude contours at $5 / 5 / 2017$ at 9:00 a.m. Sail lines shown in magenta - one mid-channel and one near the right bank.

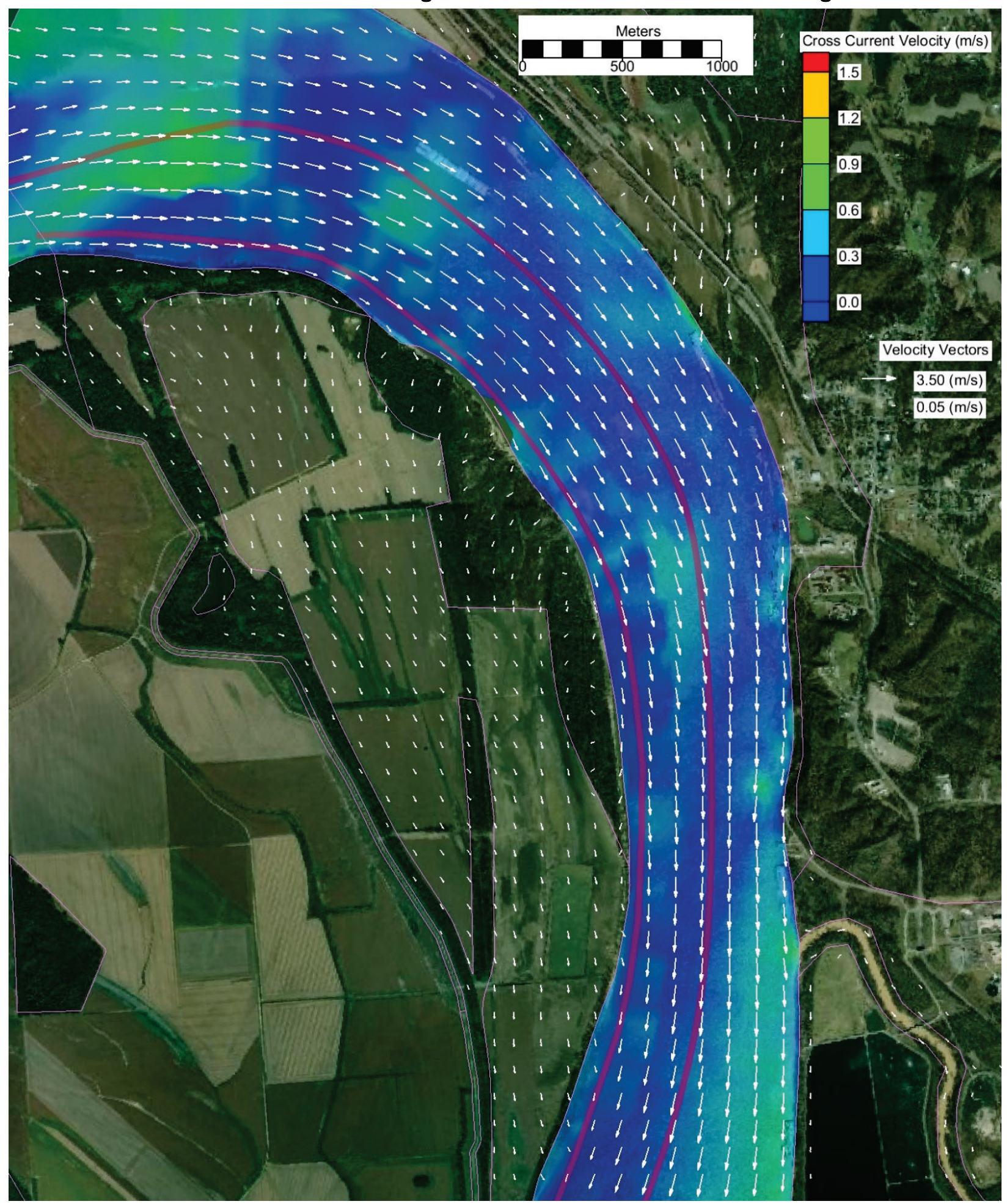


Figure 5-39. Scenario $2 A$ velocity vectors and cross-stream velocity magnitude contours at $5 / 3 / 2011$ at 9:00 a.m. Sail lines shown in magenta - one mid-channel and one near the right bank.

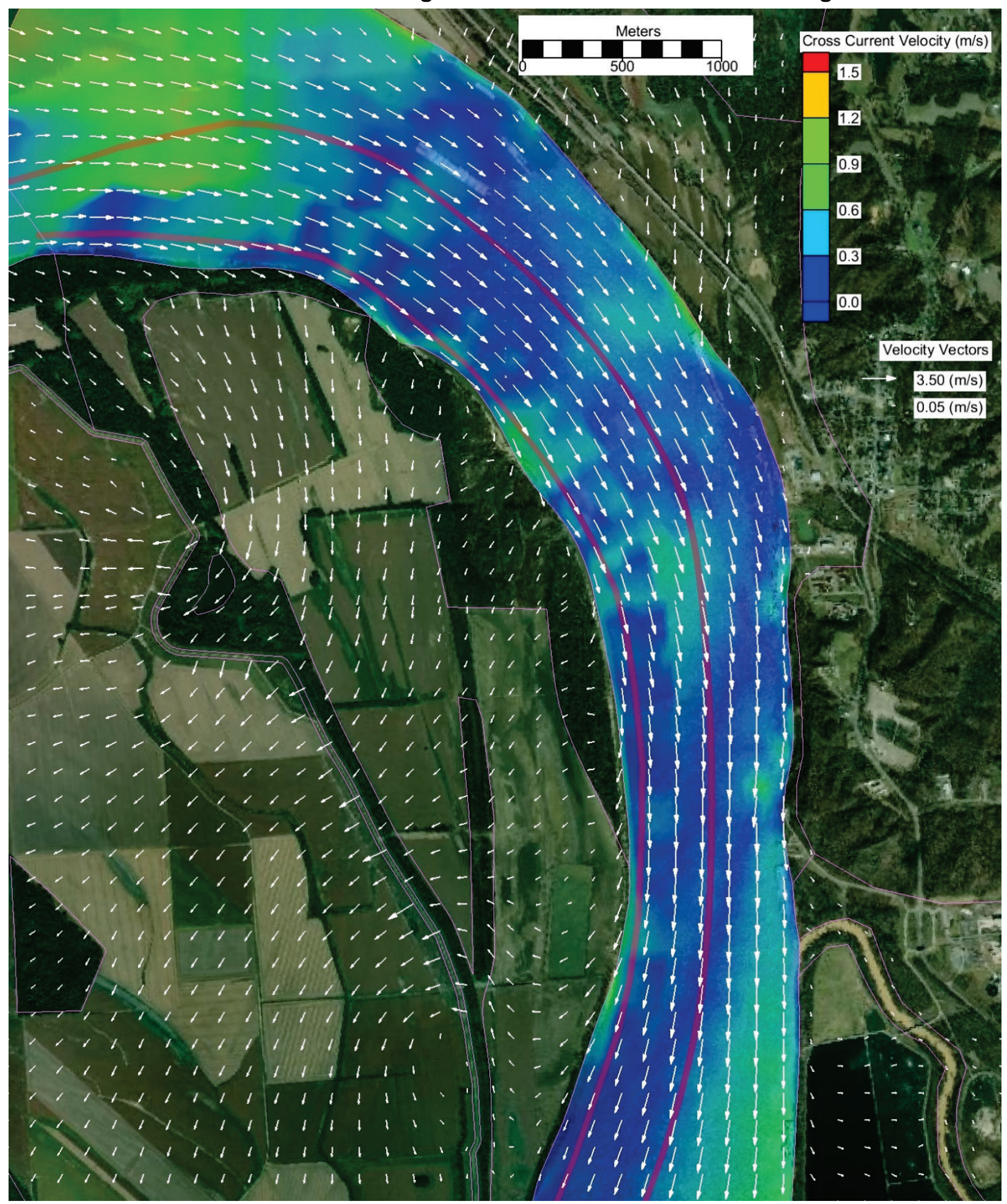


Figure 5-40. Cross-current velocity magnitude near the BPNMF upper crevasse along the right bank sail line (upstream end is distance zero) for Scenario 1A, at the velocity peak for each year.

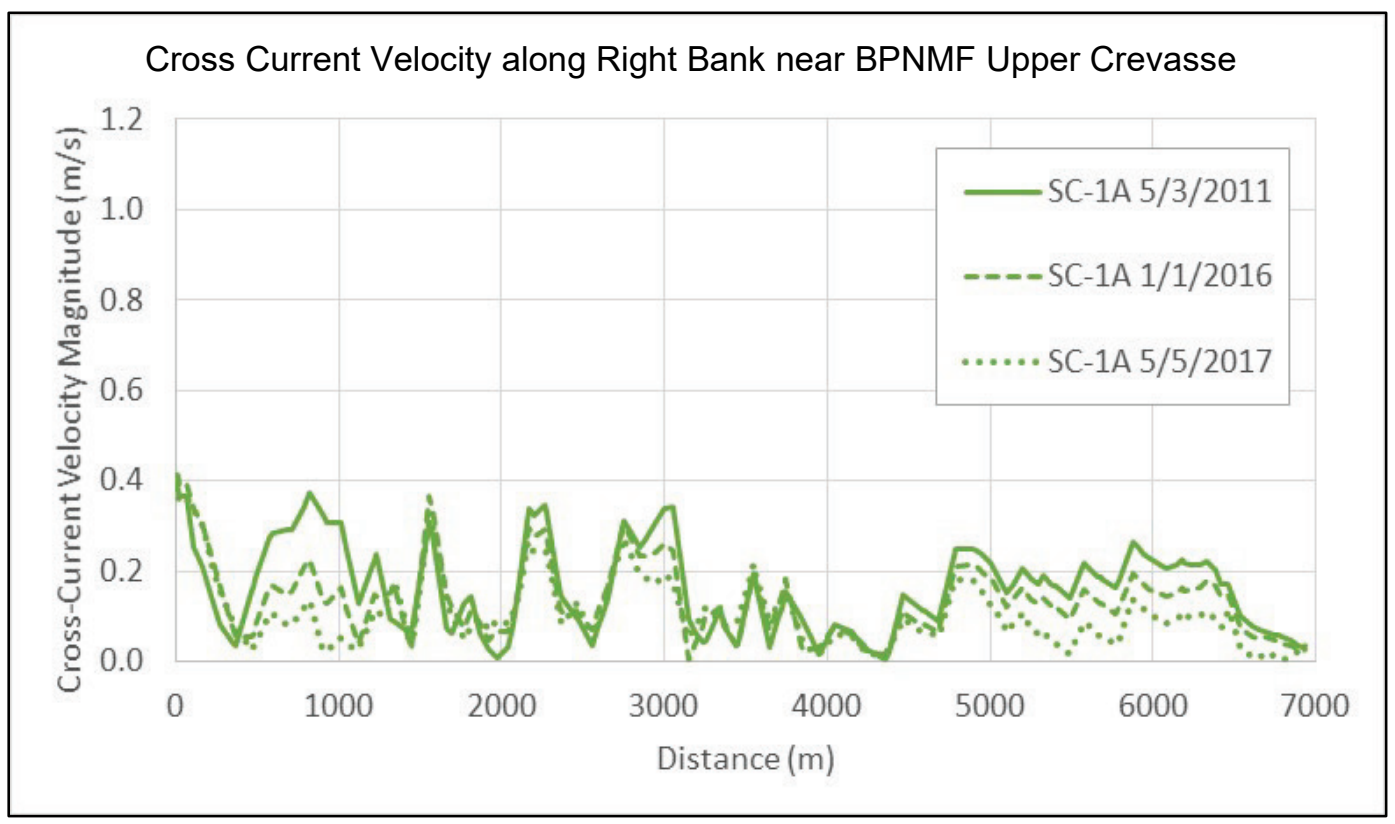

Figure 5-41. Cross-current velocity magnitude near the BPNMF upper crevasse along the right bank sail line (upstream end is distance zero) for each scenario, 5/3/2011. Note: Scenarios $1 \mathrm{~A}$ and $1 \mathrm{~B}$ and $2 \mathrm{~A}$ and $2 \mathrm{~B}$ are nearly identical.

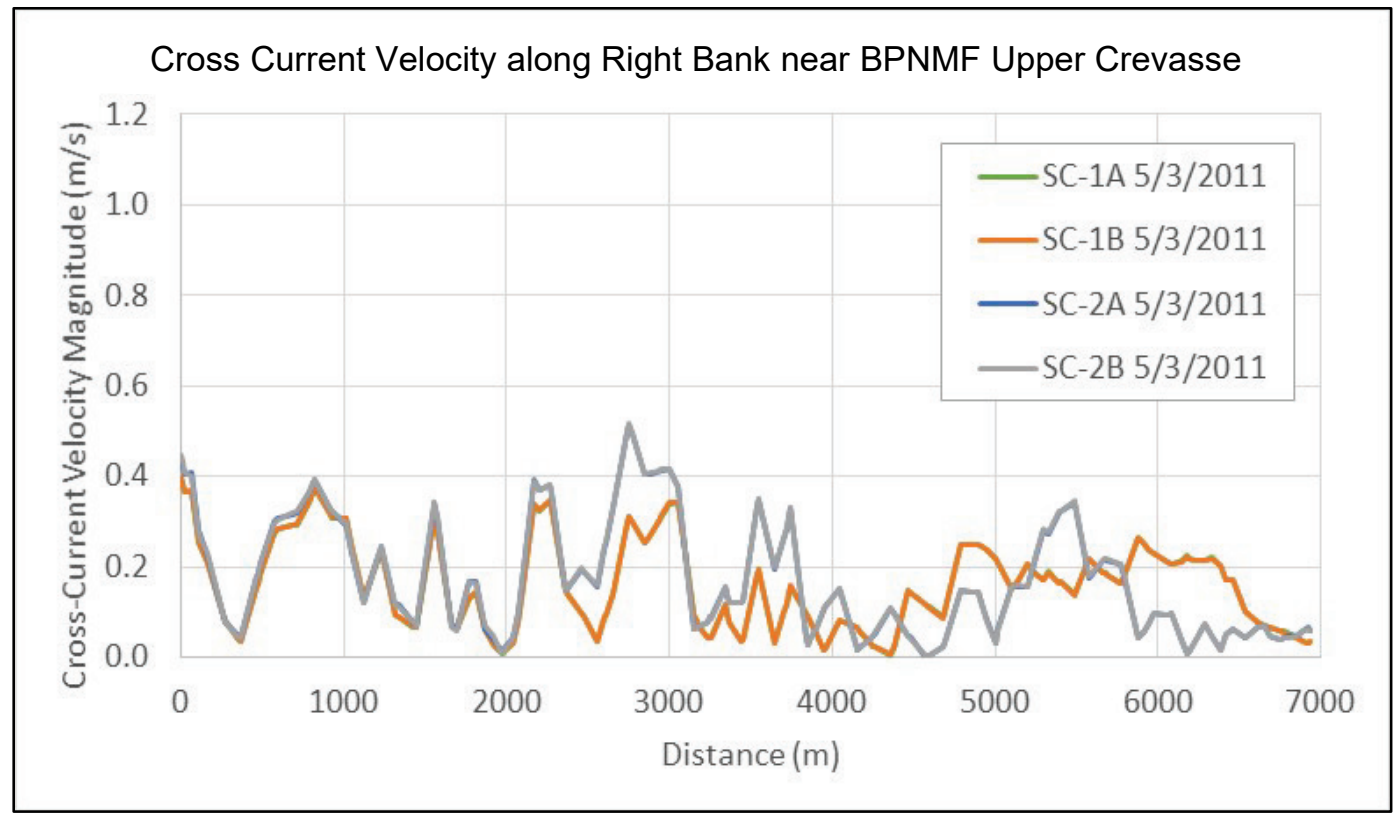


Figure 5-42. Scenario $2 A$ velocity vectors and cross-stream velocity magnitude contours on 5/6/2011 at 7:00 p.m., near peak BPNMF outflow, lower crevasse. Sail line is shown in magenta - mid-channel.

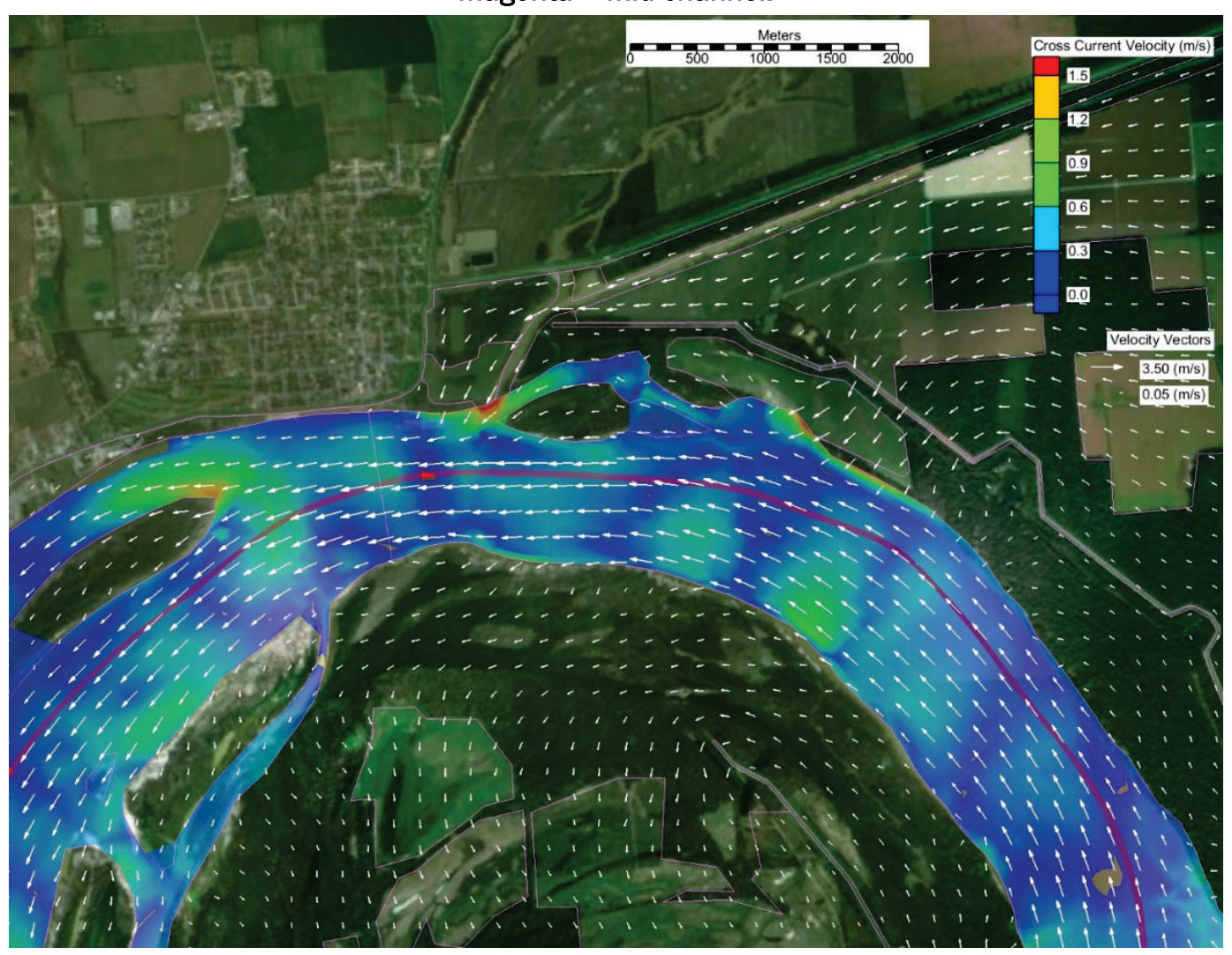

\section{Current patterns}

Current patterns near the BPNMF upper crevasse for Scenario 1A (Scenario 1B patterns are nearly identical) are shown in Figure 5-43 through Figure 5-45. Near the BPNMF, velocities in the channel were generally aligned with the channel direction. Maximum velocities for the 2011 event were generally $3.1 \mathrm{~m} / \mathrm{s}(10.2 \mathrm{ft} / \mathrm{s})$. Current patterns were similar for the 2015 and 2017 events, but with lower velocities.

Current patterns near the BPNMF upper crevasse for Scenario 2A (Scenario 2B patterns are nearly identical) are shown in Figure 5-46. Currents in the channel were still generally oriented in the streamwise direction. Currents in the right overbank near the upper crevasse bend sharply towards the open floodway. 
Figure 5-43. Velocity contours and vectors in the vicinity of the BPNMF upper crevasse, for Scenario 1A, 5/3/2011 at 9:00 a.m.

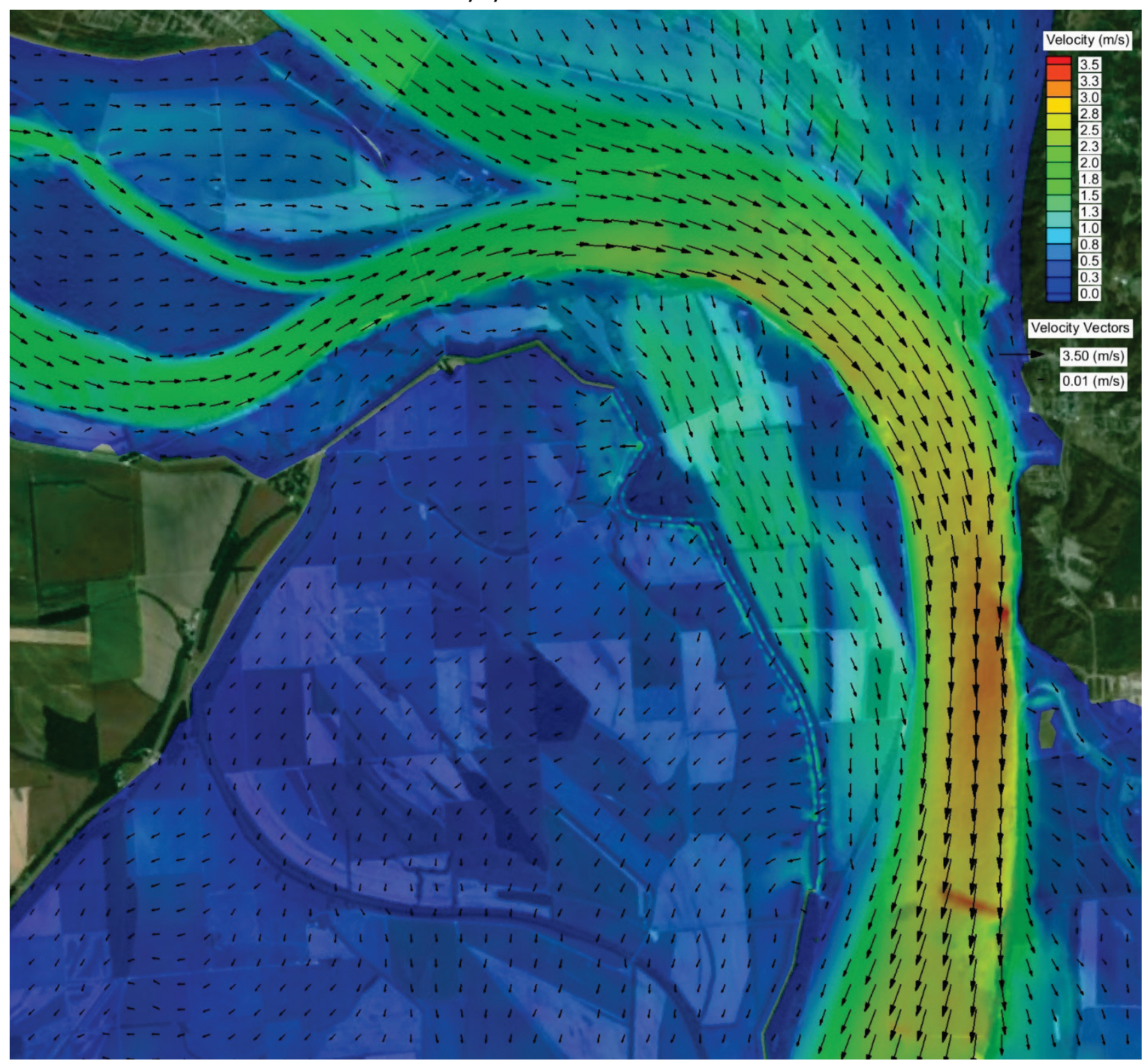


Figure 5-44. Velocity contours and vectors in the vicinity of the BPNMF upper crevasse, for Scenario $1 \mathrm{~A}$, 1/1/2016 at 9:00 p.m.

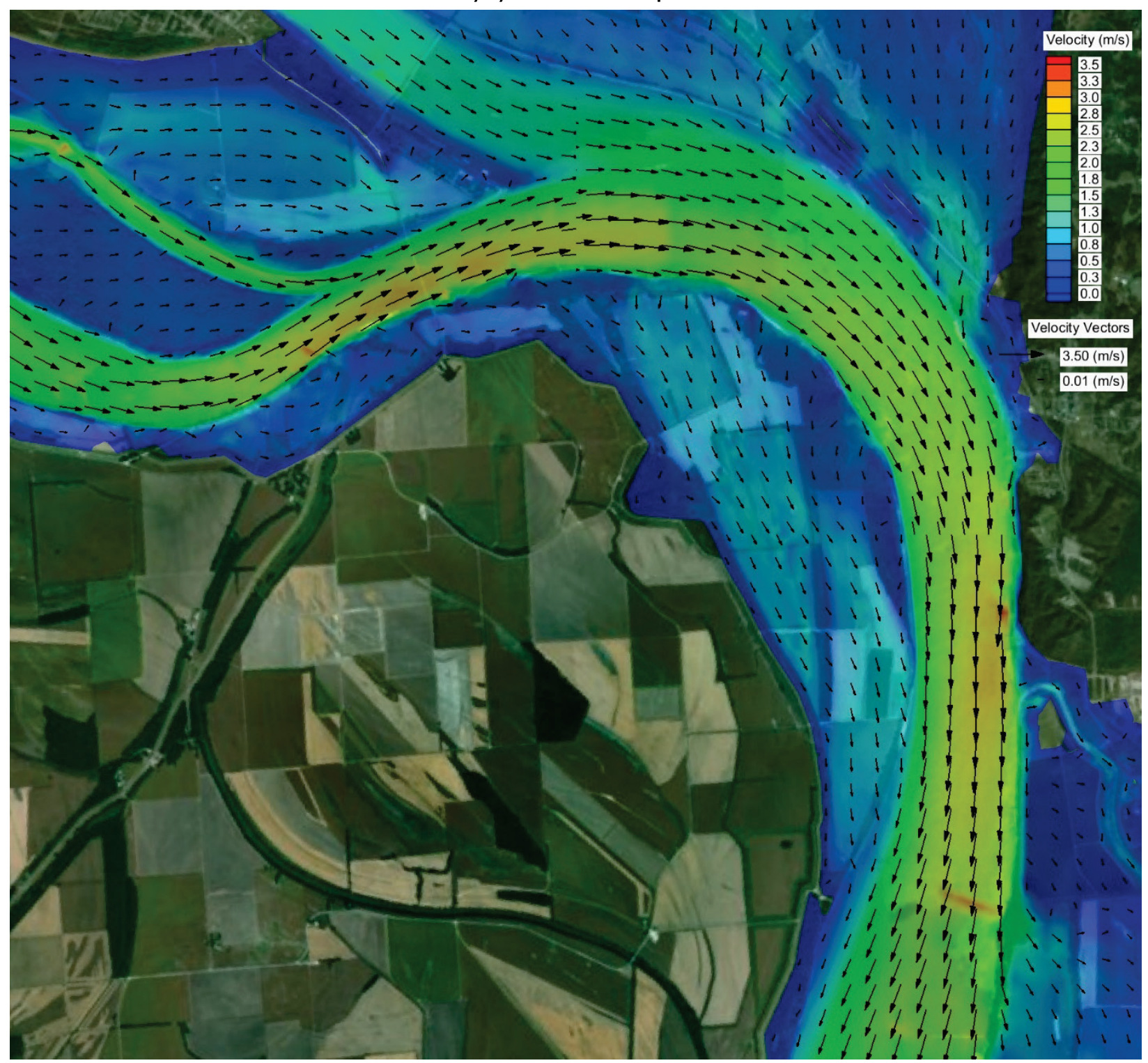


Figure 5-45. Velocity contours and vectors in the vicinity of the BPNMF upper crevasse, for Scenario $1 \mathrm{~A}$, 5/5/2017 at 9:00 a.m.

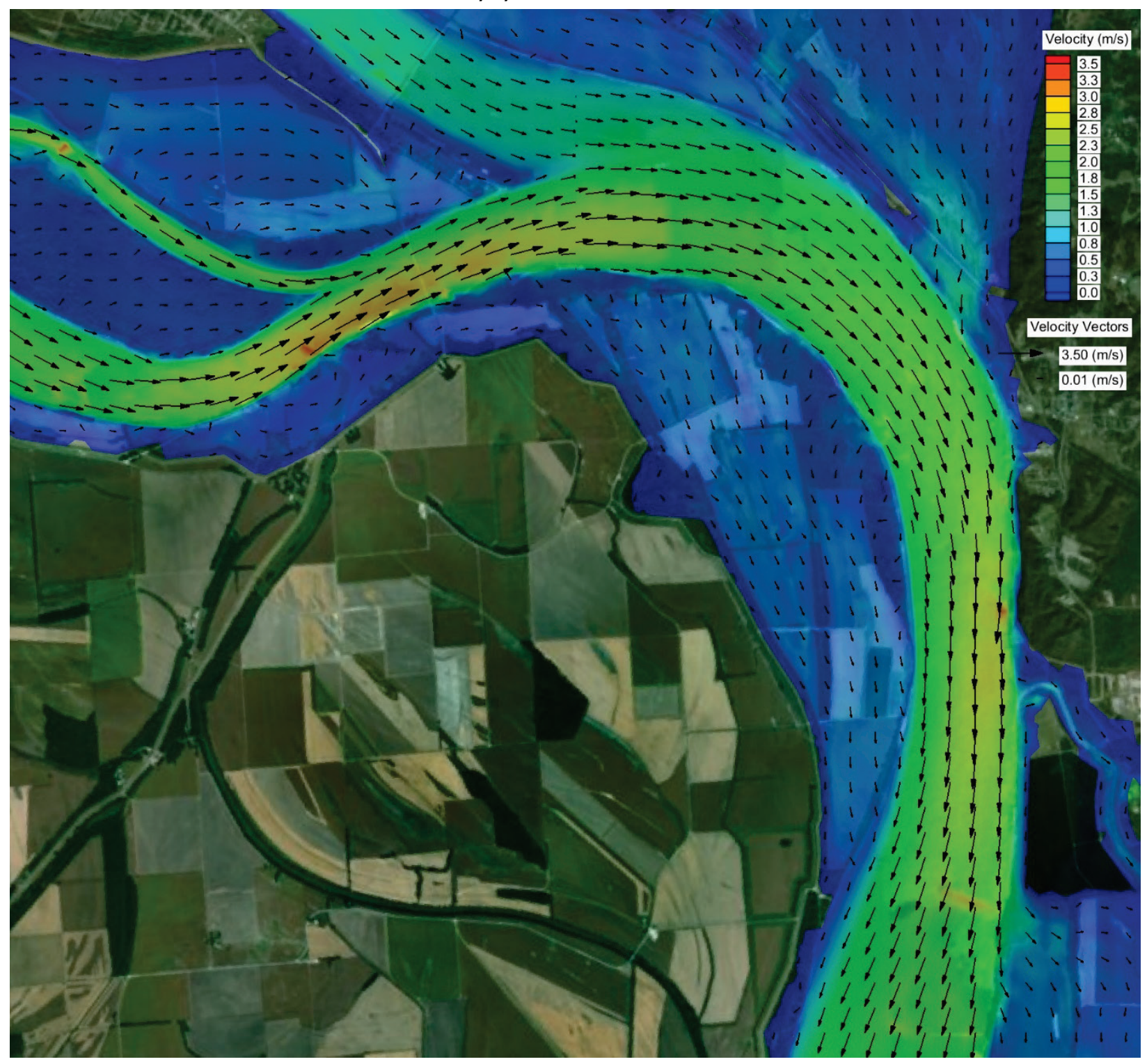


Figure 5-46. Velocity contours and vectors in the vicinity of the BPNMF upper crevasse, for Scenario $2 \mathrm{~A}$, 5/3/2011 at 9:00 a.m.

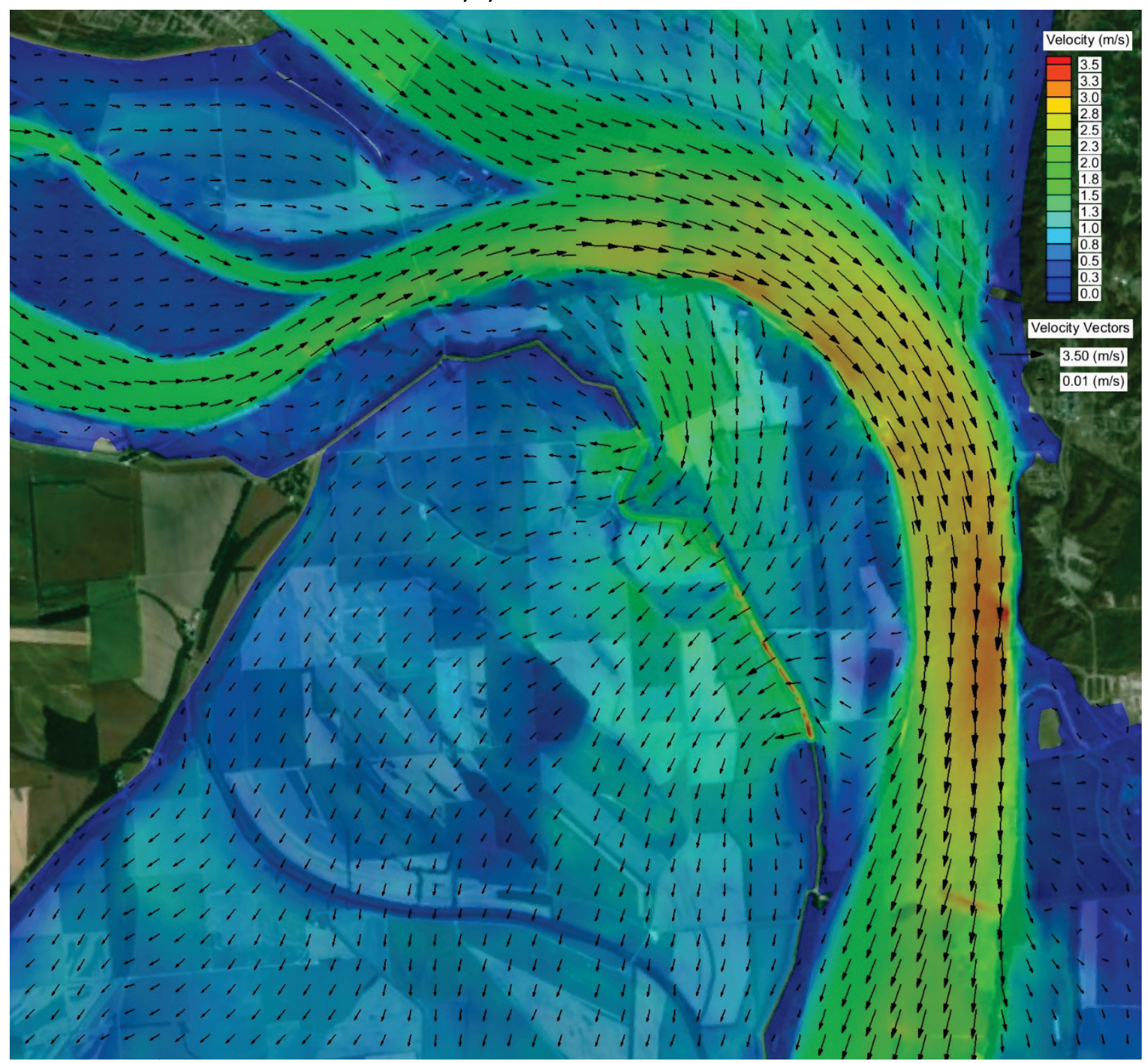




\section{BPNMF area velocity summary}

With respect to navigation issues, the primary results of analysis of velocities associated with the BPNMF breach include the following:

- Increased channel velocities were observed upstream of the breach extending to Commerce on the Upper Mississippi River and typically ranged from $0.2 \mathrm{~m} / \mathrm{s}(0.66 \mathrm{ft} / \mathrm{s})$, up to $0.5 \mathrm{~m} / \mathrm{s}(1.6 \mathrm{ft} / \mathrm{s})$ higher in the reach near Thompson Landing.

- Decreased channel velocities were observed from the breach to New Madrid and typically were $0.15 \mathrm{~m} / \mathrm{s}(0.49 \mathrm{ft} / \mathrm{s})$ lower from the breach to Hickman and $0.2-0.4 \mathrm{~m} / \mathrm{s}(0.66-1.31 \mathrm{ft} / \mathrm{s})$ lower from Hickman to New Madrid.

- Cross currents in the Mississippi River main channel near the BPNMF as a result of activation were less than $0.5 \mathrm{~m} / \mathrm{s}(1.6 \mathrm{ft} / \mathrm{s})$.

- Cross currents of greater than $0.5 \mathrm{~m} / \mathrm{s}(1.6 \mathrm{ft} / \mathrm{s})$ due to floodway outflow were evident in the Mississippi River main channel only within $100 \mathrm{~m}$ (328 ft) of the right descending bank near the BPNMF lower crevasse and within $300 \mathrm{~m}$ (984 ft) of the lower BPNMF opening.

Figure 5-47 (Upper Mississippi) and Figure 5-48 (Lower Mississippi) display the difference in velocity between Scenarios 2A and 1A (BPNMF activated and not), calculated as Scenario 2A minus 1A. Red colors indicate an increase in velocity for Scenario 2A, blue colors a decrease. This provides an illustration of the increase in velocity above the BPNMF when activated and the corresponding decrease in velocities from Wickliffe, KY, to New Madrid, MO.

The LS breach does not affect velocities below the Mississippi - Ohio River confluence. 
Figure 5-47. Difference in velocity between Scenarios $2 A$ and $1 A$ (calculated as $2 A$ minus $1 A$ ) for 5/3/2011 at 9:00 a.m.

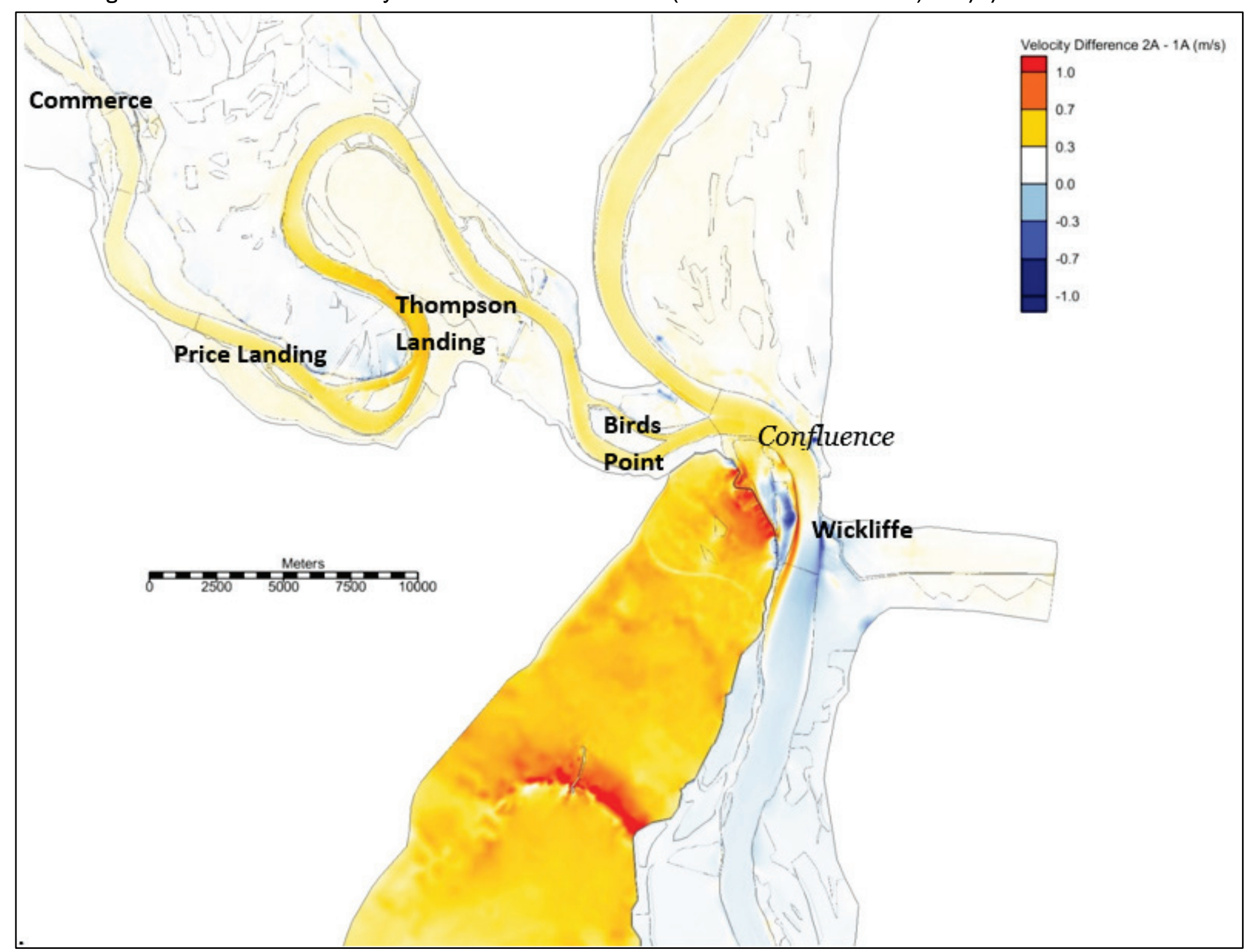


Figure 5-48. Difference in velocity between Scenarios $2 A$ and $1 A$ (calculated as $2 A$ minus $1 A$ ) for 5/3/2011 at 9:00 a.m.

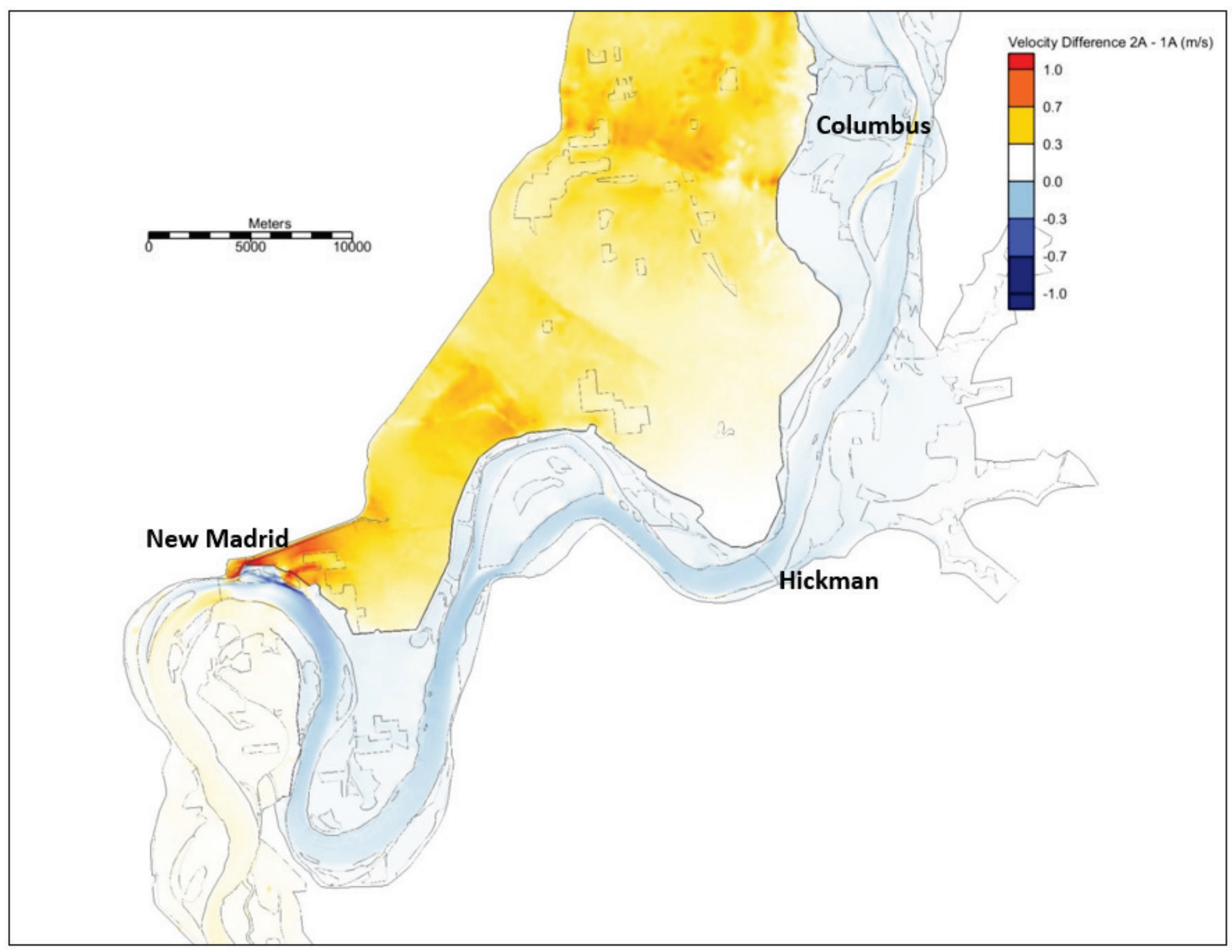




\section{Conclusions}

A numerical, 2D hydrodynamic model of the Mississippi River, from Thebes, IL, to Tiptonville, TN, was developed using AdH. The calibrated AdH model reasonably represented hydrodynamics in the system and was capable of simulating current patterns and flow distributions within the modeled reach. Flow distributions associated with the BPNMF and LS levee breach were of particular interest in the study.

The model was constructed using elevation data from the USACE and USGS. Two seamless DEMs with both channel and floodplain elevation data were used as the basis for model elevations. Detailed elevation data for levee crests and structures in the river (dikes and weirs) were superimposed to create an accurate elevation model. Bathymetric surveys of the Upper Mississippi River were utilized to update model elevations to the appropriate simulation period.

The model was developed and run for three simulation periods: the floods of 2011, 2015-2016, and 2017. Discharge data for the Upper Mississippi model boundary was taken from the USGS gage at Thebes, IL. Discharge data for the Ohio River model boundary at Metropolis, IL, came from the USACE Mississippi River Flowline model and the USGS gage at Olmsted, IL. Stage data for the downstream boundary at Tiptonville, TN, and for nine stations in the study reach, were available from the USACE. Velocity and discharge data from the USGS were abundant during the 2011 flood event; however, a limited number of discharge measurements were available for the LS levee breach. It is recommended that additional discharge measurements be obtained to monitor and assess response of the Mississippi River near the LS breach.

The model was calibrated to stage, discharge, and velocity data for the three flood events. The model is not calibrated for low flows. The average RMS error for river stages was $0.26 \mathrm{~m}$ ( $0.85 \mathrm{ft}$ ), for an rRMS error of 4.8\%. The rRMS error for discharge into the BPNMF through the upper crevasse was $12 \%$, with a Nash-Sutcliffe Model Efficiency of 0.90. The average RMS error for velocity was $0.43 \mathrm{~m} / \mathrm{s}(1.41 \mathrm{ft} / \mathrm{s})$, with an rRMS error of $11 \%$. Numerical values of model results should be expressed with their calculated uncertainty bounds, which are based on the uncertainty of the 
model and observed data. Uncertainties were calculated to be $\pm 0.26 \mathrm{~m}$ ( $0.85 \mathrm{ft}$ ), or $\pm 4.8 \%$, for stage; $\pm 15 \%$ for velocity; and $\pm 19 \%$ for discharge. Uncertainty for Base-to-Plan assessments were estimated as one-half of those values. To improve model calibration, all stream gages should be resurveyed to establish gage zero elevations in NAVD88.

The model software could be improved by implementing variable Manning's roughness in time to account for the loop effect and improve simulated stage on the falling limb of the floods. Also, further assessments of the discharge measurements near the LS levee are recommended. At the time of this report, only a portion of the raw ADCP data were available. Basic analysis of these data showed that critical discharge estimates from ADCP measurements have a high level of uncertainty. As the discharge through the LS breach was of particular interest, more rigorous analysis of ADCP data taken from this area is warranted. Model results for discharge through the LS breach fall within the uncertainty bounds of the observed data.

The calibrated model was used to run four cases, for the flood events specified:

1. Scenario 1A: No break in MC-LS levee and no BPNMF operation; for all three flood events

2. Scenario 1B: Open MC-LS levee and no BPNMF operation; for all three flood events

3. Scenario 2A: No break in MC-LS levee and with BPNMF operation; for the 2011 event

4. Scenario 2B: Breach in MC-LS levee with BPNMF operation; for the 2011 event.

Scenario hydrodynamic results were analyzed for all scenarios with an eye toward navigational interests. Discharges through open/activated breaches were tabulated, and channel velocity magnitudes along the channel centerline and at key channel cross sections were analyzed. Current patterns and differences were analyzed. Also, cross-currents in navigational areas near the breaches were analyzed.

With respect to navigation concerns, analysis of the velocity patterns associated with the LS breach provided the following results: 
- Increased velocities were observed upstream of the breach extending to Commerce in a range typically between $0.2-0.3 \mathrm{~m} / \mathrm{s}(0.66-0.98$ $\mathrm{ft} / \mathrm{s})$.

- Decreased velocities were observed from LS to Thompson Landing in a range typically $0.5 \mathrm{~m} / \mathrm{s}(1.6 \mathrm{ft} / \mathrm{s})$ to as much as $1.0 \mathrm{~m} / \mathrm{s}(3.28 \mathrm{ft} / \mathrm{s})$ lower.

- Cross-current velocities were greater than $1.0 \mathrm{~m} / \mathrm{s}(3.28 \mathrm{ft} / \mathrm{s})$ in the

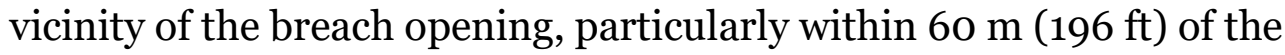
bankline revetment.

- Activation of the BPNMF results in higher velocities in the Upper Mississippi River, the difference gradually decreasing moving upstream from the BPNMF.

With respect to navigation issues, the primary results of analysis of velocities associated with the BPNMF activation include the following:

- Increased channel velocities were observed upstream of the upper crevasse breach extending to Commerce on the Upper Mississippi River and typically ranged from $0.2 \mathrm{~m} / \mathrm{s}(0.66 \mathrm{ft} / \mathrm{s})$, up to $0.5 \mathrm{~m} / \mathrm{s}(1.6$ $\mathrm{ft} / \mathrm{s}$ ) higher in the reach near Thompson Landing.

- Decreased channel velocities were observed from the Lower crevasse breach to New Madrid and typically were $0.15 \mathrm{~m} / \mathrm{s}$ lower $(0.49 \mathrm{ft} / \mathrm{s})$ from the breach to Hickman and $0.2-0.4 \mathrm{~m} / \mathrm{s}(0.66-1.31 \mathrm{ft} / \mathrm{s})$ from Hickman to New Madrid.

- Cross-currents in the Mississippi River main channel near the BPNMF as a result of activation were less than $0.5 \mathrm{~m} / \mathrm{s}(1.6 \mathrm{ft} / \mathrm{s})$.

- Cross-currents of greater than $0.5 \mathrm{~m} / \mathrm{s}(1.6 \mathrm{ft} / \mathrm{s})$ due to floodway outflow were evident in the Mississippi River main channel only within $100 \mathrm{~m}$ ( $328 \mathrm{ft}$ ) of the right descending bank near the BPNMF lower crevasse and within $300 \mathrm{~m}(984 \mathrm{ft}$ ) of the outflow of St. Johns Bayou.

- The LS breach being open or closed does not affect velocities below the Mississippi - Ohio River confluence. 


\section{References}

Aquaveo. 2010. Surface-water Modeling System (v11.1). https://www.erdc.usace.army.mil/Media/Fact-Sheets/Fact-Sheet-ArticleView/Article/919656/sms-surface-water-modeling-system/

Berger, R. C., J. N. Tate, G. L. Brown, and G. Savant. 2013. User Manual for AdH Version 4.31. Vicksburg, MS: US Army Engineer Research and Development Center.

Camillo, Charles A. 2012. Divine Providence: The 2011 Flood in the Mississippi River and Tributaries Project. Vicksburg, MS: US Army Corps of Engineers, Mississippi River Commission.

CEIWR-HEC (USACE Institute for Water Resources, Hydrologic Engineering Center). 2009. HEC-DSS Vue, User's Manual, Version 2.o. USACE Institute for Water Resources, Hydrologic Engineering Center.

EPA (Environmental Protection Agency). 2009a. Guidance on the Development, Evaluation, and Application of Environmental Models. EPA/100/K-09/003. Washington, DC: US Environmental Protection Agency, Office of the Science Advisor. Council for Regulatory Environmental Modeling.

EPA. 2009b. Understanding the Use of Models in Predicting the Effectiveness of Proposed Remedial Actions at Superfund Sediment Sites, Sediment Assessment and Monitoring Sheet (SAMS) \#2. OSWER Directive 9200.1-96FS. Washington DC: US Environmental Protection Agency, Office of Superfund Remediation and Technology Innovation.

ESRI. 2017. ArcGIS Desktop: Version 10.5. Redlands, CA. https://desktop.arcgis.com/en/system-requirements/10.5/arcgis-desktop-systemrequirements.htm

Heimann, David C., Robert R. Holmes, Jr., and Thomas E. Harris. 2018. Flooding in the Southern Midwestern United States, April-May 2017. Open-File Report 20181004. Reston, VA: US Geological Survey.

Huval, Carl J. 1979. The Dynamic Loop Effect on the Mississippi River, Project Design Flood Flow Line. Miscellaneous Paper HL-79-2. Vicksburg, MS: US Army Engineer Waterways Experiment Station. https://erdclibrary.on.worldcat.org/oclc/5026251

Koenig, Todd A., and Robert R. Holmes, Jr. 2013. Documenting Stages and Streamflows Associated with the Activation of the New Madrid Floodway, Missouri. Professional Paper 1798-E, Chapter E. Reston, VA: US Geological Survey.

Lewis, J. W., E. E. Howe, C. Cruz, M. L. Dove, W. A. Crosby, R. J. Taylor, D. A. Ramirez, M. S. Dircksen, and R. A. Gambill. 2018. Mississippi River and Tributaries Flowline Assessment Hydraulics Report. MRG\&P Report No. 24, Volume 3. Vicksburg, MS: US Army Engineer Research and Development Center. 
Luke, Adam, Jeremiah Lant, Jeffrey Neal, and Brett Sanders. 2015. "Hydraulic Modeling of the 2011 New Madrid Floodway Activation: A Case Study on Floodway Activation Controls." Natural Hazards Vol. 76. https://link.springer.com/article/10.1007/s11069-015-1680-3

Mueller, David S., and Chad R. Wagner. 2009. "Measuring Discharge with Acoustic Doppler Current Profilers from a Moving Boat.” Techniques and Methods 3-A22. Reston, VA: US Geological Survey. https://pubs.usgs.gov/tm/3a22/

Mueller, D. S. 2016. QRev-Software for Computation and Quality Assurance of Acoustic Doppler Current Profiler Moving-Boat Streamflow MeasurementsUser's Manual for Version 2.8. US Geological Survey Open-File Report 20161052. Reston, VA: USGS Office of Surface Water. http://dx.doi.org/10.3133/ofr20161052

NAS (National Academy of Science). 2012. Assessing the Reliability of Complex Models. Washington DC: US National Academy of Science, National Academies Press.

NASA (National Air and Space Administration). 2011. Earth Observatory Image. https://eoimages.gsfc.nasa.gov/images/imagerecords/50000/50457/missrv_tmo_2011124_I rg.jpg

Savant, Gaurav, Charlie Berger, Tate O. McAlpin, and Jennifer N. Tate. 2010. "Efficient Implicit Finite Element Hydrodynamic Model for Dam and Levee Breach.” Journal of Hydraulic Engineering 137(9).

Savant, G., Berger, R. C., Brown, G. L., and Trahan, C. J. 2020. Theory, Formulation, and Implementation of the Cartesian and Spherical Coordinate Two-Dimensional Depth-Averaged Module of the Adaptive Hydraulics (Adh) Finite Element Numerical Code. ERDC TR-20-8. Vicksburg, MS: US Army Engineer Research and Development Center.

Teledyne RD Instruments. 2008. WinRiver II User's Guide.

USACE (US Army Corps of Engineers). 2004. Corpscon, Version 6.x. Alexandria, VA: USACE Engineering Research Development Center. https://www.agc.army.mil/Whatwe-do/Corpscon/

USACE. 2017. RiverGages.com. https://rivergages.mvr.usace.army.mil/WaterControl/new/layout.cfm

UMRR LTRM (US Army Corps of Engineers Upper Mississippi River Restoration, Program Long Term Resource Monitoring). 2016. La Crosse, WI: UMRR Open River South Topobathy. http://dx.doi.org/10.5066/F7057CZ3

USGS (US Geological Survey). 2015. National Water Information System. US Geological Survey. http://waterdata.usgs.gov/hwis 


\section{Appendix A: Calibration Plots}




\section{1 event calibration (Figure A-1 through Figure A-70)}

\section{Stage calibration}

Figure A-1. Modeled and observed stage at New Madrid, 2011 event.

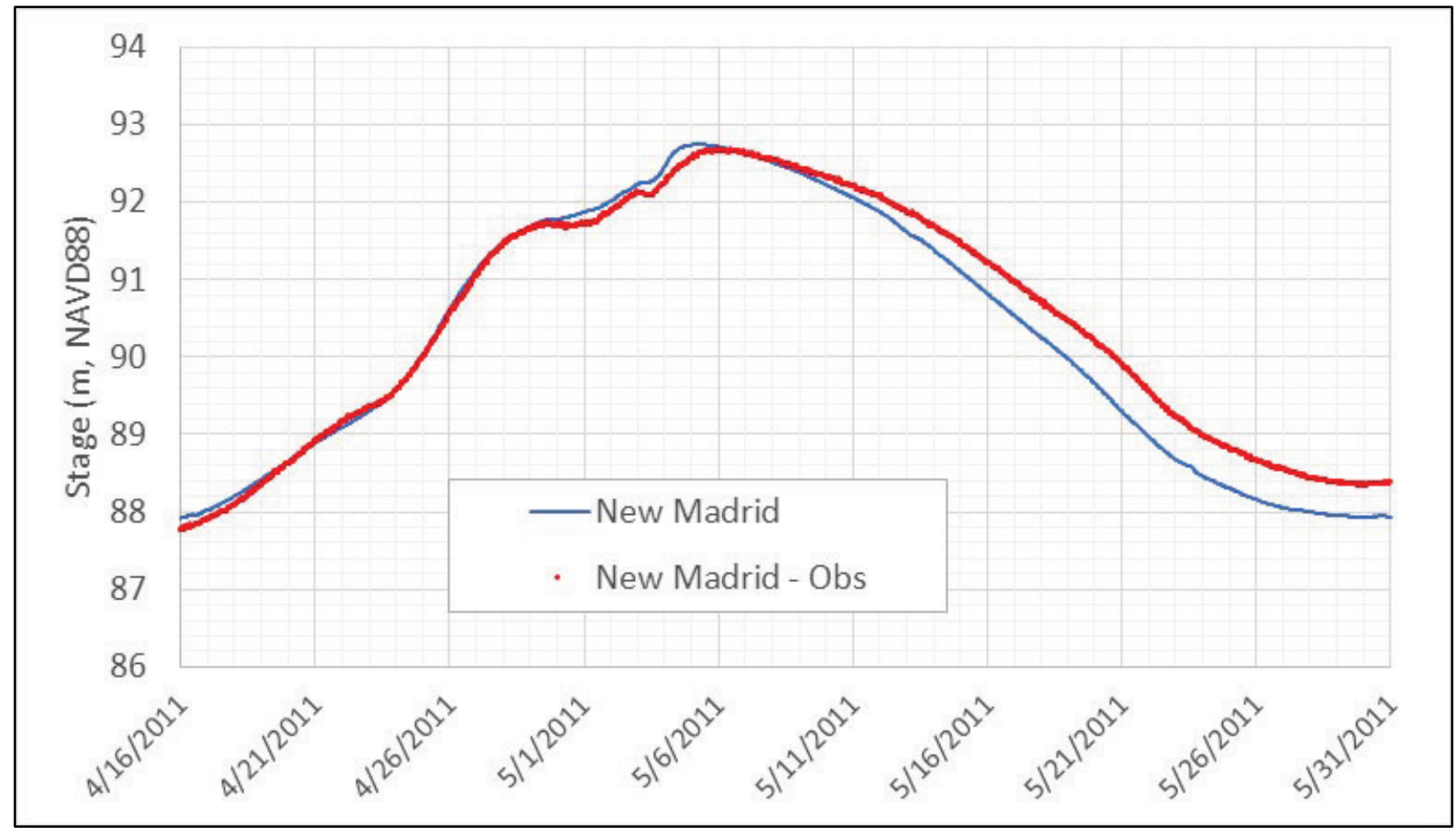

Figure A-2. Modeled and observed stage at Hickman, 2011 event.

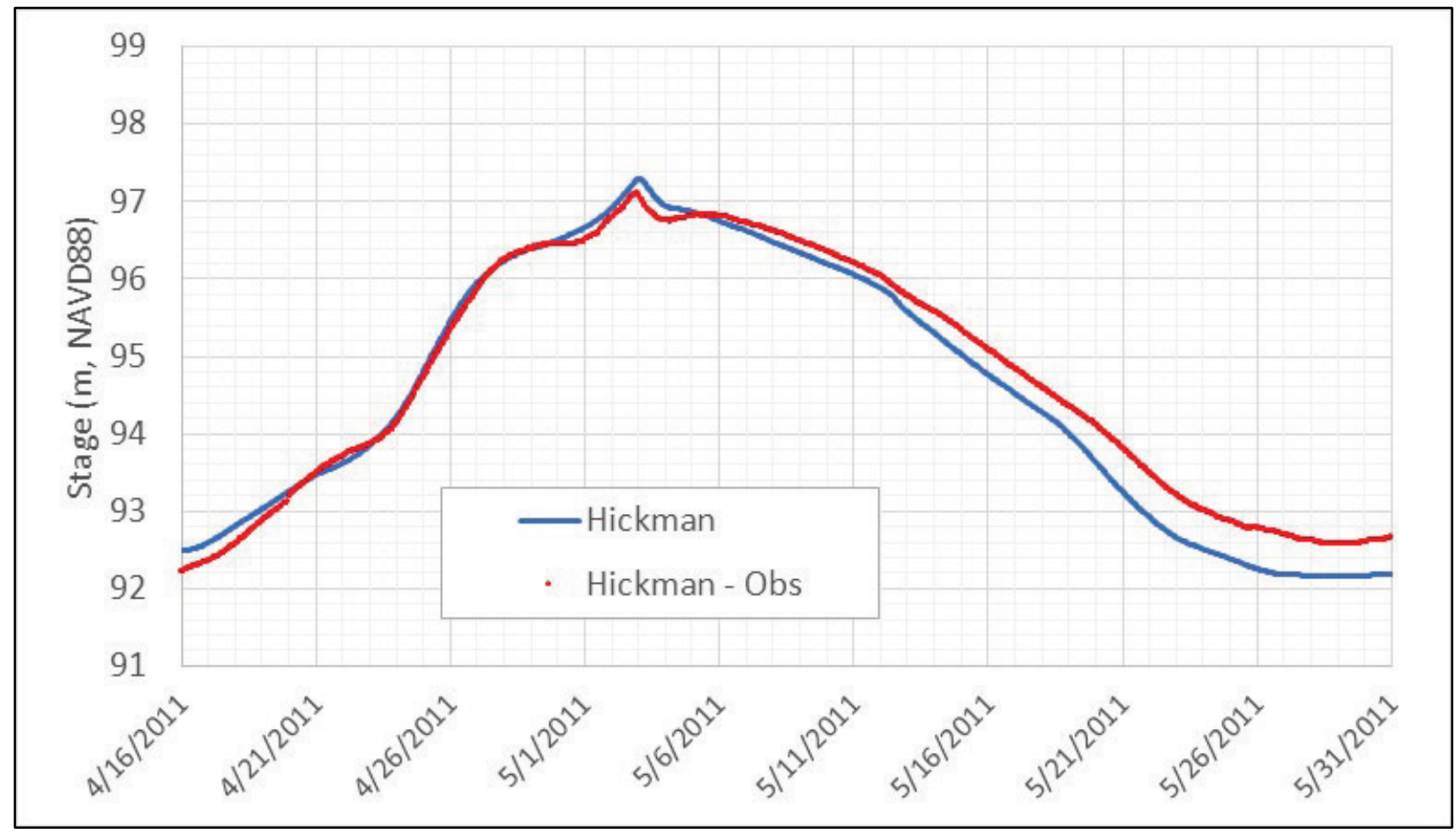


Figure A-3. Modeled and observed stage at Cairo, 2011 event.

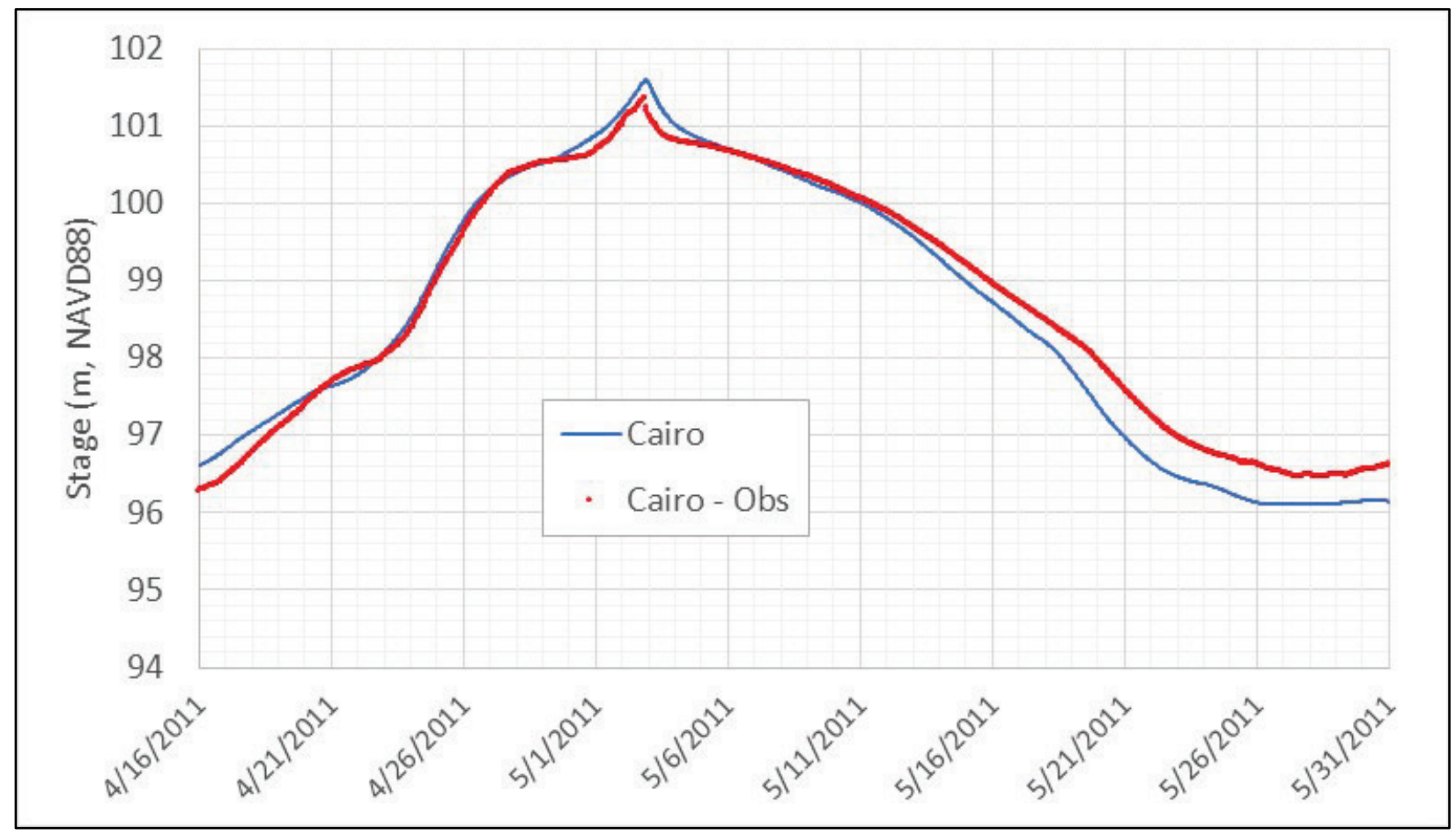

Figure A-4. Modeled and observed stage at Birds Point, 2011 event.

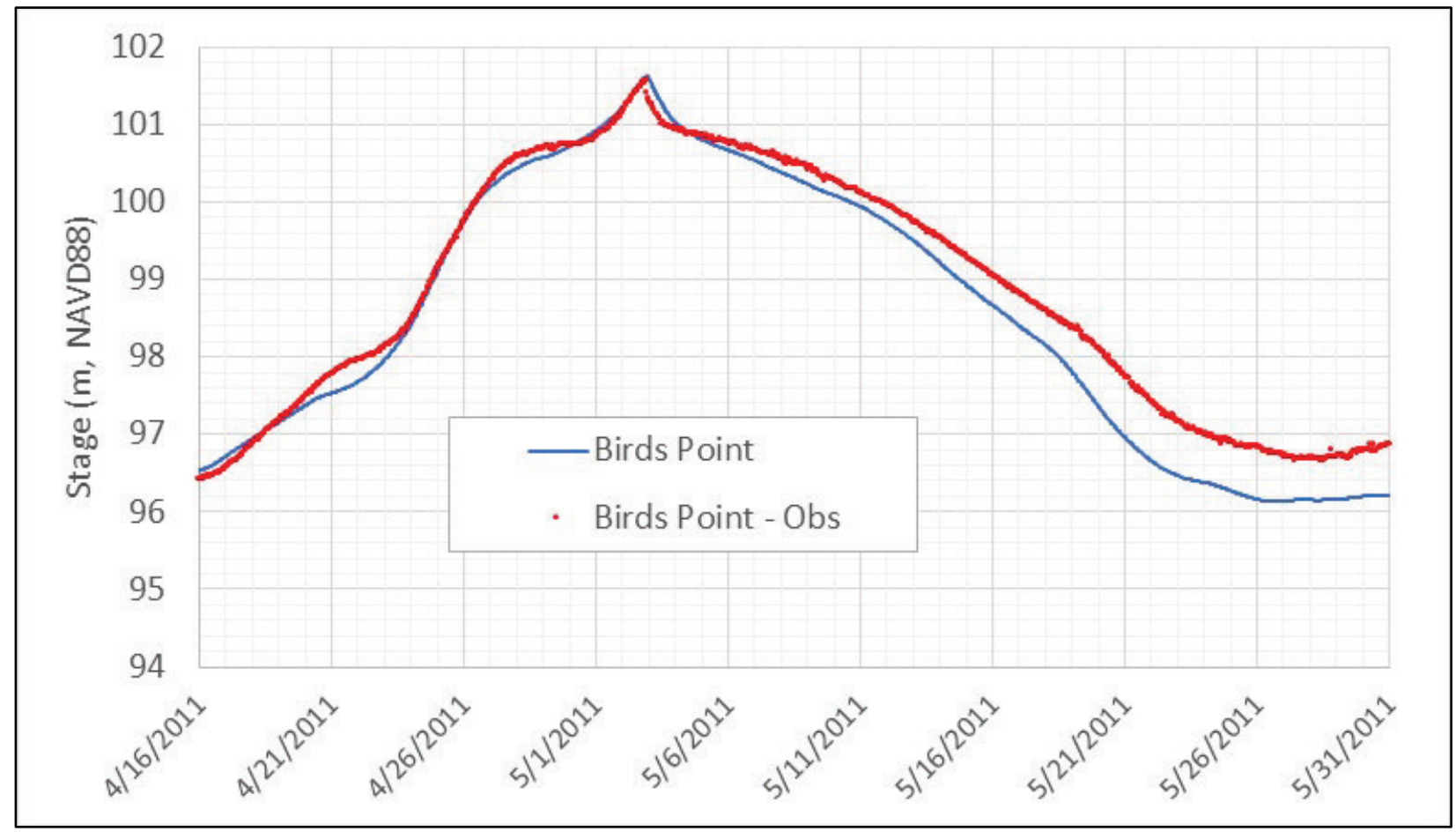


Figure A-5. Modeled and observed stage at Price Landing, 2011 event.

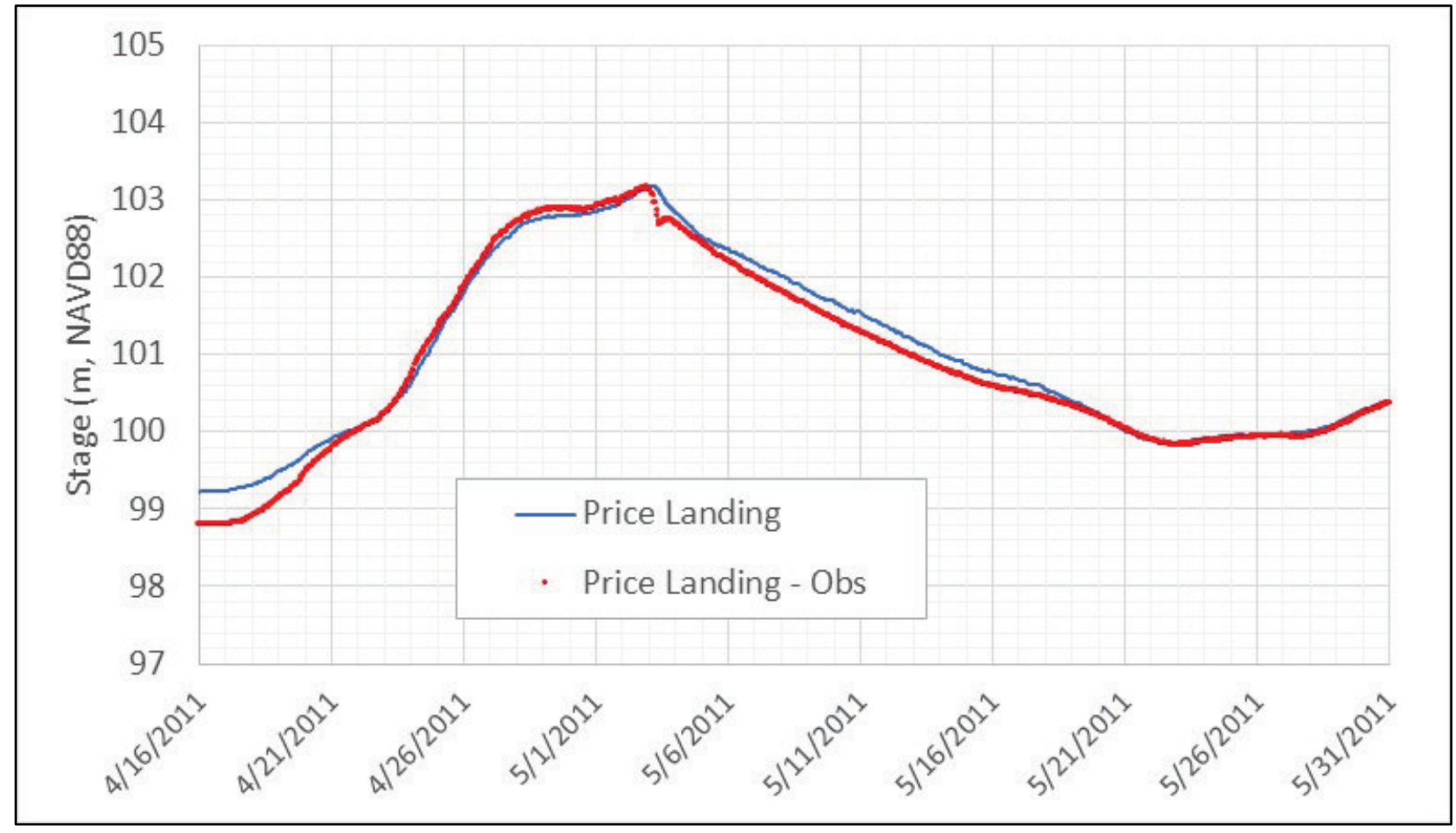




\section{BPNMF stage calibration}

Figure A-6. Modeled and observed stage at Upper BPNMF - km 0 (365751089080301), 2011 event.

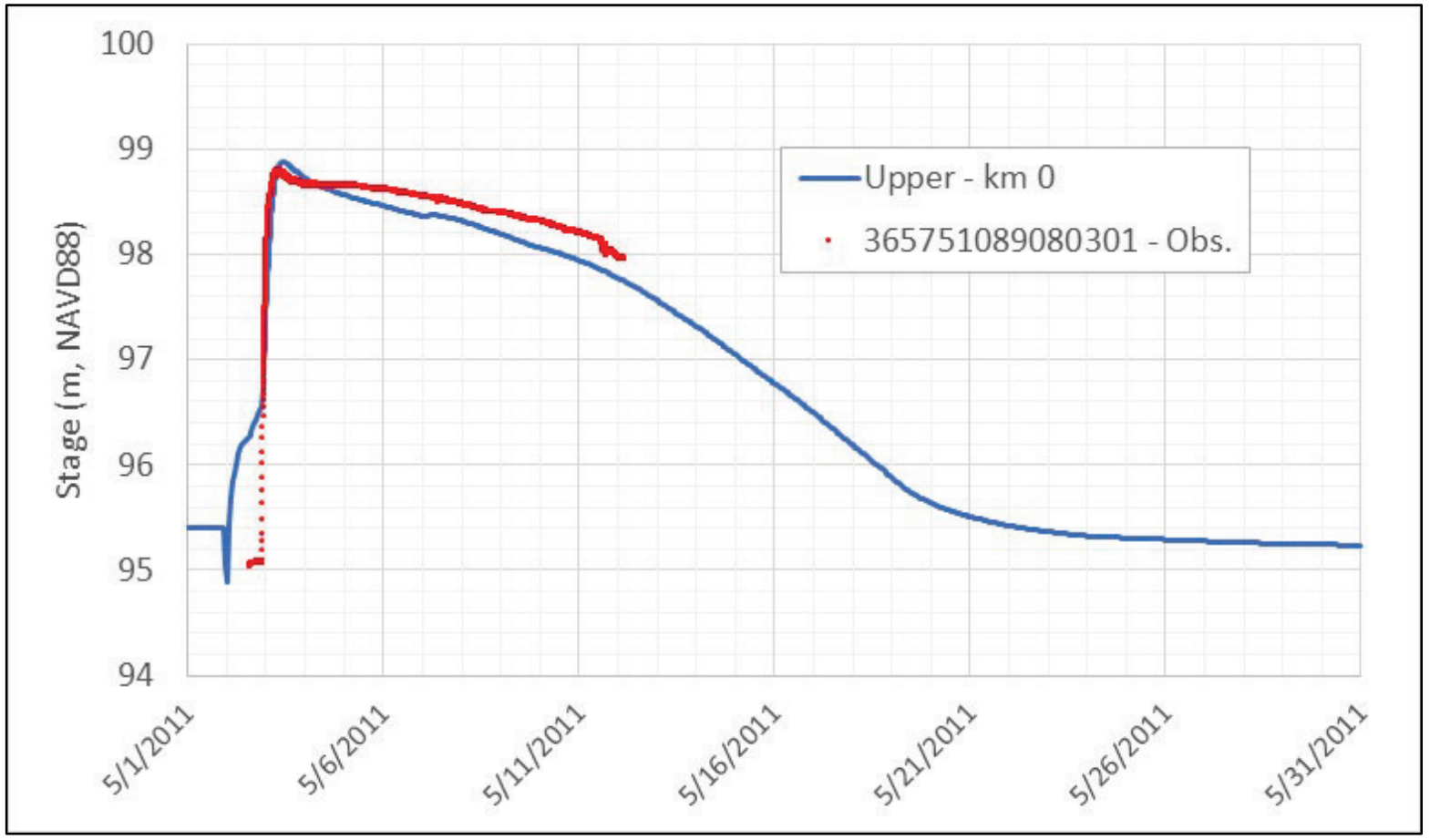

Figure A-7. Modeled and observed stage at Upper BPNMF - km 3 (365538089080001), 2011 event.

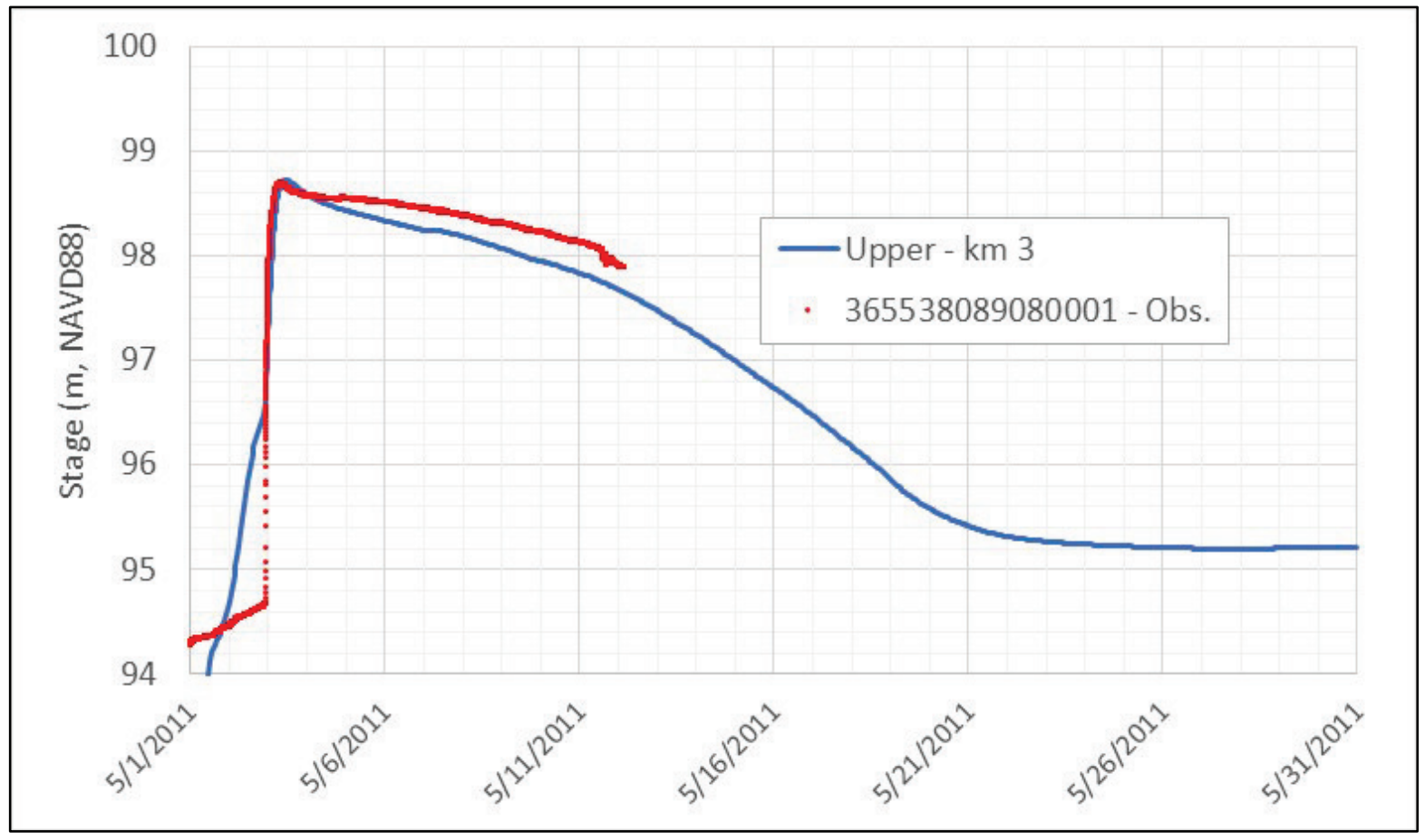


Figure A-8. Modeled and observed stage at Upper BPNMF - km 7 (365452089105201), 2011 event.

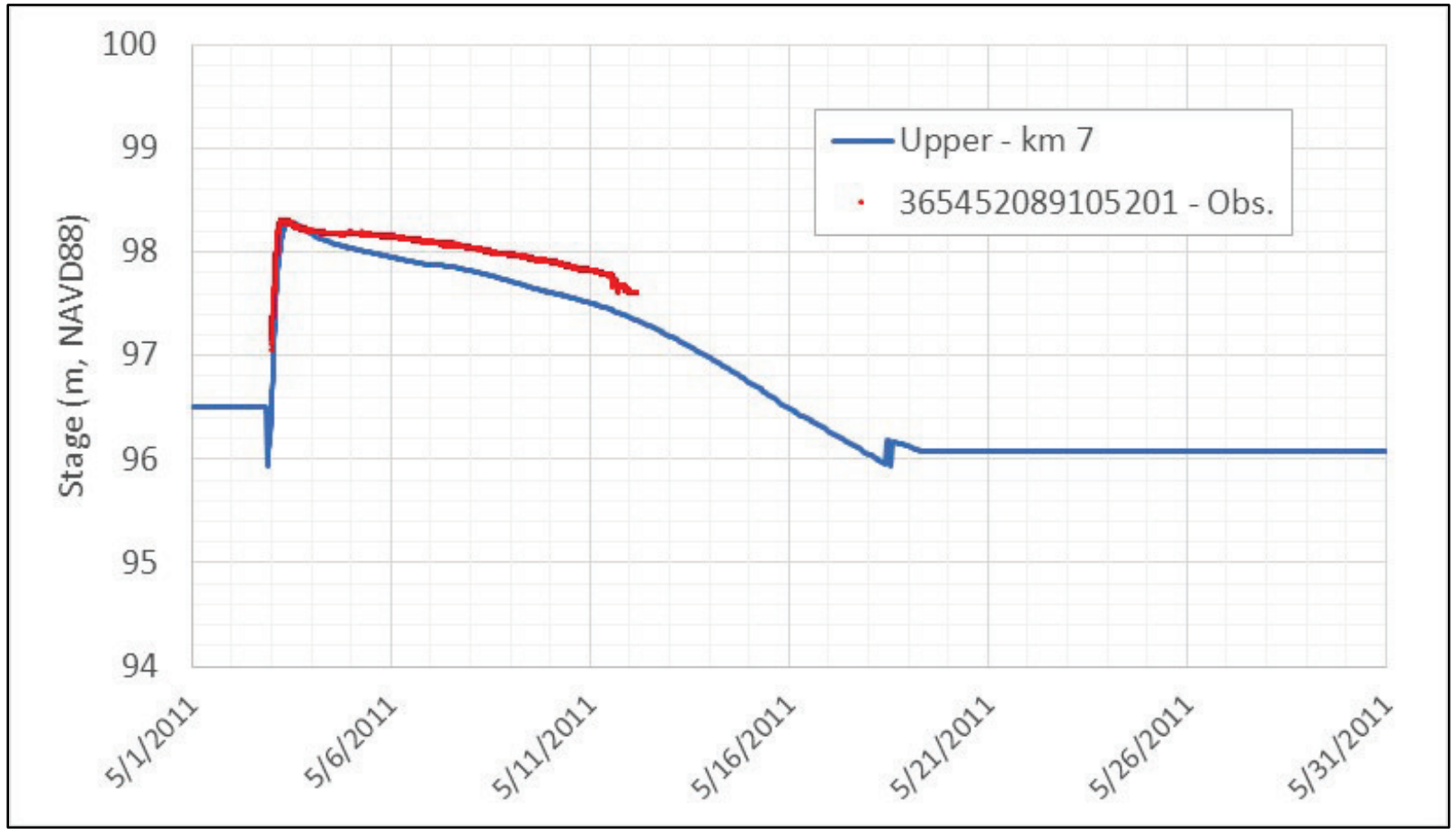

Figure A-9. Modeled and observed stage at Middle BPNMF - km 23 (364635089145003), 2011 event.

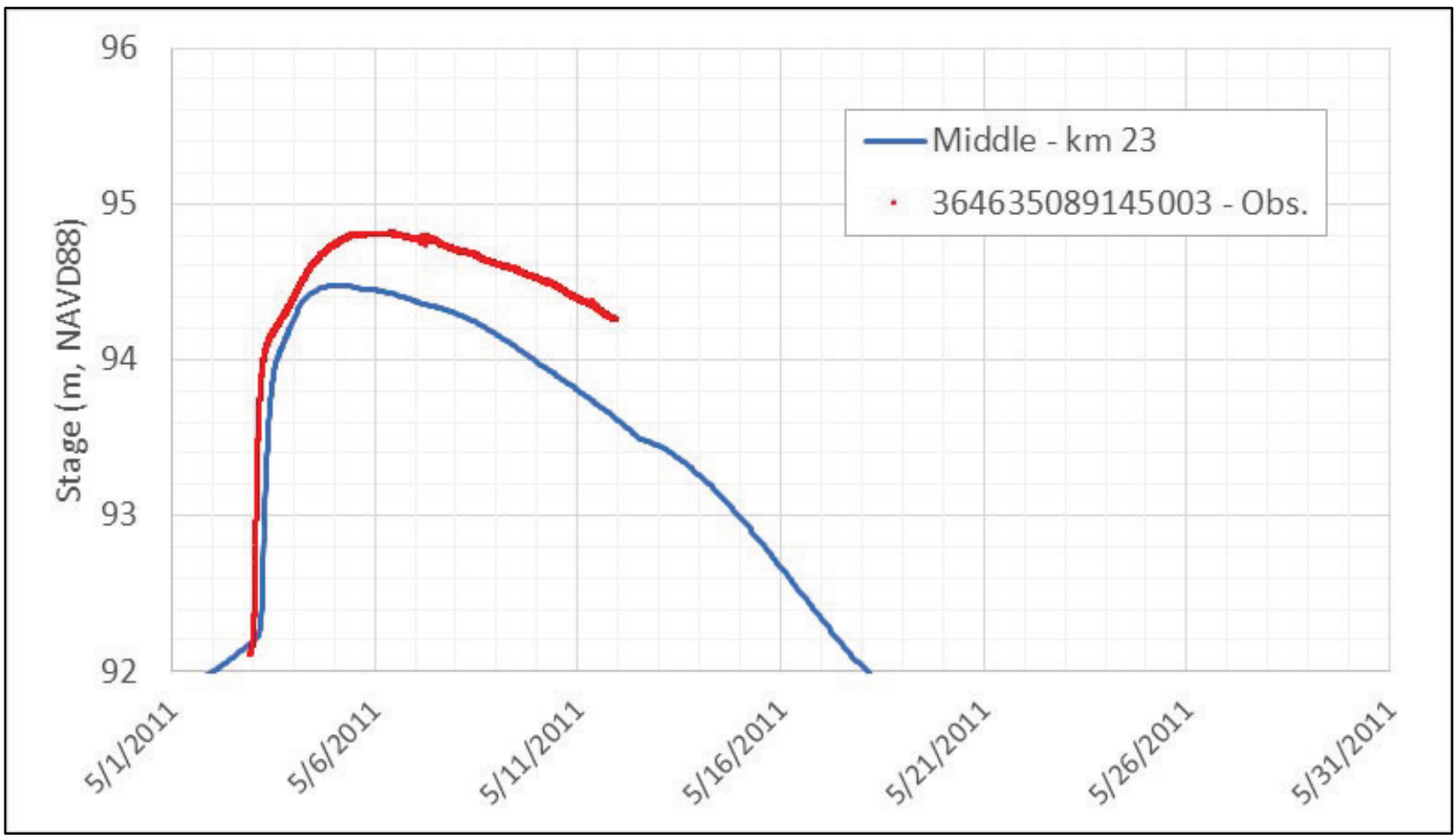


Figure A-10. Modeled and observed stage at Middle BPNMF - km 25 (364634089180501), 2011 event.

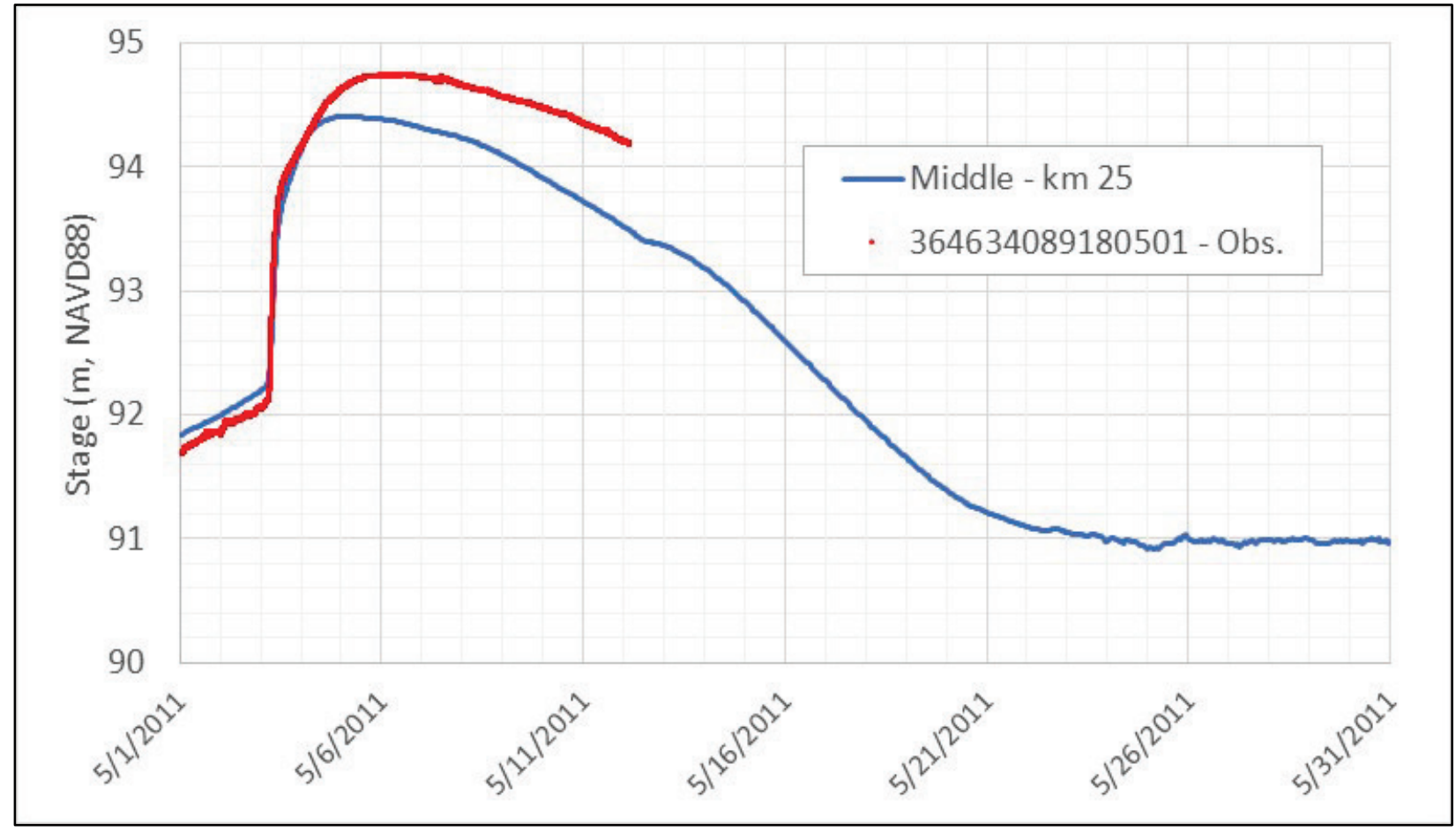

Figure A-11. Modeled and observed stage at Lower BPNMF - km 41 (363912089224801), 2011 event.

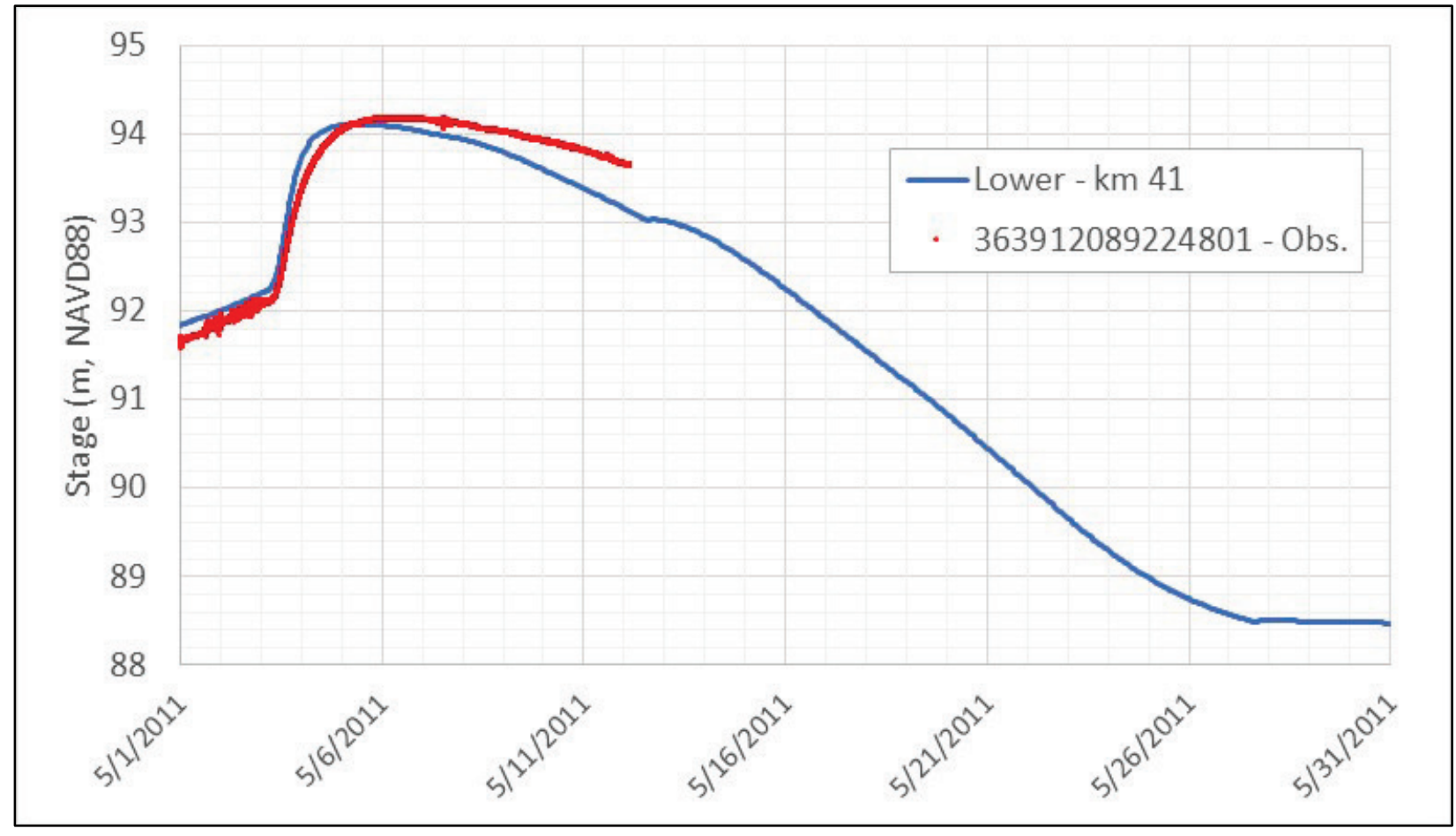


Figure A-12. Modeled and observed stage at Lower BPNMF - km 54 (363537089300001), 2011 event.

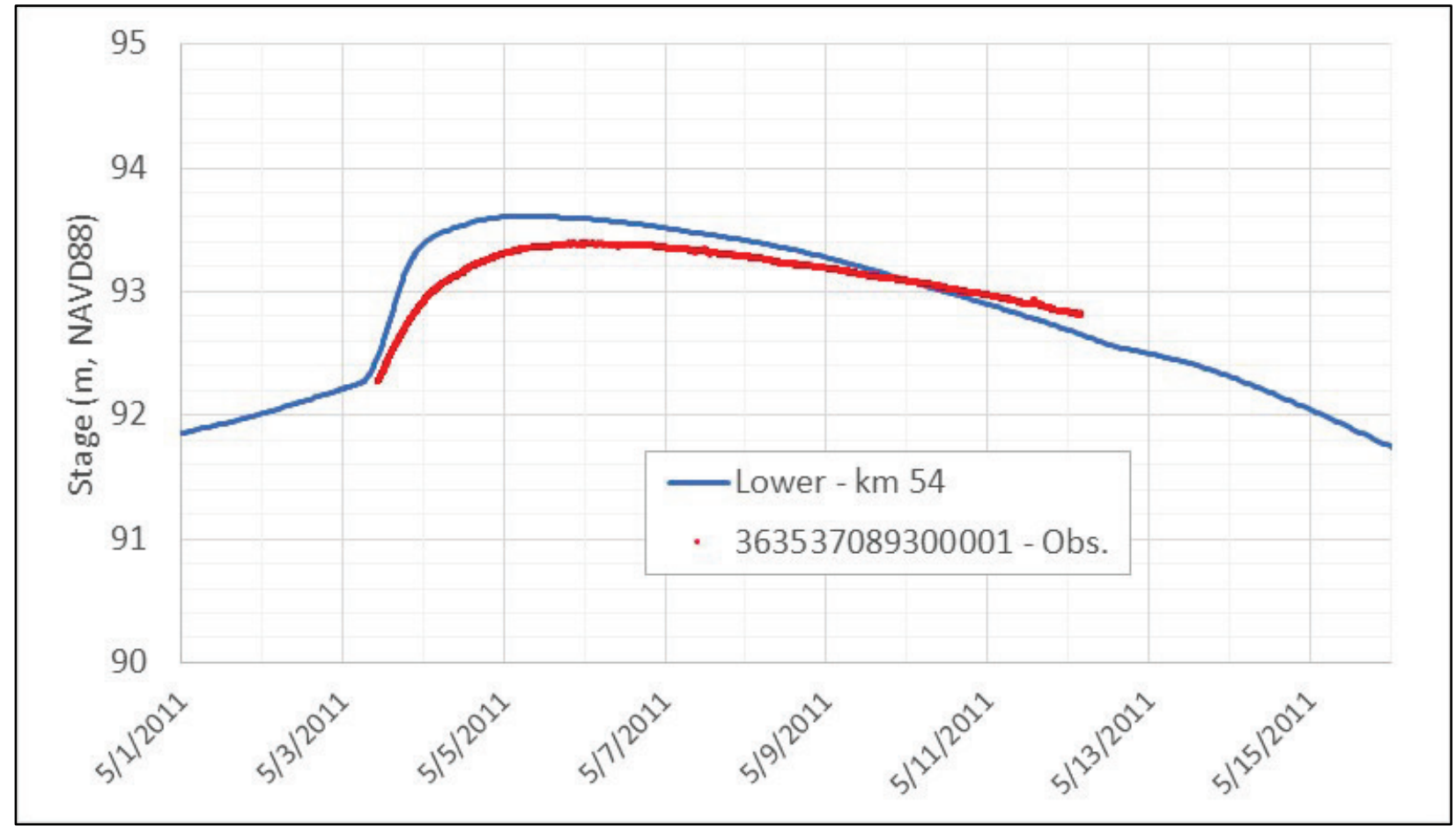

Figure A-13. Modeled and observed stage at Lower East BPNMF - km 42 (363514089134101), 2011 event.

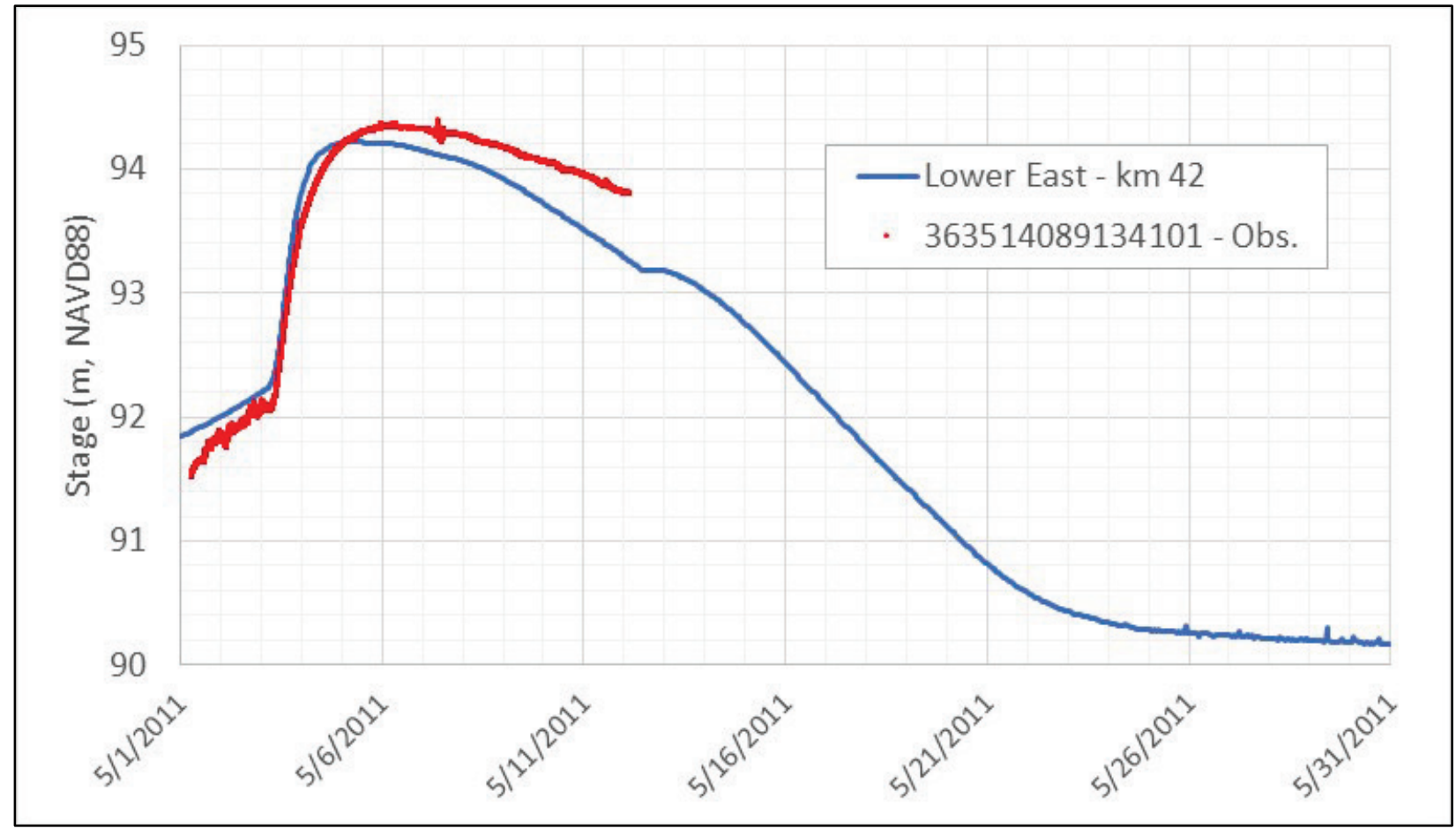




\section{Discharge Calibration}

Figure A-14. Modeled and observed discharge of the Mississippi River above Cairo, 2011 event.

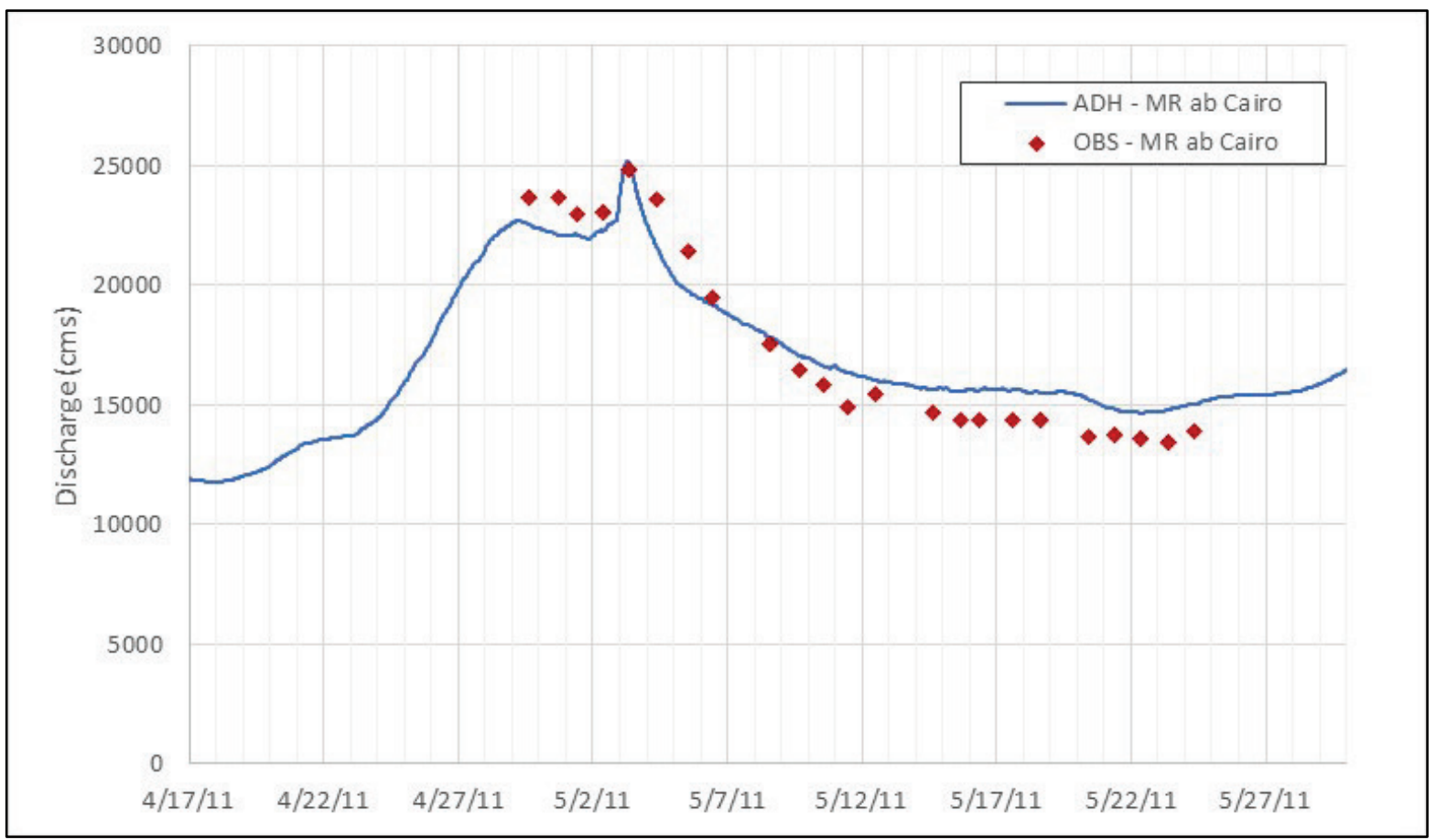

Figure A-15. Modeled and observed discharge of the Ohio River below Cairo, 2011 event.

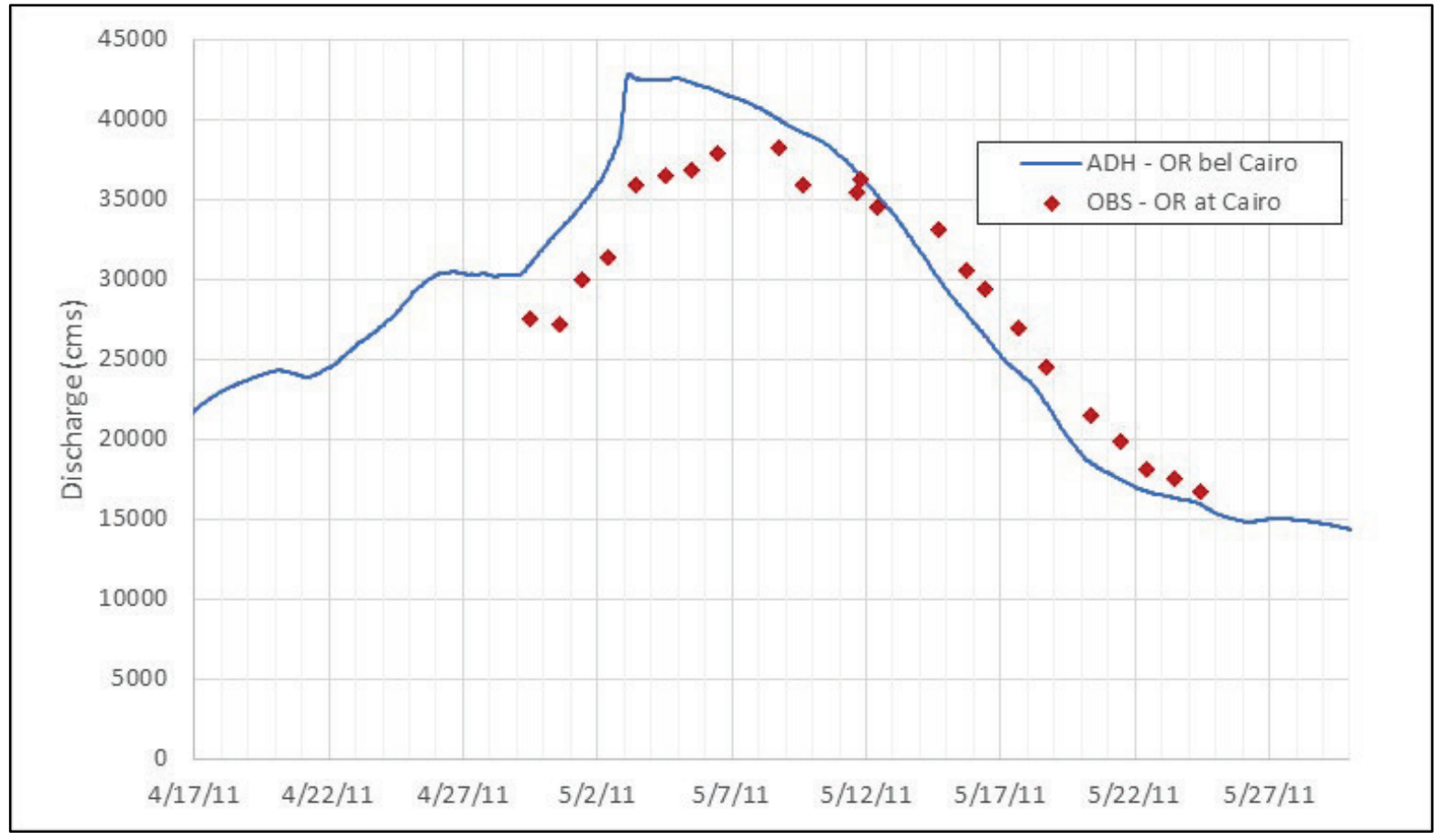


Figure A-16. Modeled and observed discharge of the Mississippi River below the confluence, 2011 event.

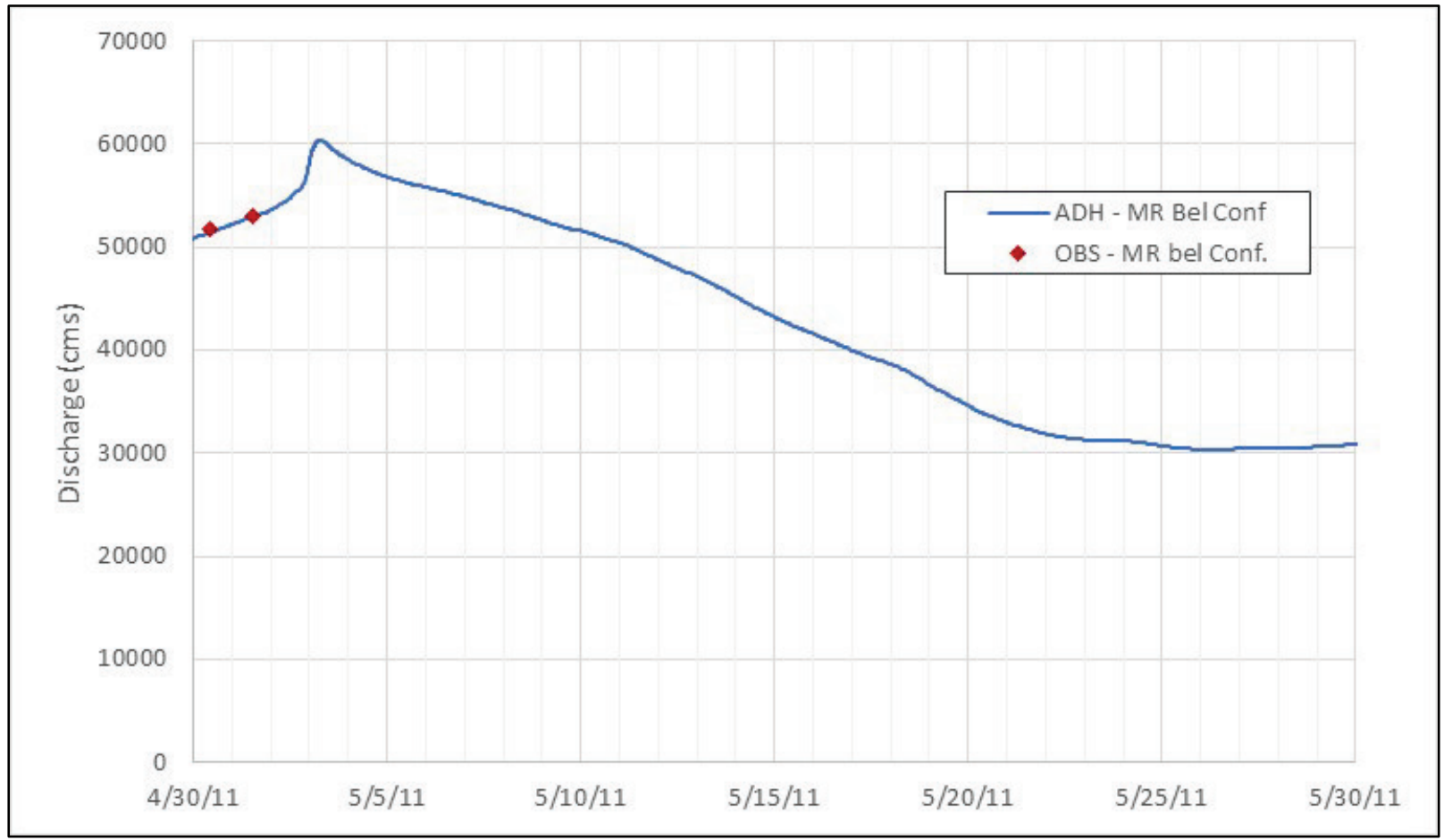

Figure A-17. Modeled and observed discharge of the Mississippi River below Birds Point, 2011 event.

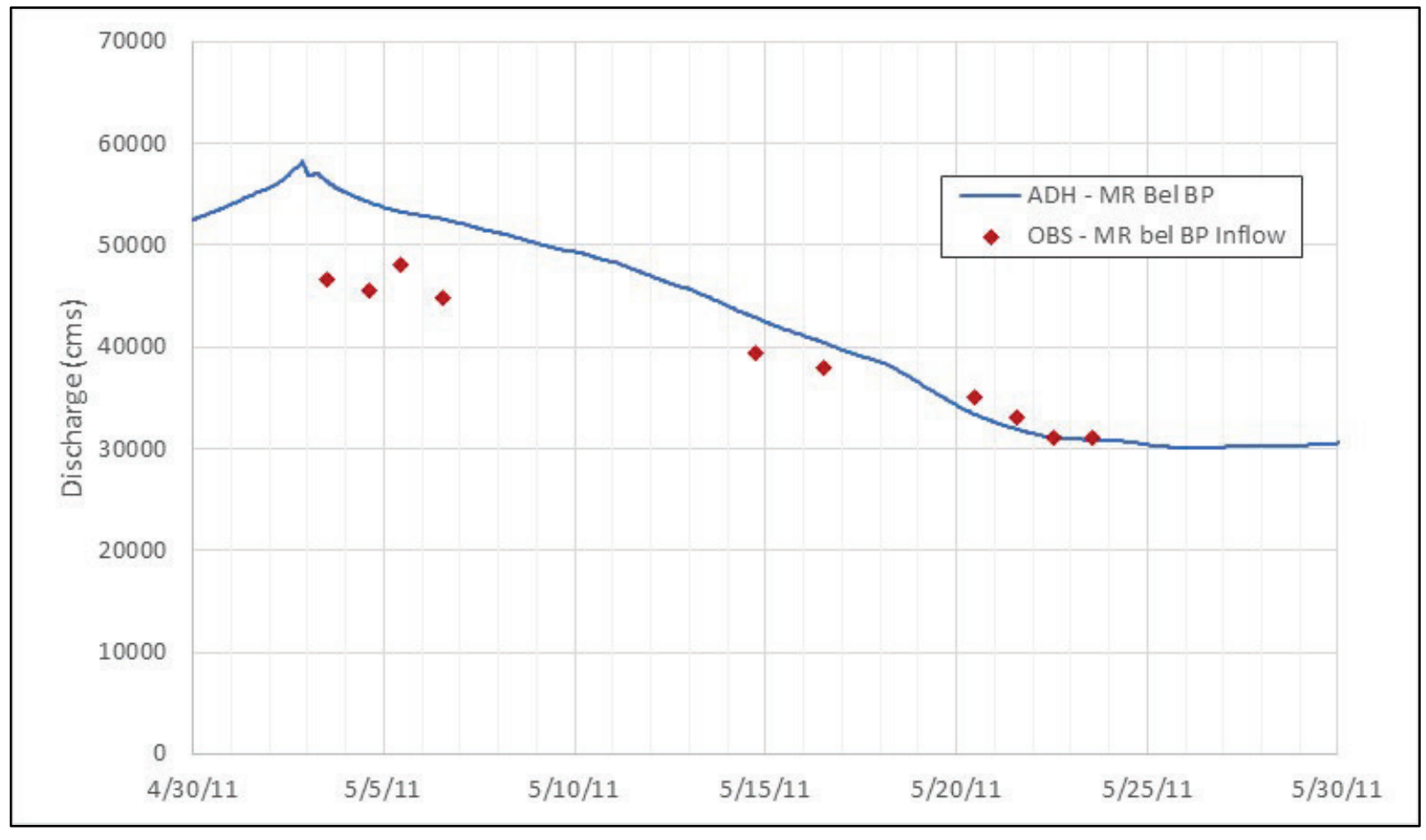


Figure A-18. Modeled and observed discharge at Birds Point Upper Crevasse, 2011 event.

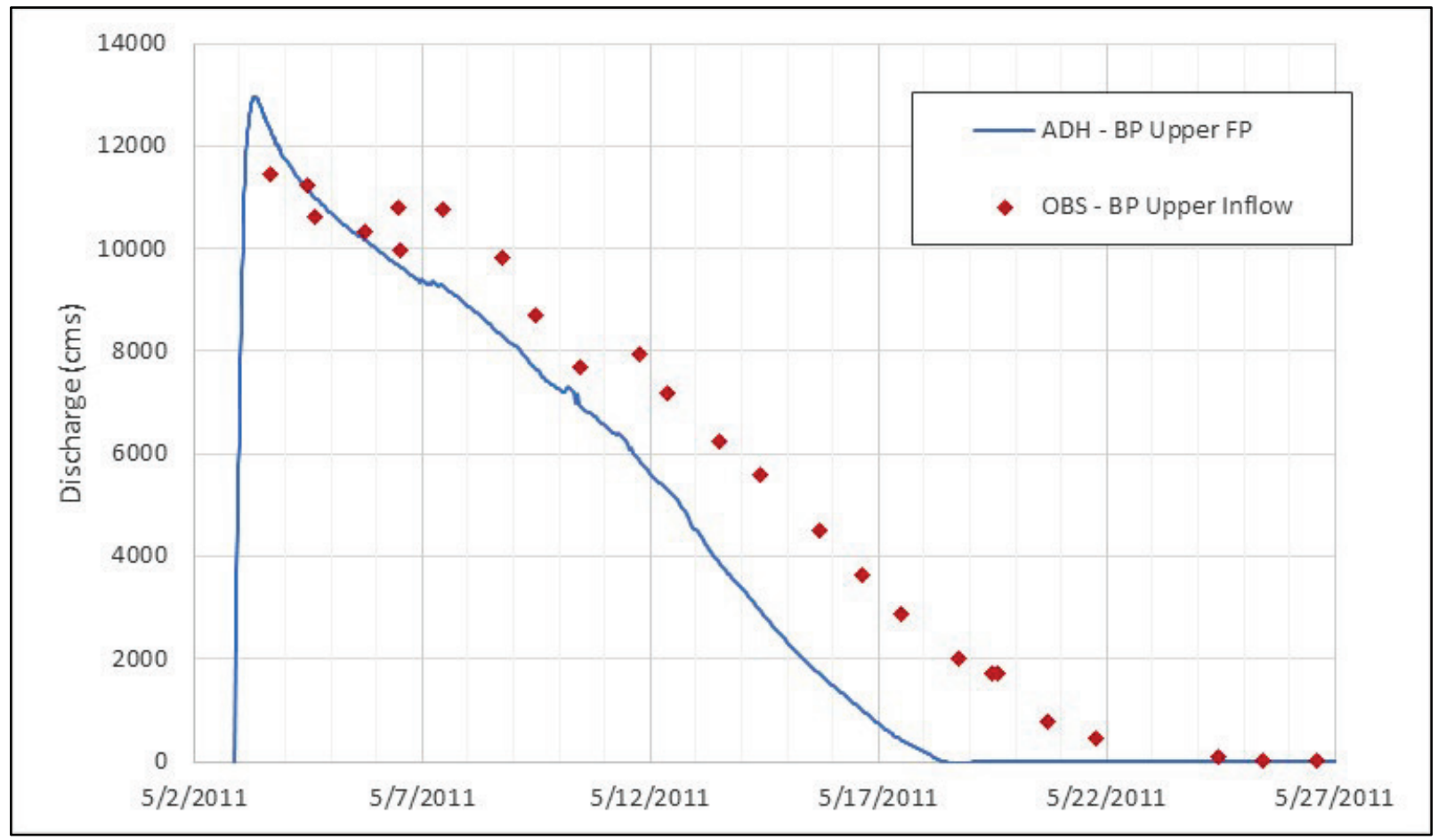

Figure A-19. Modeled and observed discharge of the Mississippi River at Hickman, 2011 event.

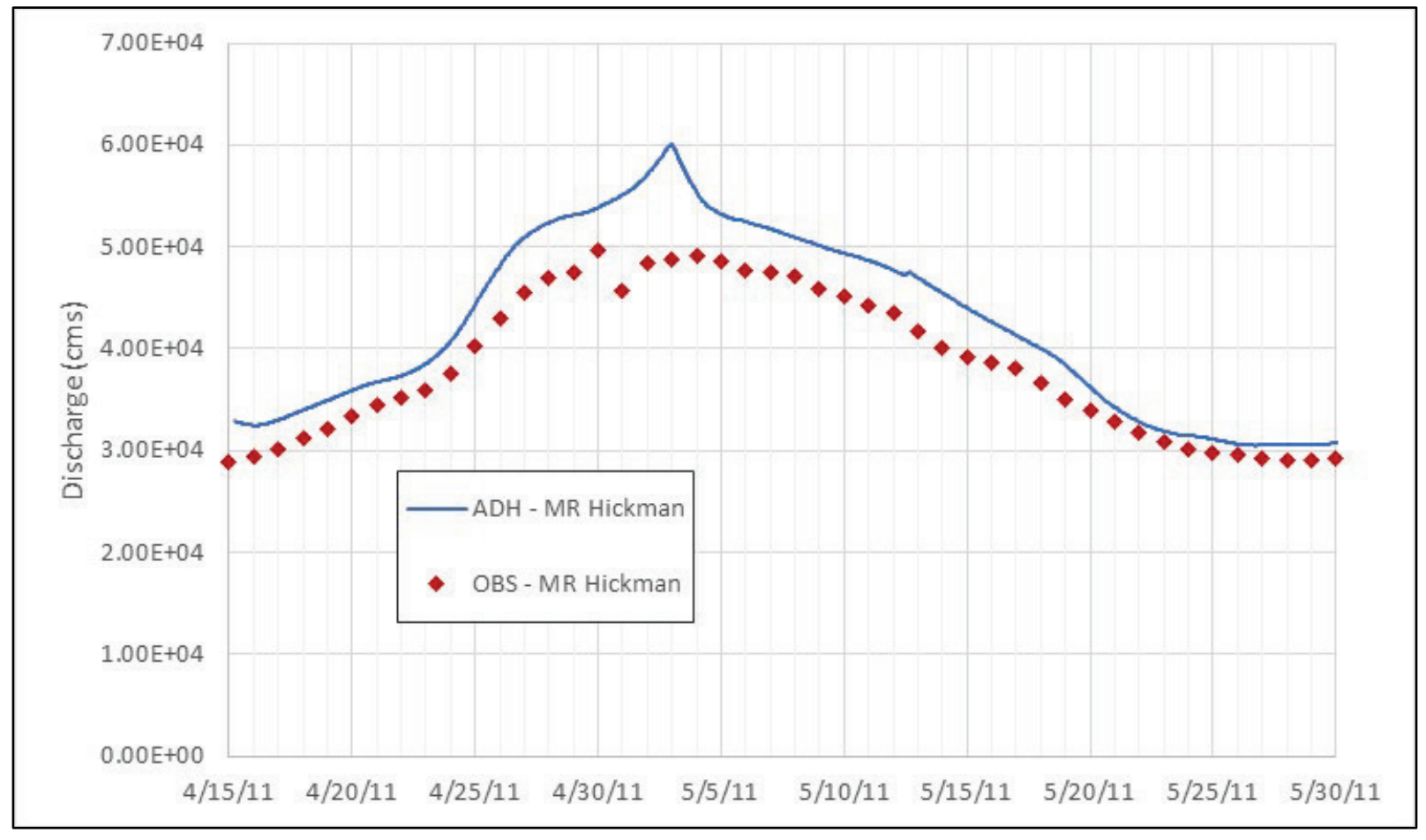


Figure A-20. Modeled and observed discharge at Birds Point Middle Crevasse, 2011 event.

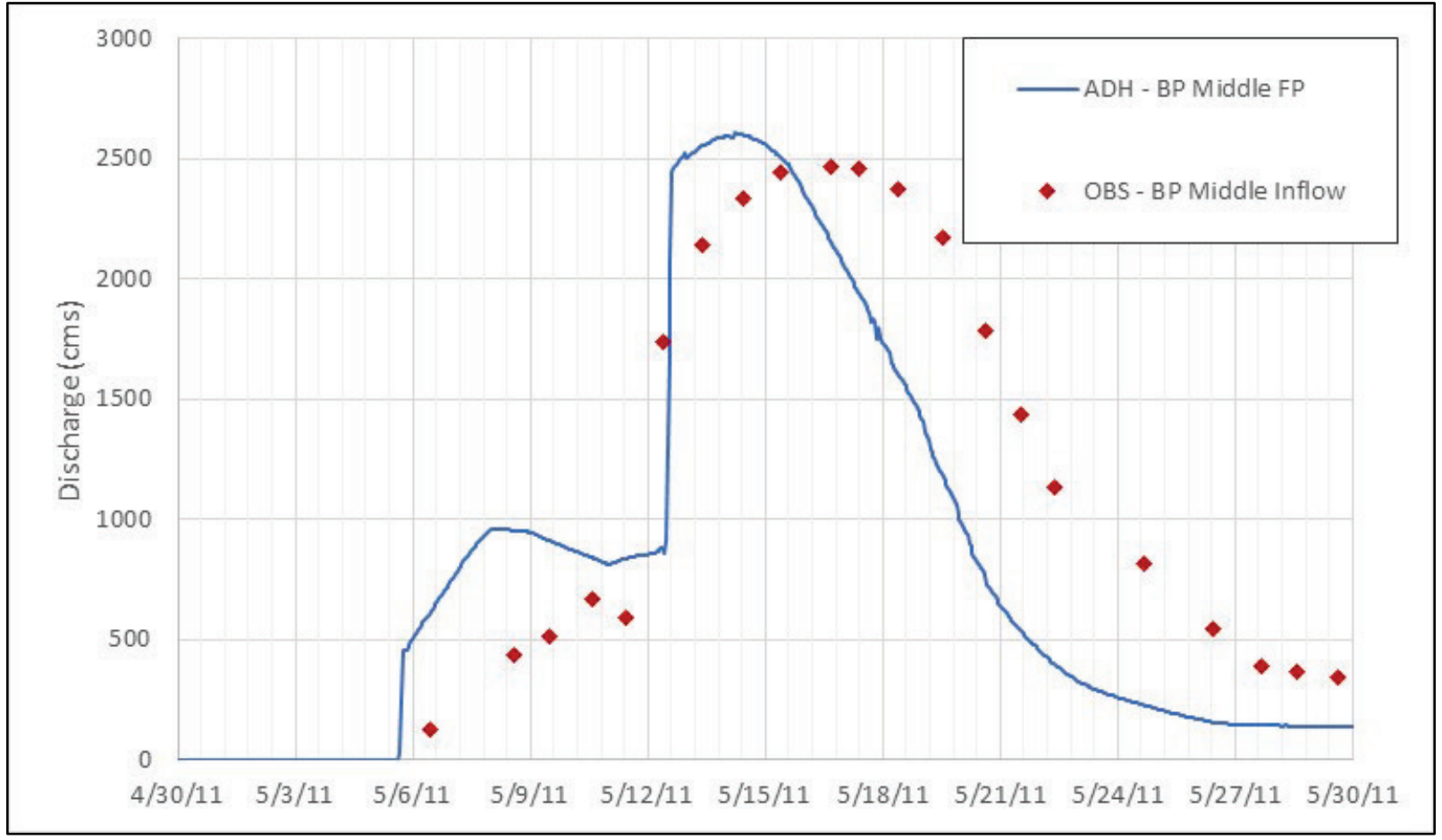

Figure A-21. Modeled and observed discharge exiting Birds Point, 2011 event.

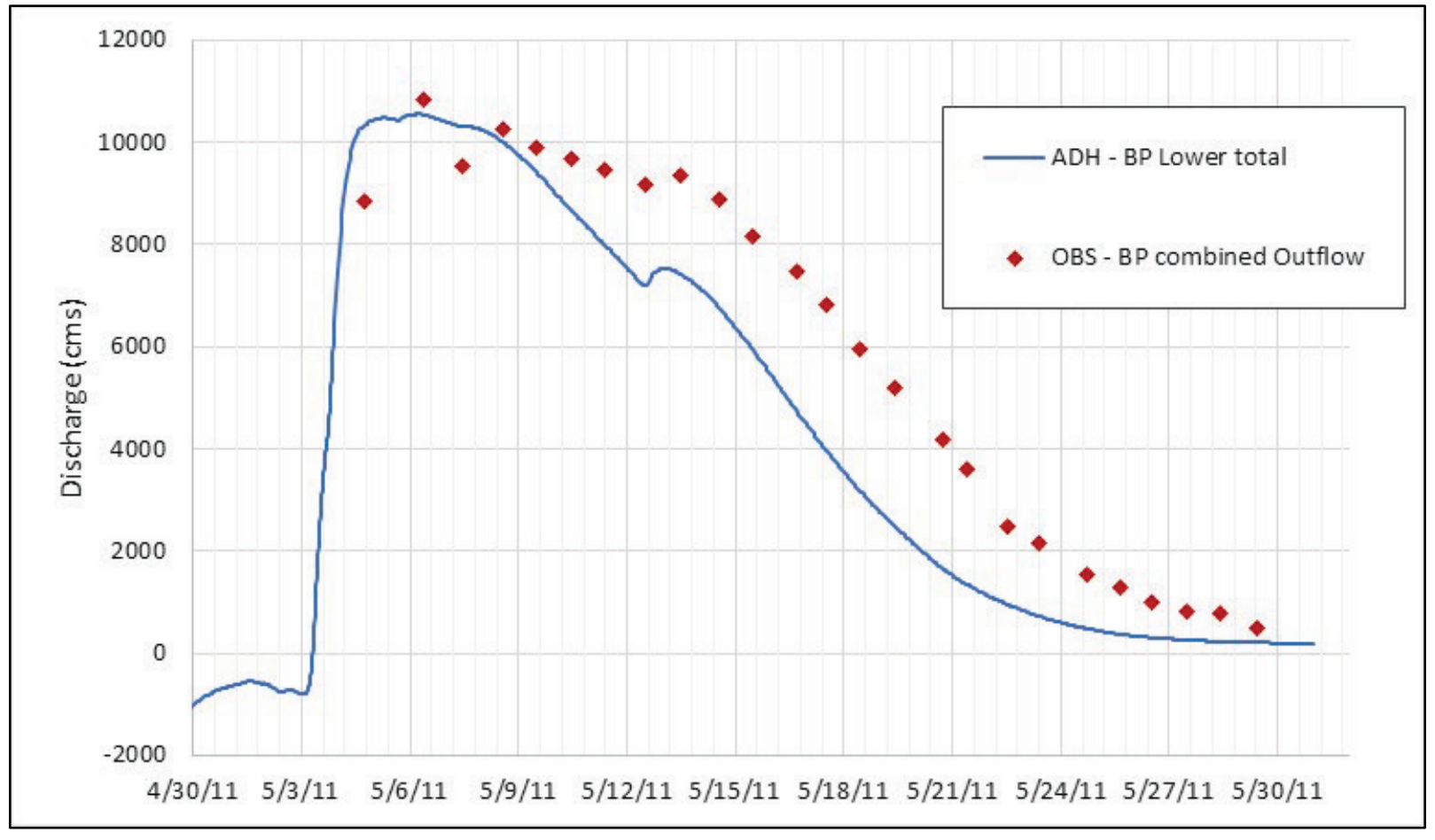


Figure A-22. Modeled and observed discharge at Birds Point Lower Crevasse, 2011 event.

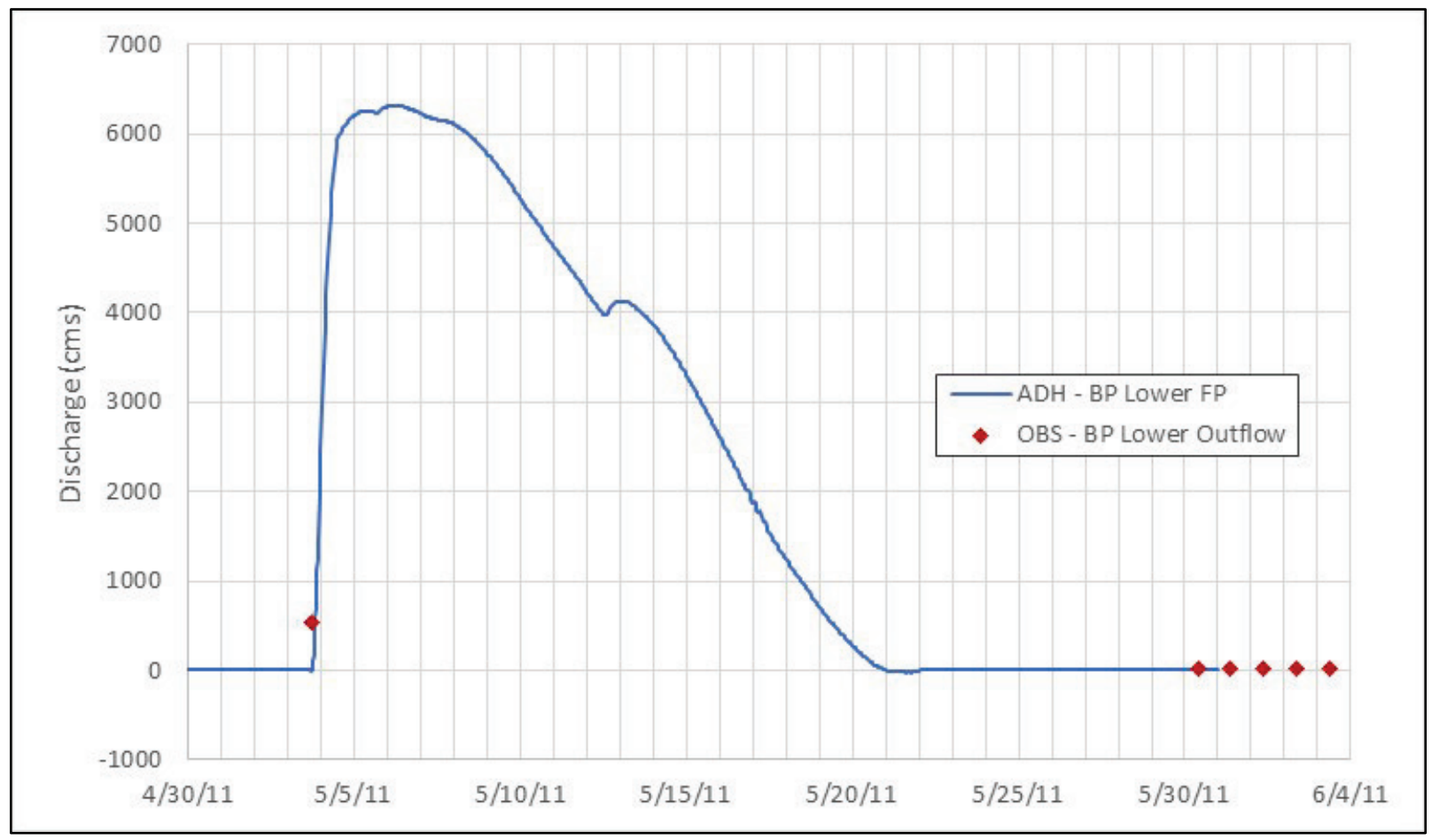

Figure A-23. Modeled and observed discharge at Birds Point Gap, 2011 event.

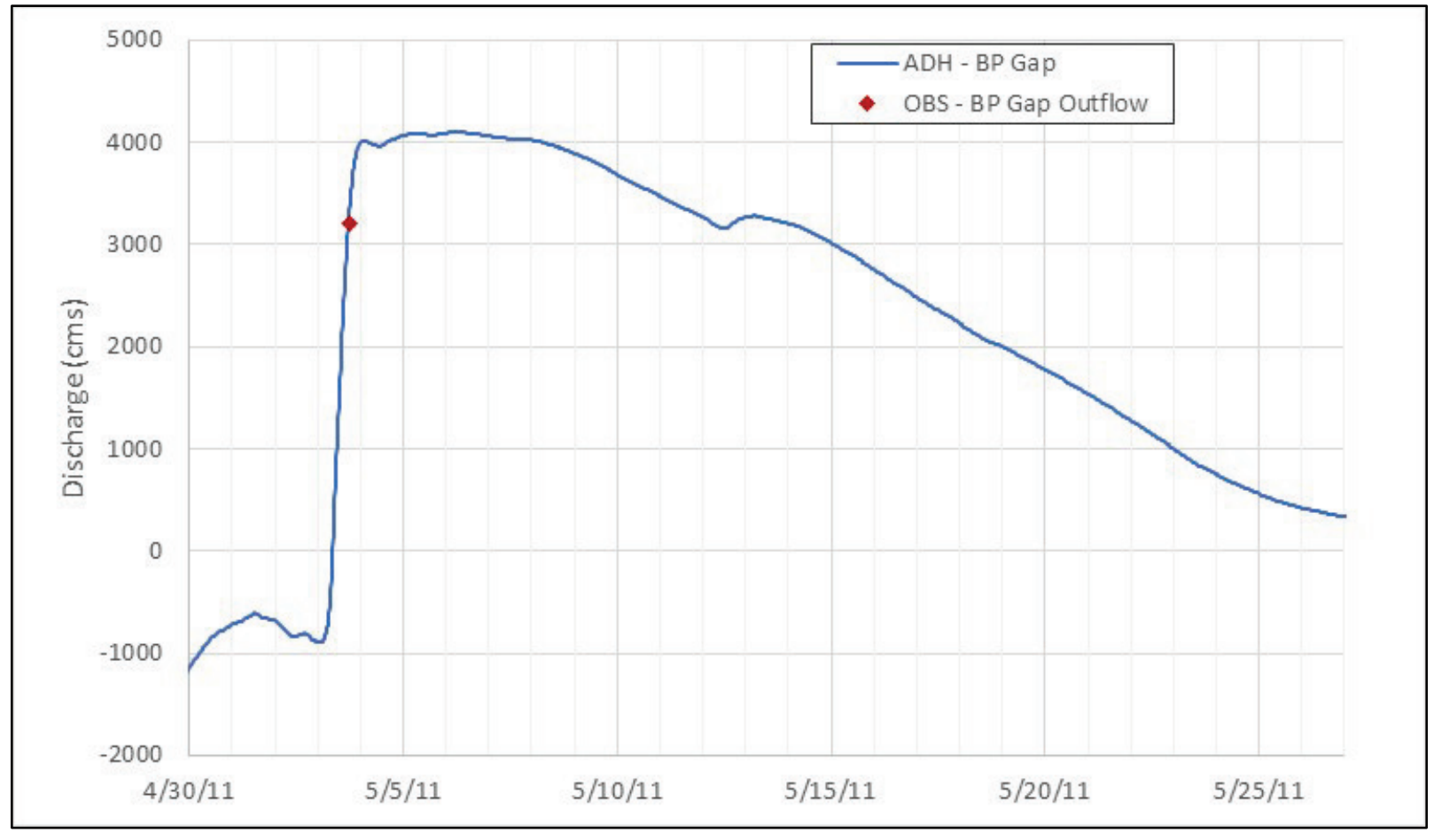


Figure A-24. Modeled and observed discharge of the Mississippi River at Tiptonville, 2011 event.

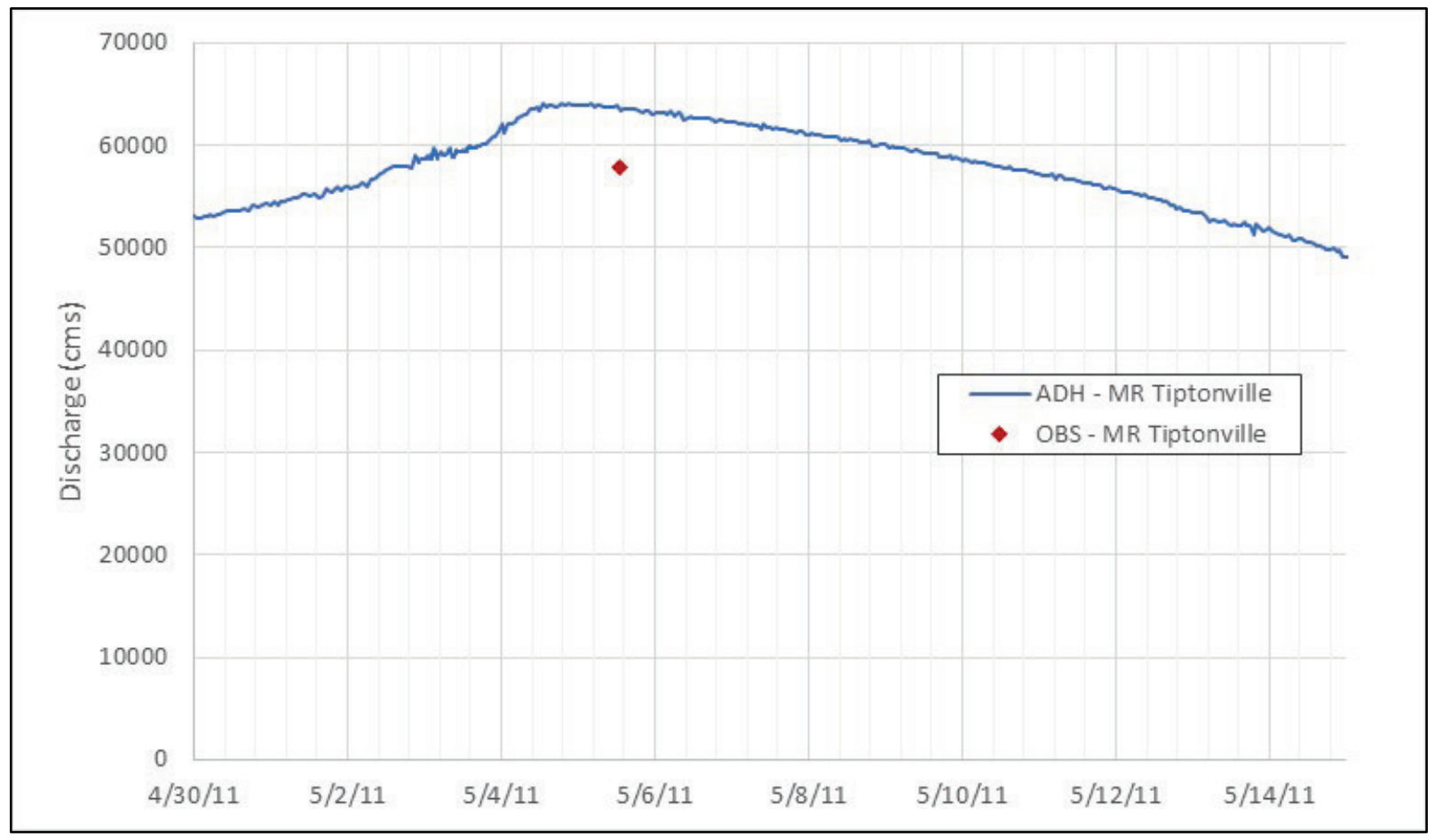




\section{Velocity magnitude calibration}

Figure A-25. Modeled and observed velocity below the confluence at Transect 002 on 4/28/2011.

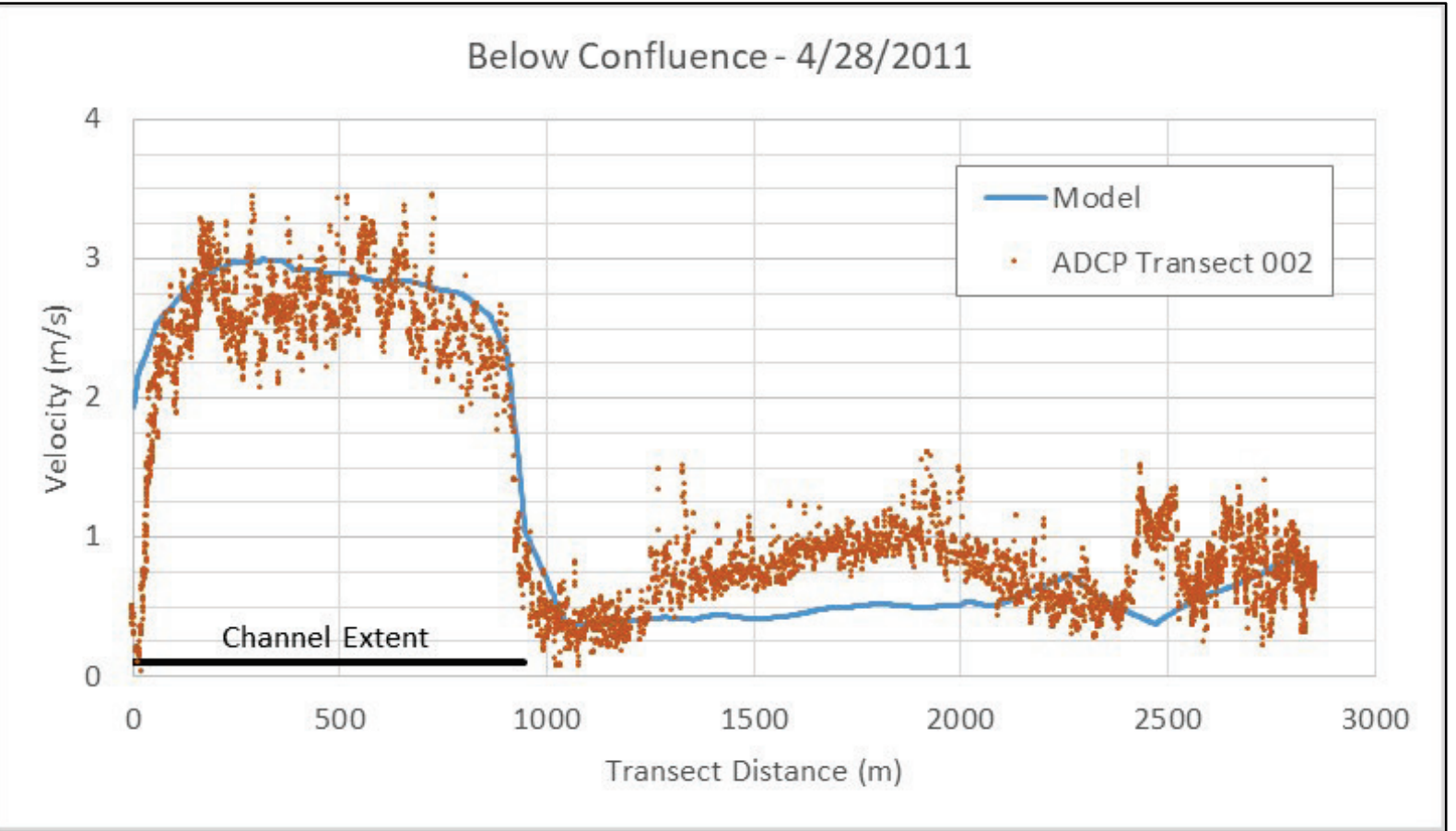

Figure A-26. Modeled and observed velocity below the confluence at Transect 003 on 4/28/2011.

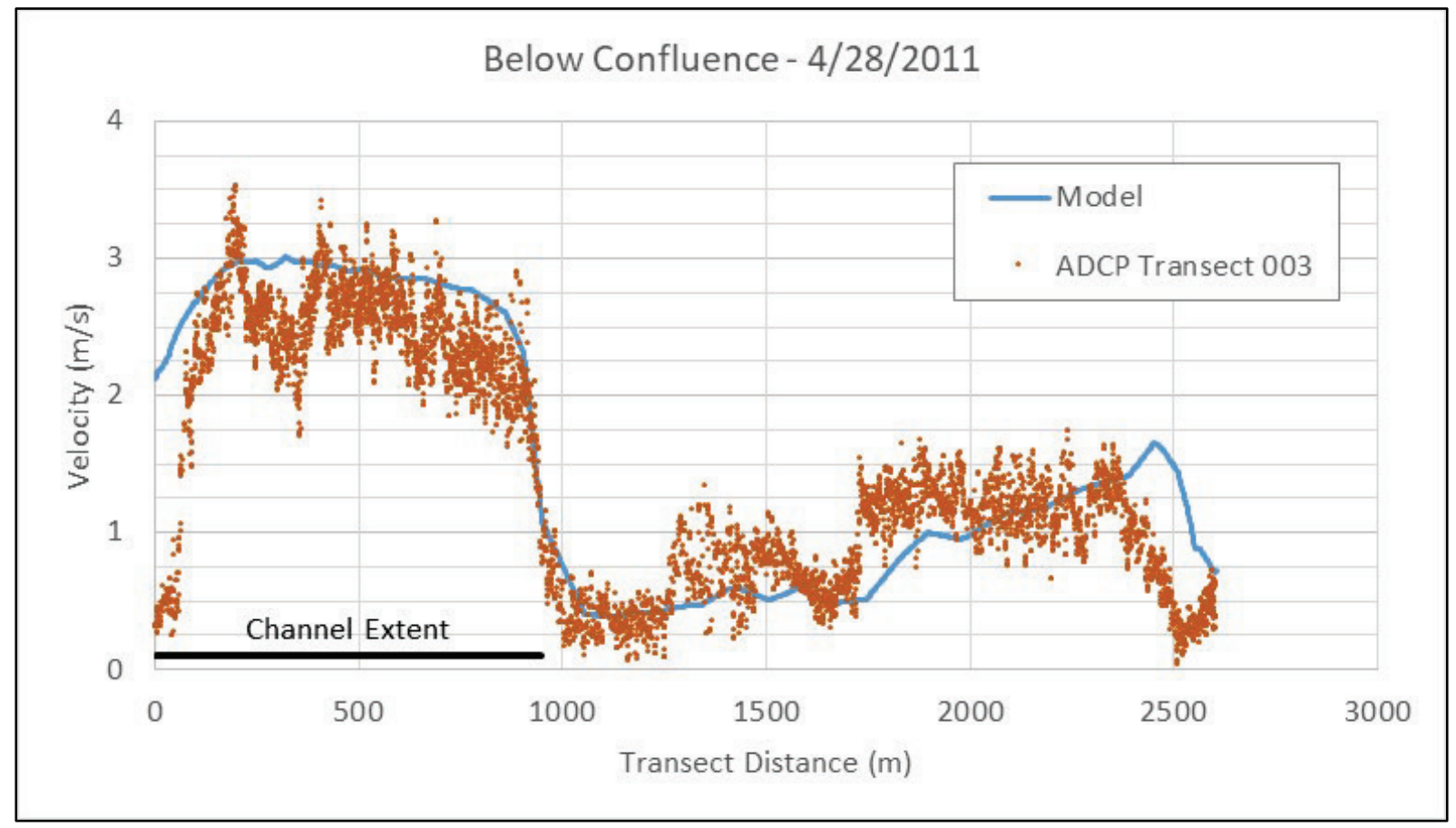


Figure A-27. Modeled and observed velocity below the confluence at Transect 000 on 4/30/2011.

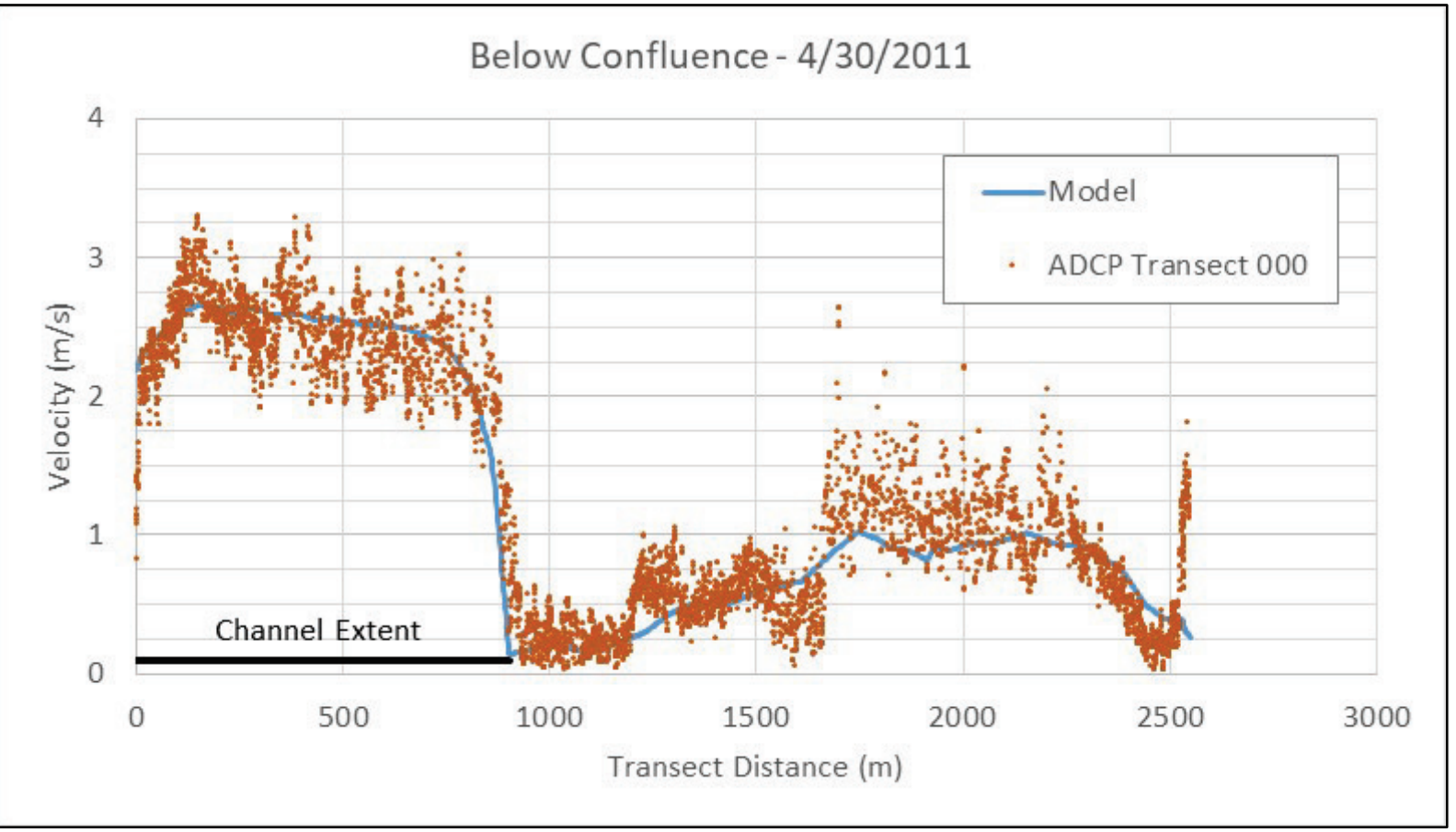

Figure A-28. Modeled and observed velocity below the confluence at Transect 001 on 4/30/2011.

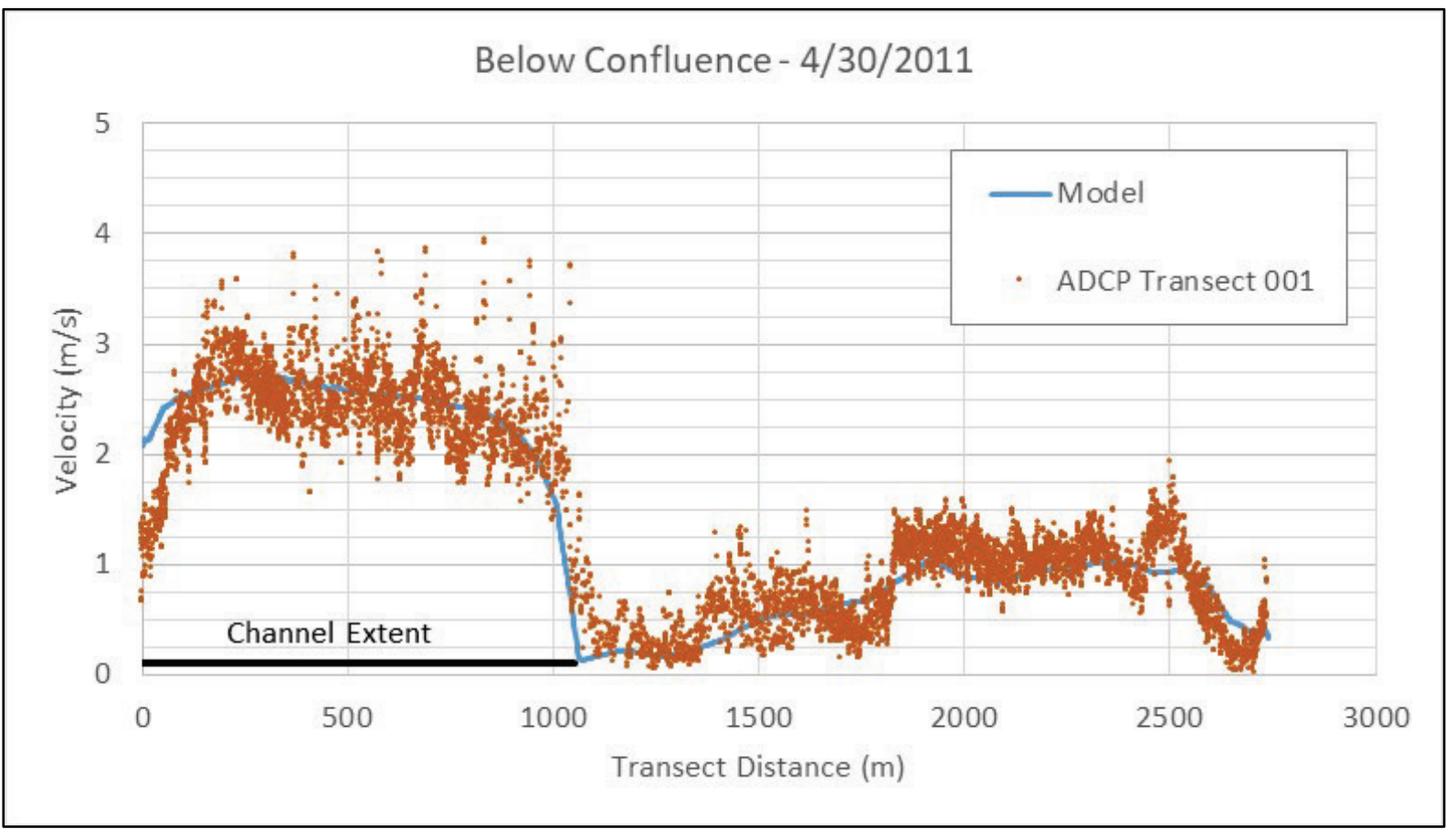


Figure A-29. Modeled and observed velocity below the confluence at Transect 000 on 5/1/2011.

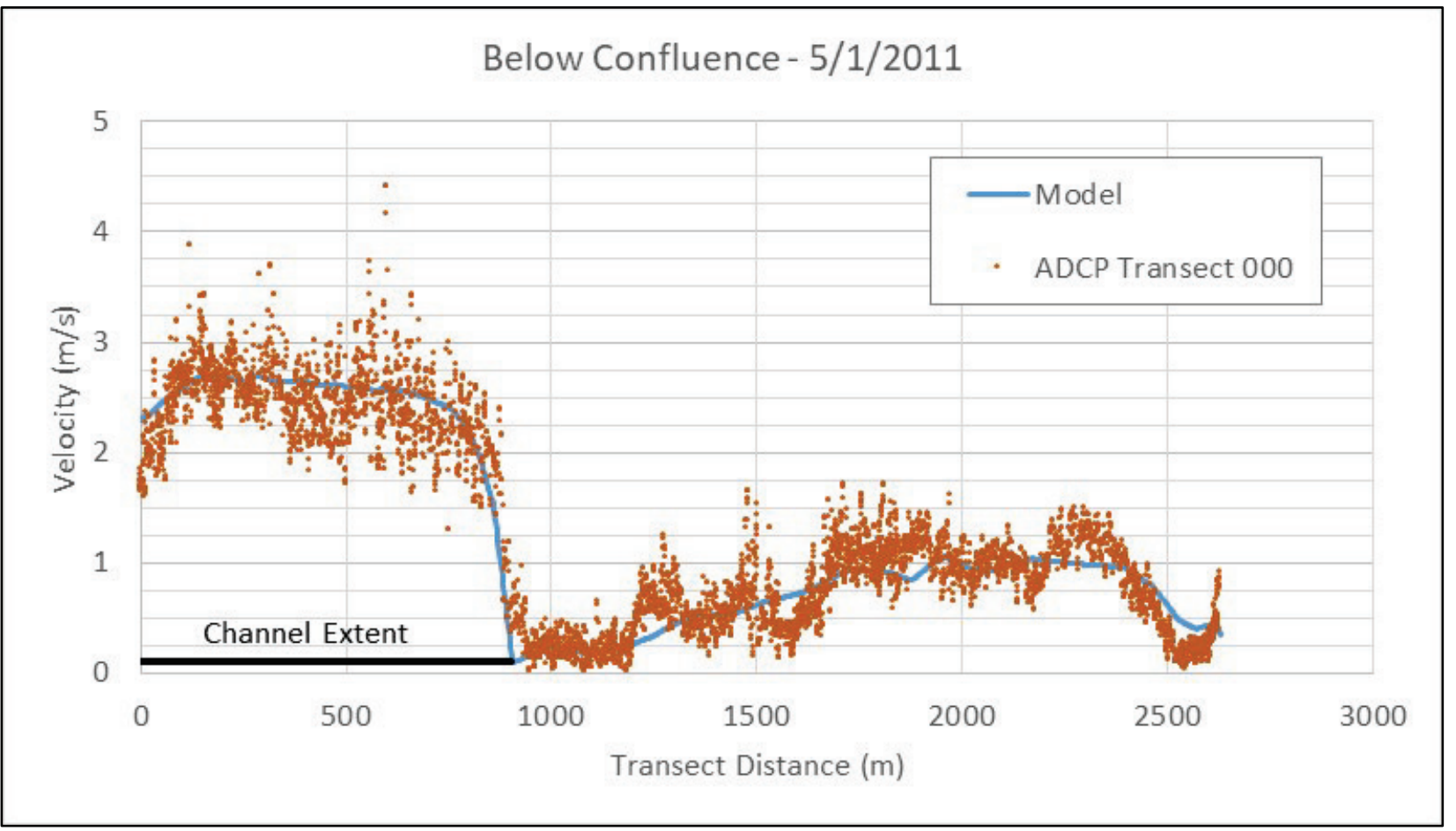

Figure A-30. Modeled and observed velocity below the confluence at Transect 001 on 5/1/2011.

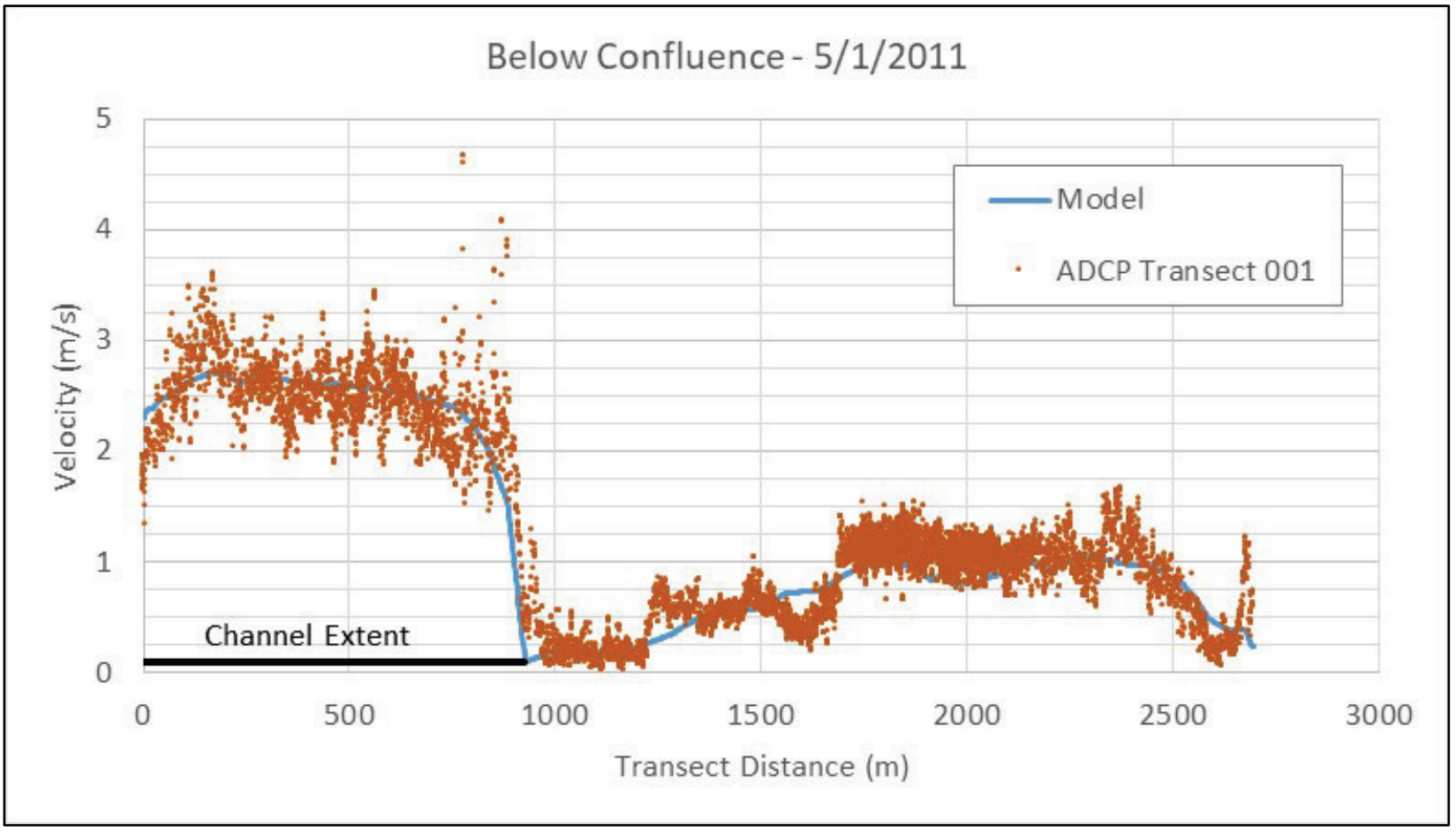


Figure A-31. Modeled and observed velocity below the breach at Transect 000 on 5/3/2011.

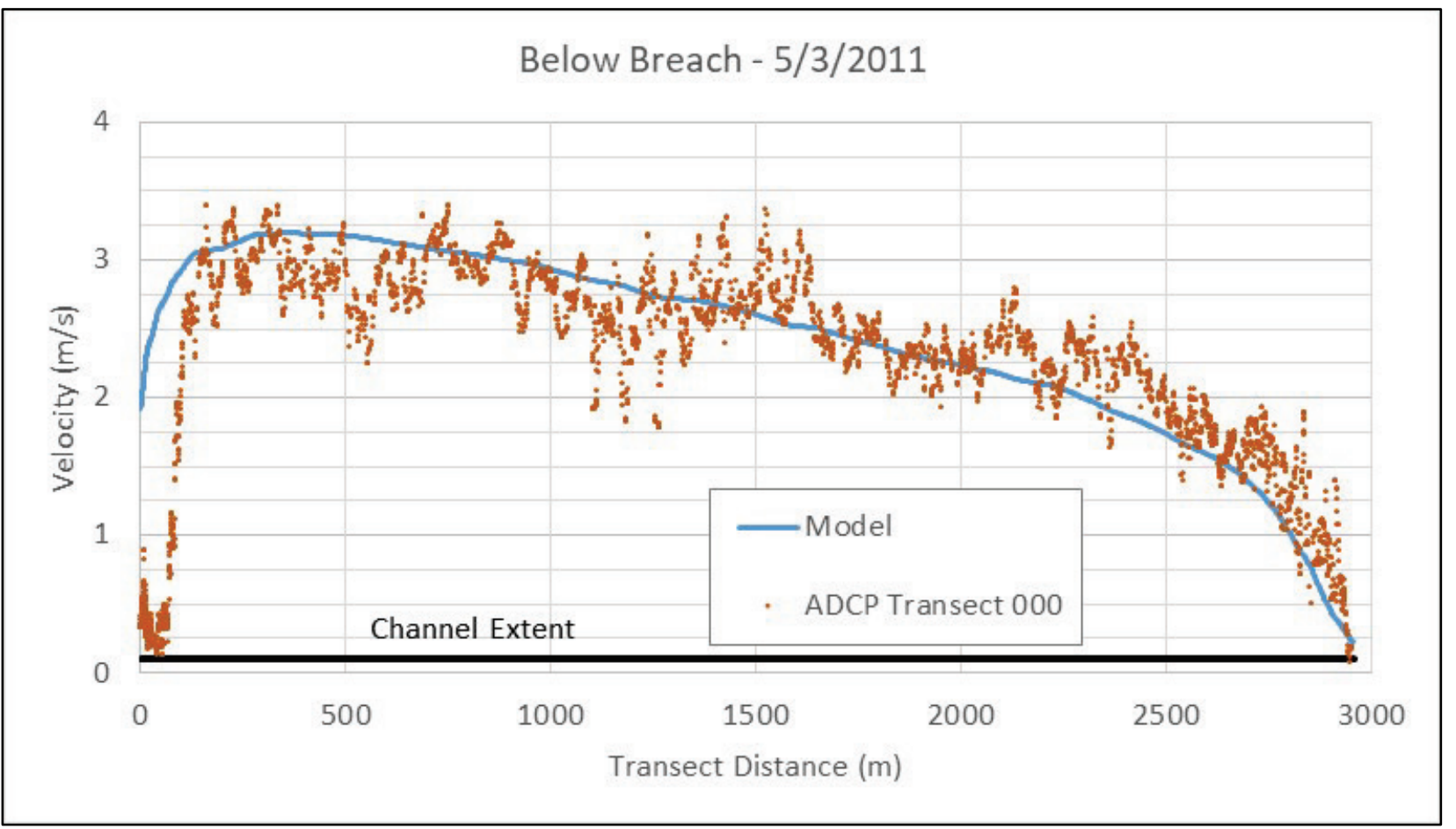

Figure A-32. Modeled and observed velocity below the breach at Transect 001 on 5/3/2011.

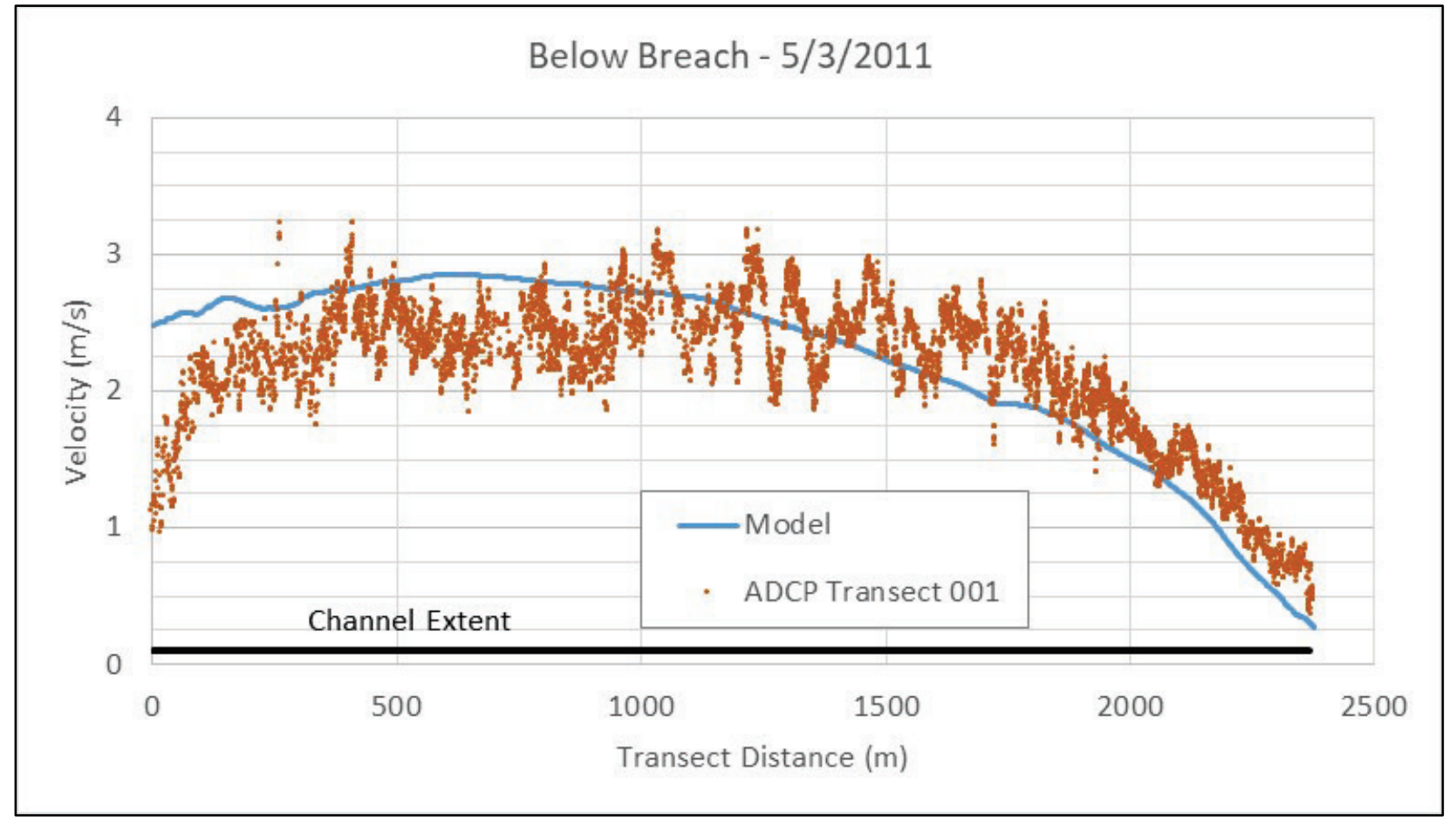


Figure A-33. Modeled and observed velocity below the breach at Transect 001 on 5/4/2011.

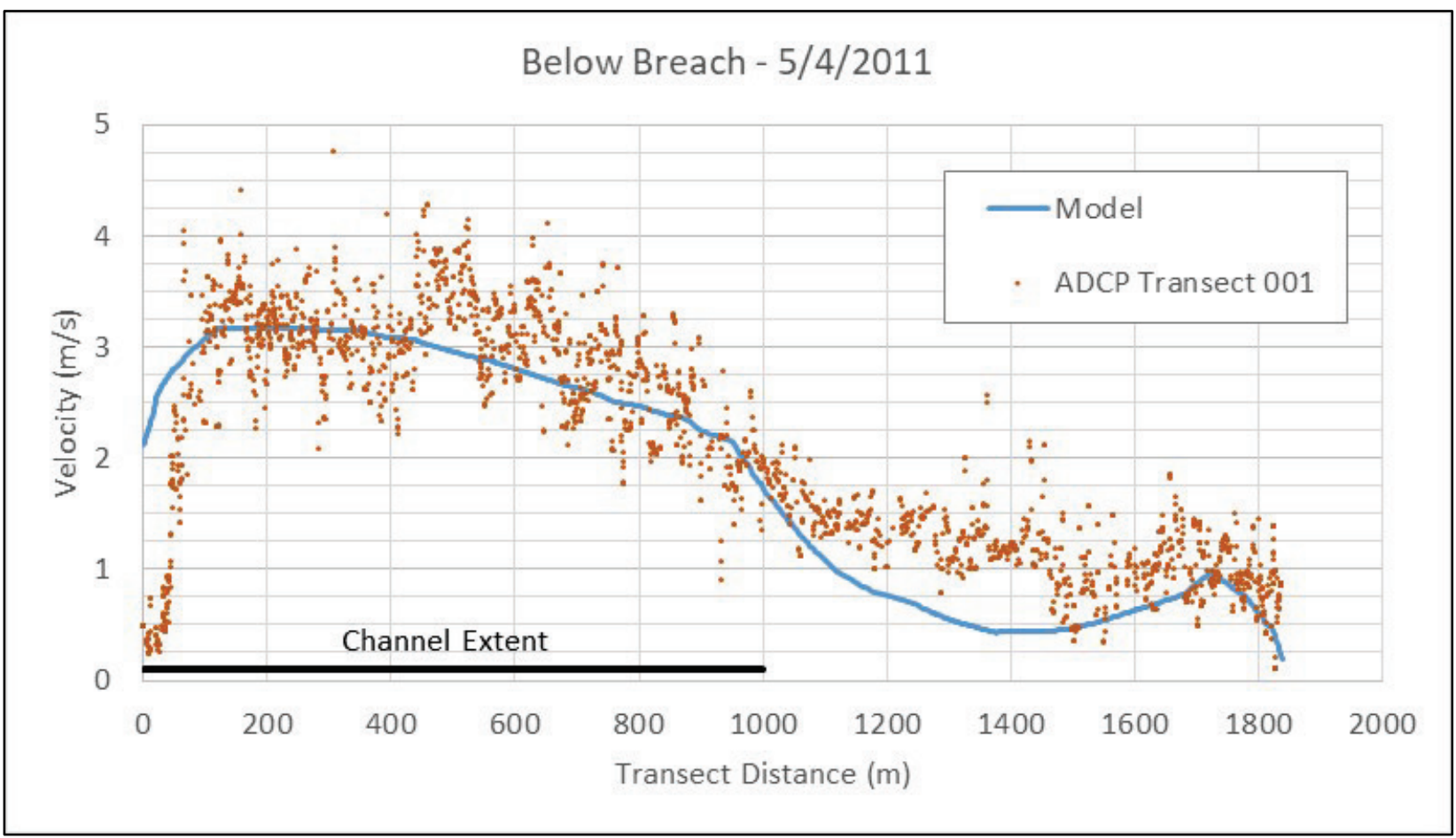

Figure A-34. Modeled and observed velocity below the breach at Transect 003 on 5/4/2011.

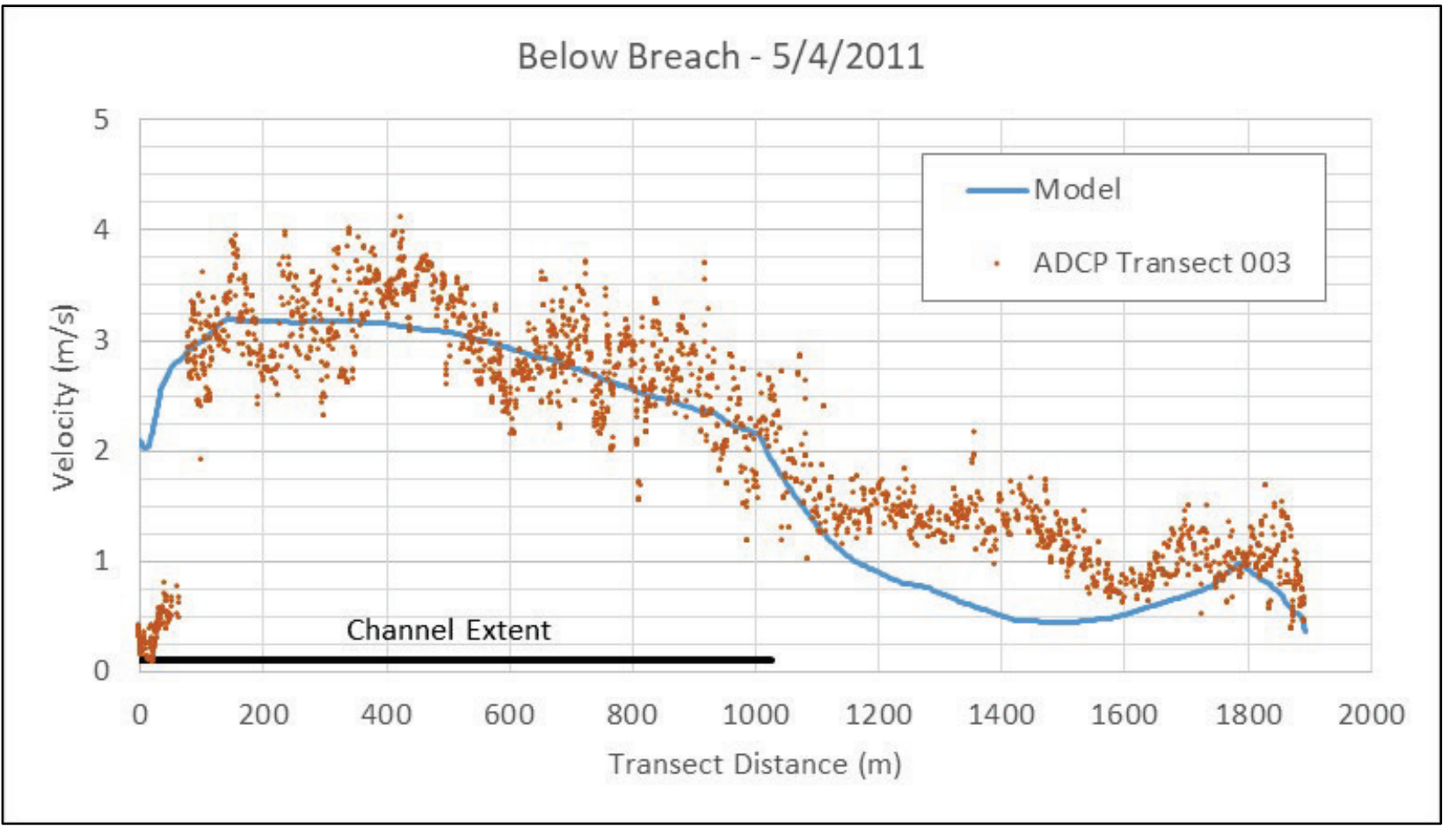


Figure A-35. Modeled and observed velocity below the breach at Transect 000 on 5/5/2011.

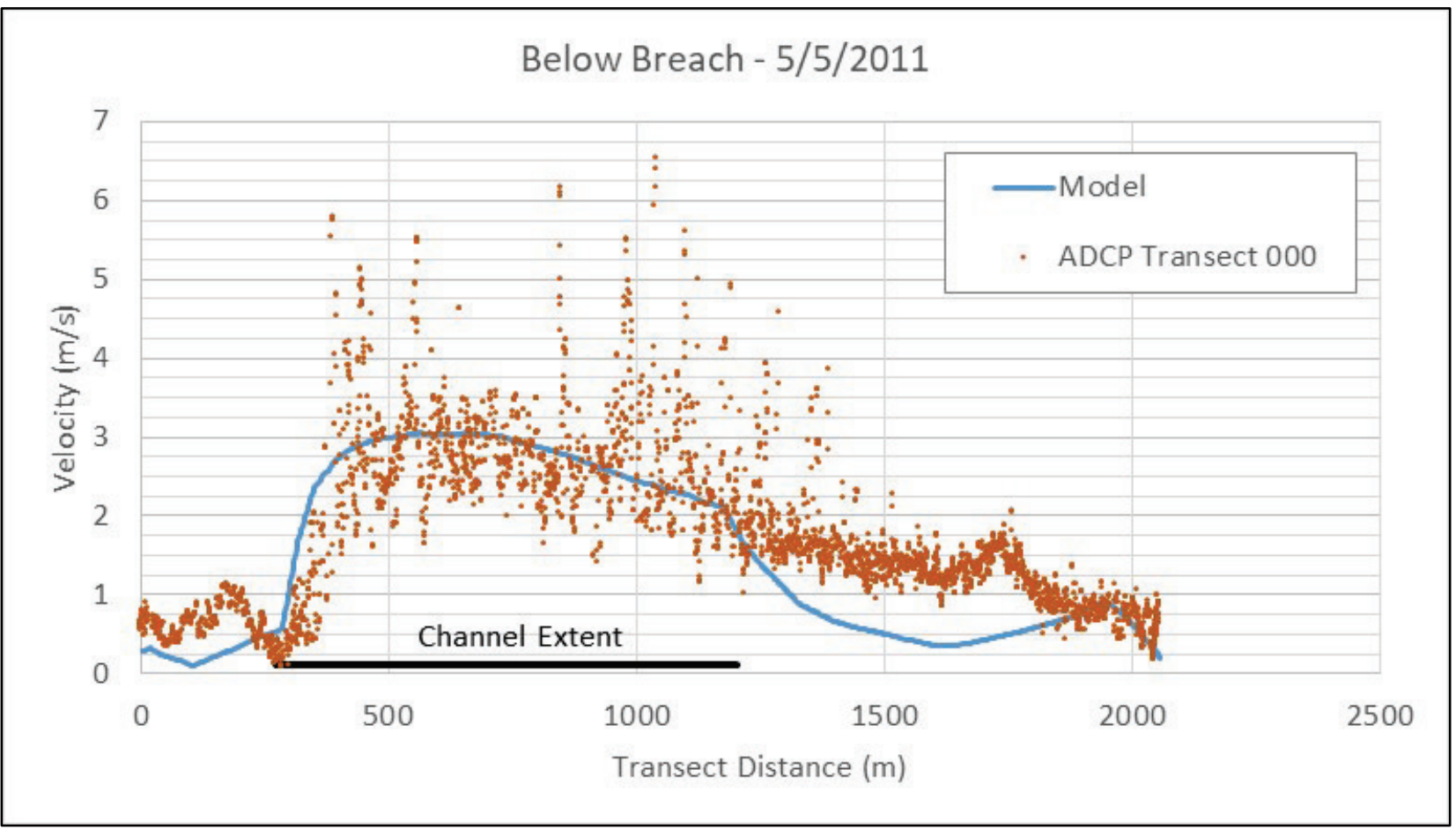

Figure A-36. Modeled and observed velocity below the breach at Transect 001 on 5/5/2011.

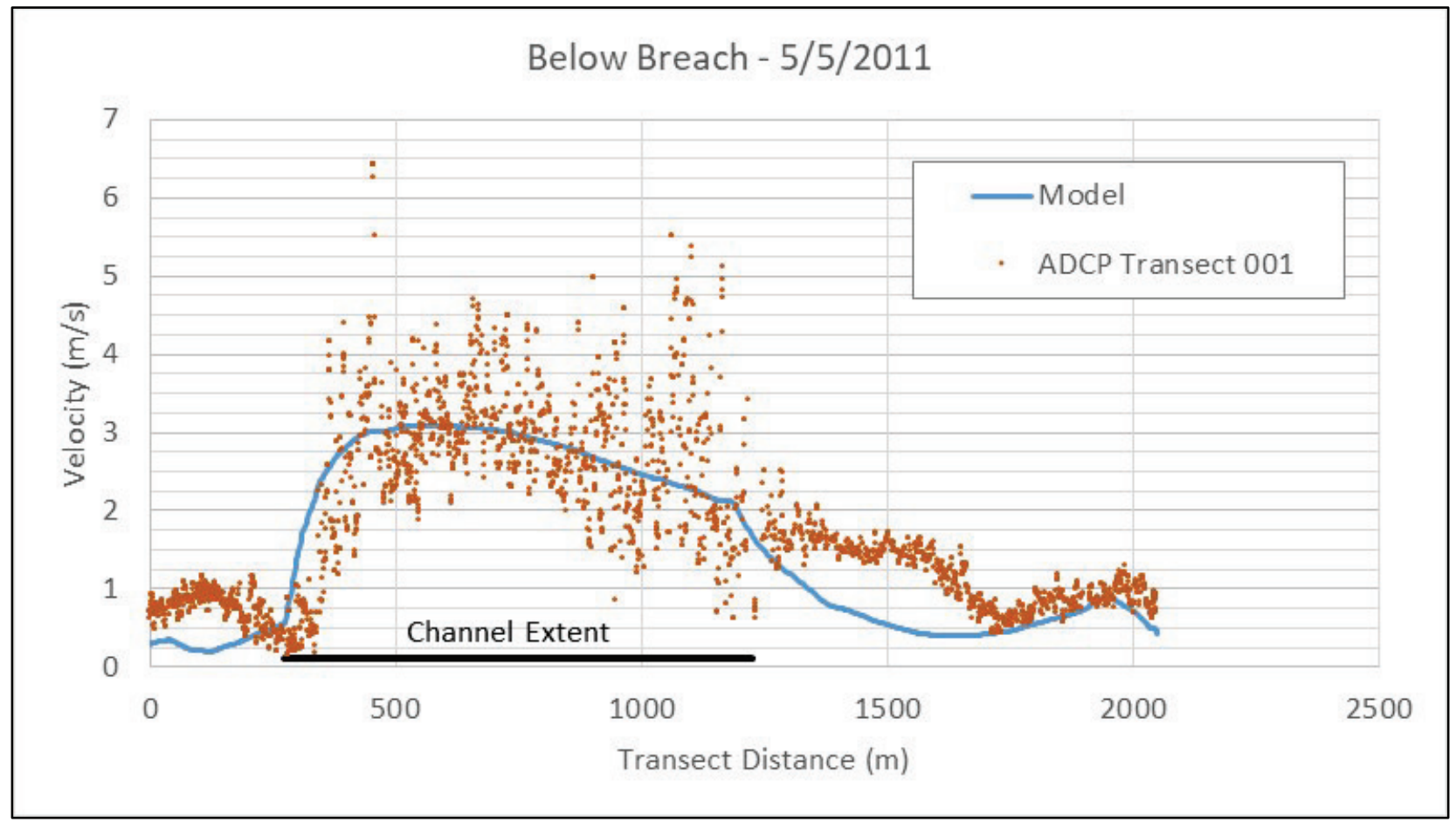


Figure A-37. Modeled and observed velocity below the breach at Transect 000 on 5/6/2011.

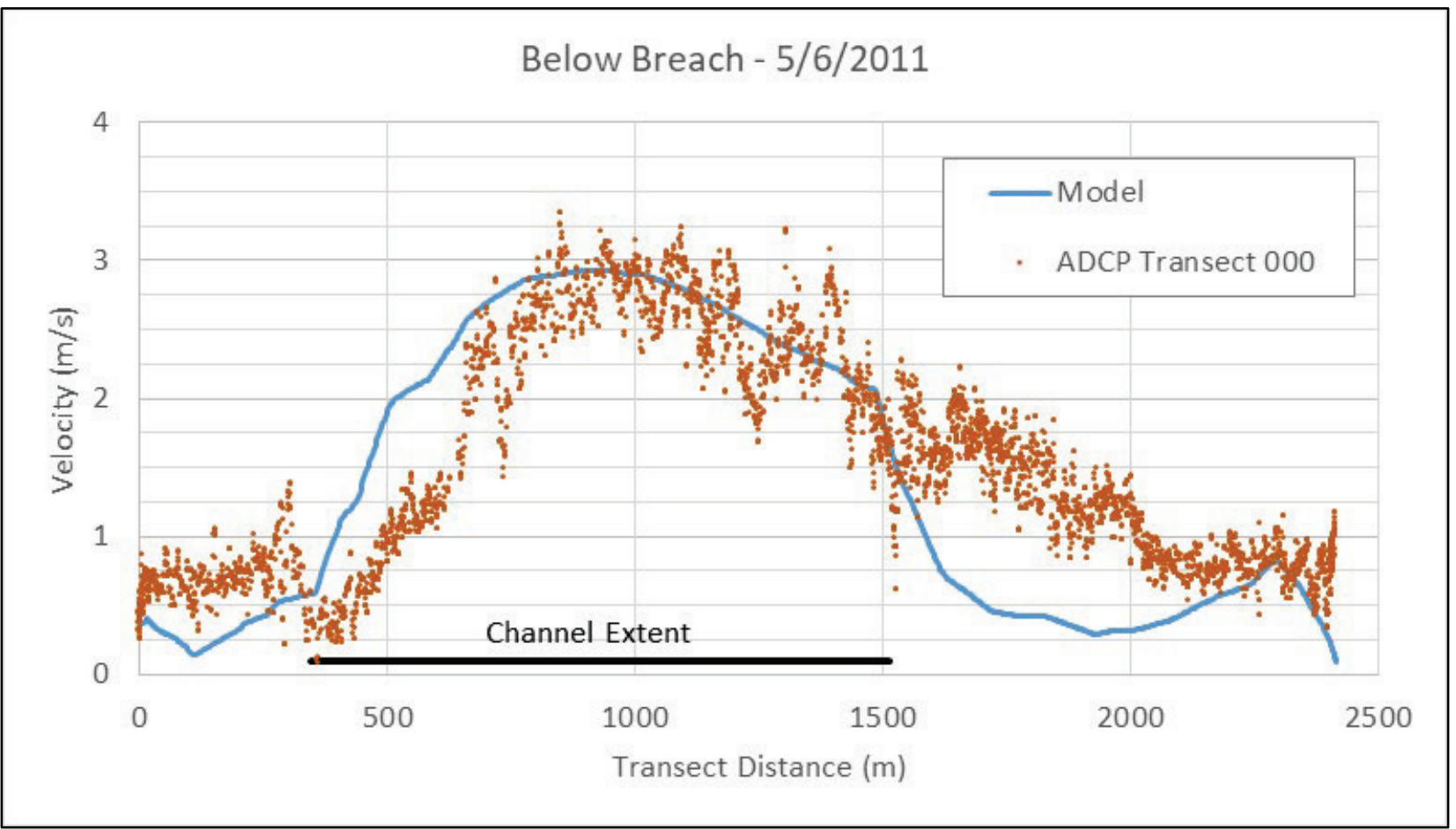

Figure A-38. Modeled and observed velocity below the breach at Transect 001 on 5/6/2011.

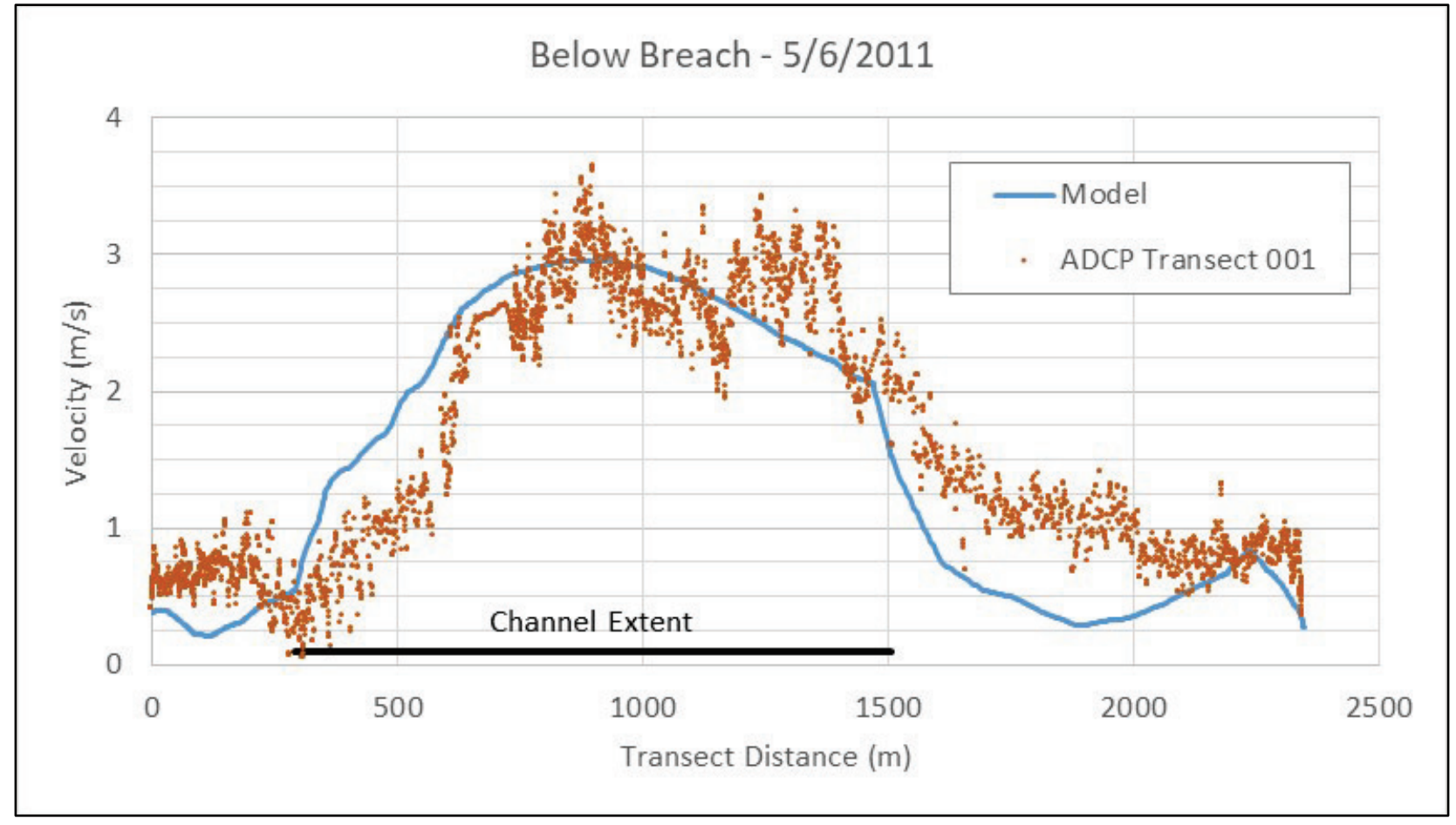


Figure A-39. Modeled and observed velocity below the breach at Transect 000 on 5/14/2011.

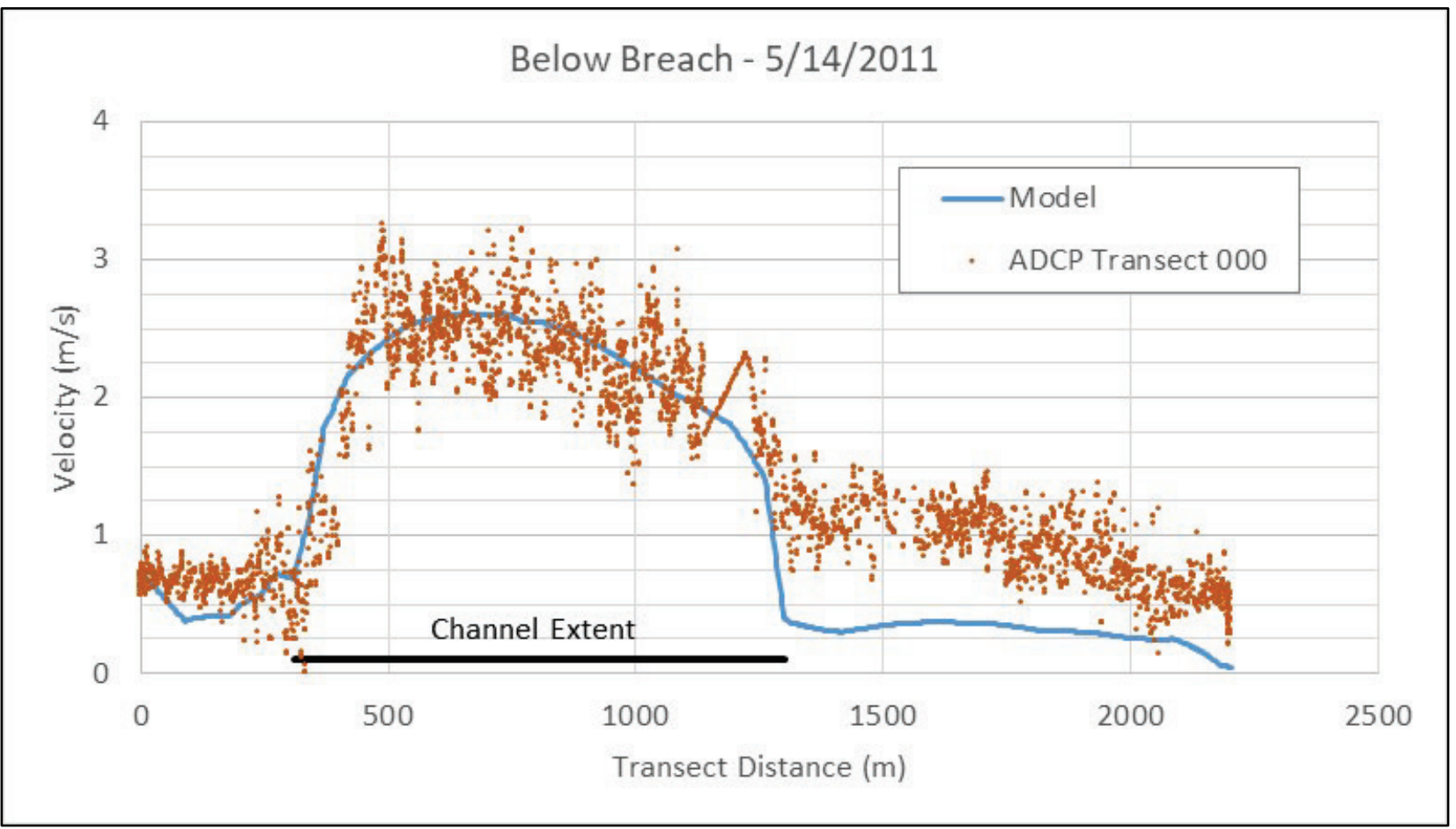

Figure A-40. Modeled and observed velocity below the breach at Transect 001 on 5/14/2011.

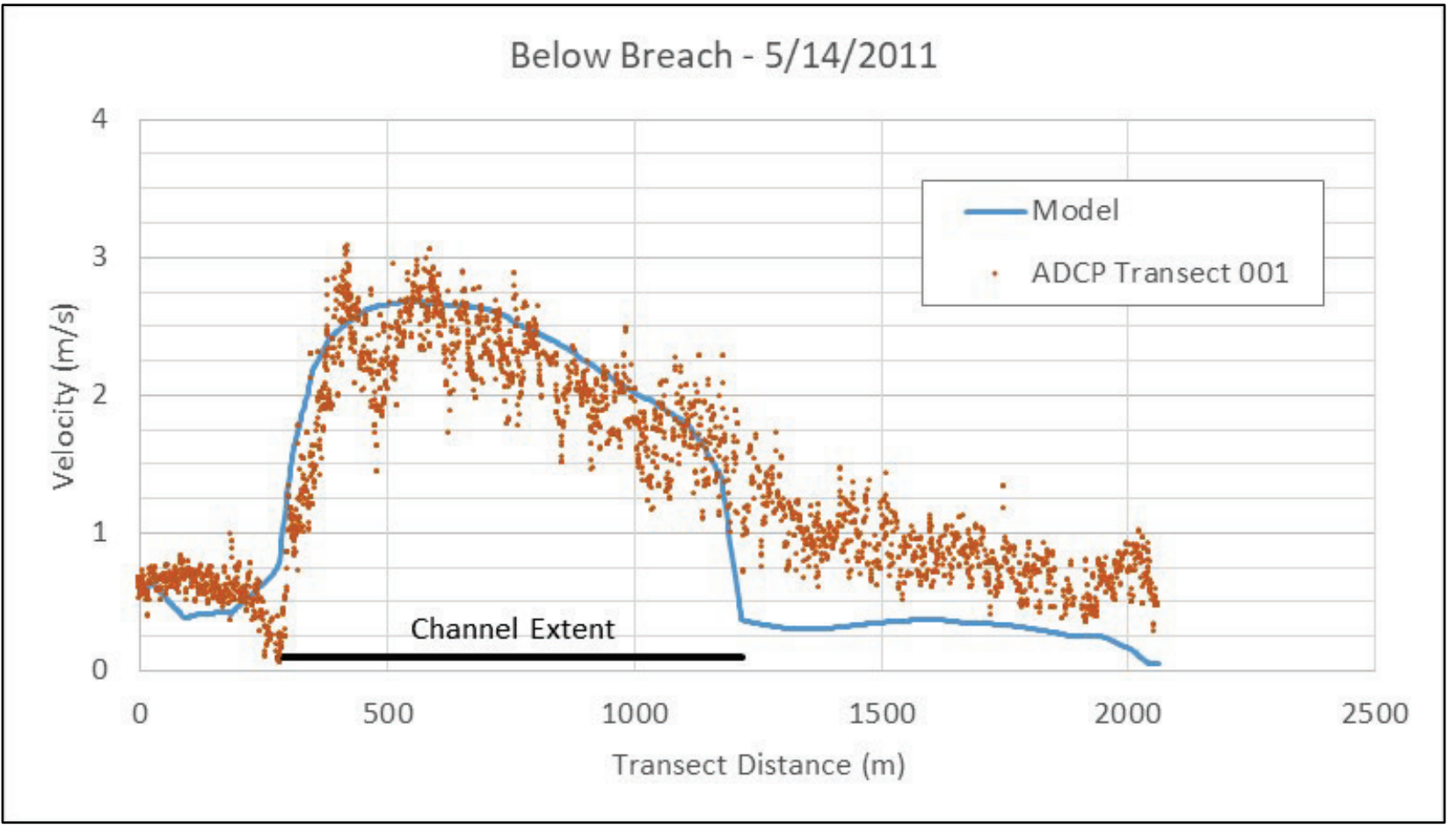




\section{Velocity direction calibration}

Figure A-41. Modeled and observed velocity direction below the confluence at Transect 002 on $4 / 28 / 2011$.

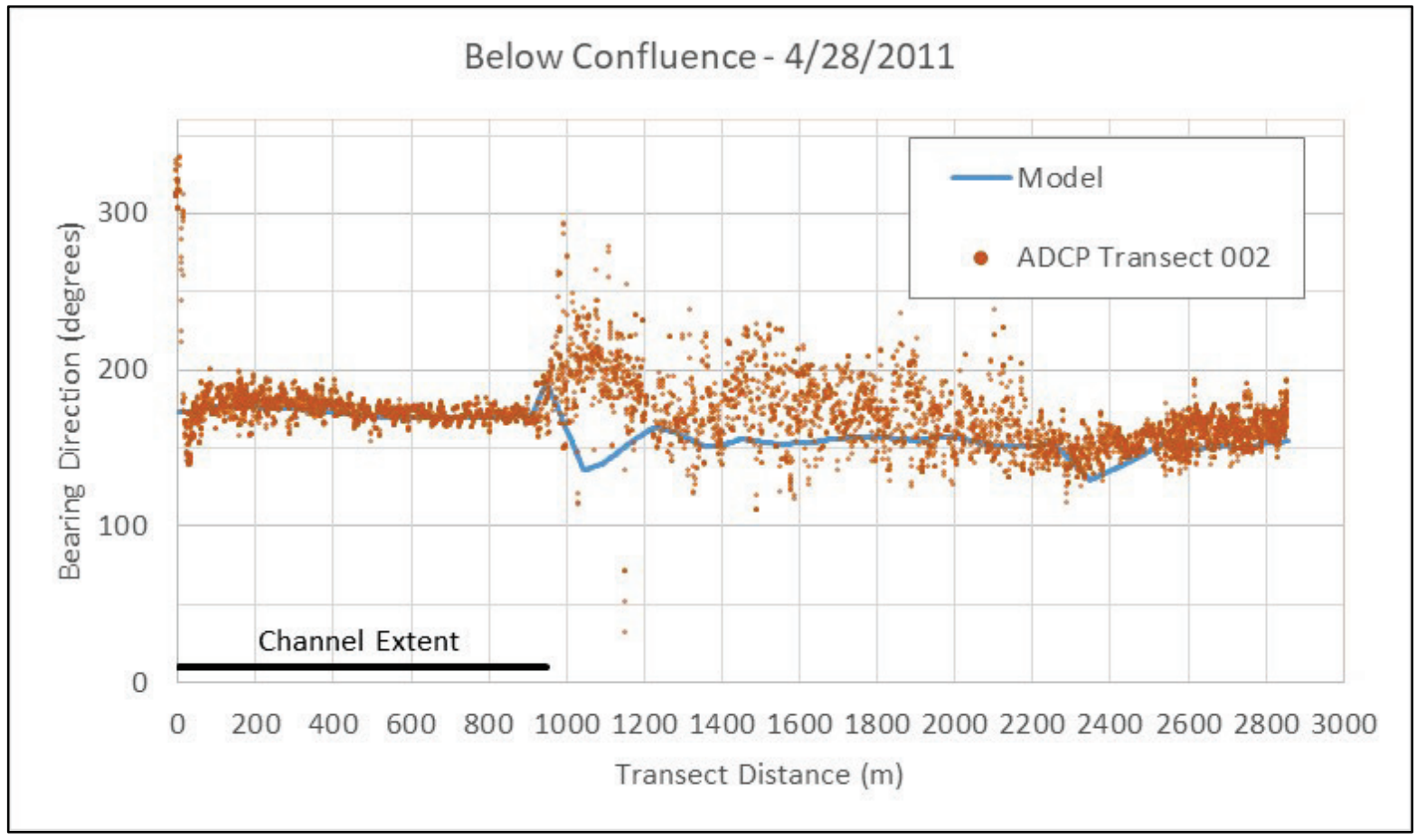

Figure A-42. Modeled and observed velocity direction below the confluence at Transect 003 on $4 / 28 / 2011$.

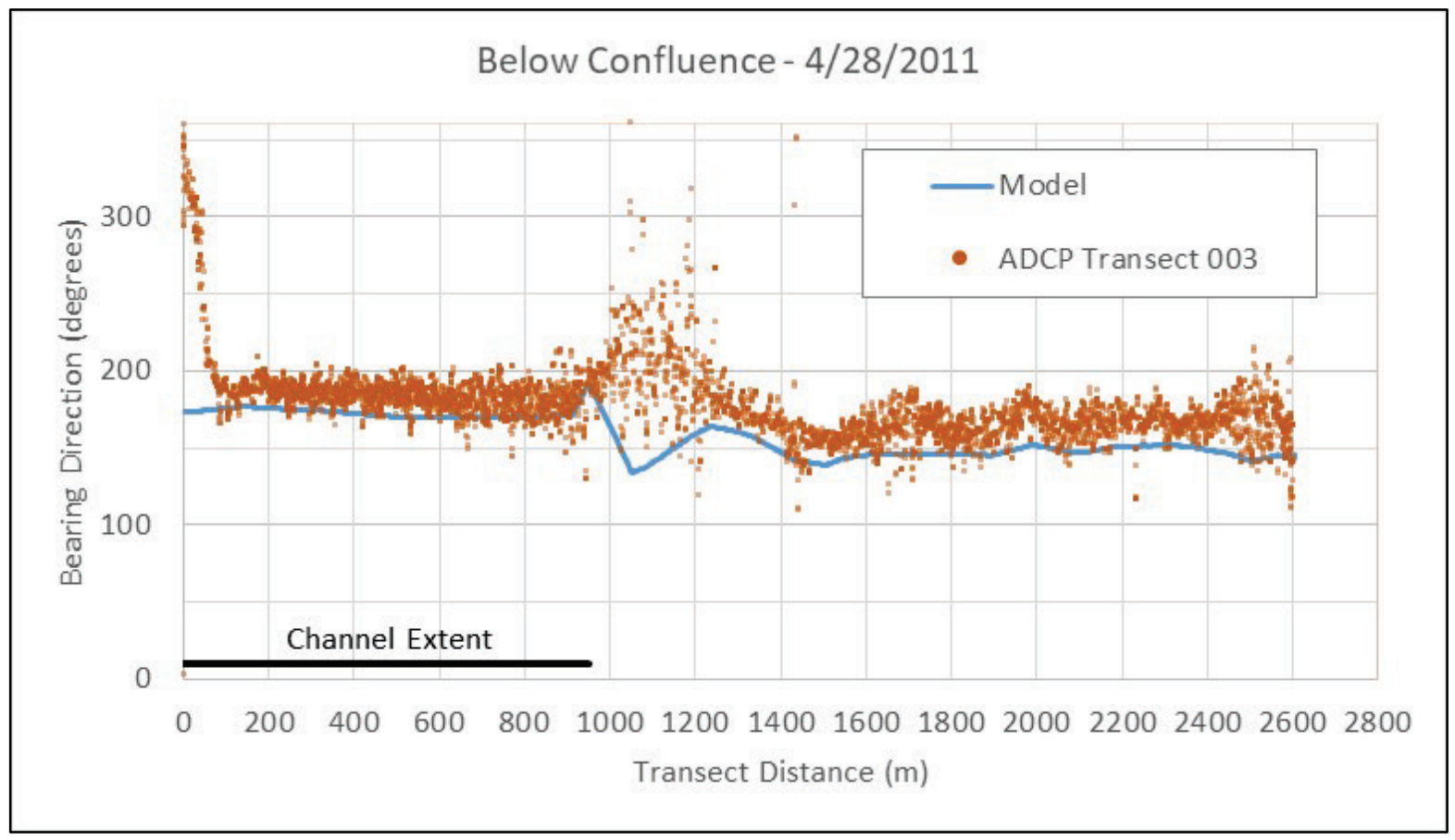


Figure A-43. Modeled and observed velocity direction below the confluence at Transect 000 on $4 / 30 / 2011$.

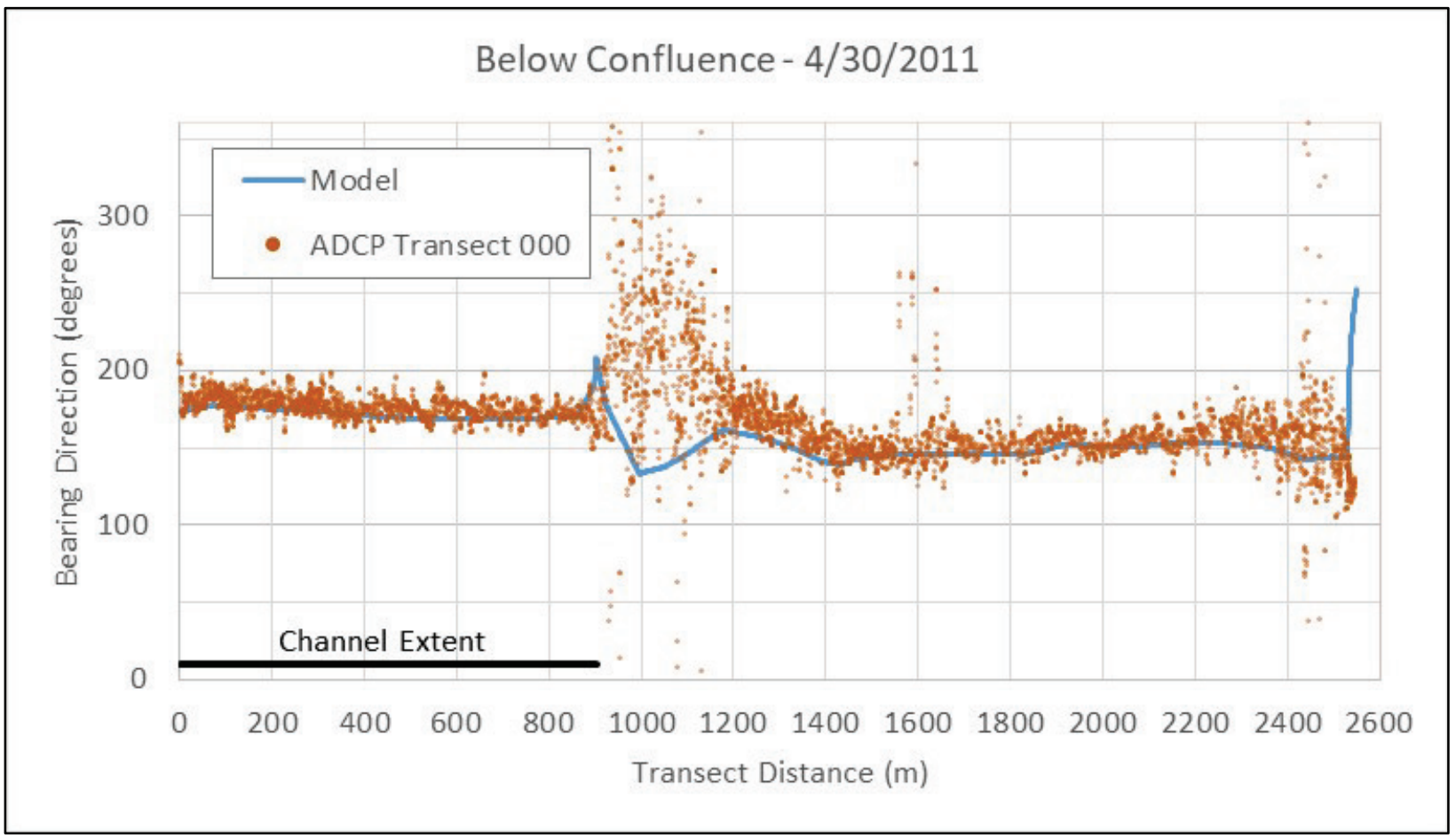

Figure A-44. Modeled and observed velocity direction below the confluence at Transect 001 on $4 / 30 / 2011$.

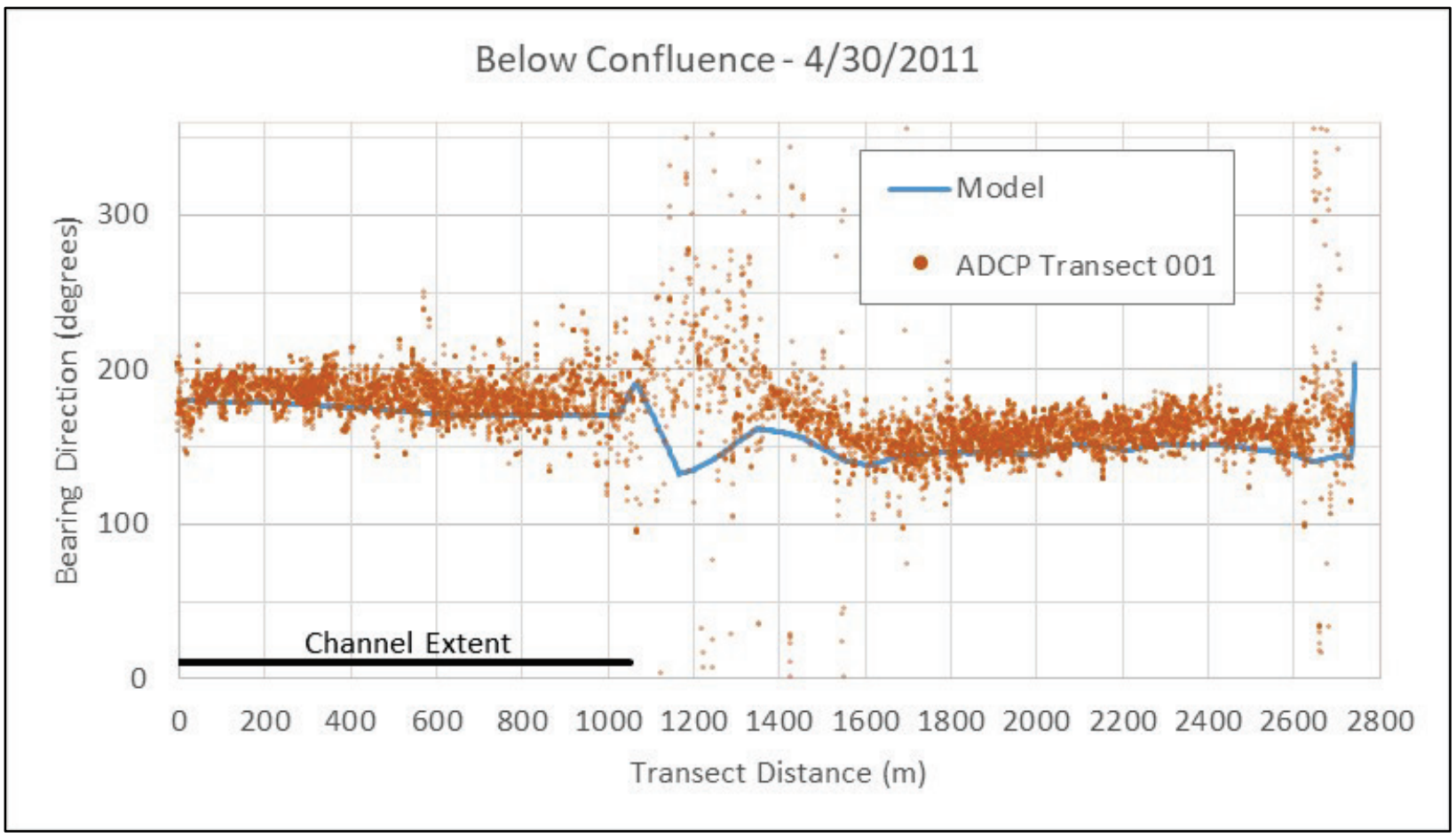


Figure A-45. Modeled and observed velocity direction below the confluence at Transect 000 on $5 / 1 / 2011$.

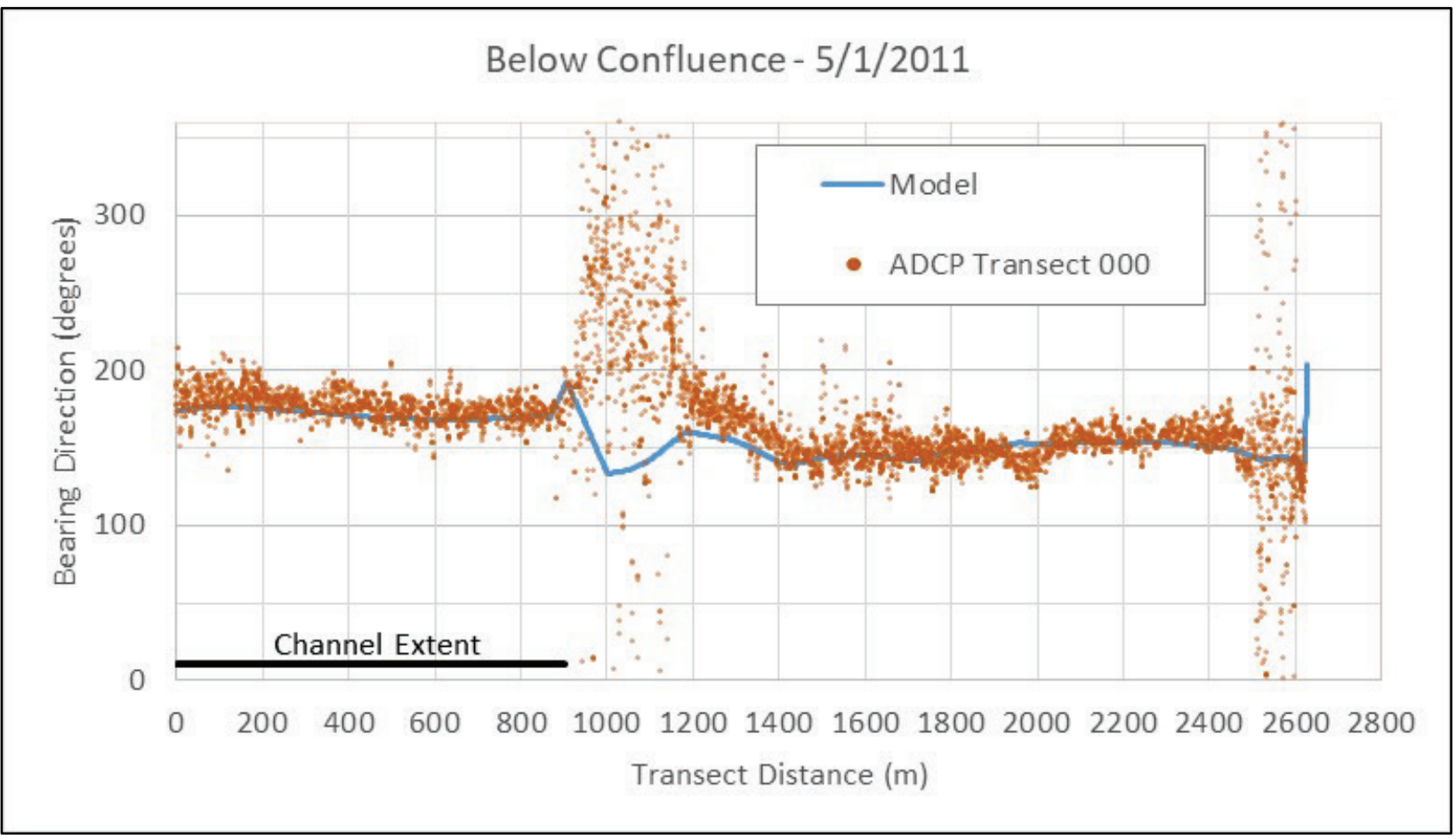

Figure A-46. Modeled and observed velocity direction below the confluence at Transect 001 on $5 / 1 / 2011$.

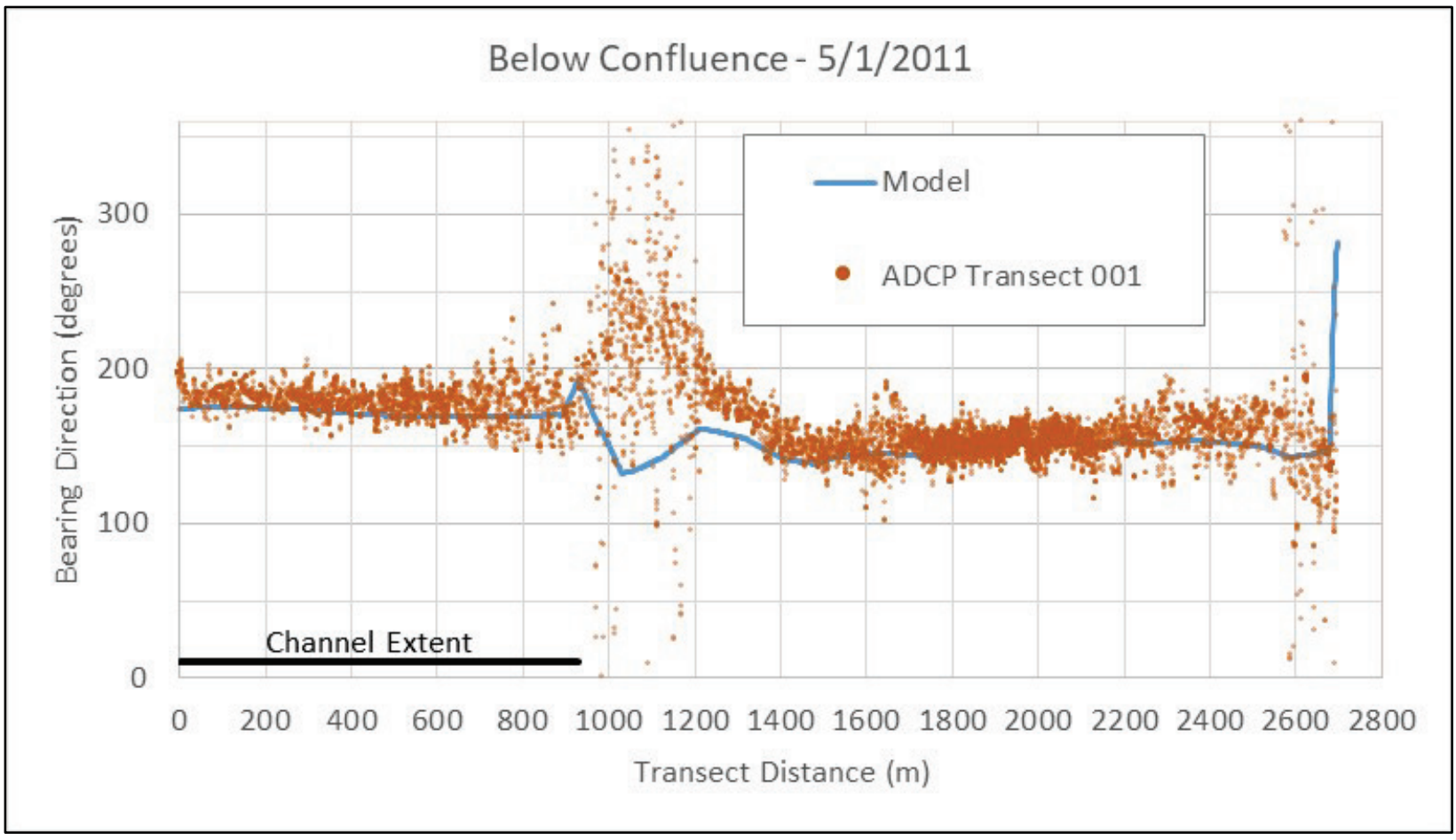


Figure A-47. Modeled and observed velocity direction below the breach at Transect 000 on $5 / 3 / 2011$.

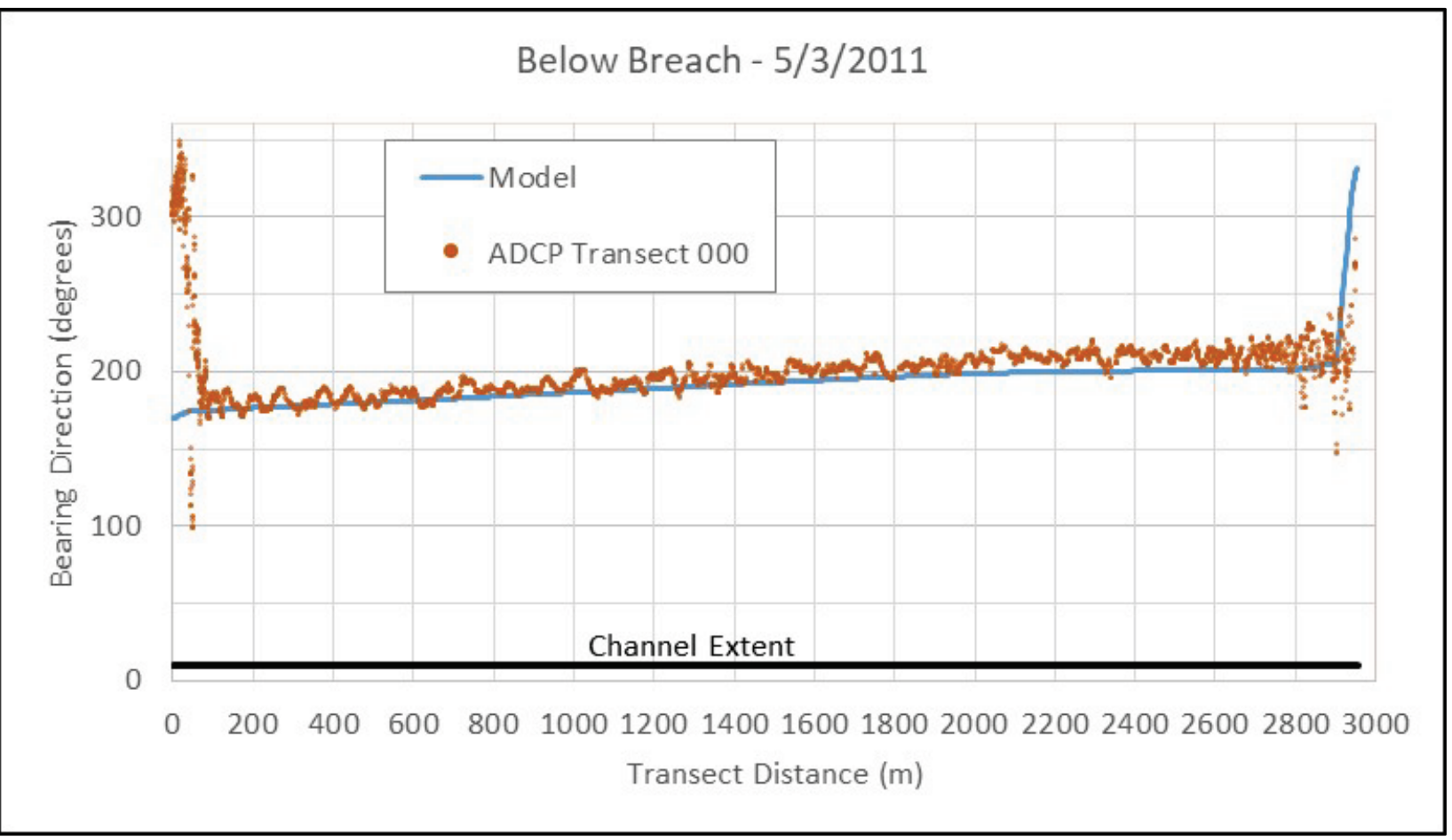

Figure A-48. Modeled and observed velocity direction below the breach at Transect 001 on $5 / 3 / 2011$.

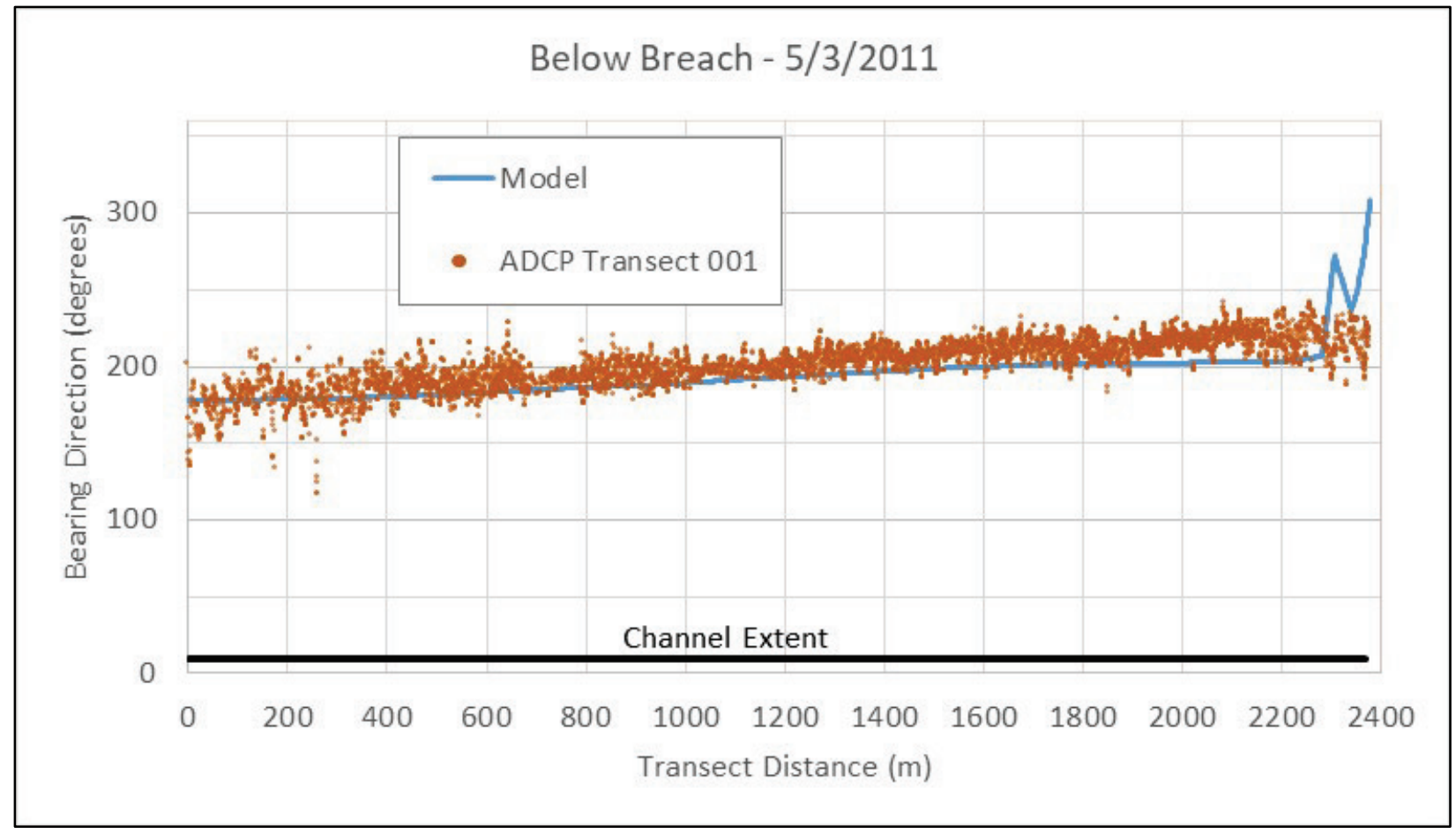


Figure A-49. Modeled and observed velocity direction below the breach at Transect 001 on $5 / 4 / 2011$.

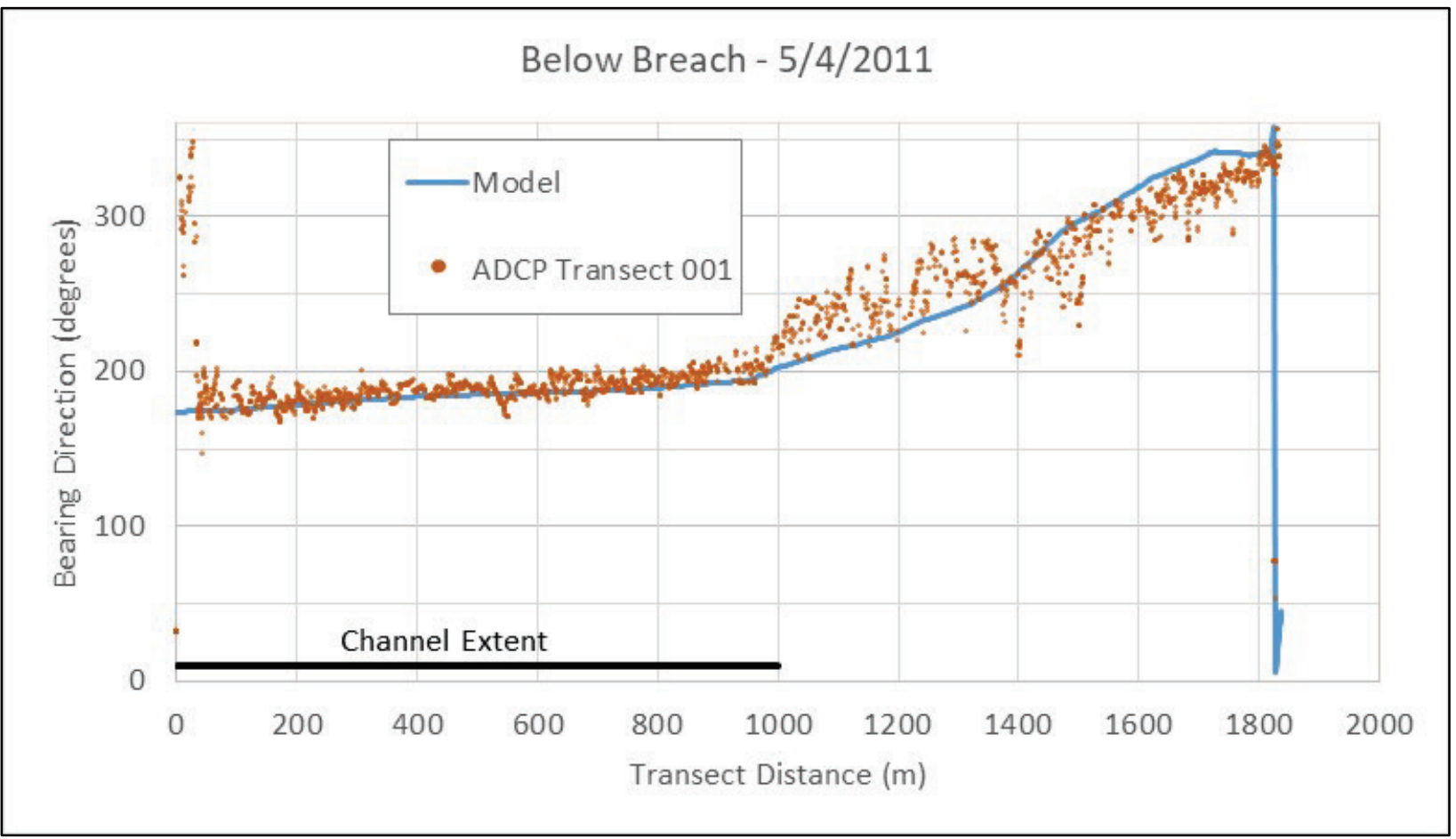

Figure A-50. Modeled and observed velocity direction below the breach at Transect 003 on $5 / 4 / 2011$.

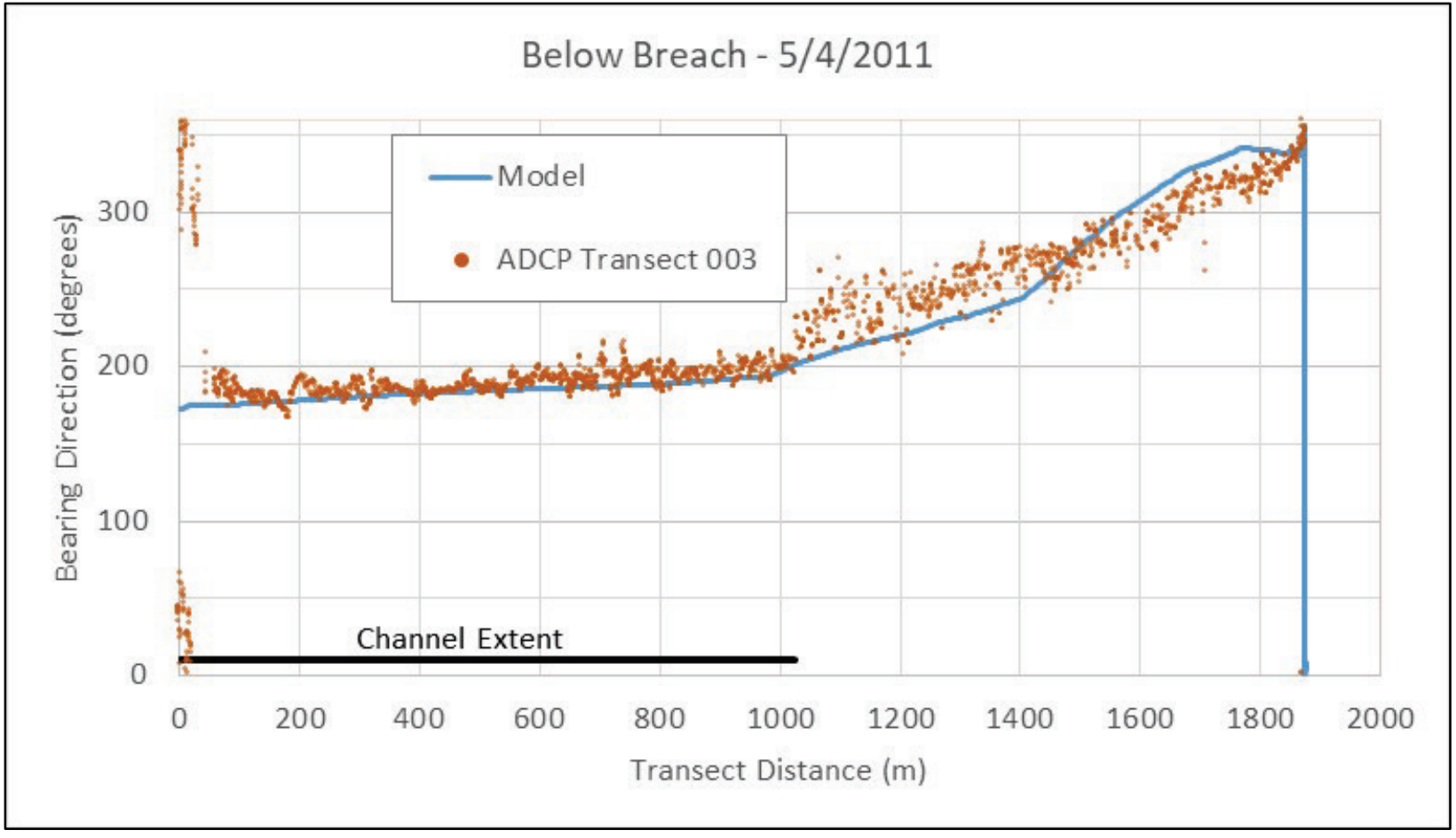


Figure A-51. Modeled and observed velocity direction below the breach at Transect 000 on $5 / 5 / 2011$.

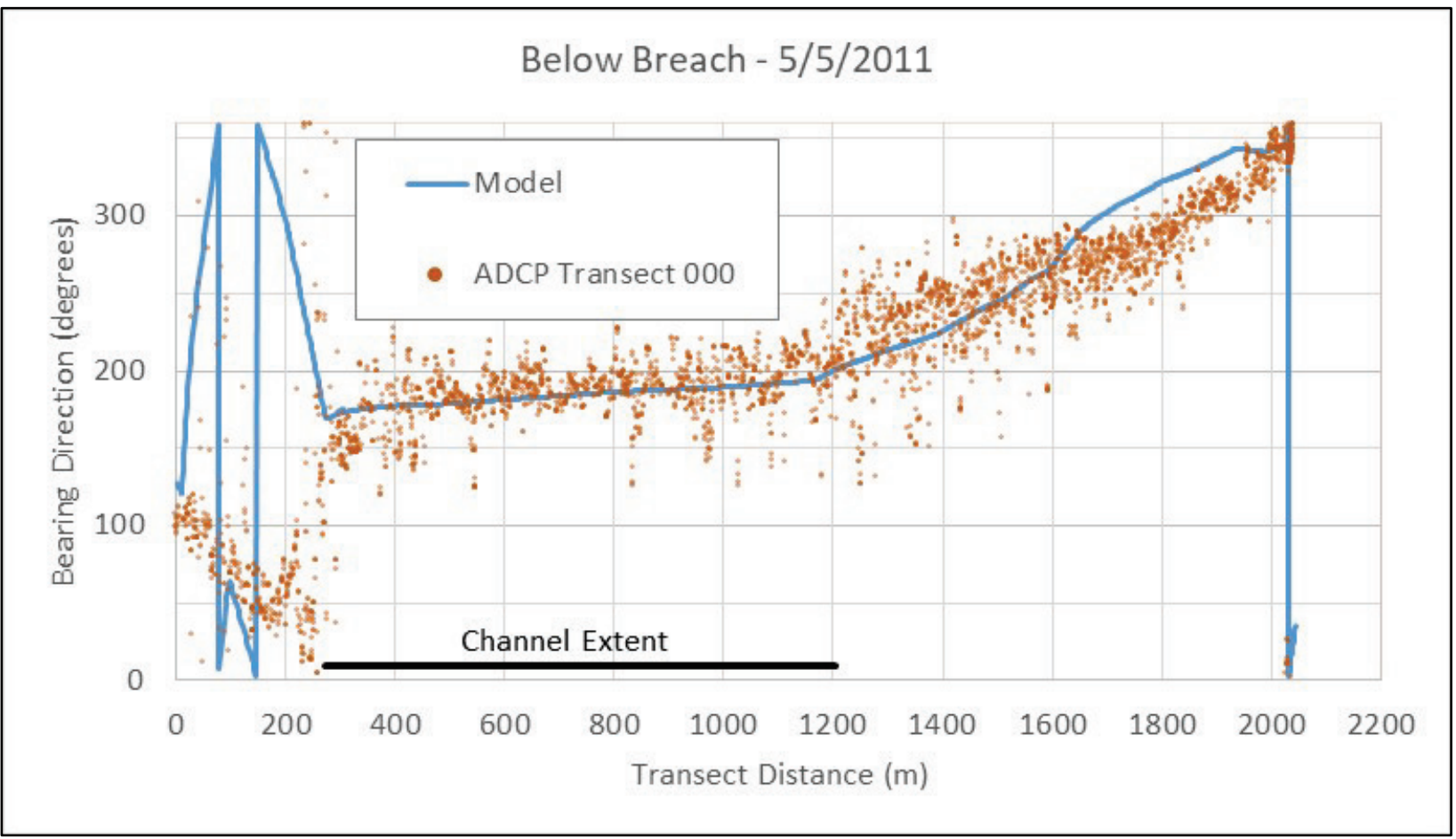

Figure A-52. Modeled and observed velocity direction below the breach at Transect 001 on $5 / 5 / 2011$.

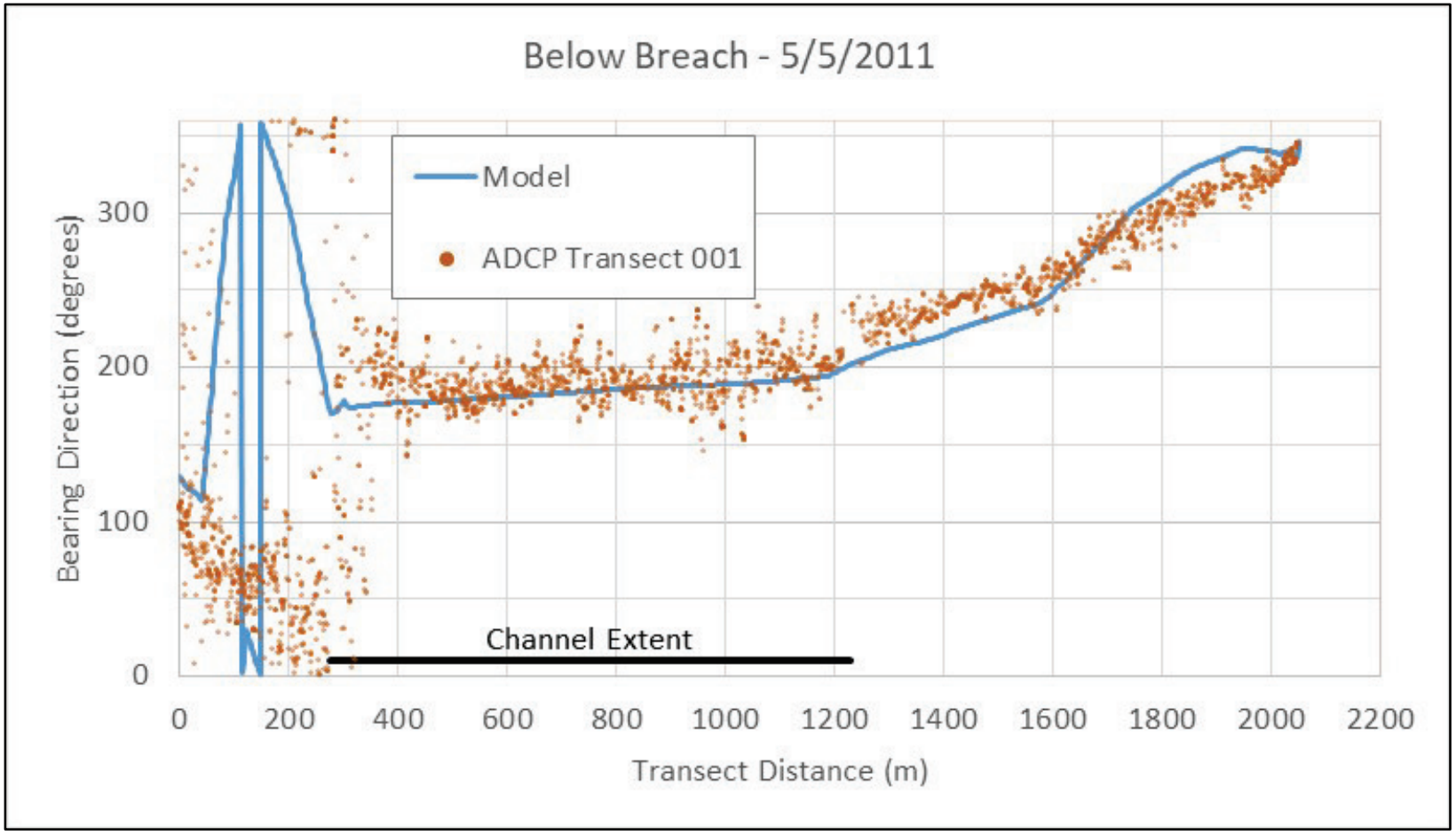


Figure A-53. Modeled and observed velocity direction below the breach at Transect 000 on $5 / 6 / 2011$.

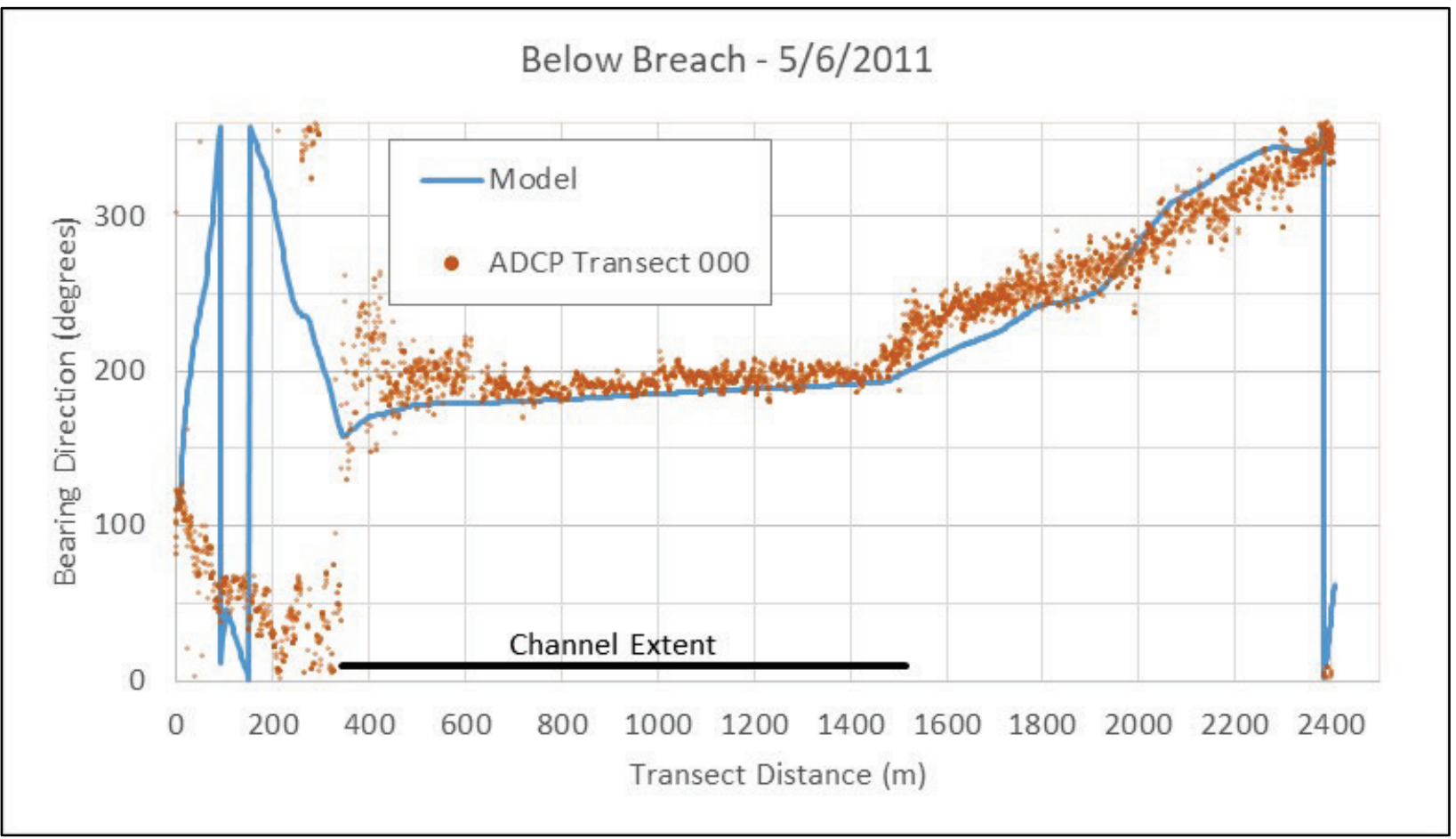

Figure A-54. Modeled and observed velocity direction below the breach at Transect 001 on $5 / 6 / 2011$.

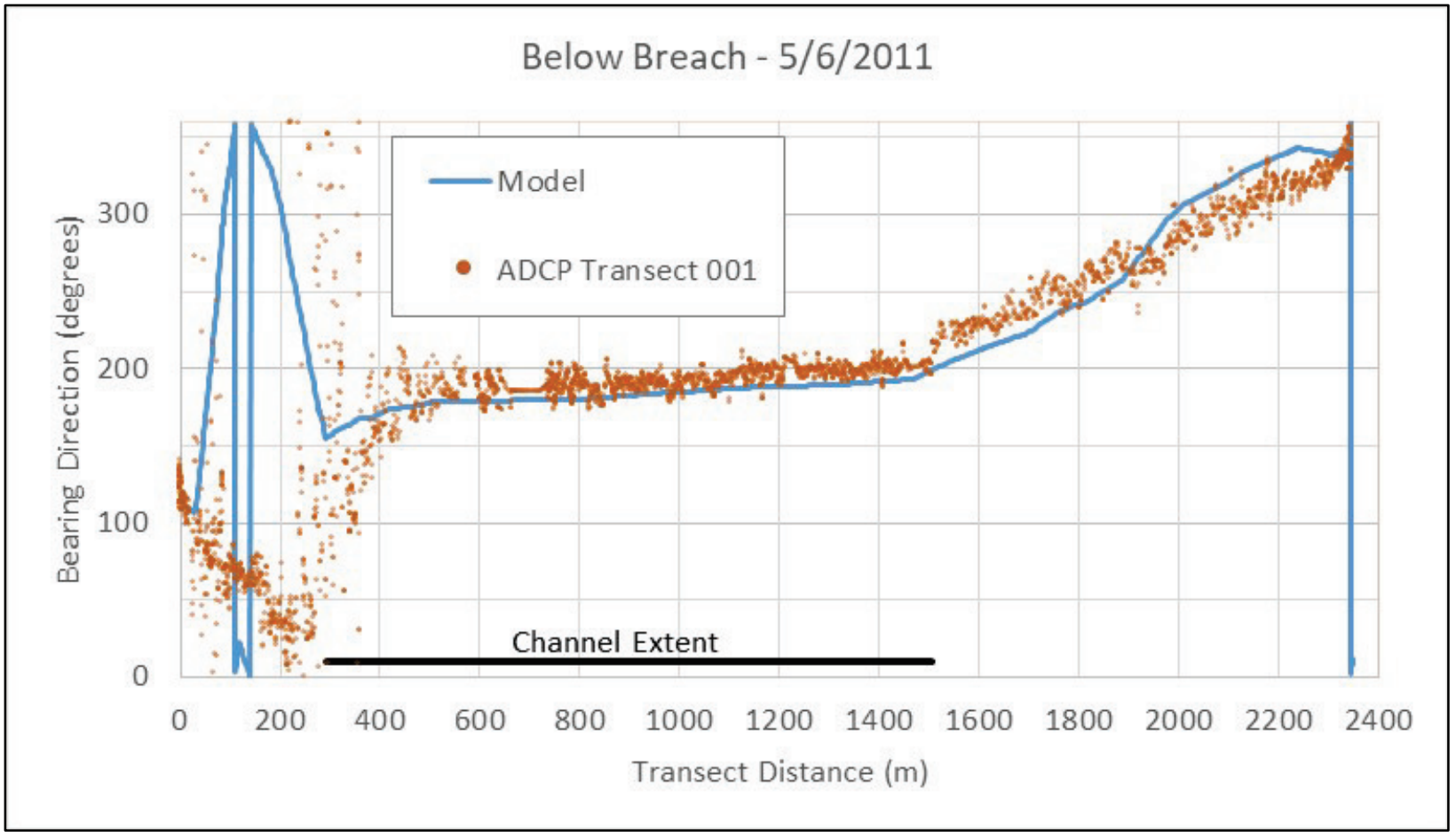


Figure A-55. Modeled and observed velocity direction below the breach at Transect 000 on $5 / 14 / 2011$.

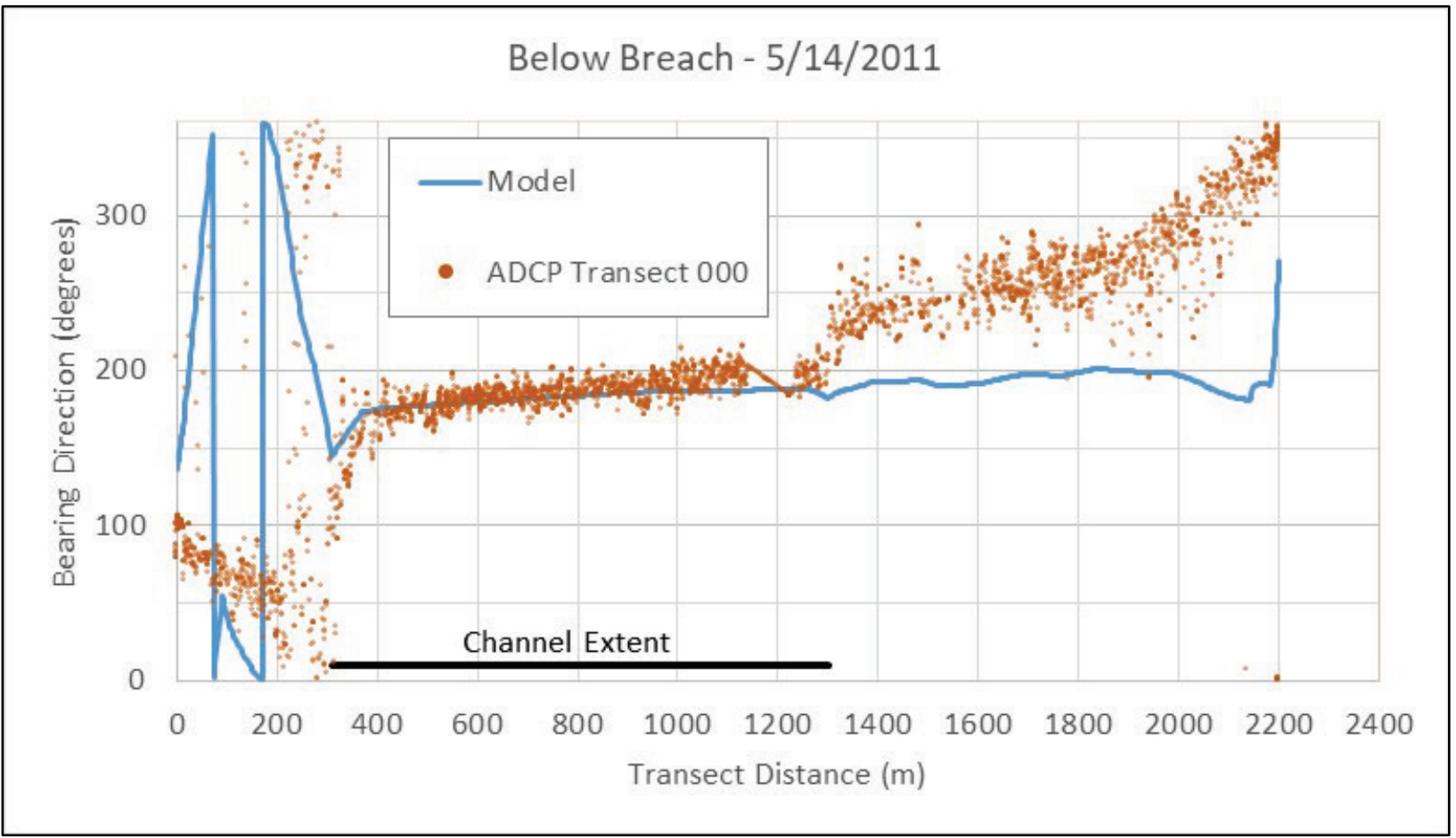

Figure A-56. Modeled and observed velocity direction below the breach at Transect 001 on $5 / 14 / 2011$.

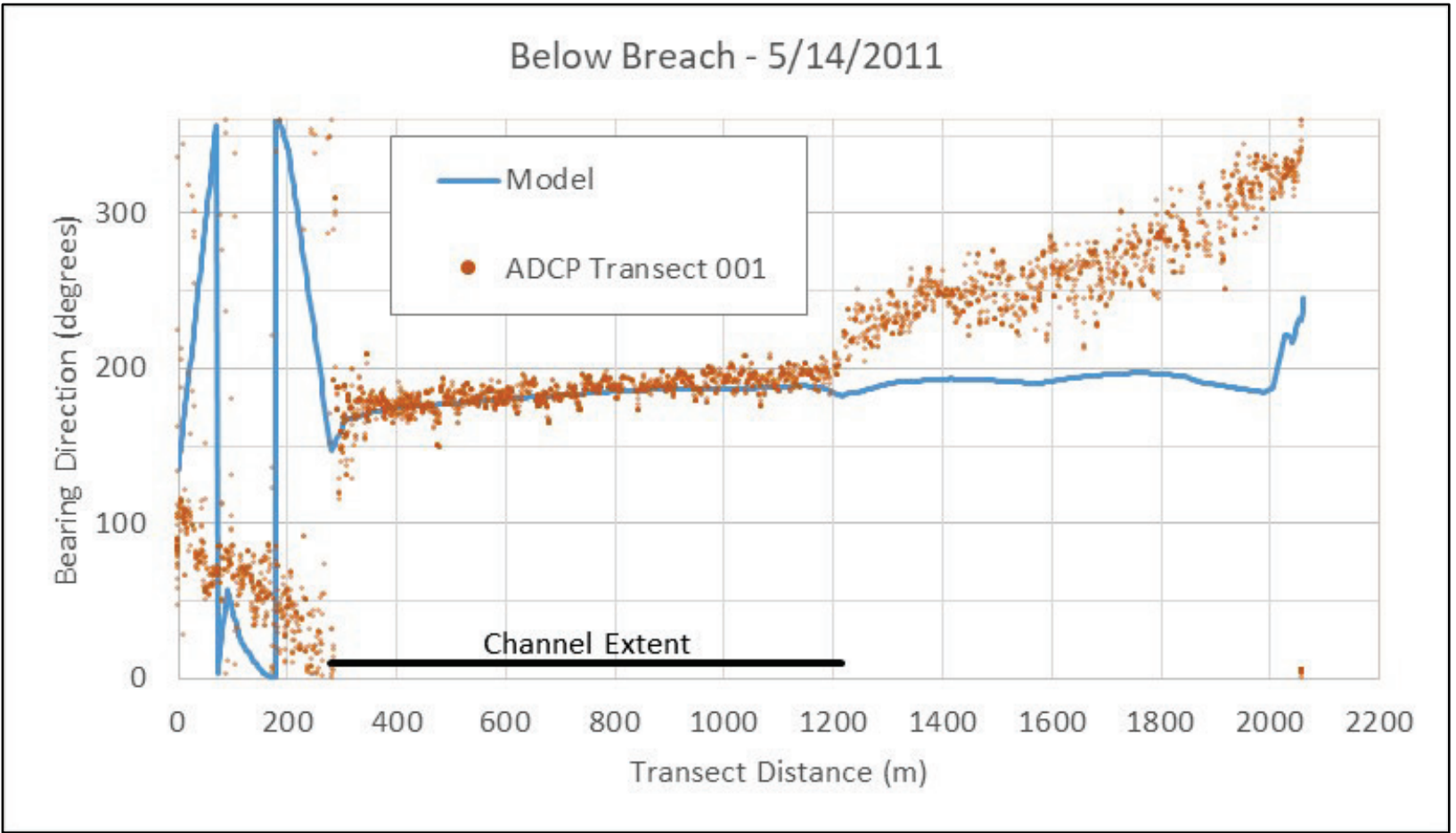




\section{5-2016 event}

Figure A-57. Modeled and observed stage at New Madrid, 2015 event.

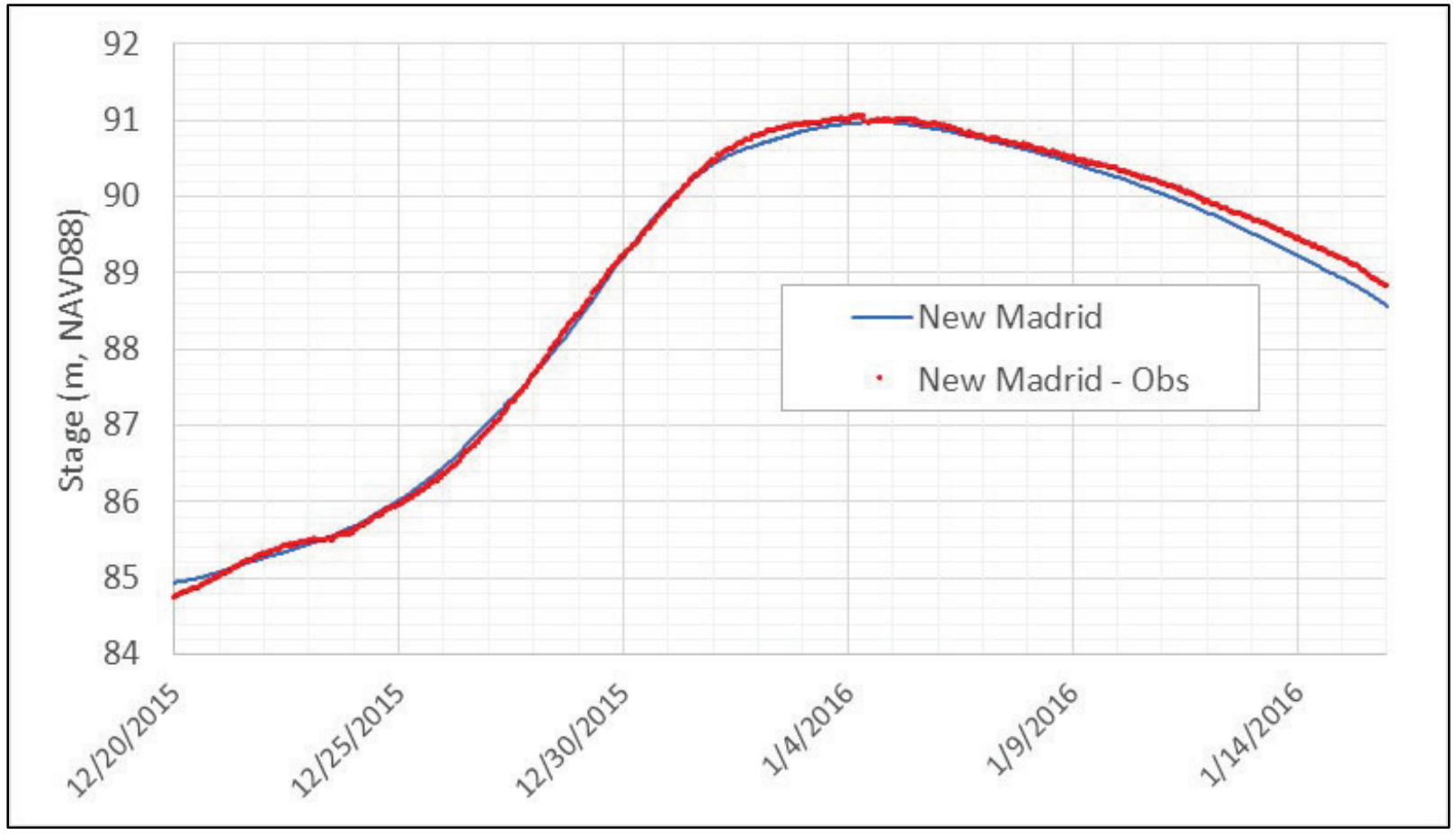

Figure A-58. Modeled and observed stage at Hickman, 2015 event.

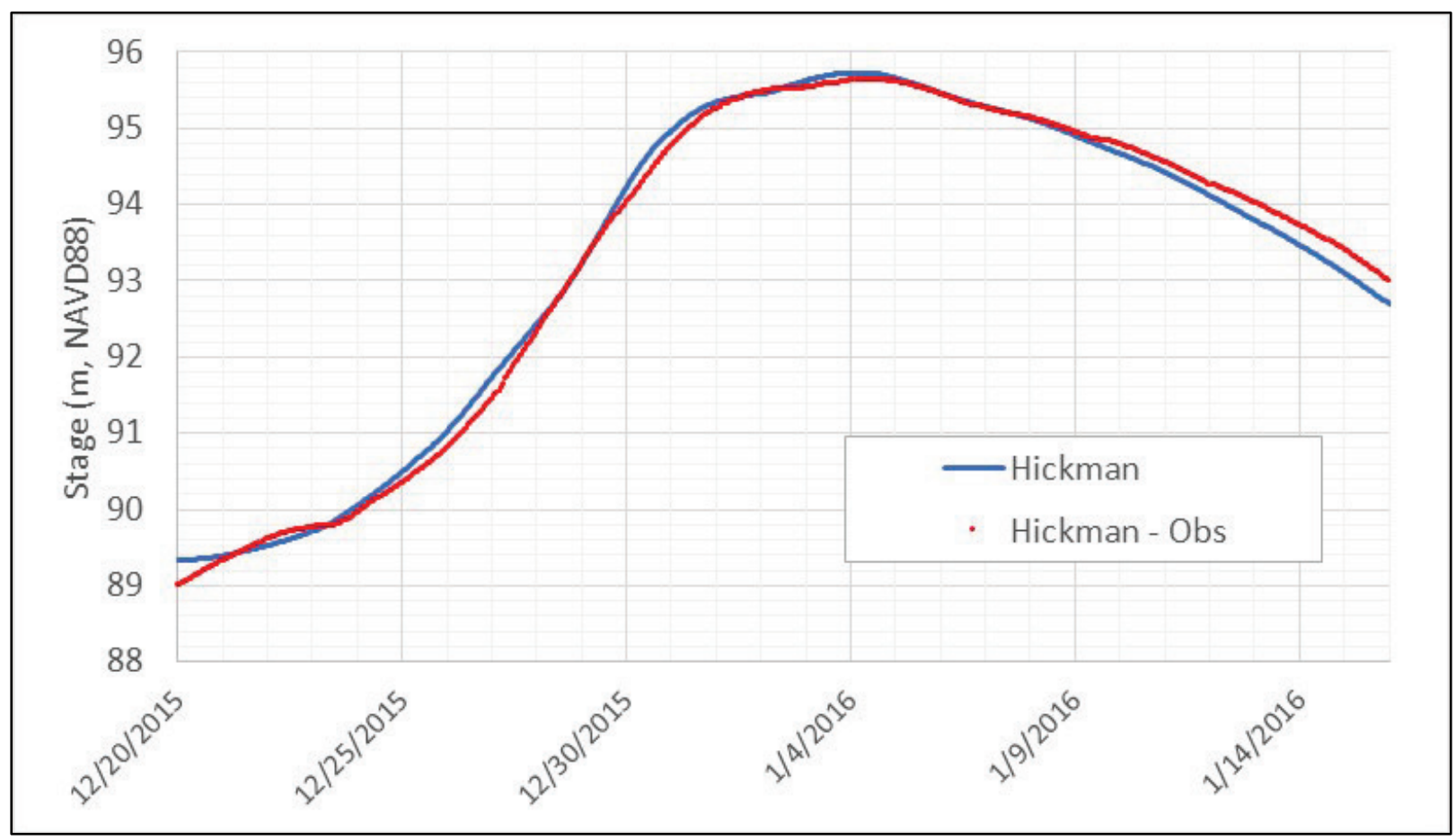


Figure A-59. Modeled and observed stage at Cairo, 2015 event.

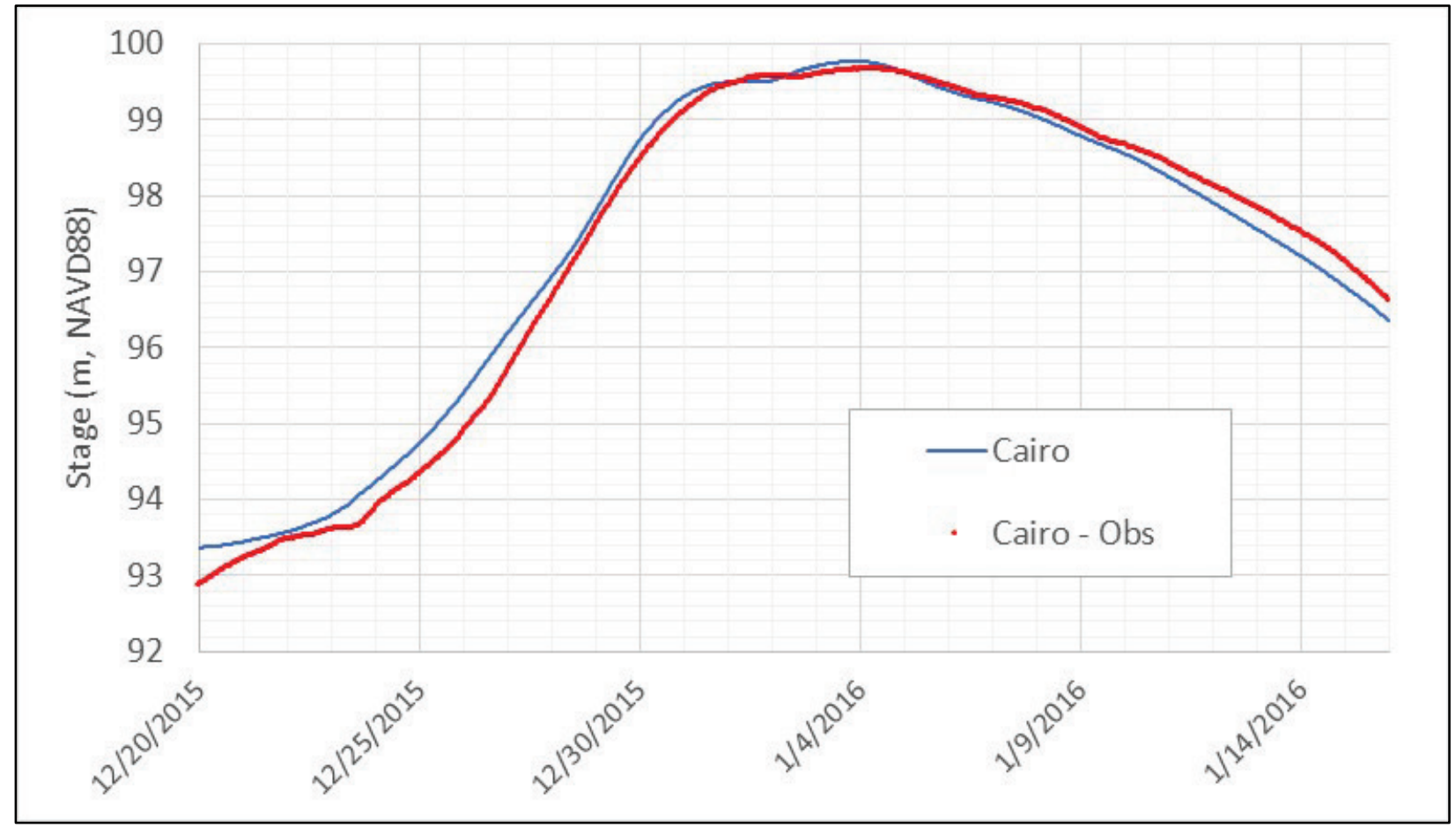

Figure A-60. Modeled and observed stage at Birds Point, 2015 event.

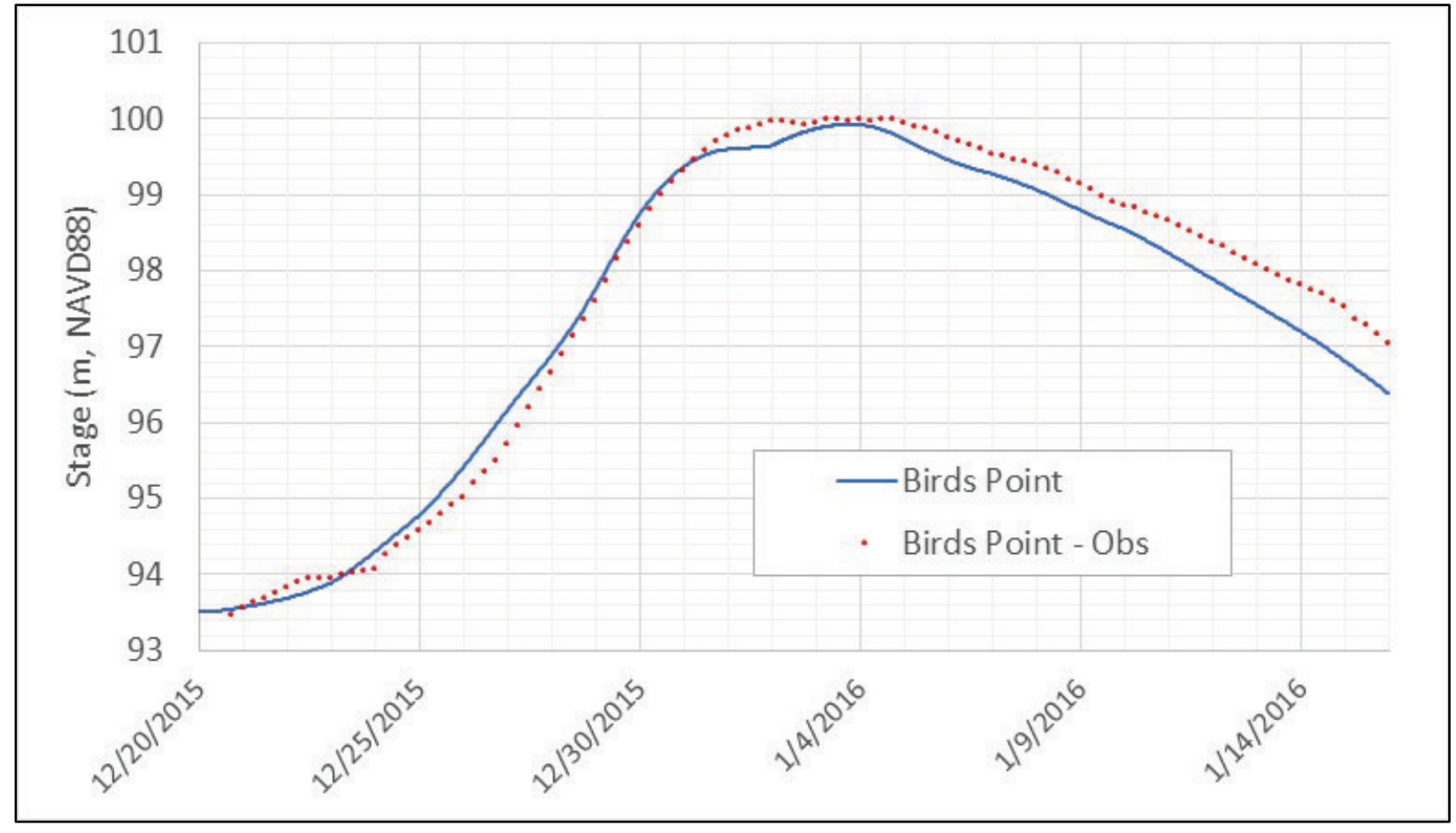


Figure A-61. Modeled and observed stage at Thompson Landing, 2015 event.

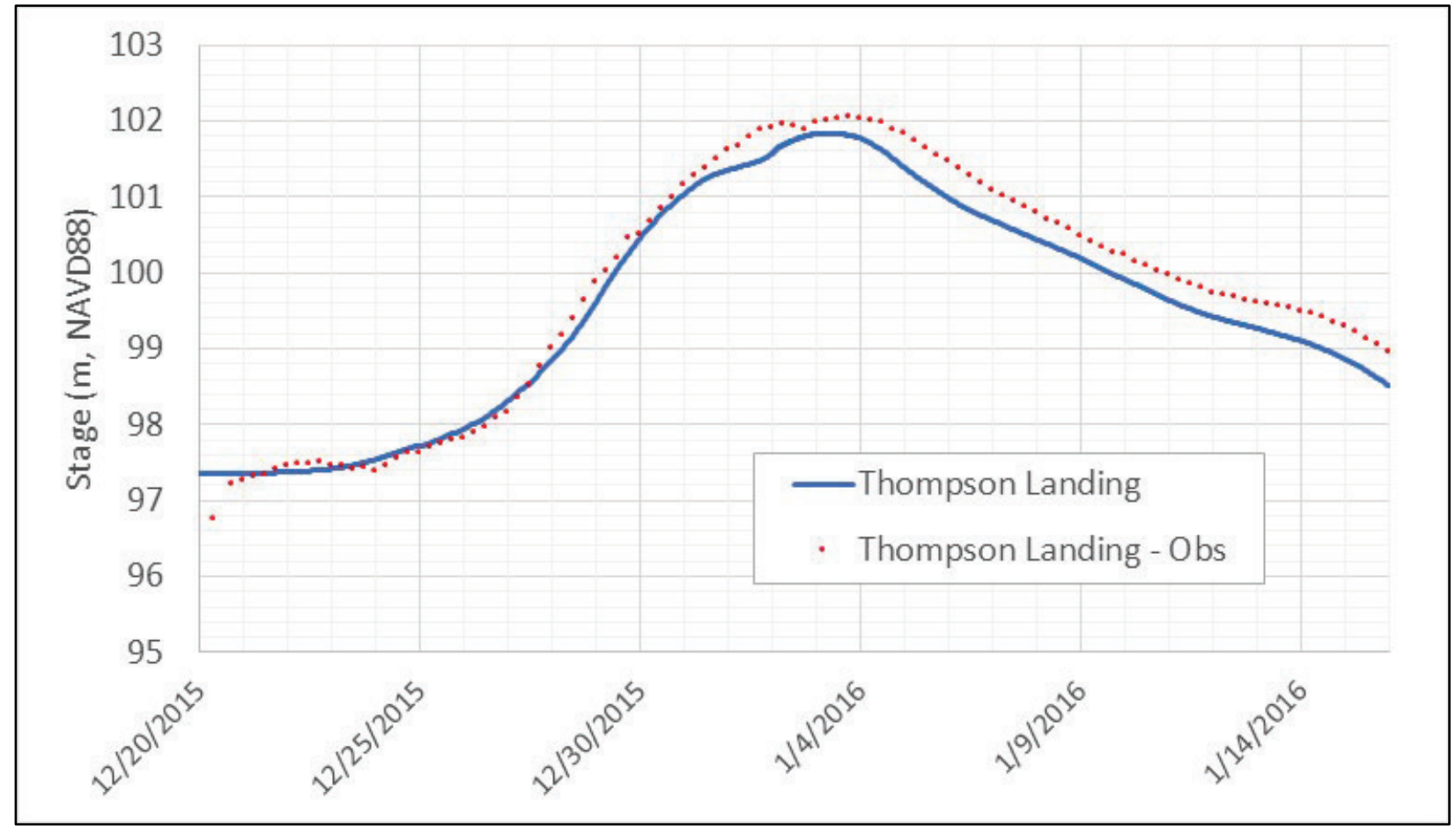

Figure A-62. Modeled and observed stage at Price Landing, 2015 event.

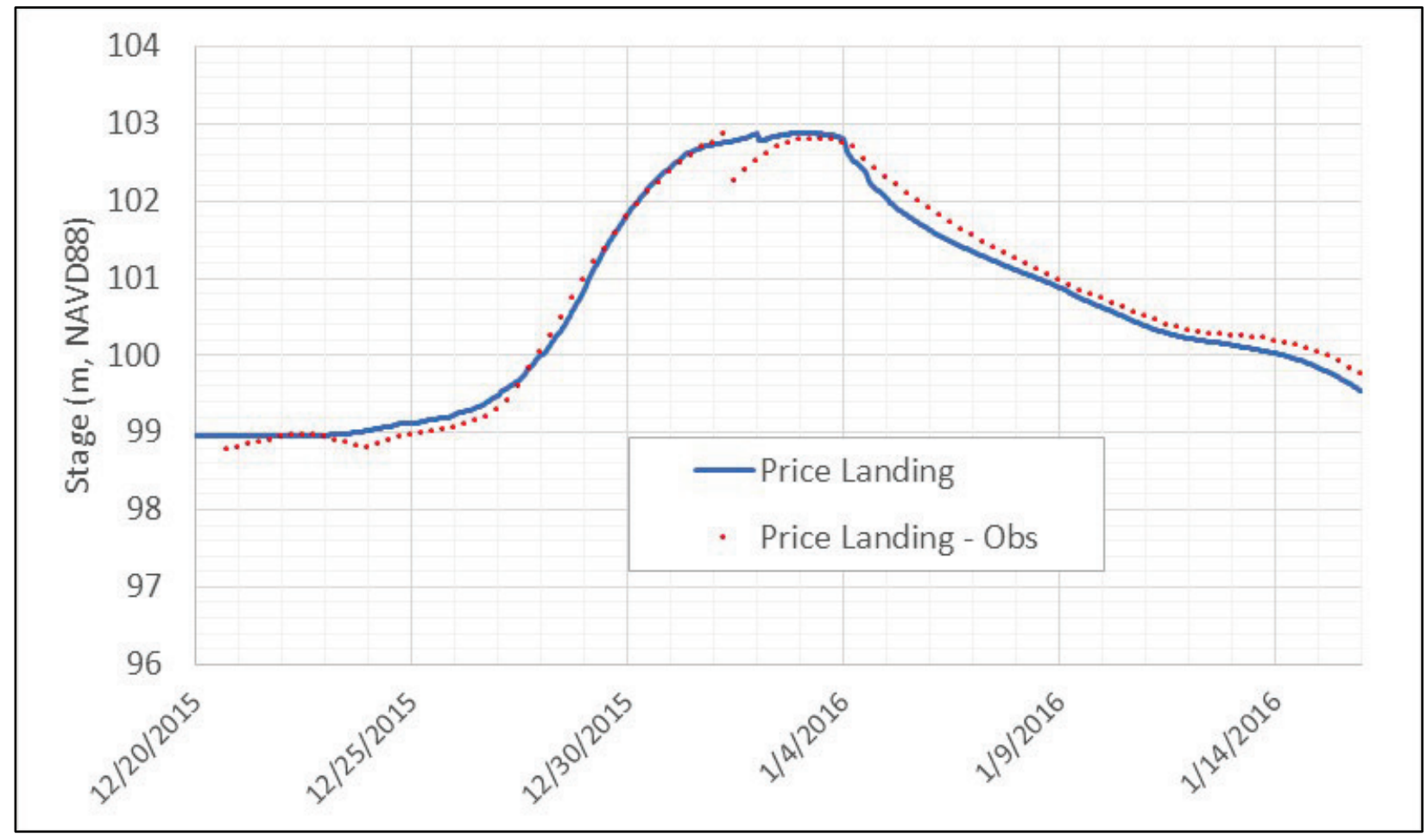


Figure A-63. Modeled and observed stage at Commerce, 2015 event.

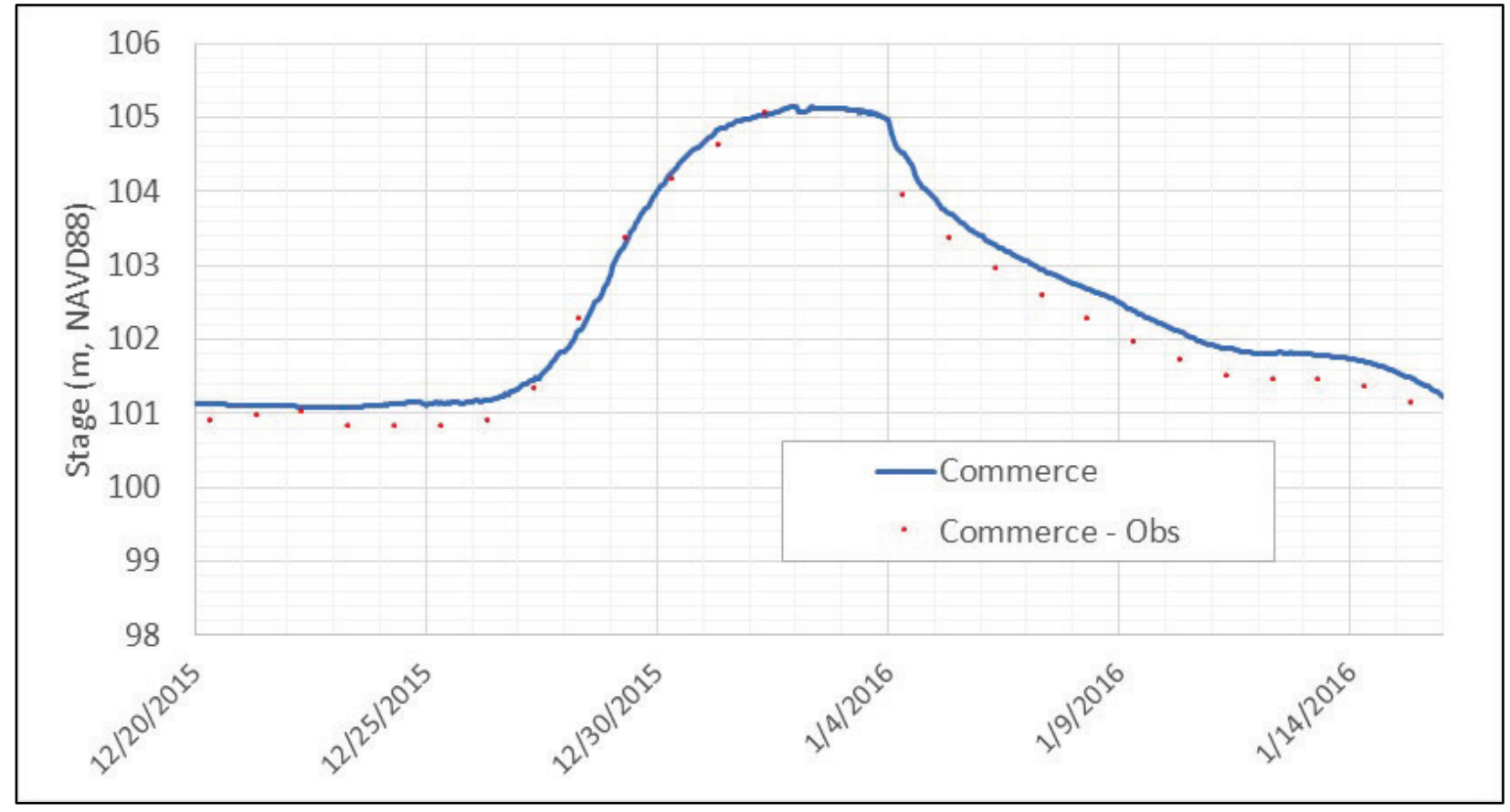




\section{7 event}

Figure A-64. Modeled and observed stage at New Madrid, 2017 event.

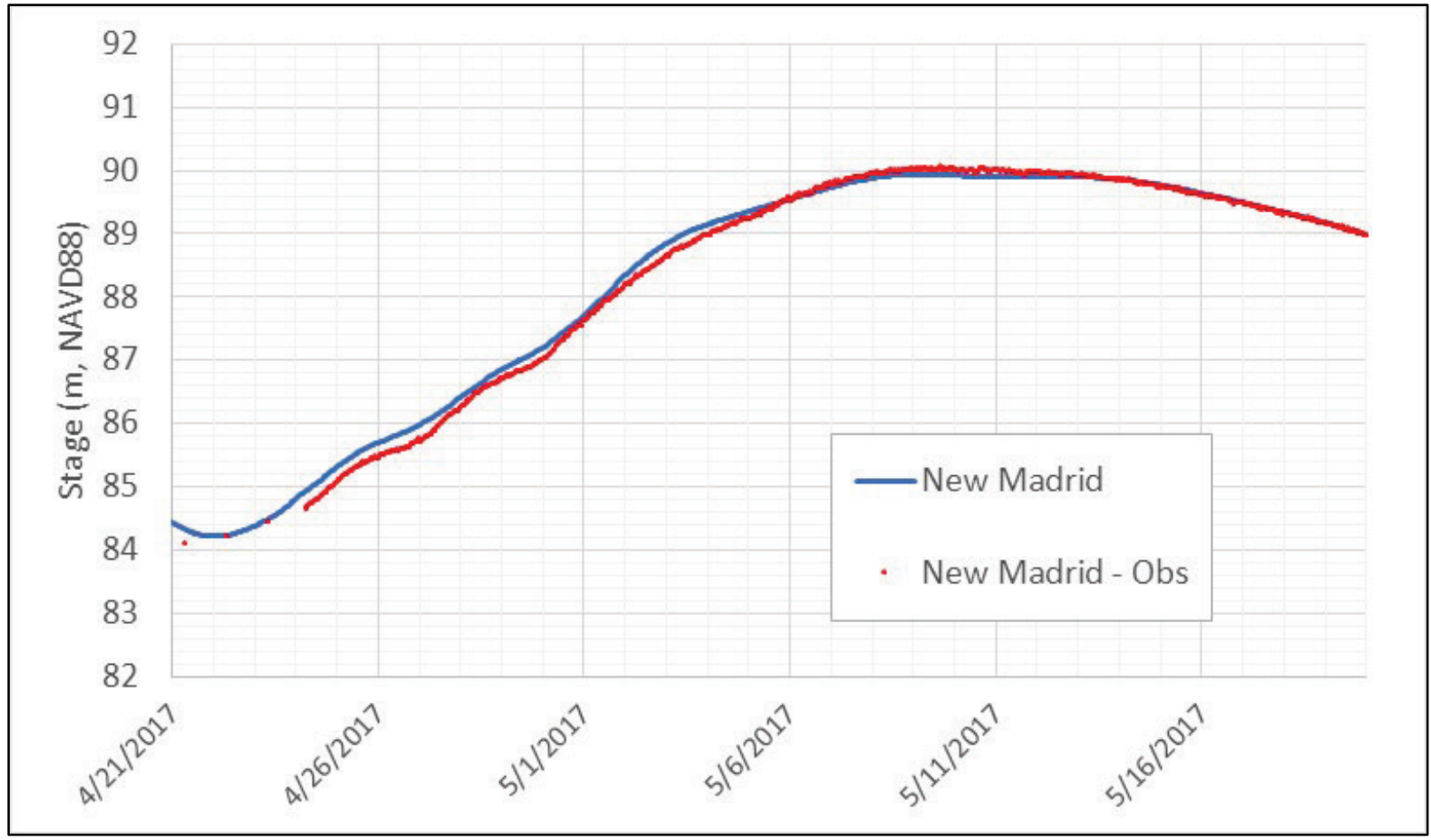

Figure A-65. Modeled and observed stage at Hickman, 2017 event.

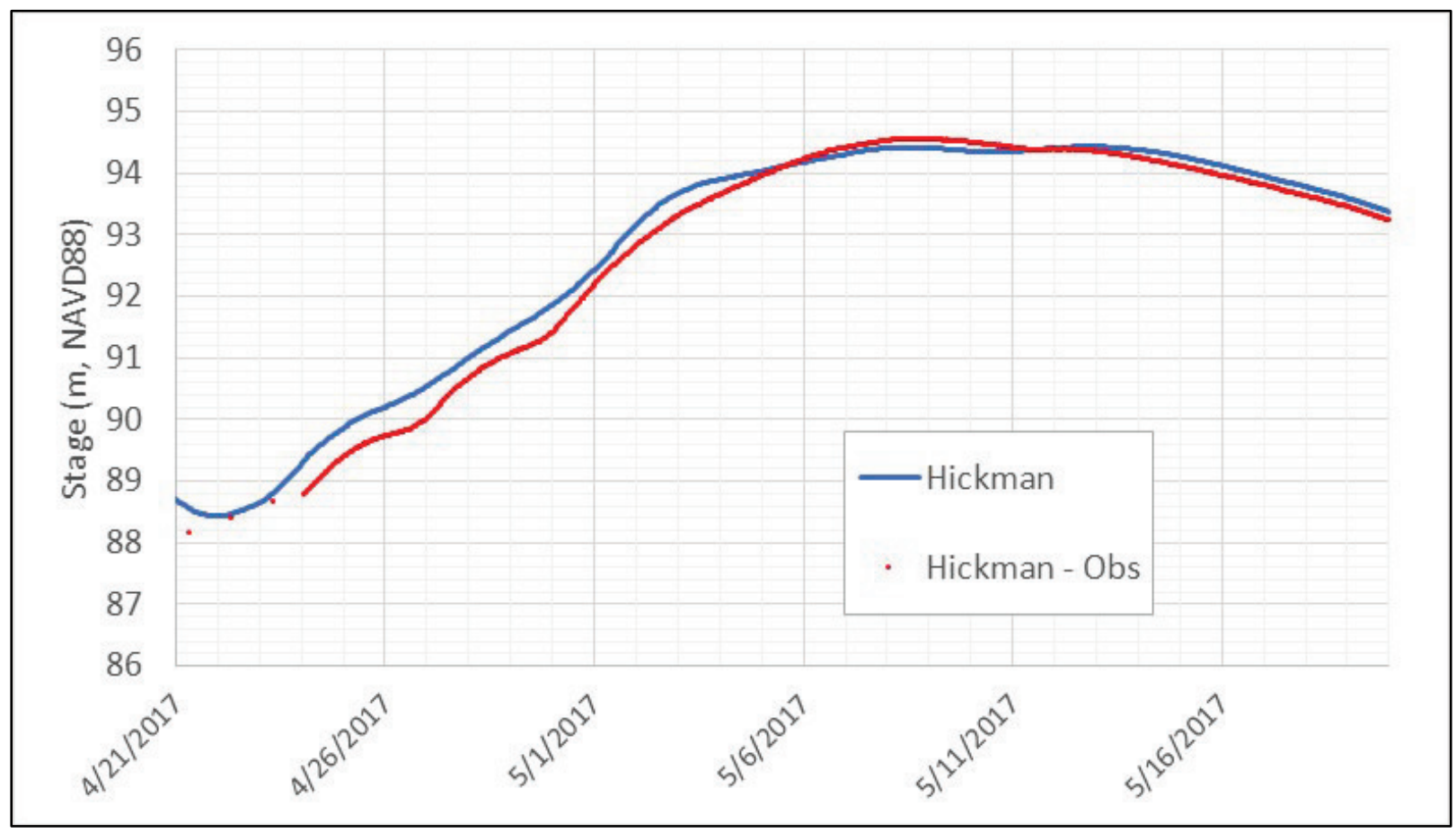


Figure A-66. Modeled and observed stage at Cairo, 2017 event.

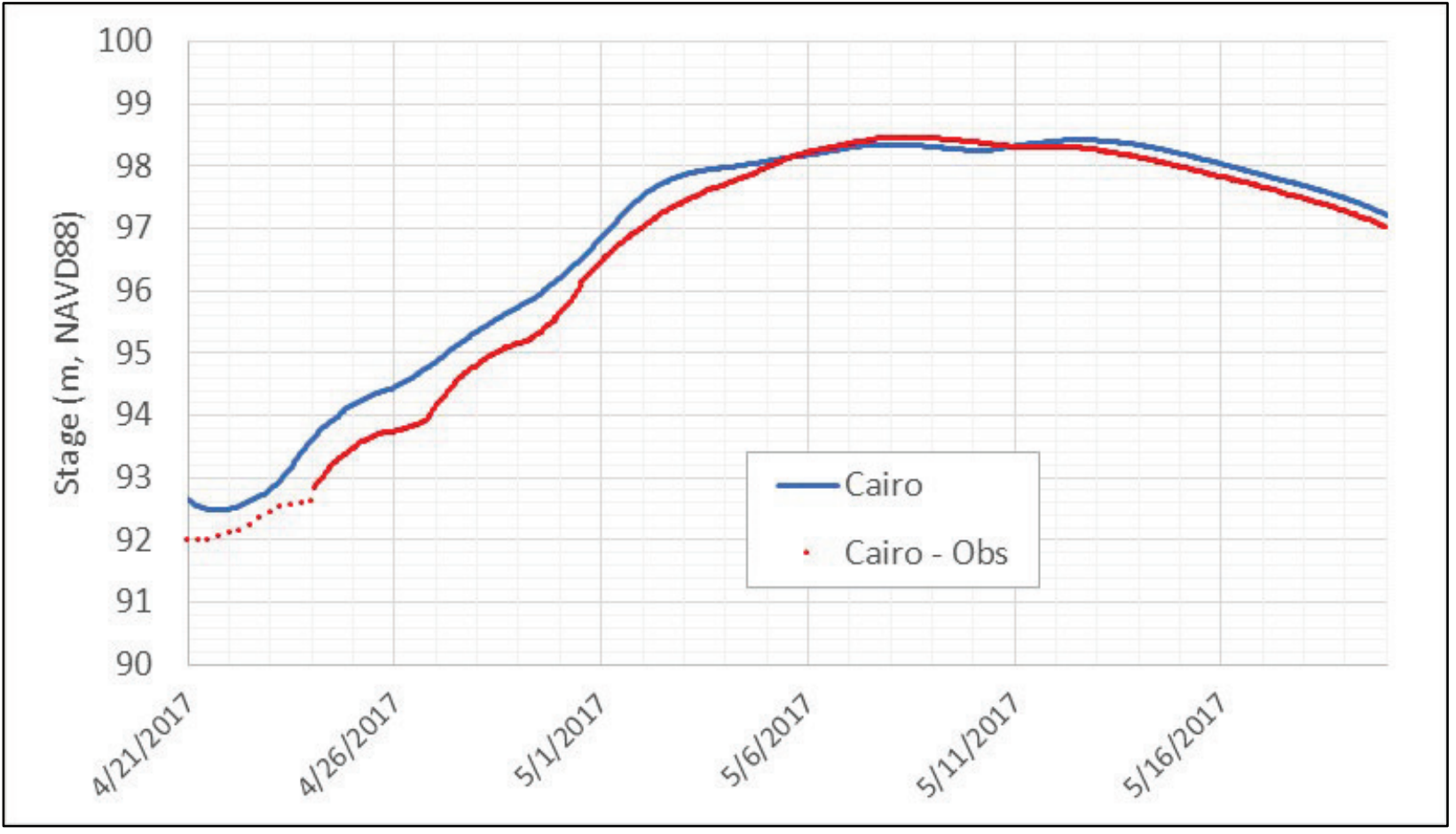

Figure A-67. Modeled and observed stage at Birds Point, 2017 event.

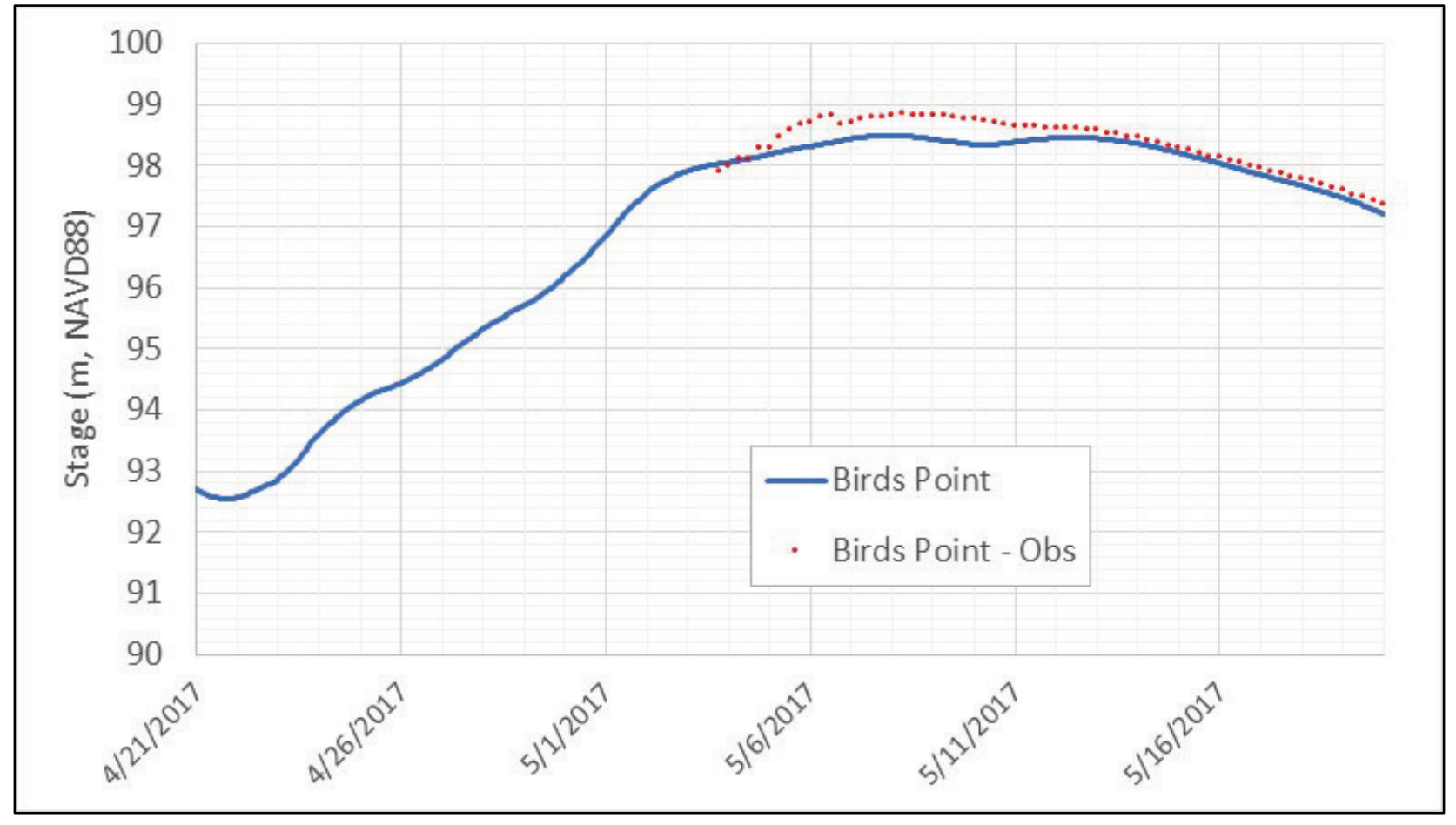


Figure A-68. Modeled and observed stage at Thompson Landing, 2017 event.

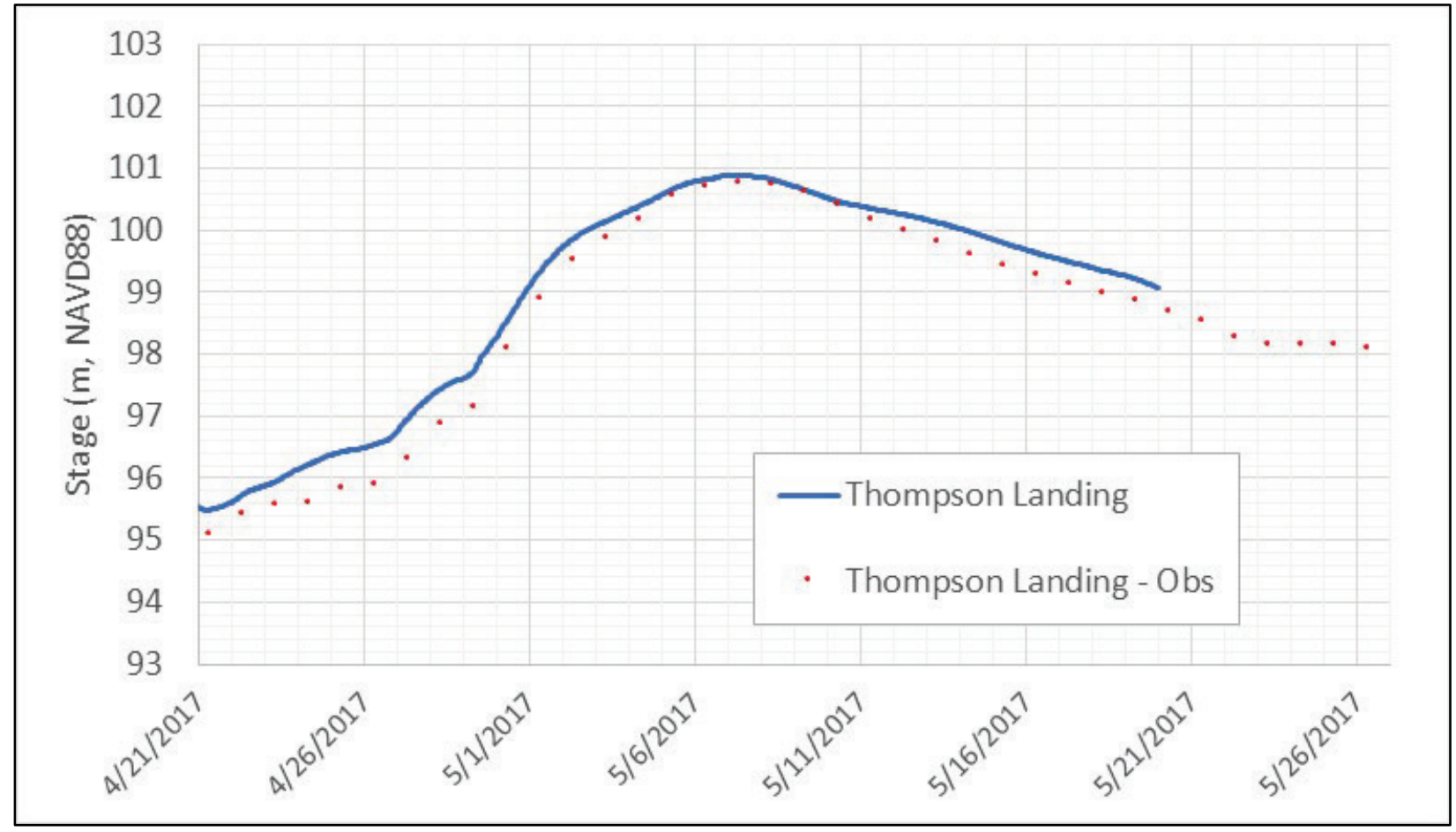

Figure A-69. Modeled and observed stage at Price Landing, 2017 event.

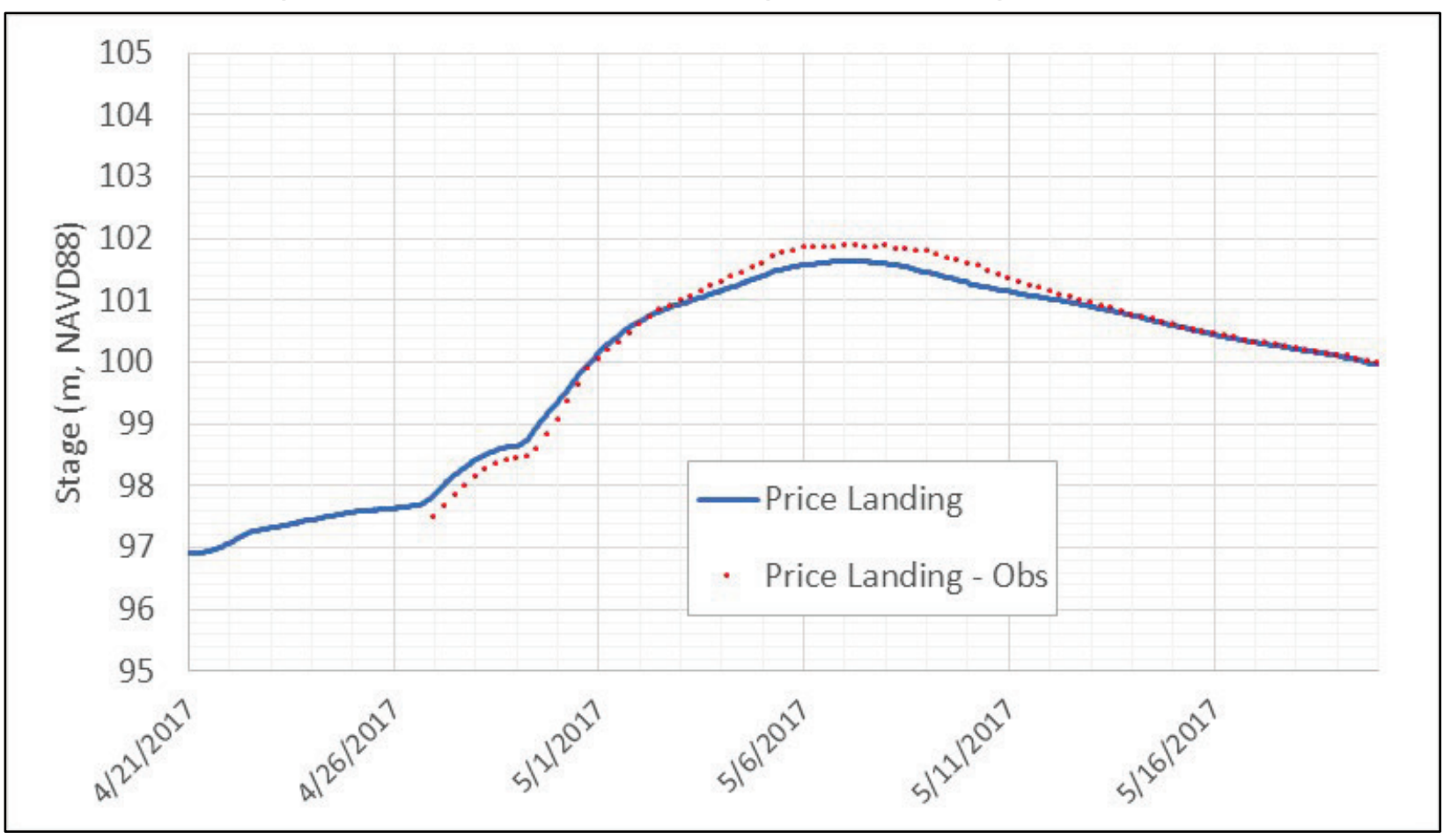


MRG\&P Report No. 35

188

Figure A-70. Modeled and observed stage at Commerce, 2017 event.

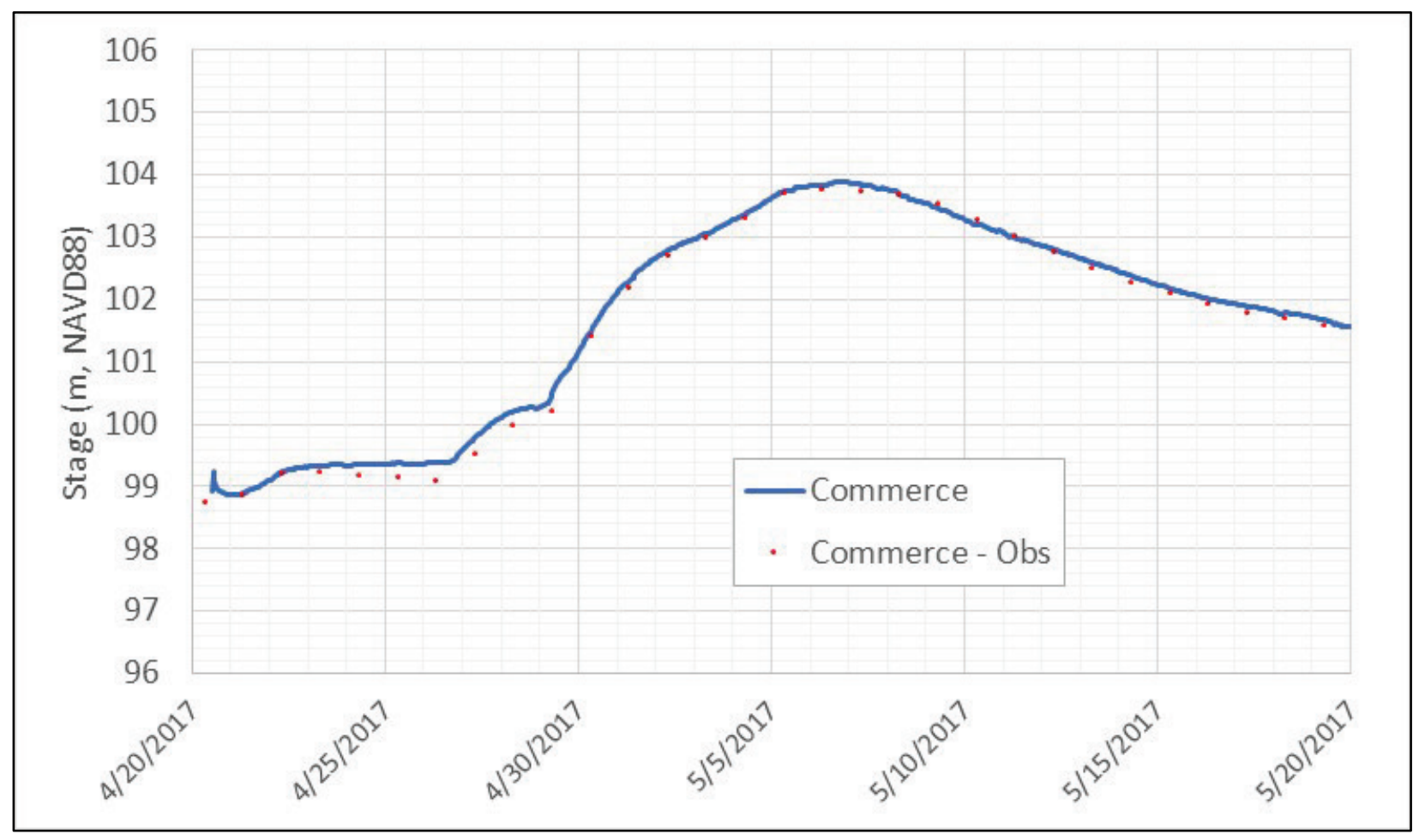




\section{Appendix B: Stage Plots for Scenarios}

To better understand the differences in the scenario simulations, comparisons of stage were made at each station and longitudinally on the Mississippi River. While these were not specifically called for as part of this task, they provide a clearer understanding of system dynamics for each scenario (Figure B-1 through B-30).

The calibrated model was used to run four cases, for the flood events specified:

1. Scenario 1A: No break in MC-LS levee and no BPNMF operation; for all three flood events

2. Scenario 1B: Break in MC-LS levee and no BPNMF operation; for all three flood events

3. Scenario 2A: No break in MC-LS levee and with BPNMF operation; for all three flood events

4. Scenario 2B: Break in MC-LS levee with BPNMF operation; for the 2011 event. 


\section{1 flood event stages}

Figure B-1. Scenario stages, 2011 event.

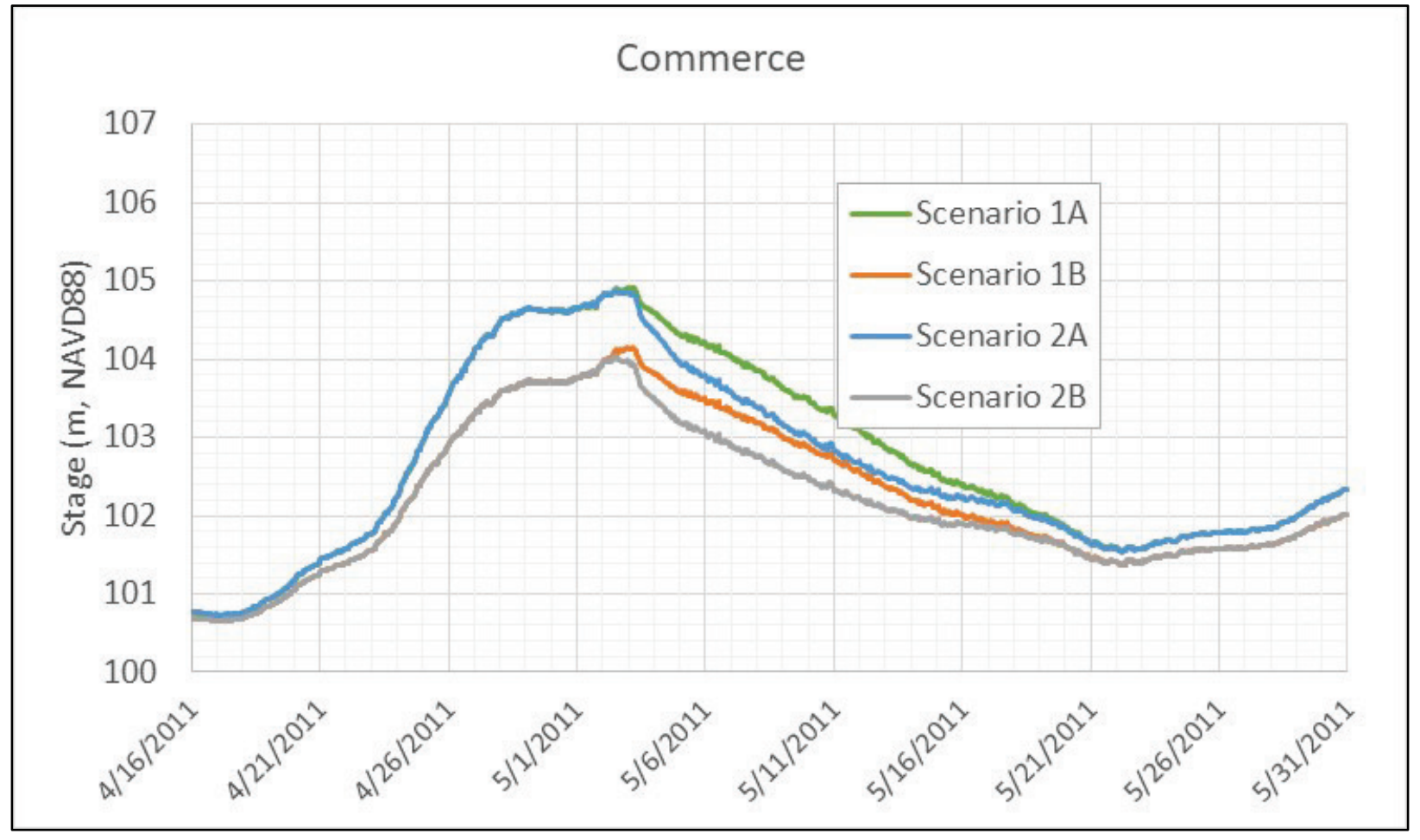

Figure B-2. Scenario stages, 2011 event.

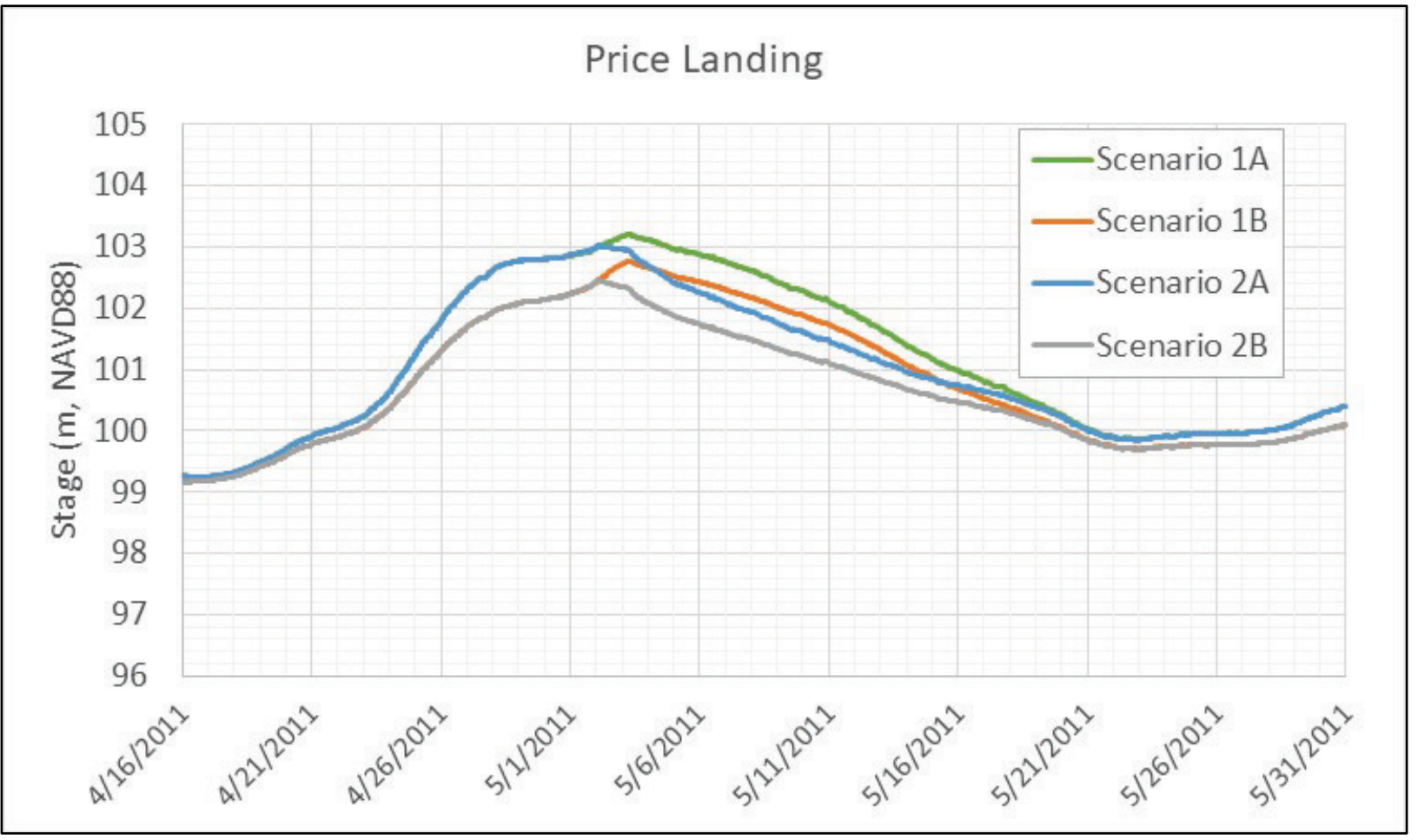


Figure B-3. Scenario stages, 2011 event.

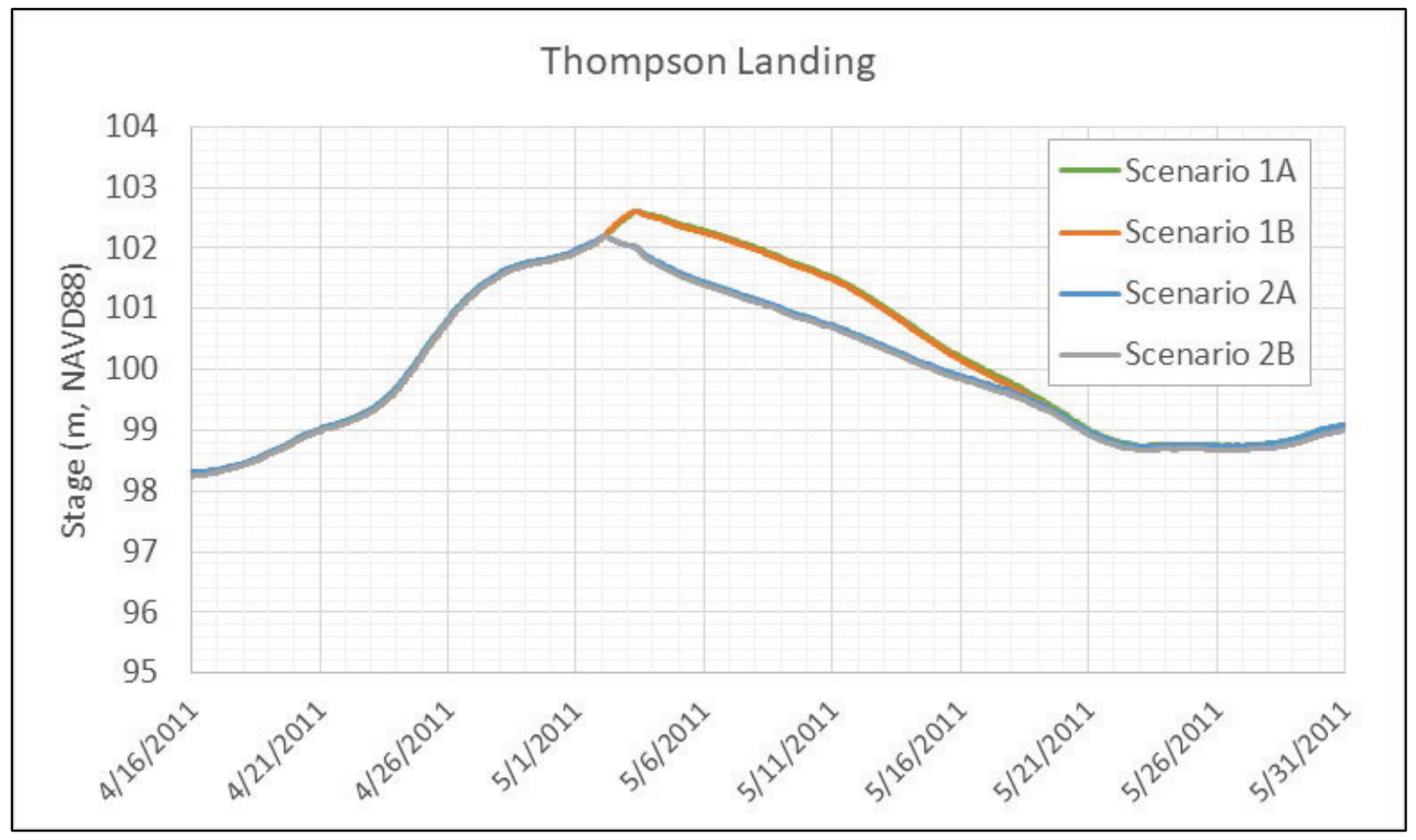

Figure B-4. Scenario stages, 2011 event.

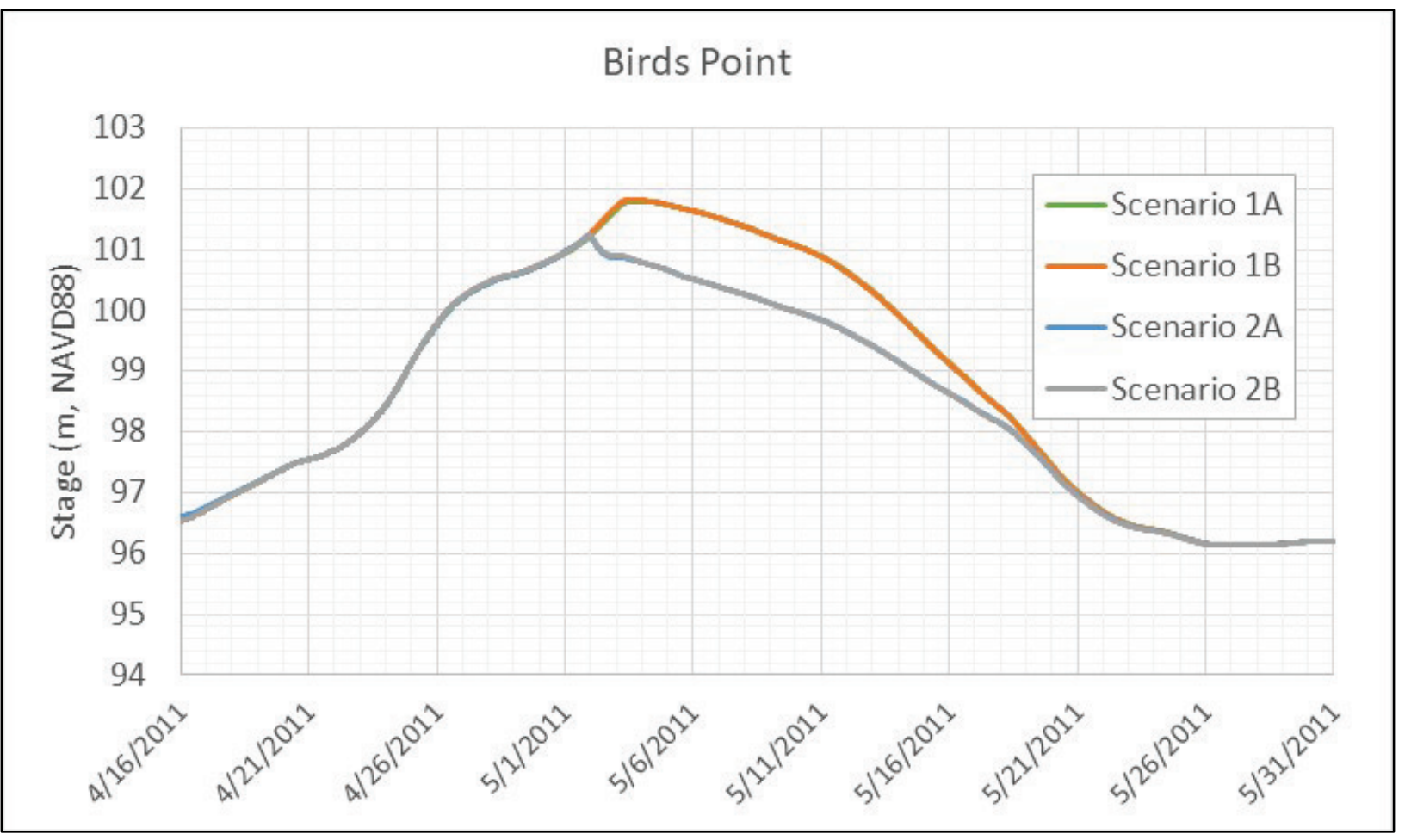


Figure B-5. Scenario stages, 2011 event.

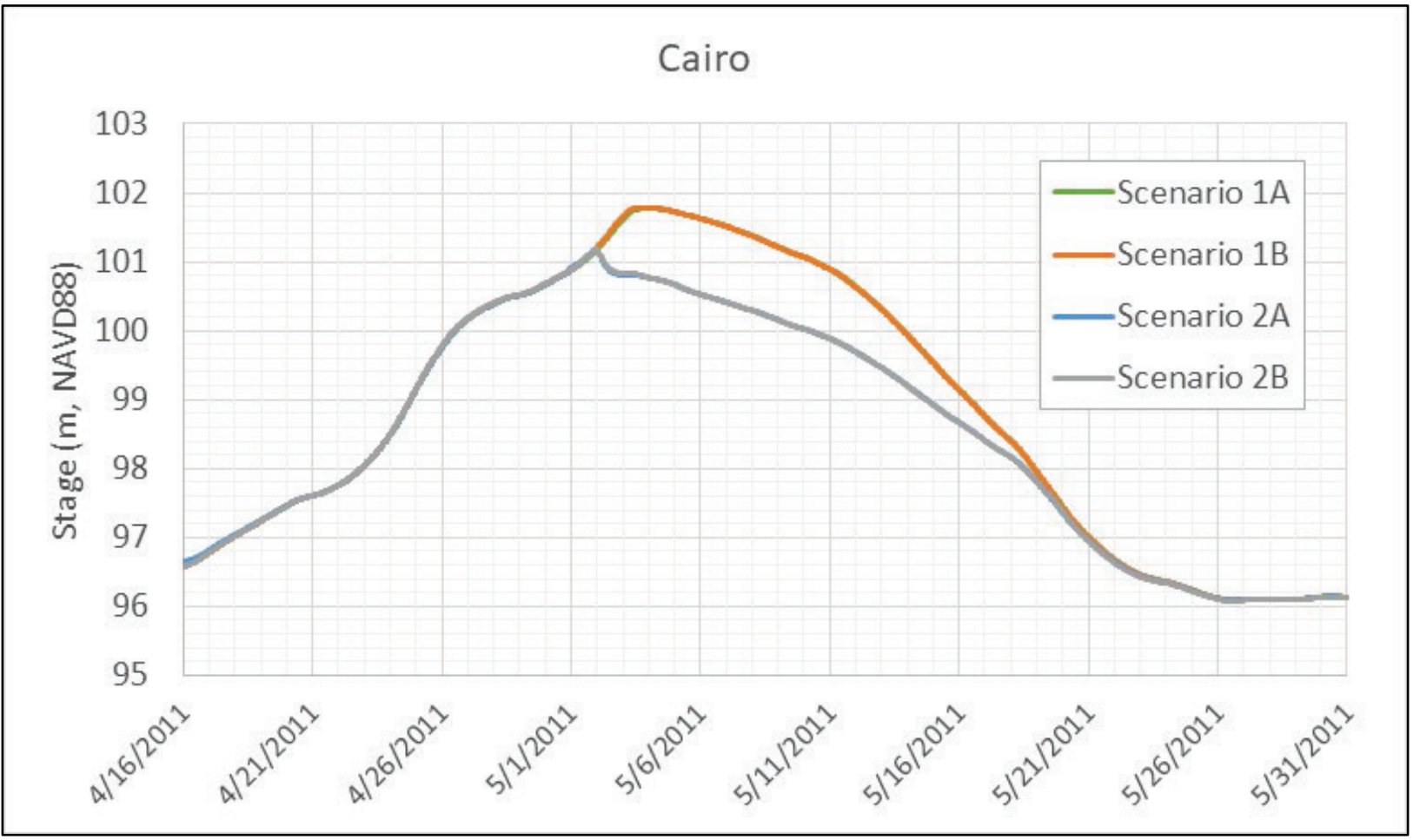

Figure B-6. Scenario stages, 2011 event.

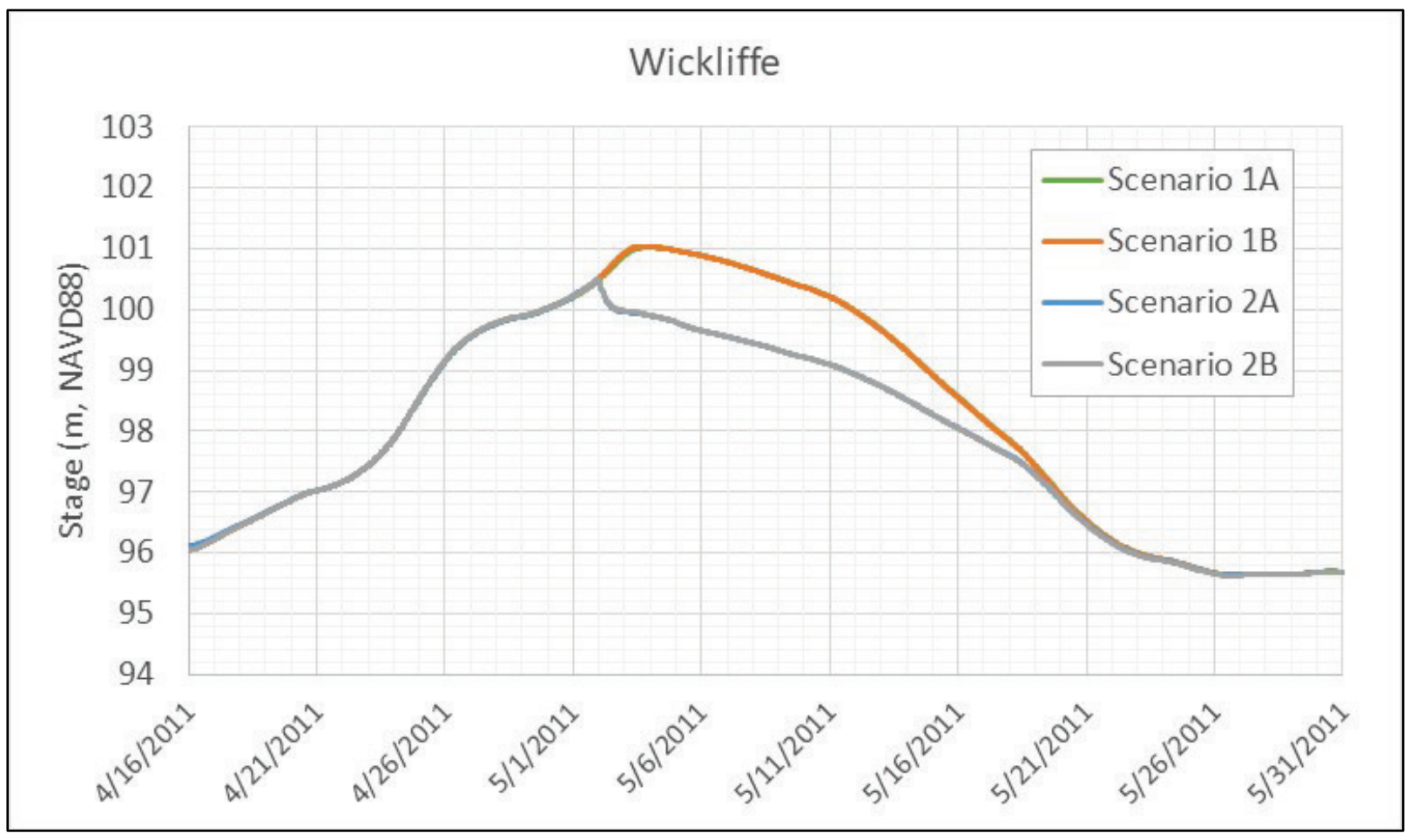


Figure B-7. Scenario stages, 2011 event.

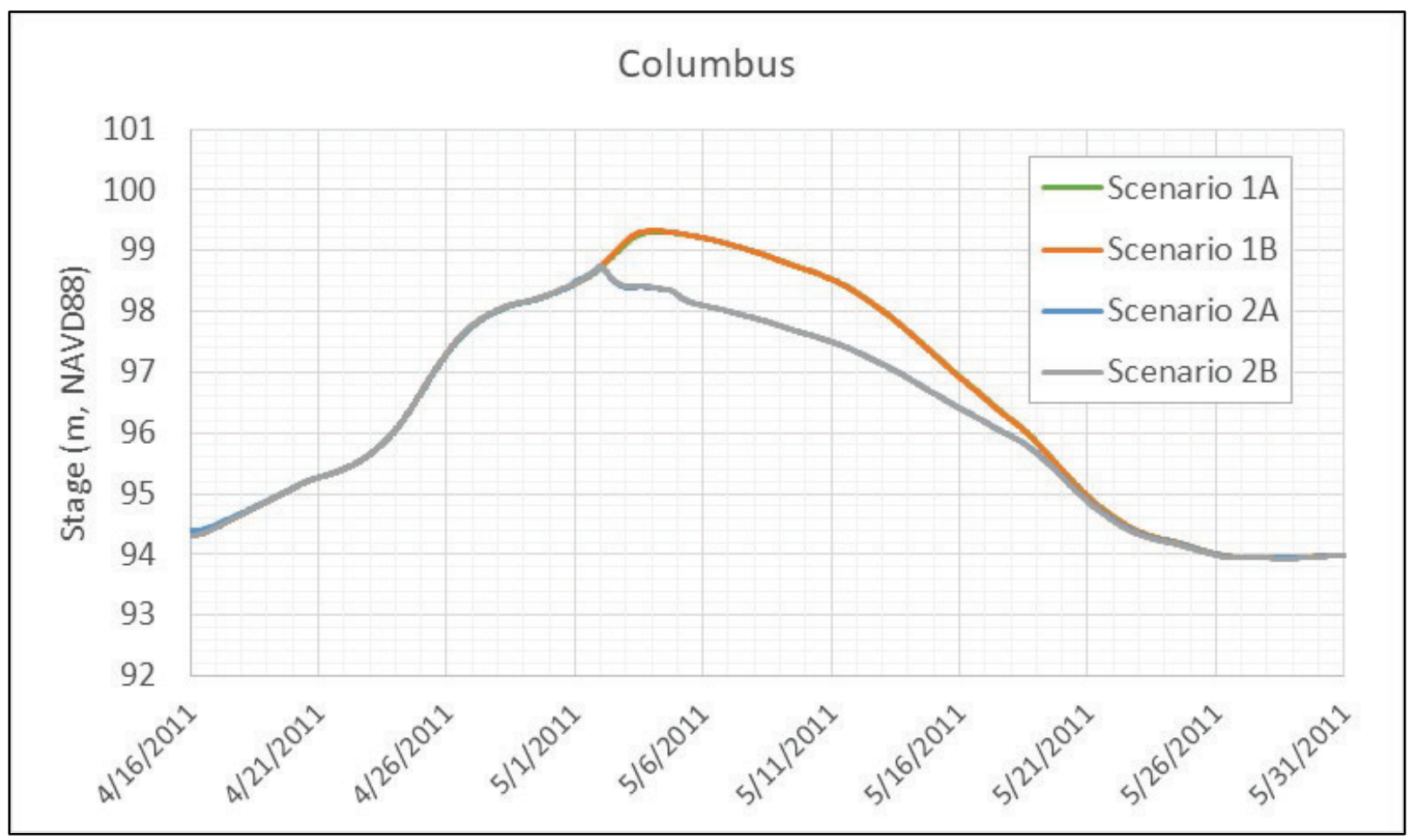

Figure B-8. Scenario stages, 2011 event.

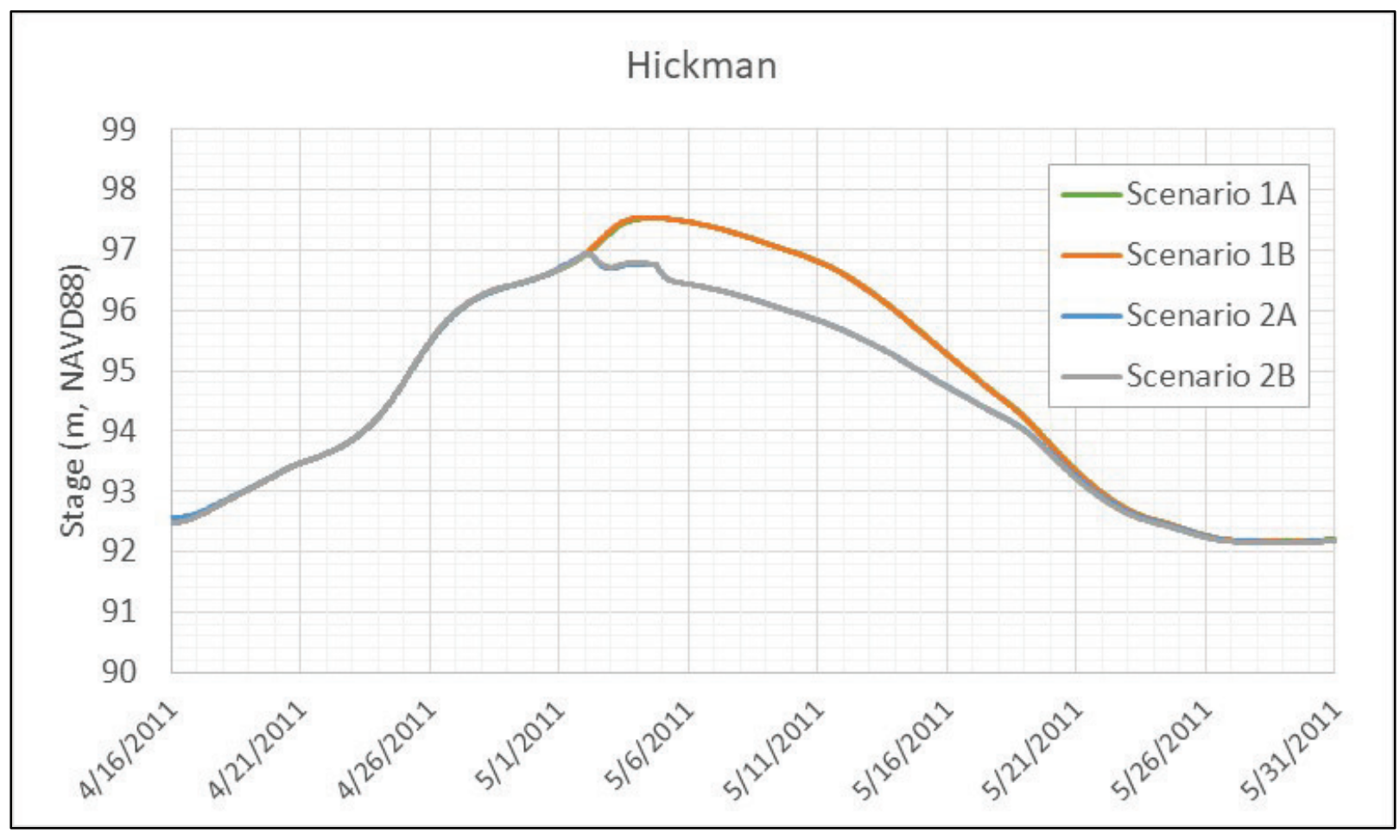


Figure B-9. Scenario stages, 2011 event.

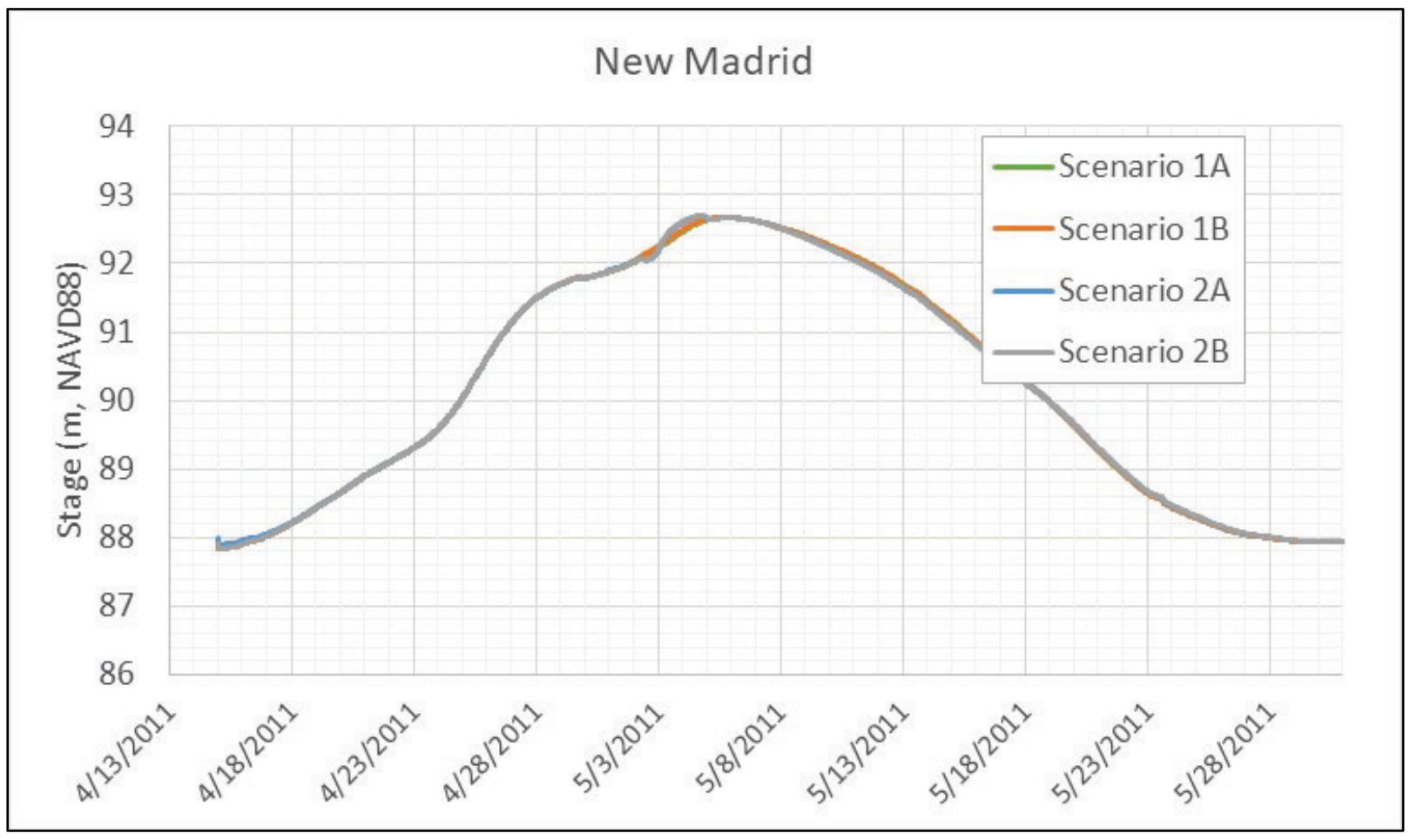




\section{5-2016 flood event stages}

Figure B-10. Scenario 1A and 1B stages, 2015 event.

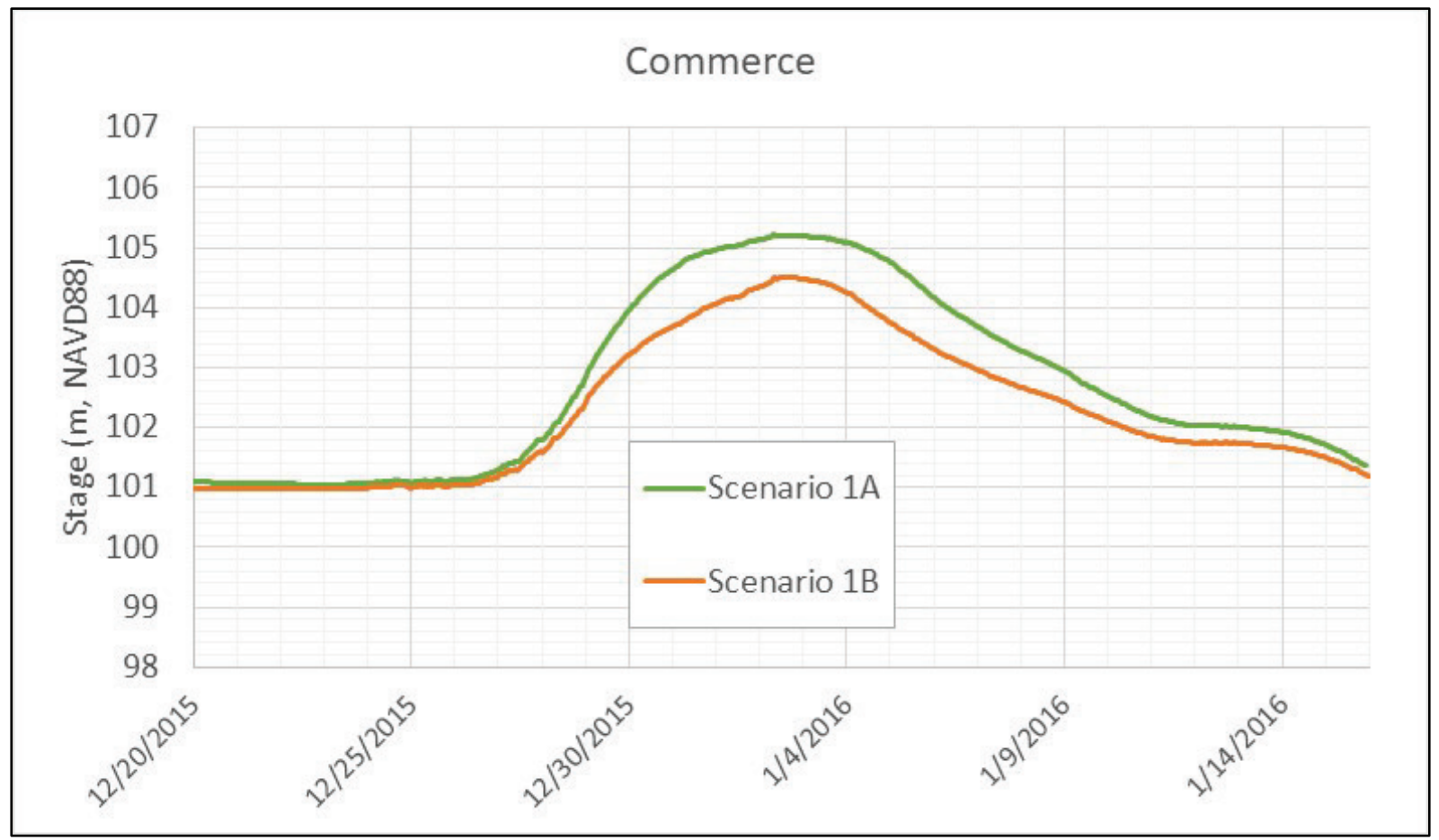

Figure B-11. Scenario 1A and 1B stages, 2015 event.

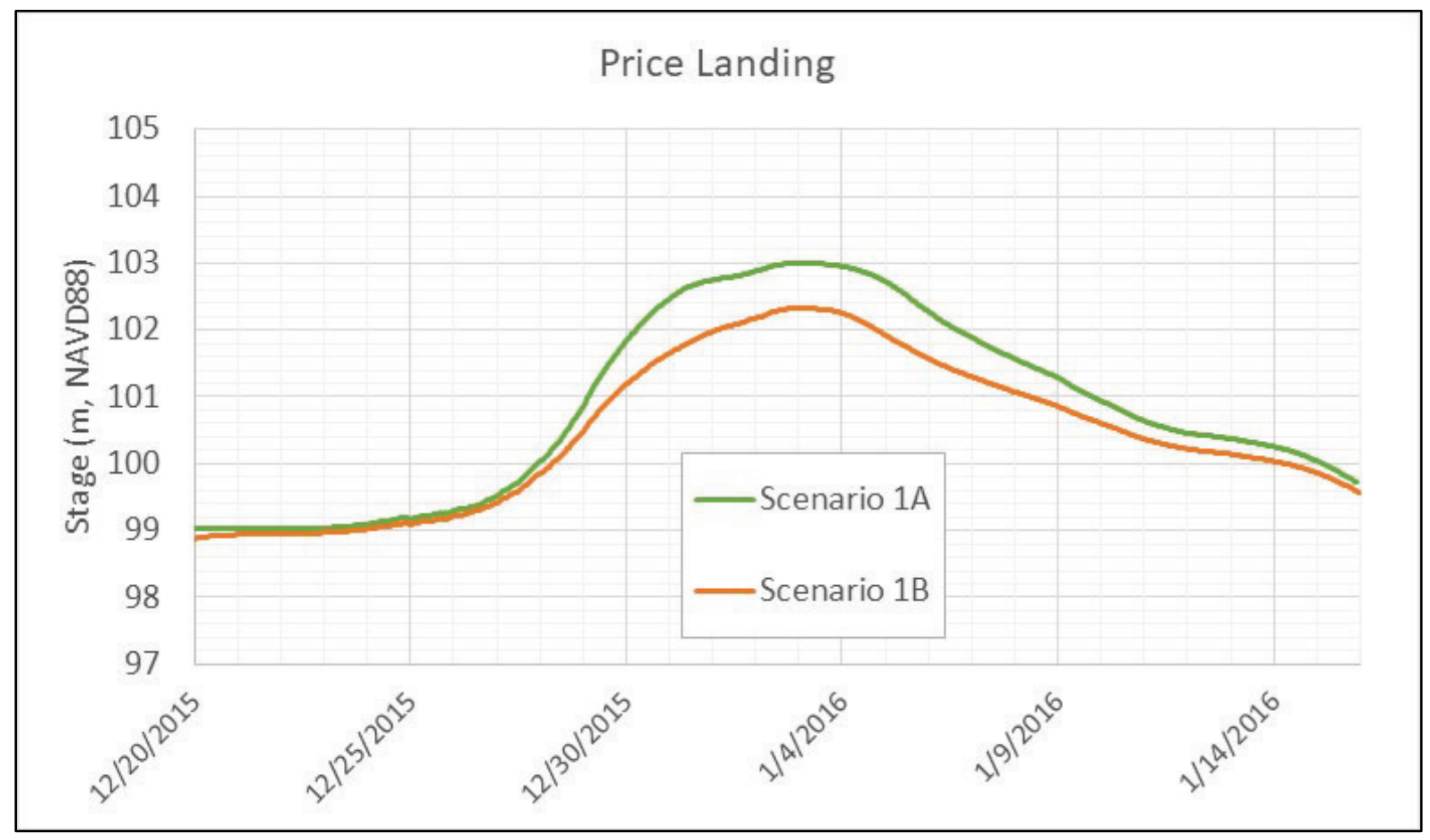


Figure B-12. Scenario 1A and 1B stages, 2015 event.

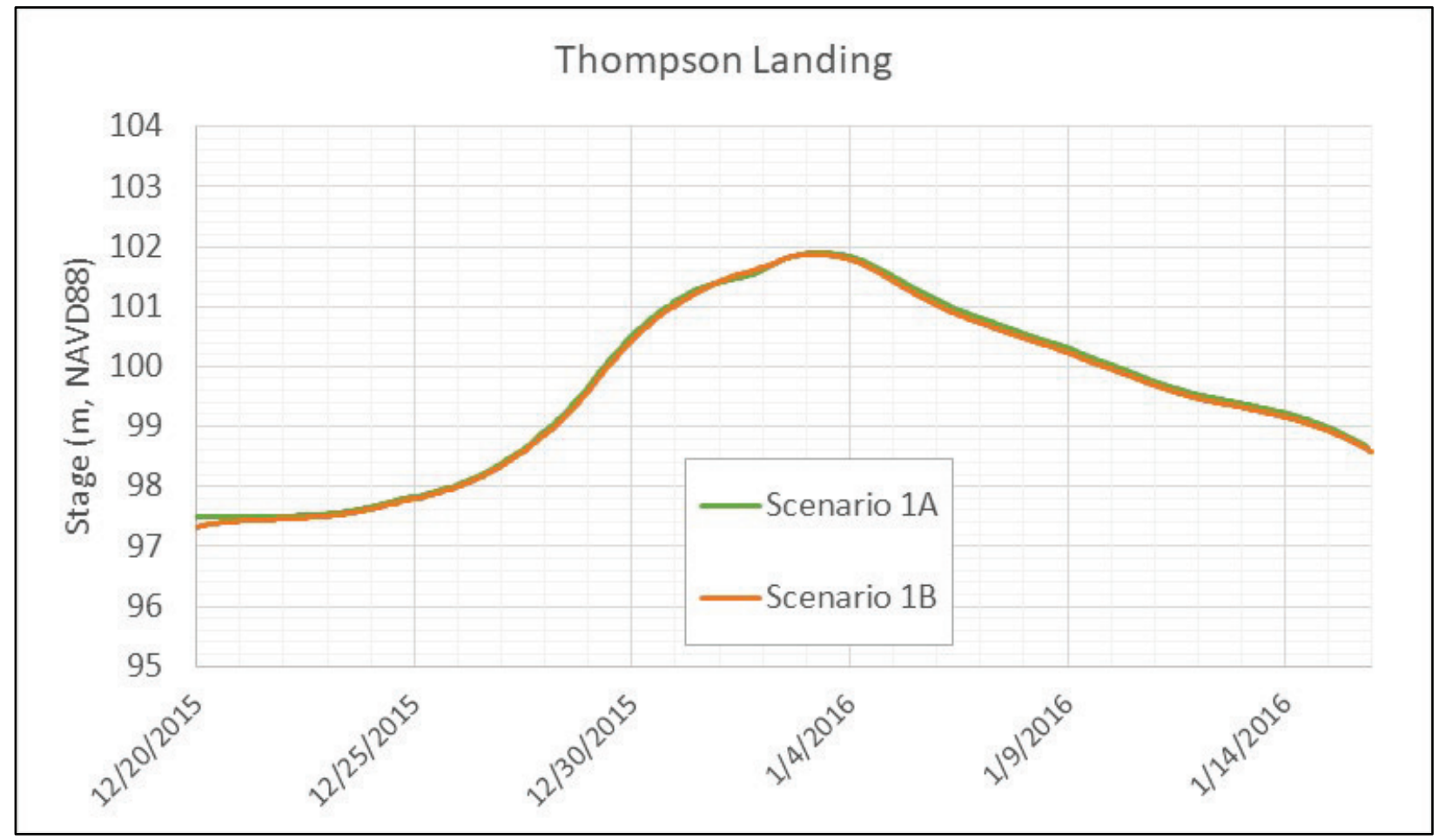

Figure B-13. Scenario 1A and 1B stages, 2015 event.

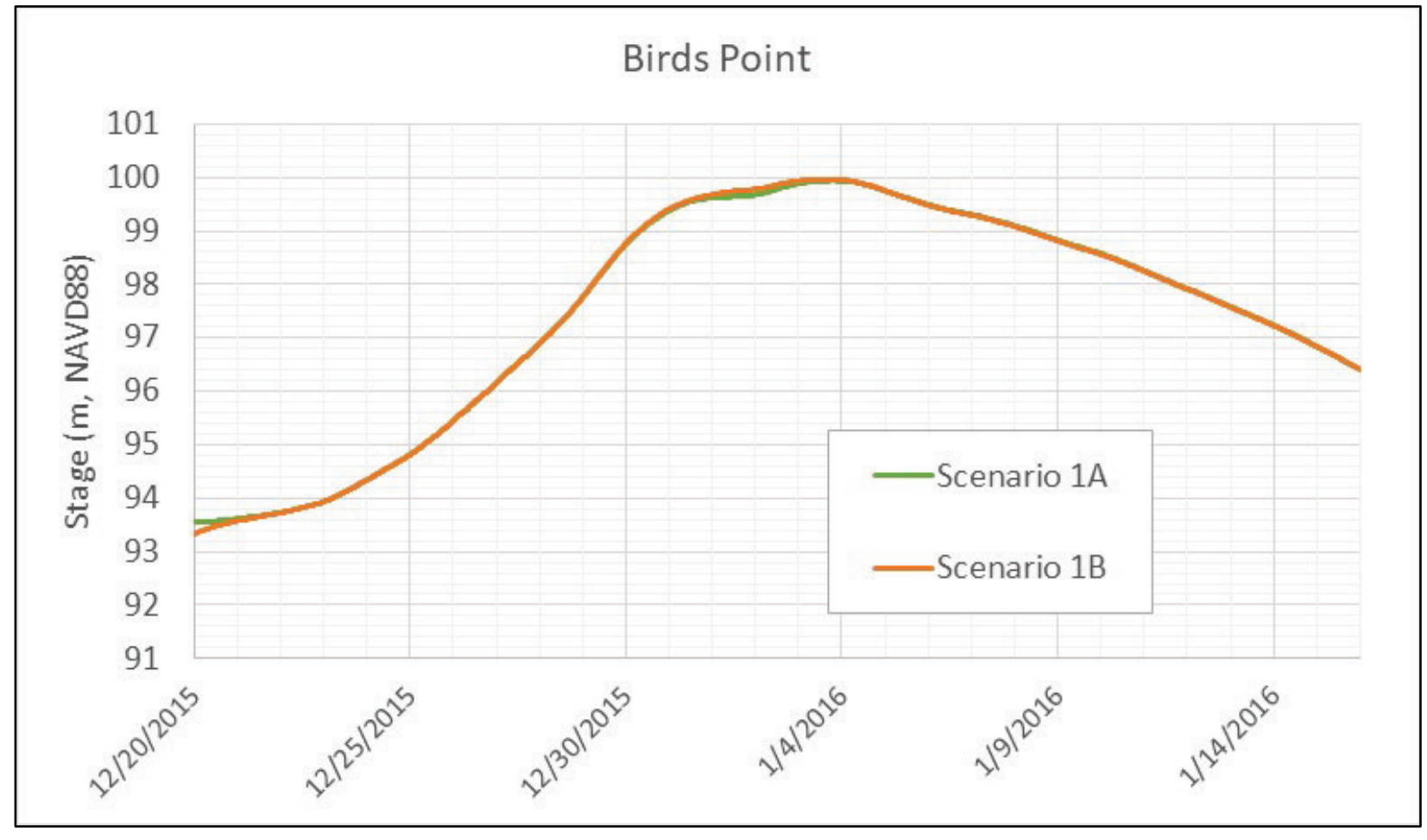


Figure B-14. Scenario 1A and 1B stages, 2015 event.

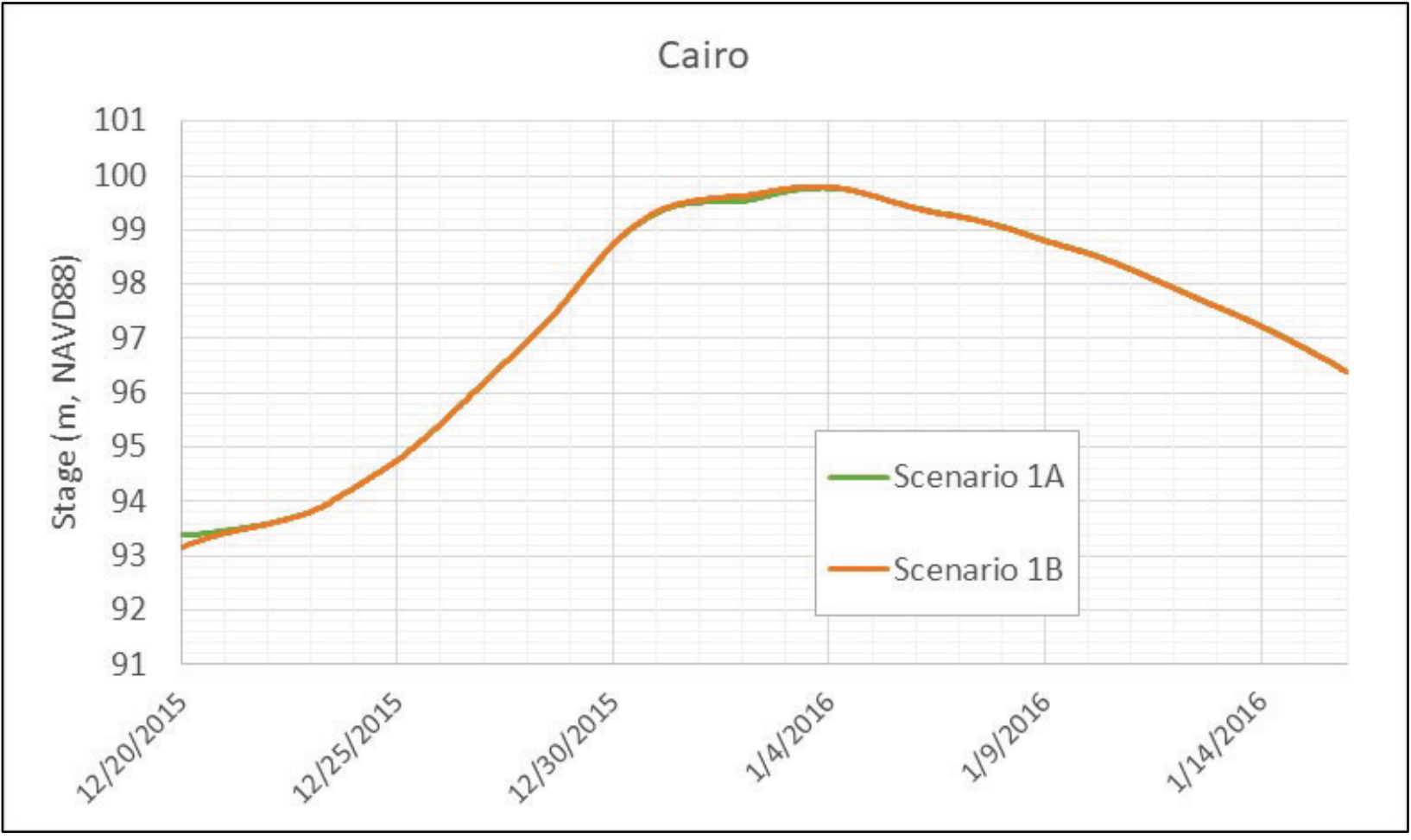

Figure B-15. Scenario 1A and 1B stages, 2015 event.

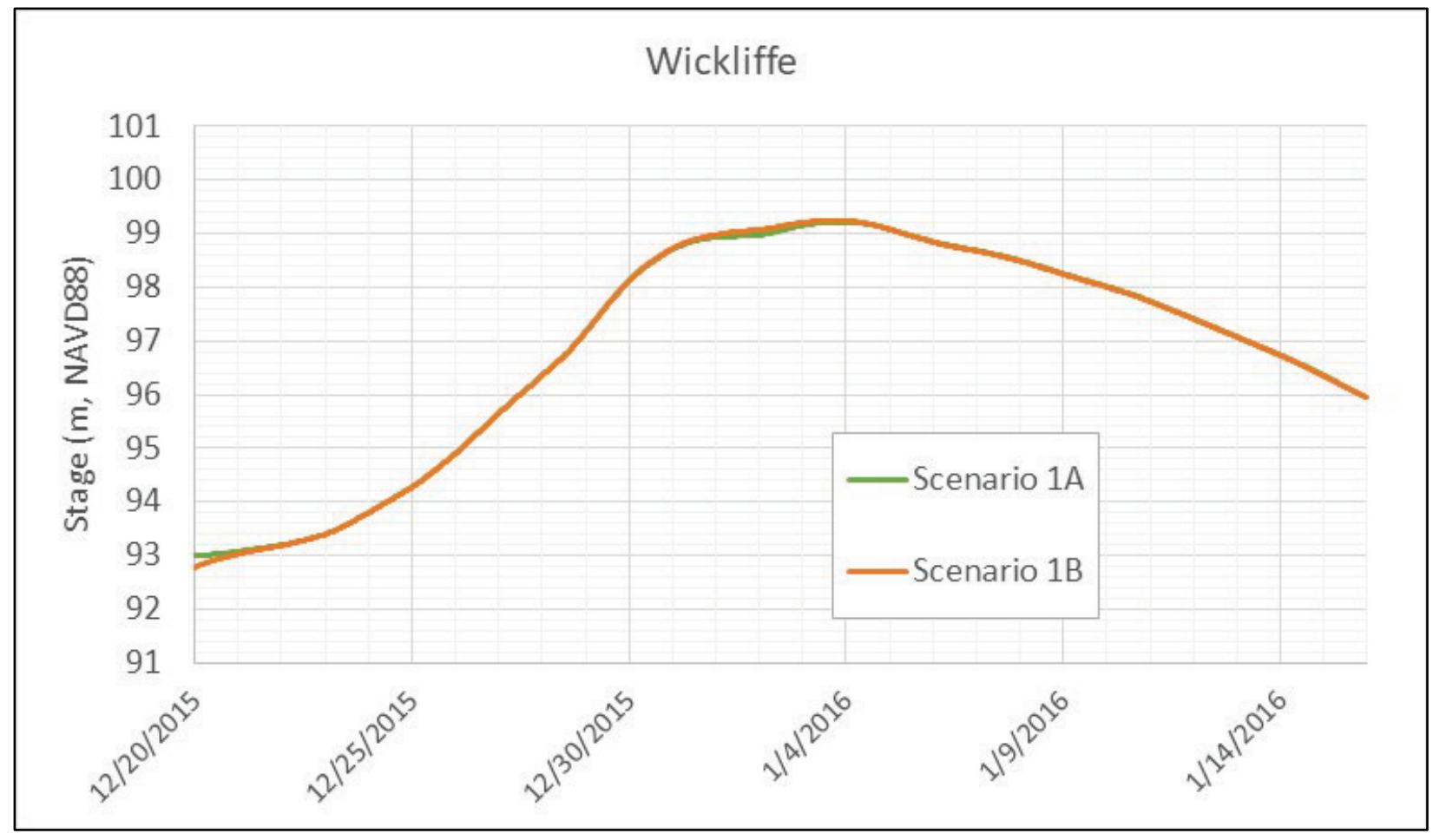


Figure B-16. Scenario 1A and 1B stages, 2015 event.

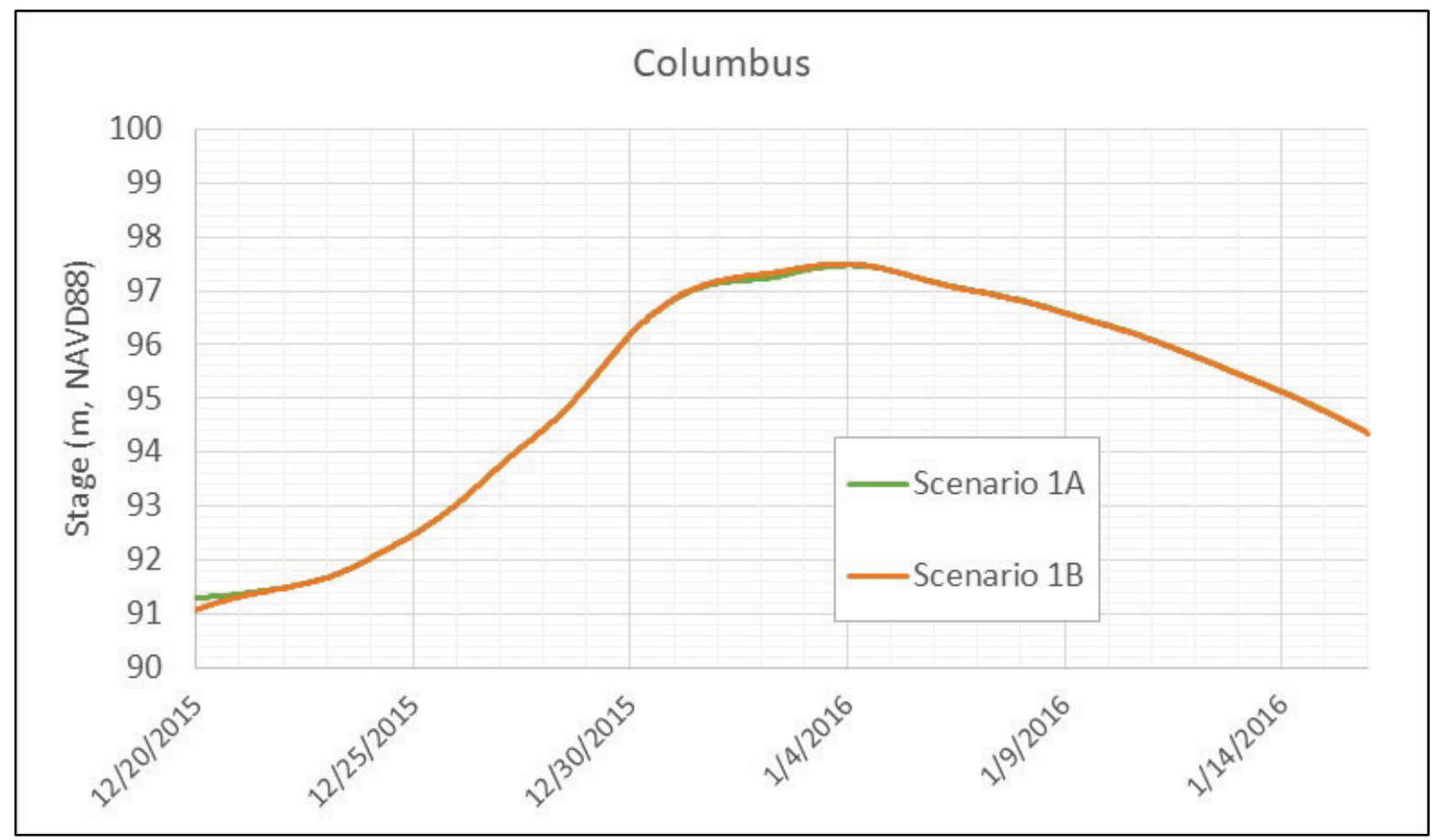

Figure B-17. Scenario 1A and 1B stages, 2015 event.

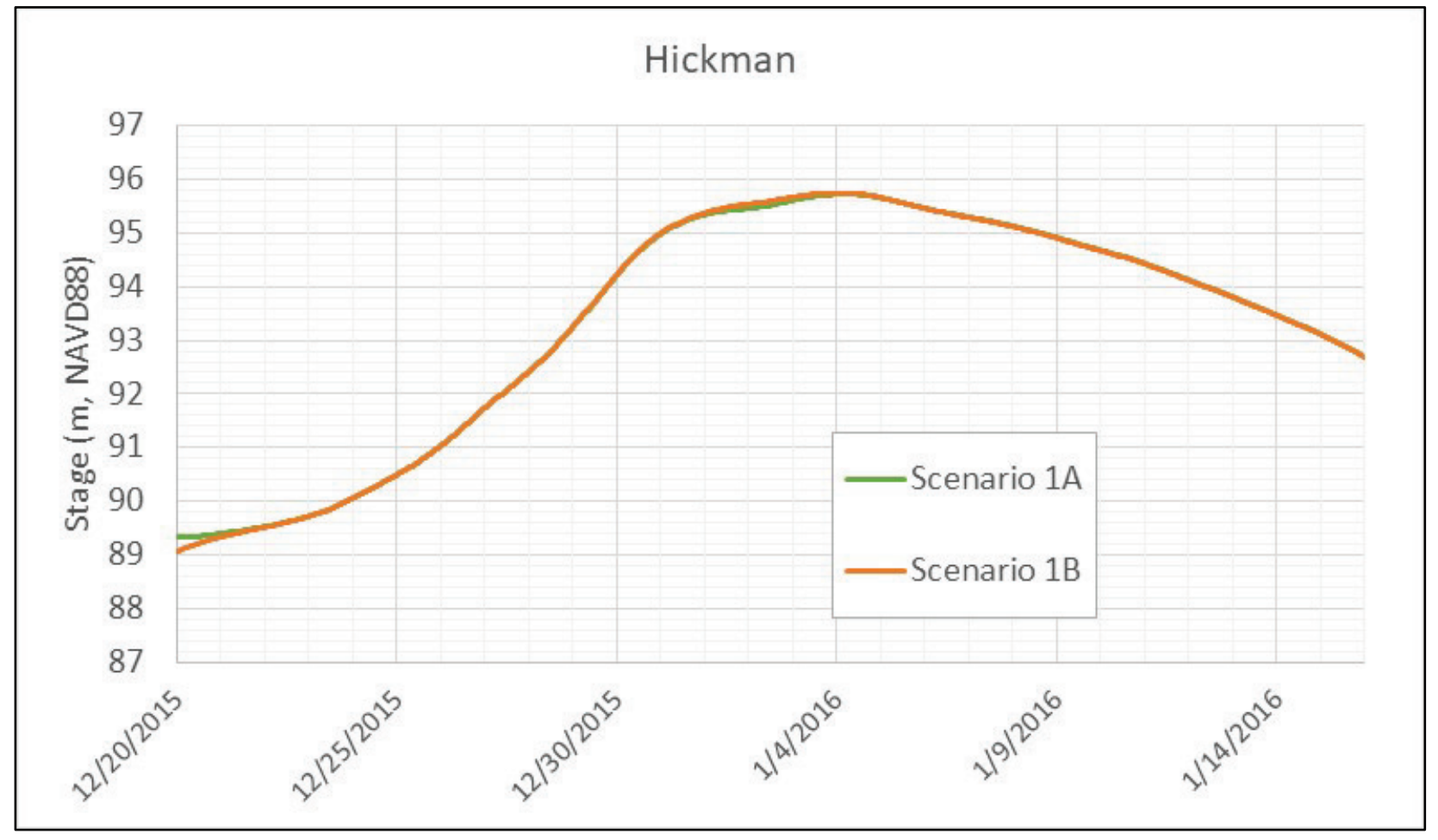


Figure B-18. Scenario 1A and 1B stages, 2015 event.

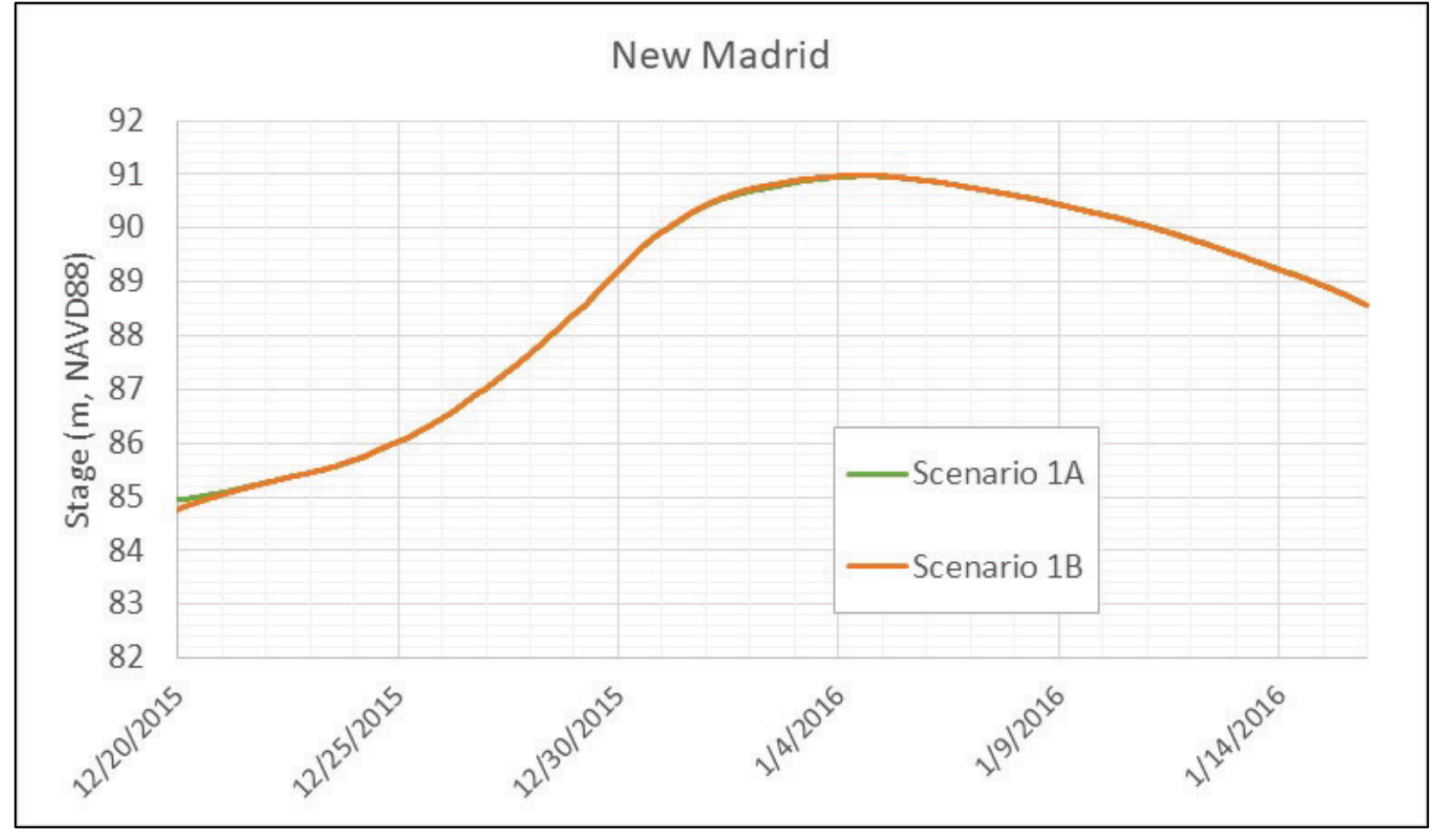




\section{7 flood event stages}

Figure B-19. Scenario 1A and 1B stages, 2017 event.

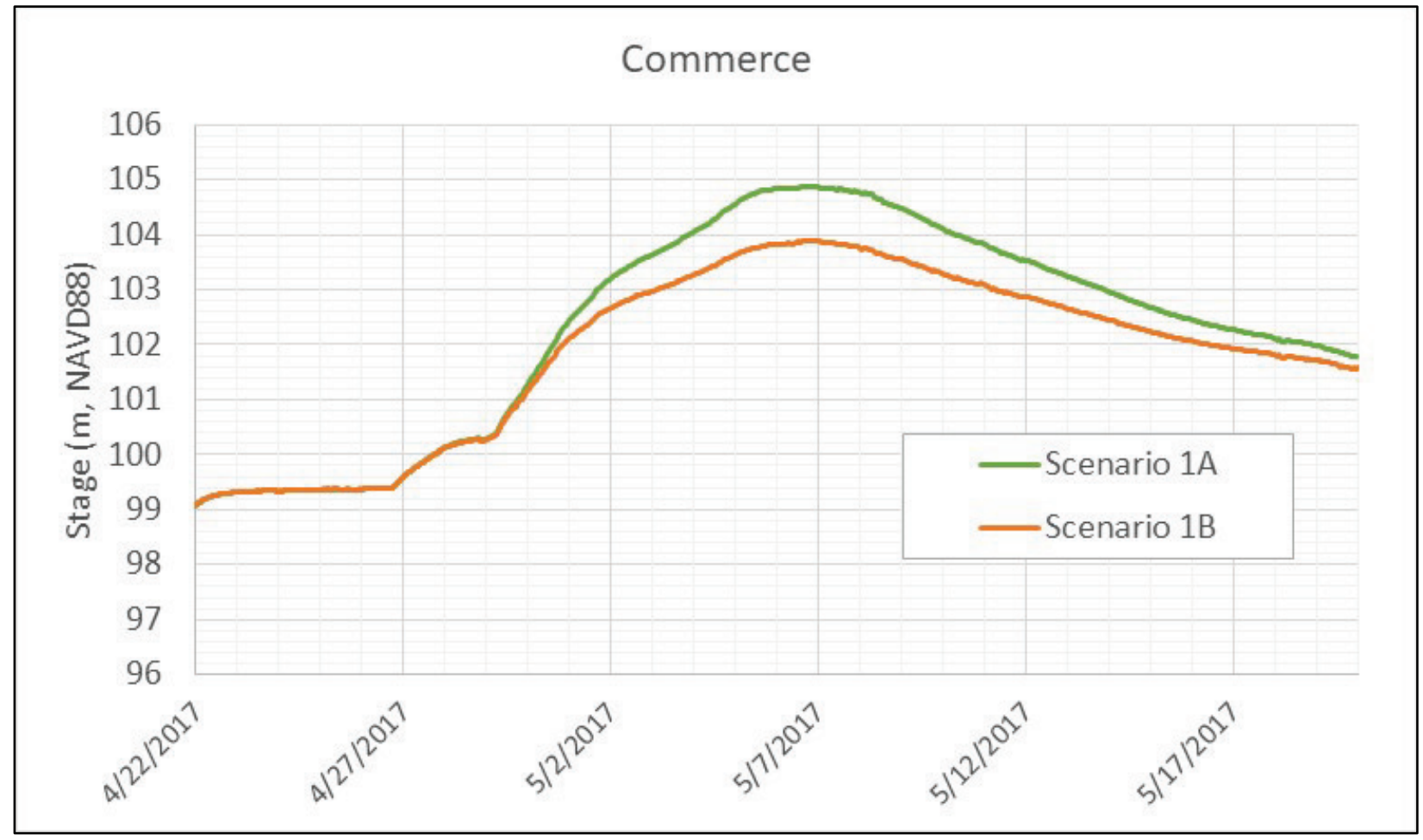

Figure B-20. Scenario 1A and 1B stages, 2017 event.

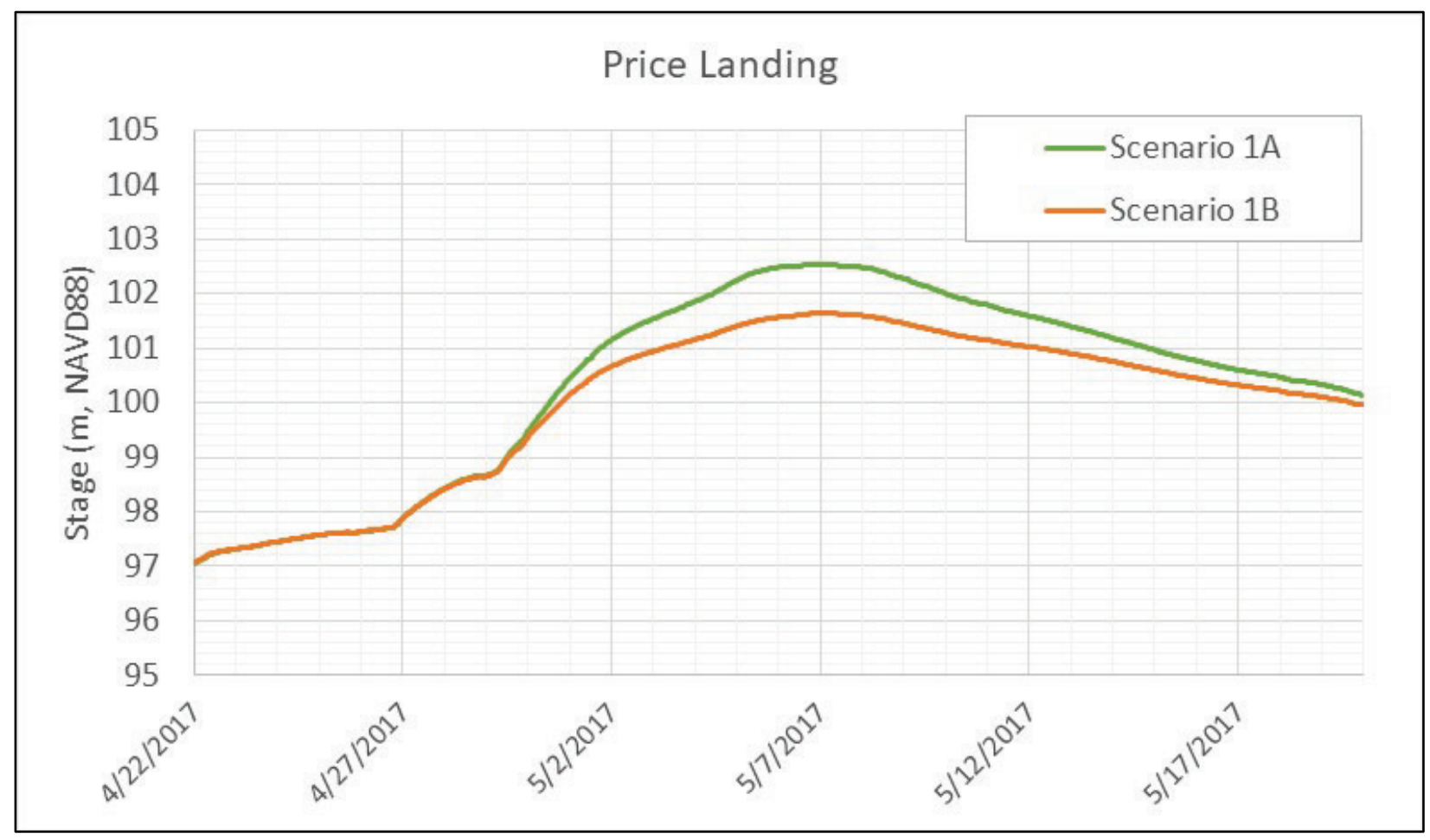


Figure B-21. Scenario 1A and 1B stages, 2017 event.

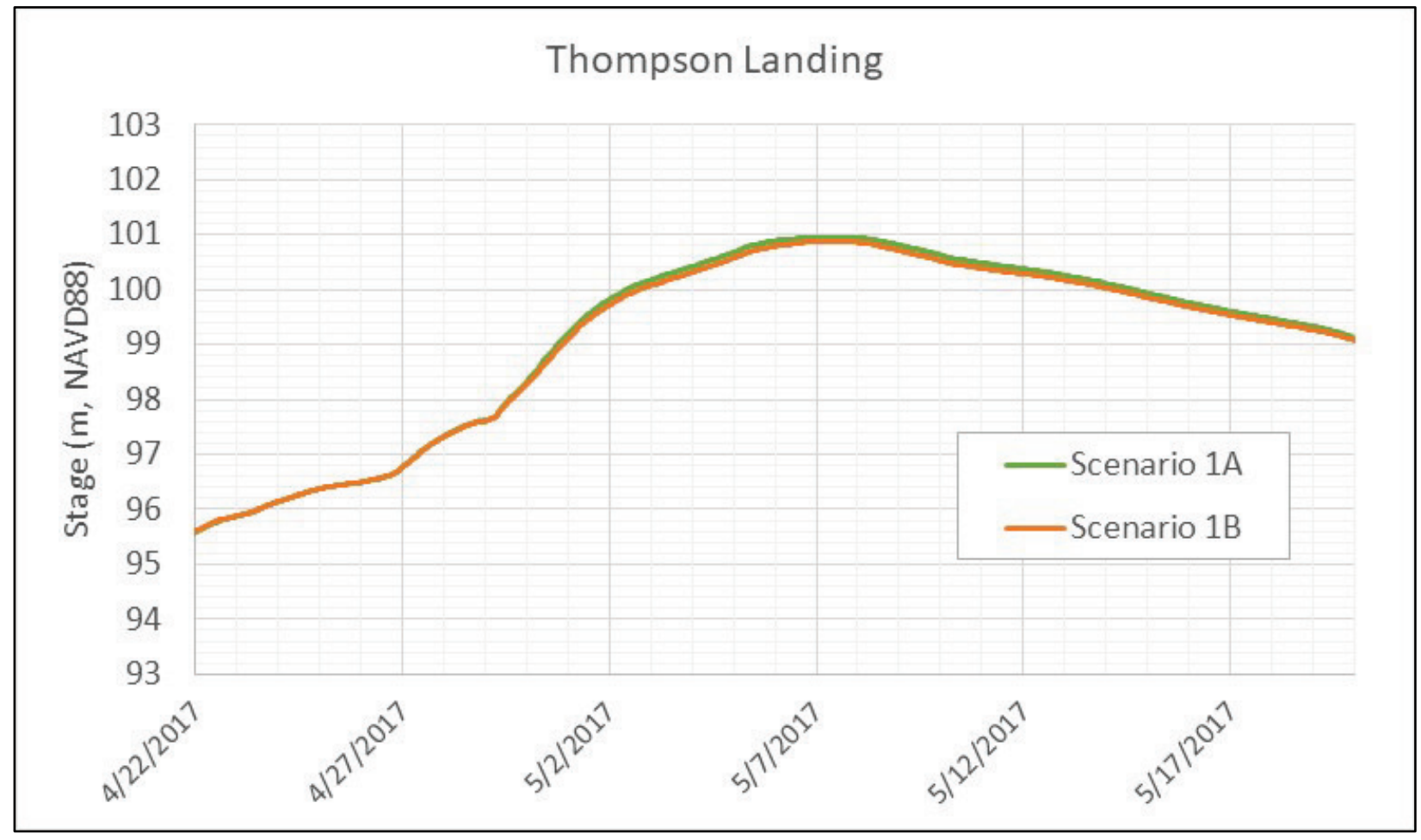

Figure B-22. Scenario 1A and 1B stages, 2017 event.

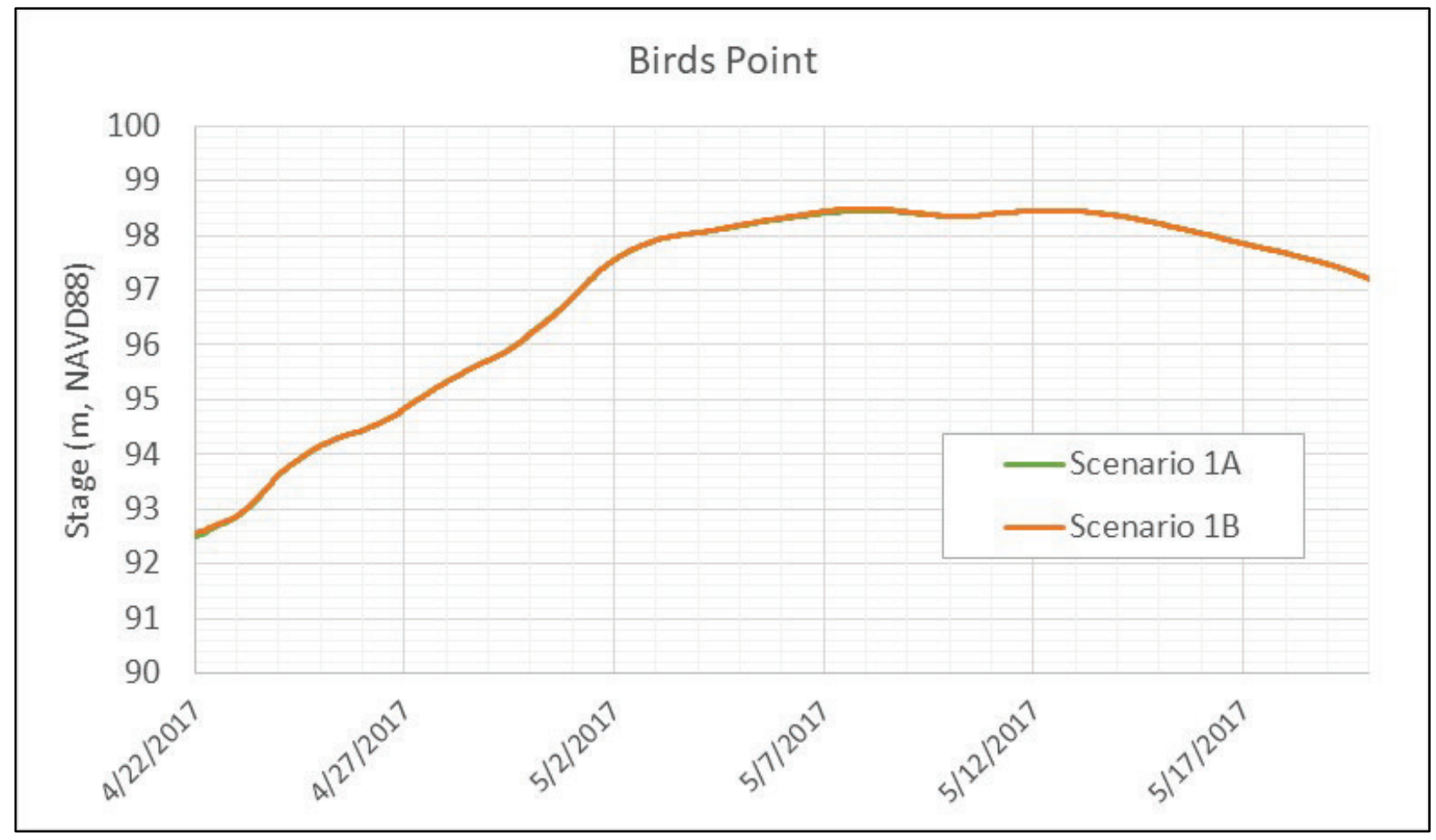


Figure B-23. Scenario 1A and 1B stages, 2017 event.

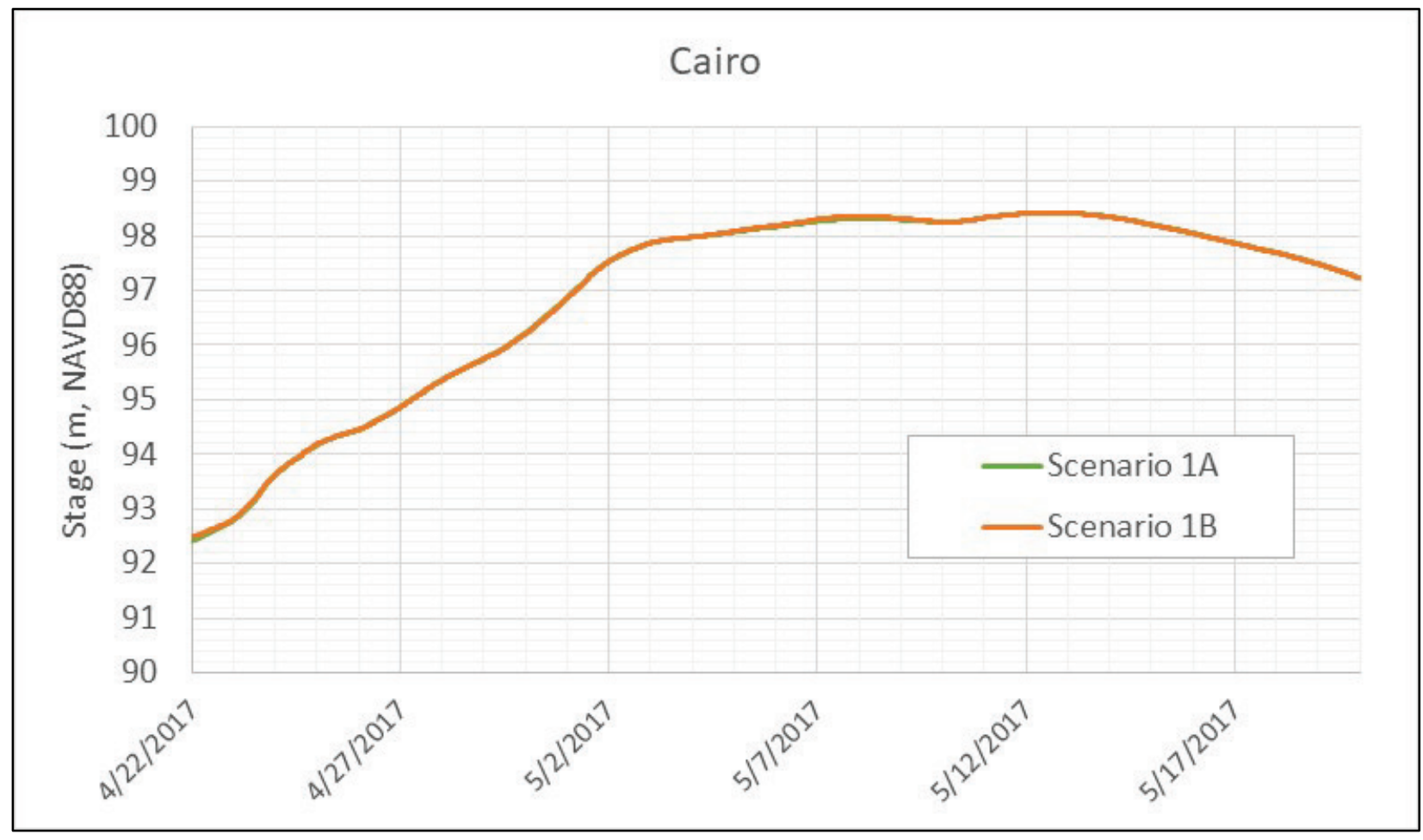

Figure B-24. Scenario 1A and 1B stages, 2017 event.

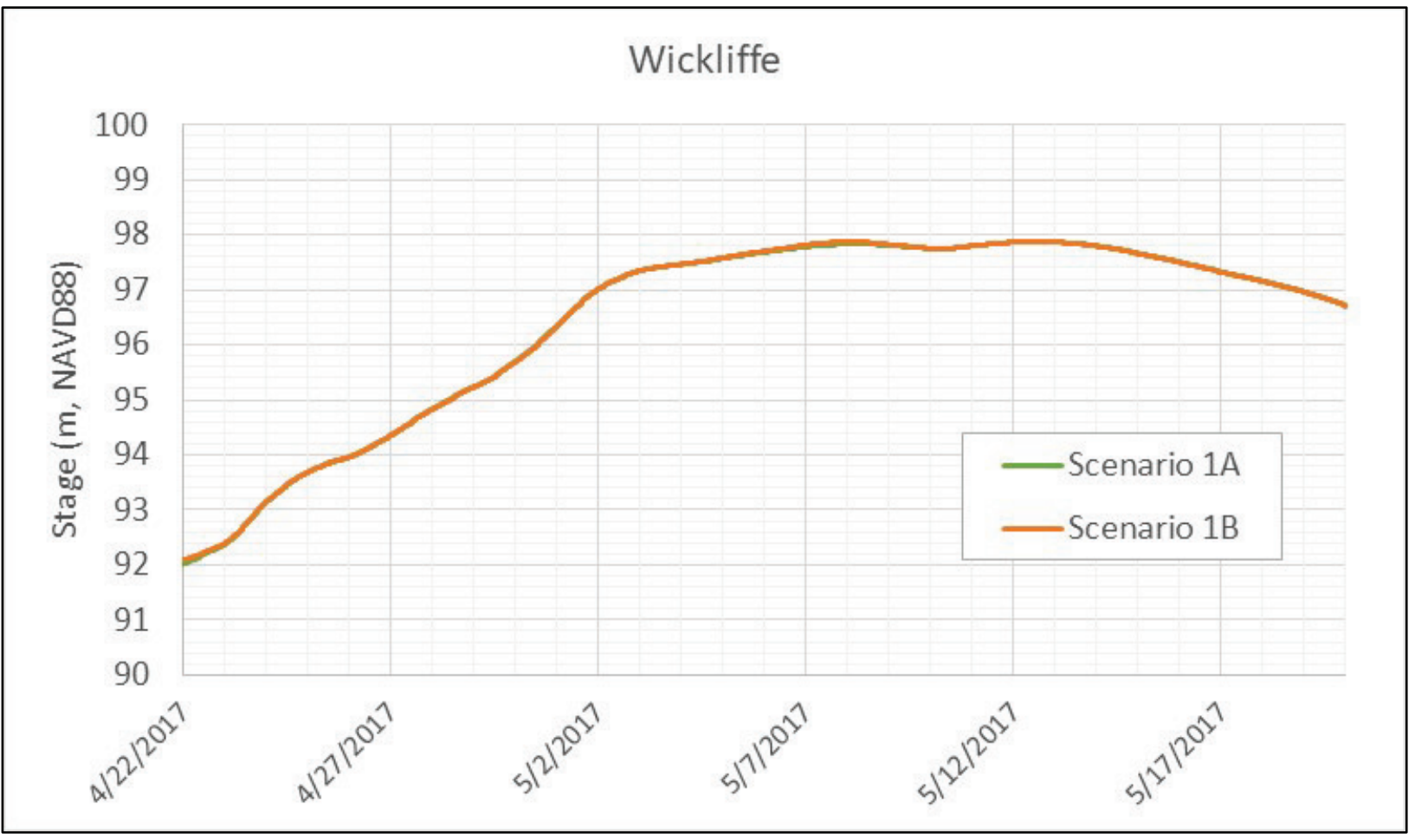


Figure B-25. Scenario 1A and 1B stages, 2017 event.

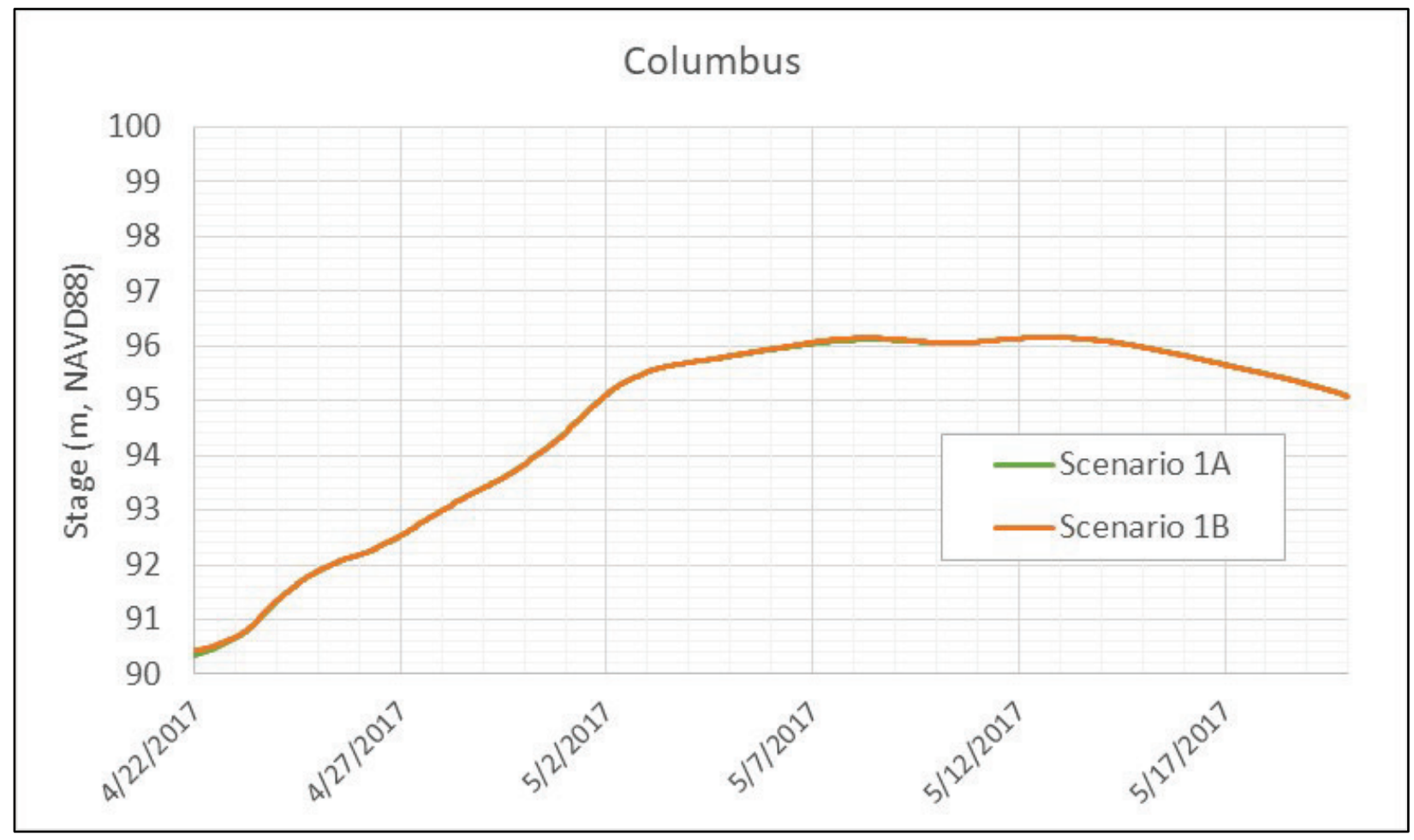

Figure B-26. Scenario 1A and 1B stages, 2017 event.

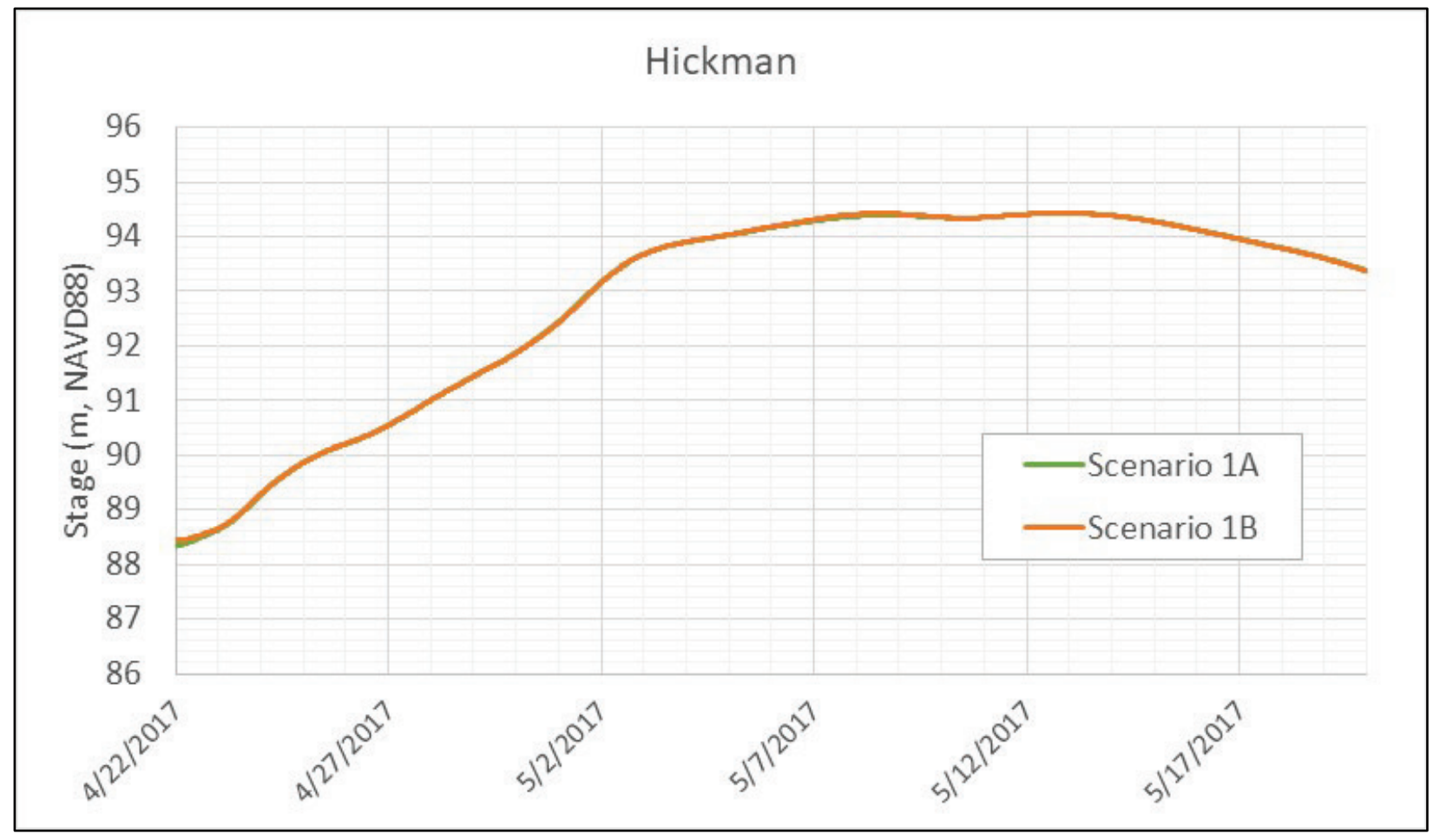


Figure B-27. Scenario 1A and 1B stages, 2017.

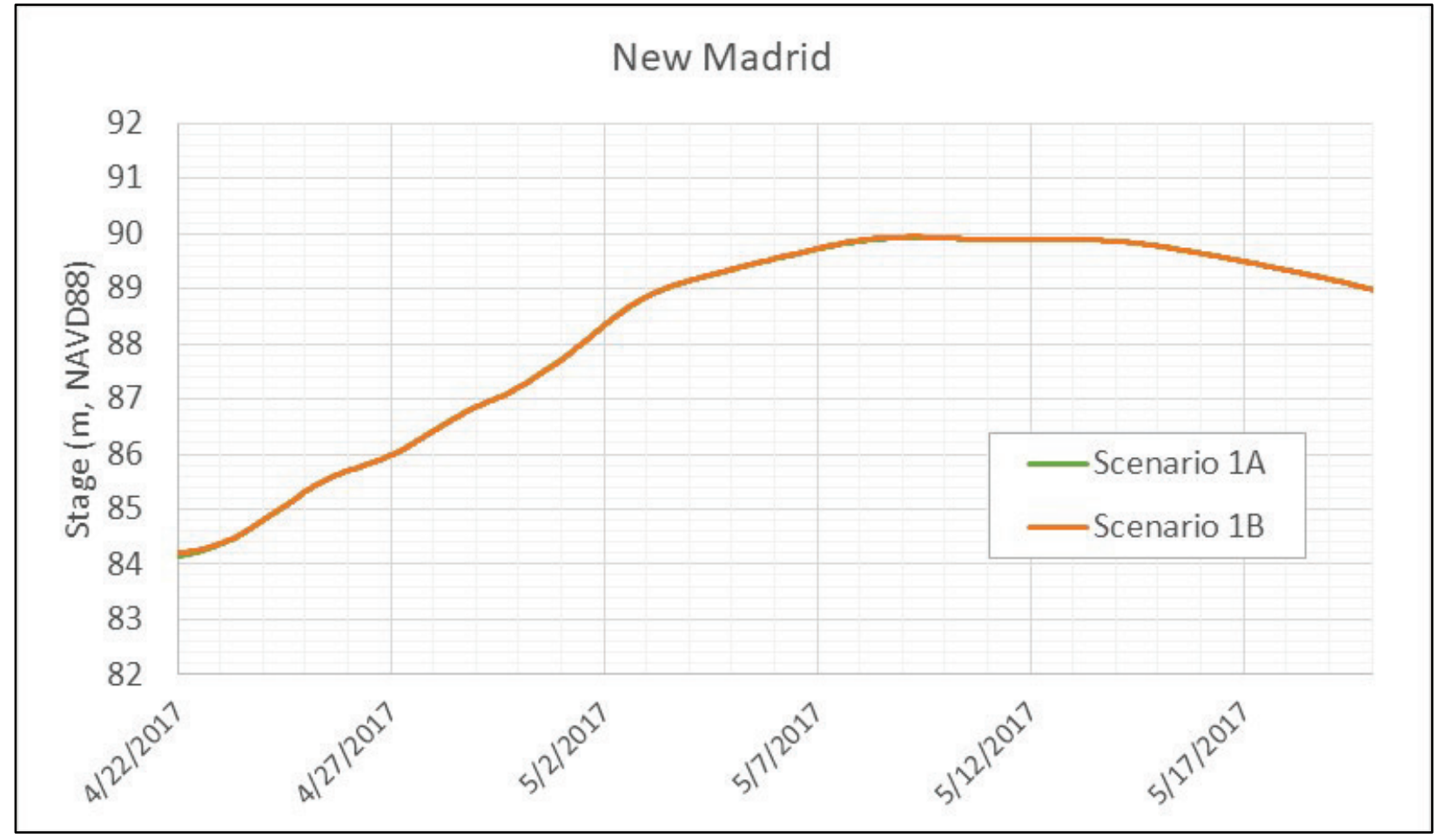




\section{Longitudinal profile plots}

Figure B-28. 5/3/2011 water surface elevation longitudinal profile.

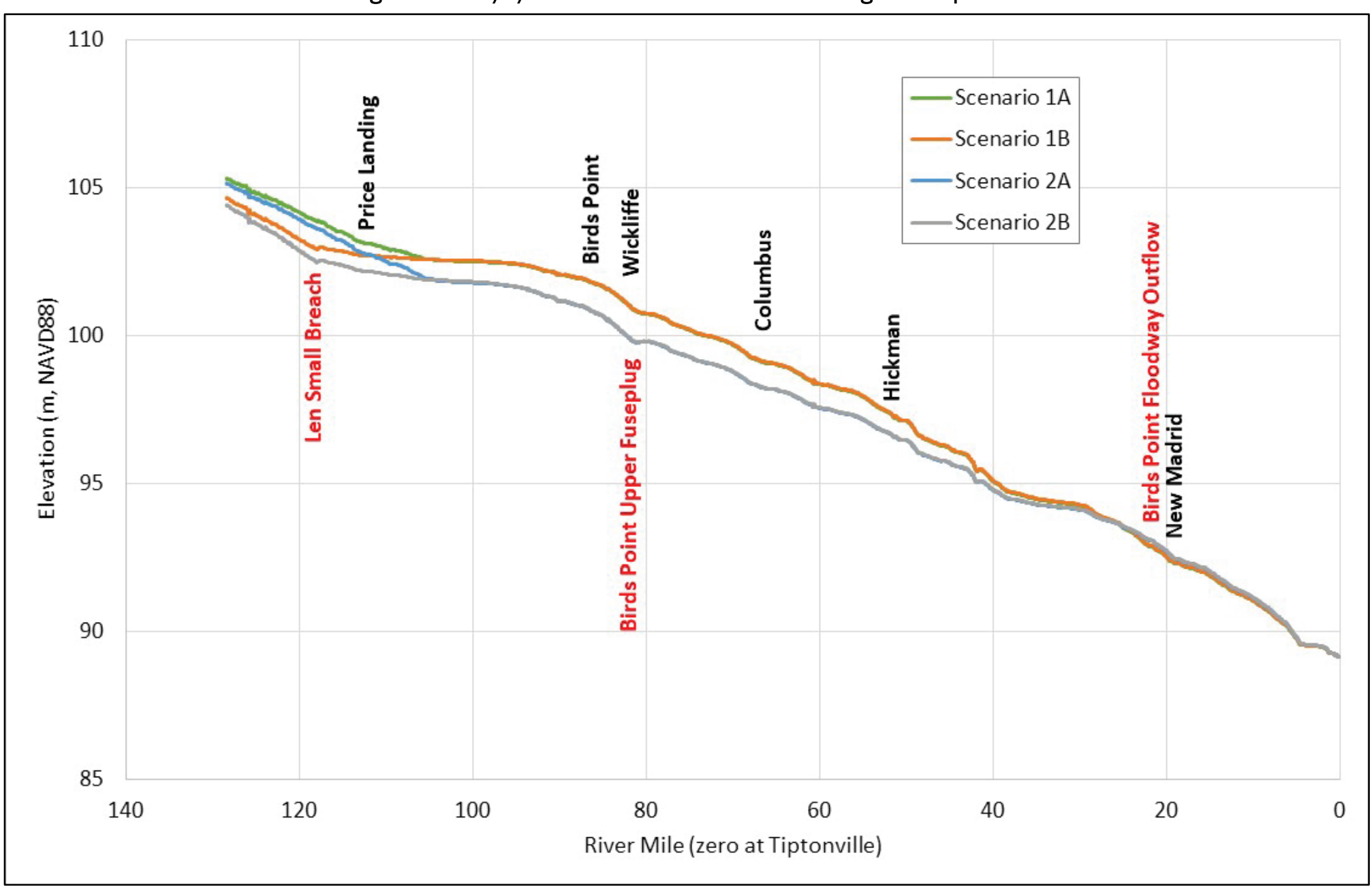


Figure B-29. 1/1/2015 water surface elevation longitudinal profile.

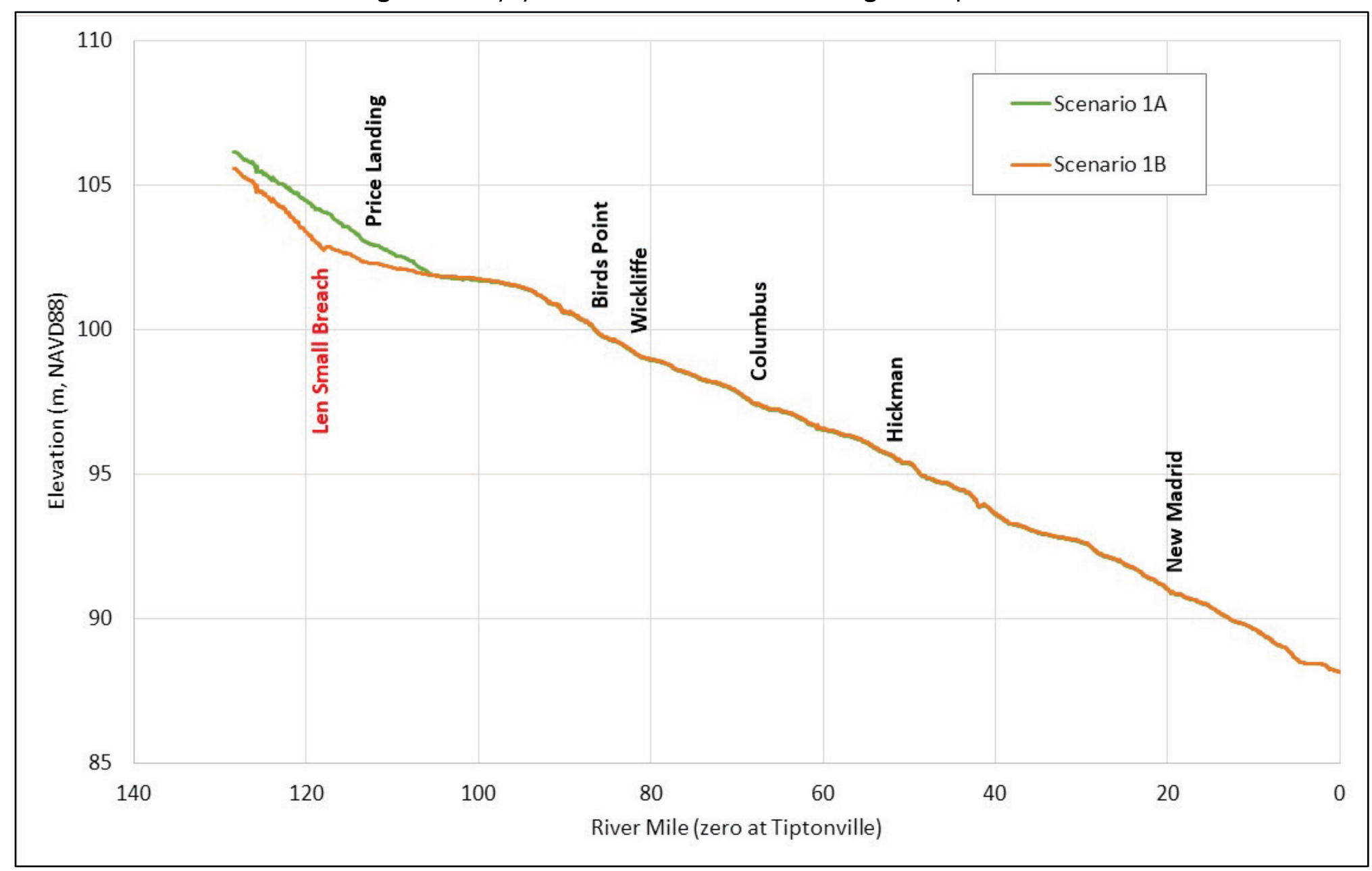


Figure B-30. 5/5/2017 water surface elevation longitudinal profile (note 2017 calibration model is identical to Scenario 1B).

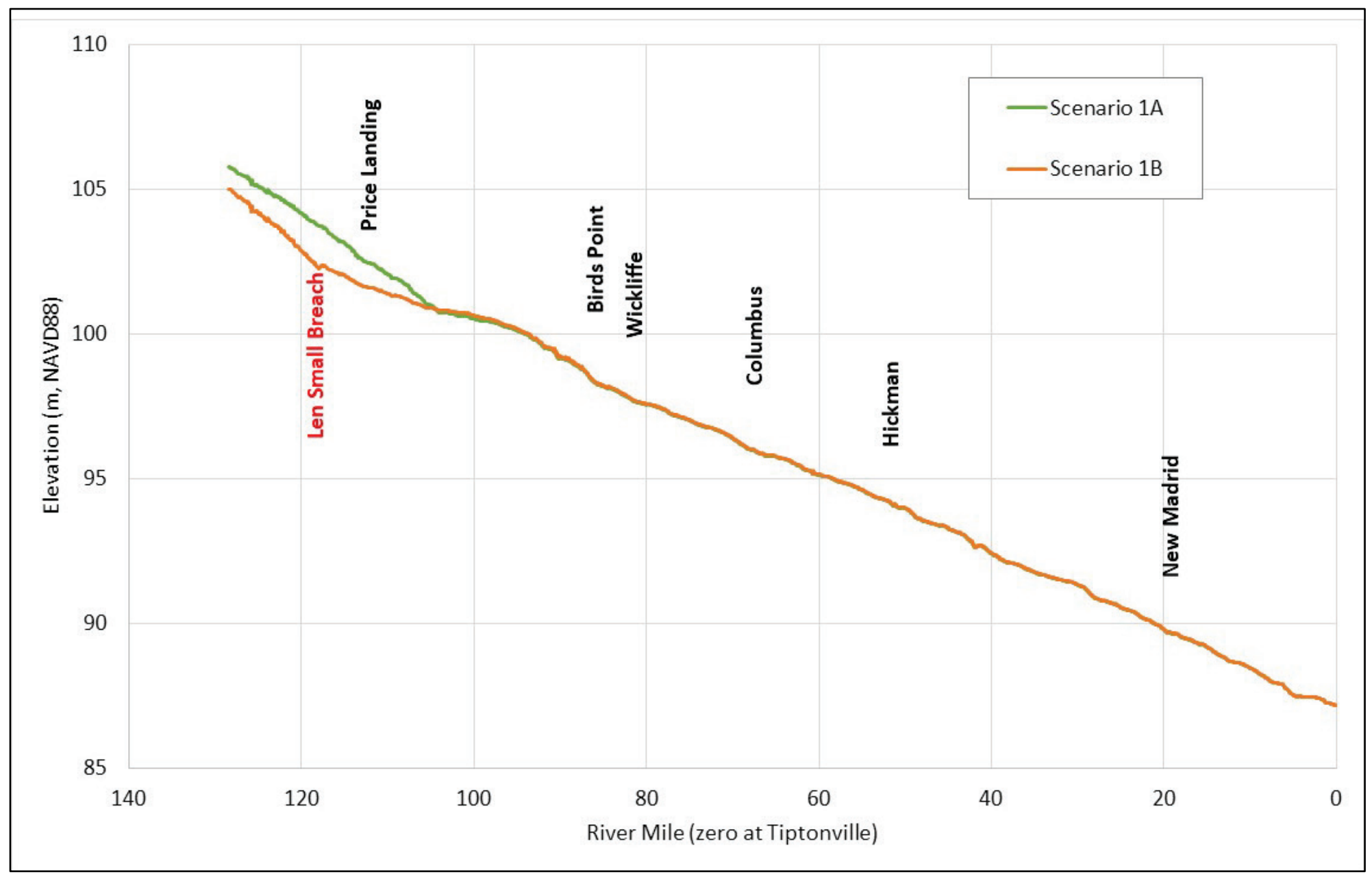




\section{Unit Conversion Factors}

\begin{tabular}{|l|c|l|}
\hline Multiply & By & To Obtain \\
\hline acres & $4,046.873$ & square meters \\
\hline cubic feet & 0.02831685 & cubic meters \\
\hline degrees (angle) & 0.01745329 & radians \\
\hline feet & 0.3048 & meters \\
\hline hectares & $1.0 \mathrm{E}+04$ & square meters \\
\hline miles (US statute) & $1,609.347$ & meters \\
\hline miles per hour & 0.44704 & meters per second \\
\hline square feet & 0.09290304 & square meters \\
\hline square miles & $2.589998 \mathrm{E}+06$ & square meters \\
\hline square yards & 0.8361274 & square meters \\
\hline yards & 0.9144 & meters \\
\hline
\end{tabular}




\section{Acronyms and Abbreviations}

1D one-dimensional

2D two-dimensional

ADCP acoustic Doppler current profiler

AdH Adaptive Hydraulics

BPNMF Birds Point New Madrid Floodway

CST Central Standard Time

DEM Digital Elevation Model

HEC-RAS Hydrologic Engineering Center's River Analysis System

LiDAR Light Detection and Ranging

LS Len Small

LWRP Low Water Reference Plane

MC-LS Miller City-Len Small

MR\&T Mississippi River and Tributaries

NLD National Levee Database

NSE Nash-Sutcliffe efficiency

rRMS relative RMS

RSM root mean squared

SMS Surface-water Modeling System

SRT solution refinement tolerance

URV unsubmerged rigid vegetation

USACE US Army Corps of Engineers

USGS US Geological Survey 


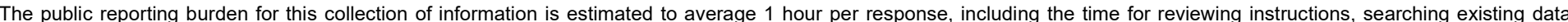

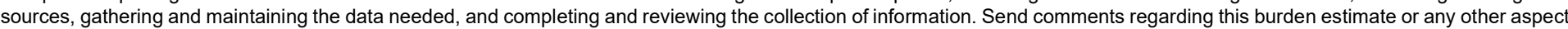

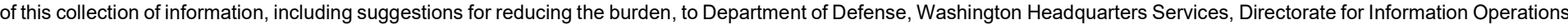

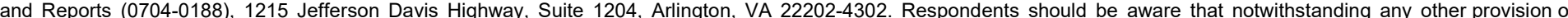
law, no person shall be subject to any penalty for failing to comply with a collection of information if it does not display a currently valid OMB control number. PLEASE DO NOT RETURN YOUR FORM TO THE ABOVE ADDRESS.

\begin{tabular}{l|l|l}
$\begin{array}{l}\text { 1. REPORT DATE } \\
\text { January } 2021\end{array}$ & $\begin{array}{l}\text { 2. REPORT TYPE } \\
\text { Final Report }\end{array}$ & 3. DATES COVERED (FrOm - To)
\end{tabular}

\section{TITLE AND SUBTITLE}

Mississippi River Adaptive Hydraulics Model Development and Evaluation, Commerce to

New Madrid, Missouri, Reach

5a. CONTRACT NUMBER

5b. GRANT NUMBER

5c. PROGRAM ELEMENT NUMBER

6. AUTHOR(S)

Roger A. Gaines, Stephen C. Sanborn, William H. McAnally, and Christopher M. Wallen

5d. PROJECT NUMBER

127672

5e. TASK NUMBER

5f. WORK UNIT NUMBER

8. PERFORMING ORGANIZATION REPORT NUMBER 6421 Deane Hill Drive Knoxville, TN 37919
US Army Corps of Engineers, Memphis District

167 North Main Street, b202

Memphis, TN 38103

\section{SPONSORING/MONITORING AGENCY NAME(S) AND ADDRESS(ES)}

USACE Mississippi Valley Division

Vicksburg, MS 39181-0080
MRG\&P Report No. 35

10. SPONSOR/MONITOR'S ACRONYM(S) USACE MVD 11. SPONSOR/MONITOR'S
REPORT NUMBER(S)

\section{DISTRIBUTION/AVAILABILITY STATEMENT}

Approved for public release; distribution is unlimited.

\section{SUPPLEMENTARY NOTES}

\section{ABSTRACT}

A numerical, two-dimensional hydrodynamic model of the Mississippi River, from Thebes, IL, to Tiptonville, TN (128 miles/206 km), was developed using the Adaptive Hydraulics model. The study objective assessed current patterns and flow distributions and their possible impacts on navigation due to Birds Point New Madrid Floodway (BPNMF) operations and the Len Small (LS) levee break. The model was calibrated to stage, discharge, and velocity data for the 2011, 2015-2016, and 2017 floods. The calibrated model was used to run four scenarios, with the BPNMF and the LS breach alternately active/open and inactive/closed. Effects from the LS breach being open are increased river velocities upstream of the breach, decreased velocities from the breach to Thompson Landing, no effects on velocity below the confluence, and cross-current velocities greater than $3.28 \mathrm{ft} / \mathrm{s}(1.0 \mathrm{~m} / \mathrm{s})$ within $1186.8 \mathrm{ft}(60 \mathrm{~m})$ of the bankline revetment. Effects from BPNMF operation are increased river velocities above the confluence, decreased velocities from the BPNMF upper inflow crevasse (Upper Fuseplug) to New Madrid, cross-current velocities greater than $1.5 \mathrm{ft} / \mathrm{s}(0.5 \mathrm{~m} / \mathrm{s})$ only near the right bank where flow re-enters the river from the BPNMF lower inflow/outflow crevasse Number 2 (Lower Fuseplug) and St. Johns Bayou.

\section{SUBJECT TERMS}

Hydrodynamics-Mathematical models, Inland navigation, Levees, Mississippi River, New Madrid Floodway (Mo.)

\section{SECURITY CLASSIFICATION OF:}

\begin{tabular}{l|l|l|} 
a. REPORT & b. ABSTRACT & c. THIS PAGE \\
Unclassified & Unclassified & Unclassified
\end{tabular}

17. LIMITATION OF ABSTRACT

SAR
18. NUMBER OF PAGES

226 19a. NAME OF RESPONSIBLE PERSON James. W. Lewis

19b. TELEPHONE NUMBER (Include area code) 601-634-5062 